\title{
ESTUDO DE INTERNAÇÕES HOSPITALARES DO \\ SISTEMA ÚNICO DE SAÚDE, EM MUNICÍPIOS EM \\ GESTÃo SEMI PLENA, NO ESTADO DE SÃo PAULO, \\ ENTRE $1994-1999$
}

\section{ESTER DE SOUZA COSTA}

Tese apresentada ao Departamento de Prática de Saúde Pública da Faculdade de Saúde Pública da Universidade de São Paulo para obtenção do Grau de Doutor

Área de Concentração: Serviços de Saúde Pública

Orientador: Professor Titular EURIVALDO SAMPAIO DE ALMEIDA

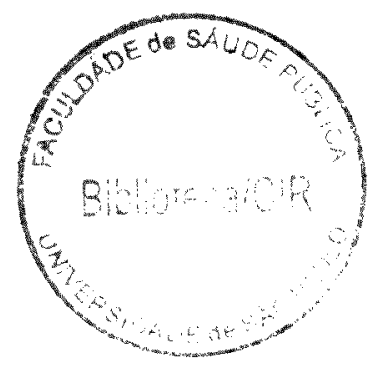

São Paulo 2001 
Autorizo, exclusivamente para fins acadêmicos e científicos, a reprodução total ou parcial desta tese, por processos fotocopiadores.

Assinatura:

Data: 
$\grave{A}$

Natalie Maisa, Beatriz e todos que

vierem por acreditarem na

continuidade da vida. 


\section{Agradeço}

Ao Prof. Dr. Eurivaldo Sampaio de Almeida pelos seus conhecimentos, sugestões, apoio e sábia orientação na realização deste trabalho. 
Em especial a Jayme Laperuta Filho, Ozana Maria Herrera e Hosana Maria Soares Candeias Bis, pela colaboração e companheirismo.

À todos que, direta ou indiretamente, contribuíram para a realização deste trabalho. 


\section{RESUMO}


Costa ES. Estudo de internações hospitalares do Sistema Único de Saúde, em municipios em gestão semi plena, no Estado de São Paulo entre 1994 1999. São Paulo; 2001. [Tese de Doutorado - Faculdade de Saúde Pública da USP].

Objetivo. O trabalho estuda o processo de implantação do Sistema Único de Saúde (SUS) com base na estratégia definida na Norma Operacional Básica do SUS 01/93. É feito uma sintese do seu eixo principal - a descentralização, desde a sua relação com a democracia no Continente Americano, no Brasil, e em especial na saúde destacando-se conceitos, fases, experiências, avanços e retrocessos até a unidade de analise que se pretende atingir: a gestão municipal. São apresentadas as várias condições previstas na norma, sua evolução e responsabilidades dentre outras enfocou-se a gestão semi plena sobre os serviços hospitalares em particular sobre suas internações. Método. O universo do estudo constituiu-se de onze municípios no Estado de São Paulo, trabalhados através do Estudo de Casos, onde foram analisados quanto a evolução na oferta de leitos hospitalares, volume de internações, permanência, procedimentos e mortalidade entre outras variáveis, utilizando-se como fonte de dados as Autorizações de Internações Hospitalares (AlHs) pagas pelo SUS entre 1994 a 1999 considerando os períodos antes e depois. Resultados. Foram identificados aspectos relacionados a alterações de indicadores, assim como seus efeitos sobre a mudança pretendida. Conclusões. O estudo mostra a ocorrência de mudanças importantes nas internações hospitalares pagas 
pelo SUS no período da gestão semi plena como indicativo que pode e deve ser complementado com outros estudos que avaliem mais profundamente as mudanças encontradas nesse municipios.

Descritores: Avaliação de Sistema de Saúde. Descentralização/Municipalização. Implantação do SUS. Modelo de Gestão. Modelos de Atenção. Pesquisa Avaliativa. 
SUMMARY 
Costa E S. Study of Hospital Admissions in the Single Health System (SUS), in Partial Administration Counties in the State of São Paulo, between 1994 and 1999. São Paulo, Brazil, 2001. [Doctoral Dissertation - School of Public Health of the University of São Paulo].

Objective. The dissertation studies the process of establishment of the Single Health System (in Portuguese, SUS), based on the strategy defined in the SUS Basic Operational Norms of January 1993. A synthesis is done of its basic principle-decentralization, starting with its relationship to democracy on the American Continent, in Brazil, and especially in health care, emphasizing concepts, phases, experiences, advances, and setbacks, up to the intended unit of analysis: county administration. The various conditions foreseen in the SUS Basic Operational Norms are presented, with their evolution and responsibilities. Among other responsibilities, the study focuses on the partial administration of hospital services, and particularly upon admissions. Method. The universe of study consisted of eleven counties (municipios) in the State of São Paulo, done in a case study mode and analyzed regarding the evolution of the supply of hospital beds, the admissions volume, length of stays, procedures, and death rates, among other variables, using as a data source the Authorizations of Hospital Admissions paid by the Single Health System between 1994 and 1999, considering as well the prior and later periods. Results. Aspects related to changes in the indicators were identified, as well as their effects on the intended change. Conclusions. The study shows the occurence of important 
changes in hospital admissions paid by the Single Health System in the period of partial administration, indicating that it can and should be complemented by other studies that evaluate more thoroughly the changes found in these counties.

Descriptive Terms: Evaluation of Healthcare Systems. Decentralization/ Municipalization. Establishment of Single Health System (Sistema Único de Saúde - SUS). Administrative Models. Patient Care Models. Evaluative Research. 
ÍNDICE 
I INTRODUÇÃO

1.1 Descentralização e Democracia ............................................... 02

1.2 Descentralização e Democracia no Brasil ................................ 08

1.3 A Descentralização da Saúde no Brasil .................................. 10

1.4 Justificativa do Estudo............................................................ 22

II OBJETIVOS 24

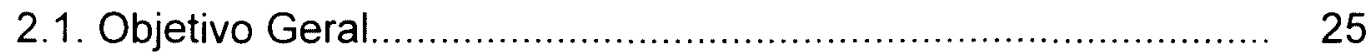

2.2 Objetivos Específicos......................................................... 25

III MATERIAL E MÉTODOS 26

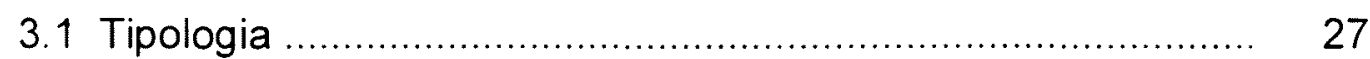

3.2 Universo do Estudo e Caracterização da Amostra................... 28

3.3 Levantamento de Dados ..................................................... 31

3.3.1 Variáveis principais................................................... 32

3.3.2 Variáveis auxiliares ................................................. 32

3.3.3 Periodização dos dados ................................................ 35

3.3.4 Cálculos com variáveis.............................................. 36

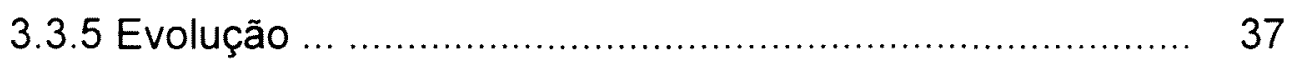

3.3.6 Ranking dos procedimentos ....................................... 38

3.3.7 Procedimentos sentinela ........................................... 38

3.4 Caracterização dos Municipios ............................................. 40

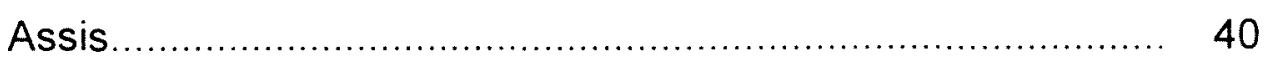

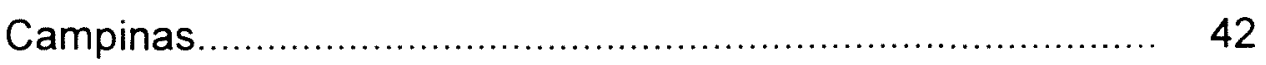

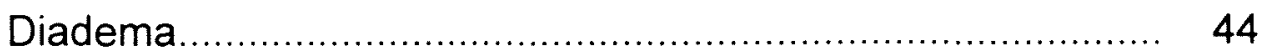

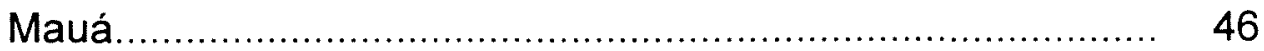

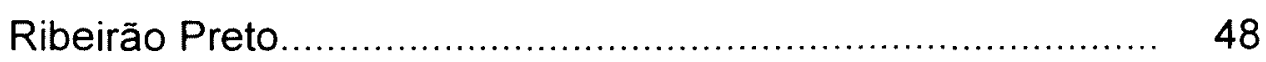

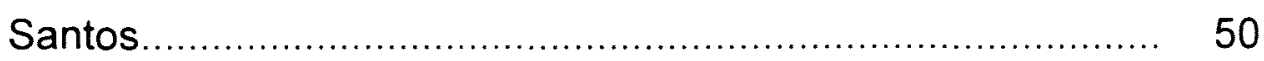

São Bernardo do Campo .................................................... 52

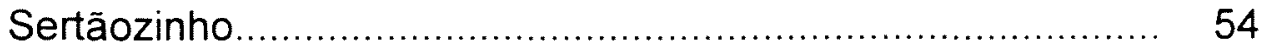

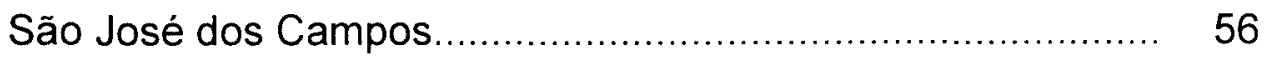

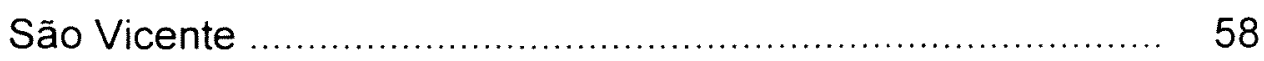

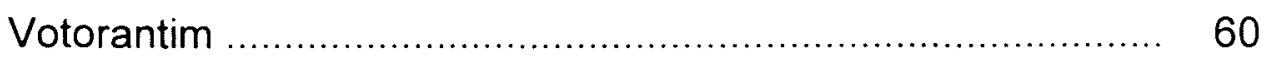


4.1 Distribuição da oferta de serviços hospitalares ....................... 64

4.1.1 Leitos por natureza do prestador ................................. 71

4.2 Volume de internações SUS ................................................ 79

4.2.1 Internações SUS e indicadores demográficos ................. 80

4.2.2 Internações SUS-AlH por habitantes............................... 81

4.2.2.1 Evolução do volume de internações.................... 83

4.2.3 Internações SUS e especialidades .................................. 90

4.2.4 Internações SUS por Capítulo do CID IX.......................... 93

4.2.5 Internações SUS por procedimentos sentinela ............... 96

4.2.6 Internações SUS e invasão ........................................... 121

4.2.7 Internações SUS e evasão ........................................... 124

4.2.8 Internações SUS e prestador.......................................... 127

4.2.9 Internações SUS e procedimentos ................................ 132

4.3 Gastos com internações SUS ............................................. 173

4.3.1 Gasto total com internações SUS ................................ 173

4.3.2 Evolução dos totais de gastos com internações............. 179

4.3.3 Gastos com internações SUS por habitante ................. 192

4.3.4 Gastos com internações SUS por especialidade.............. 192

4.3.5 Gastos com internações SUS e invasão ...................... 194

4.3.6 Gastos com internações SUS e evasão......................... 195

4.3.7 Gastos com internações SUS por prestador ................. 196

4.3.8 Gastos com internações SUS por procedimentos........... 199

4.3.9 Tempo de permanência em internações SUS hospitalares nos municipios .................................... $\quad 232$ 
4.3.10 Mortalidade Hospitalar nos municipios por prestador.................................................... 246

4.3.11 Mortalidade Hospitalar e capítulos do CID IX .............. 248

4.3.12 Evolução da taxa de mortalidade em internações SUS 255

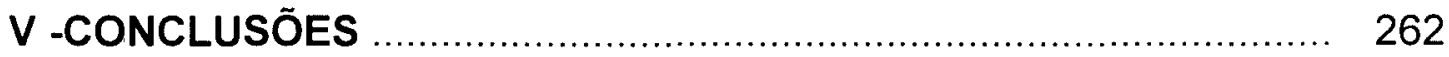

VI - REFERÊNCIAS BIBLIOGRÁFICAS ...................................... 267 
ÍNDICE DE FIGURAS 
FIGURA 1 Distribuição dos municípios do Estado de São Paulo por tipo de gestão, no ano de 1994 ..

FIGURA 1A Leitos gerais segundo padrões da MS e OPAS comparados com o número de leitos existentes no municipio (AlH), em 1994. (Antes)

FIGURA 1B Leitos gerais segundo padrões da MS e OPAS comparados com o número de leitos existentes no municipio (AlH), em 1997. (Depois)

FIGURA 2 Totais de leitos por tipo de prestador, referentes ao total dos 11 municípios, antes e depois da implantação da gestão semi-plena

FIGURA 3 Número de leitos por tipo de prestador, em Assis-SP antes e depois da implantação da gestão semi-plena ....

FIGURA 4 Número de leitos por tipo de prestador, em Campinas$\mathrm{SP}$ antes e depois da implantação da gestão semiplena

FIGURA 5 Número de leitos por tipo de prestador, em Diadema$\mathrm{SP}$ antes e depois da implantação da gestão semiplena

FIGURA 6 Número de leitos por tipo de prestador, em Mauá-SP antes e depois da implantação da gestão semi-plena....

FIGURA 7 Número de leitos por tipo de prestador, em Ribeirão Preto -SP antes e depois da implantação da gestão semi-plena

FIGURA $8 \quad$ Número de leitos por tipo de prestador, em Santos -SP antes e depois da implantação da gestão semi-plena 
FIGURA 9 Número de leitos por tipo de prestador, em São Bernardo do Campo -SP antes e depois da implantação da gestão semi-plena.

FIGURA 10 Número de leitos por tipo de prestador, em São José dos Campos -SP antes e depois da implantação da gestão semi-plena.

FIGURA 11 Número de leitos por tipo de prestador, em São Vicente -SP antes e depois da implantação da gestão semiplena

FIGURA 12 Número de leitos por tipo de prestador, em Sertãozinho -SP antes e depois da implantação da gestão semiplena.

FIGURA 13 Número de leitos por tipo de prestador, em Votorantim -SP antes e depois da implantação da gestão semiplena.

FIGURA 14 Ajuste por regressão dos totais anuais gastos com internações SUS nos 11 municipios estudados, nos periodos antes e depois da implantação da gestão semi plena.

FIGURA 15 Ajuste por regressão dos totais anuais gastos com internações SUS no municipio de Assis, nos periodos antes e depois da implantação da gestão semi plena.....

FIGURA 16 Ajuste por regressão dos totais anuais gastos com internações SUS no municipio de Campinas, nos períodos antes e depois da implantação da gestão semi plena. 
FIGURA 17 Ajuste por regressão dos totais anuais gastos com internações SUS no município de Diadema, nos periodos antes e depois da implantação da gestão semi plena

FIGURA 18 Ajuste por regressão dos totais anuais gastos com internações SUS no município de Mauá, nos períodos antes e depois da implantação da gestão semi plena

FIGURA 19 Ajuste por regressão dos totais anuais gastos com internações SUS no município de Ribeirão Preto, nos períodos antes e depois da implantação da gestão semi plena

FIGURA 20 Ajuste por regressão dos totais anuais gastos com internações SUS no município de Santos, nos periodos antes e depois da implantação da gestão semi plena.....

FIGURA 21 Ajuste por regressão dos totais anuais gastos com internações SUS no município de São Bernardo do Campo, nos períodos antes e depois da implantação da gestão semi plena

FIGURA 22 Ajuste por regressão dos totais anuais gastos com internações SUS no município de São José dos Campos, nos periodos antes e depois da implantação da gestão semi plena.

FIGURA 23 Ajuste por regressão dos totais anuais gastos com internações SUS no municipio de São Vicente, nos periodos antes e depois da implantação da gestão semi plena

FIGURA 24 Ajuste por regressão dos totais anuais gastos com internações SUS no município de Sertãozinho, nos períodos antes e depois da implantação da gestão semi plena 
FIGURA 25 Ajuste por regressão dos totais anuais gastos com internações SUS no municipio de Votorantin, nos períodos antes e depois da implantação da gestão semi plena.

FIGURA 26 Valores totais gastos com internações SUS e valor médio, por municípios, antes e depois da implantação da gestão semi plena

FIGURA 27 Ajuste por regressão dos totais anuais de internações SUS nos 11 municípios estudados, nos periodos antes e depois da implantação da gestão semi plena

FIGURA 28 Ajuste por regressão dos totais anuais de gastos com internações SUS no municipio de Assis, nos períodos antes e depois da implantação da gestão semi plena ....

FIGURA 29 Ajuste por regressão dos totais anuais de gastos com internações SUS no município de Campinas, nos periodos antes e depois da implantação da gestão semi plena

FIGURA 30 Ajuste por regressão dos totais anuais de internações SUS no municipio de Diadema, nos períodos antes e depois da implantação da gestão semi plena

FIGURA 31 Ajuste por regressão dos totais anuais de gastos com internações SUS no municipio de Mauá, nos períodos antes e depois da implantação da gestão semi plena.....

FIGURA 32 Ajuste por regressão dos totais anuais de gastos com internações SUS no municipio de Ribeirão Preto, nos períodos antes e depois da implantação da gestão semi plena 
FIGURA 33 Ajuste por regressão dos totais anuais de gastos com internações SUS no município de Santos, nos períodos antes e depois da implantação da gestão semi plena ....

FIGURA 34 Ajuste por regressão dos totais anuais de gastos com internações SUS no município de São Bernardo do Campo, nos periodos antes e depois da implantação da gestão semi plena

FIGURA 35 Ajuste por regressão dos totais anuais de gastos com internações SUS no município de Sertãozinho, nos periodos antes e depois da implantação da gestão semi plena

FIGURA 36 Ajuste por regressão dos totais anuais de gastos com internações SUS no município de São José dos Campos, nos periodos antes e depois da implantação da gestão semi plena

FIGURA 37 Ajuste por regressão dos totais anuais de gastos com internações SUS no município de São Vicente, nos periodos antes e depois da implantação da gestão semi plena

FIGURA 38 Ajuste por regressão dos totais anuais de gastos com internações SUS no município de Votorantin, nos periodos antes e depois da implantação da gestão semi plena

FIGURA 39 Ajuste por regressão dos gastos médios anuais das internações SUS nos 11 municipios estudados, nos periodos antes e depois da implantação da gestão semi plena.

FIGURA 40 Ajuste por regressão dos gastos médios anuais das internações SUS no município de Assis, nos períodos antes e depois da implantação da gestão semi plena ... 
FIGURA 41 Ajuste por regressão dos gastos médios anuais das internações SUS no município de Campinas, nos períodos antes e depois da implantação da gestão semi plena

FIGURA 42 Ajuste por regressão dos gastos médios anuais das internações SUS no município de Diadema, nos períodos antes e depois da implantação da gestão semi plena.

FIGURA 43 Ajuste por regressão dos gastos médios anuais das internações SUS no município de Mauá, nos períodos antes e depois da implantação da gestão semi plena ...

FIGURA 44 Ajuste por regressão dos gastos médios anuais das internações SUS no município de Ribeirão Preto, nos periodos antes e depois da implantação da gestão semi plena

FIGURA 45 Ajuste por regressão dos gastos médios anuais das internações SUS no município de Santos, nos periodos antes e depois da implantação da gestão semi plena ....

FIGURA 46 Ajuste por regressão dos gastos médios anuais das internações SUS no municipio de São Bernardo do Campo, nos periodos antes e depois da implantação da gestão semi plena

FIGURA 47 Ajuste por regressão dos gastos médios anuais das internações SUS no municipio de São José dos Campos, nos periodos antes e depois da implantação da gestão semi plena.

FIGURA 48 Ajuste por regressão dos gastos médios anuais das internações SUS no município de São Vicente, nos períodos antes e depois da implantação da gestão semi plena 
FIGURA 49 Ajuste por regressão dos gastos médios anuais das internações SUS no municipio de Sertãozinho, nos periodos antes e depois da implantação da gestão semi plena

FIGURA 50 Ajuste por regressão dos gastos médios anuais das internações SUS no municipio de Votorantin, nos períodos antes e depois da implantação da gestão semi plena

FIGURA 51 AlHs pagas por habitante, por municipios, antes e depois da implantação da gestão semi-plena.

FIGURA 52 Média anual de dias de permanência internações SUS por município, antes e depois da implantação da gestão semi-plena

FIGURA 53 Tendência do número anual de dias de permanência em internações SUS, por município, antes e depois da implantação da gestão semi-plena, no Estado de São Paulo

FIGURA 54 Ajuste por regressão do tempo de permanência em internações SUS nos 11 municipios estudados, nos períodos antes e depois da implantação da gestão semi plena, no Estado de São Paulo

FIGURA 55 Ajuste por regressão do tempo de permanência nas internações SUS no município de Assis, nos periodos antes e depois da implantação da gestão semi plena, no Estado de São Paulo

FIGURA 56 Ajuste por regressão do tempo de permanência em internações SUS no município de Campinas, nos períodos antes e depois da implantação da gestão semi plena, no Estado de São Paulo. 
FIGURA 57 Ajuste por regressão do tempo médio anual de permanência em internações SUS no município de Diadema, nos períodos antes e depois da implantação da gestão semi plena, no Estado de São Paulo

FIGURA 58 Ajuste por regressão do tempo de permanência em internações SUS no município de Mauá, nos períodos antes e depois da implantação da gestão semi plena, no Estado de São Paulo

FIGURA 59 Ajuste por regressão do tempo de permanência nas internações SUS no município de Ribeirão Preto, nos periodos antes e depois da implantação da gestão semi plena, no Estado de São Paulo

FIGURA 60 Ajuste por regressão do tempo de permanência nas internações SUS no município de Santos, nos períodos antes e depois da implantação da gestão semi plena, no Estado de São Paulo

FIGURA 61 Ajuste por regressão do tempo de permanência nas internações SUS no municipio de São Bernardo do Campo, nos períodos antes e depois da implantação da gestão semi plena, no Estado de São Paulo

FIGURA 62 Ajuste por regressão do tempo de permanência nas internações SUS no município de São José dos Campos, nos períodos antes e depois da implantação da gestão semi plena, no Estado de São Paulo

FIGURA 63 Ajuste por regressão do tempo médio anual de permanência em internações SUS no município de São Vicente, nos periodos antes e depois da implantação da gestão semi plena, no Estado de São Paulo. 
FIGURA 64 Ajuste por regressão do tempo de permanência nas internações SUS no município de Sertãozinho, nos periodos antes e depois da implantação da gestão semi plena, no Estado de São Paulo

FIGURA 65 Ajuste por regressão do tempo de permanência nas internações SUS no município de Votorantin, nos períodos antes e depois da implantação da gestão semi plena, no Estado de São Paulo.

FIGURA 66 Ajuste por regressão das taxas média anuais de mortalidade nas internações SUS realizadas nos 11 municípios estudados, nos períodos antes e depois da implantação da gestão semi plena.

FIGURA 67 Ajuste por regressão das taxas média anuais de mortalidade nas internações SUS realizadas no município de Assis, nos periodos antes e depois da implantação da gestão semi plena

FIGURA 68 Ajuste por regressão das taxas média anuais de mortalidade nas internações SUS realizadas no município de Campinas, nos períodos antes e depois da implantação da gestão semi plena

FIGURA 69 Ajuste por regressão das taxas média anuais de mortalidade nas internações SUS realizadas no município de Diadema, nos períodos antes e depois da implantação da gestão semi plena

FIGURA 70 Ajuste por regressão das taxas médias anuais de mortalidade nas internações SUS realizadas no municipio de Mauá, nos periodos antes e depois da implantação da gestão semi plena. 
FIGURA 71 Ajuste por regressão das taxas médias anuais de mortalidade nas internações SUS realizadas no município de Ribeirão Preto, nos períodos antes e depois da implantação da gestão semi plena.

FIGURA 72 Ajuste por regressão das taxas médias anuais de mortalidade nas internações SUS realizadas no município de Santos, nos periodos antes e depois da implantação da gestão semi plena.

FIGURA 73 Ajuste por regressão das taxas médias anuais de mortalidade nas internações SUS realizadas no municipio de São Bernardo do Campo, nos períodos antes e depois da implantação da gestão semi plena.....

FIGURA 74 Ajuste por regressão das taxas médias anuais de mortalidade nas internações SUS realizadas no municipio de São José dos Campos, nos períodos antes e depois da implantação da gestão semi plena.....

FIGURA 75 Ajuste por regressão das taxas médias anuais de mortalidade nas internações SUS realizadas no municipio de São Vicente, nos periodos antes e depois da implantação da gestão semi plena.

FIGURA 76 Ajuste por regressão das taxas médias anuais de mortalidade nas internações SUS realizadas no município de Sertãozinho, nos períodos antes e depois da implantação da gestão semi plena.

FIGURA 77 Ajuste por regressão das taxas médias anuais de mortalidade nas internações SUS realizadas no municipio de Votorantim, nos periodos antes e depois da implantação da gestão semi plena. 
ÍNDICE DOS QUADROS 


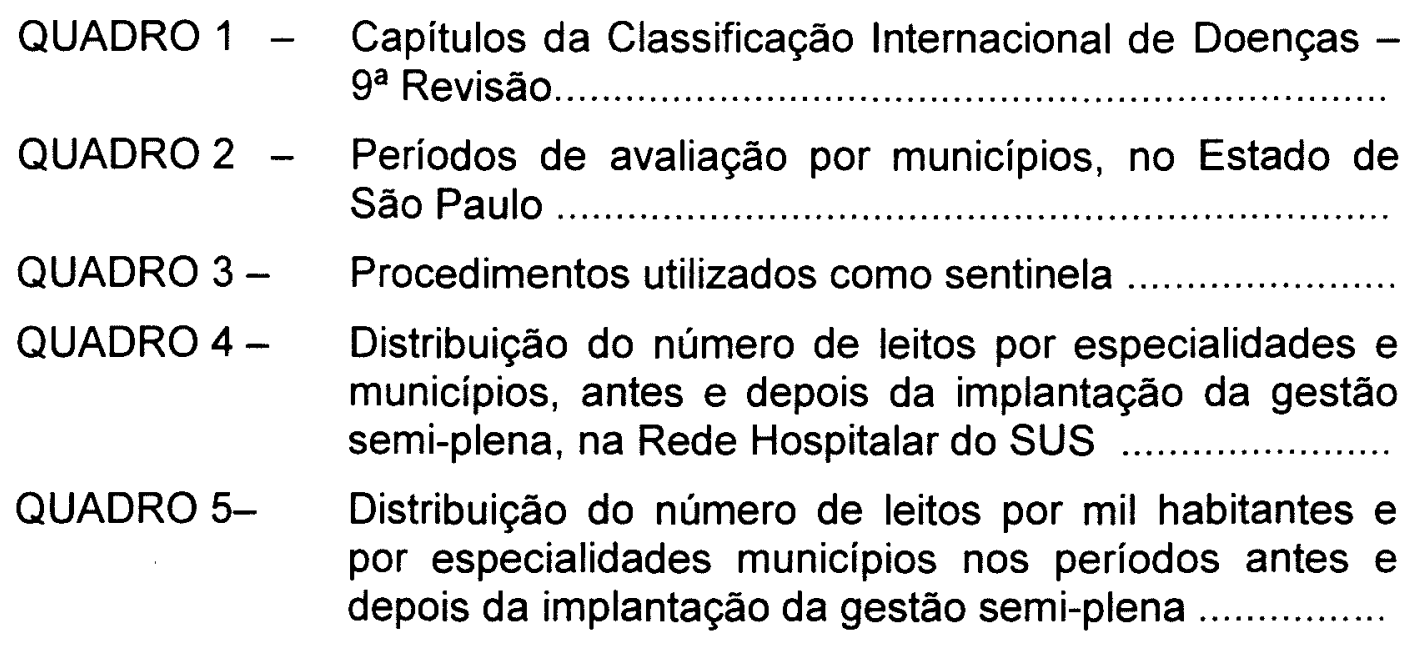

QUADRO 6- Total de leitos por natureza do prestador, contratado, estadual, municipal, filantrópico, universitário segundo municípios antes e depois da implantação da gestão semi plena

QUADRO 7 - Totais anuais de internações SUS ocorridas por municipio, antes e depois da implantação da gestão semi-plena.

QUADRO 8 - Comparação percentuais entre internações SUS e crescimento populacional, por municípios, depois da implantação da gestão semi plena.

QUADRO 9 - $\quad \mathrm{N}^{\circ}$ de internações SUS AlH por 100 habitantes, segundo período de gestão antes e depois, em municipios em gestão semi-plena

QUADRO 10 - Distribuição percentual das internações SUS por especialidades e municípios, no período antes e depois da implantação da gestão semi-plena

QUADRO 11 - Percentuais de Internações SUS por localidade de ocorrência e Capitulo CID-9, antes e depois da gestão semi-plena

QUADRO 12 - Distribuição da freqüência de internações, número total de dias de permanência, tempo médio de permanência, número de óbitos e taxa de mortalidade, nos períodos antes e depois da implantação da gestão semi plena nos 11 municípios em estudo, segundo o procedimento sentinela partos por cesária. 
QUADRO 13 - Distribuição da freqüência de internações, número total de dias de permanência, número de óbitos, percentuais de freqüência e taxa de mortalidade, por classes de permanência em internações, nos períodos antes e depois da implantação da gestão semi plena no município de Assis, segundo o procedimento sentinela infarto agudo do miocárdio

QUADRO 14 - Distribuição da freqüência de internações, número total de dias de permanência, número de óbitos, percentuais de freqüência e taxa de mortalidade, por classes de permanência em internações, nos períodos antes e depois da implantação da gestão semi plena no município de Assis, segundo o procedimento sentinela broncopneumonias.

QUADRO 15 - Distribuição da freqüência de internações, número total de dias de permanência, número de óbitos, percentuais de freqüência e taxa de mortalidade, por classes de permanência em internações, nos períodos antes e depois da implantação da gestão semi plena no município de Campinas, segundo o procedimento sentinela infarto agudo do miocárdio.

QUADRO 16 - Distribuição da freqüência de internações, número total de dias de permanência, número de óbitos, percentuais de freqüência e taxa de mortalidade, por classes de permanência em internações, nos periodos antes $e$ depois da implantação da gestão semi plena no municipio de Campinas, segundo o procedimento sentinela broncopneumonias

QUADRO 17 - Distribuição da freqüência de internações, número total de dias de permanência, número de óbitos, percentuais de freqüência e taxa de mortalidade, por classes de permanência em internações, nos periodos antes e depois da implantação da gestão semi plena no municipio de Diadema, segundo o procedimento sentinela infarto agudo do miocárdio.

QUADRO 18 - Distribuição da freqüência de internações, número total de dias de permanência, número de óbitos, percentuais de freqüência e taxa de mortalidade, por classes de permanência em internações, nos períodos antes e depois da implantação da gestão semi plena no municipio de Diadema, segundo o procedimento sentinela broncopneumonias 
QUADRO 19 - Distribuição da freqüência de internações, número total de dias de permanência, número de óbitos, percentuais de freqüência e taxa de mortalidade, por classes de permanência em internações, nos períodos antes e depois da implantação da gestão semi plena no município de Mauá, segundo o procedimento sentinela infarto agudo do miocárdio

QUADRO 20 - Distribuição da freqüência de internações, número total de dias de permanência, número de óbitos, percentuais de freqüência e taxa de mortalidade, por classes de permanência em internações, nos períodos antes e depois da implantação da gestão semi plena no município de Mauá, segundo o procedimento sentinela broncopneumonias.

QUADRO 21 - Distribuição da freqüência de internações, número total de dias de permanência, número de óbitos, percentuais de freqüência e taxa de mortalidade, por classes de permanência em internações, nos períodos antes e depois da implantação da gestão semi plena no municipio de Santos, segundo o procedimento sentinela infarto agudo do miocárdio

QUADRO 22 - Distribuição da freqüência de internações, número total de dias de permanência, número de óbitos, percentuais de freqüência e taxa de mortalidade, por classes de permanência em internações, nos períodos antes e depois da implantação da gestão semi plena no município de Santos, segundo o procedimento sentinela broncopneumonias.

QUADRO 23 - Distribuição da freqüência de internações, número total de dias de permanência, número de óbitos, percentuais de freqüência e taxa de mortalidade, por classes de permanência em internações, nos periodos antes e depois da implantação da gestão semi plena no município de Santos, segundo o procedimento sentinela infarto cirurgia extra-corpórea

QUADRO 24 - Distribuição da freqüência de internações, número total de dias de permanência, número de óbitos, percentuais de freqüência e taxa de mortalidade, por classes de permanência em internações, nos períodos antes e depois da implantação da gestão semi plena no município de Sertãozinho, segundo o procedimento sentinela infarto agudo do miocárdio. 
QUADRO 25 - Distribuição da freqüência de internações, número total de dias de permanência, número de óbitos, percentuais de freqüência e taxa de mortalidade, por classes de permanência em internações, nos periodos antes e depois da implantação da gestão semi plena no municipio de Sertãozinho, segundo o procedimento sentinela broncopneumonias.

QUADRO 26 - Distribuição da freqüência de internações, número total de dias de permanência, número de óbitos, percentuais de freqüência e taxa de mortalidade, por classes de permanência em internações, nos períodos antes e depois da implantação da gestão semi plena no município de São José dos Campos, segundo o procedimento sentinela infarto agudo do miocárdio.

QUADRO 27 - Distribuição da freqüência de internações, número total de dias de permanência, número de óbitos, percentuais de freqüência e taxa de mortalidade, por classes de permanência em internações, nos períodos antes e depois da implantação da gestão semi plena no município de São José dos Campos, segundo o procedimento sentinela broncopneumonias.

QUADRO 28 - Distribuição da freqüência de internações, número total de dias de permanência, número de óbitos, percentuais de freqüência e taxa de mortalidade, por classes de permanência em internações, nos períodos antes e depois da implantação da gestão semi plena no município de São José dos Campos, segundo o procedimento sentinela infarto cirurgia extra-corpórea...

QUADRO 29 - Distribuição da freqüência de internações, número total de dias de permanência, número de óbitos, percentuais de freqüência e taxa de mortalidade, por classes de permanência em internaçōes, nos períodos antes e depois da implantação da gestão semi plena no município de São Vicente, segundo o procedimento sentinela infarto agudo do miocárdio.

QUADRO 30 - Distribuição da freqüência de internações, número total de dias de permanência, número de óbitos, percentuais de freqüencia e taxa de mortalidade, por classes de permanência em internações, nos períodos antes e depois da implantação da gestão semi plena no municipio de São Vicente, segundo o procedimento sentinela broncopneumonias. 
QUADRO 31- Distribuição da freqüência de internações, número total de dias de permanência, número de óbitos, percentuais de freqüência e taxa de mortalidade, por classes de permanência em internações, nos períodos antes e depois da implantação da gestão semi plena no município de Votorantin, segundo o procedimento sentinela infarto agudo do miocárdio.

QUADRO 32 - Distribuição da freqüência de internações, número total de dias de permanência, número de óbitos, percentuais de freqüência e taxa de mortalidade, por classes de permanência em internações, nos períodos antes e depois da implantação da gestão semi plena no município de Votorantin, segundo o procedimento sentinela broncopneumonias.

QUADRO 33 - Distribuição da freqüência de internações, número total de dias de permanência, número de óbitos, percentuais de freqüencia e taxa de mortalidade, por classes de permanência em internações, nos períodos antes $e$ depois da implantação da gestão semi plena no município de Ribeirão Preto, segundo o procedimento sentinela infarto agudo do miocárdio.

QUADRO 34 - Distribuição da freqüência de internações, número total de dias de permanência, número de óbitos, percentuais de freqüência e taxa de mortalidade, por classes de permanência em internações, nos periodos antes $e$ depois da implantação da gestão semi plena no municipio de Ribeirão Preto, segundo o procedimento sentinela broncopneumonias.

QUADRO 35 - Distribuição da freqüência de internações, número total de dias de permanência, número de óbitos, percentuais de freqüencia e taxa de mortalidade, por classes de permanência em internações, nos períodos antes $e$ depois da implantação da gestão semi plena no município de Ribeirão Preto, segundo o procedimento sentinela infarto cirurgia extra-corpórea.

QUADRO 36 - Distribuição da freqüência de internações, número total de dias de permanência, número de óbitos, percentuais de freqüência e taxa de mortalidade, por classes de permanência em internações, nos periodos antes e depois da implantação da gestão semi plena no município de São Bernardo do Campo, segundo o procedimento sentinela infarto agudo do miocárdio. 
QUADRO 37 Distribuição da freqüência de internações, número total de dias de permanência, número de óbitos, percentuais de freqüência e taxa de mortalidade, por classes de permanência em internações, nos períodos antes e depois da implantação da gestão semi plena no municipio de São Bernardo do Campo, segundo o procedimento sentinela broncopneumonias

QUADRO 38- Distribuição percentual de internações SUS por origem do paciente e municípios no periodo antes e depois da implantação da gestão semi plena

QUADRO 38A Distribuição percentual de internações SUS por origem do paciente e municípios no período antes e depois da implantação da gestão semi plena

QUADRO 39 - Número médio anual de internações SUS por evasão e invasão após implantação da gestão semi plena, por município

QUADRO 40 - Número de internações SUS de pacientes, residentes nos municípios ocorridas em outros municipios (evasão) por municipios e períodos antes e depois da implantação da gestão semi plena

QUADRO 40A- Número de internações SUS de pacientes, residentes nos municipios ocorridas em outros municipios (evasão) por municípios e períodos antes e depois da implantação da gestão semi plena.

QUADRO 41 - Totais anuais de internações SUS por municipios, segundo prestador contratado, antes e depois da implantação da gestão semi-plena.

QUADRO 42 - Totais anuais de internações SUS por municipios, segundo prestador estadual, antes e depois da implantação da gestão semi-plena.

QUADRO 43- Totais anuais de internações SUS por municipios, segundo prestador municipal, antes e depois da implantação da gestão semi-plena

QUADRO 44 - Totais anuais de internações SUS por municipios, segundo prestador filantrópico, antes e depois da implantação da gestão semi-plena.

QUADRO 45- Totais anuais de internações SUS por municipios, segundo prestador universitário, antes e depois da implantação da gestão semi-plena.

QUADRO 46- Totais anuais de internações SUS: 50 procedimentos mais freqüentes considerando-se os 11 municipios, antes e depois da implantação da gestão semi-plena..... 
QUADRO 47 - Totais anuais de internações SUS pelos 50 procedimentos mais freqüentes, ocorridos no município de Assis - SP, antes e depois da implantação da gestão semi-plena.

QUADRO 48 - Totais anuais de internações SUS pelos 50 procedimentos mais freqüentes, ocorridos no município de Campinas - SP, antes e depois da implantação da gestão semi-plena.

QUADRO 49 - Totais anuais de internações SUS pelos 50 procedimentos mais freqüentes, ocorridos no município de Diadema - SP, antes e depois da implantação da gestão semi-plena.

QUADRO 50 - Totais anuais de internações SUS pelos 50 procedimentos mais freqüentes, ocorridos no município de Mauá - SP, antes e depois da implantação da gestão semi-plena.

QUADRO 51- Totais anuais de internações SUS pelos 50 procedimentos mais freqüentes, ocorridos no município de Ribeirão Preto - SP, antes e depois da implantação da gestão semi-plena.

QUADRO 52 - Totais anuais de internações SUS pelos 50 procedimentos mais freqüentes, ocorridos no município de Santos - SP, antes e depois da implantação da gestão semi-plena.

QUADRO 53- Totais anuais de internações SUS pelos 50 procedimentos mais freqüentes, ocorridos no municipio de São Bernardo do Campo - SP, antes e depois da implantação da gestão semi-plena.

QUADRO 54- Totais anuais de internações SUS pelos 50 procedimentos mais freqüentes, ocorridos no município de São José dos Campos - SP, antes e depois da implantação da gestão semi-plena

QUADRO 55 - Totais anuais de internações SUS pelos 50 procedimentos mais freqüentes, ocorridos no municipio de Sertãozinho - SP, antes e depois da implantação da gestão semi-plena.

QUADRO 56- Totais anuais de internações SUS pelos 50 procedimentos mais freqüentes, ocorridos no município de São Vicente - SP, antes e depois da implantação da gestão semi-plena.

QUADRO 57 - Totais anuais de internações SUS pelos 50 procedimentos mais freqüentes, ocorridos no municipio de Votorantim - SP, antes e depois da implantação da gestão semi-plena. 
QUADRO 58 - Valores gastos com internações SUS hospitalares, por municipios, antes e depois da implantação da gestão semi-plena.

QUADRO 59 - Distribuição percentual dos gastos com internações SUS por especialidades e municípios, antes da implantação da gestão semi-plena.

QUADRO 60 - Distribuição dos percentuais de gastos com internações SUS, por origem dos pacientes e municípios e procedimentos sentinela, antes e depois da implantação da gestão semi plena

QUADRO 61- Distribuição dos percentuais dos gastos com internações SUS, por origem dos pacientes $\mathrm{e}$ municípios, antes e depois da implantação da gestão semi plena.

QUADRO 62- Distribuição percentual dos gastos com internações SUS por prestadores e municípios, antes e depois da implantação da gestão semi-plena

QUADRO 63- Distribuição percentual dos gastos com internações SUS pelos 50 procedimentos mais dispendiosos ocorridos nos 11 municípios, antes e depois da implantação da gestão semi-plena.

QUADRO 64- Distribuição percentual dos gastos com internações SUS pelos $50^{\circ}$ procedimentos mais freqüentes, ocorridos no municipio de Assis - SP, antes e depois da implantação da gestão semi-plena.

QUADRO 65 - Distribuição percentual dos gastos com internações SUS pelos 50 procedimentos mais freqüentes, ocorridos no município de Campinas - SP, antes e depois da implantação da gestão semi-plena.

QUADRO 66 - Distribuição percentual dos gastos com internações SUS pelos 50 procedimentos mais freqüentes, ocorridos no município de Diadema - SP, antes e depois da implantação da gestão semi-plena.

QUADRO 67- Distribuição percentual dos gastos com internações SUS pelos 50 procedimentos mais freqüentes, ocorridos no município de Mauá - SP, antes e depois da implantação da gestão semi-plena.

QUADRO 68 - Distribuição percentual dos gastos com internações SUS pelos 50 procedimentos mais freqüentes, ocorridos no município de Ribeirão Preto - SP, antes e depois da implantação da gestão semi-plena. 
QUADRO 69- Distribuição percentual dos gastos com internações SUS pelos 50 procedimentos mais freqüentes, ocorridos no município de Santos - SP, antes e depois da implantação da gestão semi-plena.

QUADRO 70 - Distribuição percentual dos gastos com internações SUS pelos 50 procedimentos mais freqüentes, ocorridos no municipio de São Bernardo do Campo $\mathrm{SP}$, antes e depois da implantação da gestão semiplena

QUADRO 71 - Distribuição percentual dos gastos com internações SUS pelos 50 procedimentos mais freqüentes, ocorridos no município de Sertãozinho - SP, antes e depois da implantação da gestão semi-plena.

224

QUADRO 72- Distribuição percentual dos gastos com internações SUS pelos 50 procedimentos mais freqüentes, ocorridos no município de São José dos Campos - SP, antes e depois da implantação da gestão semi-plena ....

QUADRO 73 - Distribuição percentual dos gastos com internações SUS pelos 50 procedimentos mais freqüentes, ocorridos no município de São Vicente - SP, antes e depois da implantação da gestão semi-plena.

QUADRO 74 - Distribuição percentual dos gastos com internações SUS pelos 50 procedimentos mais freqüentes, ocorridos no município de Votorantim - SP, antes e depois da implantação da gestão semi-plena.

QUADRO 75- Tempo médio de permanência em internações SUS por municípios e prestador, antes e depois da implantação da gestão semi plena

QUADRO 76- Tempo médio de permanência em internações SUS por localidade e Capitulo CID IX, nos períodos antes e depois da gestão semi plena no Estado de São Paulo ..

QUADRO 77 - Taxa de mortalidade por internações SUS por percentual e localidade de ocorrência e Capitulo CID IX, nos períodos antes e depois da gestão semi plena, no Estado de São Paulo

QUADRO 78 - Taxa de mortalidade de internações SUS nos municípios, por prestador, antes e depois da implantação da gestão semi plena, no Estado de São Paulo.

QUADRO 79 - Taxa de mortalidade em percentual por localidade de ocorrência e Capitulo CID - IX, nos períodos antes e depois da gestão semi-plena, no Estado de São Paulo. 
I- INTRODUÇÃO 


\subsection{Descentralização e Democracia}

A forma federativa de governo é um fato político no continente americano ao longo da sua história.

A diversidade de situações possibilitou um processo de oscilação entre centralização e descentralização de poder; as grandes Guerras do século XX levaram à centralização do Estado na sua luta para mobilizar esforços necessários para o embate da guerra, que ao final da $2^{*}$ Guerra Mundial, entrou em declínio, apesar de teorias da época afirmarem que apenas o Estado centralizador tinha capacidade de implementar macro projetos que viessem a viabilizar o futuro desenvolvimento.

O fracasso do Estado central, especialmente depois da crise econômica dos anos 70 , juntamente com um visível descompasso entre os governantes e seus governados, resultou em questionamento dos modelos vigentes $e$, como resultado, uma expansão de experiências na descentralização e democratização.

A questão da descentralização deve ser compreendida em contexto mais complexo. O processo de descentralização reflete uma ampla reforma política e econômica na maioria dos países. Mudanças políticas através do mundo têm dado voz às demandas locais e a necessidade de aproximar os sistemas econômicos e politicos das comunidades. Mudanças tecnológicas e uma maior integração global em decorrência de fatores de mercado têm algumas vezes feito oscilar o tamanho da governança necessária para gerenciar os sistemas econômicos.

Entendida essa problemática, a descentralização das políticas públicas tem sido, um tema privilegiado na agenda pública do Brasil, principalmente a partir da Constituição de 1988. 
Definir descentralização não tem sido uma tarefa fácil. Isto porque ela toma diversas formas e dimensões na medida em que envolve uma ampla variedade de reestruturação institucional sujeita a outras tantas variantes operando dentro do mesmo país ou até do mesmo setor.

Em conferência proferida sobre o tema, RUíz (1997), assim se pronunciou: "Descentralización es un proceso político-administrativo, por medio del cual se transfiere a los órganos territoriales de gobiemo, parte o la totalidad de la autoridad o funciones que detenta el Estado. Según sea el nivel y la natureza de la transferencia que se realiza, la descentralización puede ser política o administrativa.

SHOUKAY (1996) entende que a descentralização consiste "em mudar o sistema administrativo daquele que é "uniforme e centralizado" e que enfatiza a unidade nacional para aquele que é "diversificado e descentralizado" e respeita o ponto de vista dos residentes locais e das regiōes".

Note-se, que a descentralização é um conceito diferente da desconcentração. Esta supõe a transferência de poder de decisão, contratação e execução por autoridades centrais a órgãos hierarquicamente subordinados que thes são dependentes; não é mais do que a substituição da hierarquia administrativa por uma agência local, uma relação entre órgão de uma mesma pessoa jurídica.

Descentralização supõe transferência a uma entidade com personalidade jurídica própria, podendo envolver desde funções unicamente administrativas, até legislativas, tributárias, financeiras e, em certos casos, jurisdicionais.

Esses esclarecimentos são necessários para que não se confunda autonomia política com descentralização política. A autonomia 
política implica competências funcionais e legislativas, ainda que com a coordenação e sujeição correspondente a respeito das normas constitucionais e leis nacionais, além das competências de caráter administrativo, financeiro e tributário. Implica a competência de entidades públicas territoriais com personalidade jurídica, para organizar-se juridicamente e criar direito próprio. A autonomia política pressupõe uma descentralização funcional legislativa, tributária e financeira, assim como uma regulamentação na aplicação de suas próprias leis, o poder para organizar dentro do seu âmbito territorial seus próprios poderes, e designar suas próprias autoridades dentro dos limites da Constituição Nacional.

Quando a autonomia política emana da função constituinte, tratase da forma de Estado Federal de que as coletividades territoriais que a compõem obtém diretamente da Constituição suas competências funcionais.

Por descentralização politica, entende RUIZ (1997), aquela que além de transferir as funções da administração financeira e tributária, dota os agentes públicos e uma determinada base territorial, de uma competência legislativa. Segundo o autor,

"A descentralização administrativa se limita à transferência de funções para uma melhor organização da administração e pode ser definida como um processo de transferência de competências anteriormente exercidas pela administração central, até uma pessoa jurídica diferente, não submetida hierarquicamente, que conta com um organismo decisório eleito mediante sufrágio com participação dos interessados e que pode decidir irrevogavelmente e de maneira independente no âmbito de suas novas propostas especificas."

Argumenta-se que a descentralização promove benefícios na medida em que aumenta as eficiências na produtividade. Entidades locais são direcionadas a compreenderem e responderem melhor as demandas, 
alocando de forma eficiente os exíguos recursos, elevando o grau de satisfação e bem-estar. Além disso, as entidades locais têm condição de fornecer mercadorias a preço mais baixo do que a nível nacional. Observese que essa é a visão do tecnocrata. Na prática, afirma PIRIOU (1995) que os governos têm baseado suas decisões políticas para a descentralização muito mais de uma ótica superficial dos beneficios que tal processo possa trazer. Dentre as razões para se promover a descentralização inclui-se a crise fiscal do governo central e a sua pálida atuação na prestação dos serviços e na crença que a descentralização possa ajudar a solucionar os conflitos sociais e restaurar a legitimidade do govemo.

A descentralização não é um fim, mas sim um meio para alcançar a obtenção de maior eficácia e eficiência no cumprimento de objetivos públicos e para aproximar o poder do cidadão, possibilitando assim a abertura do sistema a uma mais direta e responsável participação da população.

Em quase todos os países tem surgido uma demanda para descentralizar, com o propósito de aumentar a eficiência da ação pública e aproximar o administrador da sua comunidade. Uma relação entre descentralização e democracia implica em que um regime descentralizado goza de maior legitimidade democrática daquele que não o é, e que através da descentralização pode-se alcançar uma maior democratização institucional, social e sócio-econômica.

A democracia, pela sua própria natureza, para ser exercida em sua plenitude, impõe a adoção de um regime descentralizado; é quando certamente a descentralização pode contribuir para o fortalecimento, ampliação e plenitude do sistema democrático. A descentralização dificilmente poderá ocorrer em contextos não democráticos, devido às características intrínsecas a esses regimes que contemplam as necessidades de uma autoridade central que se estende verticalmente até 
as instâncias regionais e locais. A não existência de controles regionais, a não participação das comunidades e da população em geral nas decisões e acordos de programas e ações a implementar, assim como a escassa ou nula representatividade outorgada às autoridades locais pela população a qual atendem, constituem virtualmente a negação de postulados fundamentais da descentralização.

Nos regimes democráticos com elevado grau de estratificação econômica ou social, o processo de descentralização se aceito, pode se constituir num instrumento importante para abrir essas sociedades e gerar processos democratizadores nos diversos niveis de governo. Por outro lado, quando se transferem funções e responsabilidades aos niveis regionais e locais, se existem estruturas hierárquicas ou excessivamente estratificadas, pode ocorrer uma capitalização pelos escalões privilegiados, dos beneficios que podem derivar-se das novas funçōes nas instâncias objeto das transferências. Assim mesmo é possível que algumas regiões ou zonas com maior possibilidades ou com vinculação mais próxima e mais forte com os niveis centrais, podem por sua vez concentrar os benefícios das transferências, fortalecendo o desenvolvimento de suas áreas em detrimento das outras.

Nestes casos se o governo nacional mantém uma vontade distributiva e a busca de um nivel de equidade, poderá intervir condicionando as entregas e transferências ao cumprimento de determinados critérios de prioridade e modalidade de inversão e execução.

A questão da descentralização em um Estado em transformação apresenta diversas facetas. Um dos elementos a serem enfatizados é a criação de instituições para promoverem organização cultural e sócio econômica e organizar a sociedade em geral. A esse respeito enfatiza WICEHERS (1996) a natureza informal e geralmente espontânea do desenvolvimento. Acredita ele que "desenvolvimento e democracia devem 
ser organizados" o que não significa a criação de uma pletora de instituições com regulamentações rígidas. Para o autor, "uma sociedade estruturada tem várias formas de organizar-se, ainda que formalmente ou informalmente. $E$ em uma sociedade organizada que o desenvolvimento apresenta maiores chances de sucesso." E questiona, de forma retórica, "deve o Estado se envolver na organização da sociedade e no estabelecimento das instituições?".

Desde Alexis de Tocqueville, citado por CASTRO (1991), a relação entre governo local, participação e democracia vem sendo defendida como corolário fundamental do aprofundamento democrático. A autogestão local permite, segundo o referido autor, a compreensão prática das responsabilidades públicas entre governantes e governados na resolução de assuntos cotidianos, estimulando a participação no plano micro como base da democracia enquanto sistema macropolítico.

Sem dúvida a descentralização não é uma fórmula mágica que muda por si só as relações politicas, pode servir também para diluir responsabilidades, ou contribuir para agravar conflitos de competências e funções, sem conduzir a uma integração do sistema.

Em seu artigo Dez Anos de Descentralização, SOUZA (1998) define que o conceito de governo local no Brasil é associado ao de governo da cidade e ao de gestão urbana devido às altas taxas de urbanização no país. Tamanho geográfico, características demográficas e grau de desenvolvimento variam de um municipio para outro. No Brasil, a definição oficial de área urbana é meramente administrativa, incluindo todas as municipalidades e distritos, independentemente de tamanho.

O município é uma instituição que está nas raizes de nossa história. Foi introduzido no Brasil, há mais de quatro séculos, com a 
fundação da Vila de São Vicente, em 1532, no litoral do Estado de São Paulo.

\subsection{Descentralização e Democracia no Brasil}

O destino da democracia no Brasil estava ligado à descentralização do Poder e à participação da sociedade. O processo político brasileiro, excessivamente centralizador e autoritário, desde os tempos do Brasil-Colônia, o Poder central impôs ao País, de cima para baixo, um modelo de desenvolvimento elitista, com a marginalização e o sacrifício da maioria da população. Esse modelo tem sido retratado, de forma não menos injusta, nas estruturas dos poderes locais, denominado coronelismo.

Um exemplo atual e eloqüente das conseqüências do alto grau de centralização foi apontado no Relatório Oficial do Brasil à Cúpula Mundial de Copenhague (1995): "Em meados da década de 80 , somente $10 \%$ dos recursos empregados pelo governo brasileiro em programas sociais atingiam seu público-alvo". Isso significa que $90 \%$ dos recursos destinados à área social foram absorvidos pelo aparato institucional, pelo alto grau de centralização e por medidas de seriedade discutível, além de fraudes, superfaturamentos, corrupção. A descentralização de recursos e responsabilidades é o melhor caminho para a solução dos problemas nacionais, isto porque o que puder ser feito por uma comunidade menor não deve ser feito por um organismo de nivel superior. As iniciativas e atividades locais estão mais perto da população e são, por isso, mais realistas, econômicas e eficientes. É preciso apoiar e aproveitar o imenso potencial dos recursos da sociedade civil. Mas isto exige uma atitude democrática mais sincera do que as autoridades brasileiras geralmente manifestam, cujo objetivo tem sido tornar os cidadãos dependentes, para que possam ser controlados. O critério básico para a delimitação dessas atribuições deve 
ser sempre o bem comum, isto é o bem-estar e a qualidade de vida da população e não o interesse de determinados grupos ou setores.

Progressivamente despontou um debate contemporâneo com questões que contemplam a descentralização do Estado como resposta à crise do "Estado de Bem Estar", e que ganhou amplitude, sobretudo, a partir da década de 70 , onde, muitos países europeus desenvolveram reformas institucionais visando a descentralização do Estado e a reorganização da gestão territorial dos processos econômicos, sócio políticos e administrativos ( NETO 1990).

VIANA (1998) entende que o processo de descentralização ocorre em três períodos distintos: "O primeiro, periodo que se inicia no final dos anos 70, destacam-se o movimento municipalista, a característica desse periodo é o forte movimento de prefeitos aliados a alguns governadores e com alguma base parlamentar, no entanto sem respaldo de uma lei maior ou geral da descentralização e sem uma iniciativa coordenada no sentido de ampliar as responsabilidades e funçōes dos governos municipais; no segundo momento após 1988, iniciativas de todos os entes governamentais (federal, estadual e municipal) se combinam em torno da meta descentralizante. Esse período é marcado por expressivas transferências de recursos para Estados e Municípios; projetos setoriais de descentralização (SUS), há disseminação do lema da descentralização associada a novos tipos de participação da população e do conceito de cidadania; os conselhos. O terceiro periodo, anos 90 , se caracteriza como retrocesso no movimento mais geral da descentralização, aprofundando em 1994, quando se pode falar em processo de descentralização do ajuste fiscal ( $O$ Fundo Social de Emergência em 1994 e O Fundo de Estabilização Fiscal) são instrumento de recentralização.

MELLO (1993) identifica em seu trabalho as seguintes estratégias para que um processo de descentralização tenha êxito: 
"a) mobilização para que se manifestem a vontade e a decisão politicas indispensáveis ao processo;

b) atribuição de funções e responsabilidades que permitam aos governos locais o exercício de um papel significativo no processo de desenvolvimento;

c) alocação de recursos financeiros, compativel com o papel dos governos locais;

d) gradualismo na execução de determinados aspectos do processo de descentralização, como medida para assegurar seu êxito;

e) assessoria técnica aos governos locais para o correto desempenho de suas novas atribuições, inclusive o manejo dos recursos adicionais que thes tenham sido atribuido;

f) estabelecimento se necessário, de mecanismos de responsabilidade pública ou politica de autoridades locais."

\subsection{A Descentralização da Saúde no Brasil}

A descentralização como processo, na área de saúde, pode ser identificada a partir de meados da década de setenta com implantação de serviços de saúde, influenciados pelas propostas de atenção primária.

$\mathrm{Na}$ década de 80 dois fatos foram marcantes para a descentralização um deles, a mobilização de instâncias municipais como reação ao centralismo federal e estadual na área de saúde, associada ao esgotamento do regime autoritário com a conquista política da oposição em alguns Estados.

O segundo, a crise da assistência médica da previdência social e a proposta contida no "Plano de Reorientação de Assistência à Saúde" Plano CONASP, MS MPAS (1982) que entende a reorganização da saúde 
através de convênios trilaterais envolvendo o Ministério da Previdência Social, o da Saúde e as Secretarias Estaduais de Saúde, visando a implementação das Ações Integradas de Saúde (AIS) que se caracterizavam como estratégia de descentralização da saúde (COSTA 1986).

E meados da década de 80 , a realização da VIII Conferência Nacional de Saúde foi importante marco para a formulação do futuro Sistema Único de Saúde, consagrado na Constituição Federal de 1988, BRASIL (1995) assim como contribuiu para a organização e articulação do movimento municipalista de saúde. Também é desse periodo o $\mathrm{V}$ Encontro Nacional dos Secretários Municipais de Saúde onde é fundado o Conselho Nacional dos Secretários Municipais de Saúde (CONASEMS); fato marcado pelo momento de coincidência para as concepções e teses sobre a organização da saúde no Brasil, do "Movimento Municipalista da Saúde" e "Movimento da Reforma Sanitária" que consegue inscrever na Constituição Federal princípios e diretrizes - universalidade dos serviços, a saúde como bem público, a descentralização, e a participação da comunidade.

TEIXEIRA (1988), ressalta que a Constituição de 1988, incorpora um conjunto de conceitos, principios e diretrizes extraidos da prática corrente e hegemônica, mas propondo uma nova lógica organizacional pretendida pelo movimento da Reforma Sanitária.

Os pontos centrais consolidados no texto legal que traduzem essa nova lógica são: "A saúde é um direito de todos e um dever do Estado... que o dever do Estado de garantir a saúde consiste na formulação e execução de políticas econômicas e sociais que visem à redução de riscos de doenças e outros agravos, e ao estabelecimento de condições que assegurem acesso universal e igualitário às ações e aos serviços de proteção, defesa, promoção, prevenção, preservação e recuperação da saúde; as ações dos serviços públicos de saúde integram uma rede regionalizada e hierarquizada 
e constitui um sistema único, organizado de acordo com as seguintes diretrizes:

1. descentralização, com direção única em cada esfera de governo;

2. atendimento integral, com prioridade para as atividades preventivas, sem prejuizo dos serviços assistenciais;

3. participação da comunidade...: as instituições privadas poderão participar de forma complementar ao sistema único de saúde, tendo preferência as entidades de caráter filantrópico e as sem fins lucrativos..." (BRASIL1995).

Como decorrência da Constituição Federal, elaborou-se, as Leis e Regulamentações, que consolidaram as condições para a promoção, proteção e recuperação da saúde e também as novas Constituições Estaduais e Leis Orgânicas Municipais.

Do ponto de vista do arcabouço jurídico institucional, a regulamentação do texto constitucional, referente à saúde, chega aos municipios através das Leis Orgânicas Municipais. Apesar destas reproduzirem, na essência, os niveis federal e estadual, cada uma delas apresenta especificidades locais importantes, a partir dos atores e da própria problemática municipal.

O Artigo 200 da Constituição BRASIL (1995), estabelece a competência do SUS, além de outras atribuições nos termos da lei: 
I. controlar e fiscalizar procedimentos, produtos e substâncias de interesse para a saúde e participar na produção de medicamentos, equipamentos, imunobiológicos, hemoderivados e outros insumos;

II. executar as ações de vigilância sanitárias e epidemiológica, bem como as de saúde do trabalhador;

III. ordenar a formação de recursos humanos na área de saúde;

IV. participar da formulação da politica e da execução das ações de saneamento básico;

V. incrementar em sua área de atuação o desenvolvimento científico e tecnológico;

VI. fiscalizar e inspecionar alimentos compreendido o controle de seu teor nutricional, bem como bebidas e águas para consumo humano;

VII. participar do controle e fiscalização da produção, transporte, guarda e utilização de substâncias e produtos psicoativos, tóxicos e radioativos;

VIII. colaborar na proteção do meio ambiente, nele compreendido o do trabalho.

E ० Artigo 30, I, II e VII, também da Constituição, estabelece que compete aos municípios "legislar sobre assuntos de interesse local ... suplementar a legislação federal e a estadual no que couber... e ... prestar 
com a cooperação técnica e financeira da União e do Estado, serviços de atendimento à saúde da população".

A lei 8080 BRASIL (1990) é complementada pela Lei $8142 / 90$ BRASIL (1990), que dispõe sobre a participação da comunidade na gestão do SUS e sobre as transferências intragovernamentais de recursos financeiros na área da saúde e dá outras providências.

Quanto às instâncias gestoras a Lei 8142/90 BRASIL (1990) prevê não só o Conselho, como dispõe que a participação da burocracia governamental, dos prestadores de serviços, dos profissionais do setor e dos usuários será paritária.

Quanto aos repasses de recursos, a Lei original previu o repasse automático, baseados nos seguintes critérios: população, perfil epidemiológico, gasto proporcional em serviços, desempenho técnico/financeiro e econômico de periodo anterior e plano qüinqüenal de investimento. Estabelecia ainda um teto minimo para os repasses aos municípios (não inferior a $45 \%$ do Fundo de Saúde) e a abolição da forma Convênio.

Assim, segundo CARVALHO (1993) e NETO (1996) como "essenciais ao Sistema Único de Saúde a autonomia de Estados e Municipios ainda que pertencentes a um Estado federado, o principio da descentralização; a valorização da cidadania pela participação popular como mecanismo de controle da sociedade como um todo, tanto do público como do privado", devem ser garantidos.

No processo de implementação do SUDS e SUS, as CRIS, CIMS e os Conselhos Municipais de Saúde, foram institucionalizados como canais de participação social. Quanto mais intersetoriais, representativos e 
deliberativos esses Conselhos na formulação das Politicas de Saúde, maior será a efetividades destas.

A participação e controle social, a regulamentação do SUS e a transformação dessas instâncias em Conselhos Municipais de Saúde, embora estabelecidos na maioria dos municípios, segundo estudos realizados por IBAM (1991) "representam uma forma embrionária de participação e controle social e apesar de seu caráter deliberativo, com algumas exceções vem funcionando como instâncias de denúncias e circulação de informações sobre o sistema", no que JUNQUEIRA (1998) propõe uma nova lógica para superar a exclusão social e tornar eficaz a descentralização da gestão da cidade, será buscando superar a fragmentação das politicas e considerar o cidadão nas suas necessidades individuais e coletivas, ou seja a partir da intersetorialidade.

Do ponto de vista administrativo, a proposta de "reforma sanitária" definiu, a partir do próprio texto constitucional e através da Lei Orgânica 8080, 19 de setembro de 1990 do SUS, um conjunto de normas que destacam gerenciamento do novo modelo assistencial como fator decisivo para a melhoria de seu desempenho, mediante técnicas de planejamento, coordenação e direção que respaldem efetivamente a transferência de competências para os niveis local e regional.

As diferenças regionais entre os Estados, calcadas em diferentes situações econômico-sociais, perfis epidemiológicos, infraestrutura e poder de gestão foram vistas como fatores relevantes a serem considerados nesse processo.

O grau de efetividade do processo de descentralização e gestão, dependeu e gerou um continuum de situações de maior ou menor integração interinstitucional, a partir da capacidade administrativa, estruturas regionais concentradas ou desconcentradas existentes, determinadas em última 
instância, por atores políticos (governadores, prefeitos), e pelas diferentes realidades institucionais dos Estados. As instâncias regionais na maioria dos Estados brasileiros, com diferentes denominações (DIRES, DISTRITOS, ERSAS, DIR etc.) foram e são peças importantes, mas sua real situação quanto à descentralização (autonomia financeira, gestão de recursos humanos e materiais, etc.) acabaram delimitando o avanço do processo de municipalização (IBAÑEZ 1991).

Do ponto de vista do planejamento, o principal instrumento criado nesse processo foi o Programa de Orçamentação Integrada (POI) que com o avanço da municipalização nos Estados, constitui-se na base dos Planos Diretores Municipais.

No caso específico do Estado de São Paulo, a reforma administrativa de 1986, que cria os ERSAS (Escritórios Regionais de Saúde), em número de 65 e sua posterior transformação em SUDSRegional, e atualmente DIRs (Diretorias Regionais de Saúde), favoreceu sobremaneira o avanço da municipalização e a coordenação dos recursos regionais, dado o grau de implementação da descentralização alcançado por essas instâncias.

Todas as mudanças ocorridas nas décadas de 80 e 90, iniciaram um grande desafio para a condução, organização e gerência dos sistemas municipais. Na maioria dos municipios dois grandes processos podem ser destacados e que tem relevância para a organização e gerência desses sistemas: o primeiro, caracterizado pelo lado da demanda de serviços, com a existência de uma explosão e diversificação das expectativas da sociedade em geral, dada a crescente urbanização e a incorporação de grupos sociais marginalizados pela crise econômica e pelo próprio envelhecimento demográfico dessa população; o segundo, caracterizado pelo lado da oferta de serviços, em uma urgência em maximizar a equidade, a eficiência e o impacto, que ao incorporar à assistência grupos 
populacionais marginalizados, vem aumentando relativamente sua incapacidade operativa pela debilidade crônica nos processos de condução e gerência, frente aos requisitos dos sistemas de serviços de saúde e sua multiinstitucionalidade.

A esse respeito, argumenta SELCHER (1990) que a difusão do poder entre os diversos niveis poderia apresentar melhores resultados observado-se o que se segue, entre outros:

1) Desenvolvimento de redes cooperativas estaduais e locais, em federalismo horizontal;

2) Maior participação estadual nos órgãos de desenvolvimento regional;

3) Permissão de Brasilia para que Estados e Municipios tomem a iniciativa de projetos, bem como estímulo de várias formas, em lugar de dificuldades para a transferência uniforme e gradual de responsabilidades;

Para MEDICl (1990) no caso do Brasil, a continuidade da estratégia de descentralização posta em marcha pelo Sistema Único de Saúde, balizada por um aumento dos recursos e pela sua melhor distribuição regional, acoplada a reformas que garantam uma efetiva modernização dos sistemas gerenciais, poderão resolver boa parte dos problemas e transmitir maior flexibilidade de ajustes dos recursos para a saúde às condições regionais, bem como maior visibilidade na aplicação dos mesmos.

O processo de descentralização do SUS, ainda que apresentando avanços e retrocessos, foi continuado com a NOB 01/96, BRASIL (1996), que, por questões politicas/administrativas, só foi iniciada em 1998, dando, 
portanto, continuidade ao processo de implantação do SUS e mantendo como um dos eixos centrais a Descentralização.

Após 5 anos da vigência da Constituição, e 3 da aprovação da Lei Orgânica da Saúde, o Governo Federal deu passos firmes na implementação da descentralização, visando a "Municipalização da Saúde". $O$ instrumento fundamental para alavancar este processo foi a Norma Operacional Básica, NOB/SUS 01/93, BRASIL (1993), aprovada pela Portaria n. 545 do Ministério da Saúde. Essa NOB "regulamenta o processo de descentralização da gestão dos serviços e ações no âmbito do Sistema Único de Saúde e estabelece os mecanismos de financiamento das ações de saúde, em particular da assistência hospitalar e ambulatorial, e as diretrizes para os investimentos no setor"; marca de forma indelével o curso a ser seguido pela descentralização da saúde, balizando seus limites e suas possibilidades.

A proposta de descentralização presente na NOB 01/93 (MS 1993) é ousada pois busca dar conta de vários e complexos aspectos, tais como o modelo assistencial, a redefinição de competências das esferas de governo, e a questão dos recursos humanos, dentre outros. No entanto, em seu detalhamento operativo podem-se identificar dois pilares fundamentais: o financiamento das ações de saúde e o controle social.

Vale ressaltar, ainda, duas ordens de questões levantadas a partir da centralidade do financiamento como principal instrumento para a municipalização, segundo as concepções da NOB-01/93. A primeira delas refere-se ao papel desempenhado pela AlH (Autorização de Internação Hospitalar), e UCA (Unidade de Cobertura Ambulatorial), na condição de instrumento financeiro, como a principal ação transferida para as instâncias mais periféricas, embora sob o controle real da instância federal. Segundo VIANNA (1991), esta forma de transferência de recursos significa, uma maneira de se preservar o poder centralizado em detrimento das demais 
esferas de governo. Nestes termos, o autor concluí que "a descentralização não se consolidará, enquanto subsistirem, entre instâncias governamentais, essas formas de relacionamento, espúrias em um sistema constitucionalmente descentralizado".

A segunda questão, se refere à fórmula utilizada para se estimar o montante a ser transferido, baseada na fixação de tetos financeiros máximos para Estados e Municípios, a partir de séries históricas dos seus respectivos gastos com AlH e UCA. Com isto privilegiam-se as unidades federadas com maior capacidade instalada da rede física de serviços e aquelas com maior complexidade tecnológica, em detrimento da observância do princípio da eqüidade na distribuição dos recursos com vistas à melhoria do padrão de universalidade e do acesso aos serviços de saúde para a população, VIANNA (1991), CORDEIRO (1991).

Por outro lado, a estratégia política para implementação da NOB pressupõe "uma ação pactuada", MS (1993) entre as esferas de governo. Daí serem formalizadas duas instâncias de negociação governamental: no nivel federal, a Comissão Tripartite Intergestores, composta por representantes do Ministério da Saúde, do Conselho Nacional de Secretários de Saúde (CONASS), e do Conselho Nacional de Secretários Municipais de Saúde (CONASEMS); no nivel estadual, as Comissões Bipartites Intergestores, com representantes das Secretarias Estaduais de Saúde e membros indicados pela entidade de representação dos secretários municipais de saúde. Define-se a Comissão Bipartite como instância preferencial para os pleitos municipais, cabendo recurso à Comissão Tripartite em caso de desacordo entre as partes, configurando-se assim uma hierarquização entre as instâncias federadas, de modo a dar conta dos conflitos de interesses, sejam eles políticos, técnicos ou administrativos. 
Assim, a constituição e o funcionamento pleno dos Fundos e dos Conselhos de Saúde são requisitos indispensáveis para que Estados e Municipios se candidatem à descentralização.

A estratégia operacional contemplada pela NOB 01/93 (MS 1993) concebe 0 desenvolvimento da descentralização como um modelo de transição, composto por etapas progressivas - da menor para a maior complexidade -, a serem percorridas por Estados e Municípios, não necessariamente na ordem da seqüência prevista. A delimitação entre essas etapas é dada pelo grau de capacitação técnica e gerencial apresentada pelo Município/Estado para assumir, no âmbito de sua atuação, as atribuições relativas ao financiamento, poderem exercer de fato a autonomia que lhes é concedida constitucionalmente. O principal dentre estes tópicos é a superação da modalidade convênio como forma de administração e gerenciamento do sistema de saúde, bem como pela capacidade de promover a reorganização do modelo assistencial.

São três as situações de transição previstas, apresentadas a seguir, com um breve resumo das principais responsabilidades inerentes a cada uma delas:

Incipiente: prerrogativa na autorização de credenciamento, descredenciamento, controle e avaliação dos serviços ambulatoriais e hospitalares do município; distribuição da cota de AlH negociada na Comissão Bipartite; gerenciamento da rede ambulatorial pública existente no município; reorganização do modelo de assistência, incluindo a incorporação das ações de vigilância epidemiológica e sanitária à rede de serviços; desenvolvimento de capacitação para programar, acompanhar, avaliar e controlar suas ações de saúde;

Parcial: todas as previstas na situação anterior acrescidas do recebimento dos recursos financeiros referentes à diferença entre o teto 
fixado pela Comissão Bipartite e o efetivamente gasto na assistência ambulatorial e hospitalar; aprofundamento das responsabilidades em relação a vigilância epidemiológica e sanitária;

Semiplena: exercendo a totalidade de suas responsabilidades no gerenciamento e no reordenamento do modelo assistencial. Mantêm-se a série histórica dos gastos realizados como base para o cálculo do teto financeiro, determinado pela Comissão Bipartite a ser repassado diretamente para o município.

Prevê o documento MS (1993) que a conclusão dessas etapas se daria numa situação denominada "desejada". segundo a qual os Estados e os Municípios assumiriam plenamente a gestão do SUS e os repasses financeiros seriam globais, realizados de modo direto e automático, nos termos previstos pela Lei 8142/90 BRASIL (1990). Essa lei estabelece basicamente uma composição entre critérios populacionais e epidemiológicos para o cálculo das transferências.

O esforço empreendido pela NOB 01/93, MS (1993), definido nas situaçōes Semiplena e Plena, para superar alguns dos tópicos que historicamente têm dificultado a descentralização da saúde no sentido de as instâncias mais locais poderem exercer de fato a autonomia que thes é concedida constitucionalmente, é a superação da modalidade convênio como forma de transferência financeira, substituída pela forma de repasse Fundo a Fundo, isto é, do Fundo Nacional de Saúde para o Fundo Estadual ou Municipal, condição prevista apenas nas situações Semiplena e Plena. Apesar das intenções e do empenho dos formuladores da proposta de municipalização, mantiveram-se intocadas questōes relevantes para a descentralização, tais como a fixação do repasse financeiro através da determinação de tetos calculados a partir de séries históricas dos gastos e o controle centralizado da normalização a da fixação dos valores para tabelas de abrangência nacional referentes à AlH e UCA. 
Para CARVALHO ( ) "esse processo foi extremamente rico nos 150 municipios que assumiram a gestão semi plena municipal. Passaram a ser gestores de todos recursos municipais, estaduais e federais dentro do município, fazendo o papel de gestor único: executando, controlando, fiscalizando, controlando, avaliando..."

Segundo o Ministério da Saúde, até maio de 1995 apenas 43\% dos municípios brasileiros, ou precisamente 2584 deles, encontravam-se habilitados em alguma modalidade de gestão descentralizada do SUS, nos termos a NOB 01/93. Destes, 1979 (76,5\%) aderiram à gestão Incipiente - o nível mais elementar das modalidades de gestão - 559 (21,5\%) na Parcial, e apenas $46(2 \%)$ municipios estavam habilitados na Semiplena - o nivel mais complexo, em que a esfera local se torna gestora efetiva pelo menos dos serviços públicos de saúde. Quanto à distribuição destes municipios, 1671 $(64,5 \%)$ deles situam-se nas regiões Sul e Sudeste do pais, sendo que esta última concentrava 1071 (41,5\%) dos municipios habilitados (BRASIL, 1995).

\subsection{Justificativa do Estudo}

A revisão bibliográfica apontava entre outros aspectos:

- Decisão política do Ministério da Saúde de privilegiar os cuidados preventivos e ambulatoriais em detrimento das hospitalizações com a implantação de novos parâmetros de cobertura de $9 \%$ da população/ano que nortearam a distribuição das AlHs a partir de 1995 (PT/MS/15/95) (BRASIL 2000).

- Os recursos destinados à assistência hospitalar representaram em média aproximadamente $75 \%$ do total de recursos despendidos em serviços médicos assistenciais (UGÁ \& REIS 1994). 
A nivel hospitalar, o acompanhamento das ações é, da mesma forma vital para o monitoramento do atendimento na cidade (DONALISIO 1993).

Diante do exposto, verifica-se que a descentralização proposta e que vem ocorrendo no processo de implantação do SUS, com ênfase na municipalização é um dos seus eixos principais.

Nisto e ao lado disto a formulação e implantação do SUS contemplam os aspectos de mudanças nos modelos de gestão e atenção a saúde, ultrapassando o chamado modelo "Hospitalocentrico".

Assim, é de se esperar que, nestas mudanças haja implicações para o perfil e atuação dos hospitais e, portanto, nas internações hospitalares.

Deste modo, e por isso, este tema foi escolhido como objeto de pesquisa, ao lado de como profissional termos acompanhado e participado das fases anteriores de implantação do SUS, e considerando a importância estratégica da Norma Operacional Básica SUS 01/93 decidimos trabalhar este estudo como objeto da tese de Doutoramento do Curso de Pós Graduação da Faculdade de Saúde Pública da Universidade Estadual de São Paulo - USP.

De maneira que pudesse identificar e avaliar os efeitos da referida norma, na área da assistência médica hospitalar, como contribuição ao processo de aprimoramento do SUS, através do estudo de municipios que assumiram a modalidade de gestão definida como semi plena por considerarmos que esta modalidade representa a forma mais avançada de gestão, daquela NOB, portanto com maior probabilidade de intervenção para o alcance das mudanças. 
II- OBJETIVOS 


\subsection{Objetivo Geral}

Analisar a evolução de Internações Hospitalares em Municípios em Gestão Semi Plena, no Estado de São Paulo no período entre 1994 e 1999.

\subsection{Objetivos Específicos}

Para cada Municipio do Estudo:

2.2.1 Analisar a evolução do número de internações por AlHs pagas pelo SUS.

2.2.2 Comparar quantidade de gastos com as internações nas AlHs pagas pelo SUS, e algumas variáveis associadas a elas, antes e depois da implantação da gestão semi plena. 


\section{III- MATERIAL E MÉTODOS}




\subsection{Tipologia}

Este estudo, foi desenvolvido como uma "Pesquisa Avaliativa" que segundo HARTZ (1997), é descritiva, restrospectiva, em outras palavras a define como "o procedimento que consiste em fazer um julgamento expost de uma intervenção (é constituída pelo conjunto dos meios físicos, humanos, financeiros, simbólicos organizados em um contexto específico, em um dado momento, para produzir bens ou serviços, com o objetivo de modificar uma situação problemática) usando métodos científicos" . A intervenção, nesse estudo, é considerada a gestão semi plena no processo de implantação do Sistema Único de Saúde (SUS), em diferentes contextos, expressos em municípios habilitados nesta categoria de gestão no Estado de São Paulo.

Julgamos que nosso estudo pode ser enquadrado no tipo análise dos efeitos "é aquela que consiste em avaliar a influência dos serviços sobre os estados de saúde" podendo-se determinar a eficácia dos serviços para o alcance dessa modificação". Buscamos a eficácia da utilização definida por HARTZ (1997) como aquela que estimamos ao analisar os resultados de uma intervenção, em um contexto natural, sobre os individuos que dela se beneficiaram, nesta situação, as variáveis relativas aos usuários e aos prestadores de serviço são observadas através das internações hospitalares.

Dada a extensão de ocorrências da "intervenção" em municípios habilitados na categoria de gestão Semi-Plena, optamos por utilizar como estratégia de análise o "Estudo de Caso Múltiplo" conforme TRIVIÑOS (1987) define "estudo de caso é uma categoria de pesquisa cujo objeto é uma unidade que se analisa profundamente". Este autor cita diferentes tipos, dentre eles: estudo de caso observacionais; estudo caso denominado história de vida; estudo multicasos, destacamos o estudo de multicasos etc., que sem necessidade de perseguir objetivos de natureza comparativa, o 
pesquisados podem ter a possibilidade de estudar dois ou mais sujeitos (organizações, etc.), e DENIS, CHAMPAGNE (1997). Citando YIN (1984) "a realização de um estudo de caso múltiplo permite, operando segundo uma lógica de réplica generalizar com mais confiança os resultados de uma pesquisa", e definindo na realização de um estudo de caso múltiplo, cada meio é analisado sem agregar os dados obtidos dos diferentes casos. Cada um dos casos pode se articular em torno de um ou vários niveis de análise, ainda que considerando essa estratégia como particularmente exigente em relação aos recursos financeiros e humanos.

\subsection{Universo do estudo e caracterização da amostra}

O universo do estudo é composto por 48 municípios localizados no Estado de São Paulo que, no período de 1994 a 1999, aderiram a modalidade de gestão semi plena.

Observando-se este critério, selecionou-se para 0 presente estudo, como "unidade de análise" o estudo de caso de 11 municípios: Assis, Campinas, Diadema, Mauá, Ribeirão Preto, Santos, São Bernardo do Campo, São José dos Campos, São Vicente, Sertãozinho, e Votorantin. A figura 1 apresenta a distribuição destes municípios $e$ os situa geograficamente no Estado de São Paulo.

Os municípios do presente estudo representam $12,07 \%$ da população total do Estado assim distribuídos: (Assis 0,24\%; Campinas 2,66\%; Diadema 0,96\%; Mauá 0,95\%; Ribeirão Preto 1,39\%; Santos 1,22\%; São Bernardo do Campo 1,77\%; Sertãozinho 0,26\%; São José dos Campos $1,48 \%$; São Vicente $0,87 \%$; Votorantim $0,27 \%$ ). 
Figura 1 - Distribuição dos municípios do Estado de São Paulo por tipo de gestão, no ano de 1994.

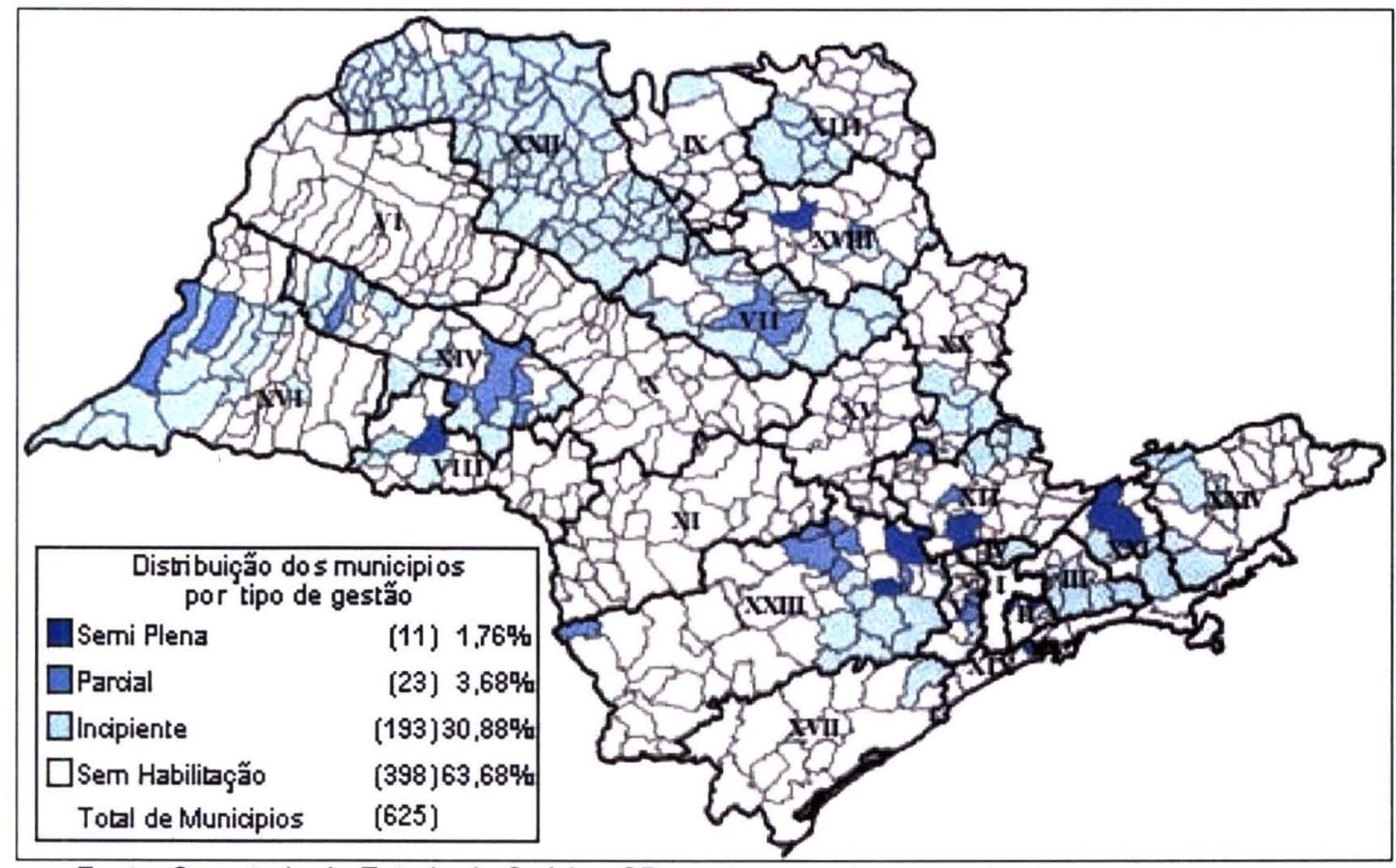

Fonte: Secretaria de Estado da Saúde - SP

Os Municípios do presente estudo estão localizados nas seguintes Diretorias Regionais de Saúde (DIRs), no Estado de São Paulo:

Assis - DIR VIII

Campinas - DIR XII

Diadema - DIR ॥

Mauá - DIR II

Ribeirão Preto - DIR XVIII

Santos - DIR XIX

São Bernardo do Campo - DIR II

São José dos Campos - DIR XXI

São Vicente - DIR XIX

Sertãozinho - DIR XVIII

Votorantim - DIR XXIII 
Esta opção se deu levando em conta: tempo de habilitação na categoria de gestão semi plena, histórico de mudanças no sistema de saúde em relação aos princípios e diretrizes do Sistema Único de Saúde (SUS), participação regional do municipio na atenção hospitalar, representação na cobertura populacional e alocação de recursos financeiros "SUS", tipologia da rede hospitalar, entre outras variáveis.

Mauá, Diadema, São Vicente, Santos, São José dos Campos, Votorantin, Assis, Sertãozinho, municipios que iniciaram a gestão semi plena em 1994 e se enquadram às variáveis referidas; além da existência de estudos anteriores: sobre a implantação da NOB 01/93 ALMEIDA (1995), CASTRO (1998) entre outros, como por exemplo, a análise de desempenho de gestão municipal colocando-os em destaque a nível Nacional e Estadual SOUTO et al. (1995).

Ribeirão Preto, município sede da região de saúde, embora não se tenha habilitado inicialmente e só em final de 1995, é município importante no contexto sócio-econômico do Estado; é sede de Região de Saúde, tem significativa rede de assistência hospitalar, inclusive Hospital Universitário, com população cerca de 480.000 habitantes e com cerca de $5 \%$ de alocação do teto financeiro "SUS" do Estado de São Paulo.

Campinas, também não habilitado inicialmente e só em abril de 1996, representa, a semelhança de Ribeirão Preto, um município importante no contexto sócio-econômico do Estado, é sede de Região de Saúde, tem significativa rede de assistência hospitalar, inclusive Hospital Universitário, com população de 918.472 habitantes, com porcentagem de participação no teto financeiro do Estado de $4,5 \%$ da alocação SUS.

Ribeirão Preto e Campinas, municipios com algumas características semelhantes ofereceram dados sobre diferentes niveis de 
complexidade de internações hospitalares com a existência de Hospitais Universitários; existência de estudo anteriores SOUTO et al (1995).

São Bernardo do Campo, habilitado em junho de 1995, faz parte da região da grande São Paulo, $A B C D$, onde estão outros municipios inicialmente habilitados, com características especiais de acesso e complexidade, com rede de assistência hospitalar e população de 617.649 habitantes.

A amostra foi definida por escolha intencional, tanto para diferentes contextos municipais e regionais o que possibilitou o uso da metodologia como definida por HARTZ (1997).

\subsection{Levantamento de dados}

Nesse estudo, utilizou-se os dados contidos nas AlHs (Autorização de Internação Hospitalar) pagas referentes ao Estado de São Paulo, obtidos nas Bases de Dados do Sistema de Informaçōes Hospitalares do Sistema Único de Saúde - SIH/SUS - DATASUS e IBGE.

A justificativa para a escolha da fonte de dados AlH deve-se a existência de estudos que definem informações passiveis de serem trabalhadas em todo o território nacional por gestores estaduais e municipais, CARVALHO (1997), BRASIL (1991) possuir um banco de dados que tenha informações sobre o equivalente a $70 \%$ das internações ocorridas no país TRAVASSOS (1996), possibilitarem o estudo de custos e outras variáveis BUSS (1993), PINTO et al. (1988) estudo de morbidade SABROSA et al. (1988) confiabilidade dos dados, VERAS, MARTINS (1994) tempo de permanência, diagnóstico e procedimentos (LEBRÃO, 1978). 
AlH é o documento hábil para identificar o paciente e os serviços prestados sob regime de internação hospitalar, BRASIL (1993).

\subsubsection{Variáveis principais}

Das bases de dados do Sistema de Informações Hospitalares do Sistema Único de Saúde (SIH/SUS) utilizou-se os arquivos das AlHs, BRASIL (1990) dos quais extraiu-se para cada município, os totais mensais das seguintes variáveis:

- Gastos com internações: Valor referente às AlHs pagas no período, expressas em US\$.

- Número de internações: Quantidade de AlHs pagas no período.

- Permanência em internações: Total de dias de internação referentes às AlHs pagas no período.

- Número de óbitos: Quantidade de internações que tiveram alta por óbito, nas AlHs pagas no período.

\subsubsection{Variáveis auxiliares}

Em cada etapa do trabalho, foram utilizadas variáveis auxiliares, com a finalidade de complementar e enriquecer as discussōes, por intermédio de comparações com as variáveis principais.

As variáveis relativas à assistência hospitalar, foram as seguintes: 
- Indicadores demográficos: Taxa média anual de crescimento da população por municípios, de 1991 a 1996, obtidas no IBGE (Instituto Brasileiro de Geografia e Estatistica)

- Especialidades: Refere-se à especialidade da internação, segundo clínicas: cirúrgica, obstétrica, médica, pediátrica e outras clínicas. Foram excluídas da análise a categoria "outras clinicas" que inclui: Pacientes Crônicos ou Fora de Possibilidade Terapêutica, Clinica Psiquiátrica, Clínica Tisiológica, Clínica de Reabilitação e Clínica Psiquiátrica Hospital-dia.

- Procedimentos: Procedimentos realizados durante a internação, descritos nas AlHs pagas no período, considerado para o estudo, antes: 1994 e depois os valores médios do período de 1995 a 1997.

Procedimentos e tabela de atos médicos

- Prestador: Corresponde ao tipo de vínculo que a Unidade Hospitalar tem com o SUS: Hospitais Contratados (privados não filantrópicos e não universitários), Hospitais Filantrópicos (privados sem fins lucrativos), Hospitais Universitários (privados ou públicos), Hospitais Estaduais e Hospitais Municipais.

- Capitulos do CID IX: Causa da internação segundo os capítulos da Classificação Internacional de Doenças - $9^{a}$ Revisão (CID-9), obtidos nas bases de dados do Sistema de Informações Hospitalares do SUS (SIH/SUS), e mostrados no quadro 1, considerando-se antes $1994 \mathrm{e}$ depois os valores médios do período de 1995 a 1997. 
Quadro 1 - Capítulos da Classificação Internacional de Doenças CID- 9a Revisão

\begin{tabular}{|c|c|c|}
\hline Capitulo & Descrição & $\begin{array}{l}\text { Códigos da } \\
\text { CID-9 }\end{array}$ \\
\hline $\begin{array}{l}1 \\
11\end{array}$ & $\begin{array}{l}\text { Doenças infecciosas e parasitárias } \\
\text { Neoplasmas }\end{array}$ & $\begin{array}{l}001-139 \\
140-239\end{array}$ \\
\hline III & $\begin{array}{l}\text { Doenças das glândulas endócrinas, da nutrição e do } \\
\text { metabolismo e transtornos imunitários }\end{array}$ & $240-279$ \\
\hline IV & $\begin{array}{l}\text { Doenças do sangue e dos órgåos hematopoéticos } \\
\text { Transtornos mentais }\end{array}$ & $\begin{array}{l}280-289 \\
290-319\end{array}$ \\
\hline VI & Doenças do sistema nervoso e dos órgãos dos sentidos & $320-389$ \\
\hline VII & Doenças do aparelho circulatório & $390-459$ \\
\hline VIII & Doenças do aparelho respiratório & $460-519$ \\
\hline IX & Doenças do aparelho digestivo & $520-569$ \\
\hline $\mathrm{x}$ & Doenças do aparelho geniturinário & $580-629$ \\
\hline $\mathrm{XI}$ & Complicaçס̃es da gravidez, do parto e do puerpério & $630-676$ \\
\hline XII & Doenças da pele e do tecido celular subcutáneo & $680-709$ \\
\hline XIII & Doenças do sistema osteomuscular e do tecido conjuntivo & $710-739$ \\
\hline XIV & Anomalias congénitas & $740-759$ \\
\hline$X V$ & Algumas afecçס̄es originadas no periodo perinatal & $760-779$ \\
\hline $\mathrm{XVI}$ & Sintomas, sinais e afecçőes mal definidas & $780-799$ \\
\hline XVII & $\begin{array}{l}\text { Lesões e envenenamentos } \\
\text { Classificaçăo suplementar de causas externas de lesões e } \\
\text { envenenamentos }\end{array}$ & $\begin{array}{c}800-999 \\
\text { E800-E999 }\end{array}$ \\
\hline Supl & $\begin{array}{l}\text { Classificaçăo suplementar de fatores que exercem influéncia } \\
\text { sobre o estado de saúde e de oportunidades de contato com } \\
\text { serviços de saúde } \\
\text { CID năo especificado ou inválido }\end{array}$ & V01-V82 \\
\hline
\end{tabular}

- Evasão e Invasão : Evasão compreende todas as internações SUS registradas nas AlHs pagas, relativas à pacientes que declararam serem domiciliados num município e foram atendidos em outro municipio. Invasão compreende todas as internações SUS registradas nas AlHs pagas, cujos pacientes eram originários e domiciliados em outro município, que não 0 de atendimento. Em ambos os casos - invasão e evasão levantaram-se as informações de gastos com internações e número de internações, para periodo do estudo, nos registros das AlHs nas bases de dados do Sistema de Informações Hospitalares do SUS (SIH/SUS). 


\subsubsection{Periodização dos dados}

Como nem todos os municipios aderiram a modalidade de gestão semi plena num mesmo momento, estabeleceu-se para este estudo quatro periodos, relacionados a seguir e mostrados no Quadro 2:

- Um ano antes da implantação da gestão semi plena no município;

- Primeiro ano após a implantação da gestão semi plena no municipio;

- Segundo ano após a implantação da gestão semi plena no municipio;

- Terceiro ano após a implantação da gestão semi plena no município.

Quadro 2- Periodos de avaliação por municipios, no Estado de São Paulo.

\begin{tabular}{|c|c|c|c|c|}
\hline \multirow{3}{*}{ Municípios } & \multicolumn{4}{|c|}{ Gestão semi plena } \\
\hline & \multirow{2}{*}{$\begin{array}{l}\text { Antes } \\
1^{\circ} \text { ano }\end{array}$} & \multicolumn{3}{|c|}{ Depois } \\
\hline & & $1^{\circ}$ ano & $2^{\circ}$ ano & $3^{\circ}$ ano \\
\hline Assis & $01 / 94$ a $11 / 94$ & $12 / 94$ a $11 / 95$ & $12 / 95$ a $11 / 96$ & $12 / 96$ a $11 / 97$ \\
\hline Campinas & $05 / 95$ a 04/96 & $05 / 96$ a 04/97 & 05/97 a 04/98 & $05 / 98$ a 04/99 \\
\hline Diadema & $01 / 94$ a $11 / 94$ & $12 / 94$ a $11 / 95$ & $12 / 95$ a $11 / 96$ & $12 / 96$ a $11 / 97$ \\
\hline Mauá & $01 / 94$ a $11 / 94$ & $12 / 94$ a $11 / 95$ & $12 / 95$ a $11 / 96$ & $12 / 96$ a $11 / 97$ \\
\hline Ribeirão Preto & $12 / 94$ a $11 / 95$ & $12 / 95$ a $11 / 96$ & $12 / 96$ a $11 / 97$ & $12 / 97$ a $11 / 98$ \\
\hline Santos & 01/94 a 11/94 & $12 / 94$ a $11 / 95$ & $12 / 95$ a $11 / 96$ & $12 / 96$ a $11 / 97$ \\
\hline São Bernardo do Campo & 07/94 a 06/95 & $07 / 95$ a 06/96 & $07 / 96$ a 06/97 & $07 / 97$ a 06/98 \\
\hline Sertãozinho & $01 / 94$ a $11 / 94$ & $12 / 94$ a $11 / 95$ & $12 / 95$ a $11 / 96$ & $12 / 96$ a $11 / 97$ \\
\hline São José dos Campos & $01 / 94$ a $11 / 94$ & $12 / 94$ a $11 / 95$ & $12 / 95$ a $11 / 96$ & $12 / 96$ a $11 / 97$ \\
\hline Săo Vicente & $01 / 94$ a $11 / 94$ & $12 / 94$ a $11 / 95$ & $12 / 95$ a $11 / 96$ & $12 / 96$ a $11 / 97$ \\
\hline Votorantim & $01 / 94$ a 11/94 & $12 / 94$ a $11 / 95$ & $12 / 95$ a $11 / 96$ & $12 / 96$ a $11 / 97$ \\
\hline
\end{tabular}

Definiu-se, para efeito de avaliação da gestão semi plena, os resultados do período referente ao primeiro ano antes da implantação como "antes" e a média aritmética das variáveis dos três anos subseqüentes à sua 
implantação como "depois". Aplicou-se esses periodos as variáveis principais citadas no item 3.3.1 e Procedimentos do item 3.3.2, para as demais variáveis considerou-se sendo o período antes o ano de 1994 e depois os valores médios do período de 1995 a 1997, extraídos do Banco de Dados DATA SUS.

\subsubsection{Cálculos com variáveis}

Utilizaram-se estatistica básica para os cálculos realizados com as variáveis:

- Porcentagem relativa à freqüência;

- Porcentagem acumulada da freqüência;

- Porcentagem relativa ao valor;

- Porcentagem acumulada do valor;

- Valor médio; e

- Gasto.

Por intermédio desses procedimentos, foi possivel obter- se novas variáveis:

- Taxa de mortalidade: Razão entre a quantidade de óbitos e o número de saídas (AlHs pagas, computadas como internações), no mesmo período, multiplicada por 100.

- Permanência Média: Razão entre o total de dias de internação referentes às AlHs pagas no período e o número de AlHs pagas, computadas como internações, no período.

- Gasto médio: Razão entre o valor referente às AlHs pagas no período e à quantidade de AlHs pagas no período. 


\subsubsection{Evolução}

Para estudo das evoluções, utilizou-se análise de regressão, considerando-se a variável independente o periodo de 4 anos $\left(1^{\circ}\right.$ ano antes da semi plena e os 3 anos após a implantação da gestão semi plena).

Como variáveis dependentes utilizou-se o total anual dos gastos com internações, do número de internações, do gasto médio com internações, tempo médio de permanência em internações e taxa média de mortalidade em internações.

Realizaram-se análises exploratórias dos dados, a partir desses resultados selecionou-se dois modelos de regressão (WONNACOTT, 1977):

$$
\begin{array}{ll}
\text { Linear }-1^{\circ} \text { grau : } & Y=\alpha+\beta \mathbf{X} \\
\text { Polinomial }-2^{\circ} \text { grau : } & Y=\alpha+\beta_{0} \mathbf{X}+\beta_{1} \mathbf{X}^{2}
\end{array}
$$

Ajustou-se os dados por esses modelos, obtendo-se as curvas de regressão e seus respectivos $r^{2}$, mostrados graficamente.

Devido a precariedade dos dados, a análise de regressão foi aplicada a apenas 4 pontos (períodos). Utilizou-se a análise de variância aplicada à Regressão Linear, onde por meio do Teste $F$, ao nível de probabilidade de $5 \%$; testou-se a hipótese nula para verificar a existência da regressão. 


\subsubsection{Ranking dos procedimentos}

Nessa etapa, utilizou-se, as seguintes variáveis: totais gastos com internações, número de internaçōes e gasto médio das internações, acumuladas por procedimento de $\mathrm{AlH}$, em cada um dos 11 municípios que compõem o estudo e os totais de cada variável. Essas informações constituíram os quadros e figuras.

Os quadros foram organizados por procedimentos para cada período $\left(1^{\circ}\right.$ ano antes e $1^{\circ}, 2^{\circ}$, e $3^{\circ}$ anos depois da implantação da gestão semi-plena) e acumulados totais (obtidos por meio da somatória dos valores de cada procedimento nos periodos). Classificando-se cada quadro por ordem descendente e utilizando-se como chave primária os acumulados totais. Assim, obteve-se o ranking dos 50 procedimentos de internação mais freqüentes, com maior gasto total e com maior gasto médio. Com base nesse ranking classificou-se, para cada período, a posição dos referidos procedimentos.

\subsubsection{Procedimentos sentinela}

Adotou-se o conceito de "Procedimento Sentinela" de RUTSTEIN e colaboradores, citado por DEVER (1988) que denominam de evento sentinela de saúde os sinais de alerta de que a qualidade de serviços pode estar precisando de uma melhoria.

"... um evento sentinela é um aviso de que algo está errado no campo da saúde. É um indicador de necessidade de mudança ou melhoria em um ou mais componentes do campo da saúde ..."

Para a determinação dos procedimentos sentinela, neste estudo, considerou-se os seguintes: 
Quadro 3 - Procedimentos utilizados como sentinela

\begin{tabular}{|c|c|}
\hline Procedimentos & Cód. Tab $^{\star}$ \\
\hline Parto Cesariana & 35009012 \\
& 35022019 \\
& 35026014 \\
\hline Broncopneumonia & 76300080 \\
& 76500071 \\
\hline Cirurgia de coronária com extracorpórea & 76400085 \\
\hline Infarto agudo do miocárdio & 32011016 \\
\hline
\end{tabular}

* Código da Tabela de Procedimentos e Atos Médicos AlH/SUS

A justificativa para a escolha destes procedimentos "sentinela" deveu-se ao fato de que:

Parto Cesariana

Broncopneumonia
- Alta incidência de partos cesariana desnecessário, ocasionando aumento de riscos e custos.

- $40 \%$ das gestantes de alto risco tem necessidade de cesariana.

- parâmetros OMS - $12 \%$ do total de partos. SPINOLA (1989) IDEC (1997), KIMURA (1995), SOUTO (1992), ROCHA et al. (1986), RODRIGUES et al. (1997)

- O grave estado geral com que a criança chega ao hospital - importante fator prognóstico de letalidade hospitalar. NORONHA (1996), BRASIL (1997), CHYIOSHI (1986).

Cirurgia de coronária - Procedimento de alta complexidade. com extracorpórea

Infarto agudo do - Doenças cardio vasculares são as principais causas de Miocárdio mortalidade proporcional no Brasil.

- Destaca-se o infarto agudo do miocardio em cidades das regiões Sul e Sudeste.

- Evento agudo que requer internação hospitalar, com diagnóstico simples e preciso.

- A letalidade hospitalar padrão estimados variou de $28 \%$ (assistência tradicional em enfermarias) a 8,5\% (unidades coronárias relativamente complexas). SILVA et al. (1996), MS (2000) 


\subsection{Caracterização dos Municípios}

\section{Assis}

Em relação aos dados demográficos, temos que a população residente totaliza 86.127 habitantes, 48,74\% masculina e 51,25\% feminina, com distribuição percentual segundo faixa etária de $\pm 22,87 \%(0-15) \pm$ $54,88 \%(15-50), \pm 19,23(50 \mathrm{e}+)$ próximo do que BERQUÓ (1971) utilizando a classificação de SUNDBARG caracteriza como população tipo estacionária. A taxa de crescimento anual estimada é de 1,7; com mulheres em idade fértil (10 - 49) em 1998 totalizando 28.154 ou $63,8 \%$ da população. A população alfabetizada representa $87,2 \%$.

No que diz respeito à infra estrutura urbana para uma população residente de 86.127 habitantes, o municipio conta, no total dos domicílios, com abastecimento de água em 96,5\%; (possui água com canalização interna $91 \%$ ligadas à rede geral); $93,1 \%$ possui instalação sanitária $(76,6 \%$ dos domicílios estão ligados à rede geral de esgotos).

O serviço de coleta de lixo abrange $89,4 \%$ dos moradores; do lixo restante $10,6 \%$ : $7,6 \%$ é queimado, $1,1 \%$ enterrado, $1,8 \%$ jogado e $0,1 \%$ tem outros fins.

A rede de serviços de saúde instalada no municipio totaliza 34 unidades, dessas 03 são hospitais. O municipio dispõe de 4,7 leitos/1000 habitantes, acima dos parâmetros preconizados pela Organização Mundial da Saúde (4,5 leitos/1000 hab.). A rede hospitalar conta com 412 leitos, dos quais $61,65 \%$ (254) são controlados pelo setor privado, desses $30,31 \%$ (77) são lucrativos e $69,68 \%$ (177) não lucrativos. Os demais $38,34 \%$ dos leitos são controlados pelo setor público, estadual (158 leitos). A rede ambulatorial conta com cerca de 31 unidades, sendo $8(25,80 \%)$ com atendimento geral e $23(74,19 \%)$ especializado. O número de consultórios médicos representa 79 
unidades que equivale a 9,0/10.000 habitantes e os equipos odontológicos, representam 13 ou $1,5 / 10.000$ habitantes.

Dados e indicadores financeiros municipais mostravam em 1999, uma Receita Total de $\mathrm{R} \$ 36.378 .271,00$ e uma Despesa Total com saúde de $R \$ 10.075 .358,00$. Despesa própria com saúde de $R \$$ 3.206.992,00. e por habitante $R \$ 37,2$.

O grau de dependência financeira municipal nas transferências externas, isto é, das esferas estadual e federal, para SUS mais ressarcimento de outros municípios estava no ano de 1999 em média 68,2\% do total das despesas com saúde. Nesse mesmo ano a despesa com saúde por habitante correspondeu a $R \$ 116,98$. Os gastos com internações entre as diversas categorias hospitalares, significaram um per capita em torno de US\$ 35,36 .

Em relação ao perfil de mortalidade proporcional por faixa etária segundo a classificação Internacional de Doenças (CID-10) em 1998, as quatro principais causas de mortalidade foram, em ordem decrescente: Causas externas 100\% ( 5 a 9 anos) 88,9\% (15 - 19 anos); Doenças do aparelho circulatório $100 \%$ (1 a 4 anos); Doenças infecciosas e parasitárias $100 \%$ (10 a 14 anos); Afecções perinatais 64,0\% (menor de 1 ano).

O coeficiente de mortalidade para algumas causas selecionadas (por 100.000 hab.) no periodo de 1994-1998) apresentou tendência de crescimento para óbitos por diabetes mellitus $(21,3 ; 14,8 ; 19,2 ; 23,6 ; 26,7)$; agressões $(20,1 ; 14,8 ; 22,9 ; 21,2 ; 26,7)$.

A porcentagem de óbitos por causas mal definidas apresentou resultados continuados de crescimento $(11,8 ; 14,2 ; 14,1 ; 16,3 ; 19,0)$. 
O coeficiente de mortalidade infantil no período (1989-1998) apresentou queda $(22,86 ; 20,64 ; 16,36 ; 15,31)$.

\section{Campinas}

Em relação aos dados demográficos, temos que a população residente totaliza 937.072 habitantes, masculina $48,85 \%$ e feminina $51,14 \%$, com distribuição percentual segundo faixa etária de $\underline{25,67} \%$ (0 -15), $\underline{57,71 \%}$ (15 - 50), $\pm 16,34 \%$ (50 ou +) próximo do que BERQUÓ (1971) utilizando a classificação SUNDBARG caracteriza como população tipo estacionária. A taxa de crescimento anual (1996-2000) estimada 1.5; com mulheres em idade fértil (10 - 49) em 1998 totalizando 318.968 (66,6\%). A população alfabetizada representa $89,1 \%$.

A infra estrutura para uma população residente de 937.072 habitantes, o municipio conta, no total dos domicilios, com abastecimento de água em $96,3 \%$ que possui água com canalização interna (92,7\% ligadas à rede geral), e $95,5 \%$ possui instalação sanitária $(79,6 \%$ dos domicilios ligadas à rede geral de esgotos).

A coleta de lixo abrange $94,5 \%$ dos moradores, sendo o lixo restante: $2,1 \%$ queimado; $0,4 \%$ enterrado; $2,9 \%$ jogado, e $0,1 \%$ outros.

A rede de serviços de saúde instalada no municipio totaliza 111 unidades, sendo 11 hospitais. O município dispõe de 2,3 leitos/1000 habitantes, que segundo os parâmetros preconizados pela Organização Mundial da Saúde (4,5 leitos/1000 habitantes) apresenta déficit de leitos. A rede hospitalar conta com 2176 leitos, dos quais $38,41 \%$ (836) são controlados pelo setor privado, sendo $14,47 \%$ dos leitos (121) contratados e $85,52 \%$ (715) filantrópicos. Os demais $61,85 \%$ (1340) dos leitos são controlados pelo setor público e assim distribuídos: $12,08 \%$ (162) do total geral de leitos vinculados ao município e $1178(87,91 \%)$ à esfera estadual. 
A rede ambulatorial conta com cerca de 100 unidades, sendo 45 (45\%) com atendimento geral e $55 \mathrm{com}$ atendimento especializado. $O$ número de consultórios médicos representou 802 unidades que equivale a $8,4 / 10.000$ habitantes; os equipos odontológicos, 369 ou $3,9 / 10.000$ habitantes.

Considerando o déficit de leitos observado (1998) e o quadro identificado por CAMPOS (1990) como um "paradoxo este caracterizado pela existência de um grande número de leitos e de recursos hospitalares, sem contudo ocorrer garantia de acesso para a maioria da população esta contradição decorre do afastamento da maioria dos hospitais Privados e Filantrópicos do SUDS", ainda segundo esse autor na época, não houve investimento em hospitais estaduais e municipais, a área pública ficou restrita a UNICAMP que cada vez mais voltava-se para um padrão de atendimento super especializado sem envolvimento com a demanda diária de urgência ou de atendimento eletivo.

Dados e indicadores financeiros municipais mostravam em 1999, uma receita total de $R \$ 643.069 .316,00$ e uma despesa total com saúde de $R \$ 207.076 .573,00$ despesas próprias gastas com saúde $R \$ 142.966 .220,00$ e despesa própria com saúde por habitante de 152,6; e despesa total com saúde por habitante de 220,98 .

O grau de dependência do orçamento municipal das transferências na despesa total com saúde, isto é das esferas estadual e federal SUS e ressarcimento de outros municipios estava em média $31,0 \%$.

Em relação ao perfil de mortalidade proporcional por faixa etária segundo a classificação Internacional de Doenças (CID-10) em 1998, as quatro principais causas de mortalidade foram, em ordem decrescente: causas externas $89,1 \%$ ( 15 - 19 anos); $72,7 \%$ (10 - 14 anos); $57,1 \%$ (5 a 9 anos); afecções perinatais $51,6 \%$ (menor de 1 ano), doenças do aparelho circulatório $42,2 \%$ (65 e mais); $40,1 \%$ ( 80 e mais); $38,7 \%$ (50 a 64 anos); 
demais causas definidas $25,6 \%$ (menor de 1 ano); $22,2 \%$ ( 1 a 4 anos) e $21,4 \%$ (5 a 9 anos).

O coeficiente de mortalidade para algumas causas selecionadas (por 100.000 hab.), no periodo de 1994-1998, apresentou tendência de crescimento para óbitos por diabetes mellitus $(11,1 ; 11,0 ; 13,6 ; 10,6 ; 12,1)$; e agressões $(30,8 ; 37,3 ; 36,2 ; 38,7 ; 55,9)$.

A porcentagem de óbitos por causas mal definidas apresentou resultados alternado de queda ou de crescimento $(2,6 ; 2,5 ; 2,8 ; 3,1 ; 2,7)$.

O coeficiente de mortalidade infantil por 1000 nascidos vivos no periodo (1994 - 1998) apresentou queda $(17,5 ; 19,6 ; 16,6 ; 15,9 ; 13,7)$.

\section{Diadema}

Em relação aos dados demográficos, temos que a população residente totaliza 331.307 habitantes, masculina 49,60 e feminina 50,39 com distribuição percentual segundo faixa etária de $+1-9,41 \%(0-15), \underline{69,99} \%$ $(15-50), \pm 10,17 \%(50 \mathrm{ou}+$ ) próximo do que BERQUO (1971) utilizando a classificação de SUNDBARG caracteriza como população tipo Progressiva. A taxa de crescimento anual estimada 1,2; com mulheres em idade fértil (10 - 49) em 1998 totalizando 117.032 (70,1\%). A população alfabetizada representa $83,1 \%$.

A infra estrutura para uma população residente de 331.307 habitantes, o municipio contava, no total dos domicilios, com abastecimento de água em $97,3 \%$ que possui água com canalização interna (96,8\% ligados à rede geral) e $92,9 \%$ possuía instalação sanitária $(69,0 \%$ dos domicilios ligados à rede geral de esgotos). 
A coleta de lixo abrangia $96,3 \%$ dos moradores, e para os demais moradores $3,7 \%$ : os lixos são $0,4 \%$ lixo são queimado; $0,1 \%$ enterrado; $0,1 \%$ jogado; $3,1 \%$ outros.

A rede de serviços instalada no municipio totalizava 34 unidades, sendo 3 hospitais. O municipio dispõe de 0,5 leitos $/ 1000$ habitantes, que segundo os parâmetros preconizados pela Organização Mundial da Saúde (4,5 leitos/1000 habitantes) apresentava um déficit de leitos. A rede hospitalar contava com 214 leitos, dos quais 100\% (214) eram controlados pelo setor público municipal. A rede ambulatorial contava com cerca de 31 unidades, sendo 14 (45,12\%) com atendimento geral e 17 (54,83\%) com atendimento especializado. $O$ número de consultórios médicos representou 152 unidades que equivale a $4,5 / 10.000$ habitantes; as equipes odontológicas, 50 ou 1,5/10.000 habitantes.

Em relação ao perfil de mortalidade proporcional por faixa etária segundo a classificação Internacional de Doenças (CID-10) em 1998, as quatro principais causas de mortalidade foram, em ordem decrescente: Causas externas 89,3 (15 a 19 anos); 71,4 (10 a 14 anos); 61,2 (20 a 49 anos); 30,8 (5 a 9 anos); 29,4 (1 a 4 anos); Afecções perinatais 54,8 (menor de 1 ano); Doenças do aparelho circulatório 49,9 (65 e mais); 48,4 (80 e mais); 39,9 (50 a 64 anos); doenças do aparelho respiratório 38,5 (5 a 9 anos) e 23,5 ( 1 a 4 anos).

O coeficiente de mortalidade para algumas causas selecionadas (por 100.000 hab.), no período de 1994-1998, apresentou tendência de crescimento para óbitos por diabetes mellitus $(11,1 ; 14,0 ; 17,0 ; 16,8 ; 13,3)$; agressões $(77,0 ; 111,9 ; 129.4 ; 140,4 ; 143,1)$.

A porcentagem de óbitos por causas mal definidas apresentou variação de resultado com queda e crescimento $(13,1 ; 11,2 ; 1,9 ; 1,7 ; 2,2)$. 
O coeficiente de mortalidade infantil no periodo (1994 - 1998) apresentou queda $(20,3 ; 22,8 ; 20,9 ; 21,4 ; 19,6)$.

\section{Mauá}

Em relação aos dados demográficos, temos que a população residente totaliza 364.919 habitantes, masculina $49,55 \%$ e feminina $50,44 \%$,

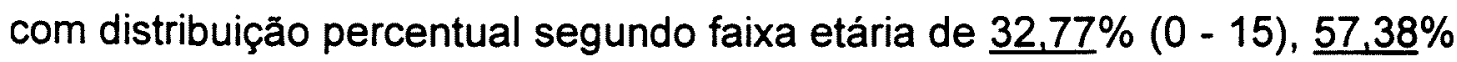
$(15-50), \pm 10,53 \%(50$ ou + ) próximo do que BERQUO (1971) utilizando a classificação de SUNDBARG caracteriza como população tipo progressiva. A taxa de crescimento anual estimada 2,9\%; com mulheres em idade fértil (10 - 49) em 1998 totalizando 125.770 68,3\%. A população alfabetizada representa $85,5 \%$.

A infra estrutura para uma população residente de 364.919 habitantes. O município conta, no total dos domicílios, com abastecimento de água em $97,3 \%$ que possui água com canalização interna ( $94,5 \%$ ligados à rede geral) e $84,6 \%$ possui instalação sanitária $(66,8 \%$ dos domicílios ligados à rede geral de esgotos).

A coleta de lixo abrange $93,1 \%$ dos moradores, sendo o lixo restante $6,9 \%: 1,9 \%$ queimado; $0,2 \%$ enterrado; $4,7 \%$ jogado; $0,1 \%$ outros.

A rede de serviços instalada no município totaliza 31 unidades, sendo 2 hospitais. O município dispõe de 0,9 leitos $/ 1000$ habitantes, que segundo os parâmetros preconizados pela Organização Mundial da Saúde (4,5 leitos/1000 habitantes) apresenta déficit de leitos. A rede hospitalar conta com 334 leitos, dos quais $65,86 \%$ (220) são controlados pelo setor público sendo $34,13 \%$ do total dos leitos (114) são controlados pelo setor filantrópico. A rede ambulatorial conta com cerca de 26 unidades, sendo 13 (50\%) com atendimento geral e $05 \mathrm{com}$ atendimento especializado. 0 
número de consultórios médicos representou 166 que equivale a 4,4/10.000 habitantes; as equipes odontológicas, 41 ou 1,1/10.000 habitantes.

Dados e indicadores financeiros municipais mostravam em 1999, uma Receita Total $(R \$)$ de 149.065.668,00. Despesa total com saúde $R \$$ 39.250.993,00; Despesa própria com saúde $R \$ 26.407 .442,00$ e Despesa própria com saúde por habitante $\mathrm{R} \$ 72,4$. Despesa total com saúde por habitante de $R \$ 107,56$.

O grau de dependência financeira nas transferências orçamentárias externas, isto é das esferas estadual e federal (SUS) e ressarcimento de outros municipios estava em média $32,7 \%$ do total das despesas com saúde.

A análise dos dados referentes ao período de 1994 - 1998, mostra como tendência geral, um gasto de aproximadamente $55,83 \%$ que beneficia hospital filantrópico e hospital municipal foi aquele que se apropriou de $44,17 \%$ dos recursos.

Em relação ao perfil de mortalidade proporcional por faixa etária e segundo a classificação Internacional de Doenças (CID-10) em 1998, as quatro principais causas de mortalidade foram, em ordem decrescente: Causas externas 87,7 (15 a 19 anos); 69,2 (10 a 14 anos); 41,6 (20 a 49 anos); 40,0 (5 a 9 anos); 26,3 (1 a 4 anos); afecções perinatais 68,3 (menor 1 ano); doenças circulatórias 48,5 (65 e mais); 48,3 (80 e mais); 42,6 (50 a 64 anos); 18,4 (20 a 49 anos); doenças infecciosas e parasitárias 36,8 (1 a 4 anos).

O coeficiente de mortalidade para algumas causas selecionadas (por 100.000 hab.), no periodo de 1994 à1998 apresentou tendência de crescimento para óbitos por diabetes mellitus $(13,3 ; 19,7 ; 16,3 ; 14,7 ; 15,1)$; agressões $(39,7 ; 58,2 ; 57,7 ; 45,1 ; 53,2)$. 
A porcentagem de óbitos por causas mal definidas apresentou resultado alternado de queda e crescimento $(1,3 ; 1,4 ; 0,9 ; 0,7 ; 9,1)$.

O coeficiente de mortalidade infantil no período (1994 -1998) 26,3; 23,$8 ; 27,1 ; 19,7 ; 24,5$.

\section{Ribeirão Preto}

Em relação aos dados demográficos, temos que a população residente totaliza 467.908 habitantes, masculina $49,51 \%$ e feminina $51,54 \%$, com distribuição percentual segundo faixa etária de $\underline{26,35 \%}(0$ - 15)

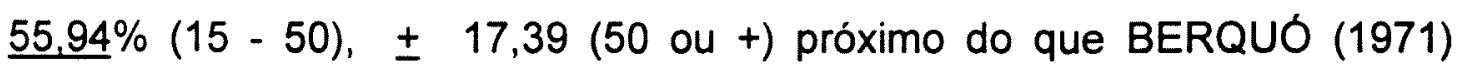
utilizando a classificação de SUNDBARG caracteriza como população tipo estacionária. A taxa de crescimento anual estimada 1,2\%; com mulheres em idade fértil (10 - 49) em 1998 totalizando $157.715(65,4 \%)$. A população alfabetizada representa $90,1 \%$.

A infra estrutura para uma população residente de 467.908 habitantes, o municipio conta, no total dos domicilios, com abastecimento de água em $98,6 \%$ possuem água com canalização interna (sendo 96,5\% ligados à rede geral) e $97,3 \%$ possuem instalação sanitária, com $90,6 \%$ dos domicilios ligados à rede geral de esgotos.

A coleta de lixo abrange $95,0 \%$ dos moradores, sendo o lixo restante $3,2 \%$ queimado; $0,3 \%$ enterrado; $1,3 \%$ jogado; $0,2 \%$ outros.

A rede de serviços instalada no município totaliza 71 unidades, sendo 9 hospitais. O município dispõe de 4,1 leitos/1000 habitantes, que segundo os parâmetros preconizados pela Organização Mundial de Saúde (4,5 leitos/1000 habitantes) apresentava déficit, no entanto, baseado em metodologia proposta por SAN MARTIN(1968) o indicado para esse municipio seria 2,0 leitos $/ 1000$ hab. considerando o baixo indice de 
hospitalização (dias/mês/ano) menor do que 0 encontrado por ROCHA(1974) que era de 2,43 leitos/1000. A rede hospitalar conta com 1937 leitos, dos quais $43,52 \%$ (843) são controlados pelo setor privado sendo $(75,80 \%$ (639) controlados pelo setor filantrópico e $24,19 \%$ (204) contratado). Os demais $56,47 \%$ (1094) dos leitos são controlados pelo setor público e assim distribuidos $740(67,64 \%)$ de leitos universitários e 354 $(32,35 \%)$ vinculados à esfera estadual (340 leitos psiquiátricos e 14 leitos de clínica médica). A rede ambulatorial conta com cerca de 62 unidades, sendo $29(46,77 \%)$ com atendimento geral e $33 \mathrm{com}$ atendimento especializado. 0 número de consultórios médicos representou 503 que equivale a 10,6/10.000 habitantes; as equipes odontológicas, 383 ou $8,1 / 10.000$ habitantes.

Dados e indicadores municipais mostravam em 1999 uma Receita Total ( $R \$$ ) $R \$ 234.707 .166,00$ uma despesa total com saúde de $R \$$ 103.019.236,00 e despesa própria com saúde de $R \$ 66.904 .545,00$ despesa própria com saúde por habitante $R \$ 143,00$; despesa total com saúde por habitante $\mathrm{R} \$ 220,17$.

O grau de dependencia financeira municipais das transferências orçamentárias externas, isto é das esferas estadual e federal, (SUS) e ressarcimento de outros municipios em 1998 estava em média $35,1 \%$ do total das despesas com saúde. Os gastos com internações distribuídos entre as diversas categorias hospitalares, significou um per capita em torno de US $\$ 67,35$.

A análise dos dados referentes ao período de 1994 - 1998, mostrava como tendência geral, um gasto que beneficiava o hospital universitário e os hospitais contratados aqueles que se apropriaram de $17,0 \%$. dos recursos. 
Em relação ao perfil de mortalidade proporcional por faixa etária segundo grupo de causas a classificação Internacional de Doenças (CID-10) em 1998, as quatro principais causas de mortalidade foram, em ordem decrescente: Causas externas 90,4 (15 a 19 anos); 53,3 (10 a 14 anos); 38,5 (5 a 9 anos); 35,6 (20 a 49 anos); afecções perinatais 59,4 (menor 1 ano); doenças do aparelho circulatório 42,3 (65 e mais); 41,6 (80 e mais); 37,8 (50 a 64 anos); neoplasias (tumores); 26,7 (10 a 14 anos); 24,7 (50 a 64 anos); 19,2 ( 80 e mais); 18,3 ( 65 e mais).

O coeficiente de mortalidade para algumas causas selecionadas (por 100.000 hab.) no periodo de 1994-1998) apresentou tendência de crescimento para óbitos por diabetes mellitus $(12,2 ; 13,6 ; 18,8 ; 12,3 ; 16,2)$; agressões $(18,1 ; 27,1 ; 41,6 ; 37,8 ; 35,9)$.

A porcentagem de óbitos por causas mal definidas apresentou variação de resultados com queda e crescimento $(1,6 ; 1,1 ; 1,3 ; 1,7 ; 1,0)$.

O coeficiente de mortalidade infantil no periodo (1994 -1998) apresentou tendência de queda $(20,0 ; 19,8 ; 18,1 ; 19,8 ; 17,0)$.

\section{Santos}

Em relação aos dados demográficos, temos que a população residente totaliza 409.850 habitantes, masculina $46,76 \%$ e feminina $53,23 \%$, com distribuição percentual segundo faixa etária de 20,91\% (0 - 15)

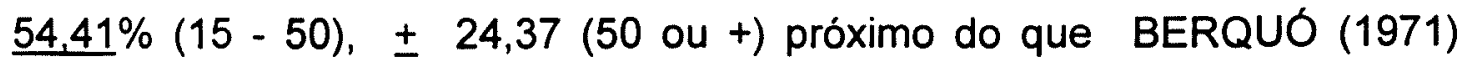
utilizou a classificação de SUNDBARG caracteriza como população tipo regressiva. A taxa de crescimento anual estimada 0,9 ; com mulheres em idade fértil (10 - 49) em 1998 totalizando 134.094 (61,5\%). A população alfabetizada representa $92,3 \%$. 
A infra estrutura para uma população residente de 409.850 habitantes. O municipio contava, no total dos domicilios, com abastecimento de água em $98,3 \%$ possuía água com canalização interna,( $97,5 \%$ ligados à rede geral) e $95,5 \%$ possuem instalação sanitária, com $82,1 \%$ dos domicilios ligados à rede geral de esgotos.

A coleta de lixo abrange $98,5 \%$ dos moradores, sendo o lixo restante $0,3 \%$ queimado; $0,1 \%$ enterrado e $1,1 \%$ jogado.

A rede de serviços de saúde instalada no município totalizava 101 unidades, sendo 08 hospitais. O municipio dispunha de 4,5 leitos/1000 habitantes, que estava dentro dos parâmetros preconizados pela Organização Mundial de Saúde (4,5 leitos/1000 habitantes). A rede hospitalar contava com 1829 leitos, dos quais $81,24 \%$ (1486) eram controlados pelo setor privado, $(20,99 \%$ do total dos leitos (312) contratados e $79 \%$ (1174) filantrópicos). Os demais 343 (18,75\%) dos leitos eram controlados pelo setor público (171 estadual e 172 municipal). A rede ambulatorial contava com cerca de 93 unidades, sendo $24(25,80 \%)$ com atendimento geral e $69(71,19 \%)$ com atendimento especializado. O número de consultórios médicos representou 404 que equivale a 9,9/10.000 habitantes; as equipes odontológicas, 90 ou 2,2/10.000 habitantes.

Dados e indicadores financeiros municipais mostravam em 1999, uma Receita Total de $R \$$ 3.68.342.187;00; uma Despesa Total com saúde de $R \$$ 81.300.136;00; Despesas Próprias gastas com saúde $\mathrm{R} \$ 46.267 .699 ; 00$, ou seja despesa própria com saúde por habitante de $\mathrm{R} \$$ 112,90 Despesa total com saúde por habitante de R\$ 198,37.

O grau de dependência financeira nas transferências orçamentárias externas, isto é das esferas estadual e federal (SUS), e ressarcimento de outros municipios estava em 1998 na média 43,1\% do total das despesas com saúde. Os gastos com internações distribuídos entre as 
diversas categorias hospitalares, significaram um per capita em torno de US $\$ 23,58$.

A análise dos dados referentes ao periodo de 1994 - 1998, mostrava como tendência geral, um gasto que beneficiava $87,06 \%$ os hospitais filantrópicos.

Em relação ao perfil de mortalidade proporcional por faixa etária segundo a classificação Internacional de Doenças (CID-10) em 1998, as quatro principais causas de mortalidade foram, em ordem decrescente: Causas externas 76,3 (15 a 19 anos); 57,1 ( 10 a 14 anos); 55,6 (5 a 9 anos); 36,6 (20 a 49 anos); afecçōes perinatais 70,4 (menor 1 ano); doenças do aparelho circulatório 41,9 (65 e mais); 41,1 ( 80 e mais); 29,7 (60 a 64 anos); 11,2 (20 a 49 anos); 11,1 (5 a 9 anos); doenças infecciosas e parasitárias 33,3 (5 a 9 anos); 20,7 ( 1 a 4 anos).

O coeficiente de mortalidade para algumas causas selecionadas (por 100.000 hab.), no periodo de 1994-1998, apresentou tendência de crescimento para óbitos por diabetes mellitus $(24,7 ; 26,8 ; 32,3 ; 30,2 ; 29,3)$; agressões $(20,0 ; 20,1 ; 22,8 ; 31,6 ; 33,4)$.

A porcentagem de óbitos por causas mal definidas apresentou tendência continua de crescimento $(11,6 ; 13,1 ; 13,6 ; 13,6 ; 14,9)$.

O coeficiente de mortalidade infantil no periodo (1994 -1998) apresentou $(25,4 ; 26,9 ; 25,3 ; 21,5$ e 18,3$)$.

\section{São Bernardo do Campo}

Em relação aos dados demográficos, temos que a população residente totaliza 703.351 habitantes, masculina $49,21 \%$ e feminina $50,78 \%$, com distribuição percentual segundo faixa etária de $\underline{28,08} \%(0$ - 15) 
$\underline{58,95 \%}(15-50), \pm 12,76 \%$ (50 ou + ) próximo do que BERQUÓ (1971) utilizou a classificação de SUNDBARG caracteriza como população tipo estacionária. A taxa de crescimento anual estimada 3,0; com mulheres em idade fértil (10 - 49) em 1998 totalizando 246.188 (68,9\%). A população alfabetizada representa $89,3 \%$.

A infra estrutura para uma população residente de 703.351 habitantes. O municipio contava, no total dos domicílios, com abastecimento de água em $96,8 \%$ possuiam água com canalização interna,(92,9\% ligados à rede geral) e $95,7 \%$ possuiam instalação sanitária, com $79,1 \%$ dos domicilios ligados à rede geral de esgotos.

A coleta de lixo abrange $97,9 \%$ dos moradores, sendo os demais lixos $0,5 \%$ queimado; $0,1 \%$ enterrado e $1,5 \%$ jogado.

A rede de serviços instalada no município totalizava 61 unidades, sendo 05 hospitais. 0 municipio dispunha de 1,0 leitos/1000 habitantes, que segundo os parâmetros preconizados pela Organização Mundial de Saúde (4,5 leitos/1000 habitantes) apresenta déficit de leitos. A rede hospitalar conta com 723 leitos, dos quais $69,15 \%$ (500) eram controlados pelo setor privado, (contratados 22,13\% (160) universitários. Os demais $8,71 \%$ (63) dos leitos eram controlados pelo setor público. A rede ambulatorial conta com cerca de 56 unidades, sendo $23(41,1 \%)$ com atendimento geral e 33 $(58,92 \%)$ com atendimento especializado. O número de consultórios médicos representou 277 que equivale a $3,8 / 10.000$ habitantes; as equipes odontológicas, 52 ou $0,7 / 10.000$ habitantes.

A análise dos dados referentes ao período de 1994 - 1998, mostrava como tendência geral, um gasto que beneficia em $72,06 \%$ o hospital universitário e os hospitais contratados os que se apropriaram dos recursos de $3,05 \%$. 
Em relação ao perfil de mortalidade proporcional por faixa etária segundo a classificação Internacional de Doenças (CID-10) em 1998, as quatro principais causas de mortalidade foram, em ordem decrescente: Causas externas 76,3 (15 a 19 anos); 58,3 (10 a 14 anos); 47,7 (20 a 49 anos); 44,4 (5 a 9 anos); afecções perinatais 59,2 (menor de 1 ano); doenças do aparelho circulatório 48,5 (65 e mais); 47,2 (80 e mais); 40,0 (50 a 64 anos); 20,2 (20 a 49 anos); 11,1 (1 a 4 anos); neoplasias (tumores) 25,6 (50 a 64 anos); 20,2 ( 80 e mais); 18,5 (65 e mais); 16,7 (5 a 9 anos).

O coeficiente de mortalidade para algumas causas selecionadas (por 100.000 hab.), no periodo de 1994-1998, apresentou tendência de crescimento para óbitos por diabetes mellitus $(13,3 ; 14,3 ; 14,8 ; 17,0 ; 15,4)$; agressões $(45,0 ; 46,8 ; 56,2 ; 53,4 ; 52,9)$.

A porcentagem de óbitos por causas mal definidas apresentou resultados alternados de queda e crescimento $(1,6 ; 1,7 ; 1,2 ; 1,0 ; 1,4)$.

O coeficiente de mortalidade infantil no período (1994-1998) apresentou 22,$5 ; 20,4 ; 21,4 ; 22,3 ; 17,2$.

\section{Sertãozinho}

Em relação aos dados demográficos, temos que a população residente totaliza 95115 habitantes $50,42 \%$ masculina e a feminina $49,57 \%$, com distribuição percentual segundo faixa etária de $\underline{29,52} \%$ ( 0 - 15) $\underline{56,53} \%(15-50), \pm 13,81(50 \mathrm{ou}+$ ) próximo do que BERQUO (1971) define como classificação de SUNDBARG caracteriza como população tipo estacionária. A taxa de crescimento anual estimada 3,4\%; com mulheres em idade fértil (10 - 49) em 1998 totalizando 31.571 ou $67,00 \%$.

A infra estrutura para uma população residente de 95.115 habitantes. O municipio contava, no total dos domicilios, com abastecimento 
de água em $98,9 \%$ possuiam água com canalização interna, $(95,7 \%$ ligados à rede geral) e $95,8 \%$ possuem instalação sanitária, com $92,2 \%$ dos domicilios ligados à rede geral de esgotos.

A coleta de lixo abrange $95,6 \%$ dos moradores, sendo o lixo restante $2,8 \%$ queimado; $0,1 \%$ enterrado e $1,5 \%$ jogado.

A rede de serviços instalada no município totalizava 14 unidades, sendo 01 hospital. O municipio dispunha de 1,2 leitos/1000 habitantes, que segundo os parâmetros preconizados pela Organização Mundial da Saúde (4,5 leitos/1000 habitantes) apresentava déficit. A rede hospitalar contava com 119 leitos, dos quais $100 \%$ eram controlados pelo setor privado filantrópico. A rede ambulatorial conta com cerca de 13 unidades, sendo 7 $(53,84 \%)$ com atendimento geral e 6 (46,13\%) com atendimento especializado. $O$ número de consultórios médicos representou 50 unidades que equivale a 5,1/10.000 habitantes; os equipos odontológicos, 24 ou $2,4 / 10.000$ habitantes.

A análise dos dados referentes ao período de 1994 - 1998, mostra como tendência geral, um gasto que beneficia o hospital filantrópico em $100 \%$.

Em relação ao perfil de mortalidade proporcional por faixa etária segundo grupo de causa da classificação Internacional de Doenças (CID-10) no período, as quatro principais causas de mortalidade foram, em ordem decrescente: Demais causas definidas 80,0 (1 a 4 anos); 50,0 (5 a 9 anos); 43,8 (menor de 1 ano); 22,3 (50 a 64 anos); causas externas 66,7 ( 15 a 19 anos); 50,0 (5 a 9 anos); 28,6 (20 a 49 anos); 20,0 (1 a 4 anos); doenças do aparelho circulatório 50,6 (65 e mais), 47,0 ( 80 e mais), 28,1 (50 a 64 anos), 22,3 (20 a 49 anos), 16,7 (10 a 14 anos); neoplasias (tumores) 50,0 (5 a 9 anos); 23, 1 (50 a 64 anos), 15,7 (80 e mais). 
O coeficiente de mortalidade para algumas causas selecionadas (por 100.000 hab.) no período de 1994-1998) apresentou tendência de crescimento para óbitos por diabetes mellitus $(9,4 ; 7,0 ; 15,8 ; 9,8 ; 15,8)$; agressões $(25,9 ; 25,5 ; 30,5 ; 21,7 ; 24,2)$.

A porcentagem de óbitos por causas mal definidas apresentou resultado alternados de queda e crescimento $(2,2 ; 0,8 ; 2,1 ; 1,7 ; 1,4)$.

O coeficiente de mortalidade infantil no período (1994 -1998) apresentou tendência de queda 19,$8 ; 16,5 ; 14,5 ; 16,4 ; 10,7$.

\section{São José dos Campos}

Em relação aos dados demográficos, temos que a população residente totaliza 506.725 habitantes, masculina $49,69 \%$ e feminina $50,30 \%$, com distribuição percentual segundo faixa etária de $\underline{29,87} \%(0-15)$

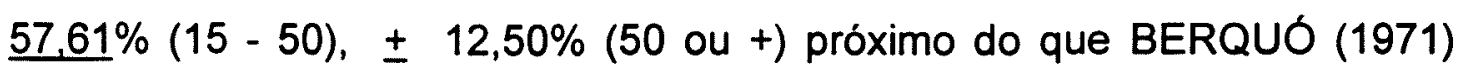
utilizando a classificação de SUNDBARG caracteriza como população tipo estacionária. $A$ taxa de crescimento anual estimada 1,9\%; com mulheres em idade fértil (10 - 49) em 1998 totalizando 174.762 (68,6\%). A população alfabetizada representa $88,7 \%$.

A infra estrutura para uma população residente de 506.725 habitantes, o municipio conta, no total dos domicilios, com abastecimento de água em $97,5 \%$ possuem água com canalização interna $(90,7 \%$ ligados à rede geral) e $96,1 \%$ possuem instalação sanitária, com $80,4 \%$ dos domicilios ligados à rede geral de esgotos.

A coleta de lixo abrange $95,6 \%$ dos moradores, sendo os demais lixos $2,2 \%$ queimado; $0,7 \%$ enterrado; $1,4 \%$ jogado; $0,1 \%$ outros. 
A rede de serviços instalada no município totaliza 87 unidades, sendo 8 hospitais. O município dispõe de 1,9 leitos/1000 habitantes, que segundo os parâmetros preconizados pela Organização Mundial de Saúde (4,5 leitos/1000 habitantes)apresenta déficit de leitos, no entanto, segundo CASTRO (1998) "houve aumento da oferta de leitos através da Secretaria Municipal de Saúde, especialmente direcionada as necessidades de clínica obstétrica, traumato, ortopedia e neuro cirurgia". A rede hospitalar conta com 998 leitos, dos quais $67,53 \%$ (674) são controlados pelo setor privado, sendo (64,83\% dos leitos (437) são privados e $35,15 \%$ (237) filantrópicos). Os demais $32,46 \%$ (324) dos leitos são controlados pelo setor público municipal. A rede ambulatorial conta com cerca de 79 unidades, sendo $37(46,83 \%)$ com atendimento geral e $42(53,16 \%)$ com atendimento especializado. $O$ número de consultórios médicos representou 386 que equivale a $7,1 / 10.000$ habitantes; os equipos odontológicos, 146 ou $2,8 / 10.000$ habitantes.

Dados e indicadores municipais mostravam em 1999, uma Receita Total R\$ 338.447.580,00; uma Despesa total com saúde de $\mathrm{R} \$$ 91.174.569,00 e Despesa própria com saúde de $\mathrm{R} \$ 62.713 .073 ; 00$; Despesa própria com saúde por habitante $R \$ 123,80$; Despesa total com saúde por habitante $R \$ 179,93$.

O grau de dependência financeira municipal das transferências orçamentárias externas, isto é das esferas estadual e federal(SUS) e ressarcimento de outros municípios, estava em média $31,2 \%$ do total das despesas com saúde.

A análise dos dados referentes ao periodo de 1994 - 1998, mostra como tendência geral, um gasto de aproximadamente $71,17 \%$ que beneficia os hospitais filantrópicos e hospitais privados contratados aqueles que se apropriaram de $1,11 \%$ dos recursos. 
Em relação ao perfil de mortalidade proporcional por faixa etária segundo grupo de causas da classificação Internacional de Doenças (CID10) em 1998, as quatro principais causas de mortalidade foram, em ordem decrescente: Causas externas (87,7 (15 a 19 anos); 61,1 (10 a 14 anos); 57,1 (20 a 49 anos); 23,8 (1 a 4 anos); 23, 1 (5 a 9 anos); Afecçōes perinatais 61,1 (menor de 1 ano); Doenças do aparelho circulatório 36,7 (80 e mais); 36,7 (65 e mais); 34,7 (50 a 64 anos); Neoplasias (tumores) 30,8 (5 a 9 anos); 25,3 (50 a 64 anos); 21,4 ( 80 e mais).

O coeficiente de mortalidade para algumas causas selecionadas (por 100.000 hab.) no periodo de 1994-1998) apresentou tendência de crescimento para óbitos por diabetes mellitus $(17,0 ; 18,2 ; 19,5 ; 19,1 ; 14,0)$ agressões $(39,9 ; 36,4 ; 49,0 ; 46,6 ; 57,8)$.

A porcentagem de óbitos por causas mal definidas apresentou resultado de queda e crescimento 11,$1 ; 11,2 ; 13,4 ; 14,0 ; 13,2$.

O coeficiente de mortalidade infantil no período (1994 -1998) apresentou queda 20,$8 ; 19,9 ; 19,4 ; 16,4 ; 17,9$.

\section{São Vicente}

Em relação aos dados demográficos, temos que a população residente totaliza 284.540 habitantes, masculina 48,925 e feminina $51,07 \%$, com distribuição percentual segundo faixa etária de $\underline{28,55} \%$ ( 0 - 15) $\underline{56,20} \%(15-50), \pm 15,09 \%$ (50 ou + ) próximo do que BERQUÓ (1971) utilizando a classificação de SUNDBARG caracteriza como população tipo estacionária. A taxa de crescimento anual estimada $0,8 \%$; com mulheres em idade fértil $(10-49)$ em 1998 totalizando $96.144(66,2 \%)$. A população alfabetizada representa $87,5 \%$. 
A infra estrutura para uma população residente de 284.540 habitantes, o município conta, no total dos domicílios, com abastecimento de água em $96,8 \%$ possuem água com canalização interna (sendo $95,3 \%$ ligados à rede geral) e $93,8 \%$ possuem instalação sanitária (com $32,8 \%$ dos domicilios ligados à rede geral de esgotos).

A coleta de lixo abrange $90,3 \%$ dos moradores, sendo os demais lixos $1,8 \%$ queimado; $0,5 \%$ enterrado; $7,3 \%$ jogado; $0,1 \%$ outros.

A rede de serviços instalada no municipio totaliza 34 unidades, sendo 1 hospital. 0 município dispõe de 0,7 leitos/1000 habitantes, que apresenta déficit, segundo os parâmetros preconizados pela Organização Mundial de Saúde (4,5 leitos/1000 habitantes). A rede hospitalar conta com 189 leitos, dos quais $100 \%$ (189) são controlados pelo setor privado filantrópicos. A rede ambulatorial conta com cerca de 33 unidades, sendo 14 $(42,42 \%)$ com atendimento geral e $19(57,57 \%)$ com atendimento especializado. $O$ número de consultórios médicos representou 118 que equivale a 4,1/10.000 habitantes; os equipos odontológicos, 25 ou $0,9 / 10.000$ habitantes.

Dados e indicadores financeiros municipais mostravam em 1999, uma Receita Total $(R \$)$ de $R \$ 104.996 .563,00$. Despesas total R\$ 28.080.559,00 com saúde, Despesas própria com saúde de $R \$ 16.094 .378,00$; despesas própria com saúde por habitante $R \$ 56,60$; despesas total com saúde por habitante $\mathrm{R} \$ 98,69$.

grau de dependência financeira municipal nas transferências orçamentárias externas, isto é das esferas estadual e federal (SUS), ressarcimento de outros municipios estava em média $42,7 \%$ do total das despesas com saúde. Em 1998 a despesa com saúde por habitante correspondeu a $\mathrm{R} \$ 98,69$. 
A análise dos dados referentes ao período de 1994 - 1998, mostra como tendência geral, um gasto que em $100 \%$ beneficia o hospital filantrópico.

Em relação ao perfil de mortalidade proporcional por faixa etária segundo grupo de causas da classificação Internacional de Doenças (CID10) em 1998, as quatro principais causas de mortalidade foram, em ordem decrescente: Afecções perinatais 70,0 (menor de 1 ano); causas externas 85,5 (15 a 19 anos); 57,1 (10 a 14 anos); 45,8 (20 a 49 anos); 25,0 (5 a 9 anos); 22,7 (1 a 4 anos); doenças do aparelho circulatório 38,6 (65 e mais) 37,0 (80 e mais); 33,3 (50 a 64 anos); 11,6 (20 a 49 anos); demais causas definidas 37,5 ( 5 a 9 anos), 22,1 (65 e mais e 80 e mais); 25,6 (50 a 64 anos); 16,2 (menor de 1 ano); 13,6 (1 a 4 anos).

O coeficiente de mortalidade para algumas causas selecionadas (por 100.000 hab.) no periodo de 1994-1998) apresentou tendência de crescimento para óbitos por diabetes mellitus $(16,8 ; 17,6 ; 21,1 ; 24,8 ; 23,2)$; agressões $(28,7 ; 26,9 ; 39,7 ; 52,1 ; 51,7)$.

A porcentagem de óbitos por causas mal definidas apresentou resultados continuados de crescimento $(15,7 ; 18,7 ; 18,3 ; 20,2 ; 22,8)$.

O coeficiente de mortalidade infantil no período (1994 -1998) apresentou queda 27,$2 ; 33,1 ; 26,2 ; 29,4 ; 25,1$.

\section{Votorantim}

Em relação aos dados demográficos, temos que a população residente totaliza 90331 habitantes, masculina 50,055 e feminina $49,94 \%$, com distribuição percentual segundo faixa etária de $\underline{28,72 \%}$ (0 - 15) $\underline{56,24} \%(15-50), \pm 12,79 \%(50$ ou + ) próximo do que BERQUO (1971) utilizando a classificação de SUNDBARG caracteriza como população tipo 
estacionária. A taxa de crescimento anual estimada 1,7\%; com mulheres em idade fértil (10 - 49) em 1998 totalizando 30108 (66,7\%). A população alfabetizada representa $87,5 \%$.

A infra estrutura para uma população residente de 90331 habitantes, o municipio conta, no total dos domicílios, com abastecimento de água em $96,6 \%$ possuem água com canalização interna (sendo 94,2\% ligados à rede geral) e $93,3 \%$ possuem instalação sanitária (com $81,3 \%$ dos domicílios ligados à rede geral de esgotos).

A coleta de lixo abrange $94,7 \%$ dos moradores; sendo os demais lixos $2,1 \%$ queimado; $0,3 \%$ enterrado e $2,9 \%$ jogado.

A rede de serviços instalada no municipio totaliza 28 unidades, sendo 02 hospitais. 0 município dispõe de 1,1 leitos/1000 habitantes, que representa déficit, segundo os parâmetros preconizados pela Organização Mundial de Saúde (4,5 leitos $/ 1000$ habitantes). A rede hospitalar conta com 102 leitos, dos quais $80,39 \%$ (82) são controlados pelo setor privado, sendo $100 \%$ (82) dos leitos contratados. Os demais $20(19,60 \%)$ do total leitos são controlados pelo setor público municipal. A rede ambulatorial conta com cerca de 26 unidades, sendo $9(34,6 \%)$ com atendimento geral e 17 $(65,38 \%)$ com atendimento especializado. O número de consultórios médicos representou 76 unidades que equivale a $8,3 / 10.000$ habitantes; os equipos odontológicos, 19 ou 2,1/10.000 habitantes.

Dados e indicadores municipais mostravam em 1999, uma Receita total $R(\$)$ de $R \$ 29.304 .340,00$; despesas total com saúde $R \$ 8.502 .322,00$; despesas própria com saúde $R \$ 5.588 .762,00$; despesas própria com saúde por habitante $R \$ 61,90$; despesas total com saúde por habitante $R \$ 94,12$.

O grau de dependência financeira municipal das transferências orçamentárias externas, isto é das esferas estadual e federal (SUS) e 
ressarcimento de outros municipios, estava em média $34,3 \%$ do total das despesas com saúde. Os gastos com internações distribuídos entre as diversas categorias hospitalares, significaram um per capita em torno de US\$ 8,17 .

Em relação ao perfil de mortalidade proporcional por faixa etária segundo grupo de causas da classificação Internacional de Doenças (CID10) em 1998, as quatro principais causas de mortalidade foram, em ordem decrescente: Causas externas 100,0 (10 a 14 anos); 100,0 (15 a 19 anos); 50,0 (5 a 9 anos); 36,3 (20 a 49 anos); 33,3 (1 a 4 anos); afecções perinatais 63,6 (menor de 1 ano); doenças do aparelho circulatório 40,9 (65 e mais e 80 e mais); 35,8 (50 a 64 anos); 25,0 (5 a 9 anos); demais causas definidas 20,2 (50 a 64 anos); 18,6 (20 a 49 anos); 18,2 (menor de 1 ano); 17,8 (65 e mais); 17,4 ( 80 e mais).

O coeficiente de mortalidade para algumas causas selecionadas (por 100.000 hab.) no período de 1994-1998) apresentou tendência de crescimento para óbitos por diabetes mellitus $(17,2 ; 18,1 ; 18,4 ; 18,0 ; 18,8)$; agressōes $(5,7 ; 5,7 ; 13,8 ; 20,2 ; 18,8)$

A porcentagem de óbitos por causas mal definidas apresentou resultado alternado de queda e crescimento $(14,0 ; 17,5 ; 14,2 ; 15,1 ; 12,8)$.

O coeficiente de mortalidade infantil no período (1994 -1998) apresentou 23,$3 ; 19,2 ; 19,7 ; 16,3 ; 19,0$. 
IV- RESULTADOS E DISCUSSÃO 


\subsection{Distribuição da oferta de leitos hospitalares}

Segundo dados do Ministério da Saúde (MS 2000), dos leitos do País, o Estado de São Paulo era responsável em: 1995, 113.40 leitos (22,5\%); 1996, 11.474 leitos (22,3\%); 1997, 109.044 leitos (21,9\%); 1998106.363 leitos (21,7\%) sendo que estavam vinculados ao SUS no mesmo periodo, respectivamente: 89.707 leitos ( $21,4 \%), 89.006$ leitos ( $21,1 \%), 87.955$ leitos $(20,7 \%)$ e 86.795 leitos $(20,7 \%)$, que registram discreta tendência de queda.

No Quadro 4 é apresentada a distribuição do número de leitos por especialidade e municípios, antes e depois da implantação da gestão semi plena.

Quadro 4 - Distribuição do número de leitos por especialidades e municípios, antes e depois da implantação da gestão semi-plena, na Rede Hospitalar do SUS.

\begin{tabular}{|c|c|c|c|c|c|c|c|c|c|c|c|c|}
\hline \multirow{2}{*}{$\begin{array}{l}\text { Municipio } \\
\text { Período } \\
\end{array}$} & \multicolumn{2}{|c|}{ Total } & \multicolumn{2}{|c|}{ Cirurgia } & \multicolumn{2}{|c|}{ Obstetricia } & \multicolumn{2}{|c|}{ Médica } & \multicolumn{2}{|c|}{ Pediatria } & \multicolumn{2}{|c|}{ Outros } \\
\hline & Antes & Depois & Antes & Depois & Antes & Depois & Antes & Depois & Antes & Depois & Antes & Depois \\
\hline Assis & 421 & 421 & 113 & 113 & 102 & 102 & 178 & 178 & 165 & 165 & 28 & 28 \\
\hline Campinas & 2473 & 2075 & 761 & 673 & 244 & 237 & 634 & 495 & 613 & 198 & 834 & 670 \\
\hline Diadema & 901 & 361 & 130 & 99 & 104 & 85 & 205 & 125 & 163 & 107 & 462 & 52 \\
\hline Mauá & 513 & 263 & 56 & 56 & 101 & 101 & 88 & 88 & 85 & 85 & 268 & 18 \\
\hline Ribeirāo Preto & 1834 & 1765 & 489 & 464 & 191 & 205 & 518 & 501 & 268 & 258 & 636 & 595 \\
\hline Santos & 1795 & 1708 & 506 & 595 & 166 & 140 & 870 & 810 & 337 & 209 & 253 & 163 \\
\hline São Bernardo do Campo & 565 & 588 & 49 & 76 & 32 & 32 & 150 & 142 & 40 & 55 & 334 & 338 \\
\hline Săo José dos Campos & 966 & 985 & 158 & 163 & 92 & 134 & 266 & 240 & 145 & 118 & 450 & 448 \\
\hline São Vicente & 198 & 155 & 61 & 45 & 36 & 26 & 91 & 76 & 60 & 40 & 10 & 8 \\
\hline Sertãozinho & 84 & 88 & 27 & 27 & 25 & 25 & 32 & 32 & 35 & 35 & 0 & 4 \\
\hline Notorantim & 114 & 86 & 18 & 20 & 18 & 10 & 73 & 49 & 28 & 21 & 5 & 7 \\
\hline Total (11 municipios) & 9864 & 8495 & 2368 & 2331 & 1111 & 1097 & 3105 & 2736 & 1939 & 1291 & 3280 & 2331 \\
\hline Estado de São Paulo* & 115991 & 106450 & 20403 & 19684 & 12583 & 11804 & 30668 & 29426 & 16110 & 14661 & 36227 & 30875 \\
\hline Brasil* & $\frac{507378}{\text { tema de }}$ & 492405 & 96904 & $\frac{93502}{\text { Hospita }}$ & $\frac{75866}{\text { lares - }}$ & $\frac{72076}{- \text { CNPS }}$ & 152285 & 147783 & 74166 & 81064 & 108157 & 97980 \\
\hline $\begin{array}{ll}{ }^{*} \mathrm{Obs}_{1}: & \text { Inclui os leitc } \\
& \text { hospital dia. } \\
\text { Obs }_{2}: & \text { Considerou-se } \\
& \text { na metodolog }\end{array}$ & para & dos 0 & רun & ios, & $0<c$ & dro & como & ntes & depo & per & & \\
\hline
\end{tabular}

Considerando o total de leitos, nos 11 municipios (9864 antes e 8495 depois) da gestão semi plena, observou-se que houve redução de $13,88 \%$. Constatou-se que para São Paulo e Brasil nos totais respectivos também ocorreu redução, de $8,23 \%$ e $2,95 \%$, se comparados os períodos antes e depois. 
VIANNA (1998) chama a atenção para a necessidade de novas políticas de saúde, de ações e de programas que atendam ao novo tecido social que terá riscos: o da velhice prolongada (pelo crescimento da esperança de vida) sem apoio familiar e sem utilidade social; o do novo desemprego, que não é mais temporário, mas pode ser permanente e de caráter estrutural; 0 da nova pobreza, ocasionada por múltiplos fatores, novos e velhos; 0 da violência e das novas doenças a que todos estão expostos (provocados pela má qualidade urbana e pelo descontrole do meio ambiente); o dos novos tipos de exclusão por renda, gênero, etnia e cultura, significando, a nosso ver, um sinal de alerta a redução progressiva dos leitos hospitalares ofertados a população.

Comparando-se o total de leitos dos municípios estudados, no periodo antes e depois da implantação da gestão semi plena, observou-se que os maiores percentuais de redução no número de leitos ocorreram em Diadema (antes 901 depois 361), (59,93\%) seguido pelos municípios de Mauá (antes 513 - depois $263),(48,73 \%)$, Votorantim (antes 114 - depois 86$),(24,56 \%)$, São Vicente (antes 198 - depois 155),(21,72\%), Campinas (antes 2473 - depois 2075),(16,09\%), Santos $(4,85 \%)$ e Ribeirão Preto $(3,76 \%)$. Somente no municipio de Assis, o número de leitos permaneceu sem alteração.

$\mathrm{O}$ aumento do número de leitos, considerando-se os 11 (onze) Municípios, ocorreu em Sertãozinho (4,76\%), São Bernardo do Campo $(4,07 \%)$ e São José dos Campos (1,97\%).

Com relação ao total de leitos, observou-se a redução em todas as especialidades, a saber: Cirúrgicos (1,56\%); Obstétricos (0,59\%); Clínica Médica $(11,88 \%)$, Pediatria $(33,94 \%)$ e outros $(28,93 \%)$.

Comparando-se o número de leitos cirúrgicos, após implantação da gestão semi plena e levando-se em conta os 3 (três) anos de avaliação, observou-se que nos municípios de Assis, Mauá e Sertãozinho foram mantidos os mesmos registros. 
Observou-se redução no número de leitos cirúrgicos em São Vicente (26,23\%), Diadema $(23,85 \%)$, Campinas $(11,56 \%)$ e Ribeirão Preto $(5,11 \%)$. E acréscimo no número de leitos cirúrgicos nos municípios de São Bernardo do Campo $(55,10 \%)$, Santos $(17,59 \%)$, Votorantim (11\%) e São José dos Campos $(3,16 \%)$.

Naqueles municipios observou-se uma redução maior do que a que foi de $3,52 \%$ e $3,51 \%$ ocorridas no Estado de São Paulo e Brasil, respectivamente.

Com relação aos leitos obstétricos nos municipios de Assis, São Bernardo do Campo, Mauá e Sertãozinho não verificou-se alterações quando confrontou-se os registros dos períodos antes e depois da implantação da gestão semi plena.

Os municípios que apresentaram redução no número de leitos obstétricos foram Votorantim $(44,44 \%)$, São Vicente $(27,78 \%)$, Diadema $(18,27 \%)$, Santos $(15,26 \%)$ e Campinas $(2,87 \%)$. Entretanto, apresentaram acréscimos, os municípios de São José dos Campos $(45,65 \%)$ e Ribeirão Preto $(7,33 \%)$. No Estado de São Paulo e Brasil a redução no número de leitos obstétricos foi de $5,00 \%$ para o mesmo periodo.

Verificou-se que para a especialidade de clínica médica nos municípios de Assis, Mauá e Sertãozinho, não ocorreram alterações no número de leitos. Entretanto, para os demais municipios verificou-se reduções em Diadema $(39,02 \%)$, Votorantim $(32,88 \%)$, Campinas $(21,92 \%)$, São Vicente $(16,48 \%)$, São José dos Campos $(9,77 \%)$, Santos $(6,90 \%)$, São Bernardo $(5,33 \%)$ e Ribeirão Preto (3,28\%). Ocorreram reduções no Estado de São Paulo $(4,05 \%)$ e também no Brasil (2,96\%).

O número de leitos para a especialidade de Pediatria não se modificou em Assis, Mauá e Sertãozinho. No entanto, observou-se reduções no número de leitos pediátricos em Campinas $(67,70 \%)$, Santos $(37,98 \%)$, Diadema $(34,36 \%)$, 
São Vicente $(33,33 \%)$, Votorantim $(25,00 \%)$, São José dos Campos em $(18,62 \%)$ e Ribeirão Preto $(3,73 \%)$, que ultrapassaram a tendência do Estado de São Paulo que apresentou redução de $(8,99 \%)$ dos leitos pediátricos.

Somente no município de São Bernardo do Campo (37,50\%), observou-se acréscimo no número de leitos pediátricos acompanhando a tendência do Brasil $(9,30 \%)$, que apresentou acréscimo.

O Quadro 5 mostra a distribuição do número de leitos por 1000 habitantes, segundo especialidades e nos períodos antes e depois da implantação da gestão semi plena.

Quadro 5 - Distribuição do número de leitos por mil habitantes e por especialidades nos municípios, nos períodos antes e depois da implantação da gestão semiplena.

\begin{tabular}{|c|c|c|c|c|c|c|c|c|c|c|c|c|}
\hline \multirow{2}{*}{ Municiplo } & \multicolumn{2}{|c|}{ Total } & \multicolumn{2}{|c|}{ Cirurgia } & \multicolumn{2}{|c|}{ Obstetricia } & \multicolumn{2}{|c|}{ Medica } & \multicolumn{2}{|c|}{ Pediatria } & \multicolumn{2}{|c|}{ Outros } \\
\hline & Antes & Depols & Antes & Depois & Antes & Depols & Antes & Depols & Antes & Depois & Antes & Depols \\
\hline Assis & 5,26 & 4,88 & 1,41 & 1,31 & 1,27 & 1,18 & 2,22 & 2,06 & 2,06 & 1,81 & 0,35 & 0,32 \\
\hline Campinas & 2,80 & 2,23 & 0,86 & 0,72 & 0,28 & 0,25 & 0,72 & 0,53 & 0,69 & 0,21 & 0,84 & 0,72 \\
\hline Dladema & 2,86 & 1,09 & 0,41 & 0,30 & 0,33 & 0,26 & 0,65 & 0,38 & 0,52 & 0,32 & 1,46 & 0,16 \\
\hline Mauá & 1,59 & 0.72 & 0,17 & 0,15 & 0,31 & 0,28 & 0,27 & 0,24 & 0,26 & 0,23 & 0,83 & 0,05 \\
\hline Ribeirăo Preto & 4,11 & 3,79 & 1,10 & 1.00 & 0,43 & 0,44 & 1,16 & 1,08 & 0,60 & 0,55 & 1,43 & 1,28 \\
\hline Santos & 4,33 & 4,16 & 1,22 & 1,45 & 0,40 & 0,34 & 2,10 & 1,97 & 0,81 & 0,51 & 0,61 & 0,40 \\
\hline Săo Bernardo do Campo & 0,91 & 0,84 & 0,08 & 0,11 & 0,05 & 0,05 & 0,24 & 0,20 & 0,06 & 0,08 & 0,54 & 0,48 \\
\hline Săo José dos Campos & 11,45 & 10,64 & 1,87 & 1,76 & 1,09 & 1,45 & 3,15 & 2,59 & 1,72 & 1,27 & 5.33 & 4,84 \\
\hline Saso Vicente & 0,42 & 0,31 & 0,13 & 0,09 & 0,08 & 0,05 & 0,19 & 0,15 & 0,13 & 0,08 & 0,02 & 0,02 \\
\hline Sertaozinho & 0,31 & 0.31 & 0.10 & 0,10 & 0,09 & 0.09 & 0,12 & 0,11 & 0.13 & 0,12 & 0,00 & 0,01 \\
\hline Votorantim & 1,35 & 0,96 & 0,21 & 0,22 & 0.21 & 0,11 & 0,86 & 0,55 & 0,33 & 0,23 & 0,06 & 0.08 \\
\hline Estado de Săo Paulo & 3,49 & 3,02 & 0,61 & 0,56 & 0,38 & 0,34 & 0,82 & 0,84 & 0,49 & 0,42 & 1,09 & 0,88 \\
\hline Brasll & 3,30 & 3,04 & 0,63 & 0,58 & 0.49 & 0,44 & 0,99 & 0.91 & 0,48 & 0,50 & 0,70 & 0,60 \\
\hline
\end{tabular}

Fonte: www.datasus.gov.br_SIH

Legenda - Homogeneizado o padrão Brasil e São Paulo

Comparou-se esses resultados com a Portaria 3046 (MS/MPAS, 1982), que recomenda para as Clínicas: Médica (inclusive Pediatria) a razão de 1,11 leitos/1000 habitantes; Cirúrgica 0,36 leitos/1000 habitantes; Obstétrica 0,35 leitos/1000 habitantes.

Observou-se na análise da oferta de leitos por 1000 habitantes por especialidade, que existe tendência de concentração de leitos cirúrgicos, antes e 
depois, em Assis (1,41 - 1,31), Campinas $(0,86$ - 0,72), Ribeirão Preto $(1,10$ $1,00)$, Santos $(1,22-1,45)$, São José dos Campos $(1,87-1,76)$ em relação à média de leitos cirúrgicos em São Paulo $(0,61-0,56)$ e Brasil $(0,63-0,58)$.

Com relação à especialidade de Clínica Cirúrgica a distribuição do número de leitos por 1000/habitantes nos municípios de Mauá, São Bernardo do Campo, São Vicente e Votorantim antes da implantação da gestão semi plena, ficaram abaixo de 0,36 leitos/1000 recomendado pela Portaria 3046 (MS/MPAS 1982). Após a implantação da gestão semi plena, não houve alteração no número de leitos da condição anterior para esses municipios. Destacando-se o município de Diadema que antes, para essa especialidade, havia uma oferta de leitos 0,41 leitos $/ 1000$ e depois passou a $0,30 / 1000$ habitantes, passando a integrar o grupo com valor abaixo daquela recomendação.

Nos casos de oferta de leitos obstétricos observou-se que estão acima dos parâmetros da Portaria 3046 (MS/MPAS 1982) (0,35/1000) e parâmetros Brasil $(0,49-0,44)$ MS (2000), os municipios de: Assis $(1,27-1,18)$; São José dos Campos $(1,33-1,45)$ MS $(2000)$, estando os demais abaixo dos referidos indicadores: São Paulo $(0,38-0,34)$ para a referida especialidade.

Com relação à especialidade de Obstetrícia, os municipios que apresentaram valores inferiores aos parâmetros recomendados pela Portaria 3046 (MS/MPAS 1982) 0,35 leitos/1000 habitantes foram Campinas, Diadema, Mauá, São Bernardo do Campo, São Vicente, Sertãozinho e Votorantim conforme Quadro 5, mantiveram-se abaixo antes e depois. No Estado de São Paulo, obteve-se no período antes da implantação 0,38 leitos/1000 habitantes e 0,34 leitos/1000 habitantes depois da implantação da gestão semi plena abaixo de acordo com a referência anterior, no entanto, para o Brasil encontramos parâmetros de 0,49 leitos $/ 1000$ habitantes e 0,44 leitos/1000 habitantes MS (2000) o que representa valores acima do esperado, segundo a portaria referida anteriormente. 
A Portaria 3046 (MS/MPAS 1982) agrupa as especialidades de Clínica Médica e Pediatria, e propõe o parâmetro de 1,11/leitos por 1000 habitantes para essa especialidade. Obtivemos para essas especialidades valores abaixo do proposto (1,11 leitos/1000 habitantes) nos municípios de Mauá $(0,53)$, São Bernardo do Campo $(0,30)$, São Vicente $(0,32)$ e Sertãozinho $(0,25)$ no período antes da implantação da gestão semi plena. Para o período após a implantação, esta condição não se alterou para o grupo de municípios relacionados anteriormente, que por sua vez foi acrescido dos municípios de Campinas (antes $=1,41$, depois $=0,74)$, Mauá (antes $=0,53$, depois $=0,47$ ) e Votorantim (antes $=$ 1,19 , depois $=0,78$ ). No Estado de São Paulo, nos períodos avaliados obteve-se: antes $=1,41$ e depois $=1,26$, e para $\circ$ Brasil obteve-se: antes $=1,47$ e depois $=$ 1,41 .

Podemos concluir, com os dados obtidos, que após a implantação da gestão semi plena, entre os municipios estudados, houve uma redução na oferta de leitos em número e especialidades, o que não foi um evento isolado, pois essa redução aconteceu também no Estado de São Paulo (antes $=3,49$ e depois $=$ 3,02 ) e no Brasil (antes $=3,30$ e depois $=3,04$ ) (MS 2000).

A Figura $1 \mathrm{~A}$, mostra a comparação do número de leitos cadastrados no município (AlH), com o proposto pela MS/MPAS Portaria 3046 (MS/MPAS 1982) e OPAS (Organização Panamericana de Saúde), nos períodos antes (A) e depois (B) da implantação da gestão semi plena.

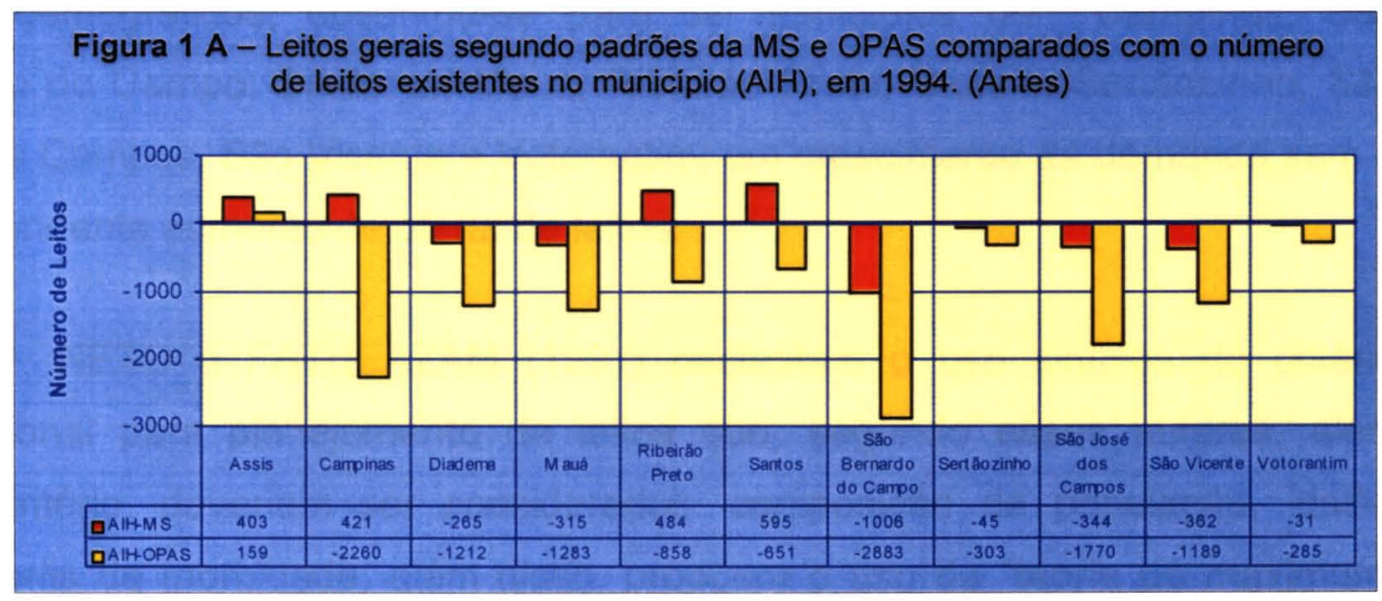




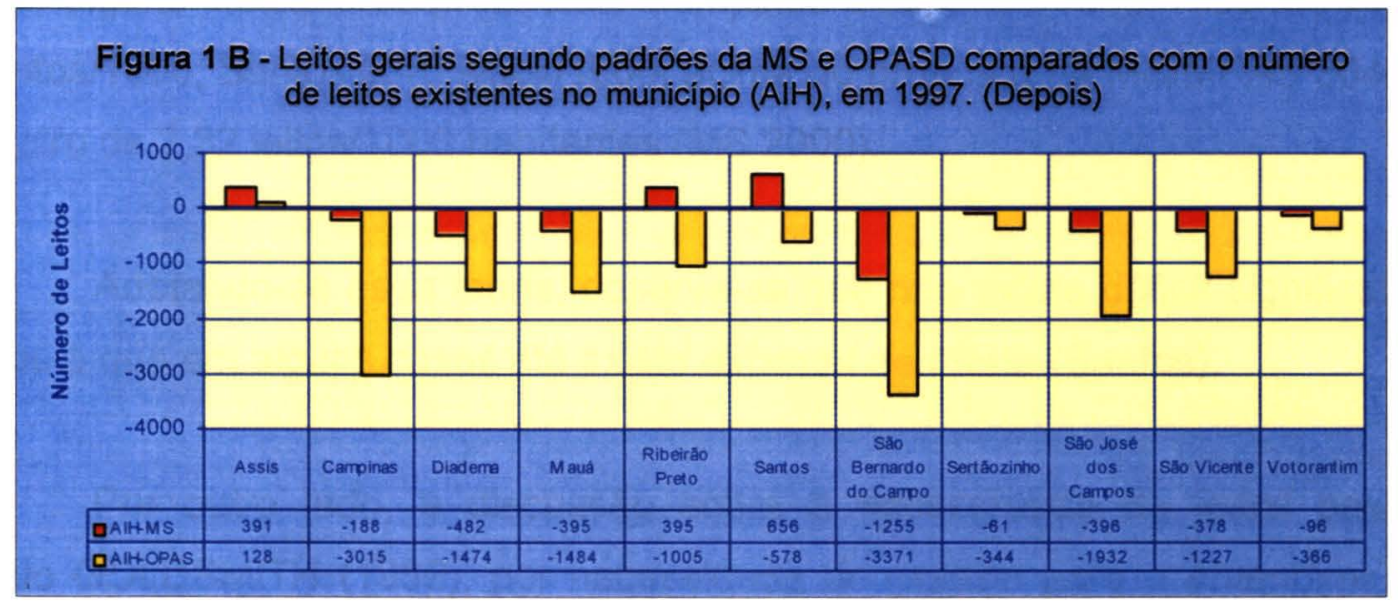

Segundo os padrões do Ministério da Saúde e Ministério da Previdência e Assistência Social, MS/MPAS (1982), os municípios que apresentaram superávit na oferta de leitos gerais, antes da implantação da gestão semi plena, foram Assis, Ribeirão Preto e Santos. Conforme o padrão OMS/OPAS (Organização Mundial de Saúde/Organização Panamericana de Saúde) somente o município de Assis apresentou o número de leitos acima do proposto. Para ambos os parâmetros (MS e OPAS), a situação de déficit ou superávit não foi alterada antes e depois da implantação da gestão semi plena, o que pode ser observado nas Figuras $1 \mathrm{~A}$ e $1 \mathrm{~B}$.

Considerando que os parâmetros MS e OPAS estão relacionados aos fatores demográficos, observou-se para os municípios de Campinas, São Bernardo do Campo, Diadema, Mauá, Ribeirão Preto, Santos, Sertãozinho, São José dos Campos, São Vicente e Votorantim, um crescimento da demanda sem o correspondente aumento de oferta de leitos.

NETO e FATHEAZAM (1991) contestam o uso simples do critério populacional para planejamento de leitos que, segundo esses autores, além desse critério, deveriam ser considerados: composição da população, idade, sexo, perfis de morbidade, além disso, propõem o uso da "teoria do maximum" para o cálculo de necessidade de leitos hospitalares para o Estado de São Paulo. 
Citamos alguns indicadores propostos: Campinas 2.59 leitos/1000; Ribeirão Preto 3.80 leitos/1000; Santos 2.40 leitos/1000, acima do proposto na MS/MPAS 3046 e parâmetro de 2,32 leitos/1000 habitantes (MS 2000).

Adotando-se essa teoria, observa-se que não existe déficit significativo de leitos e que em alguns casos até existe excesso de oferta (Santos).

Por outro lado, a discussão sobre a necessidade de leitos passa, segundo GOLDSMITH (1989), por necessidade de revisão para o entendimento de que "o hospital do futuro será uma instituição bem diferente e que concentrará os seus serviços no diagnóstico precoce e na administração dos problemas relativos às doenças crônicas. Esse hospital irá até as casas e às populações institucionalizadas..."

\subsubsection{Leitos por natureza do prestador}

O Quadro 6 apresenta o total de leitos por natureza do prestador, por municípios, nos períodos antes e depois da implantação da gestão semi plena.

Pelos totais de leitos contratados, observa-se que ocorreu redução no número de leitos relativos a essa natureza, que em termos percentuais representou uma redução de $55,87 \%$ (2533 leitos).

Em relação ao total do prestador contratado, nos municípios de Assis e São Bernardo do Campo, não houve alteração no número de leitos e em Sertãozinho, não registrou-se leitos para essa categoria. Observou-se redução no número de leitos contratados em Campinas (903 leitos - 88,20\%), Diadema (607 leitos - 69\%), Santos (437 leitos - 58,34\%), Mauá (250 leitos - 100\%), São José dos Campos (136 leitos - 28,44\%), Ribeirão Preto (82 - 28,67\%), São Vicente (63 leitos, $100 \%$ ) e Votorantim (55 leitos $-40,14 \%$ ). 
Quadro 6 - Total de leitos por natureza do prestador, contratado, estadual, municipal, filantrópico, universitário segundo municípios antes e depois da implantação da gestão nos 11 municípios em semi-plena.

\begin{tabular}{|c|c|c|c|c|c|c|c|c|c|c|c|c|}
\hline \multirow{2}{*}{ Municipios } & \multicolumn{2}{|c|}{ Contratado } & \multicolumn{2}{|c|}{ Estadual } & \multicolumn{2}{|c|}{ Municipal } & \multicolumn{2}{|c|}{ Filantrópico } & \multicolumn{2}{|c|}{ Universiturio } & \multicolumn{2}{|c|}{ Total } \\
\hline & A & D & A & D & A & D & A & D & A & D & A & D \\
\hline Asels & 77 & 77 & 320 & 320 & 0 & 0 & 177 & 177 & 0 & 0 & 574 & 574 \\
\hline Campines & 1024 & 121 & 0 & 0 & 117 & 162 & 967 & 666 & 859 & 1178 & 2867 & 2127 \\
\hline Diadems & 875 & 268 & 0 & 0 & 179 & 179 & 0 & 0 & 0 & 0 & 1054 & 47 \\
\hline Maut & 250 & 0 & 0 & 0 & 220 & 220 & 114 & 114 & 0 & 0 & 584 & 334 \\
\hline Riboirtso Proto & 286 & 204 & 437 & 414 & 0 & 0 & 625 & 639 & 652 & 668 & 2010 & 1925 \\
\hline Santos & 749 & 312 & 217 & 171 & 76 & 172 & 1007 & 1174 & 0 & 0 & 249 & 1829 \\
\hline SAO Barnurso do Campo & 500 & 500 & 0 & 0 & 40 & 63 & 0 & 0 & 53 & 64 & 593 & 627 \\
\hline Sorthozinho & 0 & 0 & 0 & 0 & 0 & 0 & 119 & 119 & 0 & 0 & 119 & 119 \\
\hline Sto Josu dos Campos & 573 & 437 & 0 & 0 & 189 & 307 & 317 & 310 & 0 & 0 & 1079 & 1054 \\
\hline Slo Vicente & 63 & 0 & 0 & 0 & 0 & 0 & 189 & 189 & 0 & 0 & 252 & 189 \\
\hline Votorantim & 137 & 82 & 0 & 0 & 0 & 20 & 0 & 0 & 0 & 0 & 137 & 102 \\
\hline Total & 4634 & 2001 & 284 & 805 & 821 & 1123 & 3516 & 3388 & 1664 & 1910 & 11418 & 9327 \\
\hline
\end{tabular}

Fonte: Cadastro de Prestadores. Movimento de autorização de internação hospitalar SIH-SUSData Sus.

Obs: Não inclui os leitos de psiquiatria, UTI, pacientes crônicos, clínica tisiológica, clinica de reabilitação e hospital-dia.

Em relação ao prestador estadual, observou-se uma redução nos totais de leitos. Existiam 984 leitos antes e 905 leitos, depois da implantação da gestão semi plena. Essa redução representou 79 leitos e correspondeu a 8,03\%. Ribeirão Preto, apresentou uma redução de 33 leitos $(7,55 \%)$ e Santos, 46 leitos $(22,11 \%)$. Os demais municipios não possuiam essa categoria de hospital.

Em relação ao prestador municipal observou-se a ampliação do número de leitos. No total, observou-se um acréscimo de 302 leitos $(36,78 \%)$. Os municipios que expandiram foram: São José dos Campos (118 leitos - 62,43\%), Santos (96 leitos - 126,31\%), Campinas (45 leitos - 38,46\%), São Bernardo do Campo (23 leitos - 57,15\%) e Votorantim (20 leitos, 100\%). Em Mauá e Diadema, não se observou alteração do número de leitos depois da semi plena. Os demais municípios não possuíam essa categoria de hospital. 
Em relação ao prestador filantrópico observou-se redução de leitos após a implantação da gestão semi-plena, que representou 127 leitos $-3,61 \%$. Os municípios que mantiveram o mesmo número de leitos foram: Assis, Mauá, Sertãozinho e São Vicente. Observou-se redução no número de leitos em Campinas (301 leitos - 31,13\%) e São José dos Campos (7 leitos - 22,08\%). Constatou-se aumento dos leitos filantrópicos em Santos (167 leitos - 16,58\%), Ribeirão Preto (14 leitos - 2,24\%). Os demais municipios não possuíam essa categoria de hospital.

Em relação ao prestador universitário verificou-se aumento no número de leitos correspondendo a 346 leitos - 22,12\%, assim distribuídos: Campinas 319 (37,13\%), Ribeirão Preto, 16 (2,45\%) e São Bernardo do Campo 11 (20,75\%). Os demais municípios não possuiam essa categoria de prestador.

SCATENA e TANAKA (1998), discutindo a distribuição dos estabelecimentos de saúde no Brasil, entendem como perspectivas futuras dos hospitais "que municipios e estados tenham aumentado sua participação no número de hospitais, enquanto o setor privado provavelmente continue reduzindo gradualmente sua participação nesse tipo de equipamento e que venha investindo no deslocamento parcial de suas atividades para ambulatórios ou transferindo setores tradicionalmente hospitalares para fora desses estabelecimentos, na forma de serviços de complementação diagnóstico e terapêutica".

O estudo dá conta de parte dessa previsão quando registra a ampliação de leitos públicos, particularmente, os municipais e redução da participação do setor contratado (privado). Esse resultado também é compatível com uma das soluções encontradas em outros países, onde "no caso de setores públicos de saúde, a compra de serviços de terceiros parece cada vez menos vantajosa, em função do crescimento da inflação setorial. Assim, alguns defendem que a saida crescer ou incrementar a produtividade dos serviços próprios do Estado ao invés de comprá-los externamente, dado que tais serviços seriam, em tese, mais fáceis de serem submetidos a uma estratégia de 
racionalização de custos sem queda de qualidade, o que dificilmente poderia ser feito no setor privado contratado mediante motivação do Estado", (MÉDICI 1990).

PORTELA et al (2000) em estudo sobre hospitais filantrópicos no Brasil, destacam que a importância desses prestadores na oferta de leitos está na região Sudeste $57,9 \%$ e Sul $67,5 \%$ do País. Nos 11 municípios estudados observou-se que os filantrópicos respondem por 30,78\% (antes) e $36,32 \%$ (depois) dos totais de leitos (Quadro 6). Esse resultado reafirma a importância dos filantrópicos, (BRASIL 1992) no processo de consolidação do Sistema Único de Saúde o que foi constatado com a garantia de $70 \%$ da capacidade instalada para a clientela do SUS, como proposta na IX Conferência Nacional de Saúde (Brasil, 1992), sendo que apenas Campinas apresentou queda de $31,13 \%$ na oferta dos leitos, não atingindo os $70 \%$ de capacidade instalada proposta, naquela conferência.

A figura 2, ilustra a distribuição dos leitos por prestador, para o total dos 11 municípios, antes e depois da implantação da gestão semi plena, o detalhamento por municípios pode ser verificado nas figuras 3 a 13 a seguir.

Figura 2 - Totais de leitos por tipo de prestador, referentes ao total dos 11 municípios, antes e depois da implantação da gestão semi-plena.

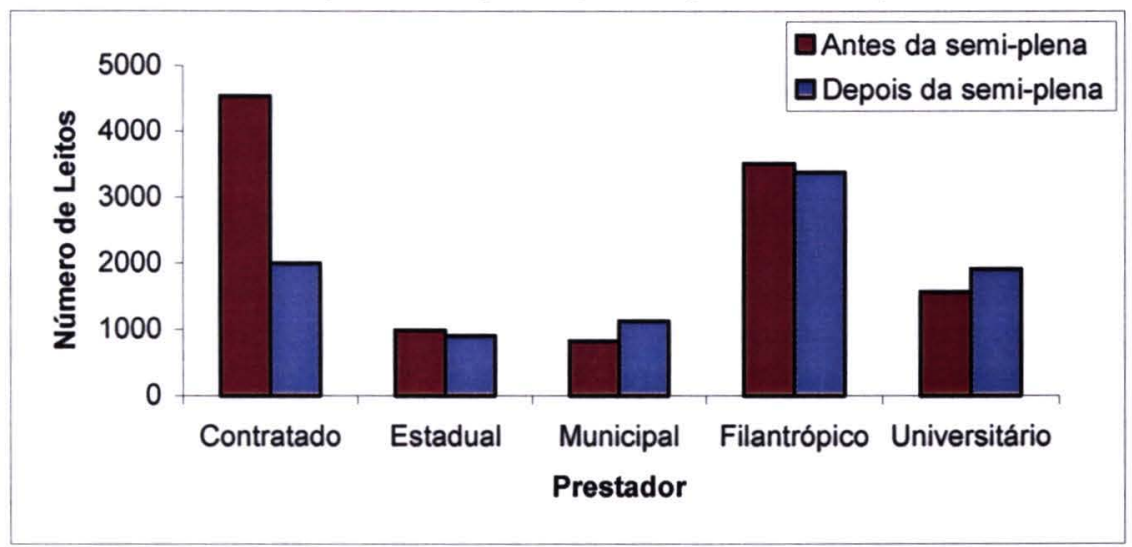


Figura 3 - Número de leitos por tipo de prestador, em Assis-SP antes e depois da implantação da gestão semi-plena.

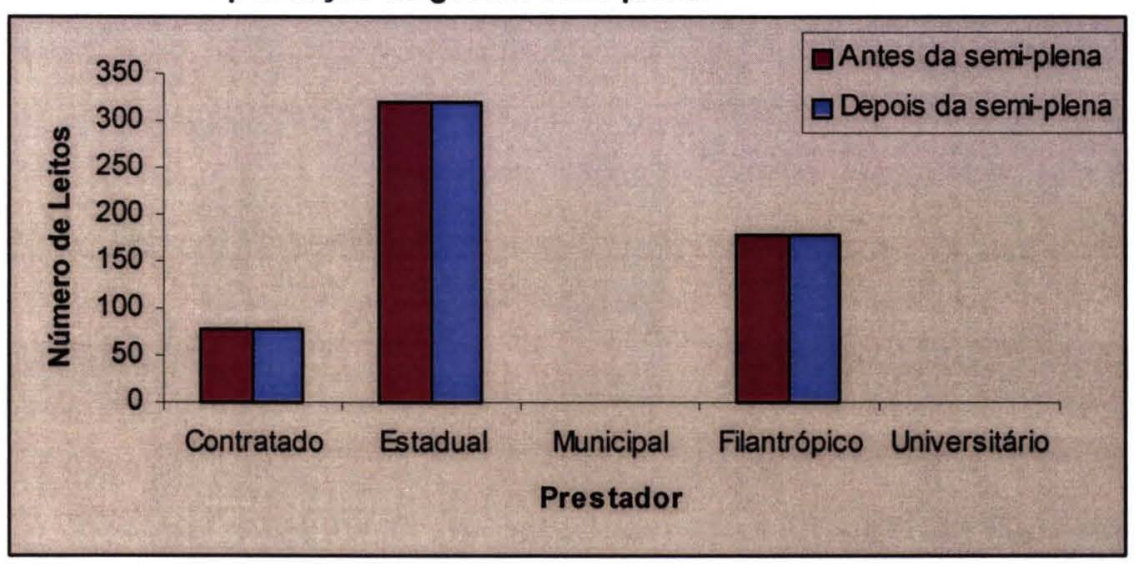

Figura 4 - Número de leitos por tipo de prestador, em Campinas-SP antes e depois da implantação da gestão semi-plena.

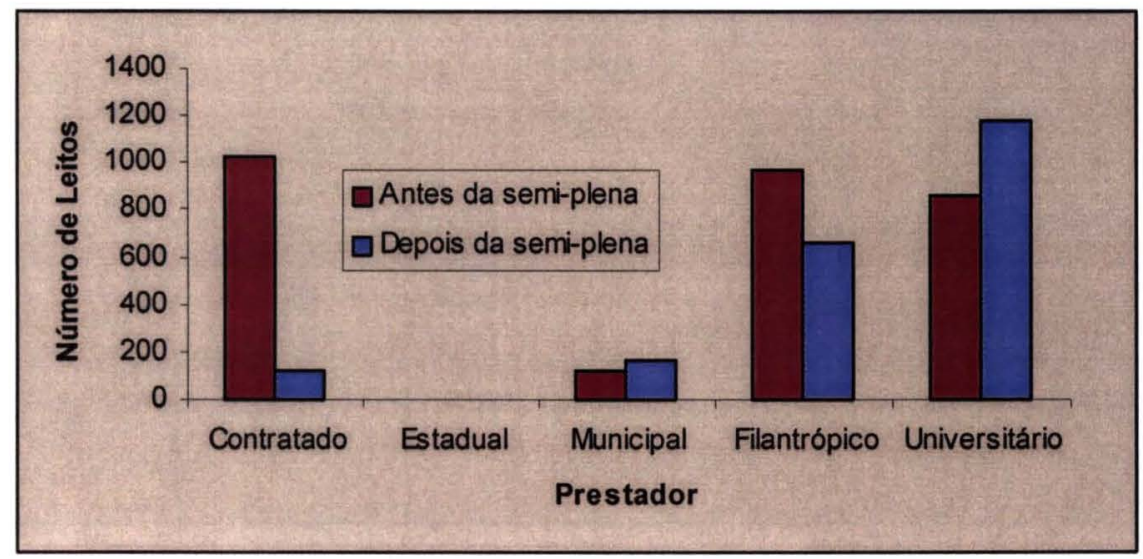

Figura 5 - Número de leitos por tipo de prestador, em Diadema-SP antes e depois da implantação da gestão semi-plena.

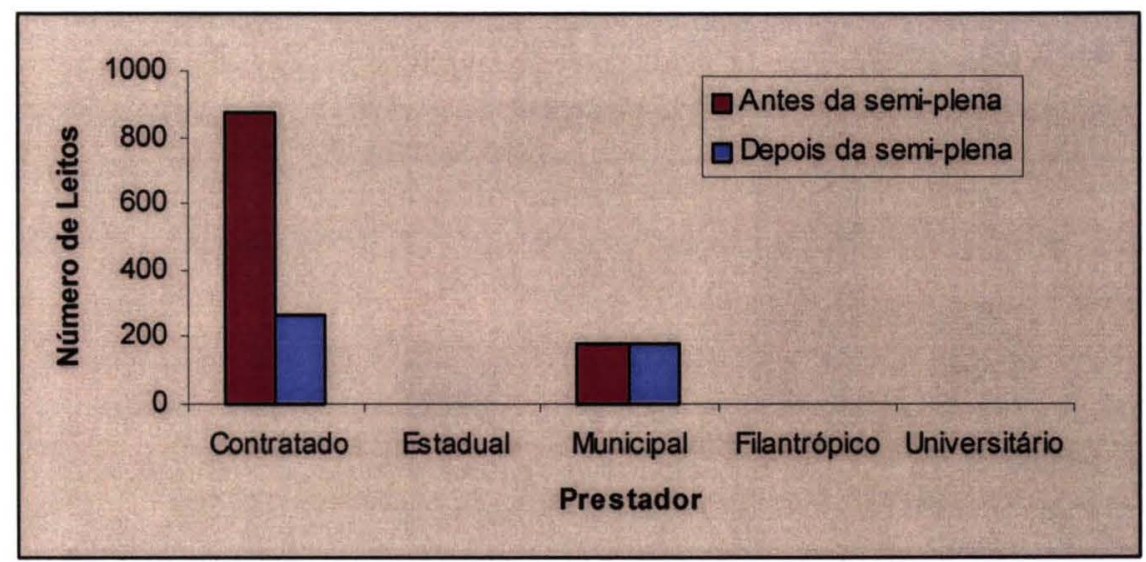


Figura 6 - Número de leitos por tipo de prestador, em Mauá-SP antes e depois da implantação da gestão semi-plena.

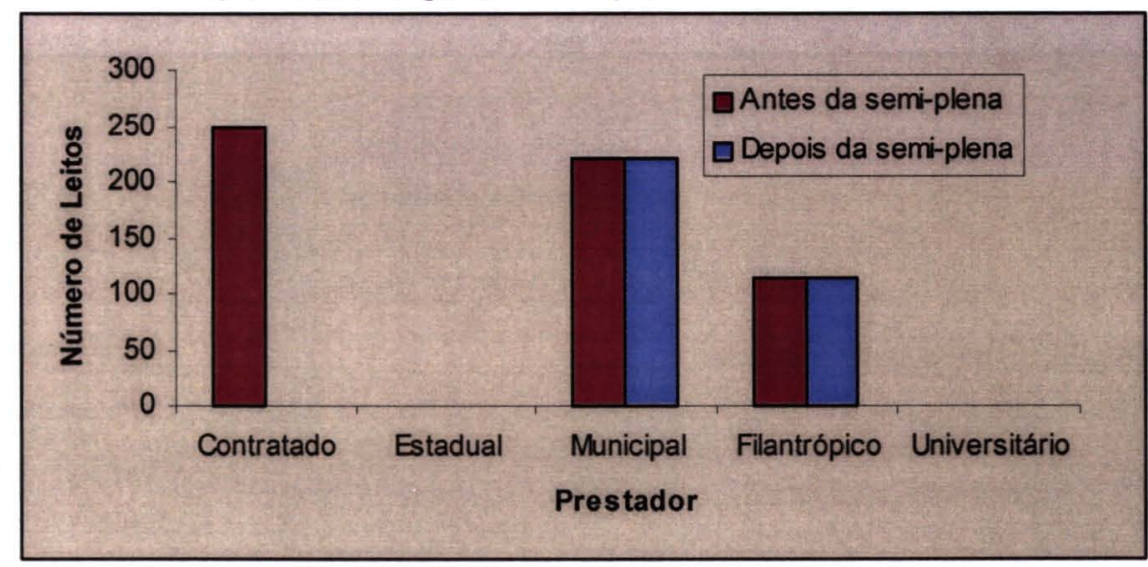

Figura 7 - Número de leitos por tipo de prestador, em Ribeirão Preto -SP antes e depois da implantação da gestão semi-plena.

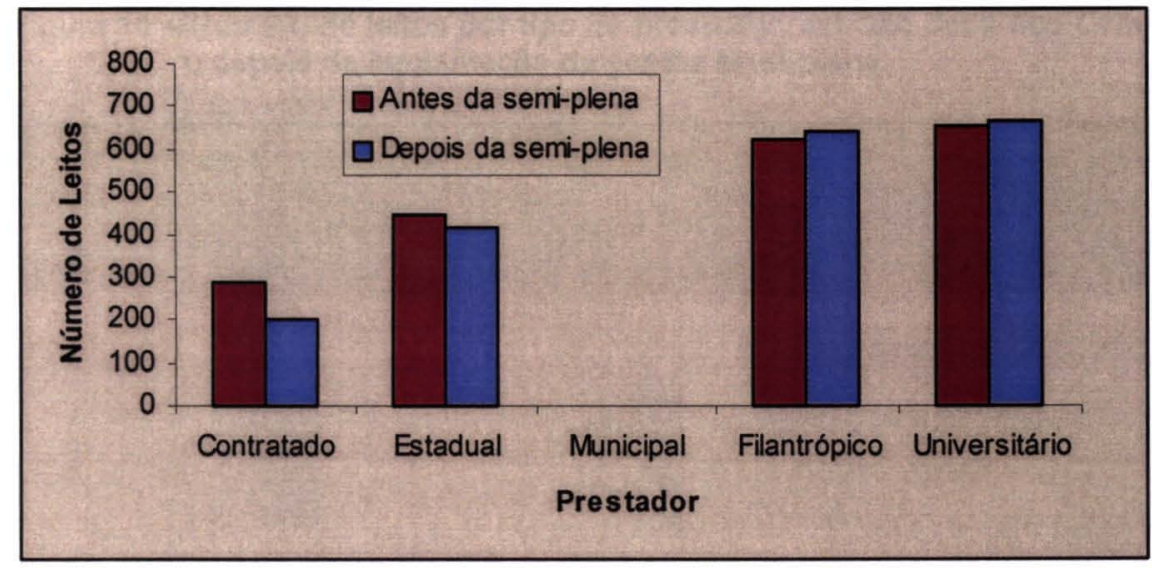

Figura 8 - Número de leitos por tipo de prestador, em Santos -SP antes e depois da implantação da gestão semi-plena.

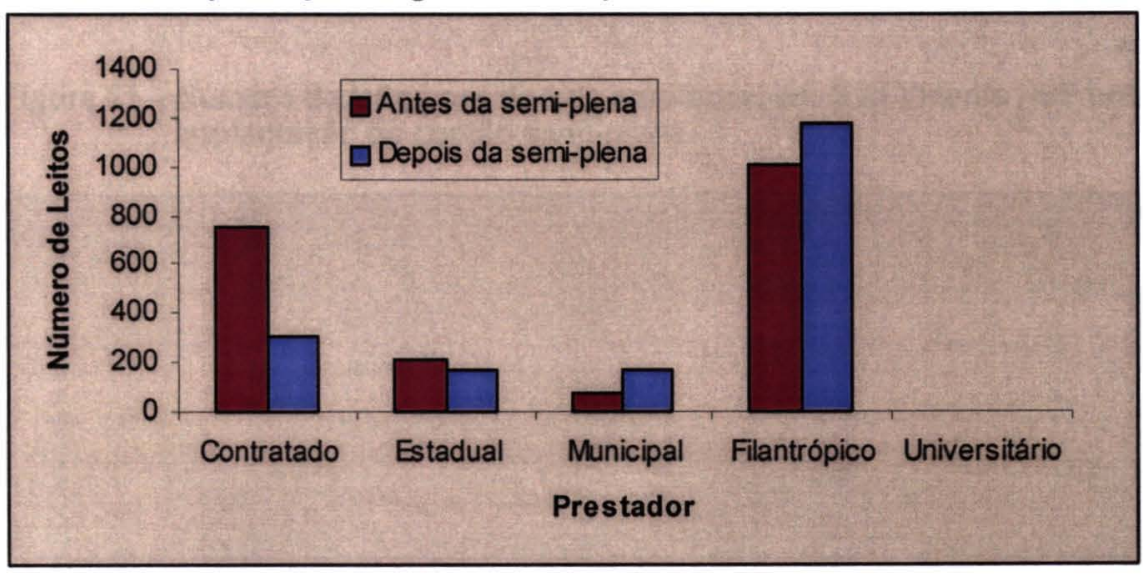


Figura 9 - Número de leitos por tipo de prestador, em São Bernardo do Campo -SP antes e depois da implantação da gestão semi-plena.

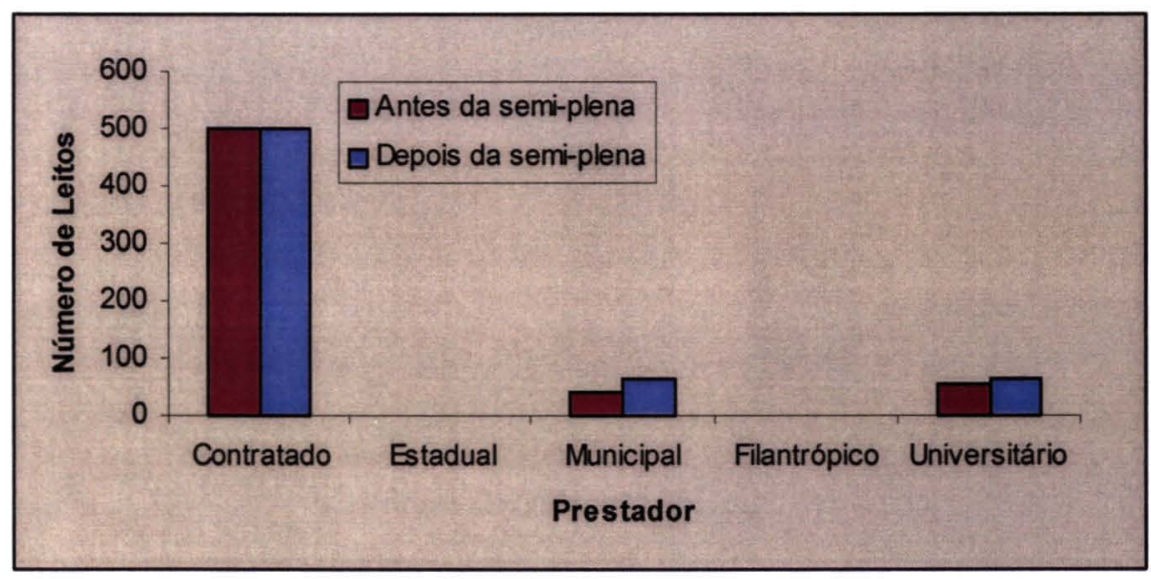

Figura 10 - Número de leitos por tipo de prestador, em São José dos Campos -SP antes e depois da implantação da gestão semi-plena.

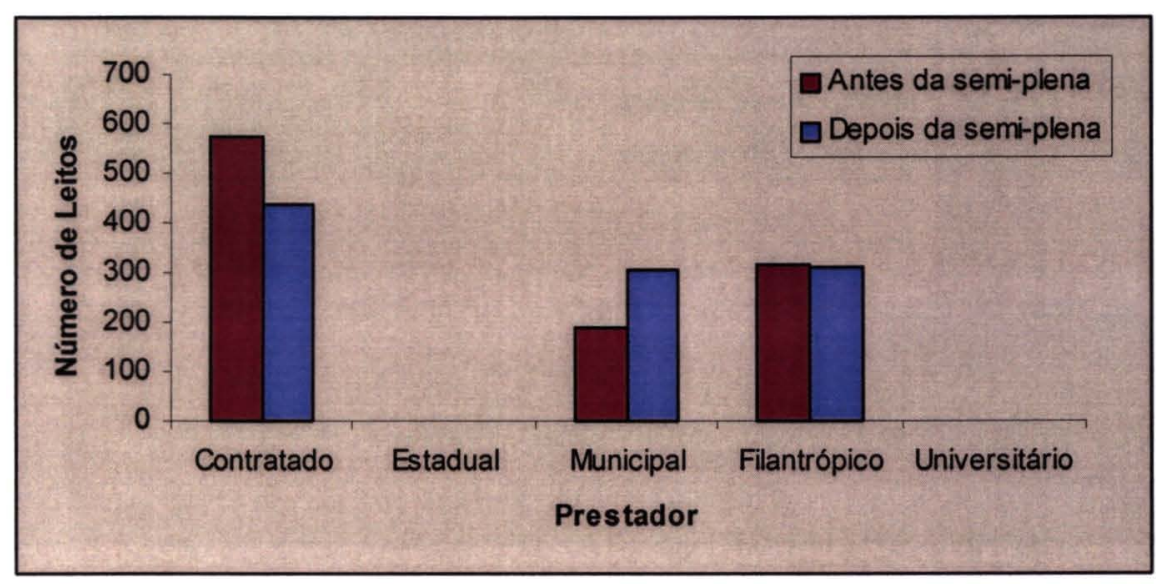

Figura 11 - Número de leitos por tipo de prestador, em São Vicente -SP antes e depois da implantação da gestão semi-plena.

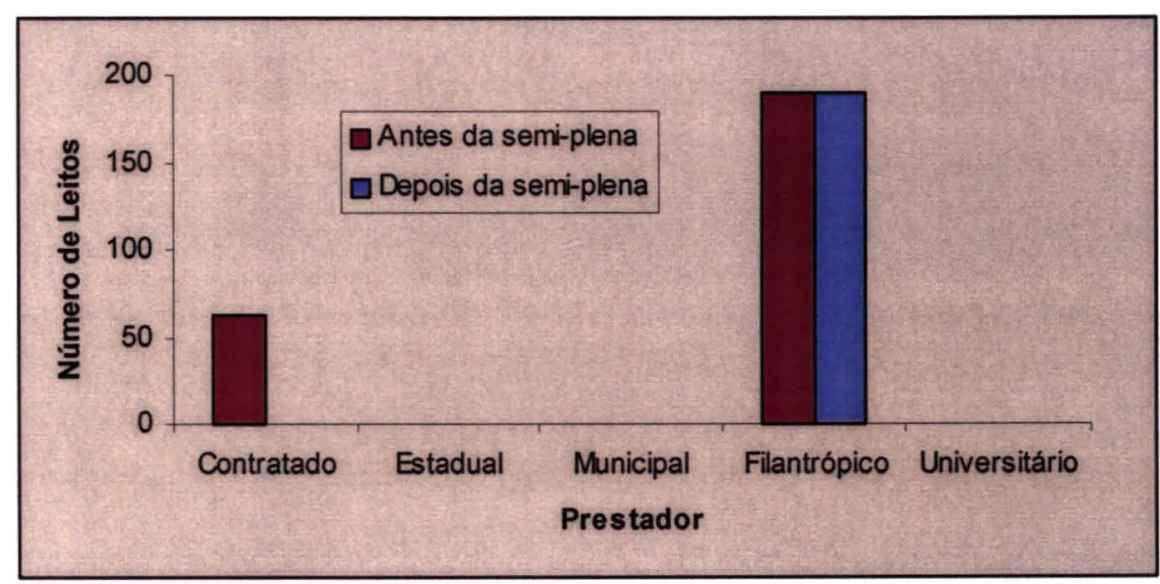


Figura 12 - Número de leitos por tipo de prestador, em Sertãozinho -SP antes e depois da implantação da gestão semi-plena.

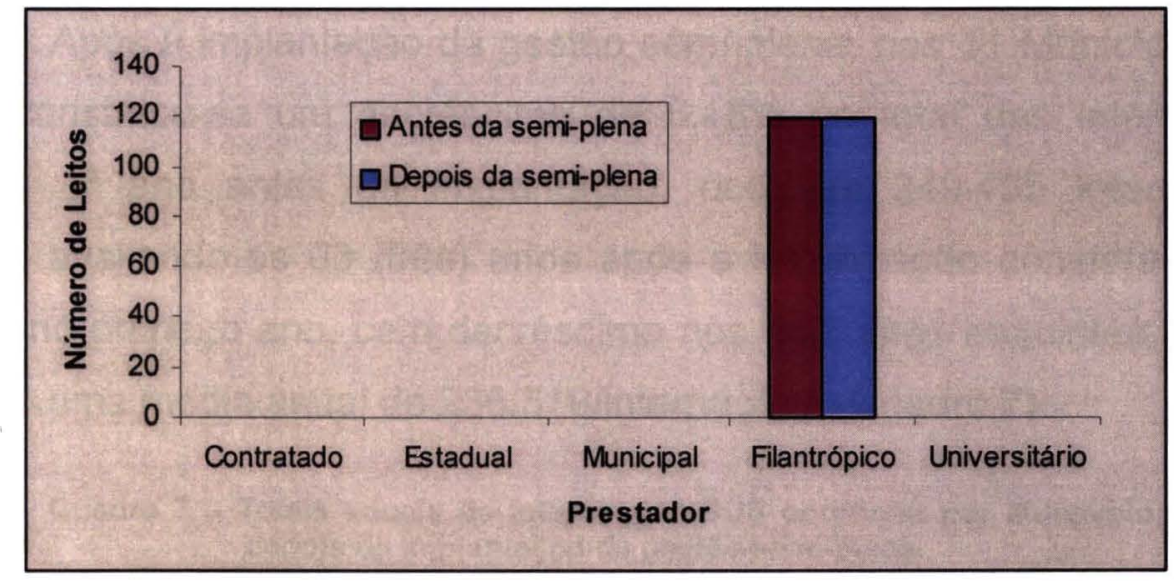

Figura 13 - Número de leitos por tipo de prestador, em Votorantim -SP antes e depois da implantação da gestão semi-plena.

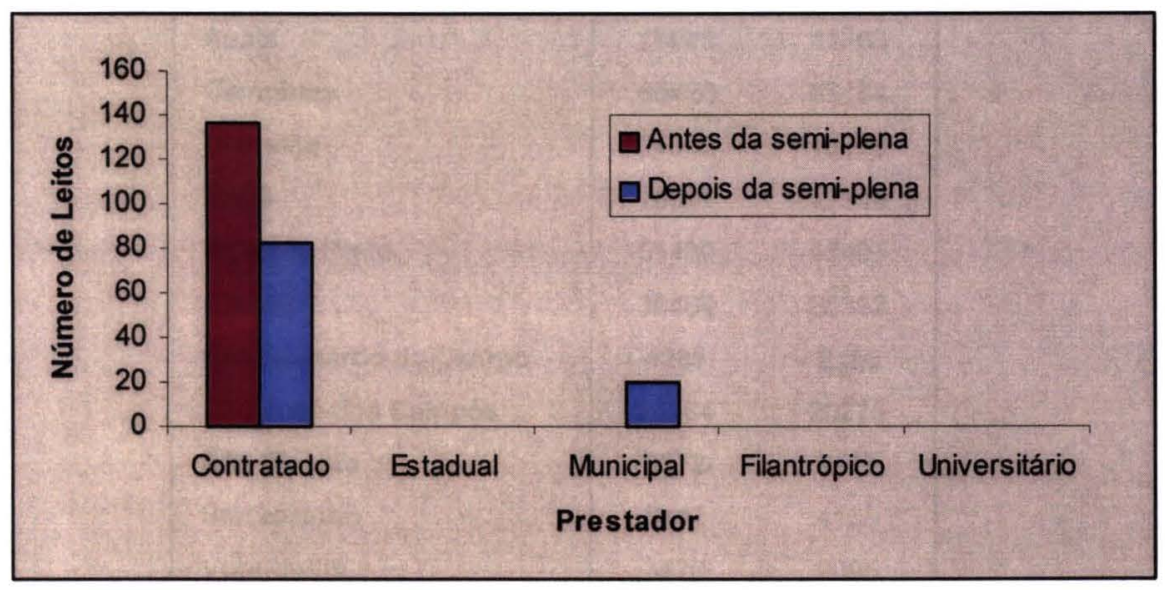




\subsection{Volume de Internações SUS}

Após a implantação da gestão semi-plena, nos 11 Municipios em estudo, constatou-se um decréscimo de $5,18 \%$ no total das internações SUS. No $1^{\circ}$ ano antes da implantação, ocorriam 249.435 internações SUS/ano, avaliando os 03 (três) anos após a implantação constata-se um aumento no primeiro ano, com decréscimo nos dois anos seguintes, porém mantendo uma média anual de 236.519/internações (Quadro 7).

\section{Quadro 7 - Totais anuais de internaçōes SUS ocorridas por Municipio, antes e depois da implantação da gestão semi-plena.}

\begin{tabular}{|c|c|c|}
\hline \multirow{2}{*}{ Municipios Periodo } & Antes & Depois* \\
\hline & $\mathbf{N}$ & $\mathbf{N}$ \\
\hline Assis & 15988 & 11783 \\
\hline Campinas & 63426 & 65154 \\
\hline Diadema & 24347 & 16876 \\
\hline Mauá & 15091 & 17109 \\
\hline Ribeirăo Preto & 51480 & 45405 \\
\hline Santos & 36469 & 36392 \\
\hline Såo Bernardo do Campo & 4286 & 8155 \\
\hline São José dos Campos & 20164 & 20278 \\
\hline Săo Vicente & 8372 & 9115 \\
\hline Sertäozinho & 6142 & 4158 \\
\hline Votorantim & 3670 & 2095 \\
\hline Total & 249435 & 236519 \\
\hline
\end{tabular}

Os Municípios que apresentaram decréscimo no número de internações SUS no período em estudo (antes e depois), foram Votorantim (42,91\%), Sertãozinho (32,03\%), Diadema (30,69\%); Assis (26,30\%); Ribeirão Preto $(11,80 \%)$ e Santos $(0,21 \%)$ e os que apresentaram acréscimo foram: São Bernardo do Campo (90,26\%), Mauá (13,37\%), São Vicente $(8,87 \%)$, Campinas $(2,72 \%)$ e São José dos Campos $(0,57 \%)$. 


\subsubsection{Internações SUS e indicadores demográficos}

A distribuição percentual do número de internações SUS comparado com as taxas de crescimento populacional estimados, são apresentados no Quadro 8, onde observa-se que comparando-se os totais, que o crescimento da população foi de $3,24 \%$ e o número de internações SUS foi de $-5,18 \%$ indicando no geral, diminuição proporcional de internações SUS apesar do aumento da população.

Os Municipios que mais cresceram em percentuais com internações SUS após a implantação da gestão semi plena, foram: São Bernardo do Campo (6,31\%), Mauá (6,13\%), Sertãozinho (4,76\%), São José dos Campos $(3,72 \%)$, Assis $(3,71 \%)$, Votorantim $(3,10 \%)$, Campinas $(2,74 \%)$, Diadema (2,28\%), Ribeirão Preto $(2,27 \%)$ e São Vicente $(1,43 \%)$.

\section{Quadro 8 - Comparação percentuais entre internações SUS e crescimento populacional, por Municípios, depois da implantação da gestão semi plena.}

\begin{tabular}{|l|c|c|}
\hline \multirow{2}{*}{ Município } & \multicolumn{2}{|c|}{ Redução ou Aumento } \\
\cline { 2 - 3 } & $\begin{array}{c}\text { *N. }{ }^{\circ} \text { de internaçōes } \\
\text { SUS (\%) }\end{array}$ & ** População (\%) \\
\hline Assis & $-26,3$ & 3,71 \\
Campinas & 2,72 & 2,74 \\
Diadema & $-30,69$ & 2,28 \\
Mauá & 13,37 & 6,13 \\
Ribeirão Preto & $-11,80$ & 2,27 \\
Santos & $-0,21$ & $-0,55$ \\
São Bernardo do Campo & 90,26 & 6,31 \\
Sertăozinho & $-32,30$ & 4,76 \\
São José dos Campos & 0,57 & 3,72 \\
Săo Vicente & 8,87 & 1,46 \\
Votorantim & $-42,91$ & 3,1 \\
\hline Total & $-5,18$ \\
\hline
\end{tabular}

Fonte: www.datasus.gov.br_SIH

- Legenda - Média de 3 anos $=$ depois $\quad 1^{\circ}$ ano antes $=$ antes

* considerado o período de 3 anos após implantação da gestão semi plena (Internaçð̃es SUS ocorridas no Municipio - Inclui Invasão).

** consideradas as taxas geométricas de crescimento populacional, estimadas para 1995-1996 e 1997. 
Depois da implantação da gestão semi plena (Quadro 8), comparando-se as taxas de crescimento da população, obtidas para o mesmo periodo, verificou-se que os Municipios de Votorantim, Diadema, Assis, Sertãozinho e Ribeirão Preto apresentaram redução no número de internações SUS, que corresponde respectivamente a 13,$8 ; 13,4 ; 7,08 ; 6,7$ e 5,19 vezes a taxa de crescimento da população. Enquanto os Municipios de São Bernardo do Campo (90,26\%); São Vicente (8,87\%); Mauá (13,37\%); Campinas $(2,72 \%)$; São José dos Campos $(0,57 \%)$ apresentaram crescimento no número de internações SUS que corresponderam respectivamente a 14,$3 ; 6,09 ; 2,18 ; 10 ; 0,15$ vezes a taxa de crescimento populacional obtida para o mesmo período.

O Municipio de Santos reduziu as internações SUS em - $0,21 \%$, sendo este o único onde se observou taxa média de crescimento populacional negativa $(-0,55)$, para o período estudado.

\subsubsection{Internações SUS - AlH por habitante}

Considerando a taxa geométrica de crescimento (IBGE-SEADE, 1991-96) e o número total de internações SUS obteve-se o Quadro 9, onde é apresentada a razão entre o número de internações SUS AIH por 100 habitantes, por Município e período de gestão

Os Municípios de Campinas, Mauá, Santos, São Bernardo do Campo, São José dos Campos e São Vicente, mantiveram os mesmos índices de internações SUS/habitantes, antes e depois da implantação da gestão semi plena. 


\section{Quadro 9 - Número de internações SUS** AlH por 100 habitantes, segundo período de gestão antes e depois, em Municípios em gestão semi- plena.}

\begin{tabular}{|c|c|c|}
\hline Municiplos & Antes & Depois* \\
\hline Assis & 20 & 14 \\
\hline Campinas & 7 & 7 \\
\hline Diadema & 8 & 5 \\
\hline Mauá & 5 & 5 \\
\hline Ribeirăo Proto & 12 & 10 \\
\hline Santos & 9 & 9 \\
\hline Săo Bernardo do Campo & 1 & 1 \\
\hline Sertăozinho & 7 & 5 \\
\hline São José dos Campos & 4 & 4 \\
\hline Săo Vicente & 3 & 3 \\
\hline Votorantim & 4 & 2 \\
\hline
\end{tabular}

Apresentaram decréscimo no número de internações SUS por habitante, os Municipios de: Assis (antes: 20 - depois: 14); Diadema (antes: 8 - depois: 5), Ribeirão Preto (antes: 12 - depois: 10), Sertãozinho (antes: 7 - depois: 5); Votorantim (antes: 4 - depois: 2).

$\mathrm{Na}$ análise dos dados apresentados no Quadro 9, ressaltamos a dificuldade de comparação com parâmetros de cobertura assistencial, o que exige aprofundamento nas informações e estudo local.

Entretanto, consideramos que dada sua importância, alguns comentários deveriam ser feitos para os Municípios.

Chama a atenção os indices de internações SUS do Município de Assis (antes: 20 - depois: 14) e Ribeirão Preto (antes: 12 - depois: 10) com valores superiores ao índice de 01/internação/beneficiário/ano estabelecido pela Portaria MPAS/INAMPS 3046/82 (1982) o que indica a tendência de elevação daqueles indices, com a implantação da cobertura universal, ainda que aquele índice não representassem proposta para $100 \%$ da população. 
RODRIGUES (1991), em estudo sobre a utilização de leitos hospitalares, focaliza as diferenças dessa utilização entre regiōes de saúde citando que na Paraiba a oferta de leitos está diretamente associada ao número de internações hospitalares, sendo que o número de leitos existentes nos Municípios estudados estão diretamente associados apenas em relação ao número de internações hospitalares obstétricas.

Segundo ZUCCHI et al. (1998) os fatores que agem na demanda e na oferta dos serviços de saúde, levando a alterações em seus gastos estariam associados a refaturamento dos diagnósticos, difusão do progresso tecnológico, fatores psicossociais (sexo, instrução, entre outros) fatores sociais econômicos, localização geográfica, etc. No nosso estudo, não pudemos comprovar, nesse modelo de gestão, alterações significativas.

A discrepância existente nos totais de leitos mostrados nos Quadros 4 e 6, é deve-se ao fato serem de fontes diferentes, conforme observação na legenda do quadro.

\subsubsection{Evolução do volume de internações}

As Figuras de 14 a 25 apresentam os ajustes de regressão entre os totais anuais das internações nos Municípios em função do tempo em anos. O primeiro ano de avaliação é representado por -1 no eixo de $x$ e corresponde ao período antes da implantação da gestão semi plena no Município. Os anos seguintes, representados por 1, 2 e 3 no eixo de $x$, correspondem aos três anos seguintes, após a implantação da gestão semi plena no Município.

A Figura 14 corresponde ao total dos 11 Municipios, onde se observa que a evolução do número de internações é decrescente em função 
do tempo. Apresenta-se nesta Figura a curva de regressão, modelo linear de primeiro grau e seu respectivo $r^{2}=0,76$ e teste $F$ de 3,718 não significativo ao nivel de probabilidade de $5 \%$.

Figura 14 - Ajuste por regressão dos totais anuais de internações SUS nos 11 Municípios estudados, nos períodos antes e depois da implantação da gestão semi plena.

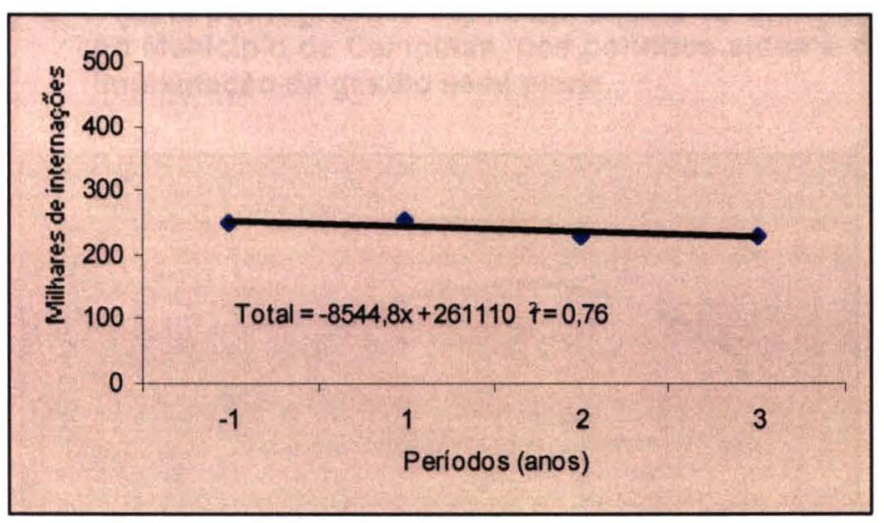

A Figura 15 corresponde ao Município de Assis, onde observa-se que a evolução do número de internações é decrescente em função do tempo. Apresenta-se nessa Figura a curva de regressão modelo linear de $1^{\circ}$ grau e seu respectivo $r^{2}=0,99$ e Teste $F$ de 92,209 significativo ao nível de probabilidade de $5 \%$.

Figura 15 - Ajuste por regressão dos totais anuais de internações SUS no Município de Assis, nos períodos antes e depois da implantação da gestão semi plena.

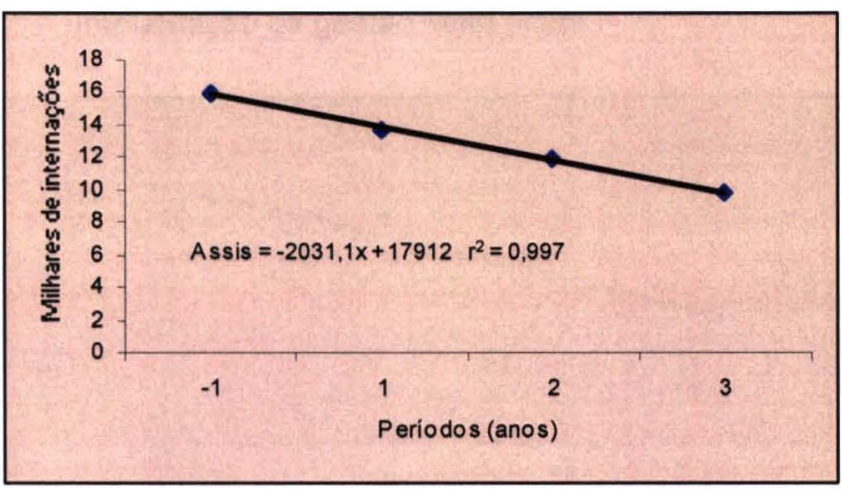


A Figura 16 corresponde ao Município de Campinas, onde observa-se que a evolução do número de internações é decrescente em função do tempo. Apresenta-se nessa Figura a curva de regressão modelo polinomial de $2^{\circ}$ grau e seu respectivo $r^{2}=0,75$ e teste $F$ de 0,663 não significativo ao nível de probabilidade de $5 \%$.

\section{Figura 16 - Ajuste por regressão dos totais anuais de internações SUS no Município de Campinas, nos períodos antes e depois da implantação da gestão semi plena.}

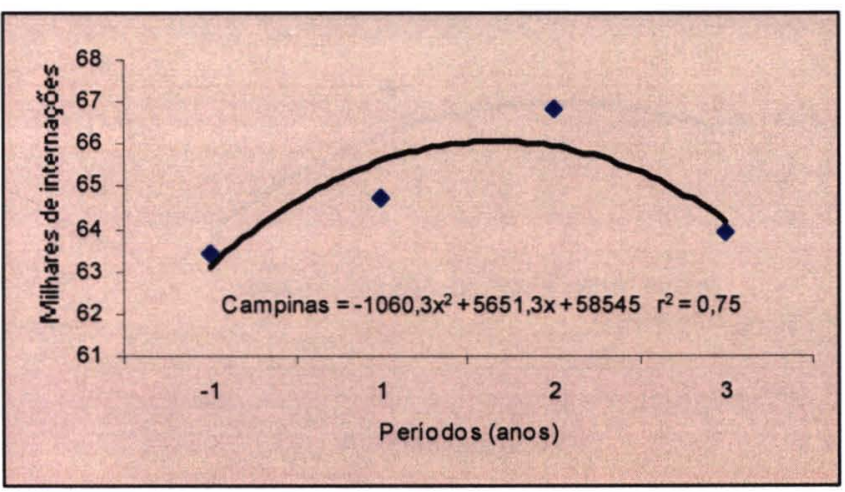

A Figura 17 corresponde ao Município de Diadema, onde observa-se que a evolução do número de internações é decrescente em função do tempo. Apresenta-se nessa Figura a curva de regressão modelo linear de $1^{\circ}$ grau e seu respectivo $r^{2}=0,88$ e teste $F$ de 8,244 não significativo ao nível de probabilidade de $5 \%$.

Figura 17 - Ajuste por regressão dos totais anuais de internações SUS no Município de Diadema, nos períodos antes e depois da implantação da gestão semi plena.

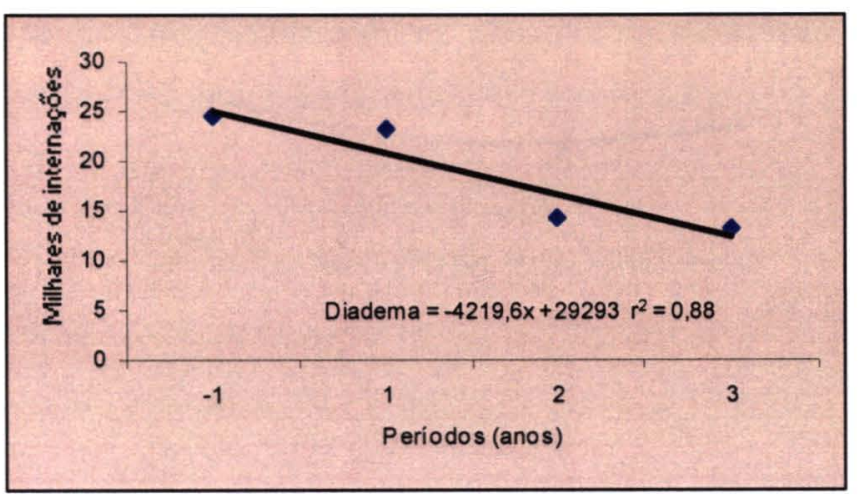


A Figura 18 corresponde ao Município de Mauá, onde observa-se que a evolução do número de internações é crescente em função do tempo. Apresenta-se nessa Figura a curva de regressão modelo polinomial de $2^{\circ}$ grau e seu respectivo $r^{2}=0,68$ e teste $F$ de 2,320 não significativo ao nível de probabilidade de $5 \%$.

\section{Figura 18 - Ajuste por regressão dos totais anuais de internações SUS no Município de Mauá, nos períodos antes e depois da implantação da gestão semi plena.}

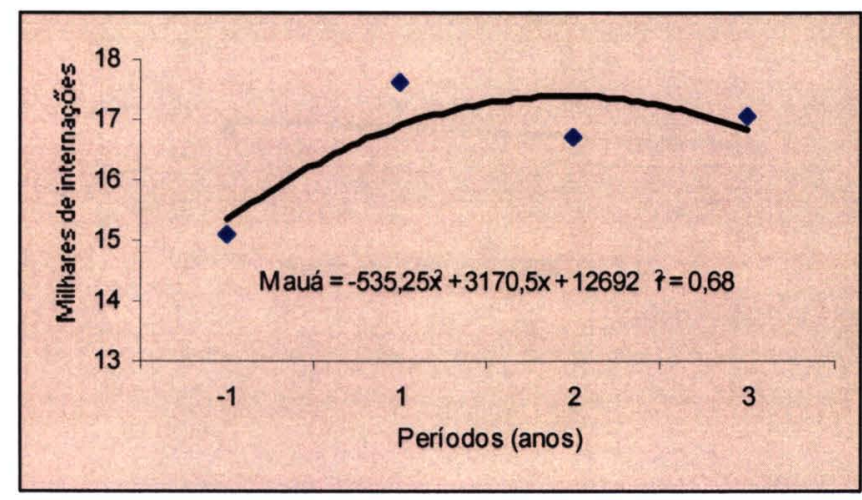

A Figura 19 corresponde ao Municipio de Ribeirão Preto, onde observa-se que a evolução do número de internações é crescente em função do tempo. Apresenta-se nessa Figura a curva de regressão modelo polinomial de $2^{\circ}$ grau e seu respectivo $r^{2}=0,90$ e teste $F$ de 1,636 não significativo ao nível de probabilidade de $5 \%$.

Figura 19- Ajuste por regressão dos totais anuais de internações SUS no Município de Ribeirão Preto, nos períodos antes e depois da implantação da gestão semi plena.

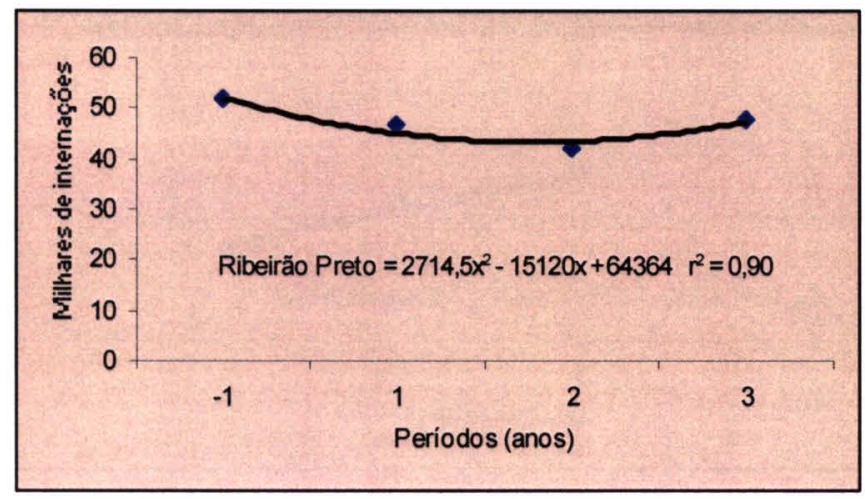


A Figura 20 corresponde ao Município de Santos, onde observase que a evolução do número de internações é decrescente em função do tempo. Apresenta-se nessa Figura a curva de regressão modelo linear de $1^{\circ}$ grau e seu respectivo $r^{2}=0,30$ e teste $F$ de 0,424 não significativo ao nível de probabilidade de $5 \%$.

Figura 20 - Ajuste por regressão dos totais anuais de internações SUS no Município de Santos, nos periodos antes e depois da implantação da gestão semi plena.

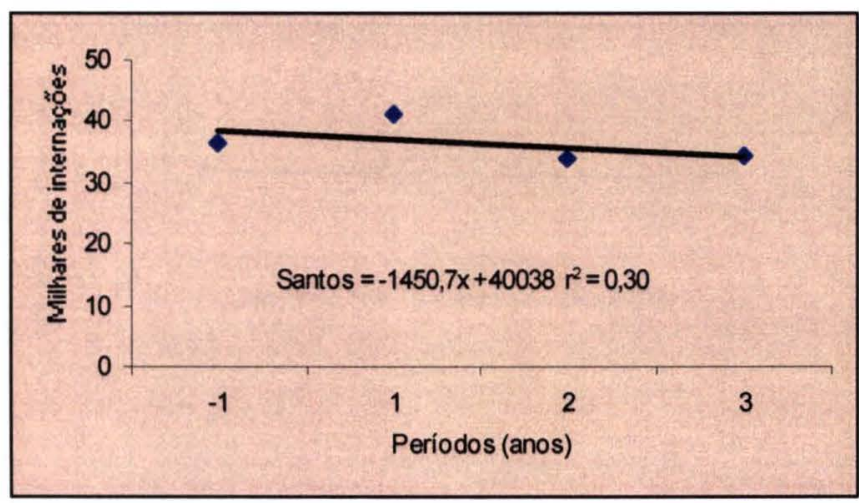

A Figura 21 corresponde ao Município de São Bernardo do Campo, onde observa-se que a evolução do número de internações é crescente em função do tempo. Apresenta-se nessa Figura a curva de regressão modelo linear de $1^{\circ}$ grau e seu respectivo $r^{2}=0,95$ e teste $F$ de 354,415 significativo ao nível de probabilidade de $5 \%$.

Figura 21 - Ajuste por regressão dos totais anuais de internações SUS no Município de São Bernardo do Campo, nos períodos antes e depois da implantação da gestão semi plena.

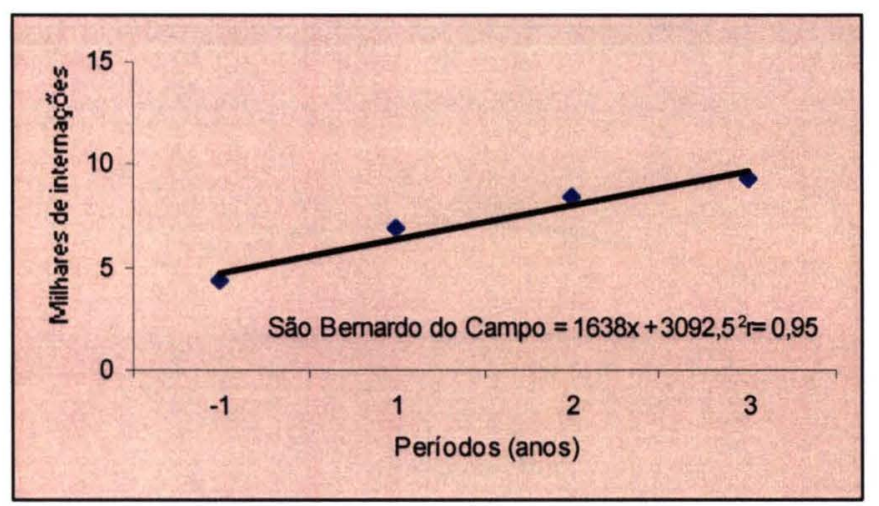


A Figura 22 corresponde ao Município de São José dos Campos, onde observa-se que a evolução do número de internações é crescente em função do tempo. Apresenta-se nessa Figura a curva de regressão modelo linear de $1^{\circ}$ grau e seu respectivo $r^{2}=0,20$ e teste $F$ de 13,400 significativo ao nivel de probabilidade de $5 \%$.

\section{Figura 22 - Ajuste por regressão dos totais anuais de internações SUS no Município de São José dos Campos, nos períodos antes e depois da implantação da gestão semi plena.}

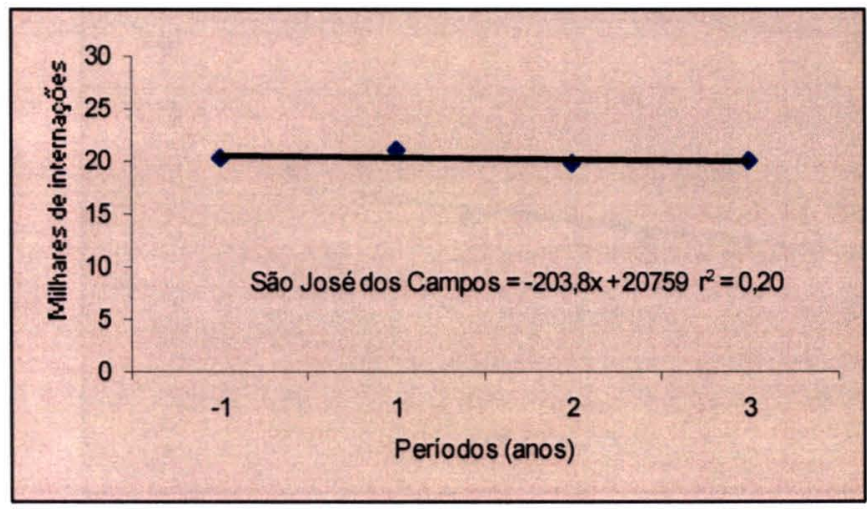

A Figura 23 corresponde ao Município de São Vicente, onde observa-se que a evolução do número de internações é decrescente em função do tempo. Apresenta-se nessa Figura a curva de regressão modelo polinomial de $2^{\circ}$ grau e seu respectivo $r^{2}=0,96$ e teste $F$ de 0,469 não significativo ao nivel de probabilidade de $5 \%$.

Figura 23 - Ajuste por regressão dos totais anuais de internações SUS no Município de São Vicente, nos períodos antes e depois da implantação da gestão semi plena.

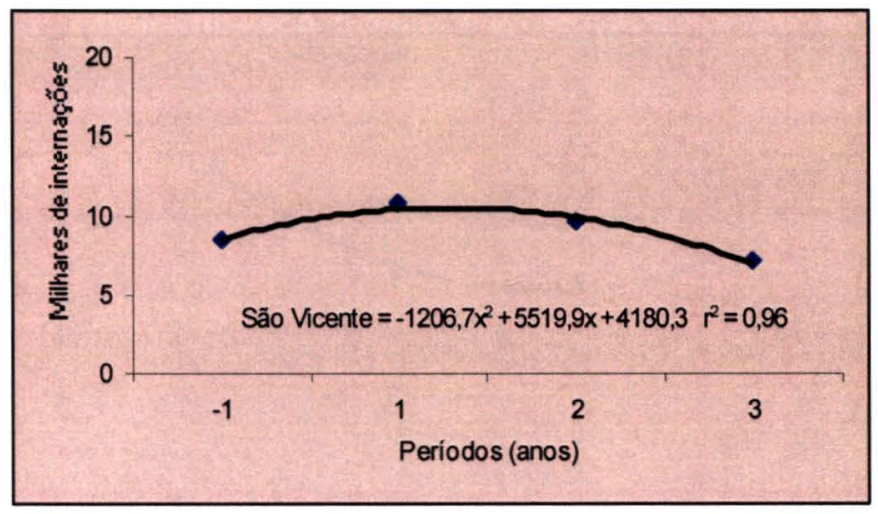


A Figura 24 corresponde ao Município de Sertãozinho, onde observa-se que a evolução do número de internações é decrescente em função do tempo. Apresenta-se nessa Figura a curva de regressão modelo linear de $1^{\circ}$ grau e seu respectivo $r^{2}=0,73$ e teste $F$ de 0,133 não significativo ao nível de probabilidade de $5 \%$.

Figura 24 - Ajuste por regressão dos totais anuais de internações SUS no Município de Sertãozinho, nos períodos antes e depois da implantação da gestão semi plena.

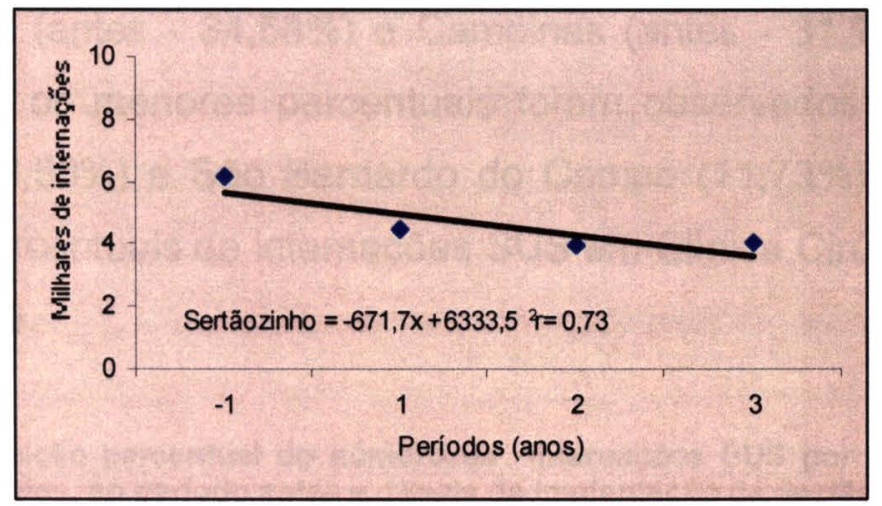

A Figura 25 corresponde ao Município de Votorantim, onde observa-se que a evolução do número de internações é crescente em função do tempo. Apresenta-se nessa Figura a curva de regressão modelo polinomial de $2^{\circ}$ grau e seu respectivo $r^{2}=0,99$ e teste $F$ de 78,977 não significativo ao nível de probabilidade de $5 \%$.

Figura 25 - Ajuste por regressão dos totais anuais de internações SUS no Município de Votorantim, nos períodos antes e depois da implantação da gestão semi plena.

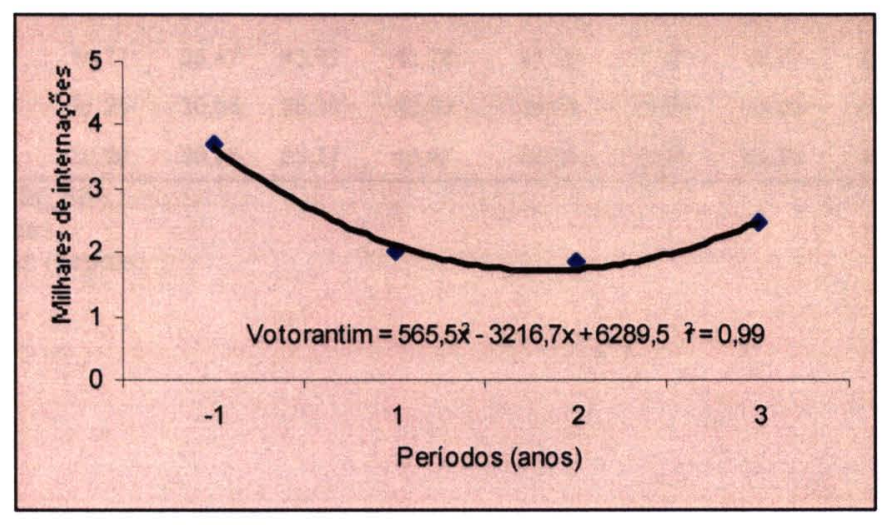




\subsubsection{Internações SUS e especialidades}

No Quadro 10, é apresentada a distribuição percentual das internações SUS por especialidades e Municípios antes e depois da implantação da gestão semi plena.

O percentual de internações SUS em Clinica Cirúrgica antes e depois da implantação apresentado pelos Municípios de Ribeirão Preto $(34,87 \%)$; Santos (antes - 34,58\%) e Campinas (antes - 31,17\%, depois 32,56 ), enquanto os menores percentuais foram observados em Diadema $(6,62 \%)$, Mauá $(9,58 \%)$ e São Bernardo do Campo (11,73\%). Nos demais Municípios, os percentuais de internações SUS em Clínica Cirúrgica ficaram entre de 18 e $20 \%$.

Quadro 10 - Distribuição percentual do número de internações SUS por especialidades e Municipios, no período antes e depois da implantação da gestão semi-plena.

\begin{tabular}{|c|c|c|c|c|c|c|c|c|c|c|c|c|}
\hline \multirow{2}{*}{ Municipio } & \multicolumn{2}{|c|}{ Cirurgla } & \multicolumn{2}{|c|}{ Obstetricla } & \multicolumn{2}{|c|}{ Clínica Médica } & \multicolumn{2}{|c|}{ Pediatria } & \multicolumn{2}{|c|}{ Outros } & \multicolumn{2}{|c|}{ TOTAL } \\
\hline & $\%$ & $\begin{array}{c}\% \\
\text { depols* }\end{array}$ & $\begin{array}{c}\% \\
\text { antes }\end{array}$ & $\begin{array}{c}\% \\
\text { depols* }\end{array}$ & $\begin{array}{c}\% \\
\text { antes }\end{array}$ & $\begin{array}{c}\% \\
\text { depois* }\end{array}$ & $\begin{array}{c}\% \\
\text { antes }\end{array}$ & $\begin{array}{c}\% \\
\text { depols* }\end{array}$ & $\begin{array}{c}\% \\
\text { antes }\end{array}$ & $\begin{array}{c}\% \\
\text { depole" }\end{array}$ & $\begin{array}{c}\% \\
\text { antes }\end{array}$ & $\frac{\mathbf{4}}{\text { depois* }}$ \\
\hline Assis & 18,05 & 21,84 & 14,66 & 18,57 & 43,19 & 37,06 & 21,49 & 20.59 & 1,61 & 1,85 & 100,00 & 100,00 \\
\hline Campinas & 31,17 & 32,56 & 19,86 & 23,52 & 33,42 & 28,97 & 9,10 & 9,48 & 6,44 & 5,48 & 100,00 & 100,00 \\
\hline Diadems & 6,62 & 10,91 & 62,73 & 46,95 & 14,26 & 23,18 & 13,43 & 18,96 & 2,96 & 0,00 & 100,00 & 100,00 \\
\hline Mout & 9,58 & 10,24 & 45,32 & 53,21 & 23,69 & 22,33 & 16,81 & $\$ 3,11$ & 4,61 & 1,12 & 100,00 & 100,00 \\
\hline Ribeiráo Preto & 34,87 & 34,68 & 13,38 & 14,95 & 34,55 & 30,94 & 11,74 & 12,59 & 5,46 & 6,83 & 100,00 & 100,00 \\
\hline Santos & 34,58 & 30,29 & 17,08 & 18,99 & 34,74 & 34,97 & 11,11 & 12,46 & 2,50 & 2,29 & 100,00 & 100,00 \\
\hline Sao Bernardo do Campo & 11,73 & 43,45 & 0,24 & 0,00 & 26,77 & 24,50 & 14,62 & 10,34 & 46,64 & 21,71 & 100,00 & 100,00 \\
\hline Sto Jost dos Campos & 19,67 & 19,86 & 29,59 & 28,33 & 25,99 & 24,41 & 13,38 & 13,59 & 11,37 & 13,81 & 100,00 & 100,00 \\
\hline Salo Vicente & 18,31 & 23,49 & 39,18 & 36,54 & 25,68 & 21,55 & 16,83 & 18,41 & 0,00 & 0,00 & 100,00 & 100,00 \\
\hline Sertiozinho & 18,00 & 24,53 & 31,50 & 32,51 & 50,50 & 37,42 & 0,00 & 5,53 & 0,00 & 0,00 & 100,00 & 100,00 \\
\hline Votorantim & 19,93 & 14,77 & 25,47 & 43,62 & 43,78 & 27,58 & 10,82 & 14,03 & 0,00 & 0,00 & 100,00 & 100,00 \\
\hline Estado de SIo Paulo & 21,62 & 21,25 & 20,66 & 25,30 & 42,53 & 36,34 & 10,08 & 12,08 & 5,11 & 5,03 & 100,00 & 100,00 \\
\hline Brasil & 19,85 & 20,20 & 23,05 & 25,77 & 40,47 & 36,36 & 13,08 & 13,33 & 3,54 & 4,35 & 100,00 & 100,00 \\
\hline
\end{tabular}

Fonte: www.datasus.gov.br_SIH 
Os maiores percentuais de internações SUS em Clínica Obstétrica foram obtidos nos Municípios de Diadema (62,73\%); Mauá $(45,32 \%)$; São Vicente $(39,18 \%)$ e Sertãozinho $(31,50 \%)$.

Os Municípios que apresentaram o menor número de internação em obstetrícia, antes da implantação da gestão semi plena, foram: São Bernardo do Campo (0,24\%); Ribeirão Preto (13,38\%), Assis (14,66\%) e Santos $(17,08 \%)$. Sendo que, os demais flutuaram entre 20 e $26 \%$.

As internações SUS em Clínica Obstétrica foram predominantes em Diadema, Mauá, São José dos Campos e São Vicente.

Sertãozinho, foi o Municipio que mais internou, em clínica médica atingindo $50,50 \%$ em relação às internações SUS, na mesma especialidade ocorridas nos Municípios de Votorantim (43,78\%) e Assis (43,19\%).

Os menores percentuais de internação em Clínica Médica, antes da implantação da gestão semi plena ocorreram em Diadema $(14,26 \%)$. Nos demais Municipios o percentual de internações SUS dessa especialidade situaram-se na faixa de 23 e $35 \%$.

Nos Municípios de Assis, Santos e Sertãozinho o maior número de internações SUS ocorreram em Clínica Médica, e estes não apresentaram alterações após a implantação da gestão semi plena. Nos Municipios de Campinas e Votorantim, antes da implantação foram mais freqüentes as internações SUS em Clínica Médica, entretanto, no período após a implantação da gestão semi plena as maiores freqüências de internações SUS passaram a ser Clínica Cirúrgica e Clínica Obstétrica, respectivamente. 
O maior percentual de internações SUS em Pediatria foi verificado no Município de Assis $(21,49 \%)$, seguido por São Vicente $(16,83 \%)$ e Mauá $(16,81 \%)$.

O menor índice ocorreu em Votorantim $(10,82 \%)$ e Campinas $(9,10 \%)$. No Município de Sertãozinho não foram registradas internações SUS nessa especialidade, no periodo.

No Município de São Bernardo do Campo verificou-se a predominância de internações SUS em outras especialidades, no periodo antes da gestão semi plena.

No Brasil e Estado de São Paulo as maiores freqüências de internações SUS ocorreram na especialidade de Clínica Médica, no periodo estudado (Quadro 10).

\subsubsection{Internações SUS por Capítulo do CID-IX}

No Brasil, no período de 1994-1997, as maiores freqüências de internações SUS, segundo CID 9, estavam inseridas nos grupos: Cap.XI Complicações da Gravidez, Parto e Puerpério (25,28\%); Cap. VIII - Doenças do Aparelho Respiratório (16,70\%); Doenças do Aparelho Circulatório (9,95\%); Doenças Infecciosas e Parasitárias $(8,77 \%)$ e Doenças do Aparelho Geniturinário (7,24\%),(Quadro 11).

No Estado de São Paulo, as cinco maiores freqüências de internações SUS, foram CAP.XI - Complicações da Gravidez, Parto e Puerpério (23,10\%); CAP. VIII - Doenças do Aparelho Respiratório (13,31\%); CAP.VII - Doenças do Aparelho Circulatório (10,99\%); CAP. XVII 
- Lesões e Envenenamentos (7,63\%) e CAP. IX - Doenças do Aparelho Digestivo (7,56\%), (Quadro 11).

Esses resultados são compatíveis com os encontrados por MATHIAS E SOBOLL (1996) em Maringá-PR onde os diagnósticos mais importantes foram as complicações da gravidez, parto e puerpério, doenças do aparelho respiratório e doenças do aparelho circulatório.

No Quadro 11 é apresentado a distribuição percentual das internações SUS por localidade de ocorrência e capítulo do CID-IX.

Considerando os onze Municípios do presente estudo, as maiores freqüências de internações SUS, foram: CAP XI - Complicações de Gravidez, Parto e Puerpério; CAP. VIII - Doenças do Aparelho Respiratório; CAP. VII - Doenças do Aparelho Circulatório; CAP. XVII - Lesões e Envenenamentos; CAP. IX - Doenças do Aparelho Digestivo. Em São Bernardo do Campo, o CAP.V - Transtornos Mentais representou 46,51\% antes e 19,10 depois da freqüência de internações SUS.

Nos Municípios estudados a principal causa de internação foi CAPXI - Complicações de gravidez, parto e puerpério. No Município de Diadema $62,90 \%$ antes e $39,94 \%$ depois Exceto São Bernardo do Campo que atendeu ao menor indice de $0,27 \%$ antes e $0,03 \%$ depois nessa morbidade.

A segunda maior freqüência de internação de doenças do Aparelho Respiratório - CAP.VIII, de acordo com CID 9, em sete (07) dos 11 (onze) Municipios estudados: Assis (antes $16,41 \%$ e depois 15,44\%); Diadema ( $9,71 \%$ antes e 15,79 depois); Mauá (12,24\% antes e 8,30 depois); Santos $(12,45 \%$ antes e $11,79 \%$ depois); São Vicente $(16,74 \%$ antes e $14,80 \%$ depois); Sertãozinho (13,54\% antes e $11,88 \%$ depois); Votorantim $(14,77 \%$ antes e $13,67 \%$ depois). No Município de Campinas Cap.II Neoplasmas representaram $8,99 \%$ antes e $8,30 \%$ depois das internações 
SUS ocorridas. Em Ribeirão Preto, as doenças do aparelho circulatório (CID10 - Cap.VII) 13,58\% antes e 11,07 depois; São Bernardo do Campo, transtornos mentais (Cap. V) foram responsáveis por $46,51 \%$ antes e $19,10 \%$ depois das internações SUS. 
Quadro 11 - Percentuais de Internaçōes SUS por localidade de ocorrência e Capitulos do CID-9, antes e depois da gestão semi plena.

\begin{tabular}{|c|c|c|c|c|c|c|c|c|c|c|c|c|c|c|c|c|c|c|c|c|c|c|c|c|}
\hline \multirow{3}{*}{ Ocorrência } & \multicolumn{2}{|c|}{ Assis } & \multicolumn{2}{|c|}{ Campinas } & \multicolumn{2}{|c|}{ Diadema } & \multicolumn{2}{|c|}{ Mauá } & \multicolumn{2}{|c|}{$\begin{array}{l}\text { Ribeirão } \\
\text { Preto }\end{array}$} & \multicolumn{2}{|c|}{ Santos } & \multicolumn{2}{|c|}{$\begin{array}{c}\text { Săo } \\
\text { Bernardo do } \\
\text { Campo }\end{array}$} & \multicolumn{2}{|c|}{$\begin{array}{l}\text { Săo José } \\
\text { dos Campos }\end{array}$} & \multicolumn{2}{|c|}{ Săo Vicente } & \multicolumn{2}{|c|}{ Sertăozinho } & \multicolumn{2}{|c|}{ Votorantim } & \multicolumn{2}{|c|}{ Total } \\
\hline & A & D & A & D & A & D & A & D & A & D & A & D & A & D & A & D & A & D & A & D & A & D & A & D \\
\hline & $\%$ & $\%$ & $\%$ & $\%$ & $\%$ & $\%$ & $\%$ & $\%$ & $\%$ & $\%$ & $\%$ & $\%$ & $\%$ & $\%$ & $\%$ & $\%$ & $\%$ & $\%$ & $\%$ & $\%$ & $\%$ & $\%$ & $\%$ & $\%$ \\
\hline - Doenças Infecciosas e parasitárias & 11,35 & 6,92 & 2,30 & 1,72 & 2,83 & 3,03 & 4,71 & 2,70 & 4,41 & 4,11 & 5,39 & 5,29 & 1,59 & 1,36 & 2,89 & 2,71 & 5,22 & 3,10 & 5,02 & 4,10 & 4,59 & 1,76 & 4,14 & 3,20 \\
\hline - Neoplasmas & 2,22 & 1,96 & 8,99 & 8,30 & 0,74 & 1,45 & 1,13 & 1,08 & 7,62 & 6.25 & 4,90 & 3,71 & 2,31 & 5,54 & 3,86 & 4,01 & 1,08 & 1,95 & 1,36 & 2,36 & 2,36 & 2,31 & 5,46 & 5,17 \\
\hline 1. Doenças glånd endócr nutriç metab transt imun & 2,23 & 1,61 & 3,60 & 3,30 & 0,88 & 2,20 & 2,81 & 2,15 & 2,54 & 2,72 & 3,75 & 4,31 & 5,55 & 3,79 & 3,59 & 2,97 & 1,77 & 1,30 & 3,62 & 1,90 & 2,69 & 2,77 & 2,97 & 3,02 \\
\hline 1. Doenças do sangue e dos órgăos hematopoéticos & 0,52 & 0,32 & 0,79 & 0,79 & 0,29 & 0,73 & 0,60 & 0,77 & 0,89 & 0,72 & 0,65 & 0,77 & 0,96 & 0,71 & 0,55 & 0,62 & 0,31 & 0,53 & 0,24 & 0,31 & 0,74 & 0,63 & 0,67 & 0,71 \\
\hline Transtornos mentais & 0,10 & 2,29 & 6,38 & 5,15 & 3,63 & 1,70 & 4,64 & 0,76 & 5,22 & 7,19 & 2,08 & 1,60 & 46,51 & 19,10 & 10,60 & 13,34 & 0,00 & 0,00 & 0,00 & 0.10 & 0,03 & 0,00 & 5.23 & 5.57 \\
\hline 1. Doenças sistema nervoso órgåos dos sentidos & 4,40 & 2,73 & 4,30 & 3,83 & 1,62 & 2,86 & 1,17 & 1,16 & 5,99 & 6,65 & 3,44 & 2,95 & 1,86 & 4,86 & 1,58 & 1,91 & 1,31 & 1,41 & 3,30 & 1,57 & 3,28 & 1,09 & 3,72 & 3,66 \\
\hline II. Doenças do aparelho circulatório & 14,16 & 10,69 & 9.25 & 7,49 & 4,42 & 7,68 & 7,50 & 6,78 & 13,58 & 11,07 & 10,80 & 9,00 & 9,95 & 8,34 & 8,80 & 8,92 & 9,42 & 6,94 & 9,26 & 8,17 & 13,88 & 8,14 & 10,17 & 8,65 \\
\hline 111. Doenças do aparelho respiratório & 16,41 & 15,84 & 8,98 & 8,01 & 9,71 & 15,79 & 12,24 & 8,30 & 10,58 & 10,19 & 12,45 & 11,79 & 11,91 & 10,80 & 11,36 & 12,02 & 16,74 & 14,80 & 13,54 & 11,88 & 14,77 & 13,67 & 11,17 & 10,60 \\
\hline X. Doenças do aparelho digestivo & 6,82 & 6,68 & 7,43 & 8.02 & 3,82 & 6,63 & 5.89 & 6,18 & 7.44 & 6.92 & 10,15 & 7,37 & 5,84 & 7,57 & 6,84 & 6,48 & 5,87 & 6,48 & 9,35 & 9,71 & 11,21 & 6,59 & 7,32 & 7,25 \\
\hline Doenças do aparelho geniturinário & 8,84 & 6,53 & 8,32 & 7,60 & 1,68 & 2,64 & 4,41 & 3,20 & 5,96 & 5,01 & 6,35 & 4,89 & 5,73 & 9,93 & 4,99 & 4,51 & 5,11 & 2.18 & 5.02 & 5.69 & 6.54 & 5,24 & 6,21 & 5,67 \\
\hline 1. Complicaçoes da gravidez parto e puerpério & 14,69 & 21,48 & 20,20 & 24,90 & 62,90 & 39,94 & 45,27 & 55,24 & 13,77 & 16,71 & 13,57 & 21,10 & 0,27 & 0,03 & 29,83 & 28,19 & 31,20 & 37,67 & 31,62 & 31,99 & 25,52 & 49,54 & 24,25 & 25,60 \\
\hline II. Doenças da pele e tecido celular subcutâneo & 0,84 & 0,93 & 1,71 & 1,65 & 0,22 & 0.76 & 0,81 & 0.92 & 1,03 & 1,07 & 4,75 & 2,29 & 1,11 & 1.67 & 1,27 & 1,22 & 3,45 & 1,37 & 1,54 & 1,54 & 1,00 & 0,59 & 1,75 & 1,44 \\
\hline III. Doenças sistema osleomusc e tecido conjuntivo & 1,90 & 2,23 & 2,00 & 2.49 & 0,27 & 0,69 & 0,32 & 0,25 & 3,90 & 3,23 & 2,04 & 1,83 & 0,42 & 4.10 & 1.53 & 1,22 & 1,93 & 1,84 & 3,94 & 2,91 & 1,74 & 1,30 & 2,12 & 2,19 \\
\hline IV. Anomalias congénitas & 0,22 & 0,15 & 1,33 & 1,36 & 0,05 & 0,16 & 0,11 & 0,20 & 2,72 & 2,28 & 0,32 & 0,54 & 0,11 & 0,44 & 0,64 & 0,32 & 0,06 & 0,73 & 0,15 & 0,17 & 0,26 & 0,13 & 1,07 & 1,01 \\
\hline V. Algumas afeccbes originadas periodo perinatal & 0,65 & 1,80 & 1,99 & 1,81 & 2,55 & 2,49 & 1,89 & 3,16 & 1,90 & 2,18 & 4,46 & 4,62 & 0,05 & 0,06 & 1.43 & 1,79 & 9,25 & 2,02 & 0,84 & 1,32 & 0,54 & 0,38 & 2,40 & 2,32 \\
\hline VI. Sintomas, sinais e afeccobes mal definidas & 1,49 & 2,24 & 2,55 & 4,69 & 0,98 & 4,29 & 2,18 & 1.77 & 1,73 & 1,71 & 3,62 & 6,14 & 0,82 & 6,94 & 2,13 & 2,60 & 0,73 & 3,11 & 3,70 & 3,28 & 2,46 & 2,06 & 2,20 & 3,81 \\
\hline VII.Lesbes e envenenamentos & 11,41 & 14.71 & 8,38 & 7,12 & 3,39 & 6.75 & 3,66 & 4,38 & 10.00 & 11,30 & 11,21 & 11,67 & 5,01 & 14,74 & 7,84 & 6,98 & 6,57 & 14,09 & 7,32 & 13,01 & 7,93 & 3,61 & 8,38 & 9,28 \\
\hline lass supl fatores oport contato serviços saúde & 1,74 & 0,80 & 1,49 & 1,79 & 0,01 & 0,23 & 0,59 & 1,01 & 0,72 & 0,69 & 0,03 & 0,14 & 0,00 & 0,03 & 0,25 & 0,18 & 0,00 & 0,49 & 0,15 & 0,00 & 0.46 & 0,21 & 0,73 & 0,83 \\
\hline ID năo especificado ou inválido & 0,02 & 0,00 & 0,01 & 0,00 & 0,01 & 0,00 & 0,06 & 0,00 & 0,00 & 0,00 & 0,05 & 0,00 & 0,00 & 0,00 & 0,03 & 0,00 & 0,00 & 0,00 & 0,02 & 0,00 & 0,00 & 0,00 & 0,02 & 0,00 \\
\hline $\begin{array}{r}\text { Total } \\
\end{array}$ & 100,00 & 100,00 & 100,00 & 100,00 & 100,00 & 100,00 & 100,00 & 100,00 & 100,00 & 100,00 & 100,00 & 100,00 & 100,00 & 100,00 & 100,00 & 100,00 & 100,00 & 100,00 & 100,00 & 100,00 & 100,00 & 100,00 & 100,00 & 100,00 \\
\hline
\end{tabular}


A terceira maior freqüência de internações SUS, 04 (quatro) Municípios, foi obtida no CAP. VII - 13,88\% antes e $8,14 \%$ depois), Mauá (7,50\% antes e $6,78 \%$ depois). Apresentaram maior freqüência do CAP XVII Lesões e Envenenamentos, Assis (11,41\% antes e 14,71\% depois), Ribeirão Preto $(10,00 \%$ antes e $11,30 \%$ depois); Santos $(11,21 \%$ antes e $11,67 \%$ depois).

Das internações SUS, Assis (16,41\% antes e 15,84 depois), São Vicente $(16,74 \%$ antes e $14,80 \%$ depois), Votorantim $(14,77 \%$ antes e $13,67 \%$ depois); Sertãozinho (13,54\% antes e $11,88 \%$ depois) respectivamente em doenças do aparelho respiratório ( CID 9 - CAP. VIII).

Segundo LEBRÃO (1999), em estudo realizado em diferente contexto, nas internações também percebeu-se queda no grupo de diagnóstico como " sintomas, sinais e afeç̧ões mal definidas, doenças infecciosas e parasitárias; crescimento de outros, em especial neoplasmas e doenças do aparelho circulatório, tendo como causas possiveis as mudanças demográficas, epidemiológicas, tecnológicas e da estrutura dos serviços. Houve, ainda, uma migração de diagnósticos pouco específicos para outros mais definidos, provavelmente, como conseqüência das mudanças na forma de remuneração do sistema de saúde".

\subsubsection{Internação SUS por procedimento sentinela}

Conforme mostra o Quadro 12, o número de procedimentos de parto por cesariana, depois da implantação da gestão semi plena, aumentaram nos Municípios de Assis, Campinas, Mauá, Santos, São José dos Campos e Votorantin e diminuíram nos Municípios de Diadema, Ribeirão Preto, São 
Vicente e Sertãozinho. Este procedimento não foi realizado no Município de São Bernardo do Campo.

O maior tempo médio de permanência no período antes da gestão semi plena foi registrado no Município de Santos (4,04 dias) e o menor ocorreu no Município de Sertãozinho (2,27 dias). Depois da implantação da gestão semi plena o maior tempo médio de permanência foi registrado em Mauá ( 3,50 dias) e o menor também em Sertãozinho (2,24 dias).

Os percentuais de óbitos registrados para essa modalidade de procedimento, no periodo antes da semi plena, foram baixíssimos, destacandose o Município de Campinas e Santos, onde os óbitos corresponderam a $0,06 \%$ e $0,13 \%$, respectivamente, do total das internações. Depois da implantação da gestão semi plena, o registro de óbitos nessa modalidade de procedimento apresentaram reduções.

\begin{tabular}{|c|c|c|c|c|c|c|c|c|c|c|}
\hline \multirow[b]{2}{*}{ Municípios } & \multicolumn{5}{|c|}{ Antes } & \multicolumn{5}{|c|}{ Depois * } \\
\hline & 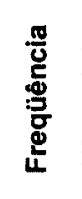 & 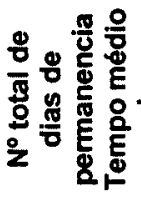 & 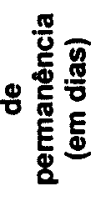 & $\begin{array}{l}: 0 \\
\stackrel{2}{0} \\
0 \\
0 \\
: \\
0 \\
2\end{array}$ & 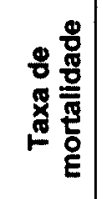 & 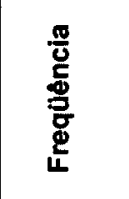 & 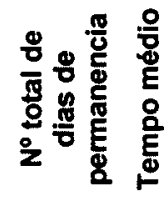 & 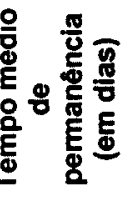 & $\begin{array}{l}\stackrel{8}{0} \\
: 0 \\
0 \\
0 \\
8 \\
2 \\
2\end{array}$ & 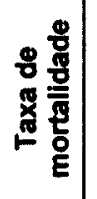 \\
\hline Assis & 1278 & 3274 & 2,56 & 0 & 0,000 & 1339,33 & 3734,00 & 2,79 & 0,67 & 0,000 \\
\hline Campinas & 4704 & 16035 & 3,41 & 3 & 0,001 & 4842,00 & 16770,33 & 3,46 & 1,67 & 0,000 \\
\hline Diadema & 4170 & 13664 & 3,28 & 0 & 0,000 & 2297,67 & 7440,00 & 3,24 & 1,00 & 0,000 \\
\hline Maua & 2045 & 7383 & 3,61 & 0 & 0,000 & 2458,33 & 8602,00 & 3,50 & 2,33 & 0,001 \\
\hline Ribeirão Preto & 2203 & 7104 & 3,22 & 1 & 0,000 & 1846,67 & 5716,67 & 3,10 & 1,67 & 0,001 \\
\hline Santos & 2217 & 8958 & 4,04 & 3 & 0,001 & 2608,33 & 8975,33 & 3,44 & 1,67 & 0,001 \\
\hline São Bernado do Campo & 0 & 0 & 0,00 & 0 & 0,000 & 0,00 & 0,00 & 0,00 & 0,00 & 0,000 \\
\hline São José dos Campos & 2170 & 5212 & 2,40 & 1 & 0,000 & 2232,67 & 5649,33 & 2,53 & 0,67 & 0,000 \\
\hline São Vicente & 674 & 1910 & 2,83 & 1 & 0,001 & 631,67 & 1641,00 & 2,60 & 0,33 & 0,001 \\
\hline Sertãozinho & 638 & 1446 & 2,27 & & 0,000 & 488,67 & 1097,00 & 2,24 & 0,00 & 0,000 \\
\hline Votorantim & 275 & 734 & 2,67 & $\underline{0}$ & 0,000 & 299,33 & 802,00 & 2,68 & 0,00 & 0,000 \\
\hline
\end{tabular}


Conforme mostra o Quadro 12, no Município de Assis, no período antes da gestão semi plena realizou-se 1278 partos por cesariana, cujo tempo médio de permanência atingiu 2,56 dias. Depois da implantação da gestão semi plena, o número médio de cesarianas no Municipio foi de 1339,33 e o tempo médio de permanência de 2,79 dias.

No período avaliado antes da gestão semi plena, 77 pacientes foram internados por infarto agudo do miocárdio no Municipio de Assis, com uma média de 6,08 dias de permanência, sendo que destes $18,20 \%$ foram a óbito. Depois da implantação da gestão semi plena, o número médio de internações por esse procedimento no Município foi de 71,67 , com um tempo médio de internação de 6,39 dias e $16,71 \%$ de óbitos.

Considerando-se as classes de tempos de permanência, mostradas no quadro 13 , verificou-se que antes da gestão semi plena, o maior número de internações $(89,61 \%)$, corresponderam a classe de 8 ou mais dias de internações e atingiram $10,10 \%$ de óbitos. Depois da implantação da gestão semi plena, a maior concentração de internações correspondeu à classe de tempo de permanência de 2 a 7 dias $(61,86 \%)$ e atingiram $12,00 \%$ de óbitos. Observou-se que a medida que reduziu-se o tempo de permanência aumentouse a taxa de mortalidade, em ambos os períodos.

Quadro 13 - Distribuição da freqüência de internaçōes, número total de dias de permanência, número de óbitos, percentuais de freqủência e taxa de mortalidade, por classes de permanência em internaçōes, nos periodos antes e depois da implantação da gestão semi plena no Município de Assis, segundo o procedimento sentinela infarto agudo do miocárdio.

\begin{tabular}{|c|c|c|c|c|c|c|c|c|c|c|}
\hline \multirow[b]{2}{*}{ Assis } & \multicolumn{5}{|c|}{ Antos } & \multicolumn{5}{|c|}{ Depois } \\
\hline & 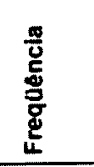 & 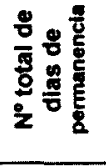 & $\begin{array}{l}88 \\
\frac{8}{2} \\
20\end{array}$ & 을 & 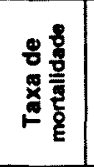 & 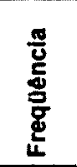 & 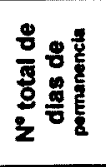 & $\begin{array}{l}\frac{8}{8} \\
20 \\
20\end{array}$ & 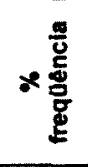 & 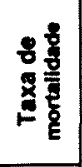 \\
\hline Permanencia de zero dias & 1,00 & 0,00 & 0,00 & 1,30 & 0,000 & 3,3 & 0,00 & 3,00 & 4,6 & 0,900 \\
\hline Permanencia de um dia & 7,00 & 0,00 & 7,00 & 9,09 & 1,000 & 4,0 & 4,00 & 2,67 & 5,5 & 0,667 \\
\hline Permanencia de 2 a 7 & 0,00 & 0,00 & 0,00 & 0,00 & 0,000 & 44,3 & 217,67 & 5,33 & 61,8 & 0,120 \\
\hline Permanencia de 8 ou + & 69,00 & 468,00 & 7,00 & 89,61 & 0,101 & 20,0 & 236,33 & 1,00 & 27,9 & 0,050 \\
\hline Total & 77,00 & 468,00 & 14,00 & 100,00 & 0,182 & 71,6 & 458,00 & 12,00 & 100,0 & 0,167 \\
\hline
\end{tabular}


O Quadro 14 apresenta a distribuição de freqüência, por classes de permanência das internações realizadas por broncopneumonias no Município de Assis, onde observou-se que no periodo antes da implantação da gestão semi plena, foram internados 709 pacientes, com um tempo médio de internação de 5,22 dias, destes $1,60 \%$ vieram à óbito. Depois da implantação da semi plena ocorreram 517 internações, com tempo médio de permanência de 5,22 dias e mortalidade de $2,20 \%$.

A classe de permanência de 6 ou mais dias representou $99,29 \%$ das internações, enquanto os óbitos nessa classe foram de 1,40\%, no período antes da implantação da gestão semi plena. Depois da implantação da gestão semi plena, a maior concentração de internações foi na classe de 3 a 5 dias, que representou $62,28 \%$ e mortalidade de $0,90 \%$

Quadro 14 - Distribuição da freqüência de internações, número total de dias de permanência, número de óbitos, percentuais de freqüência e taxa de mortalidade, por classes de permanência em internações, nos periodos antes e depois da implantação da gestão semi plena no Município de Assis, segundo 0 procedimento sentinela broncopneumonias.

\begin{tabular}{|c|c|c|c|c|c|c|c|c|c|c|}
\hline \multirow[b]{2}{*}{ Assis } & \multicolumn{5}{|c|}{ Antes } & \multicolumn{5}{|c|}{ Depois } \\
\hline & $\begin{array}{l}\frac{0}{0} \\
\frac{5}{5} \\
\frac{g}{d}\end{array}$ & 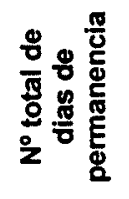 & $\begin{array}{l}8 \\
\frac{8}{0} \\
0 \\
8 \\
8 \\
2\end{array}$ & 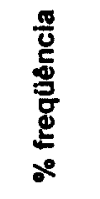 & 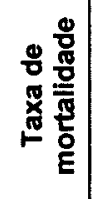 & 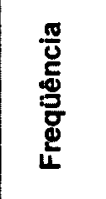 & 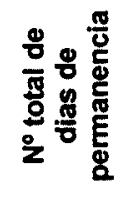 & $\begin{array}{l}8 \\
\frac{8}{0} \\
0 \\
\frac{8}{8} \\
0 \\
2\end{array}$ & 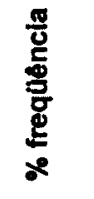 & 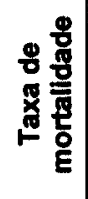 \\
\hline Permanencia de zero dias & 4,00 & 0,00 & 0,00 & 0,56 & 0,000 & 0,67 & 0,00 & 0,67 & 0,13 & 1,000 \\
\hline Permanencia de ate dois dias & 1,00 & 0,00 & 1,00 & 0,14 & 1,000 & 33,33 & 62,67 & 2,33 & 6,45 & 0,070 \\
\hline Permanencia de 3 a 5 & 0,00 & 0,00 & 0,00 & 0,00 & 0,000 & 322,00 & 1264,00 & 3,00 & 62,28 & 0,009 \\
\hline Permanencia de $60+$ & 704,00 & 3704,00 & 10,00 & 99,29 & 0,014 & 161,00 & 1375,00 & 5,33 & 31,14 & 0,033 \\
\hline Total & 709,00 & 3704,00 & 11,00 & 100,00 & 0,016 & 517,00 & 2701,67 & 11,33 & 100,00 & 0,022 \\
\hline
\end{tabular}

Conforme mostra o Quadro 12, no Município de Campinas, no período antes da gestão semi plena realizou-se 4704 partos por cesariana, cujo tempo médio de permanência atingiu 3,41 dias. Depois da implantação da 
gestão semi plena, o número médio de cesarianas no Município foi de 4842 e o tempo médio de permanência de 3,46 dias.

No período avaliado antes da gestão semi plena, 307 pacientes foram internados por infarto agudo do miocárdio no Municipio de Campinas, com uma média de 6,63 dias de permanência, sendo que destes $13,00 \%$ foram a óbito. Depois da implantação da gestão semi plena, o número médio de internações por esse procedimento no Município foi de 405,67 , com um tempo médio de internação de 11 dias e $12,60 \%$ de óbitos.

Considerando-se as classes de tempos de permanência, mostradas no quadro 15 , verificou-se que antes da gestão semi plena, o maior número de internações $(63,52 \%)$, corresponderam a classe de 8 ou mais dias de internações e atingiram $4,10 \%$ de óbitos. Depois da implantação da gestão semi plena, a maior concentração de internações correspondeu à mesma classe de tempo de permanência $(64,75 \%)$ e atingiram $3,6 \%$ de óbitos. Observou-se que a medida que reduziu-se o tempo de permanência nas internaçōes aumentouse a taxa de mortalidade, em ambos os períodos.

Quadro 15- Distribuição da frequeência de internações, número total de dias de permanência, número de óbitos, percentuais de freqüência e taxa de mortalidade, por classes de permanência em internações, nos periodos antes e depois da implantação da gestão semi plena no Municipio de Campinas, segundo o procedimento sentinela infarto agudo do miocárdio.

\begin{tabular}{|c|c|c|c|c|c|c|c|c|c|c|}
\hline \multirow[b]{2}{*}{ Campinas } & \multicolumn{5}{|c|}{ Antes } & \multicolumn{5}{|c|}{ Depois } \\
\hline & 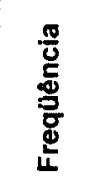 & 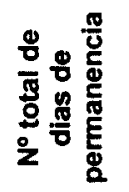 & $\begin{array}{l}0 \\
0 \\
00 \\
0 \\
0 \\
0 \\
0 \\
z\end{array}$ & $\begin{array}{l}\frac{\pi}{0} \\
\frac{c}{0} \\
\frac{9}{0} \\
\frac{9}{2} \\
20\end{array}$ & 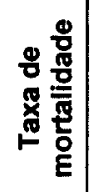 & 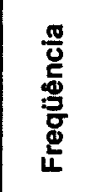 & 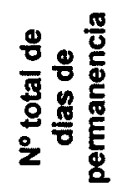 & $\begin{array}{l}8 \\
8 \\
00 \\
0 \\
8 \\
0 \\
0 \\
2\end{array}$ & 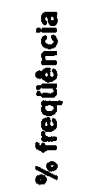 & 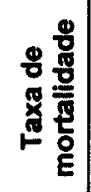 \\
\hline Permanencia de zero dias & 2,00 & 0,00 & 2,00 & 0,65 & 1,000 & 8,67 & 0,00 & 8,67 & 2,14 & 1,000 \\
\hline Permanencia de um dia & 12,00 & 12,00 & 9,00 & 3,91 & 0,750 & 11,33 & 11,33 & 11,33 & 2,79 & 1,000 \\
\hline Permanencia de 2 a 7 & 98,00 & 493,00 & 21,00 & 31,92 & 0,214 & 123,00 & 673,33 & 21,67 & 30,32 & 0,176 \\
\hline Permanencia de 8 e+ & 195,00 & 2147,00 & 8.00 & 63,52 & 0,041 & 262,67 & 3779,00 & 9,33 & 64,75 & 0,036 \\
\hline Total & 307,00 & 2652,00 & 40,00 & 100,00 & 0,130 & 405,67 & 4463,67 & 51,00 & 100,00 & 0,126 \\
\hline
\end{tabular}


O Quadro 16 apresenta a distribuição de freqüência, por classes de permanência das internações realizadas por broncopneumonias no Município de Campinas, onde observou-se que no período antes da implantação da gestão semi plena, foram internados 1217 pacientes, com um tempo médio de internação de 6,26 dias, destes $8,50 \%$ vieram à óbito. Depois da implantação da semi plena ocorreram 936 internações, com tempo médio de permanência de 8,08 dias e mortalidade de $18,80 \%$.

A classe de permanência de 6 ou mais dias representou $44,29 \%$ das internações, enquanto os óbitos nessa classe foram de $8,50 \%$, no periodo antes da implantação da gestão semi plena. Depois da implantação da gestão semi plena, a maior concentração de internações foi na mesma classe e representou $54,67 \%$ e mortalidade de $15,15 \%$

\begin{tabular}{|c|c|c|c|c|c|c|c|c|c|c|}
\hline \multirow[b]{2}{*}{ Campinas } & \multicolumn{5}{|c|}{ Antes } & \multicolumn{5}{|c|}{ Depois } \\
\hline & 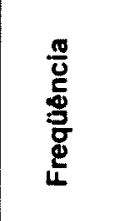 & 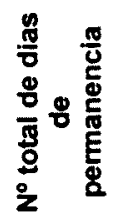 & $\begin{array}{l}8 \\
\stackrel{8}{0} \\
0 \\
0 \\
8 \\
0 \\
2\end{array}$ & 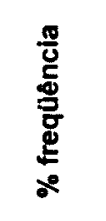 & 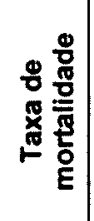 & 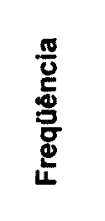 & 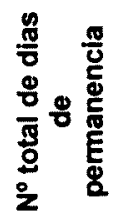 & $\begin{array}{l}\frac{8}{8} \\
\frac{8}{0} \\
8 \\
8 \\
2\end{array}$ & $\begin{array}{l}\frac{\pi}{0} \\
\frac{5}{0} \\
\frac{8}{0} \\
\frac{0}{x}\end{array}$ & 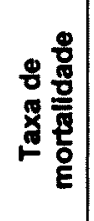 \\
\hline Permanencia de zero dias & 24,00 & 0,00 & 3,00 & 1,97 & 0,125 & 9,67 & 0,00 & 9,67 & 1,03 & 1,000 \\
\hline Permanencia de ate dois dias & 275,00 & 364,00 & 32,00 & 22,60 & 0,116 & 120,00 & 215,67 & 42,67 & 12,82 & 0,356 \\
\hline Permanencia de 3 a 5 & 379,00 & 1506,00 & 41,00 & 31,14 & 0,108 & 294,67 & 1172,67 & 44,00 & 31,48 & 0,149 \\
\hline Permanencia de $6 \theta+$ & 539,00 & 5771,00 & 46,00 & 44,29 & 0,085 & 511,67 & 6173,00 & 79,33 & 54,67 & 0,155 \\
\hline Total & 1217,00 & 7641,00 & 122,00 & 100,00 & 0,100 & 936,00 & 7561,33 & 175,67 & 100,00 & 0,188 \\
\hline
\end{tabular}

Conforme mostra o Quadro 12 no Município de Diadema, no periodo antes da gestão semi plena realizou-se 4170 partos por cesariana, cujo tempo médio de permanência atingiu 3,28 dias. Depois da implantação da gestão semi 
plena, o número médio de cesarianas no Município foi de 2297 e o tempo médio de permanência de 3,24 dias.

No período avaliado antes da gestão semi plena, 86 pacientes foram internados por infarto agudo do miocárdio no Município de Diadema, com uma média de 7,16 dias de permanência, sendo que destes $9,30 \%$ foram a óbito. Depois da implantação da gestão semi plena, o número médio de internações por esse procedimento no Município foi de 91,33, com um tempo médio de internação de 6,14 dias e $11,30 \%$ de óbitos.

Considerando-se as classes de tempos de permanência, mostradas no Quadro 17, verificou-se que antes da gestão semi plena, o maior número de internações $(94,19 \%)$, corresponderam a classe de 8 ou mais dias de internações e atingiram $6,20 \%$ de óbitos. Depois da implantação da gestão semi plena, a maior concentração de internações correspondeu à classe de tempo de permanência de 2 a 7 dias $(64,75 \%)$ e atingiram 10,60\% de óbitos. Observou-se que a medida que reduziu-se o tempo de permanência nas internações aumentou-se a taxa de mortalidade, em ambos os períodos.

Quadro 17 - Distribuição da freqüência de internaçōes, número total de dias de permanência, número de óbitos, percentuais de freqüência e taxa de mortalidade, por classes de permanência em internaçōes, nos períodos antes e depois da implantação da gestão semi plena no Município de Diadema, segundo o procedimento sentinela infarto agudo do miocárdio.

\begin{tabular}{|c|c|c|c|c|c|c|c|c|c|c|}
\hline \multirow[b]{2}{*}{ 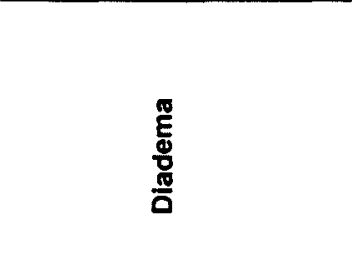 } & \multicolumn{5}{|c|}{ Antes } & \multicolumn{5}{|c|}{ Depois } \\
\hline & 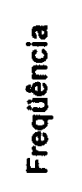 & 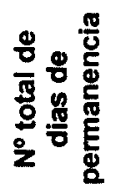 & $\begin{array}{l}\frac{8}{0} \\
\frac{0}{5} \\
0 \\
\frac{0}{0} \\
2\end{array}$ & 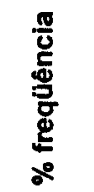 & 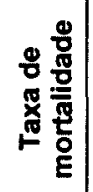 & 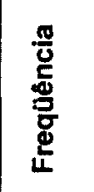 & 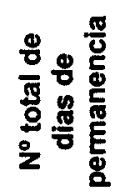 & $\begin{array}{l}o g \\
\frac{0}{0} \\
0 \\
8 \\
0 \\
0 \\
z\end{array}$ & $\begin{array}{l}\frac{\pi}{4} \\
\frac{5}{0} \\
\frac{0}{0} \\
\frac{d}{2} \\
20\end{array}$ & 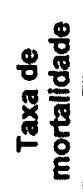 \\
\hline Permanencia de zero dias & 2,00 & 0,00 & 0,00 & 2,33 & 0,000 & 2,67 & 0,00 & 2,00 & 2,92 & 0,750 \\
\hline Permanencia de um dia & 3,00 & 0,00 & 3,00 & 3,49 & 1,000 & 5,67 & 5,67 & 1,33 & 6,20 & 0,235 \\
\hline Permanencia de 2 a 7 & 0,00 & 0,00 & 0,00 & 0,00 & 0,000 & 59,67 & 301,33 & 6,33 & 65,33 & 0,106 \\
\hline Permanencia de 8 e + & 81,00 & 316,00 & 5,00 & 94,19 & 0,062 & 23,33 & 254,00 & 0,67 & 25,55 & 0,029 \\
\hline Total & 86,00 & 316,00 & 8,00 & 100,00 & 0,093 & 91,33 & 561,00 & 10,33 & 100,00 & 0,113 \\
\hline
\end{tabular}


O Quadro 18 apresenta a distribuição de freqüência, por classes de permanência das internações realizadas por broncopneumonias no Município de Diadema, onde observou-se que no periodo antes da implantação da gestão semi plena, foram internados 803 pacientes, com um tempo médio de internação de 4,67 dias, destes $1,2 \%$ vieram à óbito. Depois da implantação da semi plena ocorreram 743,67 internações, com tempo médio de permanência de 6,22 dias e mortalidade de $3,60 \%$.

A classe de permanência de 6 ou mais dias representou $99,50 \%$ das internaçōes, enquanto os óbitos nessa classe foram de $1,10 \%$, no período antes da implantação da gestão semi plena. Depois da implantação da gestão semi plena, a maior concentração de internações ocorreu na mesma classe e representou $42,49 \%$ e mortalidade de $3,80 \%$.

\begin{tabular}{|c|c|c|c|c|c|c|c|c|c|c|}
\hline \multicolumn{11}{|c|}{$\begin{array}{l}\text { Quadro } 18 \text { - Distribuição da freqüência de internações, número total de dias de permanência, } \\
\text { número de óbitos, percentuais de freqüéncia e taxa de mortalidade, por classes dé } \\
\text { permanência em internaçōes, nos periodos antes e depois da implantação da gestăo } \\
\text { semi plena no Municipio de Diadema, segundo o procedimento sentinela }\end{array}$} \\
\hline \multirow[b]{2}{*}{ Diadema } & \multicolumn{5}{|c|}{ Antes } & \multicolumn{5}{|c|}{ Depois } \\
\hline & 兽 & 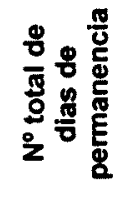 & $\begin{array}{l}8 \\
\frac{8}{0} \\
0 \\
0 \\
0 \\
2\end{array}$ & 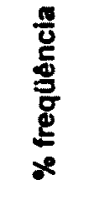 & 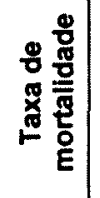 & 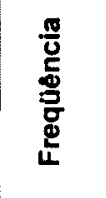 & 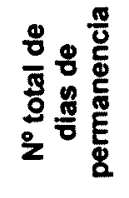 & $\begin{array}{l}8 \\
8 \\
0 \\
0 \\
0 \\
8 \\
8 \\
2\end{array}$ & 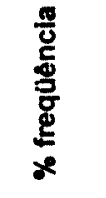 & 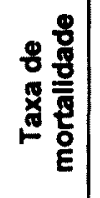 \\
\hline Permanencia de zero dias & 3,00 & 0,00 & 0,00 & 0,37 & 0,000 & 3,33 & 0,00 & 1,67 & 0.45 & 0,500 \\
\hline Permanencia de ate dois dias & 1,00 & 0,00 & 1,00 & 0,12 & 1,000 & 145,67 & 230,00 & 4,67 & 19,59 & 0,032 \\
\hline Permanencia de 3 a 5 & 0,00 & 0,00 & 0,00 & 0,00 & 0,000 & 278,67 & 1110,00 & 8,33 & 37,47 & 0,030 \\
\hline Permanencia de $60+$ & 799,00 & 3750,00 & 9,00 & 99,50 & 0,011 & 316,00 & 3292,67 & 12,00 & 42,49 & 0,038 \\
\hline Total & 803,00 & 3750,00 & 10,00 & 100,00 & 0,012 & 743,67 & 4632,67 & 26.67 & 100,00 & 0,036 \\
\hline
\end{tabular}

Conforme mostra o Quadro 12, no Municipio de Mauá, no período antes da gestão semi plena realizou-se 2045 partos por cesariana, cujo tempo médio de permanência atingiu 3,61 dias. Depois da implantação da gestão semi plena, o número médio de cesarianas no Município foi de 2458 e o tempo médio de permanência de 3,50 dias. 
No período avaliado antes da gestão semi plena, 62 pacientes foram internados por infarto agudo do miocárdio no Município de Mauá, com uma média de 5,79 dias de permanência, sendo que destes $21,00 \%$ foram a óbito. Depois da implantação da gestão semi plena, o número médio de internações por esse procedimento no Município foi de 98,33, com um tempo médio de internação de 10,35 dias e $4,80 \%$ de óbitos.

Considerando-se as classes de tempos de permanência, mostradas no quadro 19 , verificou-se que antes da gestão semi plena, o maior número de internações $(83,87 \%)$, corresponderam a classe de 8 ou mais dias de internações e atingiram $19,20 \%$ dos óbitos. Depois da implantação da gestão semi plena, a maior concentração de internações correspondeu à mesma classe de tempo de permanência $(62,67 \%)$ e atingiram $4,80 \%$ dos óbitos. Observou-se que a medida que reduziu-se o tempo de permanência nas internações aumentou-se a taxa de mortalidade, em ambos os períodos.

Quadro 19 - Distribuição da freqüéncia de internações, número total de dias de permanência,
número de óbitos, percentuais de freqüência e taxa de mortalidade, por classes de
permanéncia em internaçōes, nos periodos antes e depois da implantação da gestão
semi plena no Município de Mauá, segundo o procedimento sentinela infarto agudo do miocárdio.

\begin{tabular}{|c|c|c|c|c|c|c|c|c|c|c|}
\hline \multirow[b]{2}{*}{ Mauá } & \multicolumn{5}{|c|}{ Antes } & \multicolumn{5}{|c|}{ Depois } \\
\hline & 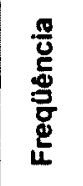 & 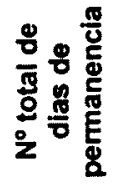 & $\begin{array}{l}8 \\
\frac{8}{0} \\
0 \\
0 \\
8 \\
0 \\
2\end{array}$ & $\begin{array}{l}\frac{\pi}{0} \\
\frac{E}{9} \\
\frac{5}{0} \\
\frac{0}{2} \\
2\end{array}$ & 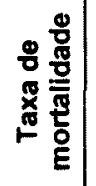 & 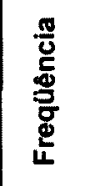 & 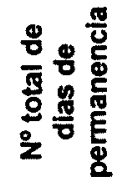 & $\begin{array}{l}8 \\
\frac{8}{0} \\
0 \\
8 \\
8 \\
2\end{array}$ & $\begin{array}{l}\frac{\pi}{0} \\
\frac{8}{0} \\
\frac{g}{g} \\
\frac{2}{2}\end{array}$ & 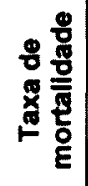 \\
\hline Permanencia de zero dias & 7,00 & 0,00 & 0,00 & 11,29 & 0,000 & 3,33 & 0,00 & 2,00 & 3,39 & 0,600 \\
\hline Permanencia de um dia & 3,00 & 0,00 & 3,00 & 4,84 & 1,000 & 5,33 & 5,33 & 2,33 & 5,42 & 0,438 \\
\hline Permanencia de 2 a 7 & 0,00 & 0,00 & 0,00 & 0,00 & 0,000 & 27,00 & 123,33 & 6,33 & 27,46 & 0,235 \\
\hline Permanencia de $80+$ & 52,00 & 359,00 & 10,00 & 83,87 & 0,192 & 62,67 & 889,67 & 3,00 & 63,73 & 0,048 \\
\hline Total & 62,00 & 359,00 & 13,00 & 100,00 & 0,210 & 98,33 & 1018,33 & 13,67 & 100,00 & 0,139 \\
\hline
\end{tabular}

O Quadro 20 apresenta a distribuição de freqüência, por classes de permanência das internações realizadas por broncopneumonias no Municipio de Mauá, onde observou-se que no período antes da implantação da gestão semi plena, foram internados 1103 pacientes, com um tempo médio de 
internação de 6,32 dias, destes $2,40 \%$ vieram à óbito. Depois da implantação da semi plena ocorreram 914,67 internações, com tempo médio de permanência de 7,22 dias e mortalidade de $6,00 \%$.

A classe de permanência de 6 ou mais dias representou $90,66 \%$ das internações, enquanto os óbitos nessa classe foram de $2,10 \%$, no periodo antes da implantação da gestão semi plena. Depois da implantação da gestão semi plena, a maior concentração de internações ocorreu na mesma classe e representou $52,37 \%$ e mortalidade de $4,80 \%$

\begin{tabular}{|c|c|c|c|c|c|c|c|c|c|c|}
\hline \multicolumn{11}{|c|}{$\begin{array}{l}\text { Quadro } 20 \text { - Distribuição da freqüência de internações, número total de dias de permanência, } \\
\text { número de óbitos, percentuais de freqüência e taxa de mortalidade, por classes de } \\
\text { permanência em internaçōes, nos periodos antes e depois da implantação da gestão } \\
\text { semi plena no Municipio de Mauá, segundo o procedimento sentinela } \\
\text { broncopneumonias. }\end{array}$} \\
\hline \multirow[b]{2}{*}{ Mauá } & \multicolumn{5}{|c|}{ Antes } & \multicolumn{5}{|c|}{ Depois } \\
\hline & 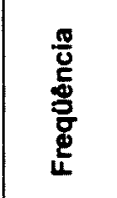 & 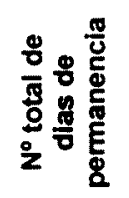 & $\begin{array}{l}\stackrel{0}{0} \\
\frac{0}{0} \\
\stackrel{8}{0} \\
\frac{0}{2}\end{array}$ & 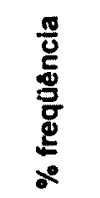 & 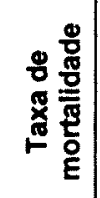 & 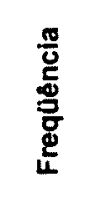 & 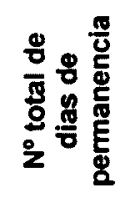 & $\begin{array}{l}8 \\
0 \\
00 \\
0 \\
8 \\
0 \\
2\end{array}$ & $\begin{array}{l}\frac{\pi}{0} \\
\frac{D}{0} \\
\frac{0}{0} \\
\frac{d}{2} \\
x\end{array}$ & 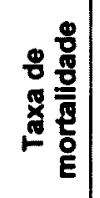 \\
\hline Permanencia de zero dias & 98,00 & 0,00 & 0,00 & 8,88 & 0,000 & 16,33 & 0,00 & 6,67 & 1,79 & 0,408 \\
\hline Permanencia de ate dois dias & 5,00 & 0,00 & 5,00 & 0,45 & 1,000 & 97,00 & 157,33 & 15,33 & 10,60 & 0,158 \\
\hline Permanencia de 3 a 5 & 0,00 & 0,00 & 0,00 & 0,00 & 0,000 & 322,33 & 1318,33 & 10,00 & 35,24 & 0,031 \\
\hline Permanencia de $60+$ & 1000,00 & 6976.00 & 21,00 & 90,66 & 0,021 & 479,00 & 5135,00 & 23,00 & 52,37 & 0,048 \\
\hline Total & 1103,00 & 6976,00 & 26,00 & 100,00 & 0,024 & 914,67 & 6610,67 & 55,00 & 100,00 & 0,060 \\
\hline
\end{tabular}

Conforme mostra o Quadro 12, no Município de Santos, no período antes da gestão semi plena realizou-se 2217 partos por cesariana, cujo tempo médio de permanência atingiu 4,04 dias. Depois da implantação da gestão semi plena, o número médio de cesarianas no Município foi de 2608 e o tempo médio de permanência de 3,44 dias.

No periodo avaliado antes da gestão semi plena, 161 pacientes foram internados por infarto agudo do miocárdio no Município de Santos, com uma média de 6,66 dias de permanência, sendo que destes $17,40 \%$ foram a 
óbito. Depois da implantação da gestão semi plena, o número médio de internaçōes por esse procedimento no Município foi de 137,33, com um tempo médio de internação de 6,56 dias e $14,30 \%$ de óbitos.

Considerando-se as classes de tempos de permanência, mostradas no quadro 21 , verificou-se que antes da gestão semi plena, o maior número de internações $(92,55 \%)$, corresponderam a classe de 8 ou mais dias de internações e atingiram $11,40 \%$ dos óbitos. Depois da implantação da gestão semi plena, a maior concentração de internações correspondeu à classe de tempo de permanência de 2 a 7 dias $(58,98 \%)$ e atingiram $7,80 \%$ dos óbitos. Observou-se que a medida que reduziu-se o tempo de permanência nas internações aumentou-se a taxa de mortalidade, em ambos os períodos.

Quadro 21 - Distribuição da freqüência de internações, número total de dias de permanência, número de óbitos, percentuais de freqüência e taxa de mortalidade, por classes de permanência em internaçōes, nos periodos antes e depois da implantação da gestão semi plena no Municipio de Santos, segundo o procedimento sentinela infarto agudo do miocárdio.

\begin{tabular}{|c|c|c|c|c|c|c|c|c|c|c|}
\hline \multirow[b]{2}{*}{ Santos } & \multicolumn{5}{|c|}{ Antes } & \multicolumn{5}{|c|}{ Depois } \\
\hline & 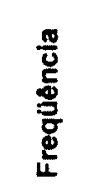 & 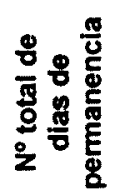 & $\begin{array}{l}8 \\
\stackrel{8}{0} \\
0 \\
0 \\
0 \\
0 \\
2\end{array}$ & 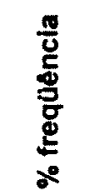 & 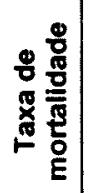 & 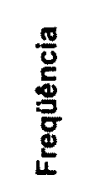 & 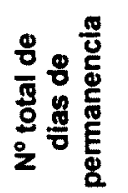 & $\begin{array}{l}\frac{8}{8} \\
\frac{0}{0} \\
\frac{8}{0} \\
2\end{array}$ & $\begin{array}{l}\frac{x}{0} \\
\frac{D}{9} \\
\frac{g}{0} \\
\frac{d}{2}\end{array}$ & 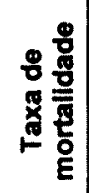 \\
\hline Permanencia de zero dias & 1,00 & 0,00 & 0,00 & 0,62 & 0,000 & 6,67 & 0,00 & 5,67 & 4,85 & 0,850 \\
\hline Permanencia de um dia & 11,00 & 0,00 & 11,00 & 6,83 & 1,000 & 10,00 & 10,00 & 4,67 & 7,28 & $0,46 \pi$ \\
\hline Permanencia de 2 a 7 & 0,00 & 0,00 & 0,00 & 0,00 & 0,000 & 81,00 & 366,33 & 6,33 & 58,98 & 0,078 \\
\hline Permanencia de $8 \theta+$ & 149,00 & 1072,00 & 17,00 & 92,55 & 0,114 & 39,67 & 525,00 & 3,00 & 28,88 & 0,076 \\
\hline Total & 161,00 & 1072,00 & 28,00 & 100,00 & 0.174 & 137,33 & 901,33 & 19,67 & 100,00 & 0,143 \\
\hline
\end{tabular}

O Quadro 22 apresenta a distribuição de freqüência, por classes de permanência das internações realizadas por broncopneumonias no Município de Santos, onde observou-se que no periodo antes da implantação da gestão semi plena, foram internados 960 pacientes, com um tempo médio de internação de 6,95 dias, destes $7,50 \%$ vieram à óbito. Depois da implantação 
da semi plena ocorreram 1148,33 internações, com tempo médio de permanência de 6,32 dias e mortalidade de 5,70\%.

Quadro 22 - Distribuição da freqüência de internações, número total de dias de permanência, número de óbitos, percentuais de freqüência e taxa de mortalidade, por classes de permanência em internações, nos periodos antes e depois da implantação da gestão semi plena no Município de Santos, segundo o procedimento sentinela broncopneumonias.

\begin{tabular}{|c|c|c|c|c|c|c|c|c|c|c|}
\hline \multirow[b]{2}{*}{ Santos } & \multicolumn{5}{|c|}{ Antes } & \multicolumn{5}{|c|}{ Depois } \\
\hline & 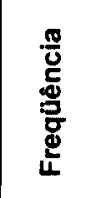 & 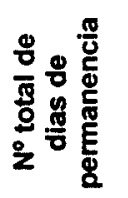 & $\begin{array}{l}\frac{8}{0} \\
\frac{3}{0} \\
0 \\
0 \\
\frac{8}{8} \\
\frac{0}{2}\end{array}$ & 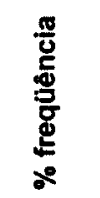 & 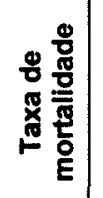 & 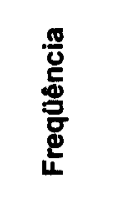 & 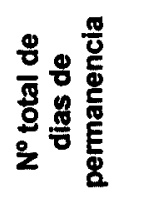 & $\begin{array}{l}8 \\
\frac{8}{0} \\
0 \\
0 \\
0 \\
0 \\
2\end{array}$ & $\begin{array}{l}\frac{\pi}{0} \\
\frac{5}{0} \\
\frac{g}{0} \\
\frac{d}{2}\end{array}$ & 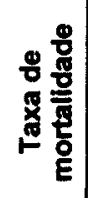 \\
\hline Permanencia de zero dias & 8,00 & 0,00 & 0,00 & 0,83 & 0,000 & 5,67 & 0,00 & 2,00 & 0,49 & 0,353 \\
\hline Permanencia de ate dois dias & 7,00 & 0,00 & 7,00 & 0,73 & 1,000 & 149,00 & 266,33 & 16,00 & 12,98 & 0,107 \\
\hline Permanencia de 3 a 5 & 0,00 & 0,00 & 0,00 & 0,00 & 0,000 & 506,33 & 2007,33 & 21,00 & 44,09 & 0,041 \\
\hline Permanencia de $60+$ & 945,00 & 6671,00 & 65,00 & 98,44 & 0,069 & 487,33 & 4984,33 & 26,67 & 42,44 & 0,055 \\
\hline Total & 960.00 & 6671.00 & 72.00 & 100.00 & 0.075 & 1148,33 & 7258,00 & 65,67 & 100,00 & 0.057 \\
\hline
\end{tabular}

A classe de permanência de 6 ou mais dias representou $98,44 \%$ das internações, enquanto os óbitos nessa classe foram de 6,90\%, no periodo antes da implantação da gestão semi plena. Depois da implantação da gestão semi plena, a maior concentração de internações ocorreu na classe de 3 a 5 dias e representou $44,09 \%$ e mortalidade de $4,10 \%$

No Município de Santos, conforme mostra o Quadro 23, 103 procedimentos de cirurgia extra-corpórea foram realizados, no período antes da gestão semiplena, com um tempo médio de permanência de 15,15 dias de internação e percentual de óbitos de 6,80\%. Depois da implantação semi plena, 64 procedimentos foram realizados, cujo tempo médio de permanência foi de 17,26 dias e a mortalidade de $8,90 \%$. Em ambos os períodos, a classe de permanência maior concentração foi a 8 ou mais dias. 
Quadro 23 - Distribuição da freqüência de internações, número total de dias de permanência, número de óbitos, percentuais de freqüência e taxa de mortalidade, por classes de permanência em internaçōes, nos períodos antes e depois da implantação da gestão semi plena no Município de Santos, segundo o procedimento sentinela infarto cirurgia extra-corpórea.

\begin{tabular}{|c|c|c|c|c|c|c|c|c|c|c|}
\hline \multirow[b]{2}{*}{ Santos } & \multicolumn{5}{|c|}{ Antes } & \multicolumn{5}{|c|}{ Depois } \\
\hline & 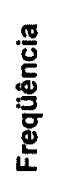 & 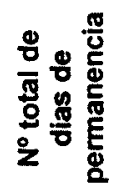 & $\begin{array}{l}8 \\
8 \\
0 \\
0 \\
8 \\
8 \\
0 \\
z\end{array}$ & 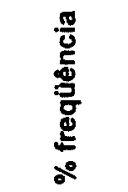 & 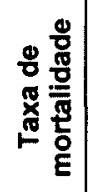 & 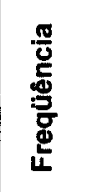 & 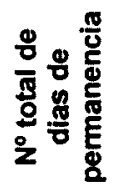 & 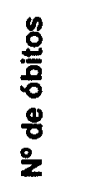 & 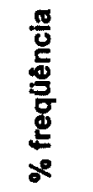 & 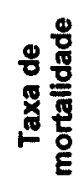 \\
\hline Permanencia de zero dias & 0 & 0 & 0 & 0,000 & 0,000 & 0,00 & 0,00 & 0,00 & 0,00 & 0,000 \\
\hline Permanencia de um dia & 0 & 0 & 0 & 0,000 & 0,000 & 0,00 & 0,00 & 0,00 & 0,00 & 0,000 \\
\hline Permanencia de 2 a 7 & 0 & 0 & 0 & 0,000 & 0,000 & 3,33 & 17,00 & 1,33 & 5,21 & 0,400 \\
\hline Permanencia de $8 \mathrm{e}+$ & 103 & 1561 & 7 & 100,000 & 0,068 & 60,67 & 1088,67 & 4,33 & 94,79 & 0,071 \\
\hline Total & 103 & 1561 & 7 & 100,000 & 0,068 & 64,00 & 1105,67 & 5,67 & 100,00 & 0,089 \\
\hline
\end{tabular}

Conforme mostra o Quadro 12, no Municipio de Sertãozinho, no período antes da gestão semi plena realizou-se 638 partos por cesariana, cujo tempo médio de permanência atingiu 2,27 dias. Depois da implantação da gestão semi plena, o número médio de cesarianas no Município foi de 488 e o tempo médio de permanência de 2,24 dias.

No período avaliado antes da gestão semi plena, 2 pacientes foram internados por infarto agudo do miocárdio no Municipio de Sertãozinho, com uma média de 5 dias de permanência, sendo que nenhum destes foi a óbito. Depois da implantação da gestão semi plena, o número médio de internações por esse procedimento no Município foi de 5 , com um tempo médio de internação de 10,15 dias e $20,00 \%$ de óbitos.

Considerando-se as classes de tempos de permanência, mostradas no Quadro 24, verificou-se que antes da gestão semi plena, o maior número de internações $(100 \%)$, corresponderam a classe de 8 ou mais dias de internações. Depois da implantação da gestão semi plena, a maior 
concentração de internações correspondeu à classe de tempo de permanência de 2 a 7 dias $(80,00 \%)$ e não ocorreram óbitos.

\begin{tabular}{|c|c|c|c|c|c|c|c|c|c|c|}
\hline \multicolumn{11}{|l|}{$\begin{array}{r}\text { Quadro } 24 \text { - Distribuição da freq } \\
\text { número de óbitos, p } \\
\text { permanência em inte } \\
\text { semi plena no Munic } \\
\text { agudo do miocárdio. }\end{array}$} \\
\hline \multirow[b]{2}{*}{ Sertãozinho } & \multicolumn{5}{|c|}{ Antes } & \multicolumn{5}{|c|}{ Depois } \\
\hline & 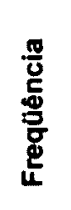 & 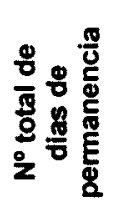 & $\begin{array}{l}\stackrel{0}{0} \\
\frac{0}{0} \\
0 \\
\stackrel{0}{0} \\
\stackrel{0}{z}\end{array}$ & $\begin{array}{l}\frac{\pi}{0} \\
\stackrel{0}{0} \\
\stackrel{0}{0} \\
\frac{2}{2}\end{array}$ & 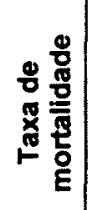 & 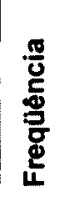 & 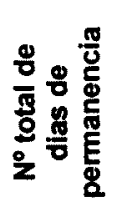 & $\begin{array}{l}\stackrel{8}{0} \\
\frac{0}{0} \\
0 \\
8 \\
0 \\
0\end{array}$ & $\frac{\frac{s}{6}}{\frac{c}{0}}$ & 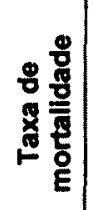 \\
\hline Permanencia de zero dias & 0,00 & 0,00 & 0,00 & 0,00 & 0,000 & 0,33 & 0,00 & 0,33 & 6,67 & 1,000 \\
\hline Permanencia de um dia & 0,00 & 0,00 & 0,00 & 0,00 & 0,000 & 0,67 & 0,67 & 0,67 & 13,33 & 1,000 \\
\hline Permanencia de 2 a 7 & 0,00 & 0,00 & 0,00 & 0,00 & 0,000 & 4,00 & 19,67 & 0,00 & 80,00 & 0,000 \\
\hline Permanencia de $80+$ & 2,00 & 10,00 & 0,00 & 0,01 & 0,000 & 0,00 & 0,00 & 0,00 & 0,00 & 0,000 \\
\hline Total & 2,00 & 10,00 & 0,00 & 0,01 & 0,000 & 5,00 & 20,33 & 1,00 & 100,00 & 0,200 \\
\hline
\end{tabular}

O Quadro 25 apresenta a distribuição de freqüência, por classes de permanência das internações realizadas por broncopneumonias no Município de Sertãozinho, onde observou-se que no período antes da implantação da gestão semi plena, foram internados 78 pacientes, com um tempo médio de internação de 6,90 dias, destes $2,60 \%$ vieram à óbito. Depois da implantação da semi plena ocorreram 56 internações, com tempo médio de permanência de 6,17 dias e mortalidade de $1,40 \%$.

A classe de permanência de 6 ou mais dias representou $100 \%$ das internações, enquanto os óbitos nessa classe foram de $2,60 \%$, no periodo antes da implantação da gestão semi plena. Depois da implantação da gestão semi plena, a maior concentração de internações ocorreu na classe de 3 a 5 dias e representou $49,40 \%$ e não ocorreram óbitos. 
Quadro 25 - Distribuição da freqüência de internações, número total de dias de permanência, número de óbitos, percentuais de freqüéncia e taxa de mortalidade, por classes de permanência em internações, nos períodos antes e depois da implantação da gestão semi plena no Municipio de Sertãozinho, segundo o procedimento sentinela broncopneumonias.

\begin{tabular}{|c|c|c|c|c|c|c|c|c|c|c|}
\hline \multirow[b]{2}{*}{ Sertãozinho } & \multicolumn{5}{|c|}{ Antes } & \multicolumn{5}{|c|}{ Depois } \\
\hline & 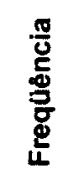 & 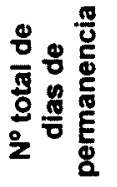 & $\begin{array}{l}0 \\
\stackrel{2}{0} \\
0 \\
0 \\
0 \\
0 \\
2\end{array}$ & 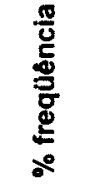 & 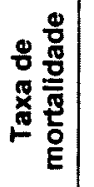 & 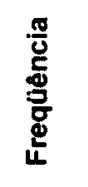 & 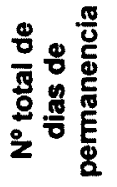 & $\begin{array}{l}8 \\
0 \\
0 \\
0 \\
0 \\
0 \\
0 \\
2\end{array}$ & $\begin{array}{l}\frac{\pi}{0} \\
\frac{g}{0} \\
\frac{g}{g} \\
\frac{g}{2}\end{array}$ & 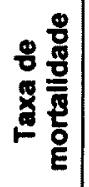 \\
\hline Permanencia de zero dias & 0,00 & 0,00 & 0,00 & 0,00 & 0,000 & 0,00 & 0,00 & 0,00 & 0,00 & 0,000 \\
\hline Permanencia de ate dois dias & 0,00 & 0,00 & 0,00 & 0,00 & 0,000 & 4,33 & 7,67 & 0,33 & 7,74 & 0,077 \\
\hline Permanencia de 3 a 5 & 0,00 & 0,00 & 0,00 & 0,00 & 0,000 & 27,67 & 109,00 & 0,00 & 49,40 & 0,000 \\
\hline Permanencia de $60+$ & 78,00 & 538,00 & 2,00 & 100,00 & 0,026 & 24,00 & 228,67 & 0,33 & 42,86 & 0,014 \\
\hline Total & 78,00 & 538,00 & 2,00 & 100,00 & 0,026 & 56,00 & 345,33 & 0,67 & 100,00 & 0,012 \\
\hline
\end{tabular}

Conforme mostra o Quadro 12, no Município de São José dos Campos, no periodo antes da gestão semi plena realizou-se 2170 partos por cesariana, cujo tempo médio de permanência atingiu 2,40 dias. Depois da implantação da gestão semi plena, o número médio de cesarianas no Município foi de 2232 e o tempo médio de permanência de 2,53 dias.

No periodo avaliado antes da gestão semi plena, 143 pacientes foram internados por infarto agudo do miocárdio no Município de São José dos Campos, com uma média de 7,02 dias de permanência, sendo que destes $11,90 \%$ foram a óbito. Depois da implantação da gestão semi plena, o número médio de internações por esse procedimento no Município foi de 159,33, com um tempo médio de internação de 8,00 dias e $14,90 \%$ de óbitos.

Considerando-se as classes de tempos de permanência, mostradas no Quadro 26 , verificou-se que antes da gestão semi plena, o maior número de internações $(99,30 \%)$, corresponderam a classe de 8 ou mais dias de internações e atingiram $11,30 \%$ dos óbitos. Depois da implantação da gestão semi plena, a maior concentração de internações correspondeu à classe de 
tempo de permanência de 2 a 7 dias $(49,58 \%)$ e atingiram $16,50 \%$ dos óbitos. Observou-se que a medida que reduziu-se o tempo de permanência nas internações aumentou-se a taxa de mortalidade, em ambos os períodos.

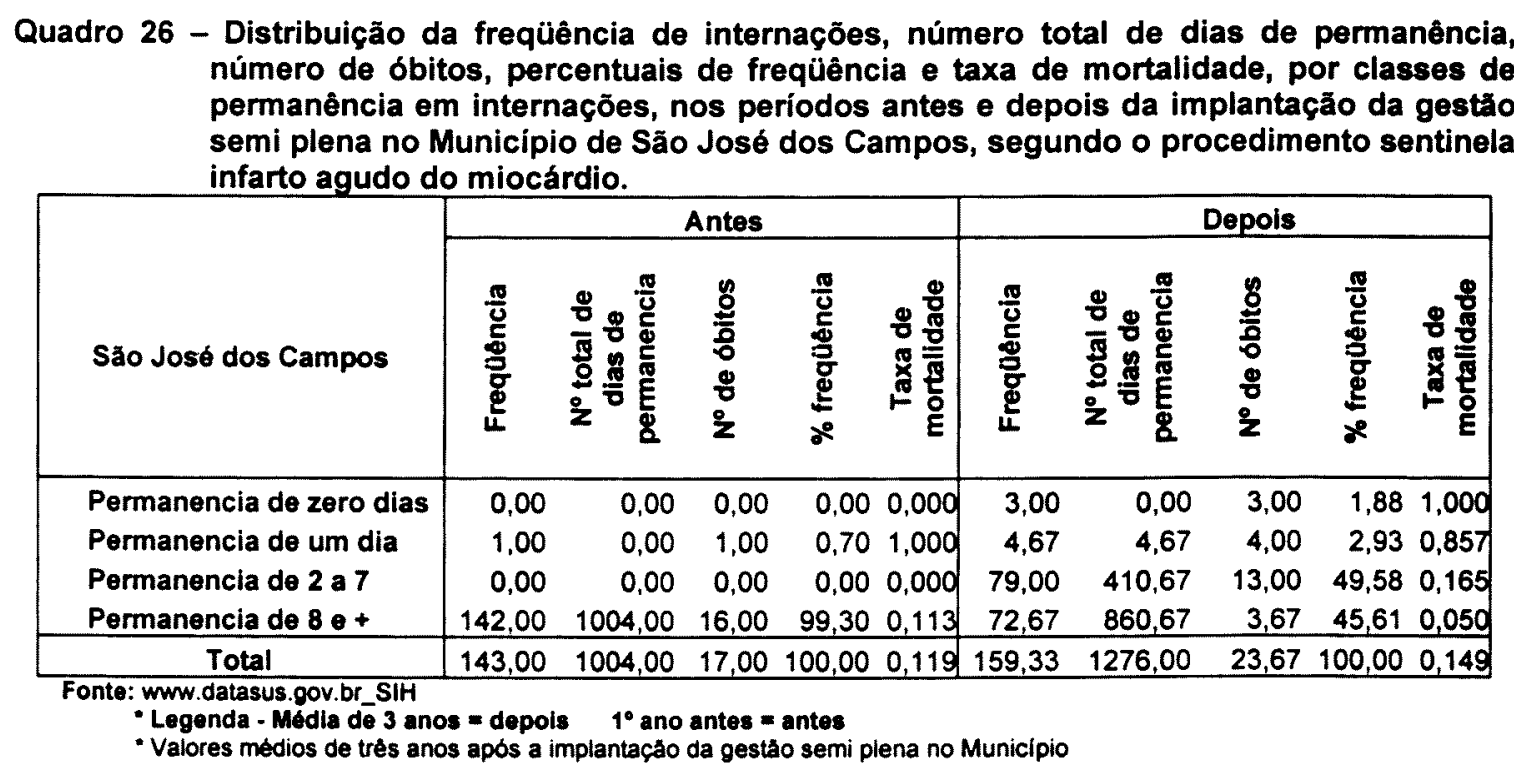

O Quadro 27 apresenta a distribuição de freqüência, por classes de permanência das internações realizadas por broncopneumonias no Municipio de São José dos Campos, onde observou-se que no período antes da implantação da gestão semi plena, foram internados 700 pacientes, com um tempo médio de internação de 5,03 dias, destes $1,70 \%$ vieram à óbito. Depois da implantação da semi plena ocorreram 530,67 internações, com tempo médio de permanência de 5,97 dias e mortalidade de $2,50 \%$.

A classe de permanência de 6 ou mais dias representou $99,86 \%$ das internações, enquanto os óbitos nessa classe foram de 1,70\%, no período antes da implantação da gestão semi plena. Depois da implantação da gestão semi plena, a maior concentração de internações ocorreu na classe de 3 a 5 dias e representou $52,45 \%$ e mortalidade de $0,80 \%$ 
Quadro 27 - Distribuição da freqüência de internações, número total de dias de permanência, número de óbitos, percentuais de freqüência e taxa de mortalidade, por classes de permanência em internaçōes, nos periodos antes e depois da implantação da gestão semi plena no Municipio de São José dos Campos, segundo o procedimento sentinela broncopneumonias.

\begin{tabular}{|c|c|c|c|c|c|c|c|c|c|c|}
\hline \multirow[b]{2}{*}{ São José dos Campos } & \multicolumn{5}{|c|}{ Antes } & \multicolumn{5}{|c|}{ Depois } \\
\hline & 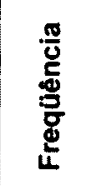 & 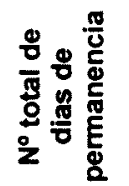 & $\begin{array}{l}8 \\
0 \\
0 \\
0 \\
0 \\
0 \\
0 \\
2\end{array}$ & 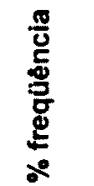 & 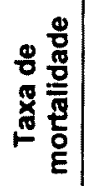 & 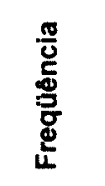 & 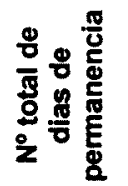 & $\begin{array}{l}8 \\
\frac{8}{0} \\
0 \\
0 \\
8 \\
\frac{0}{2}\end{array}$ & 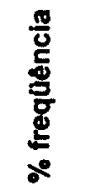 & 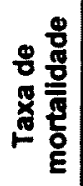 \\
\hline Permanencia de zero dias & 1,00 & 0,00 & 0,00 & 0,14 & 0,000 & 1,67 & 0,00 & 0,00 & 0,31 & 0,000 \\
\hline Permanencia de ate dois dias & 0,00 & 0,00 & 0,00 & 0,00 & 0,000 & 48,00 & 87,00 & 3,00 & 9,05 & 0,063 \\
\hline Permanencia de 3 a 5 & 0,00 & 0,00 & 0,00 & 0,00 & 0,000 & 278,33 & 1085,00 & 2,33 & 52,45 & 0,008 \\
\hline Permanencia de 6 e+ & 699,00 & 3523,00 & 12,00 & 99,86 & 0,017 & 202,67 & 1995,00 & 8,00 & 38,19 & 0,039 \\
\hline Total & 700,00 & 3523,00 & 12,00 & 100,00 & 0,017 & 530,67 & 3167,00 & 13,33 & 100,00 & 0,025 \\
\hline
\end{tabular}

No Municipio de São José dos Campos, conforme mostra o Quadro 28,38 procedimentos de cirurgia extra-corpórea foram realizados, no período antes da gestão semiplena, com um tempo médio de permanência de 9,24 dias de internação e percentual de óbitos de $1,70 \%$. Depois da implantação semi plena, 64,33 procedimentos foram realizados, cujo tempo médio de permanência foi de 9,97 dias e a mortalidade de $5,70 \%$. Em ambos os períodos, a classe de permanência maior concentração foi a 8 ou mais dias.

Quadro 28 - Distribuição da freqüência de internações, número total de dias de permanência, número de óbitos, percentuais de freqüência e taxa de mortalidade, por classes de permanência em internações, nos periodos antes e depois da implantação da gestão semi plena no Municipio de São José dos Campos, segundo o procedimento sentinela infarto cirurgia extra-corpórea.

\begin{tabular}{|c|c|c|c|c|c|c|c|c|c|c|}
\hline \multirow[b]{2}{*}{ Săo José dos Campos } & \multicolumn{5}{|c|}{ Antes } & \multicolumn{5}{|c|}{ Depols } \\
\hline & 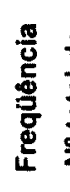 & 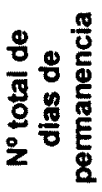 & $\begin{array}{l}0 \\
0 \\
0 \\
0 \\
8 \\
0 \\
0 \\
2\end{array}$ & 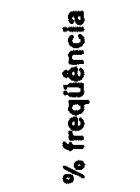 & 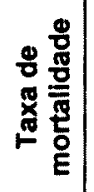 & 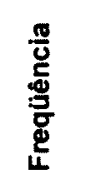 & 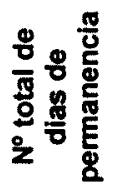 & $\begin{array}{l}8 \\
\frac{8}{5} \\
0 \\
0 \\
8 \\
0 \\
2\end{array}$ & 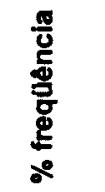 & 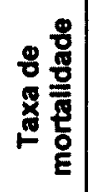 \\
\hline Permanencia de zero dias & 0 & 0 & 0 & 0,000 & 0,000 & 0,00 & 0,00 & 0.00 & 0,00 & 0,000 \\
\hline Permanencia de um dia & 0 & 0 & & 0,000 & 0,000 & 0,33 & 0,33 & 0,33 & 0,52 & 1,000 \\
\hline Permanencia de 2 a 7 & 0 & 0 & 0 & 0,000 & 0,000 & 21,67 & 136,67 & 2,67 & 33,68 & 0.123 \\
\hline Permanencia de $80+$ & 38 & 351 & & 3100,000 & 0,079 & 42,33 & 505,00 & 0,67 & 65,80 & 0,016 \\
\hline Total & 38 & 351 & & 3100,000 & 0.079 & 64,33 & 642,00 & 3,67 & 100,00 & 0,057 \\
\hline
\end{tabular}


Conforme mostra o Quadro 12, no Município de São Vicente, no período antes da gestão semi plena realizou-se 674 partos por cesariana, cujo tempo médio de permanência atingiu 2,83 dias. Depois da implantação da gestão semi plena, o número médio de cesarianas no Município foi de 631 e o tempo médio de permanência de 2,60 dias.

No periodo avaliado antes da gestão semi plena, 51 pacientes foram internados por infarto agudo do miocárdio no Município de São Vicente, com uma média de 6,29 dias de permanência, sendo que destes $21,60 \%$ foram a óbito. Depois da implantação da gestão semi plena, o número médio de internações por esse procedimento no Município foi de 62,33, com um tempo médio de internação de 8,36 dias e $15,00 \%$ de óbitos.

Considerando-se as classes de tempos de permanência, mostradas no Quadro 29, verificou-se que antes da gestão semi plena, o maior número de internações $(92,15 \%)$, corresponderam a classe de 8 ou mais dias de internações e atingiram $14,90 \%$ dos óbitos. Depois da implantação da gestão semi plena, a maior concentração de internações correspondeu à mesma classe de tempo de permanência $(58,29 \%)$ e atingiram $5,50 \%$ dos óbitos. Observou-se que a medida que reduziu-se o tempo de permanência nas internações aumentou-se a taxa de mortalidade, em ambos os períodos.

Quadro 29 - Distribuição da frequaência de internações, número total de dias de permanência, número de óbitos, percentuais de freqüência e taxa de mortalidade, por classes de permanência em internaçōes, nos periodos antes e depois da implantação da gestão semi plena no Município de São Vicente, segundo o procedimento sentinela infarto agudo do miocárdio.

\begin{tabular}{|c|c|c|c|c|c|c|c|c|c|c|}
\hline \multirow[b]{2}{*}{ São Vicente } & \multicolumn{5}{|c|}{ Antes } & \multicolumn{5}{|c|}{ Depols } \\
\hline & 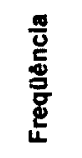 & 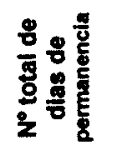 & $\begin{array}{l}8 \\
8 \\
8 \\
0 \\
8 \\
8 \\
z\end{array}$ & 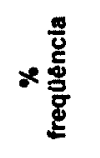 & 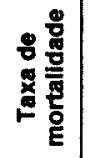 & 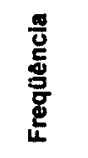 & 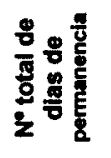 & $\begin{array}{l}8 \\
8 \\
8 \\
8 \\
8 \\
2\end{array}$ & 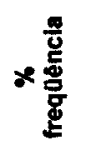 & 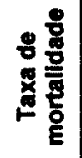 \\
\hline Permanência de zero dias & 0,00 & 0,00 & 0.00 & 0,00 & 0,000 & 1,33 & 0,00 & 1,33 & 2,14 & 1,000 \\
\hline Permanência de um dia & 4.00 & 0,00 & 4,00 & 7,84 & 1,000 & 2,00 & 2,00 & 2,00 & 3,21 & 1,000 \\
\hline Permanéncia de 2 a 7 & 0.00 & 0,00 & 0,00 & 0,00 & 0,000 & 22,67 & 112,67 & 4,00 & 36,36 & 0,176 \\
\hline Permanência de 8 et & 47,00 & 321,00 & 7,00 & 92,16 & 0,149 & 36,33 & 406,67 & 2,00 & 58,29 & 0,055 \\
\hline Total & 51,00 & 321,00 & 11,00 & 100,00 & 0,216 & 62,33 & 521,33 & 9,33 & 100,00 & 0,150 \\
\hline
\end{tabular}


O Quadro 30 apresenta a distribuição de freqüência, por classes de permanência das internações realizadas por broncopneumonias no Municipio de São Vicente, onde observou-se que no período antes da implantação da gestão semi plena, foram internados 651 pacientes, com um tempo médio de internação de 6,43 dias, destes $4,80 \%$ vieram à óbito. Depois da semi plena ocorreram 723,67 internações com tempo médio de permanência de 6,31 e mortalidade de $15,00 \%$

A classe de permanência de 6 ou mais dias representou $98,46 \%$ das internações, enquanto os óbitos nessa classe foram de $4,40 \%$, no periodo antes da implantação da gestão semi plena. Depois da implantação da gestão semi plena, a maior concentração de internações ocorreu na mesma classe e representou $46,52 \%$ e mortalidade de $4,10 \%$.

\begin{tabular}{|c|c|c|c|c|c|c|c|c|c|c|}
\hline \multirow[b]{2}{*}{ São Vicente } & \multicolumn{5}{|c|}{ Antes } & \multicolumn{5}{|c|}{ Depois } \\
\hline & 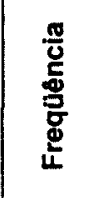 & 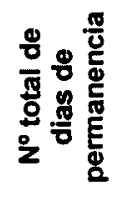 & $\begin{array}{l}8 \\
\frac{8}{5} \\
0 \\
8 \\
8 \\
2\end{array}$ & 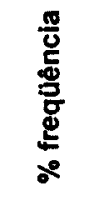 & 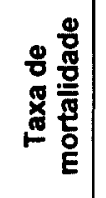 & 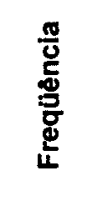 & 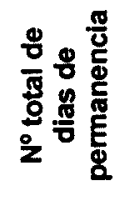 & $\begin{array}{l}8 \\
\frac{8}{0} \\
0 \\
0 \\
\frac{0}{8} \\
2\end{array}$ & 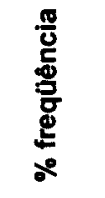 & 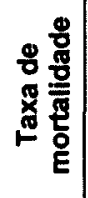 \\
\hline Permanencia de zero dias & 7,00 & 0,00 & 0.00 & 1,08 & 0,000 & 7,00 & 0,00 & 0,33 & 0,97 & 0,048 \\
\hline Permanencia de ate dois dias & 3,00 & 0,00 & 3,00 & 0,46 & 1,000 & 73,67 & 125,33 & 7,67 & 10,18 & 0,104 \\
\hline Permanencia de 3 a 5 & 0,00 & 0,00 & 0,00 & 0,00 & 0,000 & 306,33 & 1230,33 & 9,00 & 42,33 & 0,029 \\
\hline Permanencia de $60+$ & 641,00 & 4185,00 & 28,00 & 98,46 & 0,044 & 336,67 & 3209,33 & 13,67 & 46,52 & 0,041 \\
\hline Total & 651,00 & 4185,00 & 31,00 & 100,00 & 0,048 & 723,67 & 4565,00 & 30,67 & 100,00 & 0,042 \\
\hline
\end{tabular}

Conforme mostra o Quadro12, no Município de Votorantin, no período antes da gestão semi plena realizou-se 275 partos por cesariana, cujo tempo médio de permanência atingiu 2,67 dias. Depois da implantação da 
gestão semi plena, o número médio de cesarianas no Município foi de 299 e o tempo médio de permanência de 2,68 dias.

No período avaliado antes da gestão semi plena, 17 pacientes foram internados por infarto agudo do miocárdio no Município de Votorantin, com uma média de 8,35 dias de permanência, sendo que destes $23,50 \%$ foram a óbito. Depois da implantação da gestão semi plena, o número médio de internações por esse procedimento no Município foi de 21,33, com um tempo médio de internação de 6,92 dias e $28,10 \%$ de óbitos.

Considerando-se as classes de tempos de permanência, mostradas no Quadro 31, verificou-se que antes da gestão semi plena, o maior número de internações $(88,24 \%)$, corresponderam a classe de 8 ou mais dias de internações e atingiram $13,30 \%$ dos óbitos. Depois da implantação da gestão semi plena, a maior concentração de internações correspondeu à mesma classe de tempo de permanência $(42,19 \%)$ e não houve ocorrência de óbitos. Observou-se que a medida que reduziu-se o tempo de permanência nas internações aumentou-se a taxa de mortalidade, em ambos os períodos.

Quadro 31 - Distribuição da freqüência de internações, nümero total de dias de permanência,
número de óbitos, percentuais de freqüência e taxa de mortalidade, por classes de
permanéncia em internações, nos períodos antes e depois da implantação da gestão
semi plena no Municipio de Votorantin, segundo o procedimento sentinela infarto
agudo do miocárdio.

\begin{tabular}{|c|c|c|c|c|c|c|c|c|c|c|}
\hline \multirow[b]{2}{*}{ Votorantim } & \multicolumn{5}{|c|}{ Antes } & \multicolumn{5}{|c|}{ Depois } \\
\hline & $\begin{array}{l}\frac{.0}{0} \\
\frac{0}{9} \\
\frac{0}{0} \\
\frac{0}{4}\end{array}$ & 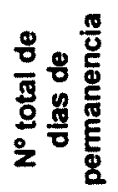 & $\begin{array}{l}8 \\
\frac{8}{0} \\
0 \\
8 \\
0 \\
0\end{array}$ & 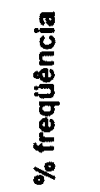 & 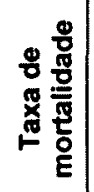 & 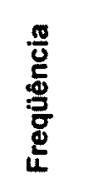 & 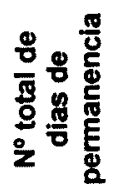 & $\begin{array}{l}8 \\
: 0 \\
: 0 \\
0 \\
8 \\
0 \\
2\end{array}$ & 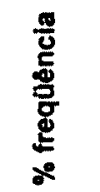 & 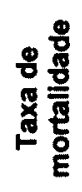 \\
\hline Permanencia de zero dias & 0,00 & 0,00 & 0,00 & 0,00 & 0,000 & 2,67 & 0,00 & 2,67 & 12,50 & 1,000 \\
\hline Permanencia de um dia & 2,00 & 0,00 & 2,00 & 11,76 & 1,000 & 1,00 & 1,00 & 0,67 & 4,69 & 0,667 \\
\hline Permanencia de 2 a 7 & 0,00 & 0,00 & 0,00 & 0,00 & 0,000 & 8,67 & 46,00 & 2,67 & 40,63 & 0,308 \\
\hline Permanencia de 8 e + & 15,00 & 142,00 & 2,00 & 88,24 & 0,133 & 9,00 & 100,67 & 0,00 & 42,19 & 0,000 \\
\hline Total & 17,00 & 142,00 & 4,00 & 100,00 & 0,235 & 21,33 & 147,67 & 6,00 & 100,00 & 0,281 \\
\hline
\end{tabular}


O Quadro 32 apresenta a distribuição de freqüência, por classes de permanência das internações realizadas por broncopneumonias no Município de Votorantin, onde observou-se que no período antes da implantação da gestão semi plena, foram internados 283 pacientes, com um tempo médio de internação de 6,08 dias, destes $5,30 \%$ vieram à óbito. Depois da semi plena ocorreram 153 internações com tempo médio de permanência de 6,40 e mortalidade de $3,30 \%$

A classe de permanência de 6 ou mais dias representou $98,23 \%$ das internações, enquanto os óbitos nessa classe foram de $4,30 \%$, no período antes da implantação da gestão semi plena. Depois da implantação da gestão semi plena, a maior concentração de internações ocorreu na mesma classe e representou $52,07 \%$ e mortalidade de $4,20 \%$.

\begin{tabular}{|c|c|c|c|c|c|c|c|c|c|c|}
\hline \multicolumn{11}{|c|}{$\begin{array}{l}\text { Quadro } 32 \text { - Distribuição da freqüência de internações, número total de dias de permanência, } \\
\text { número de óbitos, percentuais de freqüência e taxa de mortalidade, por classes de } \\
\text { permanência em internaçōes, nos periodos antes e depois da implantação da gestão } \\
\text { semi plena no Municipio de Votorantin, segundo o procedimento sentinela } \\
\text { broncopneumonias. }\end{array}$} \\
\hline \multirow[b]{2}{*}{ Votorantim } & \multicolumn{5}{|c|}{ Antes } & \multicolumn{5}{|c|}{ Depois } \\
\hline & 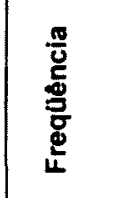 & 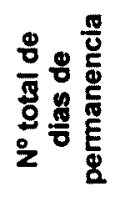 & $\begin{array}{l}\stackrel{2}{0} \\
: 0 \\
0 \\
: \\
0 \\
0\end{array}$ & $\begin{array}{l}\frac{\pi}{0} \\
\frac{c}{0} \\
\stackrel{g}{0} \\
\frac{0}{2} \\
2\end{array}$ & 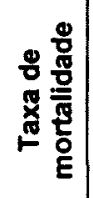 & 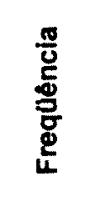 & 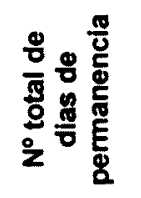 & $\begin{array}{l}8 \\
\frac{8}{0} \\
0 \\
\frac{8}{0} \\
\frac{0}{2}\end{array}$ & $\begin{array}{l}\frac{\pi}{0} \\
\frac{2}{0} \\
\frac{g}{d} \\
\frac{2}{2} \\
x\end{array}$ & 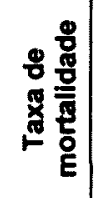 \\
\hline Permanencia de zero dias & 2,00 & 0,00 & 0,00 & 0,71 & 0,000 & 0,67 & 0,00 & 0,33 & 0,44 & 0,500 \\
\hline Permanencia de ate dois dias & 3,00 & 0,00 & 3,00 & 1,06 & 1,000 & 5,00 & 9,67 & 0,67 & 3,27 & 0,133 \\
\hline Permanencia de 3 a 5 & 0,00 & 0,00 & 0,00 & 0,00 & 0,000 & 67,67 & 270,33 & 0,67 & 44,23 & 0,010 \\
\hline Permanencia de $60+$ & 278,00 & 1720,00 & 12,00 & 98,23 & 0,043 & 79,67 & 699,67 & 3,33 & 52,07 & 0,042 \\
\hline Total & 283,00 & 1720,00 & 15,00 & 100,00 & 0.053 & 153,00 & 979,67 & 5,00 & 100,00 & 0,033 \\
\hline
\end{tabular}

Conforme mostra o Quadro 12, no Município de Ribeirão Preto, no período antes da gestão semi plena realizou-se 2203 partos por cesariana, cujo tempo médio de permanência atingiu 3,22 dias. Depois da implantação da 
gestão semi plena, o número médio de cesarianas no Município foi de 1846 e o tempo médio de permanência de 3,10 dias.

No período avaliado antes da gestão semi plena, 191 pacientes foram internados por infarto agudo do miocárdio no Município de Ribeirão Preto, com uma média de 7,72 dias de permanência, sendo que destes $13,60 \%$ foram a óbito. Depois da implantação da gestão semi plena, o número médio de internações por esse procedimento no Municipio foi de $166 \mathrm{com}$ um tempo médio de internação de 8,94 dias e $19,10 \%$ de óbitos.

Considerando-se as classes de tempos de permanência, mostradas no Quadro 33, verificou-se que antes da gestão semi plena, o maior número de internações $(51,31 \%)$, corresponderam a classe de 8 ou mais dias de internações e atingiram $4,10 \%$ dos óbitos. Depois da implantação da gestão semi plena, a maior concentração de internações correspondeu à mesma classe de tempo de permanência $(52,61 \%)$ e atingiram $5,00 \%$ dos óbitos. Observou-se que a medida que reduziu-se $\circ$ tempo de permanência nas internações aumentou-se a taxa de mortalidade, em ambos os períodos.

Quadro 33 - Distribuição da freqüência de internaçōes, número total de dias de permanência, número de óbitos, percentuais de freqüência e taxa de mortalidade, por classes de permanéncia em internações, nos periodos antes e depois da implantação da gestão semi plena no Município de Ribeirão Preto, segundo o procedimento sentinela infarto agudo do miocárdio.

\begin{tabular}{|c|c|c|c|c|c|c|c|c|c|c|}
\hline \multirow[b]{2}{*}{ Ribeirão Preto } & \multicolumn{5}{|c|}{ Antes } & \multicolumn{5}{|c|}{ Depois } \\
\hline & 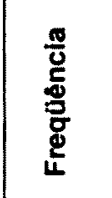 & 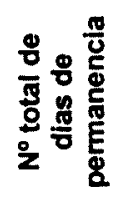 & 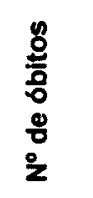 & 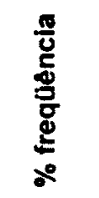 & 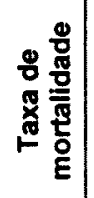 & 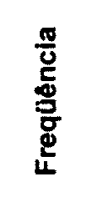 & 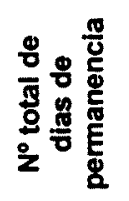 & $\begin{array}{l}8 \\
\frac{8}{0} \\
0 \\
8 \\
8 \\
0 \\
z\end{array}$ & $\begin{array}{l}\frac{x}{0} \\
\frac{E}{0} \\
\frac{g}{g} \\
\frac{g}{2}\end{array}$ & 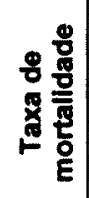 \\
\hline Permanencia de zero dias & 7,00 & 0,00 & 7,00 & 3,66 & 1,000 & 9.67 & 0,00 & 9,67 & 5,82 & 1,000 \\
\hline Permanencia de um dia & 8,00 & 8,00 & 5,00 & 4,19 & 0,625 & 5,00 & 5,00 & 5,00 & 3,01 & 1,000 \\
\hline Permanencia de 2 a 7 & 78,00 & 374,00 & 10,00 & 40,84 & 0,128 & 64,00 & 329,33 & 12,67 & 38,55 & 0,198 \\
\hline Permanencia de $80+$ & 98,00 & 1092,00 & 4,00 & 51,31 & 0,041 & 87,33 & 1151,00 & 4,33 & 52,61 & 0,050 \\
\hline Total & 191,00 & 1474,00 & 26,00 & 100,00 & 0,136 & 166,00 & 1485,33 & 31,67 & 100,00 & 0,191 \\
\hline
\end{tabular}


O Quadro 34 apresenta a distribuição de freqüência, por classes de permanência das internações realizadas por broncopneumonias no Município de Ribeirão Preto, onde observou-se que no período antes da implantação da gestão semi plena, foram internados 255 pacientes, com um tempo médio de internação de 7,95 dias, destes $8,20 \%$ vieram à óbito. No período depois, ocorreram 233 internaçōes, com tempo médio de 7,96 dias e mortalidade de $8,20 \%$.

\begin{tabular}{|c|c|c|c|c|c|c|c|c|c|c|}
\hline \multirow[b]{2}{*}{ Ribeirăo Preto } & \multicolumn{5}{|c|}{ Antes } & \multicolumn{5}{|c|}{ Depois } \\
\hline & 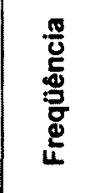 & 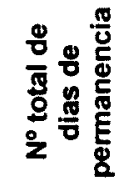 & $\begin{array}{l}80 \\
8 \\
0 \\
0 \\
0 \\
0 \\
0 \\
2\end{array}$ & 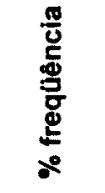 & 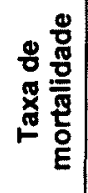 & 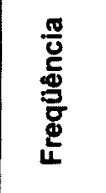 & 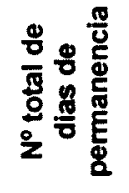 & $\begin{array}{l}8 \\
\frac{0}{0} \\
0 \\
8 \\
8 \\
2\end{array}$ & 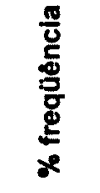 & 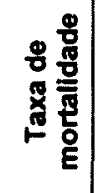 \\
\hline Permanencia de zero dias & 1,00 & 0,00 & 1,00 & 0,39 & 1,000 & 1,00 & 0,00 & 1,00 & 0,43 & 1,000 \\
\hline Permanencia de ate dois dias & 23,00 & 40,00 & 6,00 & 9,02 & 0,261 & 9,00 & 14,67 & 4,67 & 3,86 & 0.519 \\
\hline Permanencia de 3 a 5 & 72,00 & 284,00 & 4,00 & 28,24 & 0,056 & 102,00 & 392,00 & 4,00 & 43,78 & 0,039 \\
\hline Permanencia de $60+$ & 159.00 & 1881,00 & 13,00 & 62,35 & 0,082 & 121,00 & 1447,33 & 9,33 & 51,93 & 0,077 \\
\hline Total & 255,00 & 2205,00 & 24,00 & 100,00 & 0,094 & 233,00 & 1854,00 & 19,00 & 100,00 & 0,082 \\
\hline
\end{tabular}

A classe de permanência de 6 ou mais dias representou $62,35 \%$ das internações, enquanto os óbitos nessa classe foram de $8,20 \%$, no período antes da implantação da gestão semi plena. Depois da implantação da gestão semi plena, a maior concentração de internações ocorreu na mesma classe e representou $51,93 \%$ e mortalidade de $7,70 \%$

No Município de Ribeirão Preto, conforme mostra o Quadro 35, 346 procedimentos de cirurgia extra-corpórea foram realizados, no periodo antes da gestão semiplena, com um tempo médio de permanência de 12,07 dias de internação e percentual de óbitos de $12,10 \%$. Depois da implantação semi 
plena, 244,67 procedimentos foram realizados, cujo tempo médio de permanência foi de 12,32 dias e a mortalidade de $9,10 \%$. Em ambos os períodos, a classe de permanência maior concentração foi a 8 ou mais dias.

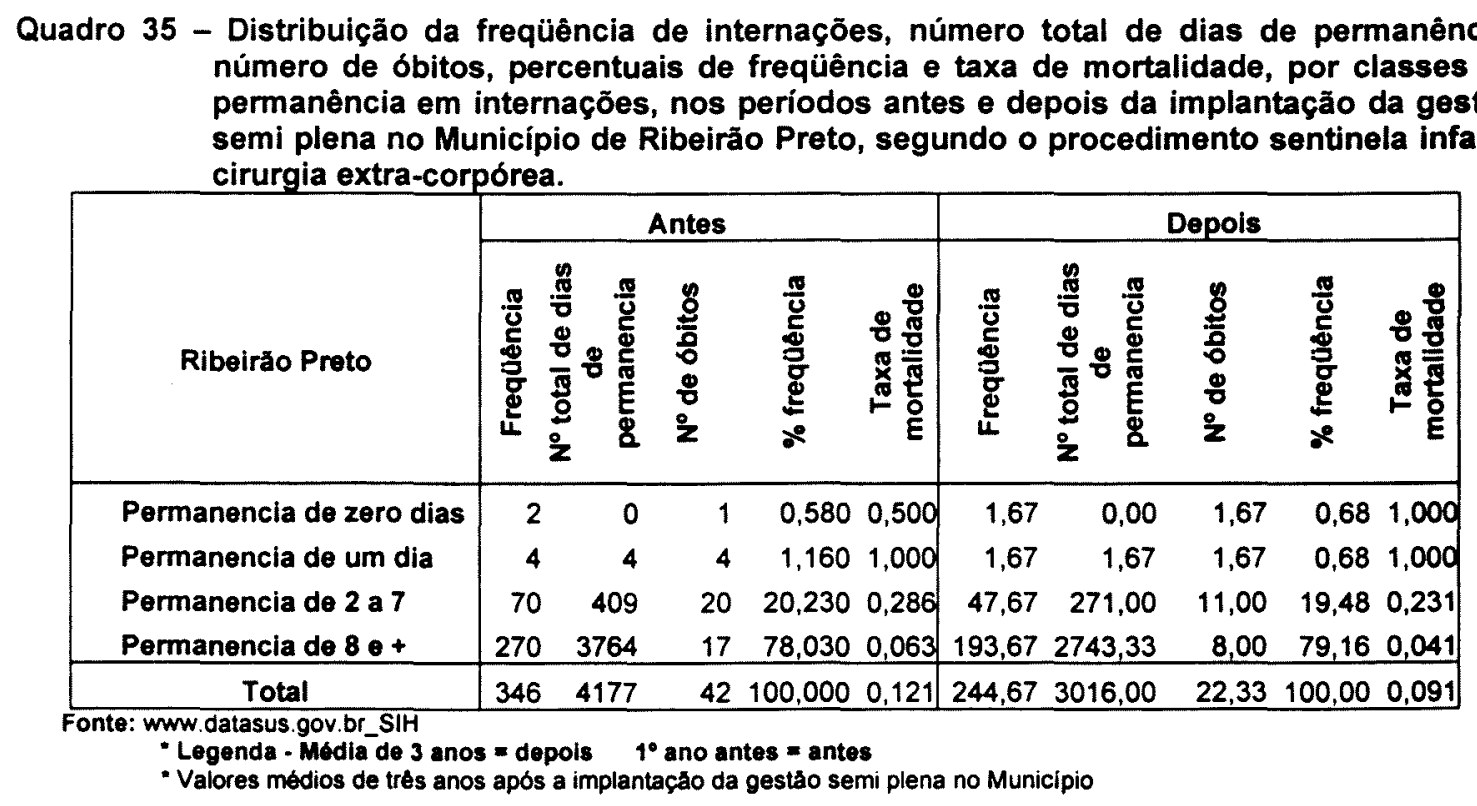

Conforme mostra o Quadro 12, no Município de São Bernardo do Campo não se realizaram o procedimento de cesarianas nos periodos antes e depois da implantação da gestão semi plena.

No período avaliado antes da gestão semi plena, 40 pacientes foram internados por infarto agudo do miocárdio no Município de São Bernardo do Campo, com uma média de 1,02 dias de permanência, sendo que destes 7,5\% foram a óbito. Depois da implantação da gestão semi plena, o número médio de internações por esse procedimento no Municipio foi de 35 , com um tempo médio de internação de 6,27 dias e $12,40 \%$ de óbitos.

Considerando-se as classes de tempos de permanência, mostradas no quadro 36 , verificou-se que antes da gestão semi plena, o maior número de internações $(37,50 \%)$, corresponderam a classe de 1 dia de internação e 
atingiram $13,30 \%$ dos óbitos. Depois da implantação da gestão semi plena, a maior concentração de internações correspondeu à classe de tempo de permanência de 2 a 7 dias $(70,48 \%)$ e com $12,20 \%$ de óbitos. Observou-se que a medida que reduziu-se o tempo de permanência nas internações aumentouse a taxa de mortalidade, em ambos os periodos.

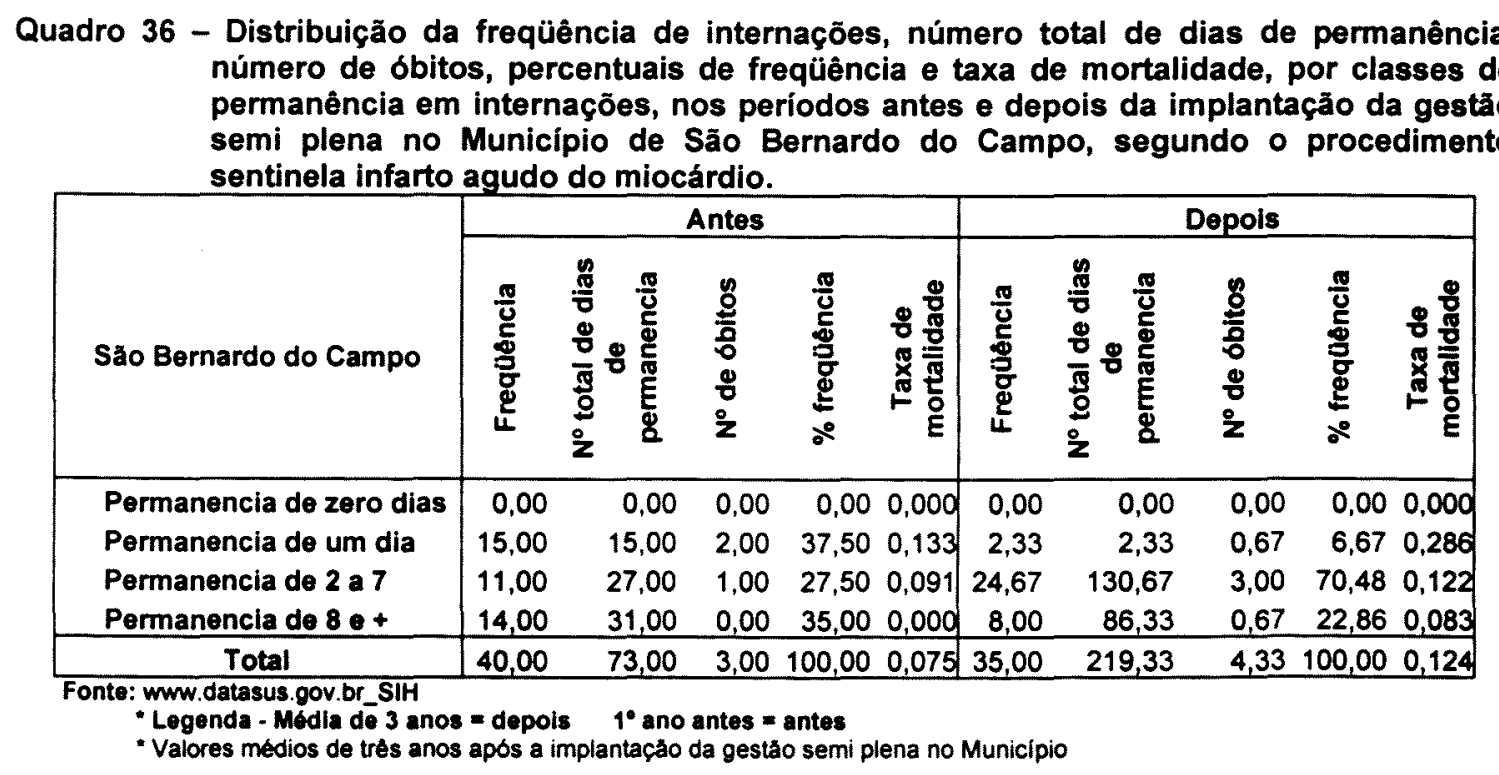

O Quadro 37 apresenta a distribuição de freqüência, por classes de permanência das internações realizadas por broncopneumonias no Municipio de São Bernardo do Campo, onde observou-se que no período antes da implantação da gestão semi plena, foram internados 324 pacientes, com um tempo médio de internação de 2,05 dias, destes $2,50 \%$ vieram à óbito. Depois da semi plena ocorreram 315,67 internações com tempo médio de permanência de 3,46 e mortalidade de $5,10 \%$

A classe de permanência de até 2 dias representou $46,60 \%$ das internações, enquanto os óbitos nessa classe foram de $2,60 \%$, no periodo antes da implantação da gestão semi plena. Depois da implantação da gestão semi plena, a maior concentração de internações ocorreu na mesma classe e representou $43,61 \%$ e mortalidade de $5,30 \%$. 
Quadro 37 - Distribuição da freqüência de internações, número total de dias de permanência, número de óbitos, percentuais de freqüência e taxa de mortalidade, por classes de permanéncia em internações, nos períodos antes e depois da implantação da gestão semi plena no Municipio de São Bernardo do Campo, segundo o procedimento sentinela broncopneumonias.

\begin{tabular}{|c|c|c|c|c|c|c|c|c|c|c|}
\hline \multirow[b]{2}{*}{ Săo Bernardo do Campo } & \multicolumn{5}{|c|}{ Antes } & \multicolumn{5}{|c|}{ Depois } \\
\hline & & 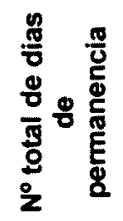 & $\begin{array}{l}\stackrel{0}{0} \\
: 0 \\
0 \\
0 \\
8 \\
0 \\
z\end{array}$ & $\begin{array}{l}\frac{\pi}{0} \\
\frac{0}{0} \\
\frac{0}{0} \\
\frac{d}{2} \\
20\end{array}$ & 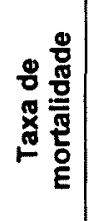 & 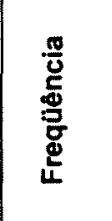 & 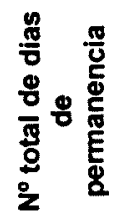 & $\begin{array}{l}y \\
\frac{8}{0} \\
0 \\
0 \\
8 \\
0 \\
z\end{array}$ & 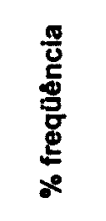 & 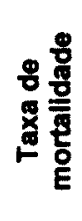 \\
\hline Permanencia de zero dias & 0,00 & 0,00 & 0,00 & 0,00 & 0,000 & 0,00 & 0,00 & 0,00 & 0,00 & 0,000 \\
\hline Permanencia de ate dois dias & 151,00 & 224,00 & 4,00 & 46,60 & 0,026 & 137,67 & 263,33 & 7,33 & 43,61 & 0,053 \\
\hline Permanencia de 3 a 5 & 46,00 & 159,00 & 2,00 & 14,20 & 0,043 & 136,33 & 486,00 & 5,33 & 43,19 & 0,039 \\
\hline Permanencia de $6 \theta+$ & 127,00 & 282,00 & 2,00 & 39,20 & 0,016 & 41,67 & 343,33 & 3,33 & 13,20 & 0,080 \\
\hline Total & 324,00 & 665.00 & 8.00 & 100,00 & 0,025 & 315.67 & 1092,67 & 16,00 & 100,00 & 0,051 \\
\hline
\end{tabular}

\subsubsection{Internações SUS e invasão}

No período estudado, baseado na fonte de dados AlH-DATASUS, correspondente a fase anterior à implantação da gestão semi plena, obtivemos os registros sobre a invasão apenas para os Municipios de Campinas, Ribeirão Preto e São Bernardo do Campo, o que dificultou a comparação dos eventos ocorridos antes e depois da gestão semi plena. O que não nos impede de registrar significativa melhoria no sistema de informação, uma vez que para o período posterior à implantação esses dados foram registrados com maior clareza e melhor precisão.

Observou-se antes da implantação da gestão semi plena, nos Municipios de Campinas, Ribeirão Preto e São Bernardo do Campo que o percentual de internações SUS sem o respectivo registro da origem do paciente foi da ordem de $10,60 \% ; 16,60 \%$ e 24,48\%, respectivamente. Essas taxas após 
a implantação da gestão semi plenas foram reduzidas em Campinas (2,60\%); Ribeirão Preto $(5,70 \%)$ e São Bernardo do Campo $(3,30 \%)$.

Os maiores percentuais de invasão registrados nesses Municípios antes e depois da implantação da gestão semi plena foram respectivamente para Campinas $(37,46 \%$ - 39,32\%); Ribeirão Preto $(40,51 \%$ - 39,76\%) e São Bernardo do Campo $(23,68 \%-23,88 \%)$.

Uma consideração a ser feita se refere a possibilidade desses Municipios continuarem atuando como "referência" para uma região de saúde ou estarem aptos ao atendimento dos procedimentos de alta complexidade.

Segundo FÁVERO (1986), ao analisar o processo de referência dos pacientes que demandaram aos hospitais universitários, identificou que $46,34 \%$ dos que procuraram o Hospital Universitário de Ribeirão Preto, eram procedentes da região de Ribeirão Preto; $37,48 \%$ do Município de Ribeirão Preto. Quando comparamos este estudo com a tendência antes e depois, observamos que a maior demanda era de atendimento a paciente de origem do Município de Ribeirão Preto $(42,89 \%$ e $54,54 \%)$.

No Quadro 38 podem ser observadas as distribuições percentuais das internações SUS quanto à origem do paciente nos Municípios estudados.

A média de invasão observada, após a implantação da gestão semi plena, considerando os 11 Municipios, correspondeu a $30,33 \%$.

Os Municipios que obtiveram as mais altas taxas de invasão foram Ribeirão Preto $(39,76 \%)$, Campinas $(39,32 \%)$, Santos $(32,78 \%)$, Diadema $(29,64 \%)$, Mauá $(27,03 \%)$ e São Bernardo do Campo $(22,89 \%)$ e as mais 
baixas foram Sertãozinho (0,26\%), São José dos Campos (5,17\%), São Vicente $(10,25 \%)$ e Assis $(17,25 \%)$.

Os mais altos índices de invasão foram encontrados em Santos e estes podem ser justificados pela população flutuante e pelo fato de o Município ser sede de região de saúde e também ser "referência" em procedimentos de alta complexidade.

Com relação aos Municípios que apresentaram as menores taxas de invasão, destacamos Sertãozinho $(0,26 \%)$ e São Vicente $(10,95 \%)$ que são Municipios limitrofes de Ribeirão Preto e Santos respectivamente que concentram recursos hospitalares de maior complexidade e referência.

Quadro 38 - Distribuição dos percentuais de internações SUS por origem do paciente e Municípios, nos periodos antes e depois da implantação da gestão semi-plena.

\begin{tabular}{|c|c|c|c|c|c|c|}
\hline \multirow[b]{2}{*}{ Municipios } & \multicolumn{3}{|c|}{ Antes } & \multicolumn{3}{|c|}{ Depois * } \\
\hline & $\begin{array}{c}\text { Sem } \\
\text { informaçáo }\end{array}$ & $\begin{array}{c}\text { Do } \\
\text { Municipio }\end{array}$ & $\begin{array}{l}\text { De outros } \\
\text { Municipios }\end{array}$ & $\begin{array}{c}\text { Sem } \\
\text { informaçåo }\end{array}$ & $\begin{array}{c}\text { Do } \\
\text { Municipio }\end{array}$ & $\begin{array}{l}\text { De outros } \\
\text { Municipios }\end{array}$ \\
\hline Assis & 100,00 & 0,00 & 0,00 & 0,05 & 82,69 & 17,25 \\
\hline Campinas & 10,60 & 51,94 & 37,46 & 2,60 & 58,08 & 39,32 \\
\hline Diadema & 100,00 & 0,00 & 0,00 & 2,51 & 67,85 & 29,64 \\
\hline Mauá & 100,00 & 0,00 & 0,00 & 0,81 & 72,16 & 27,03 \\
\hline Ribeirăo Preto & 16,60 & 42,89 & 40,51 & 5,70 & 54,54 & 39,76 \\
\hline Santos & 100,00 & 0,00 & 0,00 & 21,53 & 45,69 & 32,78 \\
\hline Săo Bernardo do Campo & 24,48 & 51,84 & 23,68 & 3,30 & 72,82 & 23,88 \\
\hline São José dos Campos & 100,00 & 0,00 & 0,00 & 0,54 & 94,29 & 5,17 \\
\hline Săo Vicente & 100,00 & 0,00 & 0,00 & 1,21 & 87,85 & 10,95 \\
\hline Sertãozinho & 100,00 & 0,00 & 0,00 & 0,25 & 99,49 & 0,26 \\
\hline Votorantim & 100,00 & 0,00 & 0,00 & 3,79 & 73,32 & 22,89 \\
\hline Total & 58,76 & 22,95 & 18,29 & 5,61 & 64,06 & 30,33 \\
\hline
\end{tabular}

Procurou-se suprir a ausência de informações do "período antes" para os Municípios com os dados encontrados por ALMEIDA (1995), fornecidos pelo CIS/SSE/SP, considerando que os dados desse mês (janeiro) refletem o perfil do ano de 1994, dado que a gestão semi plena foi assumida em 
novembro, dezembro desse ano, e assim não haveria tempo útil para mudanças significativas.

Quadro 38 A- Distribuição dos percentuais de internações SUS por origem do paciente e Municípios nos periodos antes e depois da implantação da gestão semi-plena.

\begin{tabular}{|l|ccc|ccc|}
\hline \multirow{2}{*}{ Municipios } & \multirow{2}{*}{ Periodos } & \multicolumn{3}{|c|}{ Antes } & \multicolumn{3}{c|}{ Depois * } \\
\cline { 2 - 7 } & $\begin{array}{c}\text { Sem } \\
\text { informaçăo }\end{array}$ & $\begin{array}{c}\text { Do } \\
\text { Municipio }\end{array}$ & $\begin{array}{c}\text { De outros } \\
\text { Municipios }\end{array}$ & $\begin{array}{c}\text { Sem } \\
\text { informaçăo }\end{array}$ & $\begin{array}{c}\text { Do } \\
\text { Municipio }\end{array}$ & $\begin{array}{c}\text { De outros } \\
\text { Municipios }\end{array}$ \\
\hline Assis & - & 75,1 & 24,9 & 0,05 & 82,69 & 17,25 \\
Campinas & 10,6 & 51,94 & 37,46 & 2,60 & 58,08 & 39,32 \\
Diadema & - & 80,0 & 20,0 & 2,51 & 67,85 & 29,64 \\
Mauá & 8,6 & 78,0 & 13,4 & 0,81 & 72,16 & 27,03 \\
Ribeirăo Preto & 16,6 & 42,89 & 40,51 & 5,70 & 54,54 & 39,76 \\
Santos & 22,1 & 77,9 & & 21,53 & 45,69 & 32,78 \\
Săo Bernardo do Campo & 24,48 & 51,84 & 23,68 & 3,30 & 72,82 & 23,88 \\
Săo José dos Campos & 8,2 & 82,2 & 9,6 & 0,54 & 94,29 & 5,17 \\
Săo Vicente & - & 85,9 & 14,1 & 1,21 & 87,85 & 10,95 \\
Sertãozinho & - & 100,0 & & 0,25 & 99,49 & 0,26 \\
Votorantim & - & 79,5 & 20,5 & 3,79 & 73,32 & 22,89 \\
\hline
\end{tabular}

Fonte: DATASUS - AIHS

- Valores médios relativos aos 3 anos após a implantaçăo da gestão semi-plena

* ALMEIDA (1995) dados base janeiro/95 SSE/SP

Observa-se que os Municípios de Assis, Campinas, Ribeirão Preto, São Bernardo do Campo, São José dos Campos (com destaques) São Vicente, Sertãozinho, apresentaram aumento no percentual de internações SUS de pacientes do próprio Municipio no período depois da implantação da gestão semi plena, o que confirma a tendência registrada anteriormente.

\subsubsection{Internações SUS e evasão}

Os dados de evasão em internações SUS, do período antes da implantação da gestão semi plena, a exemplo do que ocorreu com a invasão foram registrados apenas em Campinas, Ribeirão Preto e São Bernardo do Campo, segundo a fonte AIH/DATASUS.

Em Campinas, após a implantação da gestão semi plena, a evasão aumentou em média 18,43 vezes em relação ao período anterior; Ribeirão 
Preto, aumentou 77,54 ao contrário de São Bernardo do Campo que mantevese inalterado.

Quadro 39 - Número médio anual de internaçōes SUS por evasão e invasão após implantação da gestão semi plena, por Municipio no Estado de São Paulo.

\begin{tabular}{|c|c|c|}
\hline \multirow{2}{*}{$\underbrace{\text { Período }}_{\text {Municipios }}$} & \multicolumn{2}{|c|}{ Depois da Implantaçăo } \\
\hline & Evasăo* & Invasăo* \\
\hline Assis & 1935 & 2033 \\
\hline Campinas & 25568 & 25617 \\
\hline Diadema & 3489 & 5002 \\
\hline Mauá & 4724 & 4625 \\
\hline Ribeirão Preto & 17834 & 1854 \\
\hline Santos & 11298 & 11930 \\
\hline Såo Bernardo do Campo & 1914 & 1948 \\
\hline Sertăozinho & 11 & 1048 \\
\hline São José dos Campos & 985 & 998 \\
\hline Săo Vicente & 6663 & 11 \\
\hline Votorantim & 541 & 480 \\
\hline
\end{tabular}

Conforme Quadro 39, podemos observar que os valores médios da evasão e invasão são similares. Exceto, nos Municipios de: Diadema, onde ocorreu maior invasão (1513 internações SUS/ano); Santos, que apresentou invasão de 632 internações SUS/ano em média e Ribeirão Preto, com invasão de 220 internações SUS/ano, em média, apresentou redução da evasão em 2,52 , vezes ao periodo antes da implantação.

Os Municipios que apresentaram as maiores freqüências médias anuais de evasões de internações SUS após implantação em gestão semi plena foram Campinas (25568), Ribeirão Preto (17834) e Santos (11298) e os que apresentaram os menores foram Sertãozinho (11); Votorantim (541); São Vicente (912); São José dos Campos (975) conforme mostra o Quadro 40. 
Quadro 40 - Número de internaçōes SUS de pacientes, residentes nos Municípios ocorridas em outros Municípios - (evasão) por Municípios e períodos antes e depois da implantação da gestão semi plena.

\begin{tabular}{|l|cc|}
\hline \multicolumn{1}{|c|}{ Municipios } & Antes & Depois \\
\hline Assis & 0 & 1935 \\
Campinas & 1387 & 25568 \\
Diadema & 0 & 3489 \\
Mauá & 0 & 4724 \\
Ribeirăo Preto & 230 & 17834 \\
Santos & 0 & 11298 \\
São Bernardo do Campo & 4819 & 1914 \\
Sertãozinho & 0 & 11 \\
Săo José dos Campos & 0 & 985 \\
Săo Vicente & 0 & 6663 \\
Votorantim & 0 & 541 \\
\hline Fonte: www.datasus.gov.br_SIH
\end{tabular}

Procurou-se suprir a ausência de informações do "período antes" para os Municípios com os dados encontrados por ALMEIDA (1995) em janeiro de 1995, fornecidos pelo CIS/SSE/SP, considerando que os dados desse mês refletem o perfil do ano de 1994, dado que a gestão semi plena foi assumida em novembro/dezembro desse ano, e assim não haveria tempo útil para mudanças significativas, repetindo-se portanto o fato ocorrido com a invasão.

Quadro 40 A - Número de internações SUS de pacientes, residentes nos Municipios ocorridas em outros Municipios - (evasão) por Municípios e periodos antes e depois da implantação da gestão semi plena.

\begin{tabular}{|l|r|r|r|r|}
\hline \multirow{2}{*}{ Municipios Periodos } & \multicolumn{2}{|c|}{ Antes* } & \multicolumn{2}{c|}{ Depois** } \\
\cline { 2 - 5 } & Número & $\%$ & Número & $\%$ \\
\hline Assis & 126 & 11,2 & 1935 & 48,76 \\
Campinas & 1387 & & 25568 & 49,95 \\
Diadema & 525 & 32,3 & 3489 & 41,09 \\
Mauá & 266 & 18,5 & 4724 & 50,56 \\
Ribeirăo Preto & 230 & & 17834 & 90,58 \\
Santos & 299 & 12,1 & 11298 & 48,63 \\
Săo Bernardo do Campo & 4819 & & 1914 & 49,55 \\
Sertãozinho & 134 & 24,0 & 11 & 1,03 \\
Săo José dos Campos & 185 & 9,2 & 985 & 49,67 \\
São Vicente & 864 & 48,0 & 6663 & 98,80 \\
Votorantim & 305 & 62,3 & 541 & 52,98 \\
\hline
\end{tabular}

"corresponde à média de trés anos após a implantaçăo

*ALMEIDA (1995) dados base janeiro/95/SSE/SP 
Observamos que houve aumento significativo da evasão em Assis, Campinas, Diadema, Mauá, Ribeirão Preto, Santos, São José dos Campos e São Vicente, conforme quadro $40 \mathrm{~A}$.

\subsubsection{Internações SUS e prestador}

GOUVEA (1996) estudando as tendências na assistência hospitalar pelo SUS no Estado do Rio de Janeiro, 1992 - 1995, nos sub setores público, universitário e privado, observou que a freqüência de internações naquele Estado tendiam ao declínio em decorrência da retração do sub setor público a partir de 1993, o que em relação aos Municipios estudados, no presente trabalho, em São Paulo a situação é inversa como descrito a seguir.

O Quadro 41 mostra o total de internações SUS segundo prestador contratado, por Municipios, antes e depois da implantação da gestão semi plena.

Quadro 41 - Totais anuais de internações SUS por Municipios, segundo prestador contratado, antes e depois da implantação da gestão semi-plena.

\begin{tabular}{|c|c|c|c|c|}
\hline \multirow{3}{*}{ Municipio } & \multirow{2}{*}{$\begin{array}{l}\text { Antes } \\
1^{\circ} \text { ano }\end{array}$} & \multicolumn{3}{|c|}{ Depois } \\
\hline & & $1^{\circ}$ ano & $2^{\circ}$ ano & $3^{\circ}$ ano \\
\hline & $N$ & $N$ & $N$ & $\mathbf{N}$ \\
\hline Assis & 5531 & 3854 & 2881 & 2029 \\
\hline Campinas & 4099 & 152 & 19 & 41 \\
\hline Diadema & 12294 & 9522 & 2088 & 0 \\
\hline Ribeirăo Preto & 5199 & 1796 & 432 & 533 \\
\hline Santos & 48 & 0 & 0 & 0 \\
\hline Săo Bernardo do Campo & 79 & 0 & 0 & 0 \\
\hline São José dos Campos & 310 & 41 & 1 & 0 \\
\hline Votorantim & 3670 & 2023 & 1824 & 2439 \\
\hline Total & 31230 & 17388 & 7245 & 5042 \\
\hline
\end{tabular}


Nos prestadores contratados houve redução de 31230 internações SUS/ano ( $1^{\circ}$ ano antes) para 5042 SUS/ano ( $3^{\circ}$ ano após) e uma média, nos três últimos anos após implantação de 9892 internações SUS/ano, o que eqüivale a uma taxa de redução igual a $31,7 \%$. O número baixo de internações SUS chegando a internação zero (0) nos Municípios de Santos, São Bernardo do Campo nos três anos após a implantação da gestão semi plena, e zero (0) em São José dos Campos e Diadema no $3^{\circ}$ ano indicam um possivel descredenciamento ou desinteresse do prestador no atendimento ao SUS. Diadema apresentou um declínio médio de 4.031 internações SUS/ano, o que representou $31,5 \%$ considerando-se os três anos após a implantação da gestão semi plena. Esse desempenho resultou em evento significativo com impacto para essa categoria de prestador, pois dos $31,67 \%$ de decréscimo nas internações SUS, o Municipio de Diadema respondeu o equivalente a $12,4 \%$; Assis $9,3 \%$ e Votorantim $6,7 \%$ desse percentual. Campinas no periodo antes atendia 4.099 internação/ano, sendo que a média dos últimos 3 anos foi 71 internações SUS/ano.

Ribeirão Preto atendia 5199 e passou a atender uma média de 920/ano. Houve queda significativa em Votorantim que atendia a 3.670 internações SUS/ano e passou a atender a média de 2.095 internações SUS/ano após implantação.

Conforme mostra $\circ$ Quadro 42 nos prestadores estaduais houve aumento das internações SUS em Assis de 204,8 internações SUS/ano no primeiro ano antes da gestão semi-plena. 
Quadro 42 - Totais anuais de internações SUS por Municípios, segundo prestador estadual, antes e depois da implantação da gestão semi-plena.

\begin{tabular}{|l|c|ccc|}
\hline \multirow{2}{*}{ Punicipio } & Antes & \multicolumn{3}{|c|}{ Depois } \\
\cline { 2 - 5 } & $1^{\circ}$ ano & $1^{\circ}$ ano & $2^{\circ}$ ano & $3^{\circ}$ ano \\
\cline { 2 - 5 } & $\mathbf{N}$ & $\mathbf{N}$ & $\mathbf{N}$ & $\mathbf{N}$ \\
\hline Assis & 2191 & 2524 & 2886 & 2753 \\
Santos & 4662 & 5840 & 4881 & 5421 \\
\hline Total & 6853 & 8364 & 7767 & 8174 \\
\hline
\end{tabular}

Fonte: www.datasus.gov.br_SIH

- Legenda - Média de 3 anos $=$ depois

$1^{\circ}$ ano antes $=$ antes

O total de internações SUS foi de 2.191 e a média obtida nos três anos foi de 2721 internações SUS/ano, correspondendo a um acréscimo médio anual de 7,73\%. Santos apresentou acréscimo de 1178 internações SUS/ano no primeiro ano antes para o primeiro depois. Comparando $01^{\circ}$ ano antes com a média de internações SUS dos 3 anos depois obteve-se para o Municipio de Santos um acréscimo médio de 718 internações SUS/ano. Observando-se um acréscimo de $10,50 \%$ de internações SUS/ano em média após a implantação. O acréscimo de $18 \%$ nas internações SUS ano correspondeu a 6853 internações SUS/ano antes e a média depois foi de 8102 internações SUS/ano o que correspondeu a $18,22 \%$ de acréscimo. Portanto, o resultado de Assis correspondeu a $32 \%$ das internações SUS/ano e Santos $68 \%$ das internações SUS/ano.

Nos prestadores municipais ocorreu o aumento de internações SUS, especialmente, em Diadema de 12053 ( $1^{\circ}$ ano antes) para 1.325 (3 ano depois); Mauá de 6142 para 9861; Santos de 2227 para 8342; São Bernardo do Campo de 1809 para 4139 e São José dos Campos de 5588 para 10322. (Quadro 43). 
Quadro 43 - Totais anuais de internações SUS por Municípios, segundo prestador municipal, antes e depois da implantação da gestão semi-plena.

\begin{tabular}{|l|c|ccc|}
\hline \multirow{2}{*}{ Município Periodo } & Antes & \multicolumn{3}{|c|}{ Depois } \\
\cline { 2 - 5 } & $1^{\circ}$ ano & $1^{\circ}$ ano & $2^{\circ}$ ano & $3^{\circ}$ ano \\
\cline { 2 - 5 } & $\mathrm{N}$ & $\mathrm{N}$ & $\mathrm{N}$ & $\mathrm{N}$ \\
\hline Campinas & 7258 & 6662 & 6968 & 6750 \\
Diadema & 12053 & 13620 & 12146 & 13251 \\
Mauá & 6142 & 8452 & 7543 & 9861 \\
Santos & 2227 & 4699 & 7182 & 8342 \\
Săo Bernardo do Campo & 1809 & 1842 & 3282 & 4139 \\
Săo José dos Campos & 5588 & 5579 & 6137 & 10322 \\
\hline Total & $\mathbf{3 5 0 7 7}$ & $\mathbf{4 0 8 5 4}$ & $\mathbf{4 3 2 5 8}$ & $\mathbf{5 2 6 6 5}$ \\
\hline
\end{tabular}

O total de internações SUS/ano antes da gestão foi de 35077 internações SUS/ano, sendo que nos últimos 4 anos depois da implantação a média anual de internações SUS aumentou para 45.592 internações SUS/ano, o que corresponde a um acréscimo de $30 \%$ no volume de internações SUS. Os Municipios, Diadema (7,9\%), Mauá (40,3\%), São Bernardo do Campo $(70,68 \%)$ e São José dos Campos $(31,46 \%)$ apresentaram acréscimo significativo no número de internações SUS. Dentre eles destaca-se o Município de Santos que atingiu $202,7 \%$ de acréscimo no número de internações SUS. Campinas foi o único Município que apresentou redução de internação $(6,4 \%)$ se comparada às internações SUS antes e a média de internações SUS depois da implantação.

Nos prestadores filantrópicos observou-se variações, conforme mostra o Quadro 44. 
Quadro 44 - Totais anuais de internaçōes SUS por Municípios, segundo prestador filantrópico, antes e depois da implantação da gestão semi-plena.

\begin{tabular}{|c|c|c|c|c|}
\hline \multirow{3}{*}{ Periodo } & \multirow{2}{*}{$\begin{array}{l}\text { Antes } \\
1^{\circ} \text { ano }\end{array}$} & \multicolumn{3}{|c|}{ Depois } \\
\hline & & $1^{\circ}$ ano & $2^{\circ}$ ano & $3^{\circ}$ ano \\
\hline & $\mathbf{N}$ & $\mathbf{N}$ & $\mathbf{N}$ & $\mathbf{N}$ \\
\hline Assis & 8266 & 7274 & 6126 & 5022 \\
\hline Campinas & 11625 & 13914 & 13770 & 12673 \\
\hline Mauá & 8949 & 9150 & 9134 & 7186 \\
\hline Ribeirăo Preto & 17485 & 14361 & 13190 & 15446 \\
\hline Santos & 29532 & 30677 & 21819 & 20315 \\
\hline Sertãozinho & 6142 & 4450 & 3958 & 4067 \\
\hline Sảo José dos Campos & 14266 & 15484 & 13678 & 9592 \\
\hline Săo Vicente & 8372 & 10757 & 9515 & 7073 \\
\hline Total & 104637 & 106067 & 91190 & 81374 \\
\hline
\end{tabular}

Tendência de queda no periodo $1^{\circ}$ ano antes de 8.266 para $5.022\left(3^{\circ}\right.$ ano) em Assis; ao longo dos $1^{\circ}, 2^{\circ}$ e $3^{\circ}$ anos em Assis, Campinas, Mauá, Santos, São José dos Campos e São Vicente. De maneira geral houve queda representada por $104.637\left(1^{\circ}\right.$ ano antes) para 81.374 ( $3^{\circ}$ ano depois) (Quadro 44). O total de internações SUS/ano antes da gestão houve redução de $11,24 \%$ onde no primeiro ano antes ocorreram 104.637 internações SUS/ano e a média dos últimos três anos após a implantação ocorreram 92.877 internações SUS/ano. A maior redução no número de internações SUS ocorreu no Município de Sertãozinho (32,3\%), seguidos pelos Municípios de Assis $(25,71 \%)$; Ribeirão Preto $(18,03 \%)$; Santos $(17,82)$, São José dos Campos $(9,45 \%)$, Mauá $(5,13 \%)$. Nos Municípios de Campinas e São Vicente houve aumento no número de internações SUS em $15,72 \%$ e $8,87 \%$, respectivamente.

Ressalta-se que no Municipio de São Vicente o Hospital Filantrópico estava sob intervenção municipal.

Nos Prestadores Universitários houve acréscimo de $11,75 \%$ no total, conforme mostra o Quadro 45. 


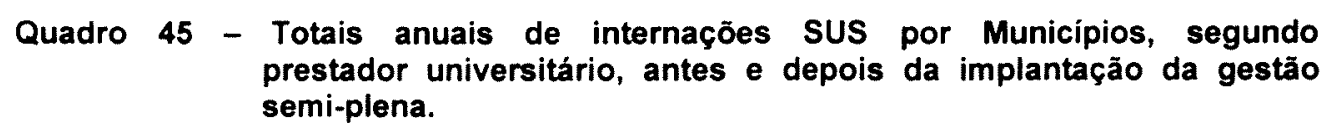

\begin{tabular}{|l|c|ccc|}
\hline \multirow{2}{*}{ Municipio Período } & Antes & \multicolumn{3}{c|}{ Depois } \\
\cline { 2 - 5 } & $1^{\circ}$ ano & $1^{\circ}$ ano & $2^{\circ}$ ano & $3^{\circ}$ ano \\
\cline { 2 - 5 } & $\mathbf{N}$ & $\mathbf{N}$ & $\mathbf{N}$ & $\mathbf{N}$ \\
\hline Campinas & 40444 & 44010 & 46069 & 44433 \\
Ribeiråo Preto & 28796 & 30262 & 28377 & 31817 \\
Săo Bernardo do Campo & 2398 & 5015 & 5081 & 5105 \\
\hline Total & 71638 & 79287 & 79527 & $\mathbf{8 1 3 5 5}$ \\
\hline Fonte: www.datasus gov.br_SIH & \multicolumn{4}{|c}{} \\
\hline
\end{tabular}

O volume mais significativo para 0 aumento do número de internações SUS foi de São Bernardo do Campo que no $1^{\circ}$ ano antes da implantação de gestão semi plena atendia 2.398 internações SUS/ano e passou a atender uma média de 5.067 internações SUS/ano após implantação, - que corresponde a um acréscimo de $111,30 \%$, seguido por Campinas (10,86\%) e Ribeirão Preto (4,71\%).

\subsubsection{Internações SUS e procedimentos}

Considerando as freqüências totais de internações SUS (onze Municipios) observou-se que os cinqüenta procedimentos de maior freqüência correspondem a $60,18 \%$ do total das ocorrências, considerando-se os períodos antes e depois. Antes da implantação da gestão semi plena atingiram $59,79 \%$ e $59,65 \%$ no terceiro ano de avaliação.

Conforme ○ "ranking" das freqüências de internações SUS por procedimentos, os oito primeiros correspondem à porcentagem acumulada de $52,02 \%$. Esses procedimentos, quando relacionados aos cinqüenta mais freqüentes no "ranking" e com a freqüência total de internações SUS no periodo, representam respectivamente: parto normal com atendimento a Recém Nascido $(16,97 \%$ e 10,22\%); cesariana com atendimento a Recém Nascido 
em Sala de parto $(11,44 \%$ e $6,89 \%)$; Diagnóstico e lou primeiro atendimento em Clínica Médica (6,12\% e 3,69\%); Curetagem pós aborto (4,82\% e 2,90\%); Parto normal $(3,94 \%$ e $2,37 \%)$; Insuficiência cardiaca $(3,75 \%$ e $2,26 \%)$; Diagnóstico e ou primeiro atendimento em clínica pediátrica $(2,65 \%$ e $1,59 \%)$; Acidente Vascular Cerebral agudo $(2,31 \%$ e $1,39 \%)$.

No Quadro 46, são apresentados esses resultados.

Destacam-se alguns eventos, que ao longo dos 4 anos observados apresentaram variações importantes no ranking de freqüência.

- 71300007 - Diagnóstico elou primeiro atendimento em Clinica Pediátrica $26^{\circ}$ lugar ( $1^{\circ}$ ano antes); $9^{\circ}$ lugar ( $1^{\circ}$ ano depois); $5^{\circ}\left(2^{\circ}\right.$ anos depois) e $5^{\circ}\left(3^{\circ}\right.$ ano depois)

- 43000002 - Diagnóstico e/ou primeiro atendimento em Clínica Cirúrgica - $30^{\circ}$ lugar ( $1^{\circ}$ ano antes); $11^{\circ}$ lugar ( $1^{\circ}$ ano depois); $8^{\circ}\left(2^{\circ}\right.$ ano depois) e $7^{\circ}$ lugar ( $3^{\circ}$ ano depois).

- 31000002 - Cirurgia Múltipla - $8^{\circ}$ lugar ( $1^{\circ}$ ano antes); $10^{\circ}\left(1^{\circ}\right.$ ano depois); $14^{\circ}\left(2^{\circ}\right.$ ano depois) e $20^{\circ}$ ( $3^{\circ}$ ano depois).

- 74300270 - Entero Infecções (Pediatria) - $16^{\circ}$ lugar ( $1^{\circ}$ ano antes); $22^{\circ}$ (1 ano depois); $38^{\circ}\left(2^{\circ}\right.$ ano depois) e $39^{\circ}$ ( $3^{\circ}$ ano depois).

- 77500121 - Crise Hipertensiva - $27^{\circ}$ lugar ( $1^{\circ}$ ano antes); $29^{\circ}\left(1^{\circ}\right.$ ano depois); $32^{\circ}$ lugar ( $2^{\circ}$ ano depois) e $29^{\circ}$ lugar ( $3^{\circ}$ ano depois). 
Quadro 46 - Totais anuais de internações SUS: 50 procedimentos mais freqüentes considerando-se os 11 Municipios, antes e depois da implantação da gestão semi-plena.

\begin{tabular}{|c|c|c|c|c|c|c|c|c|c|c|c|c|c|}
\hline \multirow{2}{*}{\multicolumn{2}{|c|}{ Procedimentos }} & \multirow{2}{*}{\multicolumn{4}{|c|}{ Total }} & \multirow{2}{*}{\multicolumn{2}{|c|}{$\begin{array}{l}\text { Antes } \\
1^{\circ} \text { ano }\end{array}$}} & \multicolumn{6}{|c|}{ Depois } \\
\hline & & & & & & & & \multicolumn{2}{|c|}{$1^{\circ}$ ano } & \multicolumn{2}{|c|}{$2^{\circ}$ ano } & \multicolumn{2}{|c|}{$3^{\circ}$ ano } \\
\hline Código & Descriçăo & Pos. & $\mathbf{N}$ & $\%$ & $\%$ ac & Pos. & $\mathbf{N}$ & Pos. & $\mathbf{N}$ & Pos. & $\mathbf{N}$ & Pos. & $\mathbf{N}$ \\
\hline 35021012 & PARTO NORMAL COM ATENDIMENTO RN SALA DE PARTO & 1 & 97969 & 16.97 & 16,97 & 1 & 26045 & 1 & 22793 & 1 & 23774 & 1 & 25357 \\
\hline 35022019 & CESARIANA COM ATENDIMENTO RN SALA DE PARTO & 2 & 66052 & 11,44 & 28,42 & 2 & 17605 & 2 & 16655 & 2 & 16247 & 2 & 15545 \\
\hline 72500000 & DIAGNOSTICO EIOU PRIMEIRO ATENDIMENTO EM CLINICA MEDICA & 3 & 35344 & 6,12 & 34,54 & 6 & 4766 & 4 & 7642 & 3 & 11700 & 3 & 11236 \\
\hline 35014016 & CURETAGEM POS-ABORTO & 4 & 27846 & 4,82 & 39,37 & 3 & 7884 & 5 & 7497 & 4 & 6248 & 4 & 6217 \\
\hline 35001011 & PARTO NORMAL & 5 & 22753 & 3,94 & 43,31 & 5 & 6546 & 3 & 9027 & 7 & 4284 & 10 & 2896 \\
\hline 77500113 & INSUFICIENCIA CARDIACA & 6 & 21649 & 3,75 & 47,06 & 4 & 6732 & 6 & 6047 & 6 & 4492 & 6 & 4378 \\
\hline 71300007 & DIAGNOSTICO EIOU PRIMEIRO ATENDIMENTO EM CLINICA PEDIATRICA & 7 & 15289 & 2,65 & 49,71 & 26 & 1754 & 9 & 3570 & 5 & 4979 & 5 & 4986 \\
\hline 81500106 & AVC AGUDO & 8 & 13335 & 2,31 & 52,02 & 7 & 4033 & 8 & 3573 & 11 & 2798 & 9 & 2931 \\
\hline 43000002 & DIAGNOSTICO E/OU PRIMEIRO ATENDIMENTO EM CLINICA CIRURGICA & 9 & 13022 & 2,26 & 54,28 & 30 & 1705 & 11 & 3092 & 8 & 4107 & 7 & 4118 \\
\hline 76300102 & CRISE ASMATICA & 10 & 11413 & 1,98 & 56,25 & 9 & 3026 & 14 & 2493 & 9 & 3053 & 11 & 2841 \\
\hline 31000002 & CIRURGIA MULTIPLA & 11 & 10880 & 1,89 & 58,14 & 8 & 3660 & 10 & 3522 & 14 & 1957 & 20 & 1741 \\
\hline 35009012 & CESARIANA & 12 & 9700 & 1,68 & 59,82 & 12 & 2750 & 7 & 4195 & 20 & 1770 & 40 & 985 \\
\hline 35024011 & PARTO COM MANOBRAS COM ATENDIMENTO RN SALA DE PARTO & 13 & 9662 & 1.67 & 61,49 & 31 & 1683 & 27 & 1813 & 10 & 2968 & 8 & 3198 \\
\hline 82500053 & DIABETE SACARINO & 14 & 9628 & 1,67 & 63,16 & 11 & 2754 & 13 & 2570 & 12 & 2158 & 13 & 2146 \\
\hline 76300080 & BRONCOPNEUMONIA & 15 & 9529 & 1,65 & 64,81 & 10 & 2794 & 16 & 2403 & 13 & 2121 & 12 & 2211 \\
\hline 70000000 & TRATAMENTO DA AIDS & 16 & 8667 & 1,50 & 66,31 & 13 & 2708 & 15 & 2423 & 18 & 1802 & 21 & 1734 \\
\hline 76400085 & BRONCOPNEUMONIA EM LACTENTE & 17 & 8643 & 1.50 & 67,81 & 15 & 2364 & 12 & 2593 & 15 & 1953 & 22 & 1733 \\
\hline 75500124 & HEMORRAGIAS DIGESTIVAS & 18 & 8188 & 1,42 & 69,23 & 14 & 2384 & 17 & 2205 & 17 & 1806 & 18 & 1793 \\
\hline 76500071 & BRONCOPNEUMONIA & 19 & 7726 & 1,34 & 70,57 & 23 & 1925 & 20 & 2137 & 23 & 1714 & 14 & 1950 \\
\hline 33011117 & HERNIORRAFIA INGUINAL(UNILATERAL) & 20 & 7712 & 1,34 & 71,90 & 17 & 2072 & 21 & 2076 & 16 & 1838 & 24 & 1726 \\
\hline 71300015 & PREMATURIDADE & 21 & 7553 & 1,31 & 73,21 & 20 & 1995 & 18 & 2159 & 24 & 1667 & 23 & 1732 \\
\hline 76300072 & OUTRAS PNEUMONIAS & 22 & 7359 & 1,28 & 74,49 & 19 & 2022 & 30 & 1753 & 21 & 1764 & 17 & 1820 \\
\hline 80500218 & OUTRAS AFECCOES DO AP. GENITO-URINARIO & 23 & 7298 & 1,26 & 75,75 & 25 & 1851 & 26 & 1815 & 22 & 1731 & 15 & 1901 \\
\hline 76500063 & PNEUMONIA NAO ESPECIFICADA & 24 & 7222 & 1,25 & 77,00 & 28 & 1731 & 23 & 1871 & 19 & 1777 & 16 & 1843 \\
\hline 40001008 & TRATAMENTO CONSERVADOR DO TRAUMATISMO CRANEO-ENCEFALICO & 25 & 6997 & 1,21 & 78,22 & 18 & 2033 & 19 & 2146 & 30 & 1390 & 28 & 1428 \\
\hline 76500225 & DOENCA PULMONAR OBSTRUTIVA CRONICA & 26 & 6922 & 1,20 & 79,42 & 24 & 1862 & 25 & 1852 & 25 & 1576 & 26 & 1632 \\
\hline 69000204 & TRABALHO DE PARTO PREMATURO & 27 & 6869 & 1,19 & 80,61 & 21 & 1965 & 24 & 1855 & 28 & 1474 & 27 & 1575 \\
\hline
\end{tabular}




\begin{tabular}{|c|c|c|c|c|c|c|c|c|c|c|c|c|c|}
\hline \multirow{2}{*}{\multicolumn{2}{|c|}{ Procedimentos }} & \multirow{2}{*}{\multicolumn{4}{|c|}{ Total }} & \multirow{2}{*}{\multicolumn{2}{|c|}{$\begin{array}{l}\text { Antes } \\
1^{\circ} \text { ano }\end{array}$}} & \multicolumn{6}{|c|}{ Depois } \\
\hline & & & & & & & & \multicolumn{2}{|c|}{$1^{\circ}$ ano } & \multicolumn{2}{|c|}{$2^{\circ}$ ano } & \multicolumn{2}{|c|}{$3^{\circ}$ ano } \\
\hline Código & Descriçăo & Pos. & $\mathbf{N}$ & $\%$ & $\%$ ac & Pos. & $\mathbf{N}$ & Pos. & $\mathbf{N}$ & Pos. & $\mathbf{N}$ & Pos. & $\mathbf{N}$ \\
\hline 74300270 & ENTERO-INFECCOES (PEDIATRIA) & 28 & 6466 & 1,12 & 81,73 & 16 & 2269 & 22 & 2013 & 38 & 1198 & 39 & 986 \\
\hline 33005060 & APENDICECTOMIA & 29 & 6230 & 1,08 & 82,81 & 38 & 1393 & 32 & 1589 & 26 & 1524 & 25 & 1724 \\
\hline 77500121 & CRISE HIPERTENSIVA & 30 & 6154 & 1,07 & 83,87 & 27 & 1745 & 29 & 1766 & 32 & 1260 & 29 & 1383 \\
\hline 33016119 & LAPAROTOMIA EXPLORADORA & 31 & 5853 & 1,01 & 84,89 & 36 & 1469 & 34 & 1529 & 27 & 1500 & 31 & 1355 \\
\hline 77500032 & INSUFICIENCIA CORONARIANA AGUDA & 32 & 5822 & 1,01 & 85,89 & 35 & 1541 & 31 & 1688 & 37 & 1210 & 30 & 1383 \\
\hline 39000001 & POLITRAUMATIZADO & 33 & 5756 & 1,00 & 86,89 & 32 & 1672 & 35 & 1520 & 33 & 1259 & 33 & 1305 \\
\hline 33004080 & COLECISTECTOMIA & 34 & 5662 & 0,98 & 87,87 & 37 & 1403 & 33 & 1545 & 29 & 1425 & 34 & 1289 \\
\hline 80500072 & PIELONEFRITES & 35 & 5461 & 0,95 & 88,82 & 39 & 1377 & 37 & 1425 & 31 & 1318 & 32 & 1341 \\
\hline 34005030 & CURETAGEM SEMIOTICA COM OU SEM DILATACAO DE COLO & 36 & 5377 & 0,93 & 89,75 & 29 & 1722 & 38 & 1370 & 36 & 1241 & 37 & 1044 \\
\hline 91904013 & TRATAMENTO DE AIDS EM HOSPITAL DIA & 37 & 5128 & 0,89 & 90,64 & 48 & 950 & 42 & 1178 & 35 & 1251 & 19 & 1749 \\
\hline 76400271 & ENTERO-INFECCOES EM LACTENTE & 38 & 4980 & 0,86 & 91,50 & 22 & 1940 & 36 & 1494 & 43 & 914 & 49 & 632 \\
\hline 76300188 & INSUFICIENCIA RESPIRATORIA AGUDA & 39 & 4950 & 0,86 & 92,36 & 33 & 1646 & 28 & 1813 & 46 & 886 & 50 & 605 \\
\hline 77500024 & INFARTO AGUDO DO MIOCARDIO & 40 & 4897 & 0,85 & 93,21 & 42 & 1137 & 41 & 1274 & 34 & 1255 & 35 & 1231 \\
\hline 76500233 & INSUFICIENCIA RESPIRATORIA AGUDA & 41 & 4866 & 0,84 & 94,05 & 34 & 1615 & 39 & 1296 & 42 & 981 & 41 & 974 \\
\hline 80500170 & INSUFICIENCIA RENAL CRONICA AACIDOSE METABOLICA & 42 & 4305 & 0,75 & 94,80 & 40 & 1355 & 43 & 1163 & 41 & 983 & 44 & 804 \\
\hline 81500076 & EPILEPSIAS & 43 & 4199 & 0,73 & 95,52 & 47 & 988 & 44 & 1162 & 40 & 1036 & 38 & 1013 \\
\hline 75500213 & CIRROSE HEPATICA & 44 & 3811 & 0,66 & 96,18 & 43 & 1129 & 47 & 1087 & 50 & 828 & 47 & 767 \\
\hline 34008020 & COLPOPERINEOPLASTIA ANTERIOR E POSTERIOR & 45 & 3771 & 0,65 & 96,84 & 41 & 1145 & 49 & 928 & 44 & 910 & 45 & 788 \\
\hline 91500079 & TRAUMATISMOS CRANIOENCEFALICO & 46 & 3747 & 0,65 & 97,49 & 45 & 1003 & 46 & 1089 & 49 & 830 & 43 & 825 \\
\hline 76400077 & PNEUMONIAS DO LACTENTE & 47 & 3682 & 0,64 & 98,13 & 44 & 1011 & 48 & 1032 & 48 & 862 & 46 & 777 \\
\hline 69000115 & AMEACA DE ABORTO & 48 & 3666 & 0,64 & 98,76 & 46 & 991 & 45 & 1127 & 47 & 879 & 48 & 669 \\
\hline 76500128 & CRISE ASMATICA & 49 & 3659 & 0,63 & 99,39 & 49 & 940 & 50 & 867 & 45 & 890 & 42 & 962 \\
\hline 35025018 & PARTO NORMAL - EXCLUSIVAMENTE PARA HOSPITAIS AMIGOS DA CRIANCA & 50 & 3495 & 0,61 & 100,00 & 50 & 41 & 40 & 1291 & 39 & 1063 & 36 & 1100 \\
\hline & Sub-Total & & 577164 & 60,18 & & & 149131 & & 153023 & & 138651 & & 136359 \\
\hline & Outros & & 381828 & 39,82 & & & 100304 & & 98937 & & 90336 & & 92251 \\
\hline & Total & & 958992 & 100,00 & & & 249435 & & 251960 & & 228987 & & 228610 \\
\hline
\end{tabular}


Delimitando a análise aos 8 (oito) procedimentos mais freqüentes observamos que:

- Parto normal com atendimento Recém Nascido em Sala de parto e Cesariana com atendimento Recém Nascido em Sala de parto mantiveram a $1^{\mathrm{a}}$ e $2^{\mathrm{a}}$ posição, antes e depois da implantação da gestão semi plena, portanto, não houve alteração;

- Diagnóstico de primeiro atendimento em Clínica Médica, encontrava-se classificado na $6^{a}$ posição após a implantação da gestão semi plena, especificamente, no $3^{\circ}$ ano passou para a $3^{a}$ posição;

- Curetagem pós-aborto, antes ocupava a $3^{a}$ posição e depois caiu para $4^{\mathrm{a}}$ posição; a $5^{\mathrm{a}}$ posição no "ranking" nos procedimentos mais freqüentes foi ocupada pelos Partos normais que após a implantação da gestão semi plena passou a ocupar a $10^{a}$ posição;

- Insuficiência cardíaca, antes da implantação da gestão semi plena ocupava a $4^{\mathrm{a}}$ posição, após caiu para a $6^{\mathrm{a}}$ posição;

- Diagnóstico e ou primeiro atendimento em clínica pediátrica, antes ocupava a $26^{a}$ posição e após passou a ocupar a $5^{a}$ posição;

- Acidente Vascular Cerebral agudo, antes da implantação da gestão semi plena ocupava a $7^{a}$ posição e depois passou a ocupar a 9a posição.

Os dez primeiros procedimentos mais freqüentes corresponderam a $52,44 \%$ do total das internações SUS no Municipio de Assis, conforme mostra o Quadro 47. O procedimento mais freqüente foi Cesariana com atendimento ao RN na sala de parto, que se considerarmos o "ranking" dos cinqüenta (50) procedimentos corresponde a $14,90 \%$ do total das internações SUS realizadas e $9,73 \%$ se considerarmos o total geral das internações SUS do Município. As 
demais posições seqüencialmente foram ocupadas por: Insuficiência cardiaca $(7,50 \% ; 4,90 \%)$; Entero infecções (Pediatria) $(6,41 \% ; 4,18 \%)$, Crise asmática $(5,32 \%, 0,47 \%)$; Parto normal com atendimento ao RN na sala de parto $(3,68 \%$; $2,40 \%)$; Acidente Vascular Cerebral agudo $(3,56 \% ; 2,32 \%)$, Bronco Pneumonia $(3,18 \% ; 2,07 \%)$; Outras afecções do aparelho geniturinário $(2,75 \% ; 1,79 \%)$; Entero infecções em lactentes $(2,60 \% ; 1,70 \%)$ outras pneumonias $(2,55 \%$ e $1,66 \%)$.

Observou-se nesse Quadro eventos de freqüências dispersas que merecem estudo em nivel local a exemplo citamos: Diagnóstico e/ou primeiro atendimento em clínica cirúrgica (cód. 43000002) antes estava em $30^{a}$ posição, no $1^{\circ}$ ano caiu para $11^{a}$, no $2^{\circ}$ ano para $8^{a}$ posição e no $3^{\circ}$ ano para $7^{a}$ posição. Diagnóstico e/ou primeiro atendimento em clínica pediátrica (cód. 71300007) antes estava em $26^{a}$ posição, no $1^{\circ}$ ano caiu para $9^{a}$, no $2^{\circ}$ e $3^{\circ}$ ano para $5^{a}$ posição. Cirurgia múltipla (cód. 31000002) antes estava em $8^{a}$ posição, no $1^{\circ}$ ano caiu para $10^{a}$, no $2^{\circ}$ ano para $14^{a}$ posição e no $3^{\circ}$ ano para $20^{a}$ posição.

Assis - Não houve alteração após a implantação da gestão semi plena, das $1^{a}$ e $2^{a}$ posições (cesarianas e insuficiência cardiaca, no Município de Assis). As entero infecções em Pediatria antes da implantação da gestão semi plena ocupavam a $3^{a}$ posição e depois passaram para a $4^{a}$ posição; crise asmática, ocupava a $4^{a}$ e passou para a $3^{a}$ posição; parto normal, antes ocupava a $7^{a}$ posição e passou para $5^{\mathrm{a}}$ posição; Acidente Vascular Cerebral agudo ocupava a $5^{\mathrm{a}}$ posição, antes e passou para a $6^{\mathrm{a}}$ depois; Bronco pneumonia ocupava a $9^{\mathrm{a}}$ posição e subiu para $7^{a}$ posição; outras afecções do aparelho geniturinário ocupavam a $6^{a}$ posição e foram para a $12^{a}$ depois; outras infecções em lactentes ocupavam a $8^{a}$ posição e passaram para a $16^{a}$ posição depois da implantação; outras pneumonias, antes da implantação da gestão semi plena, ocupavam a $11^{\mathrm{a}}$ posição e passaram para a $10^{\mathrm{a}}$ posição. Consideramos para essas avaliações o terceiro ano da gestão semi plena no Município, conforme Quadro 47. 
Quadro 47 - Totais anuais de internaçöes SUS pelos 50 procedimentos mais freqüentes, ocorridos no Municipio de Assis - SP, antes e depois da implantação da gestão semi-plena.

\begin{tabular}{|c|c|c|c|c|c|c|c|c|c|c|c|c|c|}
\hline \multirow{2}{*}{\multicolumn{2}{|c|}{ Procedimentos }} & \multirow{2}{*}{\multicolumn{4}{|c|}{ Total }} & \multirow{2}{*}{\multicolumn{2}{|c|}{$\begin{array}{l}\text { Antes } \\
1^{\circ} \text { ano }\end{array}$}} & \multicolumn{6}{|c|}{ Depois } \\
\hline & & & & & & & & \multicolumn{2}{|c|}{$1^{\circ}$ ano } & \multicolumn{2}{|c|}{$2^{\circ}$ ano } & \multicolumn{2}{|c|}{$3^{\circ}$ ano } \\
\hline Código & Descrição & Pos. & $\mathbf{N}$ & $\%$ & $\%$ ac & Pos. & $\mathbf{N}$ & Pos. & $\mathbf{N}$ & Pos. & $\mathbf{N}$ & Pos. & $\mathbf{N}$ \\
\hline 35022019 & CESARIANA COM ATENDIMENTO RN SALA DE PARTO & 1 & 4995 & 14,90 & 14,90 & 1 & 1240 & 1 & 1246 & 1 & 1270 & 1 & 1239 \\
\hline 77500113 & INSUFICIENCIA CARDIACA & 2 & 2513 & 7,50 & 22,40 & 2 & 793 & 2 & 756 & 2 & 588 & 2 & 376 \\
\hline 74300270 & ENTERO-INFECCOES (PEDIATRIA) & 3 & 2148 & 6,41 & 28,81 & 3 & 724 & 3 & 675 & 4 & 420 & 4 & 329 \\
\hline 76300102 & CRISE ASMATICA & 4 & 1783 & 5,32 & 34,13 & 4 & 621 & 4 & 388 & 3 & 444 & 3 & 330 \\
\hline 35021012 & PARTO NORMAL COM ATENDIMENTO RN SALA DE PARTO & 5 & 1232 & 3,68 & 37,80 & 7 & 335 & 6 & 324 & 5 & 287 & 5 & 286 \\
\hline 81500106 & AVC AGUDO & 6 & 1192 & 3,56 & 41,36 & 5 & 373 & 5 & 327 & 6 & 253 & 6 & 239 \\
\hline 76300080 & BRONCOPNEUMONIA & 7 & 1065 & 3,18 & 44,54 & 9 & 330 & 7 & 306 & 7 & 211 & 7 & 218 \\
\hline 80500218 & OUTRAS AFECCOES DO AP. GENITO-URINARIO & 8 & 921 & 2,75 & 47,29 & 6 & 366 & 11 & 227 & 10 & 190 & 12 & 138 \\
\hline 76400271 & ENTERO-INFECCOES EM LACTENTE & 9 & 873 & 2,60 & 49,89 & 8 & 333 & 8 & 268 & 14 & 164 & 16 & 108 \\
\hline 76300072 & OUTRAS PNEUMONIAS & 10 & 854 & 2,55 & 52,44 & 11 & 289 & 10 & 228 & 13 & 169 & 10 & 168 \\
\hline 80500072 & PIELONEFRITES & 11 & 849 & 2,53 & 54,97 & 12 & 268 & 9 & 262 & 9 & 203 & 14 & 116 \\
\hline 74500252 & ENTERO-INFECCOES (CLINICA MEDICA) & 12 & 712 & 2,12 & 57,09 & 10 & 326 & 12 & 219 & 22 & 116 & 37 & 51 \\
\hline 82500053 & DIABETE SACARINO & 13 & 672 & 2,00 & 59,10 & 14 & 213 & 13 & 200 & 15 & 150 & 15 & 109 \\
\hline 76500071 & BRONCOPNEUMONIA & 14 & 665 & 1,98 & 61,08 & 13 & 223 & 14 & 176 & 16 & 148 & 13 & 118 \\
\hline 76500063 & PNEUMONIA NAO ESPECIFICADA & 15 & 628 & 1,87 & 62,96 & 15 & 180 & 16 & 160 & 11 & 182 & 17 & 106 \\
\hline 35014016 & CURETAGEM POS-ABORTO & 16 & 608 & 1,81 & 64,77 & 16 & 172 & 23 & 122 & 12 & 175 & 11 & 139 \\
\hline 76500225 & DOENCA PULMONAR OBSTRUTIVA CRONICA & 17 & 577 & 1,72 & 66,49 & 25 & 132 & 19 & 143 & 8 & 210 & 19 & 92 \\
\hline 38025019 & PERDA SUBST CUTANEA-LESOES EXTENSAS PLANOS SUPER. & 18 & 541 & 1,61 & 68,11 & 23 & 138 & 32 & 90 & 20 & 126 & 9 & 187 \\
\hline 75500124 & HEMORRAGIAS DIGESTIVAS & 19 & 540 & 1,61 & 69,72 & 18 & 165 & 18 & 152 & 17 & 142 & 23 & 81 \\
\hline 77500121 & CRISE HIPERTENSIVA & 20 & 536 & 1,60 & 71,32 & 17 & 167 & 17 & 152 & 21 & 121 & 18 & 96 \\
\hline 76400085 & BRONCOPNEUMONIA EM LACTENTE & 21 & 530 & 1,58 & 72,90 & 21 & 156 & 15 & 176 & 24 & 109 & 21 & 89 \\
\hline 81500076 & EPILEPSIAS & 22 & 488 & 1,46 & 74,35 & 22 & 143 & 20 & 137 & 19 & 130 & 24 & 78 \\
\hline 76500128 & CRISE ASMATICA & 23 & 471 & 1,41 & 75,76 & 20 & 158 & 24 & 113 & 23 & 116 & 22 & 84 \\
\hline 72500000 & DIAGNOSTICO EIOU PRIMEIRO ATENDIMENTO EM CLINICA MEDICA & 24 & 418 & 1,25 & 77,01 & 50 & 31 & 48 & 52 & 18 & 133 & 8 & 202 \\
\hline 33011117 & HERNIORRAFIA INGUINAL(UNILATERAL) & 25 & 386 & 1,15 & 78,16 & 29 & 118 & 25 & 111 & 26 & 100 & 35 & 57 \\
\hline
\end{tabular}




\begin{tabular}{|c|c|c|c|c|c|c|c|c|c|c|c|c|c|}
\hline \multirow{2}{*}{\multicolumn{2}{|c|}{ Procedimentos }} & \multirow{2}{*}{\multicolumn{4}{|c|}{ Total }} & \multirow{2}{*}{\multicolumn{2}{|c|}{$\begin{array}{l}\text { Antes } \\
1^{\circ} \text { ano }\end{array}$}} & \multicolumn{6}{|c|}{ Depois } \\
\hline & & & & & & & & \multicolumn{2}{|c|}{$1^{\circ}$ ano } & \multicolumn{2}{|c|}{$2^{\circ}$ ano } & \multicolumn{2}{|c|}{$3^{\circ}$ ano } \\
\hline Código & Descrição & Pos. & $\mathbf{N}$ & $\%$ & $\%$ ac & Pos. & $\mathbf{N}$ & Pos. & $\mathbf{N}$ & Pos. & $\mathbf{N}$ & Pos. & $\mathbf{N}$ \\
\hline 91500079 & TRAUMATISMOS CRANIOENCEFALICO & 26 & 363 & 1,08 & 79,24 & 36 & 96 & 22 & 127 & 27 & 94 & 42 & 46 \\
\hline 70000000 & TRATAMENTO DA AIDS & 27 & 361 & 1,08 & 80,32 & 26 & 124 & 28 & 97 & 33 & 72 & 30 & 68 \\
\hline 76400077 & PNEUMONIAS DO LACTENTE & 28 & 352 & 1,05 & 81,37 & 39 & 87 & 21 & 133 & 42 & 58 & 28 & 74 \\
\hline 69000115 & AMEACA DE ABORTO & 29 & 347 & 1,04 & 82,40 & 24 & 133 & 39 & 75 & 45 & 50 & 20 & 89 \\
\hline 77500032 & INSUFICIENCIA CORONARIANA AGUDA & 30 & 316 & 0,94 & 83,35 & 30 & 118 & 43 & 70 & 32 & 78 & 38 & 50 \\
\hline 34008020 & COLPOPERINEOPLASTIA ANTERIOR E POSTERIOR & 31 & 309 & 0,92 & 84,27 & 19 & 158 & 50 & 47 & 44 & 52 & 36 & 52 \\
\hline 71300015 & PREMATURIDADE & 32 & 308 & 0,92 & 85,19 & 46 & 57 & 26 & 105 & 35 & 71 & 27 & 75 \\
\hline 76500233 & INSUFICIENCIA RESPIRATORIA AGUDA & 33 & 303 & 0,90 & 86,09 & 34 & 99 & 46 & 57 & 31 & 82 & 32 & 65 \\
\hline 35009012 & CESARIANA & 34 & 301 & 0,90 & 86,99 & 49 & 38 & 30 & 94 & 25 & 107 & 33 & 62 \\
\hline 75500035 & GASTRITE E DUODENITE & 35 & 296 & 0,88 & 87,87 & 37 & 94 & 38 & 76 & 36 & 67 & 34 & 59 \\
\hline 80500110 & COLICA NEFRETICA & 36 & 295 & 0,88 & 88,75 & 28 & 122 & 29 & 94 & 47 & 47 & 46 & 32 \\
\hline 77500024 & INFARTO AGUDO DO MIOCARDIO & 37 & 292 & 0,87 & 89,62 & 44 & 77 & 37 & 81 & 28 & 87 & 40 & 47 \\
\hline 77500180 & ARRITIMIAS & 38 & 291 & 0,87 & 90,49 & 43 & 82 & 31 & 90 & 34 & 72 & 41 & 47 \\
\hline 39024083 & REDUCAO INCRUENTA DAS FRATURAS DOS OSSOS DO ANTE-B & 39 & 287 & 0,86 & 91,35 & 47 & 53 & 41 & 72 & 29 & 85 & 25 & 77 \\
\hline 34005030 & CURETAGEM SEMIOTICA COM OU SEM DILATACAO DE COLO & 40 & 280 & 0,84 & 92,18 & 33 & 100 & 45 & 69 & 38 & 64 & 39 & 47 \\
\hline 75500272 & COLICISTITE AGUDA & 41 & 280 & 0,84 & 93,02 & 32 & 103 & 27 & 99 & 46 & 49 & 47 & 29 \\
\hline 76300021 & LARINGOTRAQUEOBRONQUITE & 42 & 275 & 0,82 & 93,84 & 31 & 104 & 47 & 53 & 30 & 82 & 44 & 36 \\
\hline 69000018 & INFECCAO DO APARELHO GENITAL DURANTE GRAVIDEZ & 43 & 273 & 0,81 & 94,65 & 45 & 74 & 44 & 69 & 41 & 61 & 29 & 69 \\
\hline 38023016 & EXTIRPACAO E SUPRESS. DE LESAO DA PELE E DO TECIDO & 44 & 263 & 0,78 & 95,44 & 27 & 122 & 35 & 83 & 50 & 33 & 48 & 25 \\
\hline 75500027 & ULCERA PEPTICA & 45 & 260 & 0,78 & 96,21 & 41 & 82 & 33 & 88 & 43 & 56 & 45 & 34 \\
\hline 77500202 & NASCULOPATIAS PERIFERICAS & 46 & 256 & 0,76 & 96,98 & 35 & 98 & 42 & 71 & 40 & 63 & 50 & 24 \\
\hline 69000204 & TRABALHO DE PARTO PREMATURO & 47 & 255 & 0,76 & 97,74 & 38 & 87 & 49 & 50 & 49 & 43 & 26 & 75 \\
\hline 75500213 & CIRROSE HEPATICA & 48 & 255 & 0,76 & 98,50 & 42 & 82 & 34 & 85 & 39 & 64 & 49 & 24 \\
\hline 80500170 & INSUFICIENCIA RENAL CRONICA AACIDOSE METABOLICA & 49 & 252 & 0,75 & 99,25 & 40 & 85 & 36 & 82 & 48 & 46 & 43 & 39 \\
\hline 33005060 & APENDICECTOMIA & 50 & 251 & 0,75 & 100,00 & 48 & 46 & 40 & 75 & 37 & 64 & 31 & 66 \\
\hline & Sub-Total & & 33518 & 65,29 & & & 10315 & & 9052 & & 7804 & & 6347 \\
\hline & Outros & & 17819 & 34,71 & & & 5673 & & 4600 & & 4089 & & 3457 \\
\hline & Total & & 51337 & 100,00 & & & 15988 & & 13652 & & 11893 & & 9804 \\
\hline
\end{tabular}


Destacam-se com variação:

- 72500000 - Diagnóstico e ou Primeiro Atendimento em Clínica Médica - $50^{\circ}$ lugar ( $1^{\circ}$ ano antes); $48^{\circ}\left(1^{\circ}\right.$ ano depois); $18^{\circ}\left(2^{\circ}\right.$ ano depois); $8^{\circ}$ ( $3^{\circ}$ ano depois).

- 76400271 - Entero Infecções em Lactente - $8^{\circ}$ lugar ( $1^{\circ}$ ano antes); $8^{\circ}$ ( $1^{\circ}$ ano depois); $14^{\circ}\left(2^{\circ}\right.$ ano depois) e $16^{\circ}$ lugar ( $3^{\circ}$ ano depois).

- 69000115 - Ameaça de Aborto $-24^{\circ}$ lugar ( $1^{\circ}$ ano antes); $39^{\circ}\left(1^{\circ}\right.$ ano depois); $45^{\circ}$ ( $2^{\circ}$ ano depois) e $20^{\circ}$ lugar ( $3^{\circ}$ ano depois).

- 71300015 - Prematuridade $-46^{\circ}$ lugar ( $1^{\circ}$ ano antes); $26^{\circ}\left(1^{\circ}\right.$ ano depois); $35^{\circ}$ ( $2^{\circ}$ ano depois) e $27^{\circ}$ lugar ( $3^{\circ}$ ano depois).

Campinas - Os 50 procedimentos mais freqüentes corresponderam a $57,68 \%$ do total das internações SUS realizadas no Município, sendo que antes da implantação da gestão semi plena representaram $56,00 \%$ das internações SUS e $59,68 \%, 58,09 \%$ e $56,87 \%$ nos três anos após, respectivamente. (Quadro 48)

Destacam-se com variação:

- 81500106 - AVC Agudo - $9^{\circ}$ lugar ( $1^{\circ}$ ano antes); $13^{\circ}\left(1^{\circ}\right.$ ano depois); $19^{\circ}$ ( $2^{\circ}$ ano depois); $18^{\circ}$ ( $3^{\circ}$ ano depois).

- 71300015 - Prematuridade $-18^{\circ}$ lugar ( $1^{\circ}$ ano antes); $15^{\circ}\left(1^{\circ}\right.$ ano depois); $12^{\circ}$ ( $2^{\circ}$ ano depois); $26^{\circ}$ ( $3^{\circ}$ ano depois).

- 85500712 - Diagnóstico de Tumor Maligno - $50^{\circ}$ lugar ( $1^{\circ}$ ano antes); $17^{\circ}$ ( $1^{\circ}$ ano depois); $15^{\circ}$ ( $2^{\circ}$ ano depois); $10^{\circ}\left(3^{\circ}\right.$ ano depois).

- 70000000 - Tratamento da AIDS - $14^{\circ}$ lugar ( $1^{\circ}$ ano antes); $23^{\circ}$ ( $1^{\circ}$ ano depois); $26^{\circ}\left(2^{\circ}\right.$ ano depois); $27^{\circ}$ ( $3^{\circ}$ ano depois). 
Quadro 48 - Totais anuais de internaçōes SUS pelos 50 procedimentos mais freqüentes, ocorridos no Município de Campinas - SP, antes e depois da implantação da gestāo semi-plena.

\begin{tabular}{|c|c|c|c|c|c|c|c|c|c|c|c|c|c|}
\hline \multirow{2}{*}{\multicolumn{2}{|c|}{ Procedimentos }} & \multirow{2}{*}{\multicolumn{4}{|c|}{ Total }} & \multirow{2}{*}{\multicolumn{2}{|c|}{$\begin{array}{l}\text { Antes } \\
1^{\circ} \text { ano }\end{array}$}} & \multicolumn{6}{|c|}{ Depois } \\
\hline & & & & & & & & \multicolumn{2}{|c|}{$1^{\circ}$ ano } & \multicolumn{2}{|c|}{$2^{\circ}$ ano } & \multicolumn{2}{|c|}{$3^{\circ}$ ano } \\
\hline Código & Descriçăo & Pos. & $\mathbf{N}$ & $\%$ & $\%$ ac & Pos. & $\mathbf{N}$ & Pos. & $\mathbf{N}$ & Pos. & $\mathbf{N}$ & Pos. & $\mathbf{N}$ \\
\hline 35021012 & PARTO NORMAL COM ATENDIMENTO RN SALA DE PARTO & 1 & 25932 & 17,37 & 17,37 & 1 & 6808 & 1 & 6913 & 1 & 6221 & 1 & 5990 \\
\hline 35022019 & CESARIANA COM ATENDIMENTO RN SALA DE PARTO & 2 & 19128 & 12,81 & 30,18 & 2 & 4689 & 2 & 5055 & 2 & 4968 & 2 & 4416 \\
\hline 72500000 & DIAGNOSTICO EIOU PRIMEIRO ATENDIMENTO EM CLINICA med & 3 & 11668 & 7,81 & 37,99 & 3 & 2398 & 3 & 3475 & 3 & 3036 & 3 & 2759 \\
\hline 35024011 & PARTO COM MANOBRAS COM ATENDIMENTO RN SALA DE PA & 4 & 7099 & 4,75 & 42,75 & 6 & 1110 & 7 & 1252 & 4 & 2488 & 4 & 2249 \\
\hline 35014016 & CURETAGEM POS-ABORTO & 5 & 6138 & 4,11 & 46,86 & 4 & 1514 & 5 & 1545 & 6 & 1517 & 5 & 1562 \\
\hline 43000002 & DIAGNOSTICO E/OU PRIMEIRO ATENDIMENTO EM CLINICA cir & 6 & 5475 & 3,67 & 50,52 & 12 & 638 & 4 & 1793 & 5 & 1736 & 6 & 1308 \\
\hline 71300007 & DIAGNOSTICO E/OU PRIMEIRO ATENDIMENTO EM CLINICA & 7 & 3876 & 2,60 & 53,12 & 13 & 603 & 6 & 1384 & 7 & 1094 & 9 & 795 \\
\hline 77500113 & INSUFICIENCIA CARDIACA & 8 & 3874 & 2,59 & 55,71 & 5 & 1124 & 8 & 1001 & 8 & 910 & 8 & 839 \\
\hline 91904013 & TRATAMENTO DE AIDS EM HOSPITAL DIA & 9 & 3829 & 2,56 & 58,28 & 7 & 873 & 9 & 998 & 10 & 818 & 7 & 1140 \\
\hline 33016119 & LAPAROTOMIA EXPLORADORA & 10 & 3137 & 2,10 & 60,38 & 8 & 806 & 10 & 786 & 9 & 863 & 11 & 682 \\
\hline 82500053 & DIABETE SACARINO & 11 & 2557 & 1,71 & 62,09 & 10 & 690 & 12 & 603 & 11 & 649 & 12 & 615 \\
\hline 69000204 & TRABALHO DE PARTO PREMATURO & 12 & 2406 & 1,61 & 63,70 & 11 & 671 & 11 & 645 & 13 & 557 & 16 & 533 \\
\hline 81500106 & AVC AGUDO & 13 & 2287 & 1,53 & 65,24 & 9 & 734 & 13 & 563 & 19 & 485 & 18 & 505 \\
\hline 76500071 & BRONCOPNEUMONIA & 14 & 2166 & 1,45 & 66,69 & 15 & 541 & 16 & 523 & 17 & 514 & 13 & 588 \\
\hline 76300072 & OUTRAS PNEUMONIAS & 15 & 2031 & 1,36 & 68,05 & 21 & 474 & 18 & 501 & 16 & 540 & 17 & 516 \\
\hline 33004080 & COLECISTECTOMIA & 16 & 1994 & 1,34 & 69,38 & 23 & 454 & 14 & 533 & 14 & 556 & 21 & 451 \\
\hline 71300015 & PREMATURIDADE & 17 & 1987 & 1,33 & 70,71 & 18 & 489 & 15 & 530 & 12 & 566 & 26 & 402 \\
\hline 34005030 & CURETAGEM SEMIOTICA COM OU SEM DILATACAO DE COLO & 18 & 1945 & 1,30 & 72,01 & 16 & 533 & 19 & 483 & 18 & 487 & 22 & 442 \\
\hline 85500712 & DIAGNOSTICO DE TUMOR MALIGNO & 19 & 1832 & 1,23 & 73,24 & 50 & 78 & 17 & 516 & 15 & 548 & 10 & 690 \\
\hline 75500124 & HEMORRAGIAS DIGESTIVAS & 20 & 1805 & 1,21 & 74,45 & 17 & 494 & 22 & 426 & 24 & 433 & 20 & 452 \\
\hline 33005060 & APENDICECTOMIA & 21 & 1803 & 1,21 & 75,66 & 26 & 395 & 20 & 473 & 20 & 454 & 19 & 481 \\
\hline
\end{tabular}


Quadro 48 - Continuação

\begin{tabular}{|c|c|c|c|c|c|c|c|c|c|c|c|c|c|}
\hline \multirow{2}{*}{\multicolumn{2}{|c|}{ Procedimentos }} & \multirow{2}{*}{\multicolumn{4}{|c|}{ Total }} & \multirow{2}{*}{\multicolumn{2}{|c|}{$\begin{array}{l}\text { Antes } \\
1^{\circ} \text { ano }\end{array}$}} & \multicolumn{6}{|c|}{ Depois } \\
\hline & & & & & & & & \multicolumn{2}{|c|}{$1^{\circ}$ ano } & \multicolumn{2}{|c|}{$2^{\circ}$ ano } & \multicolumn{2}{|c|}{$3^{\circ}$ ano } \\
\hline Código & \begin{tabular}{|c|} 
Descriçāo \\
\end{tabular} & Pos. & $\mathbf{N}$ & $\%$ & $\%$ ac & Pos. & $\mathbf{N}$ & Pos. & $N$ & Pos. & $\mathbf{N}$ & Pos. & $\mathbf{N}$ \\
\hline 80500218 & OUTRAS AFECCOES DO AP. GENITO-URINARIO & 22 & 1784 & 1,19 & 76,85 & 25 & 398 & 24 & 372 & 23 & 436 & 15 & 578 \\
\hline 70000000 & TRATAMENTO DA AIDS & 23 & 1702 & 1,14 & 77,99 & 14 & 565 & 23 & 388 & 26 & 373 & 27 & 376 \\
\hline 77500024 & INFARTO AGUDO DO MIOCARDIO & 24 & 1524 & 1,02 & 79,01 & 35 & 307 & 26 & 354 & 21 & 445 & 24 & 418 \\
\hline 80500170 & INSUFICIENCIA RENAL CRONICA AACIDOSE METABOLICA & 25 & 1506 & 1,01 & 80,02 & 20 & 477 & 21 & 444 & 27 & 368 & 45 & 217 \\
\hline 38011018 & SUTURA DE FERIDA COM OU SEM DEBRIDAMENTO & 26 & 1444 & 0,97 & 80,99 & 31 & 334 & 31 & 330 & 29 & 357 & 23 & 423 \\
\hline 76300102 & CRISE ASMATICA & 27 & 1438 & 0,96 & 81,95 & 34 & 320 & 33 & 314 & 22 & 441 & 29 & 363 \\
\hline 34001042 & SALPINGECTOMIA UNI OU BILATERAL & 28 & 1436 & 0,96 & 82,91 & 30 & 345 & 50 & 178 & 37 & 330 & 14 & 583 \\
\hline 33011117 & HERNIORRAFIA INGUINAL(UNILATERAL) & 29 & 1424 & 0,95 & 83,87 & 19 & 485 & 25 & 363 & 33 & 339 & 42 & 237 \\
\hline 34008020 & COLPOPERINEOPLASTIA ANTERIOR E POSTERIOR & 30 & 1363 & 0,91 & 84,78 & 27 & 394 & 40 & 277 & 25 & 411 & 38 & 281 \\
\hline 76300188 & INSUFICIENCIA RESPIRATORIA AGUDA & 31 & 1345 & 0,90 & 85,68 & 33 & 324 & 28 & 347 & 31 & 344 & 32 & 330 \\
\hline 76500063 & PNEUMONIA NAO ESPECIFICADA & 32 & 1327 & 0,89 & 86,57 & 39 & 290 & 27 & 349 & 34 & 339 & 30 & 349 \\
\hline 91500125 & LESOES SUPERFICIAIS INFECTADAS & 33 & 1316 & 0,88 & 87,45 & 37 & 291 & 32 & 316 & 40 & 303 & 25 & 406 \\
\hline 42002079 & EXTIRPACAO DE TUMOR OU ADENOMA & 34 & 1287 & 0,86 & 88,31 & 28 & 356 & 36 & 305 & 30 & 346 & 39 & 280 \\
\hline 31000002 & CIRURGIA MULTIPLA & 35 & 1275 & 0,85 & 89,17 & 45 & 225 & 30 & 343 & 35 & 335 & 28 & 372 \\
\hline 42008069 & TORACOTOMIA COM DRENAGEM FECHADA & 36 & 1239 & 0,83 & 90,00 & 38 & 291 & 35 & 306 & 38 & 329 & 35 & 313 \\
\hline 77500032 & INSUFICIENCIA CORONARIANA AGUDA & 37 & 1203 & 0,81 & 90,80 & 42 & 268 & 39 & 294 & 41 & 298 & 31 & 343 \\
\hline 76500225 & DOENCA PULMONAR OBSTRUTIVA CRONICA & 38 & 1202 & 0,81 & 91,61 & 36 & 304 & 38 & 302 & 44 & 268 & 33 & 328 \\
\hline 34010033 & HISTERECTOMIA TOTAL & 39 & 1196 & 0.80 & 92,41 & 43 & 260 & 41 & 270 & 32 & 344 & 34 & 322 \\
\hline 36005045 & FACECTOMIA COM LENTE INTRA-OCULAR & 40 & 1187 & 0,79 & 93,20 & 24 & 442 & 34 & 308 & 28 & 362 & 50 & 75 \\
\hline 76300080 & BRONCOPNEUMONIA & 41 & 1183 & 0,79 & 94,00 & 22 & 471 & 44 & 247 & 45 & 246 & 44 & 219 \\
\hline 31005055 & RESSECCAO ENDOSCOPICA DA PROSTATA & 42 & 1177 & 0,79 & 94,78 & 40 & 285 & 29 & 344 & 36 & 333 & 46 & 215 \\
\hline 91500079 & TRAUMATISMOS CRANIOENCEFALICO & 43 & 1161 & 0,78 & 95,56 & 29 & 351 & 37 & 303 & 43 & 283 & 43 & 224 \\
\hline 80500072 & PIELONEFRITES & 44 & 1059 & 0,71 & 96,27 & 47 & 208 & 43 & 255 & 42 & 294 & 36 & 302 \\
\hline 77500121 & CRISE HIPERTENSIVA & 45 & 1023 & 0,69 & 96,96 & 32 & 329 & 42 & 256 & 48 & 232 & 48 & 206 \\
\hline 75500299 & AFECCOES PANCREATICAS & 46 & 952 & 0,64 & 97,59 & 49 & 160 & 46 & 234 & 39 & 304 & 40 & 254 \\
\hline 42004039 & TRAQUEOTOMIA(INCLUSIVE CURATIVOS) & 47 & 950 & 0,64 & 98,23 & 48 & 174 & 45 & 247 & 46 & 242 & 37 & 287 \\
\hline 75500213 & CIRROSE HEPATICA & 48 & 899 & 0,60 & 98,83 & 44 & 251 & 47 & 222 & 50 & 216 & 47 & 210 \\
\hline 31004105 & POSTECTOMIA(CIRCUNCISAO) & 49 & 876 & 0,59 & 99,42 & 41 & 281 & 48 & 188 & 49 & 231 & 49 & 176 \\
\hline 76500233 & INSUFICIENCIA RESPIRATORIA AGUDA & 50 & 868 & 0.58 & 100,00 & 46 & 216 & 49 & 181 & 47 & 233 & 41 & 238 \\
\hline & Sub-Total & & 149315 & 57,68 & & & 35518 & & 38635 & & 38822 & & 36340 \\
\hline & Outros & & 109572 & 42,32 & & & 27908 & & 26103 & & 28004 & & 27557 \\
\hline & Total & & 258887 & 100,00 & & & 63426 & & 64738 & & 66826 & & 63897 \\
\hline
\end{tabular}


Os 06 (seis) primeiros procedimentos mais freqüentes corresponderam a $50,52 \%$ do total das internações suS que pode ser observado no Quadro 48. O procedimento mais freqüente foi Parto Normal com atendimento ao RN na sala de parto, se considerarmos o "ranking" dos (50) cinqüenta procedimentos corresponde a $17,37 \%$ do total das internações SUS realizadas e $10,02 \%$ se considerarmos o total geral das internações SUS do Município; seguido por Cesariana com atendimento do $\mathrm{RN}$ na sala de parto $(12,81 \% ; 7,39 \%)$; Diagnóstico de primeiro atendimento em Clínica Médica (7,81\% e 4,51\%); Parto com manobras (4,75\% e 2,74\%); Curetagem pós aborto $(4,11 \%$ e $2,37 \%)$; Diagnóstico e ou primeiro atendimento em Clínica Cirúrgica $(3,67 \%$ e $2,11 \%)$. Os três primeiros no "ranking" não apresentaram alterações de posição antes de depois da implantação da gestão semi plena. Parto com manobras com atendimento do $\mathrm{RN}$, antes ocupava a $6^{\mathrm{a}}$ posição e depois, no terceiro ano, passou a ocupar a $4^{a}$ posição; Curetagem ocupava a $4^{a}$ posição $e$ passou para a $5^{\mathrm{a}}$ posição depois; Diagnóstico de primeiro atendimento Clinica Cirúrgica ocupava $10^{\circ}$ posição depois passou a ocupar a $6^{a}$ posição.

Diadema - Os 50 procedimentos mais freqüentes corresponderam a $85,95 \%$ do total das internações SUS realizadas no Municipio, sendo que antes da implantação da gestão semi plena representaram $88,08 \%$ das internações SUS e $87,29 \%, \quad 58,09 \%, \quad 84,35 \%$ e $81,42 \%$ nos três anos após, respectivamente.

Os 04 (quatro) primeiros procedimentos mais freqüentes corresponderam a $54,22 \%$ do total das internações SUS, conforme mostra 0 Quadro 49.

Destacam-se com variação:

- 35001011 - Parto Normal $-4^{\circ}$ lugar ( $1^{\circ}$ ano antes); $1^{\circ}\left(1^{\circ}\right.$ ano depois); $2^{\circ}\left(2^{\circ}\right.$ ano depois); $49^{\circ}$ ( $3^{\circ}$ ano depois).

- 35009012 - Cesariana - $5^{\circ}$ lugar ( $1^{\circ}$ ano antes); $2^{\circ}\left(1^{\circ}\right.$ ano depois); $5^{\circ}\left(2^{\circ}\right.$ ano depois); $50^{\circ}$ ( $3^{\circ}$ ano depois). 
Quadro 49 - Totais anuais de internações SUS pelos 50 procedimentos mais freqüentes, ocorridos no Municipio de Diadema - SP, antes e depois da implantação da gestão semi-plena.

\begin{tabular}{|c|c|c|c|c|c|c|c|c|c|c|c|c|c|}
\hline \multirow{2}{*}{\multicolumn{2}{|c|}{ Procedimentos }} & \multirow{2}{*}{\multicolumn{4}{|c|}{ Total }} & \multirow{2}{*}{\multicolumn{2}{|c|}{$\begin{array}{l}\text { Antes } \\
1^{\circ} \text { ano }\end{array}$}} & \multicolumn{6}{|c|}{ Depois } \\
\hline & & & & & & & & \multicolumn{2}{|c|}{$1^{\circ}$ ano } & \multicolumn{2}{|c|}{$2^{\circ}$ ano } & \multicolumn{2}{|c|}{$3^{\circ}$ ano } \\
\hline Código & Descriçăo & Pos. & $\mathbf{N}$ & $\%$ & $\%$ ac & Pos. & $\mathbf{N}$ & Pos. & $\mathbf{N}$ & Pos. & $\mathbf{N}$ & Pos. & $\mathbf{N}$ \\
\hline 35021012 & PARTO NORMAL COM ATENDIMENTO RN SALA DE PARTO & 1 & 14594 & 22,65 & 22,65 & 1 & 7000 & 3 & 2282 & 1 & 2408 & 1 & 2904 \\
\hline 35001011 & PARTO NORMAL & 2 & 7985 & 12,39 & 35,04 & 4 & 1572 & 1 & 5224 & 2 & 1188 & 49 & 1 \\
\hline 35022019 & CESARIANA COM ATENDIMENTO RN SALA DE PARTO & 3 & 6867 & 10,66 & 45,69 & 2 & 3277 & 5 & 1121 & 3 & 1188 & 2 & 1281 \\
\hline 35014016 & CURETAGEM POS-ABORTO & 4 & 5496 & 8,53 & 54,22 & 3 & 2348 & 4 & 1813 & 6 & 647 & 5 & 688 \\
\hline 35009012 & CESARIANA & 5 & 4196 & 6,51 & 60,73 & 5 & 893 & 2 & 2655 & 5 & 648 & 50 & 0 \\
\hline 72500000 & DIAGNOSTICO EIOU PRIMEIRO ATENDIMENTO EM CLINICA MEDICA & 6 & 2443 & 3,79 & 64,53 & 12 & 231 & 10 & 347 & 4 & 1097 & 3 & 768 \\
\hline 76300102 & CRISE ASMATICA & 7 & 1876 & 2,91 & 67,44 & 6 & 628 & 8 & 544 & 8 & 422 & 8 & 282 \\
\hline 76400085 & BRONCOPNEUMONIA EM LACTENTE & 8 & 1791 & 2,78 & 70,22 & 7 & 484 & 6 & 599 & 10 & 328 & 6 & 380 \\
\hline 77500113 & INSUFICIENCIA CARDIACA & 9 & 1664 & 2,58 & 72,80 & 8 & 456 & 7 & 549 & 9 & 343 & 7 & 316 \\
\hline 71300007 & DIAGNOSTICO E/OU PRIMEIRO ATENDIMENTO EM CLINICA PEDIATRICA & 10 & 1497 & 2,32 & 75,12 & 28 & 102 & 13 & 242 & 7 & 447 & 4 & 706 \\
\hline 81500106 & AVC AGUDO & 11 & 971 & 1,51 & 76,63 & 9 & 293 & 12 & 257 & 12 & 181 & 9 & 240 \\
\hline 71300015 & PREMATURIDADE & 12 & 839 & 1,30 & 77,93 & 10 & 261 & 9 & 349 & 19 & 110 & 19 & 119 \\
\hline 76300080 & BRONCOPNEUMONIA & 13 & 784 & 1,22 & 79,15 & 11 & 241 & 11 & 278 & 17 & 127 & 15 & 138 \\
\hline 75500124 & HEMORRAGIAS DIGESTIVAS & 14 & 683 & 1,06 & 80,21 & 14 & 206 & 17 & 184 & 13 & 158 & 17 & 135 \\
\hline 33005060 & APENDICECTOMIA & 15 & 656 & 1,02 & 81,22 & 23 & 128 & 19 & 170 & 11 & 195 & 13 & 163 \\
\hline 76500225 & DOENCA PULMONAR OBSTRUTIVA CRONICA & 16 & 626 & 0,97 & 82,20 & 16 & 187 & 20 & 166 & 16 & 129 & 14 & 144 \\
\hline 71300082 & ICTERICIAS NEO-NATAIS & 17 & 619 & 0,96 & 83,16 & 15 & 189 & 14 & 242 & 27 & 85 & 22 & 103 \\
\hline 82500053 & DIABETE SACARINO & 18 & 580 & 0,90 & 84,06 & 18 & 175 & 18 & 172 & 20 & 110 & 18 & 123 \\
\hline 76300072 & OUTRAS PNEUMONIAS & 19 & 538 & 0,83 & 84,89 & 22 & 144 & 22 & 147 & 15 & 133 & 21 & 114 \\
\hline 35024011 & PARTO COM MANOBRAS COM ATENDIMENTO RN SALA DE PARTO & 20 & 536 & 0,83 & 85,72 & 24 & 113 & 28 & 113 & 26 & 86 & 10 & 224 \\
\hline 76400271 & ENTERO-INFECCOES EM LACTENTE & 21 & 514 & 0,80 & 86,52 & 17 & 176 & 15 & 203 & 23 & 92 & 38 & 43 \\
\hline 91500079 & TRAUMATISMOS CRANIOENCEFALICO & 22 & 490 & 0,76 & 87,28 & 50 & 13 & 21 & 163 & 14 & 140 & 12 & 174 \\
\hline 76500071 & BRONCOPNEUMONIA & 23 & 459 & 0,71 & 87,99 & 32 & 78 & 26 & 130 & 18 & 114 & 16 & 137 \\
\hline 76300056 & BRONQUIOLITE AGUDA & 24 & 452 & 0,70 & 88,70 & 20 & 157 & 29 & 89 & 21 & 105 & 23 & 101 \\
\hline 69000204 & TRABALHO DE PARTO PREMATURO & 25 & 410 & 0,64 & 89,33 & 13 & 212 & 25 & 136 & 45 & 37 & 45 & 25 \\
\hline 81500181 & POLINEUROPATIAS & 26 & 409 & 0,63 & 89,97 & 25 & 112 & 16 & 202 & 44 & 39 & 33 & 56 \\
\hline
\end{tabular}


Contiunua

\begin{tabular}{|c|c|c|c|c|c|c|c|c|c|c|c|c|c|}
\hline \multirow{2}{*}{\multicolumn{2}{|c|}{ Procedimentos }} & \multirow{2}{*}{\multicolumn{4}{|c|}{ Total }} & \multirow{2}{*}{\multicolumn{2}{|c|}{$\begin{array}{l}\text { Antes } \\
1^{\circ} \text { ano }\end{array}$}} & \multicolumn{6}{|c|}{ Depois } \\
\hline & & & & & & & & \multicolumn{2}{|c|}{$1^{\circ}$ ano } & \multicolumn{2}{|c|}{$2^{\circ}$ ano } & \multicolumn{2}{|c|}{$3^{\circ}$ ano } \\
\hline \multicolumn{2}{|c|}{\begin{tabular}{|l|l} 
Código & Descriçăo \\
\end{tabular}} & Pos. & $\mathbf{N}$ & $\%$ & $\%$ ac & Pos. & $\mathbf{N}$ & Pos. & $\mathbf{N}$ & Pos. & $\mathbf{N}$ & Pos. & $\mathbf{N}$ \\
\hline 74300229 & ESTREPTOCOCCIAS (PEDIATRIA) & 27 & 401 & 0,62 & 90,59 & 29 & 96 & 23 & 141 & 28 & 83 & 25 & 81 \\
\hline 74300270 & ENTERO-INFECCOES (PEDIATRIA) & 28 & 391 & 0,61 & 91,20 & 21 & 152 & 24 & 138 & 36 & 61 & 40 & 40 \\
\hline 75500299 & AFECCOES PANCREATICAS & 29 & 371 & 0,58 & 91,77 & 27 & 104 & 27 & 115 & 32 & 71 & 26 & 81 \\
\hline 77500024 & INFARTO AGUDO DO MIOCARDIO & 30 & 360 & 0.56 & 92,33 & 30 & 86 & 34 & 86 & 22 & 102 & 24 & 86 \\
\hline 81500076 & EPILEPSIAS & 31 & 351 & 0,54 & 92,87 & 40 & 60 & 31 & 88 & 25 & 87 & 20 & 116 \\
\hline 43000002 & DIAGNOSTICO EIOU PRIMEIRO ATENDIMENTO EM CLINICA CIRURGICA & 32 & 337 & 0,52 & 93,40 & 48 & 39 & 50 & 14 & 24 & 92 & 11 & 192 \\
\hline 31000002 & CIRURGIA MULTIPLA & 33 & 334 & 0,52 & 93,92 & 26 & 109 & 35 & 84 & 29 & 82 & 32 & 59 \\
\hline 42008069 & TORACOTOMIA COM DRENAGEM FECHADA & 34 & 307 & 0,48 & 94,39 & 34 & 73 & 30 & 89 & 30 & 82 & 30 & 63 \\
\hline 80500218 & OUTRAS AFECCOES DO AP. GENITO-URINARIO & 35 & 287 & 0,45 & 94,84 & 33 & 78 & 32 & 88 & 31 & 79 & 39 & 42 \\
\hline 76500128 & CRISE ASMATICA & 36 & 271 & 0,42 & 95,26 & 37 & 69 & 38 & 75 & 34 & 62 & 28 & 65 \\
\hline 76500063 & PNEUMONIA NAO ESPECIFICADA & 37 & 261 & 0,41 & 95,66 & 36 & 71 & 33 & 88 & 35 & 62 & 41 & 40 \\
\hline 40001008 & TRATAMENTO CONSERVADOR DO TRAUMATISMO CRANEO-ENCEFALICO & 38 & 249 & 0,39 & 96,05 & 19 & 159 & 48 & 45 & 49 & 30 & 48 & 15 \\
\hline 71300112 & OUTRAS AFECCOES DO RECEM-NASCIDO & 39 & 239 & 0,37 & 96,42 & 44 & 52 & 40 & 69 & 38 & 58 & 31 & 60 \\
\hline 33004080 & COLECISTECTOMIA & 40 & 237 & 0,37 & 96,79 & 47 & 41 & 42 & 68 & 33 & 63 & 29 & 65 \\
\hline 77500121 & CRISE HIPERTENSIVA & 41 & 235 & 0,36 & 97.15 & 38 & 67 & 37 & 81 & 48 & 35 & 34 & 52 \\
\hline 76400077 & PNEUMONIAS DO LACTENTE & 42 & 234 & 0,36 & 97,52 & 39 & 62 & 39 & 71 & 40 & 53 & 36 & 48 \\
\hline 34005030 & CURETAGEM SEMIOTICA COM OU SEM DILATACAO DE COLO & 43 & 226 & 0,35 & 97,87 & 31 & 82 & 36 & 83 & 46 & 36 & 46 & 25 \\
\hline 75500213 & CIRROSE HEPATICA & 44 & 214 & 0,33 & 98,20 & 45 & 51 & 41 & 69 & 42 & 43 & 35 & 51 \\
\hline 33016119 & LAPAROTOMIA EXPLORADORA & 45 & 210 & 0,33 & 98,52 & 41 & 55 & 43 & 64 & 43 & 43 & 37 & 48 \\
\hline 35019018 & SUTURA DE LACERACOES DO TRAJETO PELVICO & 46 & 204 & 0,32 & 98,84 & 49 & 38 & 49 & 38 & 37 & 60 & 27 & 68 \\
\hline 74500201 & ESTREPTOCOCCIAS (CLINICA MEDICA) & 47 & 196 & 0,30 & 99,14 & 42 & 54 & 46 & 56 & 41 & 46 & 42 & 40 \\
\hline 75500035 & GASTRITE E DUODENITE & 48 & 185 & 0,29 & 99,43 & 43 & 53 & 44 & 64 & 47 & 36 & 44 & 32 \\
\hline 81300042 & EPILEPSIAS & 49 & 185 & 0,29 & 99,72 & 46 & 46 & 47 & 47 & 39 & 56 & 43 & 36 \\
\hline 74500252 & ENTERO-INFECCOES (CLINICA MEDICA) & 50 & 181 & 0,28 & 100,00 & 35 & 73 & 45 & 62 & 50 & 27 & 47 & 19 \\
\hline & Sub-Total & & 64441 & 85,95 & & & 21446 & & 20200 & & 12006 & & 10789 \\
\hline & Outros & & 10533 & 14,05 & & & 2901 & & 2942 & & 2228 & & 2462 \\
\hline & Total & & 74974 & 100,00 & & & 24347 & & 23142 & & 14234 & & 13251 \\
\hline
\end{tabular}


O procedimento mais freqüente foi Parto Normal com atendimento ao RN na sala de parto. Se considerarmos o "ranking" dos (50) cinqüenta procedimentos, ele corresponde a $22,65 \%$ do total das internações SUS e se considerarmos o total das internações SUS (períodos antes e depois) eles representam $19,47 \%$ dos mesmos realizadas no Município.

Seguindo essa linha, os demais procedimentos foram: Parto normal $(12,39 \% ; 10,65 \%)$; Cesariana com atendimento ao recém-nascido na sala de parto $(10,66 \% ; 9,16 \%)$ e Curetagem pós-aborto $(8,53 \% ; 7,33 \%)$.

Com relação à gestão semi plena, o procedimento parto normal com atendimento ao Recém Nascido na sala de parto manteve-se inalterado, nos períodos antes e depois.

O procedimento parto normal ocupava a $4^{\mathrm{a}}$ posição antes e depois a $49^{\mathrm{a}}$ posição. $O$ procedimento cesariana não se alterou, mantendo-se na $2^{\mathrm{a}}$ posição antes e depois.

Curetagem pós aborto ocupava a $3^{a}$ posição antes da implantação da gestão semi plena passou para $5^{\text {a }}$ posição.

Mauá - Os 50 procedimentos mais freqüentes corresponderam a $85,52 \%$ do total das internações SUS realizadas no Município, sendo que antes da implantação da gestão semi plena representaram $85,14 \%$ das internações SUS e $83,28 \%, 87,64 \%, 86,10 \%$ nos três anos após, respectivamente.

Os 03 (três) primeiros procedimentos mais freqüentes corresponderam a $53,38 \%$ do total das internações SUS no Município de Mauá, apresentados no Quadro 50. 


\begin{tabular}{|c|c|c|c|c|c|c|c|c|c|c|c|c|c|}
\hline \multirow{2}{*}{\multicolumn{2}{|c|}{ Procedimentos }} & \multirow{2}{*}{\multicolumn{4}{|c|}{ Total }} & \multirow{2}{*}{\multicolumn{2}{|c|}{$\begin{array}{l}\text { Antes } \\
1^{\circ} \text { ano }\end{array}$}} & \multicolumn{6}{|c|}{ Depois } \\
\hline & & & & & & & & \multicolumn{2}{|c|}{$1^{\circ}$ ano } & \multicolumn{2}{|c|}{$2^{\circ}$ ano } & \multicolumn{2}{|c|}{$3^{\circ}$ ano } \\
\hline Código & Descriçåo & Pos. & $\mathbf{N}$ & $\%$ & $\%$ ac & Pos. & $\mathbf{N}$ & Pos. & $\mathbf{N}$ & Pos. & $\mathbf{N}$ & Pos. & $\mathbf{N}$ \\
\hline 35021012 & PARTO NORMAL COM ATENDIMENTO RN SALA DE PARTO & 1 & 17214 & 30,31 & 30,31 & 1 & 2673 & 1 & 3776 & 1 & 5292 & 1 & 5473 \\
\hline 35022019 & CESARIANA COM ATENDIMENTO RN SALA DE PARTO & 2 & 8605 & 15,15 & 45,46 & 2 & 1613 & 2 & 2322 & 2 & 2431 & 2 & 2239 \\
\hline 35014016 & CURETAGEM POS-ABORTO & 3 & 4498 & 7,92 & 53,38 & 4 & 959 & 3 & 1097 & 3 & 1414 & 3 & 1028 \\
\hline 35001011 & PARTO NORMAL & 4 & 1627 & 2,86 & 56,24 & 3 & 1002 & 6 & 474 & 32 & 68 & 33 & 83 \\
\hline 76400085 & BRONCOPNEUMONIA EM LACTENTE & 5 & 1621 & 2,85 & 59,09 & 8 & 421 & 4 & 493 & 5 & 401 & 6 & 306 \\
\hline 77500113 & INSUFICIENCIA CARDIACA & 6 & 1504 & 2,65 & 61,74 & 7 & 424 & 5 & 484 & 6 & 278 & 5 & 318 \\
\hline 72500000 & DIAGNOSTICO E/OU PRIMEIRO ATENDIMENTO EM CLINICA MEDICA & 7 & 1487 & 2,62 & 64,36 & 16 & 191 & 24 & 144 & 4 & 487 & 4 & 665 \\
\hline 76300080 & BRONCOPNEUMONIA & 8 & 1298 & 2,29 & 66,64 & 6 & 429 & 7 & 383 & 7 & 269 & 10 & 217 \\
\hline 81500106 & AVC AGUDO & 9 & 1056 & 1,86 & 68,50 & 9 & 274 & 8 & 357 & 11 & 195 & 9 & 230 \\
\hline 76500071 & BRONCOPNEUMONIA & 10 & 928 & 1,63 & 70,14 & 10 & 253 & 11 & 232 & 9 & 204 & 8 & 239 \\
\hline 35009012 & CESARIANA & 11 & 815 & 1,43 & 71,57 & 5 & 432 & 9 & 328 & 48 & 31 & 49 & 24 \\
\hline 77500121 & CRISE HIPERTENSIVA & 12 & 732 & 1,29 & 72,86 & 11 & 242 & 13 & 223 & 17 & 136 & 20 & 131 \\
\hline 69000204 & TRABALHO DE PARTO PREMATURO & 13 & 731 & 1,29 & 74,15 & 23 & 140 & 16 & 197 & 10 & 201 & 11 & 193 \\
\hline 82500053 & DIABETE SACARINO & 14 & 723 & 1,27 & 75,42 & 13 & 196 & 12 & 231 & 18 & 132 & 14 & 164 \\
\hline 71300082 & ICTERICIAS NEO-NATAIS & 15 & 708 & 1,25 & 76,67 & 38 & 64 & 10 & 265 & 8 & 213 & 13 & 166 \\
\hline 71300007 & DIAGNOSTICO EIOU PRIMEIRO ATENDIMENTO EM CLINICA PEDIATRICA & 16 & 704 & 1,24 & 77,91 & 17 & 169 & 37 & 79 & 12 & 192 & 7 & 264 \\
\hline 71300015 & PREMATURIDADE & 17 & 689 & 1,21 & 79,12 & 19 & 161 & 19 & 169 & 15 & 175 & 12 & 184 \\
\hline 33011117 & HERNIORRAFIA INGUINAL(UNILATERAL) & 18 & 678 & 1,19 & 80,31 & 18 & 166 & 18 & 174 & 14 & 181 & 15 & 157 \\
\hline 34005030 & CURETAGEM SEMIOTICA COM OU SEM DILATACAO DE COLO & 19 & 653 & 1,15 & 81,46 & 20 & 152 & 20 & 169 & 13 & 190 & 18 & 142 \\
\hline 74300270 & ENTERO-INFECCOES (PEDIATRIA) & 20 & 652 & 1,15 & 82,61 & 12 & 231 & 14 & 220 & 34 & 63 & 19 & 138 \\
\hline 75500124 & HEMORRAGIAS DIGESTIVAS & 21 & 587 & 1,03 & 83,64 & 21 & 146 & 22 & 162 & 19 & 123 & 16 & 156 \\
\hline 76400271 & ENTERO-INFECCOES EM LACTENTE & 22 & 523 & 0,92 & 84,57 & 15 & 193 & 15 & 206 & 25 & 89 & 46 & 35 \\
\hline 70000000 & TRATAMENTO DA AIDS & 23 & 497 & 0,88 & 85,44 & 24 & 130 & 23 & 147 & 21 & 116 & 25 & 104 \\
\hline 33005060 & APENDICECTOMIA & 24 & 492 & 0,87 & 86,31 & 34 & 80 & 25 & 136 & 20 & 123 & 17 & 153 \\
\hline 69000115 & AMEACA DE ABORTO & 25 & 485 & 0,85 & 87,16 & 29 & 113 & 26 & 125 & 16 & 159 & 29 & 88 \\
\hline 74500252 & ENTERO-INFECCOES (CLINICA MEDICA) & 26 & 448 & 0,79 & 87,95 & 22 & 145 & 17 & 192 & 37 & 57 & 40 & 54 \\
\hline 91500079 & TRAUMATISMOS CRANIOENCEFALICO & 27 & 427 & 0,75 & 88,70 & 28 & 114 & 21 & 168 & 35 & 58 & 30 & 87 \\
\hline 43000002 & DIAGNOSTICO EIOU PRIMEIRO ATENDIMENTO EM CLINICA CIRURGICA & 28 & 418 & 0,74 & 89,44 & 25 & 127 & 33 & 84 & 23 & 90 & 21 & 117 \\
\hline 76300102 & CRISE ASMATICA & 29 & 411 & 0,72 & 90,16 & 14 & 195 & 31 & 89 & 49 & 22 & 24 & 105 \\
\hline 76500225 & DOENCA PULMONAR OBSTRUTIVA CRONICA & 30 & 391 & 0,69 & 90,85 & 27 & 123 & 28 & 105 & 33 & 67 & 26 & 96 \\
\hline 77500024 & INFARTO AGUDO DO MIOCARDIO & 31 & 357 & 0,63 & 91,48 & 42 & 62 & 34 & 82 & 22 & 96 & 22 & 117 \\
\hline
\end{tabular}

Continua 


\begin{tabular}{|c|c|c|c|c|c|c|c|c|c|c|c|c|c|}
\hline \multirow{2}{*}{\multicolumn{2}{|c|}{ Procedimentos }} & \multirow{2}{*}{\multicolumn{4}{|c|}{ Total }} & \multirow{2}{*}{\multicolumn{2}{|c|}{$\begin{array}{l}\text { Antes } \\
1^{\circ} \text { ano }\end{array}$}} & \multicolumn{6}{|c|}{ Depois } \\
\hline & & & & & & & & \multicolumn{2}{|c|}{$1^{\circ}$ ano } & \multicolumn{2}{|c|}{$2^{\circ}$ ano } & \multicolumn{2}{|c|}{$3^{\circ}$ ano } \\
\hline \multicolumn{2}{|r|}{ Descriçăo } & Pos. & $\mathbf{N}$ & $\%$ & $\%$ ac & Pos. & $\mathbf{N}$ & Pos. & $\mathbf{N}$ & Pos. & $\mathbf{N}$ & Pos. & \multirow{2}{*}{$\begin{array}{l}\mathbf{N} \\
75\end{array}$} \\
\hline 73500011 & DESNUTRICAO (CLINICA MEDICA) & \multicolumn{4}{|c|}{$\begin{array}{llll}32 & 355 & 0,63 & 92,10\end{array}$} & \multicolumn{2}{|c|}{$30 \quad 95$} & \multicolumn{2}{|c|}{$29 \quad 105$} & \multicolumn{2}{|c|}{$26 \quad 80$} & 36 & \\
\hline 76300072 & OUTRAS PNEUMONIAS & 33 & 344 & 0,61 & 92,71 & 26 & 126 & 27 & 106 & 42 & 50 & 38 & 62 \\
\hline 80500218 & OUTRAS AFECCOES DO AP. GENITO-URINARIO & 34 & 327 & 0,58 & 93,28 & 32 & 83 & 38 & 77 & 28 & 75 & 28 & 92 \\
\hline 34008020 & COLPOPERINEOPLASTIA ANTERIOR E POSTERIOR & 35 & 298 & 0,52 & 93,81 & 31 & 92 & 44 & 67 & 24 & 90 & 42 & 49 \\
\hline 76500063 & PNEUMONIA NAO ESPECIFICADA & 36 & 286 & 0,50 & 94,31 & 33 & 83 & 35 & 82 & 44 & 41 & 34 & 80 \\
\hline 72500018 & DESIDRATACAO AGUDA (CLINICA MEDICA) & 37 & 269 & 0,47 & 94,79 & 39 & 63 & 32 & 88 & 30 & 70 & 44 & 48 \\
\hline 35024011 & PARTO COM MANOBRAS COM ATENDIMENTO RN SALA DE PARTO & 38 & 257 & 0,45 & 95,24 & 50 & 19 & 45 & 59 & 29 & 73 & 23 & 106 \\
\hline 79500013 & ANEMIAS CARENCIAIS & 39 & 257 & 0,45 & 95,69 & 40 & 63 & 47 & 57 & 38 & 53 & 32 & 84 \\
\hline 33004080 & COLECISTECTOMIA & 40 & 250 & 0,44 & 96,13 & 45 & 55 & 39 & 76 & 39 & 53 & 37 & 66 \\
\hline 69000107 & FALSO TRABALHO DE PARTO & 41 & 248 & 0,44 & 96,57 & 43 & 62 & 36 & 82 & 27 & 79 & 48 & 25 \\
\hline 69000050 & PRE-ECLAMPSIA GRAVE & 42 & 237 & 0,42 & 96,98 & 46 & 46 & 48 & 43 & 31 & 70 & 35 & 78 \\
\hline 33016119 & LAPAROTOMIA EXPLORADORA & 43 & 236 & 0,42 & 97,40 & 41 & 63 & 42 & 71 & 43 & 47 & 39 & 55 \\
\hline 34010033 & HISTERECTOMIA TOTAL & 44 & 231 & 0,41 & 97,81 & 36 & 72 & 43 & 68 & 36 & 58 & 47 & 33 \\
\hline 91300061 & TRAUMATISMO CRANIO ENCEFALICO & 45 & 220 & 0,39 & 98,19 & 35 & 79 & 30 & 103 & 50 & 14 & 50 & 24 \\
\hline 77500032 & INSUFICIENCIA CORONARIANA AGUDA & 46 & 213 & 0,38 & 98,57 & 44 & 58 & 41 & 72 & 47 & 34 & 43 & 49 \\
\hline 76500128 & CRISE ASMATICA & 47 & 207 & 0,36 & 98,93 & 37 & 70 & 46 & 58 & 46 & 36 & 45 & 43 \\
\hline 74500210 & ESTAFILOCOCCIAS (CLINICA MEDICA) & 48 & 204 & 0,36 & 99,29 & 48 & 30 & 49 & 37 & 40 & 51 & 31 & 86 \\
\hline 81500076 & EPILEPSIAS & 49 & 204 & 0,36 & 99,65 & 47 & 40 & 40 & 73 & 45 & 37 & 41 & 54 \\
\hline 71300112 & OUTRAS AFECCOES DO RECEM-NASCIDO & 50 & 198 & 0,35 & 100,00 & 49 & 29 & 50 & 22 & 41 & 51 & 27 & 96 \\
\hline & Sub-Total & & 56800 & 85,52 & & & 12848 & & 14659 & & 14615 & & 14678 \\
\hline & Outros & & 9617 & 14,48 & & & 2243 & & 2943 & & 2062 & & 2369 \\
\hline & Total & & 66417 & 100,00 & & & 15091 & & 17602 & & 16677 & & 17047 \\
\hline
\end{tabular}


O procedimento mais freqüente foi Parto Normal com atendimento ao Recém Nascido na sala de parto. Se considerarmos o "ranking" dos (50) cinqüenta procedimentos, corresponde a $30,31 \%$ do total das internações SUS e se considerarmos o total das internações SUS (periodos antes de depois) eles representaram $25,92 \%$.

Seguindo essa linha, os demais procedimentos foram: Cesariana com atendimento ao recém-nascido na sala de parto $(15,15 \% ; 12,96 \%)$ e Curetagem pós-aborto $(7,92 \% ; 6,77 \%)$.

Com relação à gestão semi plena, o procedimento parto normal com atendimento ao Recém Nascido na sala de parto e cesariana não se alteraram apenas curetagem pós aborto sofreu alteração passando da $4^{\mathrm{a}}$ para a $3^{\mathrm{a}}$ posição.

Ribeirão Preto - Os 50 procedimentos mais freqüentes apresentados no Quadro 51, corresponderam a $54,44 \%$ do total das internações SUS realizadas no Municipio, sendo que antes da implantação da gestão semi plena representaram $51,15 \%$ das internações SUS e $54,98 \%$, $56,01 \%, 56,09 \%$ nos três anos após, respectivamente.

Destacam-se com variações:

- 43000002 - Diagnóstico e/ou Primeiro Atendimento em Clínica Cirúrgica - $48^{\circ}$ lugar ( $1^{\circ}$ ano antes); $26^{\circ}$ ( $1^{\circ}$ ano depois); $5^{\circ}$ ( $2^{\circ}$ ano depois); $4^{\circ}\left(3^{\circ}\right.$ ano depois).

- 91904013 - Tratamento de AIDS em Hospital dia - 50 lugar ( $1^{\circ}$ ano antes); $38^{\circ}\left(1^{\circ}\right.$ ano depois); $20^{\circ}$ ( $2^{\circ}$ ano depois); $17^{\circ}$ ( $3^{\circ}$ ano depois). 
Quadro 51 - Totais anuais de internações SUS pelos 50 procedimentos mais freqüentes, ocorridos no Municipio de Ribeirão Preto - SP, antes e depois da implantação da gestão semi-plena.

\begin{tabular}{|c|c|c|c|c|c|c|c|c|c|c|c|c|c|}
\hline \multirow{2}{*}{\multicolumn{2}{|c|}{ Procedimentos }} & \multirow{2}{*}{\multicolumn{4}{|c|}{ Total }} & \multirow{2}{*}{\multicolumn{2}{|c|}{$\frac{\text { Antes }}{1^{\circ} \text { ano }}$}} & \multicolumn{6}{|c|}{ Depois } \\
\hline & & & & & & & & \multicolumn{2}{|c|}{$1^{\circ}$ ano } & \multicolumn{2}{|c|}{$2^{\circ}$ ano } & \multicolumn{2}{|c|}{$3^{\circ}$ ano } \\
\hline Código & Descriçăo & Pos. & $\mathbf{N}$ & $\%$ & $\%$ ac & Pos. & $\mathbf{N}$ & Pos. & $\mathbf{N}$ & Pos. & $\mathbf{N}$ & Pos. & $\mathbf{N}$ \\
\hline 35021012 & PARTO NORMAL COM ATENDIMENTO RN SALA DE PARTO & 1 & 15233 & 14,91 & 14,91 & 1 & 3953 & 1 & 3636 & 1 & 3707 & 1 & 3937 \\
\hline 72500000 & DIAGNOSTICO E/OU PRIMEIRO ATENDIMENTO EM CLINICA MEDICA & 2 & 8751 & 8.56 & 23,47 & 4 & 1236 & 2 & 2711 & 2 & 2186 & 2 & 2618 \\
\hline 35022019 & CESARIANA COM ATENDIMENTO RN SALA DE PARTO & 3 & 7729 & 7,56 & 31,04 & 2 & 2199 & 3 & 1909 & 3 & 1779 & 3 & 1842 \\
\hline 77500113 & INSUFICIENCIA CARDIACA & 4 & 5086 & 4,98 & 36,01 & 3 & 1892 & 5 & 1297 & 6 & 909 & 7 & 988 \\
\hline 71300007 & DIAGNOSTICO EIOU PRIMEIRO ATENDIMENTO EM CLINICA PEDIATRICA & 5 & 4511 & 4,41 & 40,43 & 20 & 458 & 4 & 1436 & 4 & 1191 & 5 & 1426 \\
\hline 35014016 & CURETAGEM POS-ABORTO & 6 & 3647 & 3.57 & 44,00 & 5 & 974 & 6 & 892 & 7 & 785 & 6 & 996 \\
\hline 43000002 & DIAGNOSTICO EIOU PRIMEIRO ATENDIMENTO EM CLINICA CIRURGICA & 7 & 2964 & 2.90 & 46,90 & 48 & 134 & 26 & 312 & 5 & 1045 & 4 & 1473 \\
\hline 76300102 & CRISE ASMATICA & 8 & 2577 & 2,52 & 49,42 & 13 & 536 & 8 & 583 & 8 & 759 & 8 & 699 \\
\hline 76500063 & PNEUMONIA NAO ESPECIFICADA & 9 & 2262 & 2,21 & 51,63 & 15 & 511 & 9 & 558 & 9 & 553 & 9 & 640 \\
\hline 70000000 & TRATAMENTO DA AIDS & 10 & 2256 & 2,21 & 53,84 & 9 & 672 & 10 & 539 & 10 & 497 & 12 & 548 \\
\hline 77500032 & INSUFICIENCIA CORONARIANA AGUDA & 11 & 2164 & 2,12 & 55,96 & 14 & 523 & 7 & 670 & 12 & 412 & 11 & 559 \\
\hline 71300015 & PREMATURIDADE & 12 & 2069 & 2,02 & 57,98 & 6 & 705 & 11 & 524 & 18 & 369 & 14 & 471 \\
\hline 32023014 & CORONARIOPLASTIA & 13 & 2010 & 1,97 & 59,95 & 8 & 677 & 12 & 504 & 14 & 394 & 18 & 435 \\
\hline 81500106 & AVC AGUDO & 14 & 1826 & 1,79 & 61,74 & 7 & 688 & 17 & 399 & 24 & 334 & 21 & 405 \\
\hline 76400077 & PNEUMONIAS DO LACTENTE & 15 & 1739 & 1,70 & 63,44 & 12 & 577 & 15 & 409 & 11 & 423 & 25 & 330 \\
\hline 82500053 & DIABETE SACARINO & 16 & 1729 & 1,69 & 65,13 & 11 & 586 & 22 & 362 & 19 & 368 & 19 & 413 \\
\hline 76500225 & DOENCA PULMONAR OBSTRUTIVA CRONICA & 17 & 1632 & 1,60 & 66,73 & 22 & 437 & 14 & 459 & 22 & 360 & 22 & 376 \\
\hline 76300072 & OUTRAS PNEUMONIAS & 18 & 1622 & 1,59 & 68,32 & 17 & 483 & 23 & 362 & 17 & 370 & 20 & 407 \\
\hline 31000002 & CIRURGIA MULTIPLA & 19 & 1620 & 1,59 & 69,90 & 21 & 441 & 13 & 469 & 21 & 366 & 24 & 344 \\
\hline 33011117 & HERNIORRAFIA INGUINAL(UNILATERAL) & 20 & 1592 & 1,56 & 71,46 & 24 & 373 & 18 & 394 & 25 & 319 & 13 & 506 \\
\hline 80500218 & OUTRAS AFECCOES DO AP. GENITO-URINARIO & 21 & 1587 & 1,55 & 73,01 & 25 & 363 & 20 & 375 & 15 & 385 & 15 & 464 \\
\hline 80500072 & PIELONEFRITES & 22 & 1541 & 1,51 & 74,52 & 29 & 283 & 19 & 393 & 13 & 402 & 16 & 463 \\
\hline 36005045 & FACECTOMIA COM LENTE INTRA-OCULAR & 23 & 1476 & 1,44 & 75,97 & 18 & 470 & 21 & 365 & 23 & 352 & 28 & 289 \\
\hline 35024011 & PARTO COM MANOBRAS COM ATENDIMENTO RN SALA DE PARTO & 24 & 1455 & 1,42 & 77,39 & 33 & 256 & 30 & 266 & 26 & 318 & 10 & 615 \\
\hline 81500076 & EPILEPSIAS & 25 & 1396 & 1,37 & 78,76 & 34 & 255 & 16 & 409 & 16 & 373 & 23 & 359 \\
\hline 75500124 & 4 HEMORRAGIAS DIGESTIVAS & 26 & 1346 & 1,32 & 80,07 & 23 & 401 & 24 & 346 & 27 & 274 & 26 & 325 \\
\hline 76400271 & 1 ENTERO-INFECCOES EM LACTENTE & 27 & 1278 & 1,25 & 81,32 & 10 & 637 & 36 & 232 & 33 & 196 & 36 & 213 \\
\hline 33005060 & APENDICECTOMIA & 28 & 1136 & 1,11 & 82,44 & 32 & 269 & 29 & 270 & 28 & 272 & 27 & 325 \\
\hline 32011016 & CIRURGIA DE CORONARIA COM EXTRA-CORPOREA & 29 & 1080 & 1,06 & 83,49 & 26 & 346 & 32 & 259 & 30 & 245 & 34 & 230 \\
\hline
\end{tabular}




\begin{tabular}{|c|c|c|c|c|c|c|c|c|c|c|c|c|c|}
\hline \multirow{2}{*}{\multicolumn{2}{|c|}{ Procedimentos }} & \multirow{2}{*}{\multicolumn{4}{|c|}{ Total }} & \multirow{2}{*}{\multicolumn{2}{|c|}{$\begin{array}{l}\text { Antes } \\
1^{\circ} \text { ano }\end{array}$}} & \multicolumn{6}{|c|}{ Depois } \\
\hline & & & & & & & & \multicolumn{2}{|c|}{$1^{\circ}$ ano } & \multicolumn{2}{|c|}{$2^{\circ}$ ano } & \multicolumn{2}{|c|}{$3^{\circ}$ ano } \\
\hline Código & Descriçăo & Pos. & $\mathbf{N}$ & $\%$ & $\%$ ac & Pos. & $\mathbf{N}$ & Pos. & $\mathbf{N}$ & Pos. & $\mathbf{N}$ & Pos. & $\mathbf{N}$ \\
\hline 91904013 & TRATAMENTO DE AIDS EM HOSPITAL DIA & 30 & 1080 & 1,06 & 84,55 & 50 & 77 & 38 & 180 & 20 & 367 & 17 & 456 \\
\hline 33004080 & COLECISTECTOMIA & 31 & 1058 & 1,04 & 85,59 & 28 & 285 & 25 & 331 & 32 & 208 & 33 & 234 \\
\hline 32015011 & MARCA-PASSO CARDIACO(INTRACAVITARIO) & 32 & 1037 & 1.01 & 86,60 & 40 & 226 & 31 & 262 & 29 & 268 & 29 & 281 \\
\hline 76500233 & INSUFICIENCIA RESPIRATORIA AGUDA & 33 & 1016 & 0,99 & 87,59 & 16 & 488 & 27 & 301 & 49 & 107 & 49 & 120 \\
\hline 34008020 & COLPOPERINEOPLASTIA ANTERIOR E POSTERIOR & 34 & 945 & 0,92 & 88,52 & 30 & 272 & 34 & 252 & 37 & 177 & 31 & 244 \\
\hline 91500109 & LACERACAO E FERIMENTOS DE LOCALIZACOES DIVERSAS & 35 & 906 & 0,89 & 89,41 & 19 & 466 & 42 & 175 & 45 & 129 & 47 & 136 \\
\hline 33016119 & LAPAROTOMIA EXPLORADORA & 36 & 893 & 0,87 & 90,28 & 42 & 212 & 35 & 239 & 31 & 223 & 35 & 219 \\
\hline 77500121 & CRISE HIPERTENSIVA & 37 & 866 & 0,85 & 91,13 & 36 & 247 & 28 & 284 & 41 & 156 & 39 & 179 \\
\hline 40061019 & NENTRICULO-PERITONIOSTOMIA COM INTERPOSICAO DE VAL & 38 & 803 & 0,79 & 91,91 & 44 & 189 & 39 & 179 & 34 & 193 & 32 & 242 \\
\hline 80500170 & INSUFICIENCIA RENAL CRONICA AACIDOSE METABOLICA & 39 & 792 & 0,78 & 92,69 & 35 & 248 & 33 & 256 & 38 & 175 & 50 & 113 \\
\hline 76500128 & CRISE ASMATICA & 40 & 774 & 0,76 & 93,45 & 46 & 152 & 43 & 165 & 35 & 193 & 30 & 264 \\
\hline 69000204 & TRABALHO DE PARTO PREMATURO & 41 & 767 & 0,75 & 94,20 & 38 & 228 & 41 & 176 & 40 & 160 & 37 & 203 \\
\hline 77500024 & INFARTO AGUDO DO MIOCARDIO & 42 & 689 & 0,67 & 94,87 & 43 & 191 & 40 & 177 & 43 & 138 & 38 & 183 \\
\hline 34010033 & HISTERECTOMIA TOTAL & 43 & 683 & 0,67 & 95,54 & 45 & 187 & 37 & 181 & 42 & 152 & 42 & 163 \\
\hline 77500180 & ARRITIMIAS & 44 & 682 & 0,67 & 96,21 & 27 & 307 & 48 & 139 & 50 & 91 & 45 & 145 \\
\hline 34005030 & CURETAGEM SEMIOTICA COM OU SEM DILATACAO DE COLO & 45 & 677 & 0,66 & 96,87 & 31 & 271 & 47 & 155 & 47 & 119 & 48 & 132 \\
\hline 75500213 & CIRROSE HEPATICA & 46 & 649 & 0,64 & 97,50 & 41 & 219 & 49 & 123 & 44 & 136 & 41 & 171 \\
\hline 32020015 & IMPLANTE DE PROTESE VALVULAR & 47 & 647 & 0,63 & 98,14 & 39 & 228 & 46 & 159 & 46 & 122 & 46 & 138 \\
\hline 42004039 & TRAQUEOTOMIA(INCLUSIVE CURATIVOS) & 48 & 636 & 0,62 & 98,76 & 49 & 121 & 45 & 160 & 36 & 178 & 40 & 177 \\
\hline 91500079 & TRAUMATISMOS CRANIOENCEFALICO & 49 & 635 & 0,62 & 99,38 & 37 & 242 & 50 & 122 & 48 & 114 & 43 & 157 \\
\hline 33012113 & HERNIORRAFIA INGUINAL(BILATERAL) & 50 & 632 & 0,62 & 100,00 & 47 & 141 & 44 & 164 & 39 & 173 & 44 & 154 \\
\hline & Sub-Total & & 102181 & 54,44 & & & 26332 & & 25520 & & 23522 & & 26807 \\
\hline & Outros & & 85513 & 45,56 & & & 25148 & & 20899 & & 18477 & & 20989 \\
\hline & Total & & 187694 & 100,00 & & & 51480 & & 46419 & & 41999 & & 47796 \\
\hline
\end{tabular}


Os 09 (nove) primeiros procedimentos mais freqüentes corresponderam a $51,63 \%$ do total das internações SUS.

O procedimento mais freqüente foi Parto Normal com atendimento ao Recém Nascido na sala de parto. Se considerarmos o "ranking" dos (50) cinqüenta procedimentos, corresponde a $14,91 \%$ do total das internações SUS e se considerarmos o total das internações SUS (periodos antes de depois) eles representaram $8,12 \%$ dos mesmos.

Seguindo essa linha, os demais procedimentos foram: Diagnóstico e ou primeiro atendimento em Clínica Médica $(8,56 \% ; 4,66 \%)$; Cesariana com atendimento $(7,56 \% ; 4,12 \%)$; Insuficiência Cardíaca $(4,98 \% ; 2,71 \%)$; Diagnóstico e ou primeiro atendimento em Clínica Pediátrica $(4,41 \% ; 2,40 \%)$; Curetagem pós-aborto $(3,57 \% ; 1,94 \%)$; Diagnóstico e ou primeiro atendimento em Clinica Cirúrgica (2,90\%; 1,58\%); Crise Asmática $(2,52 \%$ e 1,37\%); Pneumonia não especificada $(2,21 \% ; 1,21 \%)$.

Com relação à gestão semi plena, o procedimento parto normal manteve a $1^{a}$ posição em ambos os períodos. Diagnóstico e ou Primeiro atendimento em Clínica Médica passou da $4^{\mathrm{a}}$ posição para a $2^{\mathrm{a}}$ posição após a implantação de gestão semi plena. Cesariana com atendimento a Recém Nascido na sala de parto passou da $2^{a}$ para a $3^{a}$ posição. Diagnóstico e primeiro atendimento em Clínica Pediátrica antes era $020^{\circ}$ e passou para a $5^{a}$ posição. Curetagem pós aborto passou da $5^{\mathrm{a}}$ para a $6^{\mathrm{a}}$. Diagnóstico e ou primeiro atendimento em Clínica Cirúrgica passou de $48^{a}$ posição para a $4^{a}$ posição, após; Crise asmática passou da $13^{a}$ posição para a $8^{a}$ posição. Pneumonia não especificada passou da $15^{\mathrm{a}}$ para a nona posição.

Santos - Os 50 procedimentos mais freqüentes corresponderam a $65,72 \%$ do total das internações SUS realizadas no Município, sendo que antes 
da implantação da gestão semi plena representaram $65,05 \%$ das internações SUS e $63,69 \%, 67,17 \%, 67,46 \%$ nos três anos após, respectivamente.

Os 10 (dez) primeiros procedimentos mais freqüentes, mostrados no Quadro 52 corresponderam a $52,60 \%$ do total das internações SUS no Município de Santos.

Para Santos destacam-se com variações:

- 72500000 - Diagnóstico e/ou Primeiro Atendimento em Clínica Médica - $46^{\circ}$ lugar ( $1^{\circ}$ ano antes); $36^{\circ}$ ( $1^{\circ}$ ano depois); $1^{\circ}\left(2^{\circ}\right.$ ano depois); $3^{\circ}\left(3^{\circ}\right.$ ano depois).

- 35025018 - Parto Normal $-49^{\circ}$ lugar ( $1^{\circ}$ ano antes); $5^{\circ}\left(1^{\circ}\right.$ ano depois); $4^{\circ}\left(2^{\circ}\right.$ ano depois); $4^{\circ}$ ( $3^{\circ}$ ano depois).

- 76300188 - Insuficiência Respiratória Aguda - $5^{\circ}$ lugar ( $1^{\circ}$ ano antes); $6^{\circ}\left(1^{\circ}\right.$ ano depois); $19^{\circ}\left(2^{\circ}\right.$ ano depois); $43^{\circ}$ ( $3^{\circ}$ ano depois).

- 91500141 - Complicações de Procedimentos Cirúrgicos ou Médicos - $16^{\circ}$ lugar ( $1^{\circ}$ ano antes); $20^{\circ}$ ( $1^{\circ}$ ano depois); $33^{\circ}$ ( $2^{\circ}$ ano depois); $24^{\circ}\left(3^{\circ}\right.$ ano depois). 
Quadro 52 - Totais anuais de internações SUS pelos 50 procedimentos mais freqüentes, ocorridos no Município de Santos - SP, antes e depois da implantação da gestão semi-plena.

\begin{tabular}{|c|c|c|c|c|c|c|c|c|c|c|c|c|c|}
\hline \multirow{2}{*}{\multicolumn{2}{|c|}{ Procedimentos }} & \multirow{2}{*}{\multicolumn{4}{|c|}{ Total }} & \multirow{2}{*}{\multicolumn{2}{|c|}{$\begin{array}{l}\text { Antes } \\
1^{\circ} \text { ano } \\
\end{array}$}} & \multicolumn{6}{|c|}{ Depois } \\
\hline & & & & & & & & \multicolumn{2}{|c|}{$1^{\circ}$ ano } & \multicolumn{2}{|c|}{$2^{\circ}$ ano } & \multicolumn{2}{|c|}{$3^{\circ}$ ano } \\
\hline Código & Descrição & Pos. & $\mathbf{N}$ & $\%$ & $\%$ ac & Pos. & $\mathbf{N}$ & Pos. & $\mathbf{N}$ & Pos. & $\mathbf{N}$ & Pos. & $\mathbf{N}$ \\
\hline 35021012 & PARTO NORMAL COM ATENDIMENTO RN SALA DE PARTO & 1 & 10584 & 11,06 & 11,06 & 1 & 2791 & 2 & 2171 & 2 & 2444 & 1 & 3178 \\
\hline 35022019 & CESARIANA COM ATENDIMENTO RN SALA DE PARTO & 2 & 8285 & 8,66 & 19,71 & 3 & 2198 & 1 & 2197 & 3 & 1884 & 2 & 2006 \\
\hline 31000002 & CIRURGIA MULTIPLA & 3 & 5577 & 5,83 & 25,54 & 2 & 2254 & 3 & 1793 & 7 & 851 & 10 & 679 \\
\hline 40001008 & TRATAMENTO CONSERVADOR DO TRAUMATISMO CRANEO-ENC & 4 & 4746 & 4,96 & 30,50 & 4 & 1474 & 4 & 1411 & 5 & 935 & 6 & 926 \\
\hline 72500000 & DIAGNOSTICO EIOU PRIMEIRO ATENDIMENTO EM CLINICA mEd & 5 & 4477 & 4,68 & 35,17 & 46 & 102 & 36 & 211 & 1 & 2488 & 3 & 1676 \\
\hline 39000001 & POLITRAUMATIZADO & 6 & 3497 & 3,65 & 38,83 & 10 & 771 & 8 & 964 & 6 & 852 & 7 & 910 \\
\hline 35025018 & PARTO NORMAL - EXCLUSIVAMENTE PARA HOSPITAIS AMI & 7 & 3495 & 3,65 & 42,48 & 49 & 41 & 5 & 1291 & 4 & 1063 & 4 & 1100 \\
\hline 81500106 & AVC AGUDO & 8 & 3321 & 3,47 & 45,95 & 8 & 814 & 9 & 961 & 9 & 781 & 8 & 765 \\
\hline 77500113 & INSUFICIENCIA CARDIACA & 9 & 3212 & 3,36 & 49,30 & 7 & 884 & 10 & 926 & 11 & 641 & 9 & 761 \\
\hline 70000000 & TRATAMENTO DA AIDS & 10 & 3152 & 3,29 & 52,60 & 6 & 995 & 7 & 1029 & 12 & 597 & 13 & 531 \\
\hline 35014016 & CURETAGEM POS-ABORTO & 11 & 3125 & 3,26 & 55,86 & 11 & 708 & 11 & 749 & 10 & 736 & 5 & 932 \\
\hline 76300188 & INSUFICIENCIA RESPIRATORIA AGUDA & 12 & 2606 & 2,72 & 58,58 & 5 & 1003 & 6 & 1149 & 19 & 322 & 43 & 132 \\
\hline 76500071 & BRONCOPNEUMONIA & 13 & 1984 & 2,07 & 60,66 & 14 & 448 & 12 & 744 & 16 & 356 & 16 & 436 \\
\hline 38025019 & PERDA SUBST CUTANEA-LESOES EXTENSAS PLANOS SUPER & 14 & 1779 & 1,86 & 62,51 & 9 & 781 & 14 & 577 & 28 & 214 & 32 & 207 \\
\hline 76300080 & BRONCOPNEUMONIA & 15 & 1772 & 1,85 & 64,37 & 20 & 356 & 31 & 282 & 13 & 539 & 11 & 595 \\
\hline 35026014 & CESARIANA - EXCLUSIVAMENTE PARA HOSPITAIS AMIGOS & 16 & 1756 & 1,83 & 66,20 & 50 & 19 & 13 & 697 & 15 & 479 & 12 & 561 \\
\hline 43000002 & DIAGNOSTICO EIOU PRIMEIRO ATENDIMENTO EM CLINICA & 17 & 1686 & 1,76 & 67,96 & 19 & 381 & 24 & 335 & 14 & 483 & 14 & 487 \\
\hline 82500053 & DIABETE SACARINO & 18 & 1583 & 1,65 & 69,62 & 17 & 413 & 16 & 493 & 18 & 332 & 20 & 345 \\
\hline 33011117 & HERNIORRAFIA INGUINAL(UNILATERAL) & 19 & 1529 & 1,60 & 71,21 & 13 & 464 & 17 & 438 & 20 & 319 & 22 & 308 \\
\hline 75500124 & HEMORRAGIAS DIGESTIVAS & 20 & 1494 & 1,56 & 72,77 & 12 & 479 & 15 & 499 & 24 & 269 & 26 & 247 \\
\hline 71300007 & DIAGNOSTICO EIOU PRIMEIRO ATENDIMENTO EM CLINICA & 21 & 1392 & 1,45 & 74,23 & 48 & 65 & 50 & 68 & 8 & 788 & 15 & 471 \\
\hline 91500141 & COMPLICACOES DE PROCED. CIRURGICOS OU MEDICOS & 22 & 1261 & 1,32 & 75,54 & 16 & 434 & 20 & 375 & 33 & 195 & 24 & 257 \\
\hline 75500132 & PERITONITE & 23 & 1251 & 1,31 & 76,85 & 15 & 438 & 18 & 401 & 35 & 193 & 31 & 219 \\
\hline 76500233 & INSUFICIENCIA RESPIRATORIA AGUDA & 24 & 1225 & 1,28 & 78,13 & 22 & 283 & 30 & 290 & 17 & 333 & 21 & 319 \\
\hline 77500202 & VASCULOPATIAS PERIFERICAS & 25 & 1179 & 1,23 & 79,36 & 21 & 297 & 21 & 361 & 22 & 284 & 29 & 237 \\
\hline 76500225 & DOENCA PULMONAR OBSTRUTIVA CRONICA & 26 & 1110 & 1,16 & 80,52 & 24 & 253 & 23 & 342 & 29 & 214 & 23 & 301 \\
\hline 74300270 & ENTERO-INFECCOES (PEDIATRIA) & 27 & 1090 & 1,14 & 81,66 & 18 & 385 & 19 & 385 & 27 & 217 & 47 & 103 \\
\hline 77500121 & CRISE HIPERTENSIVA & 28 & 1044 & 1,09 & 82,75 & 27 & 240 & 22 & 359 & 31 & 200 & 27 & 245 \\
\hline 76500063 & PNEUMONIA NAO ESPECIFICADA & 29 & 1013 & 1,06 & 83,81 & 26 & 246 & 25 & 319 & 32 & 196 & 25 & 252 \\
\hline 72300019 & DESIDRATACAO AGUDA(PEDIATRIA) & 30 & 966 & 1,01 & 84,82 & 43 & 137 & 47 & 141 & 21 & 308 & 18 & 380 \\
\hline
\end{tabular}


Quadro 52 - Continuação

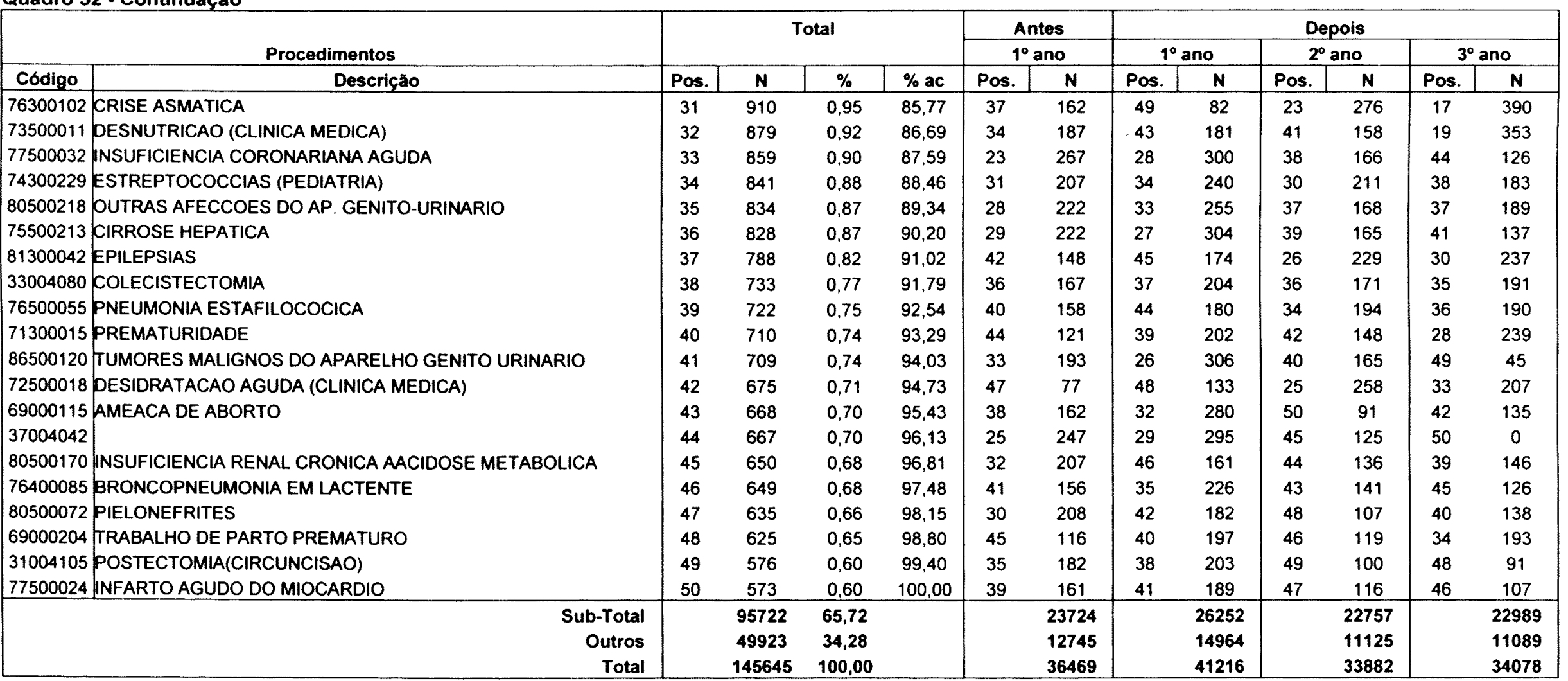


O procedimento mais freqüente foi Parto Normal com atendimento ao RN na sala de parto. Se considerarmos o "ranking" dos (50) cinqüenta procedimentos, corresponde a $11,06 \%$ do total das internações SUS e se considerarmos o total das internações SUS (periodos antes de depois) eles representaram $7,27 \%$ dos mesmos.

Seguindo essa linha, os demais procedimentos foram: Cesariana com atendimento RN na sala de parto $(8,66 \% ; 5,69 \%)$; Cirurgia Múltipla $(5,83 \% ; 13,83)$; Tratamento conservador do traumatismo crânio encefálico $(4,96 \% ; 3,26 \%)$; Diagnóstico e ou primeiro atendimento em Clínica Médica $(4,68 \% ; \quad 3,07 \%)$; Politraumatizado $(3,65 \% ; 2,40 \%)$; Parto normal exclusivamente para cirurgias da criança $(3,62 \% ; 2,40 \%)$; AVC agudo $(3,47 \%$ e $2,28 \%)$; Insuficiência cardíaca $(3,36 \% ; 2,21 \%)$; Tratamento de AIDS $(3,29 \%$; $2,16 \%)$.

Com relação à gestão semi plena, o procedimento parto normal manteve a $1^{\text {a }}$ posição antes e depois da implantação da gestão semi plena. Cesariana com atendimento a $R N$ na sala de parto ocupava a $3^{a}$ posição e foi para a $2^{\mathrm{a}}$; Cirurgia Múltipla ocupava a $2^{\mathrm{a}}$ posição e foi para a $10^{\mathrm{a}}$ posição no terceiro ano; Tratamento conservador do traumatismo crânio encefálico da $4^{\mathrm{a}}$ posição foi para a $6^{\mathbf{a}}$ posição. Diagnóstico e primeiro atendimento em Clínica Médica da $46^{a}$ posição foi para a $3^{a}$ posição. Politraumatizado do $10^{\circ}$ para a $7^{a}$ posição. Parto normal exclusivo para hospitais amigos das crianças estava na $49^{a}$ posição passando para o $4^{\circ}$ lugar (depois). Acidente Vascular Cerebral agudo manteve-se em $8^{\circ}$ lugar em ambas as posições; Insuficiência Cardiaca antes era $\circ 7^{\circ}$ e passou para $\circ 9^{\circ}$; Tratamento de AIDS era $\circ 6^{\circ}$ e passou para a $13^{\mathrm{a}}$ posição.

São Bernardo do Campo - Os 50 procedimentos mais freqüentes corresponderam a $60,76 \%$ do total das internações SUS realizadas no Municipio, sendo que antes da implantação da gestão semi plena 
representaram $57,07 \%$ das internações SUS; $65,28 \%$ e $62,26 \%$ nos três anos após, respectivamente. O Quadro 53 mostra esses resultados.

Destacam-se com variações:

- 71300007 - Diagnóstico e/ou Primeiro Atendimento em Clínica Pediátrica $40^{\circ}$ lugar ( $1^{\circ}$ ano antes); $9^{\circ}\left(1^{\circ}\right.$ ano depois); $2^{\circ}$ ( $2^{\circ}$ ano depois); $2^{\circ}$ ( $3^{\circ}$ ano depois).

- 34005030 - Curetagem Semiótica com ou sem Dilatação de Colo - $1^{\circ}$ lugar ( $1^{\circ}$ ano antes); $13^{\circ}$ ( $1^{\circ}$ ano depois); $33^{\circ}$ ( $2^{\circ}$ ano depois); $48^{\circ}$ ( $3^{\circ}$ ano depois).

- 39011151 - Redução Cirúrgica da Diafise da Tíbia, com Fixação - $38^{\circ}$ lugar ( $1^{\circ}$ ano antes); $4^{\circ}\left(1^{\circ}\right.$ ano depois); $5^{\circ}$ ( $2^{\circ}$ ano depois); $10^{\circ}\left(3^{\circ}\right.$ ano depois).

- 39011160 - Redução Cirúrgica das Fraturas de Tornozelo com F - $39^{\circ}$ lugar ( $1^{\circ}$ ano antes); $8^{\circ}$ ( $1^{\circ}$ ano depois); $10^{\circ}$ ( $2^{\circ}$ ano depois); $34^{\circ}$ ( $3^{\circ}$ ano depois).

- 72300019 - Desidratação Aguda (Pediatria) - $5^{\circ}$ lugar ( $1^{\circ}$ ano antes); $11^{\circ}\left(1^{\circ}\right.$ ano depois); $50^{\circ}$ ( $2^{\circ}$ ano depois); $50^{\circ}$ ( $3^{\circ}$ ano depois).

- 81500106 - AVC Agudo - $17^{\circ}$ lugar ( $1^{\circ}$ ano antes); $46^{\circ}$ (1 $1^{\circ}$ ano depois); $41^{\circ}$ ( $2^{\circ}$ ano depois); $35^{\circ}$ ( $3^{\circ}$ ano depois). 
Quadro 53 - Totais anuais de internaçōes SUS pelos 50 procedimentos mais freqüentes, ocorridos no Município de São Bernardo do Campo - SP, antes e depois da implantação da gestão semi-plena.

\begin{tabular}{|c|c|c|c|c|c|c|c|c|c|c|c|c|c|}
\hline \multirow{2}{*}{\multicolumn{2}{|c|}{ Procedimentos }} & \multirow{2}{*}{\multicolumn{4}{|c|}{ Total }} & \multirow{2}{*}{\multicolumn{2}{|c|}{$\begin{array}{l}\text { Antes } \\
1^{\circ} \text { ano }\end{array}$}} & \multicolumn{6}{|c|}{ Depois } \\
\hline & & & & & & & & \multicolumn{2}{|c|}{$1^{\circ}$ ano } & \multicolumn{2}{|c|}{$2^{\circ}$ ano } & \multicolumn{2}{|c|}{$3^{\circ}$ ano } \\
\hline Código & Descrição & Pos. & $\mathbf{N}$ & $\%$ & $\%$ ac & Pos. & $\mathbf{N}$ & Pos. & $\mathbf{N}$ & Pos. & $\mathbf{N}$ & Pos. & $\mathbf{N}$ \\
\hline 72500000 & DIAGNOSTICO E/OU PRIMEIRO ATENDIMENTO EM CLINICA MEDICA & 1 & 2761 & 15,81 & 15,81 & 30 & 24 & 2 & 228 & 1 & 1200 & 1 & 1309 \\
\hline 43000002 & DIAGNOSTICO E/OU PRIMEIRO ATENDIMENTO EM CLINICA CIRURGICA & 2 & 1325 & 7,58 & 23,39 & 2 & 246 & 1 & 415 & 3 & 345 & 3 & 319 \\
\hline 71300007 & DIAGNOSTICO EIOU PRIMEIRO ATENDIMENTO EM CLINICA PEDIATRICA & 3 & 1052 & 6,02 & 29,41 & 40 & 7 & 9 & 113 & 2 & 478 & 2 & 454 \\
\hline 39009130 & REDUCAO CIRURGICA DE FRATURA DA DIAFISE DO FEMUR, & 4 & 599 & 3,43 & 32,84 & 33 & 20 & 3 & 189 & 4 & 247 & 7 & 143 \\
\hline 38022010 & EXCISAO E ENXERTO DE PELE(HEMANGIOMA NEVUS OU TUMO & 5 & 537 & 3,07 & 35,92 & 4 & 153 & 7 & 123 & 6 & 146 & 11 & 115 \\
\hline 76300080 & BRONCOPNEUMONIA & 6 & 534 & 3,06 & 38.97 & 6 & 100 & 10 & 112 & 13 & 99 & 4 & 223 \\
\hline 34005030 & CURETAGEM SEMIOTICA COM OU SEM DILATACAO DE COLO & 7 & 437 & 2,50 & 41,47 & 1 & 261 & 13 & 104 & 33 & 52 & 48 & 20 \\
\hline 39011151 & REDUCAO CIRURGICA DA DIAFISE DA TIBIA, COM FIXACAO & 8 & 433 & 2,48 & 43.95 & 38 & 10 & 4 & 129 & 5 & 177 & 10 & 117 \\
\hline 76300102 & CRISE ASMATICA & 9 & 408 & 2,34 & 46,29 & 8 & 91 & 22 & 70 & 20 & 78 & 6 & 169 \\
\hline 76500071 & BRONCOPNEUMONIA & 10 & 396 & 2,27 & 48,55 & 11 & 68 & 28 & 56 & 18 & 80 & 5 & 192 \\
\hline 33011117 & HERNIORRAFIA INGUINAL(UNILATERAL) & 11 & 388 & 2,22 & 50,78 & 9 & 86 & 6 & 125 & 12 & 104 & 23 & 73 \\
\hline 39013081 & REDUC. CIR. FRAT. DOS OSSOS DO ANTE-BRACO COM FIXA & 12 & 384 & 2,20 & 52,97 & 42 & 4 & 5 & 127 & 7 & 145 & 17 & 108 \\
\hline 75500124 & HEMORRAGIAS DIGESTIVAS & 13 & 375 & 2.15 & 55.12 & 7 & 96 & 16 & 92 & 15 & 87 & 19 & 100 \\
\hline 31000002 & CIRURGIA MULTIPLA & 14 & 367 & 2,10 & 57,22 & 15 & 65 & 19 & 76 & 9 & 112 & 12 & 114 \\
\hline 77500121 & CRISE HIPERTENSIVA & 15 & 361 & 2,07 & 59,29 & 13 & 66 & 24 & 66 & 14 & 94 & 8 & 135 \\
\hline 80500218 & OUTRAS AFECCOES DO AP. GENITO-URINARIO & 16 & 356 & 2,04 & 61,33 & 19 & 42 & 20 & 75 & 8 & 114 & 9 & 125 \\
\hline 76400085 & BRONCOPNEUMONIA EM LACTENTE & 17 & 341 & 1,95 & 63,28 & 3 & 156 & 12 & 106 & 44 & 37 & 43 & 42 \\
\hline 33004080 & COLECISTECTOMIA & 18 & 336 & 1,92 & 65,20 & 16 & 63 & 18 & 81 & 17 & 82 & 14 & 110 \\
\hline 80500170 & INSUFICIENCIA RENAL CRONICA AACIDOSE METABOLICA & 19 & 320 & 1,83 & 67,03 & 12 & 67 & 26 & 59 & 16 & 85 & 15 & 109 \\
\hline 31003052 & PROSTATECTOMIA & 20 & 313 & 1,79 & 68,82 & 27 & 28 & 23 & 67 & 11 & 105 & 13 & 113 \\
\hline 36005045 & FACECTOMIA COM LENTE INTRA-OCULAR & 21 & 293 & 1,68 & 70,50 & 32 & 22 & 14 & 97 & 24 & 70 & 18 & 104 \\
\hline 39011160 & REDUCAO CIRURGICA DAS FRATURAS DO TORNOZELO, COM F & 22 & 286 & 1,64 & 72,14 & 39 & 9 & 8 & 115 & 10 & 111 & 34 & 51 \\
\hline 72300019 & DESIDRATACAO AGUDA(PEDIATRIA) & 23 & 273 & 1,56 & 73,70 & 5 & 132 & 11 & 109 & 50 & 18 & 50 & 14 \\
\hline 76300056 & BRONQUIOLITE AGUDA & 24 & 255 & 1,46 & 75,16 & 29 & 25 & 31 & 44 & 21 & 77 & 16 & 109 \\
\hline 72500018 & DESIDRATACAO AGUDA (CLINICA MEDICA) & 25 & 249 & 1,43 & 76,59 & 10 & 73 & 15 & 96 & 32 & 54 & 47 & 26 \\
\hline 31004105 & POSTECTOMLA(CIRCUNCISAO) & 26 & 228 & 1,31 & 77,89 & 23 & 36 & 17 & 85 & 38 & 48 & 28 & 59 \\
\hline 33016119 & LAPAROTOMIA EXPLORADORA & 27 & 214 & 1,23 & 79,12 & 24 & 36 & 25 & 64 & 28 & 56 & 30 & 58 \\
\hline 82500053 & DIABETE SACARINO & 28 & 205 & 1,17 & 80,29 & 18 & 47 & 39 & 32 & 27 & 60 & 25 & 66 \\
\hline 39004210 & RETIRADA DE PLACA E PARAFUSO & 29 & 185 & 1,06 & 81,35 & 48 & 0 & 42 & 27 & 23 & 72 & 20 & 86 \\
\hline 38011018 & ISUTURA DE FERIDA COM OU SEM DEBRIDAMENTO & 30 & 183 & 1,05 & 82,40 & 28 & 27 & 37 & 34 & 25 & 65 & 31 & 57 \\
\hline
\end{tabular}


Quadro 53 - Continuação

\begin{tabular}{|c|c|c|c|c|c|c|c|c|c|c|c|c|c|}
\hline \multirow{2}{*}{\multicolumn{2}{|c|}{ Procedimentos }} & \multirow{2}{*}{\multicolumn{4}{|c|}{ Total }} & \multirow{2}{*}{\multicolumn{2}{|c|}{$\begin{array}{l}\text { Antes } \\
1^{\circ} \text { ano }\end{array}$}} & \multicolumn{6}{|c|}{ Depois } \\
\hline & & & & & & & & \multicolumn{2}{|c|}{$1^{\circ}$ ano } & \multicolumn{2}{|c|}{$2^{\circ}$ ano } & \multicolumn{2}{|c|}{$3^{\circ}$ ano } \\
\hline \multicolumn{2}{|r|}{ Descriçăo } & Pos. & $\mathbf{N}$ & $\%$ & $\%$ ac & Pos. & $\mathbf{N}$ & Pos. & $\mathbf{N}$ & Pos. & $\mathbf{N}$ & Pos. & $\mathbf{N}$ \\
\hline 39009068 & REDUCAO CIRURGICA DE FRATURAS DE DIAFASE DO UMERO, & 31 & 179 & 1,02 & 83,42 & 43 & 3 & 36 & 40 & 22 & 77 & 29 & 59 \\
\hline 42002079 & EXTIRPACAO DE TUMOR OU ADENOMA & 32 & 179 & 1,02 & 84,45 & 14 & 66 & 21 & 71 & 49 & 27 & 49 & 15 \\
\hline 77500113 & INSUFICIENCIA CARDIACA & 33 & 177 & 1,01 & 85,46 & 25 & 29 & 38 & 34 & 42 & 41 & 24 & 73 \\
\hline 91500079 & TRAUMATISMOS CRANIOENCEFALICO & 34 & 176 & 1,01 & 86,47 & 22 & 38 & 30 & 45 & 39 & 46 & 38 & 47 \\
\hline 75500299 & AFECCOES PANCREATICAS & 35 & 171 & 0,98 & 87,45 & 20 & 40 & 40 & 31 & 30 & 55 & 41 & 45 \\
\hline 81500106 & AVC AGUDO & 36 & 168 & 0,96 & 88,41 & 17 & 49 & 46 & 24 & 41 & 44 & 35 & 51 \\
\hline 39013073 & REDUC. CIR. FRAT. DOS OSSOS DO COTOVELO COM FIXACA & 37 & 166 & 0,95 & 89,36 & 44 & 3 & 27 & 57 & 19 & 79 & 46 & 27 \\
\hline 36001112 & CORRECAO CIRUGICA DO ESTRABISMO & 38 & 159 & 0,91 & 90,27 & 34 & 16 & 35 & 42 & 35 & 51 & 36 & 50 \\
\hline 40007049 & NEUROLISE & 39 & 154 & 0,88 & 91,15 & 46 & 1 & 49 & 14 & 29 & 56 & 22 & 83 \\
\hline 34001042 & SALPINGECTOMIA UNI OU BILATERAL & 40 & 149 & 0,85 & 92,00 & 41 & 5 & 29 & 48 & 40 & 46 & 37 & 50 \\
\hline 77500202 & NASCULOPATIAS PERIFERICAS & 41 & 149 & 0,85 & 92,86 & 36 & 13 & 43 & 27 & 26 & 62 & 39 & 47 \\
\hline 39002217 & RETIRADA DE FIO DE KIRSCHNER TRANS-OSSEO & 42 & 146 & 0,84 & 93,69 & 49 & 0 & 32 & 44 & 31 & 55 & 40 & 47 \\
\hline 75500094 & OBSTRUCAO INTESTINAL & 43 & 146 & 0,84 & 94,53 & 26 & 29 & 44 & 25 & 43 & 39 & 32 & 53 \\
\hline 77500024 & INFARTO AGUDO DO MIOCARDIO & 44 & 145 & 0,83 & 95,36 & 21 & 40 & 47 & 20 & 46 & 33 & 33 & 52 \\
\hline 39003124 & ARTROPLASTIA COXO-FEMURAL & 45 & 140 & 0,80 & 96,16 & 47 & 1 & 41 & 28 & 36 & 50 & 27 & 61 \\
\hline 39020100 & RED CIRUR DE FRAT DOS METACARPIANOS C/FIXACAO & 46 & 140 & 0,80 & 96,96 & 45 & 2 & 33 & 43 & 34 & 52 & 42 & 43 \\
\hline 81500076 & EPILEPSIAS & 47 & 138 & 0,79 & 97,75 & 31 & 23 & 45 & 25 & 37 & 49 & 45 & 41 \\
\hline 77500032 & INSUFICIENCIA CORONARIANA AGUDA & 48 & 133 & 0,76 & 98.51 & 35 & 16 & 48 & 19 & 47 & 33 & 26 & 65 \\
\hline 39015130 & TRATAMENTO CIRURGICO DE OSTEOMIELITE DO FEMUR & 49 & 131 & 0,75 & 99,26 & 50 & 0 & 50 & 13 & 45 & 34 & 21 & 84 \\
\hline 34010033 & HISTERECTOMIA TOTAL & 50 & 129 & 0,74 & 100,00 & 37 & 12 & 34 & 43 & 48 & 32 & 44 & 42 \\
\hline & Sub-Total & & 17469 & 60,76 & & & 2446 & & 3809 & & 5459 & & 5755 \\
\hline & Outros & & 11281 & 39,24 & & & 1840 & & 3048 & & 2904 & & 3489 \\
\hline & Total & & 28750 & 100,00 & & & 4286 & & 6857 & & 8363 & & 9244 \\
\hline
\end{tabular}


Os 11 (onze) primeiros procedimentos mais freqüentes corresponderam a $50,78 \%$ do total das internações SUS.

O procedimento mais freqüente foi Diagnóstico e ou Primeiro atendimento a Clinica Médica. Se considerarmos o "ranking" dos (50) cinqüenta procedimentos, corresponde a $15,81 \%$ do total das internações SUS.

Se considerarmos o total de internações SUS (periodos antes e depois) eles representaram $9,60 \%$ dos mesmos.

Seguindo essa linha, os demais procedimentos foram: Diagnóstico e ou Primeiro atendimento em Clínica Cirúrgica $(7,58 \% ; 4,61 \%)$; Diagnóstico e atendimento em Clinica Pediátrica $(6,02 \% ; 3,66 \%)$; Redução Cirúrgica de fratura da diáfise do fêmur $(3,43 \% ; 2,08 \%)$; Excisão e enxerto de pele (hemangioma nervas ou TUMO) $(3,07 \% ; 1,87 \%)$; Broncopneumonia $(3,06 \%$; $1,86 \%)$; Curetagem semiótica com ou sem dilatação do colo $(2,50 \% ; 1,52 \%)$; Redução Cirúrgica da diáfise da tíbia com fixação $(2,48 \%$ e $1,51 \%)$; Crise asmática $(2,34 \% ; 1,42 \%)$; Broncopneumonia $(2,27 \% ; 1,38 \%)$; Herniorrafia inguinal (unilateral) $(2,22 \% ; 1,35 \%)$.

O diagnóstico e ou Primeiro atendimento em Clínica Médica ocupava a $30^{\mathrm{a}}$ posição antes da implantação da gestão semi plena passando para a $1^{\mathrm{a}}$ depois; Diagnóstico e ou Primeiro atendimento em Clínica Cirúrgica era a $1^{\text {a }}$ posição antes, passou para a $3^{\mathrm{a}}$; Diagnóstico e ou Primeiro atendimento Clínica Pediátrica era $40 \%$ e após veio para a $2^{\mathrm{a}}$ posição; Redução Cirúrgica de fratura de diáfise do fêmur era $33^{a}$ e passou à $7^{a}$ posição; Excisão e enxerto de pele (hemagioma nevus ou tumo) era da $4^{a}$ posição e passou para a $11^{a}$ posição. Bronco Pneumonia era $6^{a}$ posição passou para a $4^{a}$ posição; Curetagem semiótica com ou sem dilatação do colo era a $1^{a}$ posição passou para Redução Cirúrgica da diáfise de tíbia com fixação era $38^{a}$ e passou para a $10^{a}$ posição; 
Crise asmática ocupava a $8^{a}$ posição e passou para a $6^{a}$ posição; Bronco pneumonia ocupava a $11^{\mathrm{a}}$ posição e passou para a $5^{\mathrm{a}}$ posição; Hemorragia inguinal (unilateral) ocupava a $9^{\mathrm{a}}$ e passou para a $23^{\mathrm{a}}$ posição.

São José dos Campos - Os 50 procedimentos mais freqüentes corresponderam a $69,47 \%$ do total das internações SUS realizadas no Município, sendo que antes da implantação da gestão semi plena representaram $68,85 \%$ das internações SUS; $68,82 \%, 70,87 \%$ e $69,39 \%$ nos três anos, respectivamente.

Os 06 (seis) primeiros procedimentos mais freqüentes corresponderam a $50,56 \%$ do total das internações SUS, são mostrados no Quadro 54.

Destacam-se as variações:

- 350001011 - Parto Normal - $3^{\circ}$ lugar ( $1^{\circ}$ ano antes); $20^{\circ}$ ( $1^{\circ}$ ano depois); $28^{\circ}$ ( $2^{\circ}$ ano depois); $33^{\circ}$ ( $3^{\circ}$ ano depois).

- 71300007 - Diagnóstico e/ou Primeiro Atendimento em Clínica Pediátrica $12^{\circ}$ lugar ( $1^{\circ}$ ano antes); $15^{\circ}\left(1^{\circ}\right.$ ano depois); $4^{\circ}\left(2^{\circ}\right.$ ano depois); $4^{\circ}\left(3^{\circ}\right.$ ano depois).

- 77500121 - Crise Hipertensiva - $27^{\circ}$ lugar ( $1^{\circ}$ ano antes); $26^{\circ}$ ( $1^{\circ}$ ano depois); $20^{\circ}$ ( $2^{\circ}$ ano depois); $12^{\circ}$ ( $3^{\circ}$ ano depois).

- 39000001 - Politraumatizado - $26^{\circ}$ lugar ( $1^{\circ}$ ano antes); $36^{\circ}\left(1^{\circ}\right.$ ano depois); $30^{\circ}$ ( $2^{\circ}$ ano depois); $24^{\circ}$ ( $3^{\circ}$ ano depois).

- 35009012 - Cesariana - $7^{\circ}$ lugar ( $1^{\circ}$ ano antes); $50^{\circ}\left(1^{\circ}\right.$ ano depois); $50^{\circ}\left(2^{\circ}\right.$ ano depois); $50^{\circ}$ ( $3^{\circ}$ ano depois).

- 76400271 - Entero Infecções em Lactente - $24^{\circ}$ lugar ( $1^{\circ}$ ano antes); $24^{\circ}\left(1^{\circ}\right.$ ano depois); $38^{\circ}$ ( $2^{\circ}$ ano depois); $48^{\circ}$ ( $3^{\circ}$ ano depois). 
Quadro 54 - Totais anuais de internaçōes SUS pelos 50 procedimentos mais freqüentes, ocorridos no Município de São José dos Campos - SP, antes e depois da implantação da gestão semi-plena.

\begin{tabular}{|c|c|c|c|c|c|c|c|c|c|c|c|c|c|}
\hline \multirow{2}{*}{\multicolumn{2}{|c|}{ Procedimentos }} & \multirow{2}{*}{\multicolumn{4}{|c|}{ Total }} & \multirow{2}{*}{\multicolumn{2}{|c|}{$\begin{array}{r}\text { Antes } \\
1^{\circ} \text { ano }\end{array}$}} & \multicolumn{6}{|c|}{ Depois } \\
\hline & & & & & & & & \multicolumn{2}{|l|}{$1^{\circ}$ ano } & \multicolumn{2}{|c|}{$2^{\circ}$ ano } & \multicolumn{2}{|c|}{$3^{\circ}$ ano } \\
\hline Código & Descriçăo & Pos. & $\mathbf{N}$ & $\%$ & $\%$ ac & Pos. & $\mathbf{N}$ & Pos. & $\mathbf{N}$ & Pos. & $\mathbf{N}$ & Pos. & $\mathbf{N}$ \\
\hline 35021012 & PARTO NORMAL COM ATENDIMENTO RN SALA DE PARTO & 1 & 11377 & 20,22 & 20,22 & 1 & 2036 & 1 & 3209 & 1 & 2972 & 1 & 3160 \\
\hline 35022019 & CESARIANA COM ATENDIMENTO RN SALA DE PARTO & 2 & 8358 & 14,85 & 35,07 & 2 & 1765 & 2 & 2318 & 2 & 2249 & 2 & 2026 \\
\hline 72500000 & DIAGNOSTICO E/OU PRIMEIRO ATENDIMENTO EM CLINICA MEDICA & 3 & 2698 & 4,79 & 39,87 & 6 & 457 & 5 & 423 & 3 & 903 & 3 & 915 \\
\hline 35014016 & CURETAGEM POS-ABORTO & 4 & 2242 & 3,98 & 43,85 & 5 & 587 & 3 & 660 & 6 & 462 & 5 & 533 \\
\hline 77500113 & INSUFICIENCIA CARDIACA & 5 & 2082 & 3,70 & 47,55 & 4 & 620 & 4 & 539 & 7 & 437 & 6 & 486 \\
\hline 35001011 & PARTO NORMAL & 6 & 1692 & 3,01 & 50,56 & 3 & 1272 & 20 & 181 & 28 & 135 & 33 & 104 \\
\hline 71300007 & DIAGNOSTICO E/OU PRIMEIRO ATENDIMENTO EM CLINICA PEDIATRICA & 7 & 1652 & 2,94 & 53,49 & 12 & 306 & 15 & 228 & 4 & 520 & 4 & 598 \\
\hline 76300102 & CRISE ASMATICA & 8 & 1437 & 2,55 & 56,05 & 13 & 273 & 8 & 326 & 5 & 463 & 7 & 375 \\
\hline 81500106 & AVC AGUDO & 9 & 1224 & 2,18 & 58,22 & 8 & 352 & 9 & 317 & 11 & 249 & 8 & 306 \\
\hline 76400085 & BRONCOPNEUMONIA EM LACTENTE & 10 & 1162 & 2.07 & 60,29 & 9 & 328 & 6 & 359 & 8 & 326 & 23 & 149 \\
\hline 33011117 & HERNIORRAFIA INGUINAL(UNILATERAL) & 11 & 1101 & 1,96 & 62,25 & 15 & 220 & 7 & 331 & 9 & 324 & 11 & 226 \\
\hline 76300072 & OUTRAS PNEUMONIAS & 12 & 1002 & 1,78 & 64,03 & 16 & 216 & 14 & 237 & 10 & 253 & 9 & 296 \\
\hline 76500047 & PNEUMONIA BACTERIANA & 13 & 982 & 1,75 & 65,77 & 11 & 307 & 10 & 304 & 17 & 178 & 15 & 193 \\
\hline 82500053 & DIABETE SACARINO & 14 & 935 & 1,66 & 67,43 & 14 & 239 & 11 & 287 & 13 & 214 & 14 & 195 \\
\hline 76300080 & BRONCOPNEUMONIA & 15 & 876 & 1,56 & 68,99 & 10 & 315 & 13 & 238 & 27 & 137 & 16 & 186 \\
\hline 33005060 & APENDICECTOMIA & 16 & 835 & 1,48 & 70,47 & 21 & 186 & 23 & 180 & 12 & 217 & 10 & 252 \\
\hline 69000115 & AMEACA DE ABORTO & 17 & 760 & 1,35 & 71,82 & 23 & 170 & 16 & 222 & 15 & 201 & 21 & 167 \\
\hline 76500225 & DOENCA PULMONAR OBSTRUTIVA CRONICA & 18 & 733 & 1,30 & 73,13 & 20 & 198 & 21 & 181 & 18 & 176 & 19 & 178 \\
\hline 77500121 & CRISE HIPERTENSIVA & 19 & 711 & 1,26 & 74,39 & 27 & 149 & 26 & 175 & 20 & 167 & 12 & 220 \\
\hline 33004080 & COLECISTECTOMIA & 20 & 684 & 1,22 & 75,61 & 18 & 208 & 25 & 176 & 14 & 205 & 37 & 95 \\
\hline 70000000 & TRATAMENTO DA AIDS & 21 & 674 & 1,20 & 76,80 & 17 & 210 & 17 & 220 & 24 & 147 & 35 & 97 \\
\hline 71300015 & PREMATURIDADE & 22 & 668 & 1,19 & 77,99 & 30 & 133 & 19 & 189 & 21 & 167 & 18 & 179 \\
\hline 74300270 & ENTERO-INFECCOES (PEDIATRIA) & 23 & 646 & 1,15 & 79,14 & 25 & 153 & 22 & 181 & 16 & 182 & 27 & 130 \\
\hline 75500124 & HEMORRAGIAS DIGESTIVAS & 24 & 640 & 1,14 & 80,28 & 22 & 177 & 28 & 159 & 26 & 146 & 22 & 158 \\
\hline 77500024 & INFARTO AGUDO DO MIOCARDIO & 25 & 621 & 1,10 & 81,38 & 28 & 143 & 18 & 192 & 25 & 147 & 26 & 139 \\
\hline 69000204 & TRABALHO DE PARTO PREMATURO & 26 & 597 & 1,06 & 82,44 & 32 & 119 & 29 & 146 & 23 & 152 & 17 & 180 \\
\hline 39000001 & POLITRAUMATIZADO & 27 & 543 & 0,97 & 83,41 & 26 & 153 & 36 & 109 & 30 & 133 & 24 & 148 \\
\hline 72500018 & DESIDRATACAO AGUDA (CLINICA MEDICA) & 28 & 523 & 0,93 & 84,34 & 36 & 110 & 12 & 244 & 36 & 95 & 41 & 74 \\
\hline
\end{tabular}


Quadro 54 - Continuação

\begin{tabular}{|c|c|c|c|c|c|c|c|c|c|c|c|c|c|}
\hline \multirow{2}{*}{\multicolumn{2}{|c|}{ Procedimentos }} & \multirow{2}{*}{\multicolumn{4}{|c|}{ Total }} & \multirow{2}{*}{\multicolumn{2}{|c|}{$\begin{array}{l}\text { Antes } \\
1^{\circ} \text { ano }\end{array}$}} & \multicolumn{6}{|c|}{ Depois } \\
\hline & & & & & & & & \multicolumn{2}{|l|}{$1^{\circ}$ ano } & \multicolumn{2}{|l|}{$2^{\circ}$ ano } & \multicolumn{2}{|l|}{$3^{\circ}$ ano } \\
\hline \multicolumn{2}{|r|}{ Descrição } & Pos. & $\mathbf{N}$ & $\%$ & $\%$ ac & \multicolumn{2}{|c|}{$\begin{array}{l}1^{\circ} \text { ano } \\
\text { Pos. }\end{array}$} & Pos. & $\mathbf{N}$ & Pos. & $\mathbf{N}$ & Pos. & $\mathbf{N}$ \\
\hline 76400077 & PNEUMONIAS DO LACTENTE & 29 & 522 & 0,93 & 85,26 & 33 & 116 & 27 & 161 & 29 & 135 & 32 & 110 \\
\hline 80500218 & OUTRAS AFECCOES DO AP. GENITO-URINARIO & 30 & 518 & 0,92 & 86,18 & 44 & 82. & 30 & 138 & 33 & 126 & 20 & 172 \\
\hline 35009012 & CESARIANA & 31 & 510 & 0,91 & 87,09 & 7 & 405 & 50 & 55 & 50 & 32 & 50 & 18 \\
\hline 76500063 & PNEUMONIA NAO ESPECIFICADA & 32 & 502 & 0,89 & 87,98 & 50 & 35 & 39 & 85 & 19 & 171 & 13 & 211 \\
\hline 80500072 & PIELONEFRITES & 33 & 499 & 0,89 & 88,87 & 31 & 123 & 33 & 120 & 31 & 128 & 28 & 128 \\
\hline 76400271 & ENTERO-INFECCOES EM LACTENTE & 34 & 484 & 0,86 & 89,73 & 24 & 167 & 24 & 177 & 38 & 93 & 48 & 47 \\
\hline 80500170 & INSUFICIENCIA RENAL CRONICA AACIDOSE METABOLICA & 35 & 459 & 0,82 & 90,55 & 19 & 203 & 47 & 73 & 43 & 80 & 34 & 103 \\
\hline 75500213 & CIRROSE HEPATICA & 36 & 455 & 0,81 & 91,35 & 29 & 134 & 31 & 133 & 39 & 92 & 36 & 96 \\
\hline 76500128 & CRISE ASMATICA & 37 & 425 & 0,76 & 92,11 & 37 & 106 & 40 & 83 & 40 & 92 & 25 & 144 \\
\hline 31004105 & POSTECTOMIA(CIRCUNCISAO) & 38 & 414 & 0,74 & 92,85 & 48 & 50 & 34 & 115 & 22 & 159 & 39 & 90 \\
\hline 77500032 & INSUFICIENCIA CORONARIANA AGUDA & 39 & 409 & 0,73 & 93,57 & 35 & 112 & 35 & 111 & 41 & 92 & 38 & 94 \\
\hline 72300019 & DESIDRATACAO AGUDA(PEDIATRIA) & 40 & 397 & 0,71 & 94,28 & 46 & 74 & 45 & 77 & 32 & 127 & 29 & 119 \\
\hline 34005030 & CURETAGEM SEMIOTICA COM OU SEM DILATACAO DE COLO & 41 & 369 & 0,66 & 94,93 & 42 & 92 & 37 & 102 & 34 & 109 & 43 & 66 \\
\hline 76300056 & BRONQUIOLITE AGUDA & 42 & 362 & 0,64 & 95,58 & 45 & 81 & 48 & 71 & 37 & 95 & 30 & 115 \\
\hline 33016119 & LAPAROTOMIA EXPLORADORA & 43 & 333 & 0,59 & 96,17 & 38 & 105 & 41 & 83 & 45 & 68 & 40 & 77 \\
\hline 71300112 & OUTRAS AFECCOES DO RECEM-NASCIDO & 44 & 325 & 0,58 & 96,75 & 34 & 113 & 32 & 123 & 49 & 35 & 47 & 54 \\
\hline 31000002 & CIRURGIA MULTIPLA & 45 & 322 & 0,57 & 97,32 & 39 & 95 & 42 & 81 & 42 & 91 & 46 & 55 \\
\hline 43000002 & DIAGNOSTICO EIOU PRIMEIRO ATENDIMENTO EM CLINICA CIRURGICA & 46 & 318 & 0,57 & 97,88 & 40 & 95 & 38 & 100 & 47 & 60 & 45 & 63 \\
\hline 40001008 & TRATAMENTO CONSERVADOR DO TRAUMATISMO CRANEO-ENCEFALICO & 47 & 306 & 0,54 & 98,43 & 49 & 43 & 46 & 77 & 44 & 75 & 31 & 111 \\
\hline 39027139 & TRAT.CONSERV.DE FRAT.NIVEL SUP.DO FEMUR SEM APAREL & 48 & 300 & 0,53 & 98,96 & 41 & 95 & 43 & 80 & 48 & 59 & 44 & 66 \\
\hline 34010033 & HISTERECTOMIA TOTAL & 49 & 294 & 0,52 & 99,48 & 47 & 66 & 44 & 79 & 35 & 104 & 49 & 45 \\
\hline \multirow[t]{4}{*}{77500202} & VASCULOPATIAS PERIFERICAS & 50 & 291 & 0,52 & 100,00 & 43 & 89 & 49 & 69 & 46 & 64 & 42 & 69 \\
\hline & Sub-Total & & 56269 & 69,47 & & & 13883 & & 14524 & & 14044 & & 13818 \\
\hline & Outros & & 24729 & 30,53 & & & 6281 & & 6580 & & 5772 & & 6096 \\
\hline & Total & & 80998 & 100,00 & & & 20164 & & 21104 & & 19816 & & 19914 \\
\hline
\end{tabular}


O procedimento mais freqüente foi Parto normal com atendimento ao RN na sala de parto. Se considerarmos o "ranking" dos (50) cinqüenta procedimentos, corresponde a $20,22 \%$ do total das internações SUS.

Se considerarmos o total de internações SUS (periodos antes e depois) eles representaram $14,05 \%$ dos mesmos.

Seguido por Cesariana com atendimento ao RN (14,85\%; $10,32 \%)$; Diagnóstico e ou Primeiro atendimento em Clínica Médica $(4,79 \% ; 3,33 \%$ ); Curetagem pós aborto $(3,98 \% ; 2,77 \%)$; Insuficiência cardiaca $(3,70 \% ; 2,57 \%)$; Parto normal $(3,01 \% ; 2,09 \%)$.

Com relação à gestão semi plena, os procedimentos partos normal com atendimento ao $\mathrm{RN}$ e curetagem pós aborto não se alteraram. Diagnóstico e ou primeiro atendimento em Clínica Médica ocupava a $6^{a}$ posição e passou para a $3^{a}$ posição. Parto normal ocupava a $3^{a}$ posição antes e foi para a $33^{a}$ posição depois da implantação.

Sertãozinho, - Os 50 procedimentos mais freqüentes corresponderam a $75,33 \%$ do total das internações SUS realizadas no Município, sendo que antes da implantação da gestão semi plena representaram $76,96 \%$ das internações SUS e $75,98 \%, 73,93 \%$ e $73,52 \%$ nos três anos, respectivamente.

Os 09 (nove) primeiros procedimentos mais freqüentes corresponderam a $51,51 \%$ do total das internações SUS, conforme mostra o Quadro 55.

Destacam-se as variações:

- 72500000 - Diagnóstico e/ou Primeiro Atendimento em Clinica Médica - $19^{\circ}$ lugar ( $1^{\circ}$ ano antes); $46^{\circ}$ ( $1^{\circ}$ ano depois); $8^{\circ}$ ( $2^{\circ}$ ano depois); $3^{\circ}\left(3^{\circ}\right.$ ano depois). 
Quadro 55 - Totais anuais de internações SUS pelos 50 procedimentos mais freqüentes, ocorridos no Municipio de Sertãozinho - SP, antes e depois da implantação da gestão semi-plena.

\begin{tabular}{|c|c|c|c|c|c|c|c|c|c|c|c|c|c|}
\hline \multirow{2}{*}{\multicolumn{2}{|c|}{ Procedimentos }} & \multirow{2}{*}{\multicolumn{4}{|c|}{ Total }} & \multirow{2}{*}{\multicolumn{2}{|c|}{$\begin{array}{l}\text { Antes } \\
1^{\circ} \text { ano }\end{array}$}} & \multicolumn{6}{|c|}{ Depois } \\
\hline & & & & & & & & \multicolumn{2}{|c|}{$1^{\circ}$ ano } & \multicolumn{2}{|c|}{$2^{\circ}$ ano } & \multicolumn{2}{|c|}{$3^{\circ}$ ano } \\
\hline Código & Descriçăo & Pos. & $\mathbf{N}$ & $\%$ & $\%$ ac & Pos. & $\mathbf{N}$ & Pos. & $\mathbf{N}$ & Pos. & $\mathbf{N}$ & Pos. & $\mathbf{N}$ \\
\hline 35022019 & CESARIANA COM ATENDIMENTO RN SALA DE PARTO & 1 & 2076 & 14,80 & 14,80 & 1 & 618 & 1 & 485 & 1 & 477 & 1 & 496 \\
\hline 35021012 & PARTO NORMAL COM ATENDIMENTO RN SALA DE PARTO & 2 & 1800 & 12,84 & 27,64 & 2 & 446 & 2 & 482 & 2 & 443 & 2 & 429 \\
\hline 35014016 & CURETAGEM POS-ABORTO & 3 & 685 & 4,88 & 32,52 & 6 & 204 & 4 & 168 & 3 & 171 & 4 & 142 \\
\hline 69000204 & TRABALHO DE PARTO PREMATURO & 4 & 682 & 4,86 & 37,39 & 4 & 241 & 3 & 185 & 4 & 132 & 5 & 124 \\
\hline 76500063 & PNEUMONIA NAO ESPECIFICADA & 5 & 559 & 3,99 & 41,37 & 5 & 226 & 6 & 122 & 5 & 107 & 6 & 104 \\
\hline 77500113 & INSUFICIENCIA CARDIACA & 6 & 487 & 3,47 & 44,84 & 7 & 183 & 5 & 140 & 6 & 85 & 7 & 79 \\
\hline 72500000 & DIAGNOSTICO E/OU PRIMEIRO ATENDIMENTO EM CLINICA MEDICA & 7 & 329 & 2,35 & 47,19 & 19 & 73 & 46 & 19 & 8 & 61 & 3 & 176 \\
\hline 80500072 & PIELONEFRITES & 8 & 304 & 2,17 & 49,36 & 10 & 112 & 9 & 75 & 7 & 63 & 14 & 54 \\
\hline 35001011 & PARTO NORMAL & 9 & 302 & 2,15 & 51,51 & 3 & 252 & 19 & 50 & 50 & 0 & 50 & 0 \\
\hline 76500225 & DOENCA PULMONAR OBSTRUTIVA CRONICA & 10 & 285 & 2,03 & 53,54 & 11 & 112 & 8 & 79 & 12 & 53 & 22 & 41 \\
\hline 83500022 & LUMBAGO AGUDO & 11 & 284 & 2,03 & 55,57 & 8 & 131 & 17 & 56 & 22 & 40 & 13 & 57 \\
\hline 81500106 & AVC AGUDO & 12 & 267 & 1,90 & 57,47 & 12 & 108 & 10 & 73 & 23 & 40 & 18 & 46 \\
\hline 76300072 & OUTRAS PNEUMONIAS & 13 & 265 & 1,89 & 59,36 & 9 & 114 & 21 & 48 & 10 & 56 & 16 & 47 \\
\hline 76400271 & ENTERO-INFECCOES EM LACTENTE & 14 & 257 & 1,83 & 61,20 & 20 & 70 & 14 & 59 & 9 & 60 & 8 & 68 \\
\hline 91500125 & LESOES SUPERFICIAIS INFECTADAS & 15 & 254 & 1,81 & 63,01 & 14 & 94 & 13 & 66 & 13 & 51 & 21 & 43 \\
\hline 33005060 & APENDICECTOMIA & 16 & 246 & 1,75 & 64,76 & 17 & 81 & 11 & 67 & 24 & 38 & 10 & 60 \\
\hline 74500252 & ENTERO-INFECCOES (CLINICA MEDICA) & 17 & 239 & 1,70 & 66,46 & 16 & 86 & 7 & 80 & 16 & 47 & 34 & 26 \\
\hline 75500124 & HEMORRAGIAS DIGESTIVAS & 18 & 236 & 1,68 & 68,15 & 18 & 78 & 16 & 57 & 11 & 56 & 20 & 45 \\
\hline 76400077 & PNEUMONIAS DO LACTENTE & 19 & 224 & 1,60 & 69,74 & 26 & 60 & 15 & 58 & 17 & 46 & 11 & 60 \\
\hline 74300270 & ENTERO-INFECCOES (PEDIATRIA) & 20 & 220 & 1,57 & 71,31 & 15 & 89 & 12 & 67 & 27 & 37 & 29 & 27 \\
\hline 33011117 & HERNIORRAFIA INGUINAL(UNILATERAL) & 21 & 215 & 1,53 & 72,85 & 27 & 59 & 22 & 47 & 15 & 48 & 9 & 61 \\
\hline 76500047 & PNEUMONIA BACTERIANA & 22 & 204 & 1,45 & 74,30 & 22 & 65 & 27 & 40 & 21 & 41 & 12 & 58 \\
\hline
\end{tabular}




\begin{tabular}{|c|c|c|c|c|c|c|c|c|c|c|c|c|c|}
\hline \multirow{2}{*}{\multicolumn{2}{|c|}{ Procedimentos }} & \multirow{2}{*}{\multicolumn{4}{|c|}{ Total }} & \multirow{2}{*}{\multicolumn{2}{|c|}{$\begin{array}{l}\text { Antes } \\
1^{\circ} \text { ano }\end{array}$}} & \multicolumn{6}{|c|}{ Depois } \\
\hline & & & & & & & & \multicolumn{2}{|c|}{$1^{\circ}$ ano } & \multicolumn{2}{|c|}{$2^{\circ}$ ano } & \multicolumn{2}{|c|}{$3^{\circ}$ ano } \\
\hline \multicolumn{2}{|r|}{ Descriçăo } & Pos. & $\mathrm{N}$ & \multirow{2}{*}{$\begin{array}{c}\% \\
138\end{array}$} & $\%$ ac & Pos. & $\mathbf{N}$ & Pos. & \multirow{2}{*}{$\begin{array}{l}\mathrm{N} \\
41\end{array}$} & \multirow{2}{*}{$\begin{array}{c}\text { Pos. } \\
18\end{array}$} & \multirow{2}{*}{$\begin{array}{c}N \\
46\end{array}$} & Pos. & $\mathbf{N}$ \\
\hline 34005030 & CURETAGEM SEMIOTICA COM OU SEM DILATACAO DE COLO & 23 & 194 & & 75,68 & 21 & 66 & 26 & & & & 23 & 41 \\
\hline 34010033 & HISTERECTOMIA TOTAL & 24 & 184 & 1,31 & 77,00 & 30 & 52 & 24 & 45 & 19 & 46 & 24 & 41 \\
\hline 77500121 & CRISE HIPERTENSIVA & 25 & 165 & 1,18 & 78,17 & 23 & 65 & 20 & 50 & 36 & 26 & 38 & 24 \\
\hline 69000077 & HIPEREMESE GRAVIDICA (FORMA MEDIA) & 26 & 162 & 1,16 & 79,33 & 31 & 52 & 18 & 52 & 31 & 30 & 28 & 28 \\
\hline 82500053 & DIABETE SACARINO & 27 & 161 & 1,15 & 80,48 & 28 & 55 & 23 & 46 & 33 & 28 & 27 & 32 \\
\hline 73500011 & DESNUTRICAO (CLINICA MEDICA) & 28 & 153 & 1,09 & 81,57 & 13 & 98 & 37 & 29 & 47 & 14 & 49 & 12 \\
\hline 34008020 & COLPOPERINEOPLASTIA ANTERIOR E POSTERIOR & 29 & 149 & 1,06 & 82,63 & 36 & 44 & 25 & 42 & 28 & 36 & 30 & 27 \\
\hline 76400085 & BRONCOPNEUMONIA EM LACTENTE & 30 & 146 & 1,04 & 83,67 & 39 & 40 & 35 & 32 & 25 & 38 & 25 & 36 \\
\hline 75500272 & COLICISTITE AGUDA & 31 & 144 & 1,03 & 84,70 & 34 & 48 & 28 & 40 & 32 & 29 & 31 & 27 \\
\hline 39012190 & TENORRAFIA & 32 & 140 & 1,00 & 85,70 & 35 & 47 & 41 & 24 & 39 & 23 & 19 & 46 \\
\hline 75500159 & LINFADENITE AGUDA MESENTERICA & 33 & 139 & 0,99 & 86,69 & 33 & 50 & 36 & 30 & 30 & 34 & 35 & 25 \\
\hline 77500202 & VASCULOPATIAS PERIFERICAS & 34 & 139 & 0,99 & 87.68 & 50 & 16 & 32 & 34 & 20 & 42 & 17 & 47 \\
\hline 75500094 & OBSTRUCAO INTESTINAL & 35 & 128 & 0,91 & 88,59 & 42 & 31 & 33 & 34 & 26 & 38 & 36 & 25 \\
\hline 69000115 & AMEACA DE ABORTO & 36 & 126 & 0,90 & 89,49 & 41 & 33 & 29 & 39 & 34 & 27 & 32 & 27 \\
\hline 39024083 & REDUCAO INCRUENTA DAS FRATURAS DOS OSSOS DO ANTE-B & 37 & 123 & 0,88 & 90,37 & 29 & 53 & 43 & 20 & 45 & 16 & 26 & 34 \\
\hline 32019041 & BYPASS OU TROMBOENDARTERECTOMIA FEMURO-POPLITEIA & 38 & 119 & 0,85 & 91,22 & 49 & 18 & 30 & 35 & 14 & 50 & 43 & 16 \\
\hline 71300007 & DIAGNOSTICO EIOU PRIMEIRO ATENDIMENTO EM CLINICA PEDIATRICA & 39 & 114 & 0,81 & 92,03 & 47 & 24 & 50 & 5 & 29 & 35 & 15 & 50 \\
\hline 71300015 & PREMATURIDADE & 40 & 114 & 0,81 & 92,84 & 44 & 29 & 31 & 35 & 40 & 23 & 33 & 27 \\
\hline 75500213 & CIRROSE HEPATICA & 41 & 113 & 0,81 & 93,65 & 38 & 43 & 34 & 33 & 43 & 21 & 44 & 16 \\
\hline 80500110 & COLICA NEFRETICA & 42 & 113 & 0,81 & 94,45 & 25 & 62 & 47 & 16 & 44 & 19 & 45 & 16 \\
\hline 75500027 & ULCERA PEPTICA & 43 & 112 & 0,80 & 95,25 & 37 & 44 & 38 & 29 & 41 & 22 & 42 & 17 \\
\hline 33004080 & COLECISTECTOMIA & 44 & 109 & 0,78 & 96,03 & 45 & 29 & 39 & 28 & 35 & 27 & 37 & 25 \\
\hline 76300102 & CRISE ASMATICA & 45 & 107 & 0,76 & 96,79 & 24 & 63 & 48 & 15 & 46 & 15 & 47 & 14 \\
\hline 75500299 & AFECCOES PANCREATICAS & 46 & 92 & 0,66 & 97,45 & 46 & 26 & 40 & 26 & 42 & 22 & 41 & 18 \\
\hline 39000001 & POLITRAUMATIZADO & 47 & 90 & 0,64 & 98,09 & 40 & 35 & 44 & 20 & 48 & 11 & 39 & 24 \\
\hline 72500018 & DESIDRATACAO AGUDA (CLINICA MEDICA) & 48 & 90 & 0,64 & 98,73 & 43 & 30 & 45 & 20 & 37 & 25 & 46 & 15 \\
\hline 80500218 & OUTRAS AFECCOES DO AP. GENITO-URINARIO & 49 & 90 & 0,64 & 99,37 & 48 & 20 & 42 & 23 & 38 & 24 & 40 & 23 \\
\hline \multirow[t]{4}{*}{81500076} & EPILEPSIAS & 50 & 88 & 0,63 & 100,00 & 32 & 52 & 49 & 15 & 49 & 7 & 48 & 14 \\
\hline & Sub-Total & & 14024 & 75,33 & & & 4727 & & 3381 & & 2926 & & 2990 \\
\hline & Outros & & 4593 & 24,67 & & & 1415 & & 1069 & & 1032 & & 1077 \\
\hline & Total & & 18617 & 100,00 & & & 6142 & & 4450 & & 3958 & & 4067 \\
\hline
\end{tabular}


O procedimento mais freqüente foi Cesariana com atendimento ao Recém Nascido. Se considerarmos o "ranking" dos (50) cinqüenta procedimentos, corresponde a $14,80 \%$ do total das internações SUS.

Se considerarmos o total de internações SUS (periodos antes e depois) eles representaram $11,15 \%$ dos mesmos.

Seguido por Parto normal com atendimento ao RN (12,84\%; $9,67 \%)$; Curetagem pós aborto $(4,88 \% ; 3,68 \%)$; Trabalho de parto prematuro $(4,86 \%$; $3,66 \%)$; Pneumonia não especificada $(3,99 \% ; 3,00 \%)$; Insuficiência cardiaca $(3,47 \% ; 2,62 \%)$; Diagnóstico e ou primeiro atendimento em Clínica Médica $(2,35 \% ; 1,77 \%)$; Pielonefrites $(2,17 \% ; 1,63 \%)$; Parto normal $(2,15 \% ; 1,62 \%)$.

Com relação à gestão semi plena, os procedimentos Cesariana com atendimento ao Recém Nascido e Parto normal com atendimento ao Recém Nascido não se alteraram nas avaliações antes e depois dos períodos estudados. Curetagem pós aborto ocupava a $6^{\mathrm{a}}$ posição passando para a $4^{\mathrm{a}}$ posição e passou para a $5^{a}$ posição; Pneumonia não especificada era $5^{\mathrm{a}} \mathrm{e}$ passou para a $6^{a}$ posição. Insuficiência cardiaca não se alterou; Diagnóstico e primeiros atendimentos em Clínica Médica da $10^{\mathrm{a}}$ passou para $14^{\mathrm{a}}$ posição; Parto normal ocupava a $3^{\mathrm{a}}$ posição antes e deixou de ser realizado depois da implantação.

São Vicente - Os 50 procedimentos mais freqüentes corresponderam a $78,40 \%$ do total das internações SUS realizadas no Municipio, sendo que antes da implantação da gestão semi plena representaram $81,31 \%$ das internações SUS e $82,02 \%, 74,41 \%$ e $74,81 \%$ nos três anos, respectivamente.

Os 05 (cinco) primeiros procedimentos mais freqüentes corresponderam a $52,87 \%$ do total das internações SUS. O Quadro 56, apresenta esses resultados. 
Quadro 56 - Totais anuais de internaçōes SUS pelos 50 procedimentos mais freqüentes, ocorridos no Município de São Vicente - SP, antes e depois da implantação da gestão semi-plena.

\begin{tabular}{|c|c|c|c|c|c|c|c|c|c|c|c|c|c|}
\hline \multirow{2}{*}{\multicolumn{2}{|c|}{ Procedimentos }} & \multirow{2}{*}{\multicolumn{4}{|c|}{ Total }} & \multirow{2}{*}{\multicolumn{2}{|c|}{$\begin{array}{l}\text { Antes } \\
1^{\circ} \text { ano }\end{array}$}} & \multicolumn{6}{|c|}{ Depois } \\
\hline & & & & & & & & \multicolumn{2}{|c|}{$1^{\circ}$ ano } & \multicolumn{2}{|c|}{$2^{\circ}$ ano } & \multicolumn{2}{|c|}{$3^{\circ}$ ano } \\
\hline Codigo & Descrição & Pos. & $\mathbf{N}$ & $\%$ & $\%$ ac & Pos. & $\mathbf{N}$ & Pos. & $\mathbf{N}$ & Pos. & $\mathbf{N}$ & Pos. & $\mathbf{N}$ \\
\hline 35001011 & PARTO NORMAL & 1 & 8471 & 30,25 & 30,25 & 1 & 1874 & 1 & 2485 & 1 & 2229 & 1 & 1883 \\
\hline 35009012 & CESARIANA & 2 & 2560 & 9,14 & 39,40 & 2 & 668 & 2 & 803 & 2 & 634 & 2 & 455 \\
\hline 76300080 & BRONCOPNEUMONIA & 3 & 1440 & 5,14 & 44,54 & 4 & 369 & 4 & 428 & 3 & 370 & 3 & 273 \\
\hline 31000002 & CIRURGIA MULTIPLA & 4 & 1192 & 4,26 & 48,79 & 3 & 443 & 3 & 633 & 29 & 55 & 18 & 61 \\
\hline 35014016 & CURETAGEM POS-ABORTO & 5 & 1142 & 4,08 & 52,87 & 5 & 340 & 5 & 380 & 4 & 287 & 6 & 135 \\
\hline 76400085 & BRONCOPNEUMONIA EM LACTENTE & 6 & 891 & 3,18 & 56,06 & 9 & 201 & 9 & 249 & 5 & 230 & 5 & 211 \\
\hline 77500113 & INSUFICIENCIA CARDIACA & 7 & 778 & 2,78 & 58,83 & 7 & 217 & 7 & 275 & 6 & 208 & 14 & 78 \\
\hline 40001008 & TRATAMENTO CONSERVADOR DO TRAUMATISMO CRANEO-ENCEFALICO & 8 & 758 & 2,71 & 61,54 & 43 & 18 & 6 & 360 & 11 & 159 & 4 & 221 \\
\hline 81500106 & AVC AGUDO & 9 & 758 & 2,71 & 64,25 & 8 & 214 & 11 & 227 & 8 & 200 & 8 & 117 \\
\hline 76500233 & INSUFICIENCIA RESPIRATORIA AGUDA & 10 & 613 & 2,19 & 66,44 & 6 & 265 & 8 & 250 & 26 & 62 & 30 & 36 \\
\hline 69000115 & AMEACA DE ABORTO & 11 & 583 & 2,08 & 68,52 & 10 & 138 & 10 & 241 & 10 & 173 & 34 & 31 \\
\hline 76500071 & BRONCOPNEUMONIA & 12 & 491 & 1,75 & 70,27 & 18 & 81 & 13 & 122 & 9 & 180 & 10 & 108 \\
\hline 80500218 & OUTRAS AFECCOES DO AP. GENITO-URINARIO & 13 & 419 & 1,50 & 71,77 & 12 & 123 & 12 & 142 & 14 & 105 & 24 & 49 \\
\hline 76300102 & CRISE ASMATICA & 14 & 394 & 1,41 & 73,18 & 14 & 115 & 25 & 73 & 13 & 112 & 11 & 94 \\
\hline 74300270 & ENTERO-INFECCOES (PEDIATRIA) & 15 & 377 & 1,35 & 74,52 & 13 & 116 & 14 & 122 & 22 & 78 & 19 & 61 \\
\hline 77500121 & CRISE HIPERTENSIVA & 16 & 377 & 1,35 & 75,87 & 16 & 108 & 19 & 105 & 18 & 84 & 13 & 80 \\
\hline 75500124 & HEMORRAGIAS DIGESTIVAS & 17 & 352 & 1,26 & 77,13 & 19 & 81 & 20 & 105 & 15 & 102 & 16 & 64 \\
\hline 82500053 & DIABETE SACARINO & 18 & 345 & 1,23 & 78,36 & 17 & 91 & 15 & 117 & 19 & 84 & 23 & 53 \\
\hline 69000204 & TRABALHO DE PARTO PREMATURO & 19 & 333 & 1,19 & 79,55 & 11 & 135 & 18 & 108 & 27 & 58 & 33 & 32 \\
\hline 76400271 & ENTERO-INFECCOES EM LACTENTE & 20 & 314 & 1,12 & 80,67 & 15 & 109 & 16 & 110 & 23 & 77 & 45 & 18 \\
\hline 43000002 & DIAGNOSTICO EIOU PRIMEIRO ATENDIMENTO EM CLINICA CIRURGICA & 21 & 310 & 1,11 & 81,78 & 48 & 0 & 48 & 12 & 7 & 206 & 12 & 92 \\
\hline 76300072 & OUTRAS PNEUMONIAS & 22 & 283 & 1,01 & 82,79 & 24 & 58 & 29 & 59 & 17 & 95 & 15 & 71 \\
\hline 33011117 & HERNIORRAFIA INGUINAL(UNILATERAL) & 23 & 271 & 0,97 & 83,75 & 20 & 75 & 26 & 72 & 24 & 67 & 20 & 57 \\
\hline 75300060 & OBSTRUCAO INTESTINAL & 24 & 259 & 0,92 & 84,68 & 25 & 54 & 21 & 84 & 20 & 80 & 28 & 41 \\
\hline 71300007 & DIAGNOSTICO E/OU PRIMEIRO ATENDIMENTO EM CLINICA PEDIATRICA & 25 & 245 & 0,87 & 85,55 & 49 & 0 & 49 & 1 & 12 & 133 & 9 & 111 \\
\hline 77500024 & NFARTO AGUDO DO MIOCARDIO & 26 & 238 & 0,85 & 86,40 & 26 & 51 & 28 & 64 & 25 & 67 & 22 & 56 \\
\hline 77500180 & ARRITIMLAS & 27 & 237 & 0,85 & 87,25 & 22 & 71 & 23 & 75 & 30 & 53 & 29 & 38 \\
\hline 76500063 & PNEUMONIA NAO ESPECIFICADA & 28 & 232 & 0,83 & 88,08 & 38 & 32 & 22 & 76 & 16 & 99 & 37 & 25 \\
\hline 71300112 & OUTRAS AFECCOES DO RECEM-NASCIDO & 29 & 226 & 0,81 & 88,89 & 21 & 72 & 24 & 75 & 48 & 15 & 17 & 64 \\
\hline 76300188 & INSUFICIENCIA RESPIRATORIA AGUDA & 30 & 224 & 0,80 & 89,69 & 28 & 47 & 17 & 109 & 35 & 43 & 38 & 25 \\
\hline 72500000 & DIAGNOSTICO E/OU PRIMEIRO ATENDIMENTO EM CLINICA MEDICA & 31 & 214 & 0,76 & 90,45 & 50 & 0 & 50 & 0 & 21 & 79 & 7 & 135 \\
\hline 33005060 & APENDICECTOMIA & 32 & 181 & 0,65 & 91,10 & 36 & 34 & 43 & 39 & 31 & 51 & 21 & 57 \\
\hline 74300261 & SEPTICEMIAS (PEDIATRIA) & 33 & 178 & 0,64 & 91,73 & 34 & 39 & 33 & 50 & 33 & 47 & 27 & 42 \\
\hline 90500164 & ACIDENTES POR QUEDA & 34 & 176 & 0,63 & 92,36 & 33 & 40 & 37 & 47 & 34 & 45 & 26 & 44 \\
\hline
\end{tabular}


Quadro 56 - Continuação

\begin{tabular}{|c|c|c|c|c|c|c|c|c|c|c|c|c|c|}
\hline & \multirow{2}{*}{\multicolumn{4}{|c|}{ Total }} & \multirow{2}{*}{\multicolumn{2}{|c|}{$\begin{array}{l}\text { Antes } \\
1^{\circ} \text { ano }\end{array}$}} & \multicolumn{6}{|c|}{ Depois } \\
\hline & & & & & & & & \multicolumn{2}{|c|}{$1^{\circ}$ ano } & \multicolumn{2}{|c|}{$2^{\circ}$ ano } & \multicolumn{2}{|c|}{$3^{\circ}$ ano } \\
\hline \multicolumn{2}{|r|}{$\begin{array}{l}\text { Descriçăo } \\
\text { Decedimentos }\end{array}$} & Pos. & $\mathbf{N}$ & $\%$ & $\%$ ac & Pos. & $\mathbf{N}$ & Pos. & $\mathbf{N}$ & Pos. & $\mathbf{N}$ & Pos. & $\mathbf{N}$ \\
\hline 81300042 & EPILEPSIAS & 35 & 166 & 0,59 & 92,95 & 42 & 26 & 38 & 45 & 32 & 48 & 25 & 47 \\
\hline 76500225 & DOENCA PULMONAR OBSTRUTIVA CRONICA & 36 & 159 & 0,57 & 93,52 & 32 & 41 & 40 & 44 & 28 & 58 & 46 & 16 \\
\hline 71300015 & PREMATURIDADE & 37 & 157 & 0,56 & 94,08 & 40 & 30 & 31 & 54 & 38 & 38 & 31 & 35 \\
\hline 74500252 & ENTERO-INFECCOES (CLINICA MEDICA) & 38 & 157 & 0,56 & 94,64 & 23 & 60 & 35 & 48 & 43 & 26 & 39 & 23 \\
\hline 77500032 & INSUFICIENCIA CORONARIANA AGUDA & 39 & 156 & 0,56 & 95,20 & 29 & 46 & 32 & 52 & 40 & 37 & 43 & 21 \\
\hline 75500213 & CIRROSE HEPATICA & 40 & 147 & 0,52 & 95,73 & 30 & 43 & 36 & 48 & 36 & 41 & 48 & 15 \\
\hline 42008069 & TORACOTOMIA COM DRENAGEM FECHADA & 41 & 144 & 0,51 & 96,24 & 31 & 42 & 45 & 35 & 41 & 34 & 32 & 33 \\
\hline 39000001 & POLITRAUMATIZADO & 42 & 138 & 0,49 & 96,73 & 35 & 37 & 27 & 65 & 49 & 14 & 41 & 22 \\
\hline 72500018 & DESIDRATACAO AGUDA (CLINICA MEDICA) & 43 & 125 & 0,45 & 97,18 & 37 & 34 & 30 & 56 & 46 & 23 & 50 & 12 \\
\hline 38025019 & PERDA SUBST CUTANEA-LESOES EXTENSAS PLANOS SUPER. & 44 & 118 & 0,42 & 97,60 & 27 & 49 & 41 & 41 & 50 & 12 & 47 & 16 \\
\hline 75500272 & COLICISTITE AGUDA & 45 & 118 & 0,42 & 98,02 & 41 & 30 & 46 & 34 & 37 & 40 & 49 & 14 \\
\hline 88300234 & OUTRAS ANOMALIAS DA PELE, FANEROS E SISTEMA LINFAT & 46 & 118 & 0,42 & 98,44 & 39 & 31 & 44 & 36 & 45 & 24 & 35 & 27 \\
\hline 38023016 & EXTIRPACAO E SUPRESS. DE LESAO DA PELE E DO TECIDO & 47 & 115 & 0,41 & 98,85 & 44 & 18 & 47 & 32 & 39 & 38 & 36 & 27 \\
\hline 33016119 & LAPAROTOMIA EXPLORADORA & 48 & 110 & 0,39 & 99,25 & 45 & 17 & 34 & 50 & 47 & 23 & 44 & 20 \\
\hline 75500094 & OBSTRUCAO INTESTINAL & 49 & 107 & 0,38 & 99,63 & 46 & 13 & 42 & 40 & 42 & 31 & 40 & 23 \\
\hline 31004105 & POSTECTOMIA(CIRCUNCISAO) & 50 & 104 & 0,37 & 100,00 & 47 & 11 & 39 & 45 & 44 & 26 & 42 & 22 \\
\hline & $\begin{array}{r}\text { Sub-Total } \\
\text { Outros } \\
\text { Total }\end{array}$ & & $\begin{array}{c}28001 \\
7716 \\
35717\end{array}$ & $\begin{array}{c}78,40 \\
21,60 \\
100,00\end{array}$ & & & $\begin{array}{l}6807 \\
1565 \\
8372\end{array}$ & & $\begin{array}{c}8823 \\
1934 \\
10757\end{array}$ & & $\begin{array}{l}7080 \\
2435 \\
9515\end{array}$ & & $\begin{array}{l}5291 \\
1782 \\
7073\end{array}$ \\
\hline
\end{tabular}


O procedimento mais freqüente foi Parto normal. Se considerarmos o "ranking" dos (50) cinqüenta procedimentos, corresponde a $30,25 \%$ do total das internações SUS.

Se considerarmos o total de internações SUS (periodos antes e depois) eles representaram $23,72 \%$, seguido por Cesariana $(9,14 \% ; 7,17 \%)$; Broncopneumonia $(5,14 \% ; 4,03 \%)$; Cirurgia Múltipla $(4,26 \% ; 3,34 \%)$; Curetagem pós aborto $(4,08 \% ; 3,20 \%)$.

Com relação à gestão semi plena, os procedimentos Cesariana e Parto normal não se alteraram; Broncopneumonia que ocupava a $4^{\mathrm{a}}$ posição foi para a $3^{\mathrm{a}}$ posição; Cirurgia múltipla que ocupava a $3^{\mathrm{a}}$ posição antes foi para a $18^{\mathrm{a}}$ depois; Curetagem pós aborto que ocupava a $5^{\mathrm{a}}$ foi para a $6^{\mathrm{a}}$ posição.

Destacam-se as variações:

- 31000002 - Cirurgia Múltipla - $3^{\circ}$ lugar ( $1^{\circ}$ ano antes); $3^{\circ}$ ( $1^{\circ}$ ano depois); $29^{\circ}$ ( $2^{\circ}$ ano depois); $18^{\circ}$ ( $3^{\circ}$ ano depois).

- 69000115 - Ameaça de Aborto - $10^{\circ}$ lugar ( $1^{\circ}$ ano antes); $10^{\circ}$ ( $1^{\circ}$ ano depois); $10^{\circ}\left(2^{\circ}\right.$ ano depois); $34^{\circ}$ ( $3^{\circ}$ ano depois).

Votorantim - Os 50 procedimentos mais freqüentes corresponderam a $79,24 \%$ do total das internações SUS realizadas no Município, sendo que antes da implantação da gestão semi plena representaram $73,27 \%$ das internações SUS e $81,71 \%, 84,92 \%$ e $81,92 \%$ nos três anos, respectivamente.

Os 06 (seis) primeiros procedimentos mais freqüentes corresponderam a $51,62 \%$ do total das internações SUS no Município de Votorantim, conforme mostra o Quadro 57. 
Quadro 57 - Totais anuais de internações SUS pelos 50 procedimentos mais freqüentes, ocorridos no Município de Votorantim - SP, antes e depois da implantação da gestão semi-plena.

\begin{tabular}{|c|c|c|c|c|c|c|c|c|c|c|c|c|c|}
\hline \multirow{2}{*}{\multicolumn{2}{|c|}{ Procedimentos }} & \multirow{2}{*}{\multicolumn{4}{|c|}{ Total }} & \multirow{2}{*}{\multicolumn{2}{|c|}{$\begin{array}{l}\text { Antes } \\
1^{\circ} \text { ano }\end{array}$}} & \multicolumn{6}{|c|}{ Depois } \\
\hline & & & & & & & & \multicolumn{2}{|c|}{$1^{\circ}$ ano } & \multicolumn{2}{|c|}{$2^{\circ}$ ano } & \multicolumn{2}{|c|}{$3^{\circ}$ ano } \\
\hline Código & Descrição & Pos. & $\mathbf{N}$ & $\%$ & $\%$ ac & Pos. & $\mathbf{N}$ & Pos. & $\mathbf{N}$ & Pos. & $\mathbf{N}$ & Pos. & $\mathbf{N}$ \\
\hline 35001011 & PARTO NORMAL & 1 & 1807 & 22,91 & 22,91 & 1 & 461 & 1 & 362 & 1 & 385 & 1 & 599 \\
\hline 35009012 & CESARIANA & 2 & 1173 & 14,87 & 37,77 & 2 & 275 & 2 & 213 & 2 & 283 & 2 & 402 \\
\hline 76300080 & BRONCOPNEUMONIA & 3 & 290 & 3,68 & 41,45 & 5 & 109 & 5 & 65 & 4 & 54 & 5 & 62 \\
\hline 77500113 & INSUFICIENCIA CARDIACA & 4 & 272 & 3,45 & 44,90 & 4 & 110 & 7 & 46 & 6 & 52 & 4 & 64 \\
\hline 35014016 & CURETAGEM POS-ABORTO & 5 & 265 & 3,36 & 48,26 & 8 & 78 & 3 & 71 & 5 & 54 & 6 & 62 \\
\hline 81500106 & AVC AGUDO & 6 & 265 & 3,36 & 51,62 & 3 & 134 & 4 & 68 & 7 & 36 & 15 & 27 \\
\hline 76400085 & BRONCOPNEUMONIA EM LACTENTE & 7 & 253 & 3,21 & 54,82 & 10 & 70 & 6 & 47 & 3 & 55 & 3 & 81 \\
\hline 76500071 & BRONCOPNEUMONIA & 8 & 199 & 2,52 & 57,35 & 6 & 104 & 8 & 45 & 15 & 25 & 16 & 25 \\
\hline 80500218 & DUTRAS AFECCOES DO AP. GENITO-URINARIO & 9 & 175 & 2,22 & 59,56 & 9 & 74 & 11 & 43 & 12 & 29 & 12 & 29 \\
\hline 76500233 & INSUFICIENCIA RESPIRATORIA AGUDA & 10 & 157 & 1,99 & 61,55 & 16 & 56 & 12 & 41 & 9 & 31 & 13 & 29 \\
\hline 77500032 & INSUFICIENCIA CORONARIANA AGUDA & 11 & 151 & 1,91 & 63,47 & 11 & 66 & 15 & 31 & 13 & 26 & 14 & 28 \\
\hline 40001008 & TRATAMENTO CONSERVADOR DO TRAUMATISMO CRANEO-ENCEFALICO & 12 & 150 & 1,90 & 65,37 & 7 & 87 & 9 & 45 & 34 & 9 & 37 & 9 \\
\hline 74300270 & ENTERO-INFECCOES (PEDIATRIA) & 13 & 141 & 1,79 & 67,16 & 15 & 60 & 10 & 44 & 17 & 23 & 30 & 14 \\
\hline 82500053 & DIABETE SACARINO & 14 & 138 & 1,75 & 68,91 & 17 & 49 & 16 & 27 & 10 & 31 & 9 & 31 \\
\hline 76500225 & DOENCA PULMONAR OBSTRUTIVA CRONICA & 15 & 137 & 1,74 & 70,64 & 12 & 65 & 18 & 22 & 21 & 19 & 10 & 31 \\
\hline 77500180 & ARRITIMIAS & 16 & 134 & 1,70 & 72,34 & 20 & 44 & 13 & 38 & 8 & 32 & 21 & 20 \\
\hline 75500124 & HEMORRAGIAS DIGESTIVAS & 17 & 130 & 1,65 & 73,99 & 14 & 61 & 17 & 23 & 25 & 16 & 11 & 30 \\
\hline 77500121 & CRISE HIPERTENSIVA & 18 & 104 & 1,32 & 75,31 & 13 & 65 & 26 & 15 & 35 & 9 & 28 & 15 \\
\hline 72500000 & DIAGNOSTICO E/OU PRIMEIRO ATENDIMENTO EM CLINICA MEDICA & 19 & 98 & 1,24 & 76,55 & 32 & 23 & 14 & 32 & 11 & 30 & 32 & 13 \\
\hline 31004105 & POSTECTOMIA(CIRCUNCISAO) & 20 & 90 & 1,14 & 77,69 & 47 & 9 & 22 & 19 & 16 & 24 & 7 & 38 \\
\hline 43000002 & DIAGNOSTICO E/OU PRIMEIRO ATENDIMENTO EM CLINICA CIRURGICA & 21 & 90 & 1,14 & 78,83 & 22 & 36 & 29 & 14 & 19 & 20 & 22 & 20 \\
\hline 76500063 & PNEUMONIA NAO ESPECIFICADA & 22 & 89 & 1,13 & 79,96 & 23 & 33 & 21 & 21 & 29 & 13 & 17 & 22 \\
\hline 77500024 & INFARTO AGUDO DO MIOCARDIO & 23 & 81 & 1,03 & 80,99 & 39 & 17 & 19 & 22 & 20 & 20 & 18 & 22 \\
\hline 33005060 & APENDICECTOMIA & 24 & 78 & 0,99 & 81,97 & 26 & 31 & 20 & 22 & 33 & 11 & 31 & 14 \\
\hline 33012113 & HERNIORRAFIA INGUINAL(BILATERAL) & 25 & 78 & 0,99 & 82,96 & 38 & 19 & 32 & 13 & 30 & 12 & 8 & 34 \\
\hline 80500072 & PIELONEFRITES & 26 & 75 & 0,95 & 83,91 & 19 & 45 & 30 & 14 & 36 & 9 & 44 & 7 \\
\hline 69000115 & AMEACA DE ABORTO & 27 & 72 & 0,91 & 84,83 & 28 & 28 & 31 & 14 & 38 & 8 & 19 & 22 \\
\hline 76300102 & CRISE ASMATICA & 28 & 72 & 0,91 & 85,74 & 34 & 22 & 40 & 9 & 18 & 21 & 23 & 20 \\
\hline 81300042 & EPILEPSIAS & 29 & 70 & 0,89 & 86,63 & 29 & 28 & 27 & 15 & 22 & 18 & 38 & 9 \\
\hline 33004080 & COLECISTECTOMIA & 30 & 68 & 0,86 & 87,49 & 18 & 47 & 36 & 12 & 46 & 3 & 45 & 6 \\
\hline
\end{tabular}

Continua 
Quadro 57 - Continuação

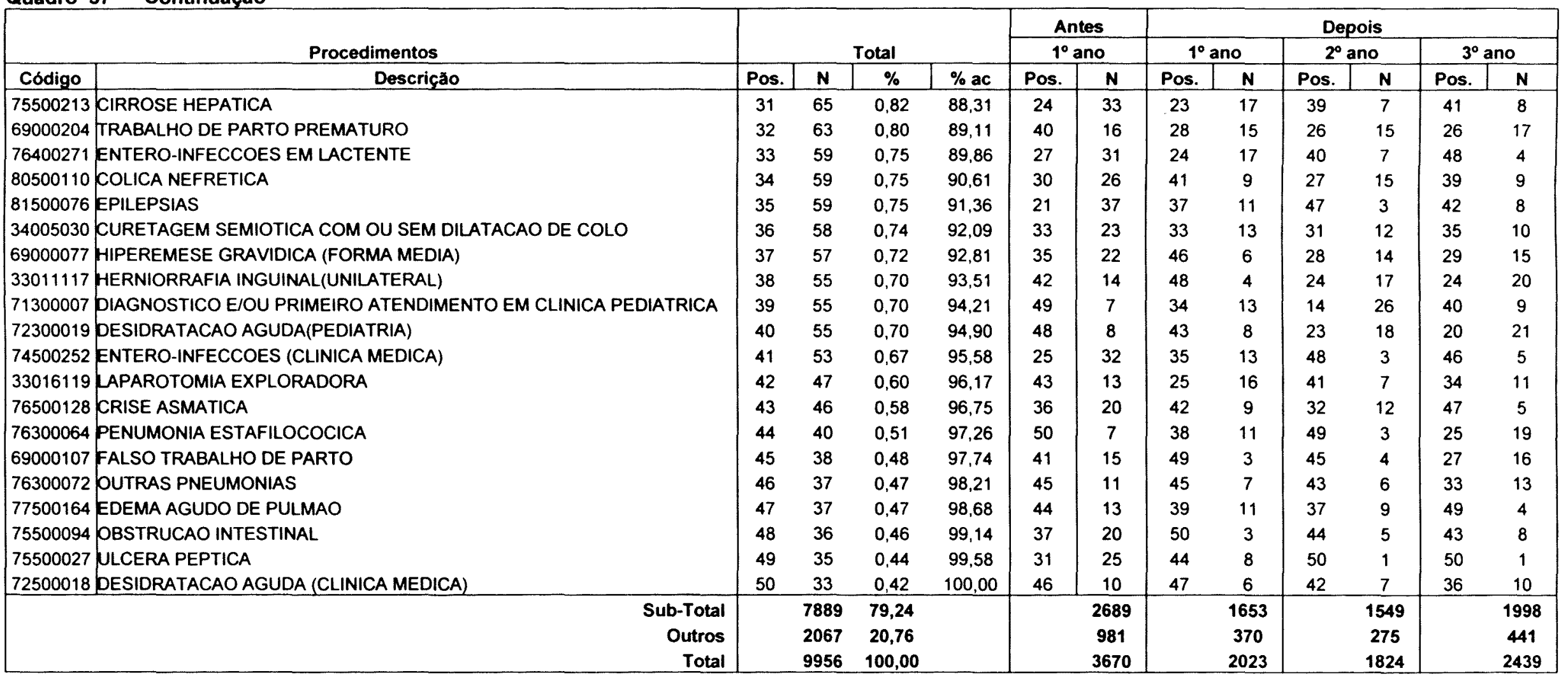


Destacam-se as variações:

- 81500106- AVC Agudo - $3^{\circ}$ lugar ( $1^{\circ}$ ano antes); $4^{\circ}\left(1^{\circ}\right.$ ano depois); $7^{\circ}\left(2^{\circ}\right.$ ano depois); $15^{\circ}$ ( $3^{\circ}$ ano depois).

- 40001008 - Tratamento Conservador do Traumatismo Craneo-Encefálico - $7^{\circ}$ lugar ( $1^{\circ}$ ano antes); $9^{\circ}\left(1^{\circ}\right.$ ano depois); $34^{\circ}$ ( $2^{\circ}$ ano depois); $37^{\circ}\left(3^{\circ}\right.$ ano depois).

O procedimento mais freqüente foi Parto Normal. Se considerarmos o "ranking" dos (50) cinqüenta procedimentos, corresponde a $22,91 \%$ do total das internações SUS.

Se considerarmos o total de internações SUS (periodos antes e depois) eles representaram 18,15\% seguido por: Cesariana $(14,87 \% ; 11,78)$; Broncopneumonia (3,68\%; 2,91\%); Insuficiência cardiaca $(3,45 \% ; 2,73 \%)$; Curetagem pós aborto $(3,36 \% ; 2,66 \%)$; AVC agudo $(3,36 \% ; 2,66 \%)$.

Com relação à gestão semi plena, os procedimentos Parto normal, Cesariana, Broncopneumonia; Insuficiência Cardiaca, não se alteraram. Curetagem pós aborto era a $8^{\mathrm{a}}$ posição e passou para $6^{\mathrm{a}}$ posição; AVC agudo era $3^{a}$ posição passou para a $15^{a}$ posição.

\subsection{Gastos com Internações SUS}

\subsubsection{Gastos total com internações SUS}

Considerando-se os 11 Municipios estudados, observou-se que houve um decréscimo no total de gastos com internações SUS, equivalente a $4,84 \%$ (US $\$ 4210351$ ), quando comparados os valores gastos antes e depois da implantação da gestão semi plena.

No Quadro 58 são apresentados os totais gastos por Municipio e períodos de avaliação. 
Quadro 58 - Valores gastos com internaçōes SUS hospitalares, por municípios, antes e depois da implantação da gestão semi-plena.

\begin{tabular}{|c|c|c|}
\hline $7^{2}$ & Antes" & Depois"*\# \\
\hline Municipio & US\$ & US\$ \\
\hline Assis & 2831811 & 2417511 \\
\hline Campinas & 29774935 & 30038512 \\
\hline Diadema & 3658404 & 2686108 \\
\hline Mauá & 2304436 & 2720840 \\
\hline Ribeirāo Preto & 30020873 & 25832446 \\
\hline Santos & 9780410 & 9130310 \\
\hline Săo Bernardo do Campo & 1063365 & 2211439 \\
\hline São José dos Campos & 4459353 & 4887653 \\
\hline São Vicente & 1571175 & 1826965 \\
\hline Sertãozinho & 913084 & 689419 \\
\hline Votorantim & 690112 & 416403 \\
\hline Total & 87067957 & 82857606 \\
\hline
\end{tabular}

Os municipios que apresentaram redução nos gastos com internações SUS, depois da implantação da gestão semi-plena, foram: Assis $(14,63 \%)$, Diadema $(26,58 \%)$, Ribeirão Preto $(13,95 \%)$, Santos $(6,65 \%)$, Sertãozinho $(24,50 \%)$ e Votorantim (39,66\%). Apresentaram aumento nos gastos os municipios de Campinas (0,89\%), Mauá (18,07\%), São Bernardo do Campo $(107,97 \%)$, São José dos Campos $(9,60 \%)$ e São Vicente $(16,28 \%)$.

Destaca-se Sertãozinho, Assis e São José dos Campos que introduziram adicional financeiro à tabela SUS.

Nos gráficos mostrados na Figura 26, correspondentes ao total e a cada um dos municipios, são apresentadas as comparações dos valores gastos antes e depois da implantação da gestão semi-plena, com a média 
geral, obtida considerando-se todo periodo de avaliação $\left(1^{\circ}\right.$ ano antes e 3 anos depois).

Analisando-se o comportamento dos gastos com internações SUS com relação aos valores médios, verificou-se que os municipios de Assis, Diadema, Ribeirão Preto, Santos, Sertãozinho e Votorantim, apresentaram gastos com internações SUS hospitalares superiores à média antes da implantação da gestão semi plena, e dentre estes observou-se redução nos gastos, somente os municipios de Assis, Diadema, Santos, Sertãozinho e Votorantim, no $3^{\circ}$ ano após a implantação da gestão semi plena encontravam-se abaixo da média.

Os municipios de Campinas, Mauá, São Bernardo do Campo, São José dos Campos e São Vicente, que apresentaram valores inferiores à média antes da semi plena, no terceiro ano após sua implantação, foi encontrada uma mudança no cenário, onde Campinas e São Bernardo do Campo ficaram posicionados acima da média. Ribeirão Preto manteve-se em ambos os períodos acima da média e os municípios de Mauá, São José dos Campos e São Vicente, não alteraram suas posições, mantiveram-se abaixo da média antes e depois da implantação da gestão semi plena. 
Figura 26- Valores totais gastos com internações SUS e valor médio, por municípios, antes e depois da implantação da gestão semi plena.
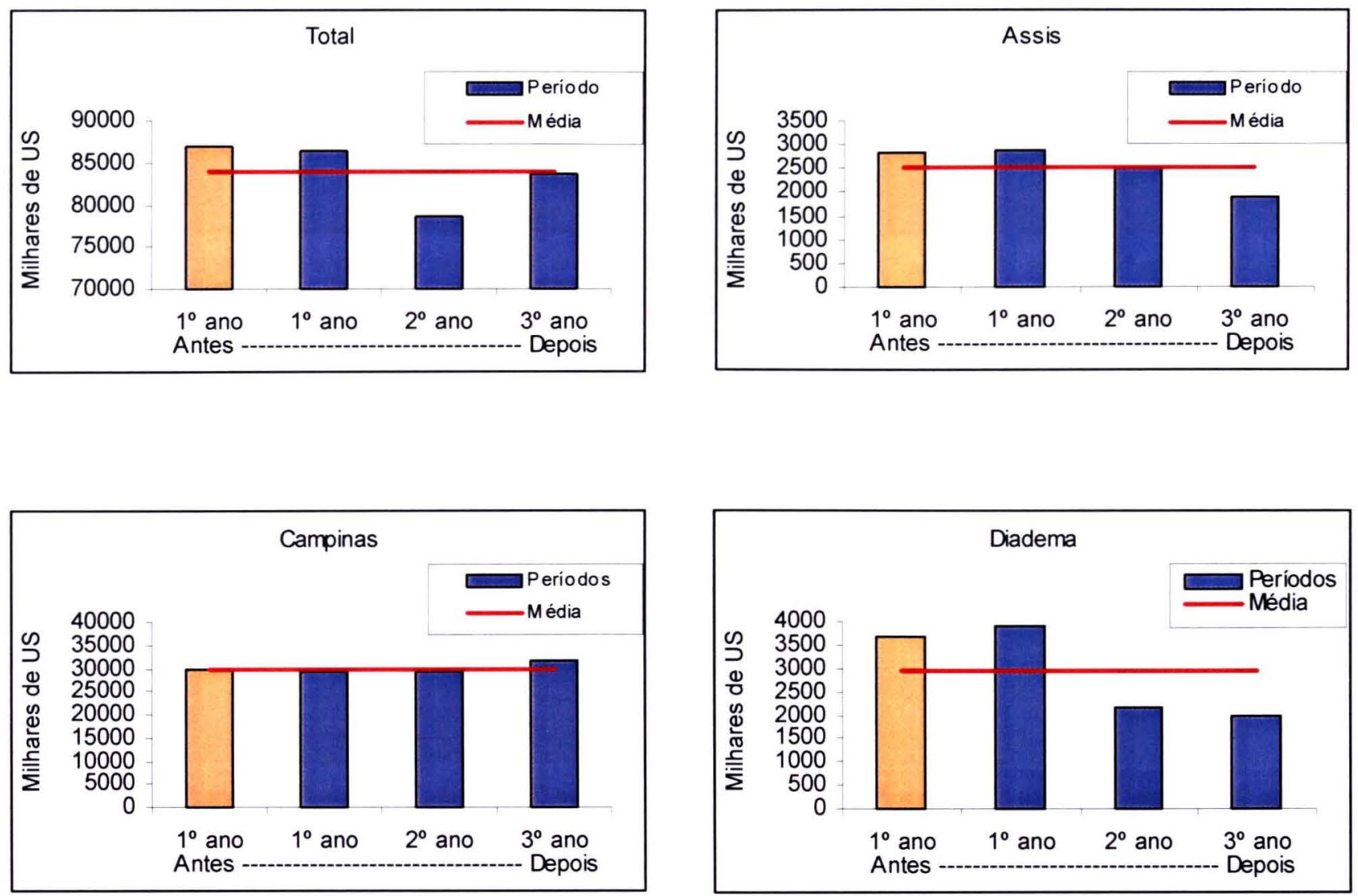

Continua 
Figura 26 - Continuação
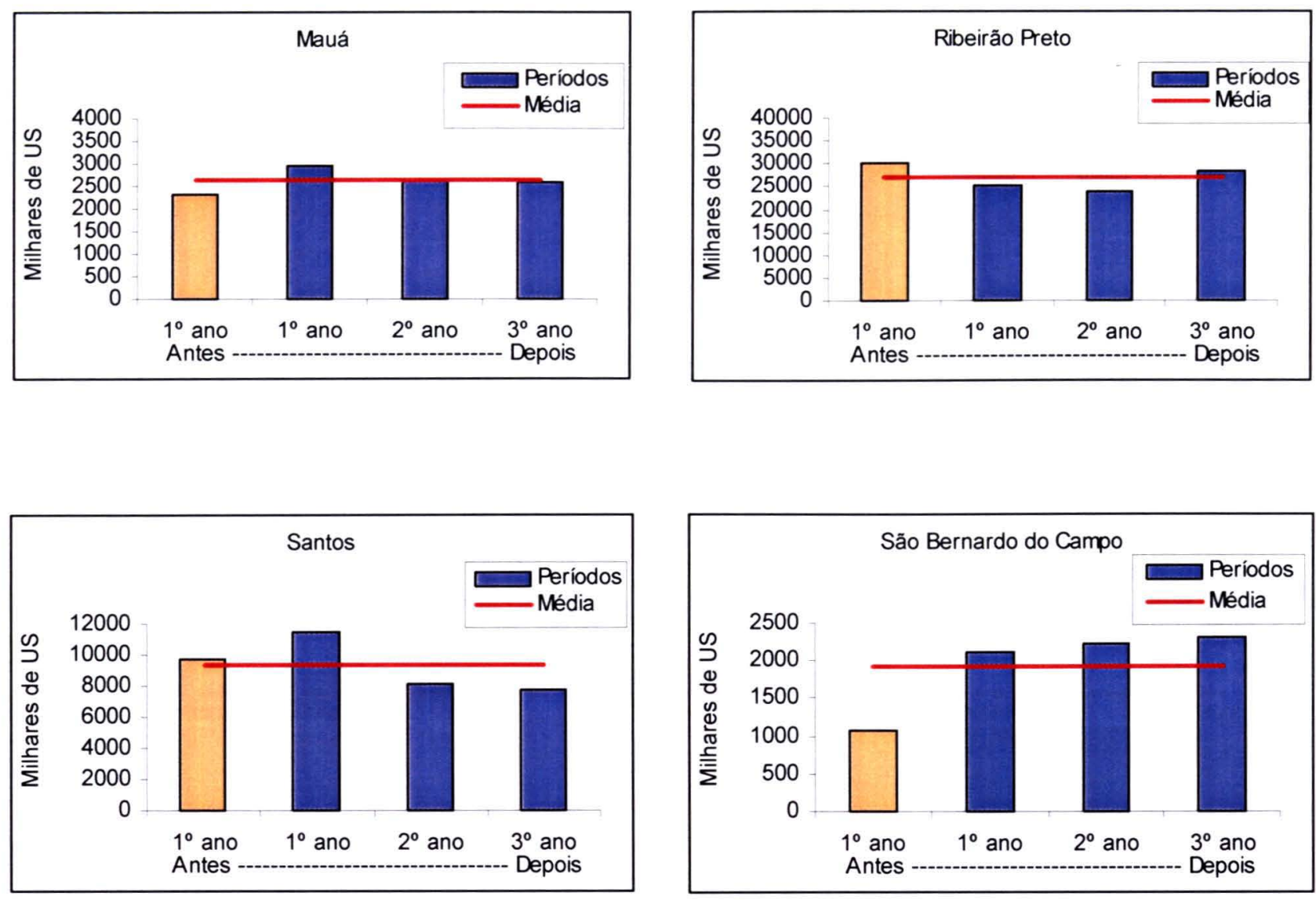

Continua 

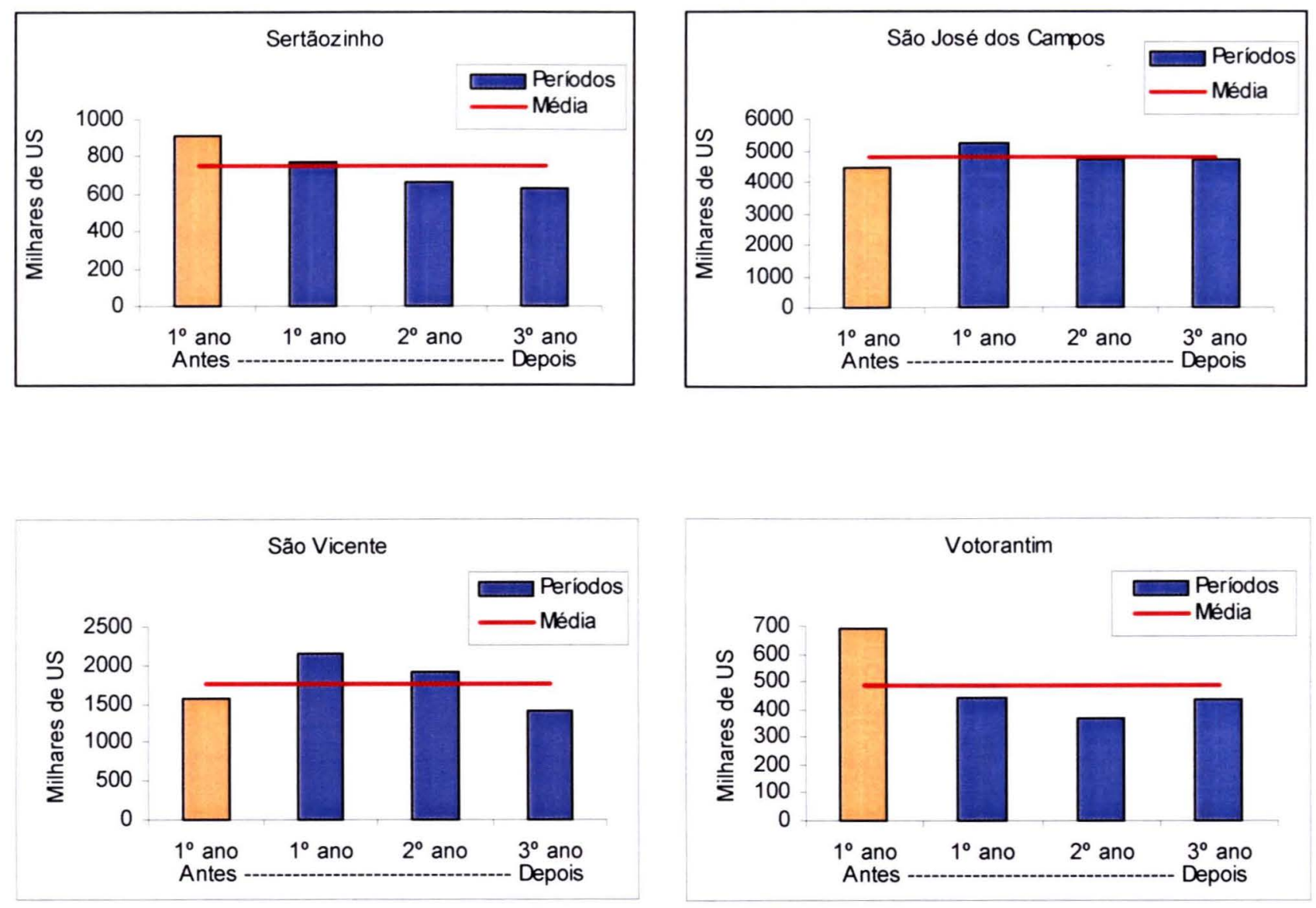


\subsubsection{Evolução dos Totais de Gastos com Internações}

As Figuras de 27 a 38 apresentam os ajustes de regressão entre os totais anuais dos gastos com internações nos municípios em função do tempo em anos. O primeiro ano de avaliação é representado por -1 no eixo $x$ e corresponde ao período antes da implantação da gestão semi plena no município. Os anos seguintes, representados por 1,2 e 3 no eixo $x$, correspondem aos três anos seguintes, após a implantação da gestão semi plena no município.

A Figura 27 corresponde ao total dos 11 municípios, onde se observa que a evolução dos gastos é decrescente em função do tempo. Apresenta-se nesta figura a curva de regressão, modelo polinomial de segundo grau e seu respectivo $r^{2}=0,55$ e teste $F$ de 0,353 não significativo ao nivel de probabilidade de $5 \%$.

$\begin{aligned} & \text { Figura } 27 \text { - } \text { Ajuste por regressão dos totais anuais gastos com } \\ & \text { internações SUS nos } 11 \text { municipios estudados, nos } \\ & \text { períodos antes e depois da implantação da gestão semi } \\ & \text { plena. }\end{aligned}$

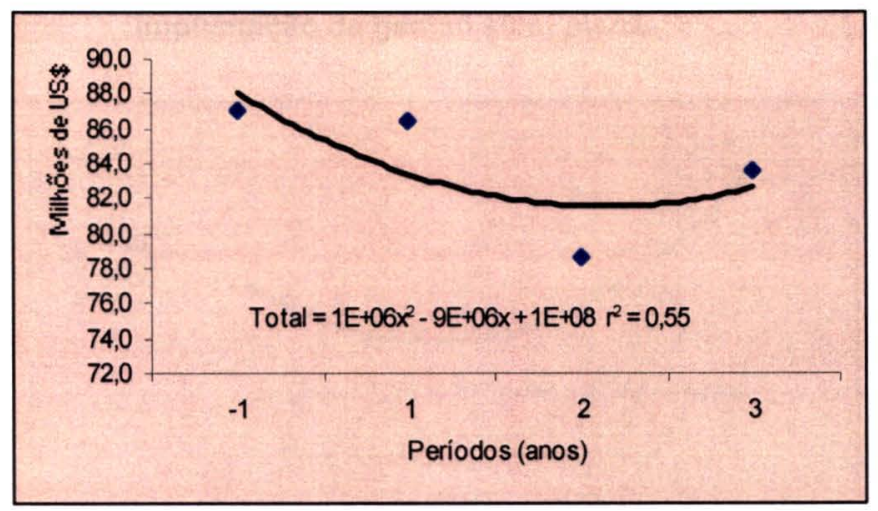

Na Figura 28 é apresentado o ajuste por regressão relativo ao municipio de Assis, onde se observa que a evolução dos gastos é decrescente em função do tempo. Apresenta-se nesta figura a curva de regressão, modelo linear simples e seu respectivo $r^{2}=0,82$ e teste $F$ de 3,955 não significativo ao nível de probabilidade de $5 \%$. 
Figura 28 - Ajuste por regressão dos totais anuais gastos com internações SUS no município de Assis, nos períodos antes e depois da implantação da gestão semi plena.

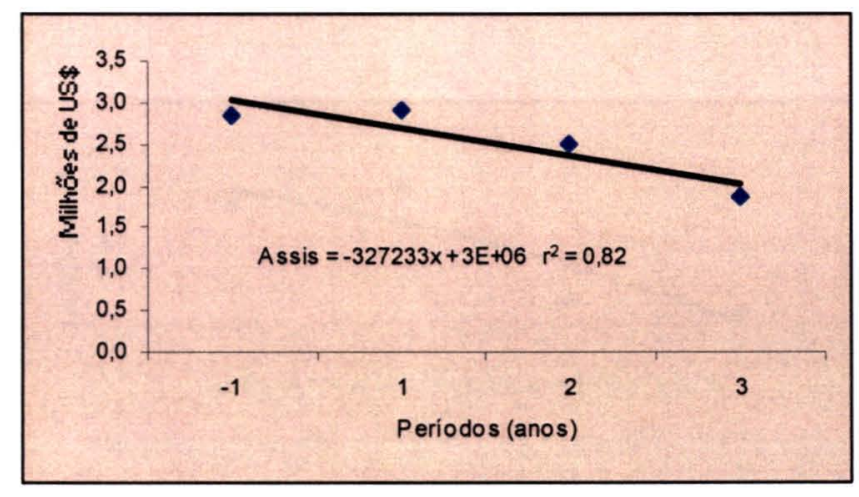

A Figura 29 mostra o ajuste por regressão relativo ao município de Campinas, onde se observa que a evolução dos gastos é crescente em função do tempo. Apresenta-se nesta figura a curva de regressão, modelo polinomial de segundo grau e seu respectivo $r^{2}=0,98$ e teste $F$ de 8,281 não significativo ao nivel de probabilidade de $5 \%$.
Figura 29 - Ajuste por regressão dos totais anuais gastos com internações SUS no município de Campinas, nos períodos antes e depois da implantação da gestão semi plena.

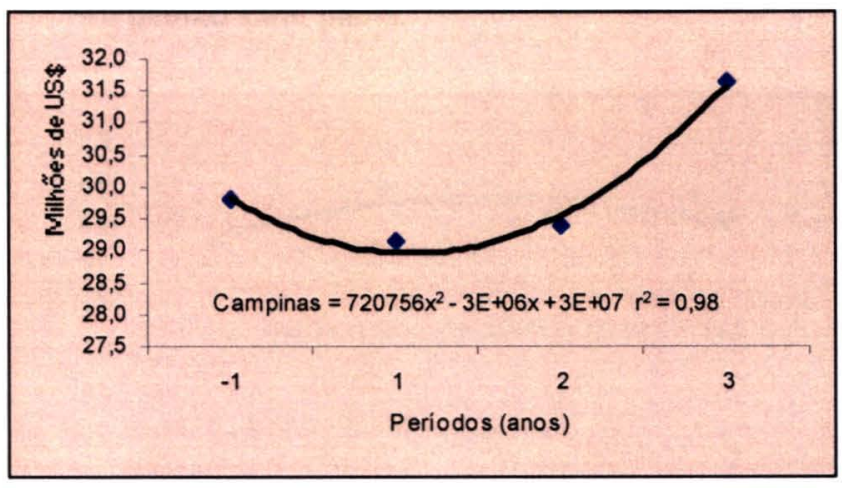

A Figura 30 mostra o ajuste por regressão relativo ao município de Diadema, onde se observa que a evolução dos gastos é decrescente em função do tempo. Apresenta-se nesta figura a curva de regressão, modelo polinomial de segundo grau e seu respectivo $r^{2}=0,79$ e teste $F$ de 1,793 não significativo ao nivel de probabilidade de $5 \%$. 
Figura 30 - Ajuste por regressão dos totais anuais gastos com internações SUS no município de Diadema, nos períodos antes e depois da implantação da gestão semi plena.

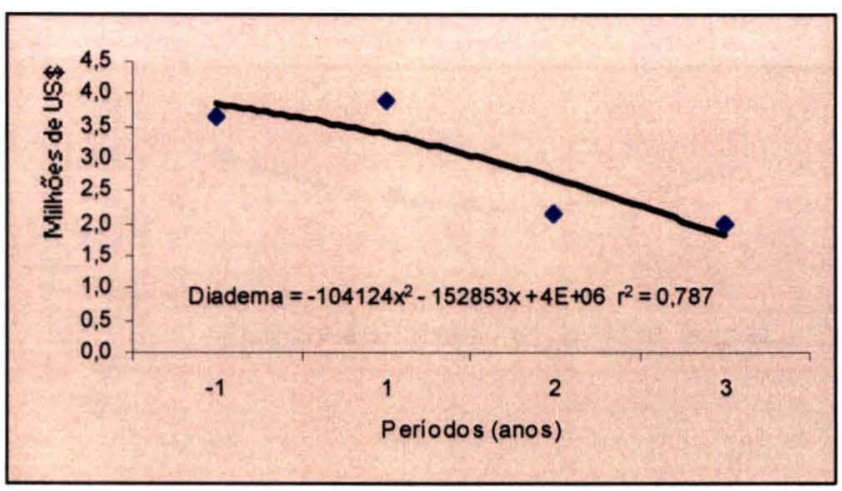

A Figura 31 mostra o ajuste por regressão relativo ao municipio de Mauá, onde se observa que a evolução dos gastos é decrescente em função do tempo. Apresenta-se nesta figura a curva de regressão, modelo polinomial de segundo grau e seu respectivo $r^{2}=0,60$ e teste $F$ de 1,792 não significativo ao nível de probabilidade de $5 \%$.

Figura 31 - Ajuste por regressão dos totais anuais gastos com internações SUS no município de Mauá, nos períodos antes e depois da implantação da gestão semi plena.

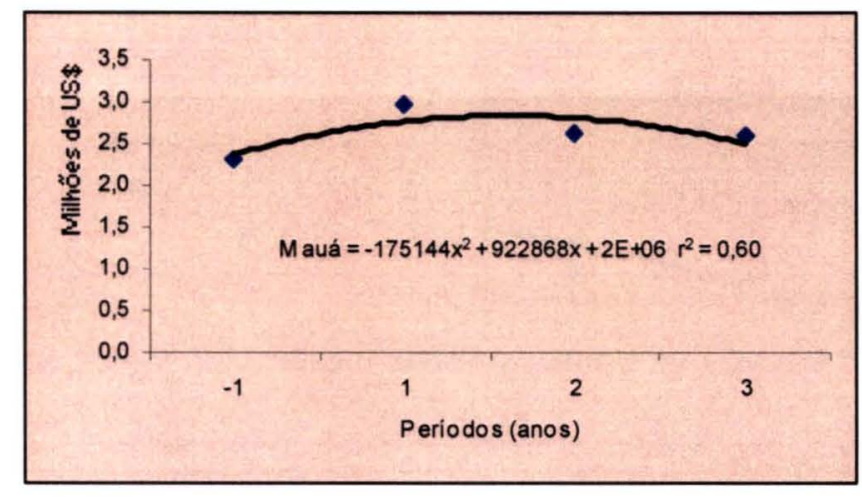

A Figura 32 mostra o ajuste por regressão relativo ao município de Ribeirão Preto, onde se observa que a evolução dos gastos é decrescente em função do tempo. Apresenta-se nesta figura a curva de 
regressão, modelo polinomial de segundo grau e seu respectivo $r^{2}=0,98$ e teste $\mathrm{F}$ de 4,426 não significativo ao nível de probabilidade de $5 \%$.

Figura 32 - Ajuste por regressão dos totais anuais gastos com internações SUS no município de Ribeirão Preto, nos periodos antes e depois da implantação da gestão semi plena.

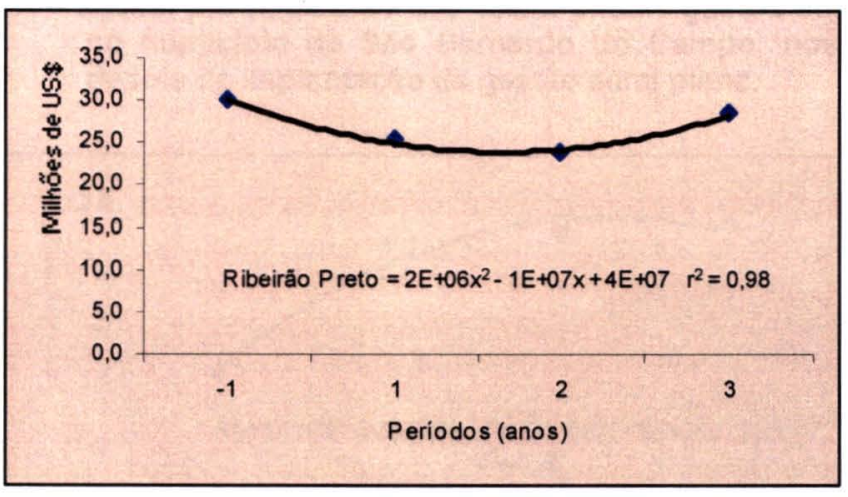

A Figura 33 mostra o ajuste por regressão relativo ao municipio de Santos, onde se observa que a evolução dos gastos é decrescente em função do tempo. Apresenta-se nesta figura a curva de regressão, modelo polinomial de segundo grau e seu respectivo $r 2=0,64$ e teste $F$ de 1,181 não significativo ao nivel de probabilidade de $5 \%$.

Figura 33 - Ajuste por regressão dos totais anuais gastos com internações SUS no município de Santos, nos períodos antes e depois da implantação da gestão semi plena.

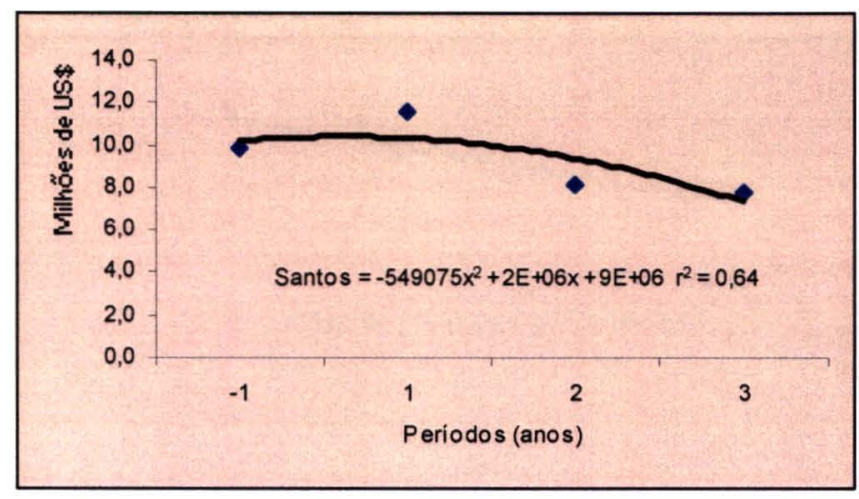

A Figura 34 mostra o ajuste por regressão relativo ao município de São Bernardo do Campo, onde se observa que a evolução dos gastos é 
crescente em função do tempo. Apresenta-se nesta figura a curva de regressão, modelo polinomial de segundo grau e seu respectivo $r 2=0,96$ e teste $\mathrm{F}$ de 164,682 não significativo ao nível de probabilidade de $5 \%$.

Figura 34 - Ajuste por regressão dos totais anuais gastos com internações SUS no município de São Bernardo do Campo, nos períodos antes e depois da implantação da gestão semi plena.

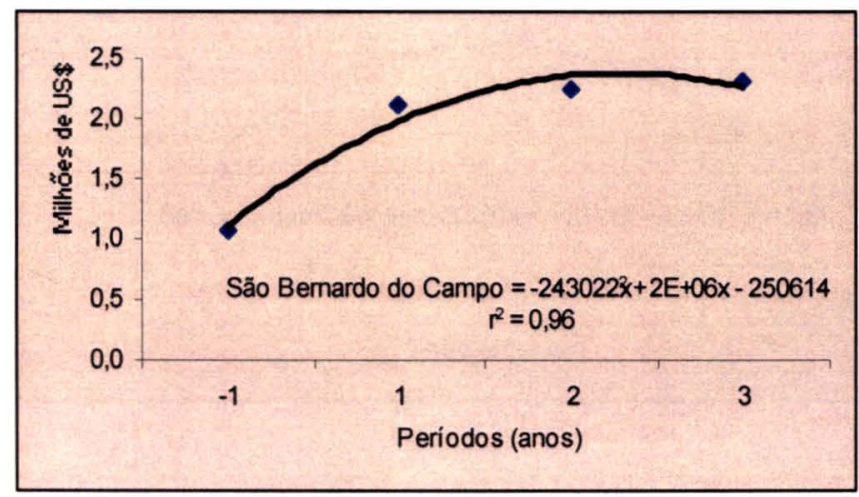

A Figura 35 mostra o ajuste por regressão relativo ao municipio de Sertãozinho, onde se observa que a evolução dos gastos é decrescente em função do tempo. Apresenta-se nesta figura a curva de regressão, modelo linear de primeiro grau e seu respectivo $r^{2}=0,95$ e teste $F$ de 137,528 significativo ao nível de probabilidade de $5 \%$.

Figura 35 - Ajuste por regressão dos totais anuais gastos com internações SUS no município de Sertãozinho, nos períodos antes e depois da implantação da gestão semi plena.

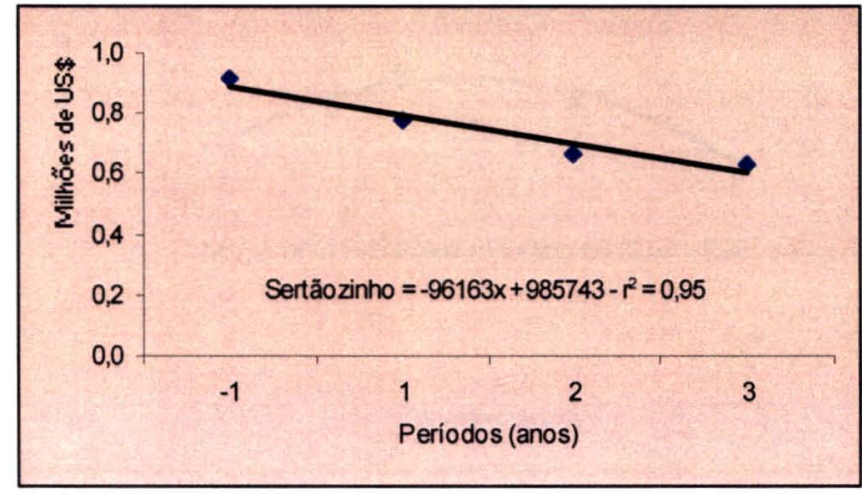

A Figura 36 mostra o ajuste por regressão relativo ao município de São José dos Campos, onde se observa que a evolução dos gastos não é crescente em função do tempo. Apresenta-se nesta figura a curva de 
regressão, modelo polinomial de segundo grau e seu respectivo $r^{2}=0,51$ e teste $\mathrm{F}$ de 1,166 não significativo ao nível de probabilidade de $5 \%$.

Figura 36 - Ajuste por regressão dos totais anuais gastos com internações SUS no município de São José dos Campos, nos períodos antes e depois da implantação da gestão semi plena.

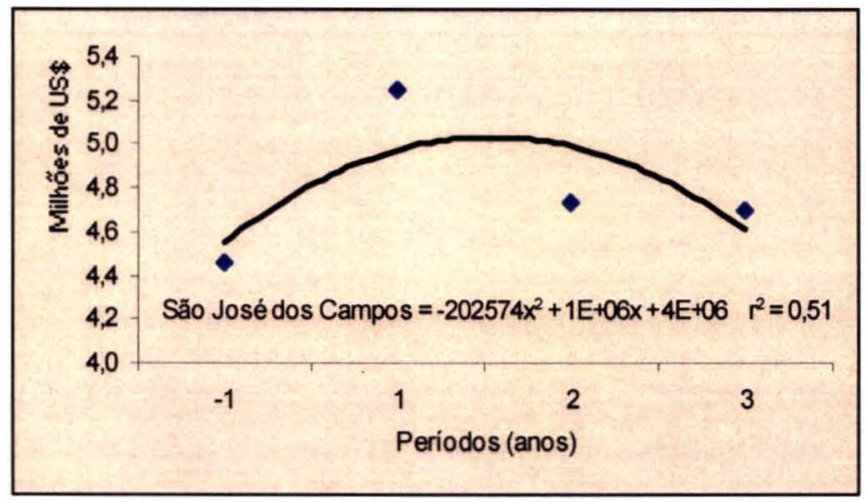

A Figura 37 mostra o ajuste por regressão relativo ao município de São Vicente, onde se observa que a evolução dos gastos não é crescente em função do tempo. Apresenta-se nesta figura a curva de regressão, modelo polinomial de segundo grau e seu respectivo $r^{2}=0,95 \mathrm{e}$ teste $\mathrm{F}$ de 250,106 significativo ao nível de probabilidade de $5 \%$.

Figura 37 - Ajuste por regressão dos totais anuais gastos com internações SUS no município de São Vicente, nos períodos antes e depois da implantação da gestão semi plena.

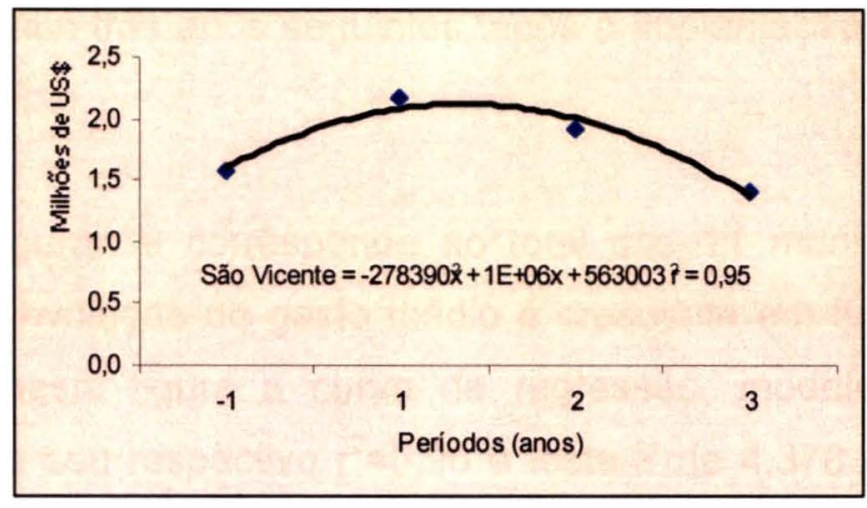

A Figura 38 mostra o ajuste por regressão relativo ao município de Votorantin, onde se observa que a evolução dos gastos é decrescente 
em função do tempo. Apresenta-se nesta figura a curva de regressão, modelo polinomial de segundo grau e seu respectivo $r^{2}=0,99$ e teste $F$ de 23,425 não significativo ao nível de probabilidade de $5 \%$.

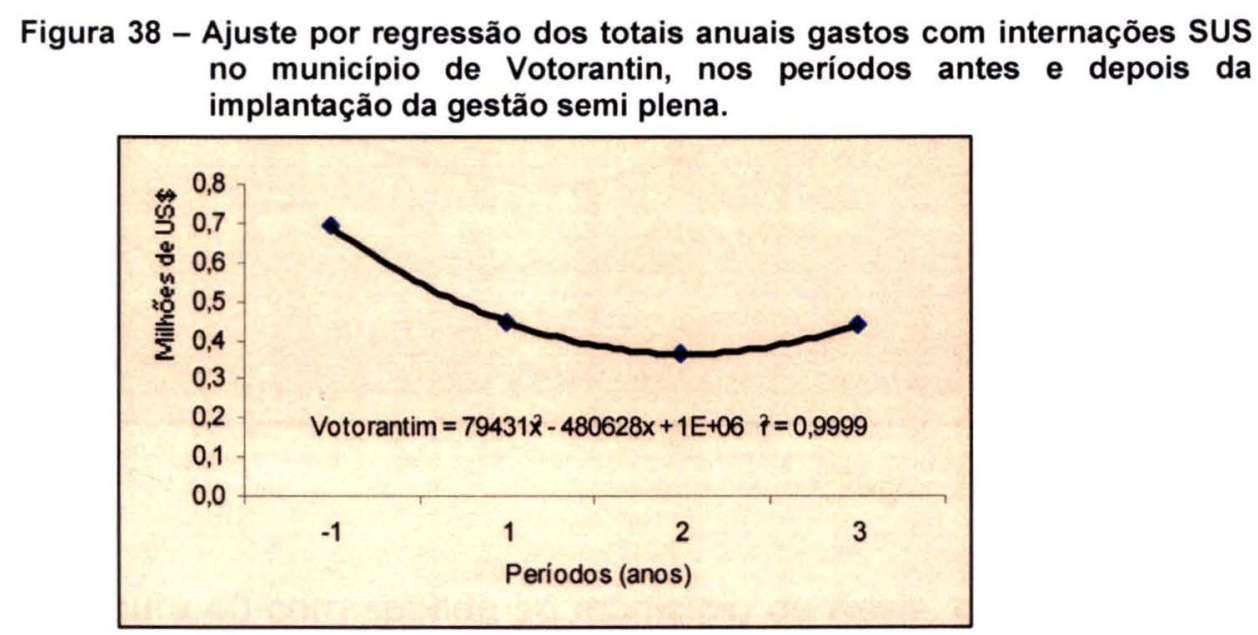

\section{Evolução do Gasto Médio por Internação SUS}

As Figuras de 39 a 50 apresentam os ajustes de regressão entre gastos médios anuais das internações nos municípios em função do tempo em anos. O primeiro ano de avaliação é representado por -1 no eixo $x \mathrm{e}$ corresponde ao período antes da implantação da gestão semi plena no município. Os anos seguintes, representados por 1,2 e 3 no eixo $x$, correspondem aos três anos seguintes, após a implantação da gestão semi plena no municipio.

A Figura 39 corresponde ao total dos 11 municípios, onde se observa que a evolução do gasto médio é crescente em função do tempo. Apresenta-se nesta figura a curva de regressão, modelo polinomial de segundo grau e seu respectivo $r^{2}=0,96$ e teste $F$ de 4,378 não significativo ao nivel de probabilidade de $5 \%$. 
Figura 39 - Ajuste por regressão dos gastos médios anuais das internações SUS nos 11 municípios estudados, nos períodos antes e depois da implantação da gestão semi plena.

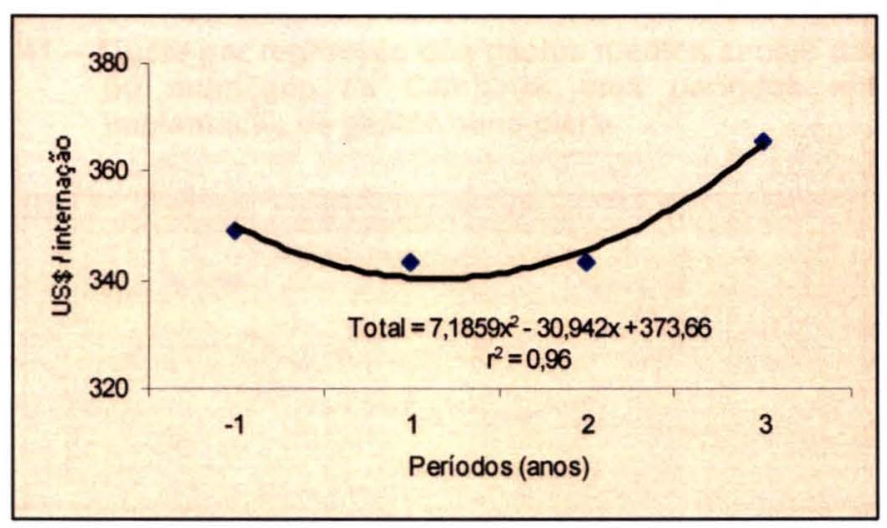

A Figura 40 corresponde ao município de Assis, onde observa-se que a evolução do gasto médio por internação é decrescente em função do tempo. Apresenta-se nessa figura a curva de regressão modelo polinomial de $2^{\circ}$ grau e seu respectivo $r^{2}=0,98$ e teste $F$ de 259,793 significativo ao nivel de probabilidade de $5 \%$. Figura 40 - Ajuste por regressão dos gastos médios anuais das internações SUS
no município de Assis, nos períodos antes e depois da implantação
da gestão semi plena.

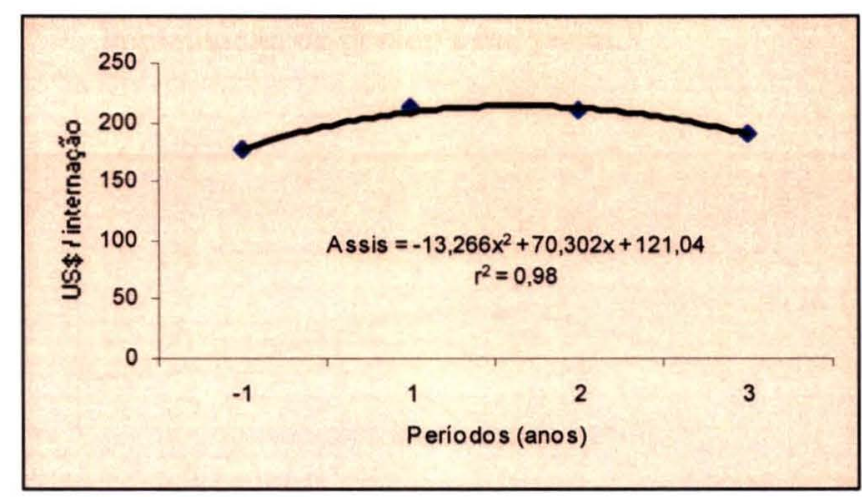

A Figura 41 corresponde ao município de Campinas, onde observa-se que a evolução do gasto médio por internação é crescente em função do tempo. Apresenta-se nessa figura a curva de regressão modelo 
polinomial de $2^{\circ}$ grau e seu respectivo $r^{2}=0,91$ e teste $F$ de 1,969 não significativo ao nível de probabilidade de $5 \%$. Figura 41 - Ajuste por regressão dos gastos médios anuais das internações SUS
no municipio de Campinas, nos períodos antes e depois da
implantação da gestão semi plena.

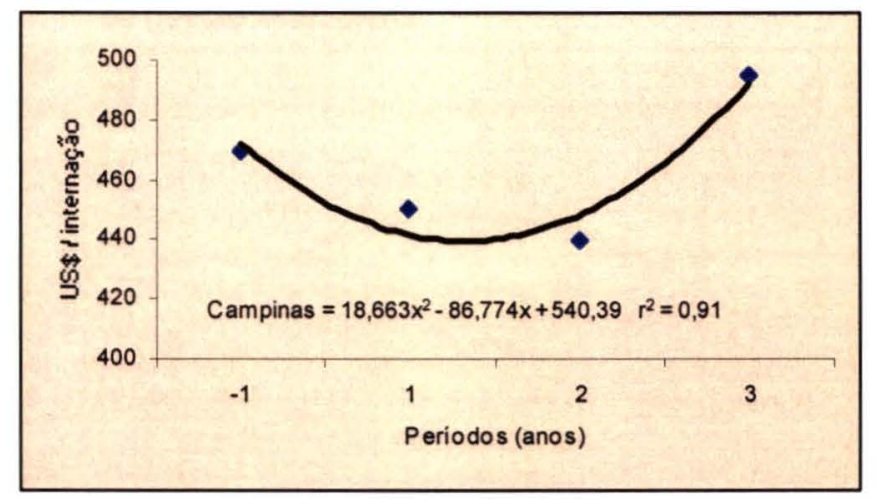

A Figura 42 corresponde ao município de Diadema, onde observa-se que a evolução do gasto médio por internação é decrescente em função do tempo. Apresenta-se nessa figura a curva de regressão modelo polinomial de $2^{\circ}$ grau e seu respectivo $r^{2}=0,49$ e teste $F$ de 0,948 não significativo ao nivel de probabilidade de $5 \%$.

Figura 42 - Ajuste por regressão dos gastos médios anuais das internações SUS no município de Diadema, nos periodos antes e depois da implantação da gestão semi plena.

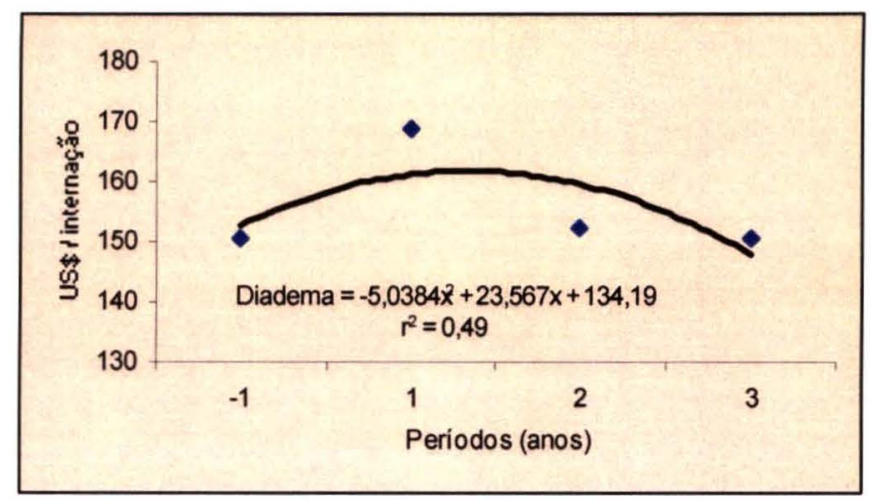

A Figura 43 corresponde ao município de Mauá, onde observa-se que a evolução do gasto médio por internação é decrescente em função do 
tempo. Apresenta-se nessa figura a curva de regressão modelo polinomial de $2^{\circ}$ grau e seu respectivo $r^{2}=0,69$ e teste $F$ de 2,557 não significativo ao nivel de probabilidade de $5 \%$.

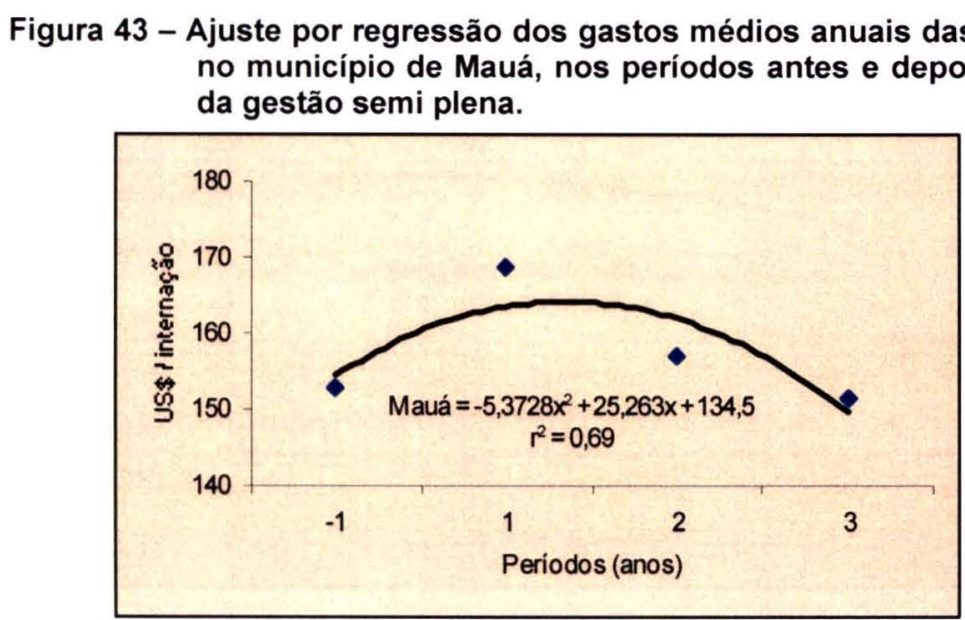

A Figura 44 corresponde ao município de Ribeirão Preto, onde observa-se que a evolução do gasto médio por internação é crescente em função do tempo. Apresenta-se nessa figura a curva de regressão modelo polinomial de $2^{\circ}$ grau e seu respectivo $r^{2}=0,88$ e teste $F$ de 15,304 não significativo ao nível de probabilidade de $5 \%$.

Figura 44 - Ajuste por regressão dos gastos médios anuais das internações SUS no município de Ribeirão Preto, nos períodos antes e depois da implantação da gestão semi plena.

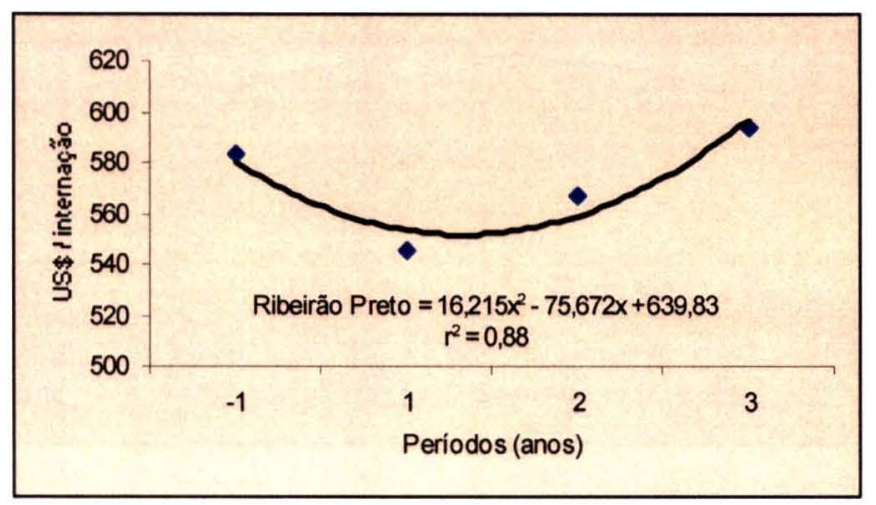

A Figura 45 corresponde ao município de Santos, onde observase que a evolução do gasto médio por internação é decrescente em função do tempo. Apresenta-se nessa figura a curva de regressão modelo 
polinomial de $2^{\circ}$ grau e seu respectivo $r^{2}=0,85$ e teste $F$ de 3,382 não significativo ao nível de probabilidade de $5 \%$.

Figura 45 - Ajuste por regressão dos gastos médios anuais das internações SUS no município de Santos, nos períodos antes e depois da implantação da gestão semi plena.

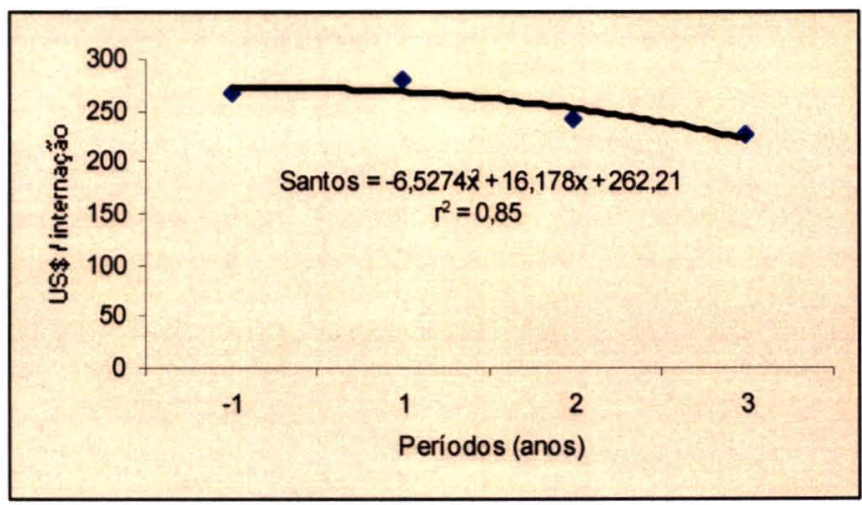

A Figura 46 corresponde ao município de São Bernardo do Campo, onde observa-se que a evolução do gasto médio por internação é decrescente em função do tempo. Apresenta-se nessa figura a curva de regressão modelo polinomial de $2^{\circ}$ grau e seu respectivo $r^{2}=0,68$ e teste $F$ de 2,565 não significativo ao nível de probabilidade de $5 \%$.

Figura 46 - Ajuste por regressão dos gastos médios anuais das internações SUS no município de São Bernardo do Campo, nos períodos antes e depois da implantação da gestão semi plena.

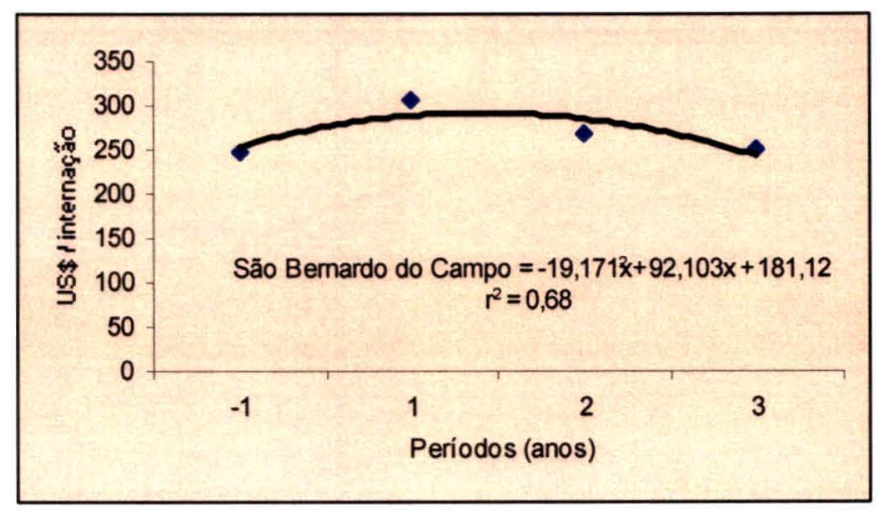

A Figura 47 corresponde ao município de São José dos Campos, onde observa-se que a evolução do gasto médio por internação é decrescente em função do tempo. Apresenta-se nessa figura a curva de 
regressão modelo polinomial de $2^{\circ}$ grau e seu respectivo $r^{2}=0,74$ e teste $F$ de 591,010 significativo ao nivel de probabilidade de $5 \%$.

Figura 47 - Ajuste por regressão dos gastos médios anuais das internações SUS
no municipio de São José dos Campos, nos períodos antes e depois
da implantação da gestão semi plena.

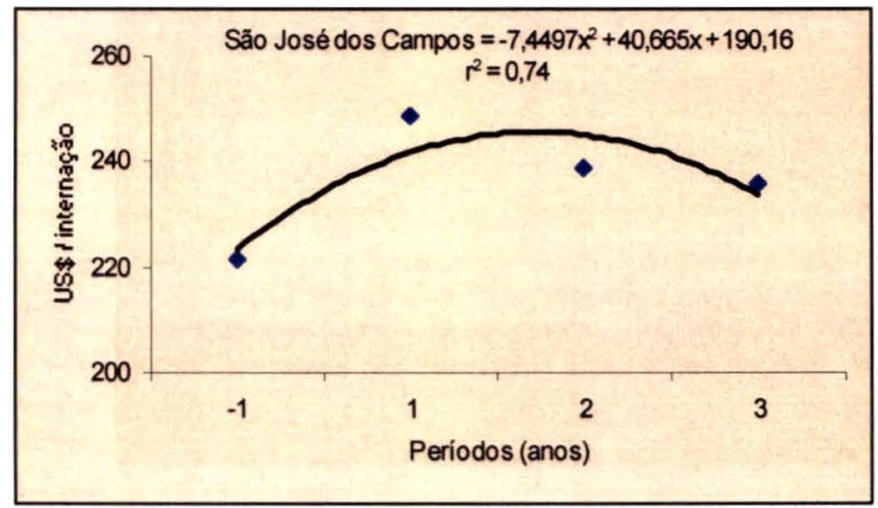

A Figura 48 corresponde ao município de São Vicente, onde observa-se que a evolução do gasto médio por internação é crescente em função do tempo. Apresenta-se nessa figura a curva de regressão modelo polinomial de $2^{\circ}$ grau e seu respectivo $r^{2}=0,96$ e teste $F$ de 3,892 não significativo ao nível de probabilidade de $5 \%$.

Figura 48 - Ajuste por regressão dos gastos médios anuais das internações SUS no município de São Vicente, nos períodos antes e depois da implantação da gestão semi plena.

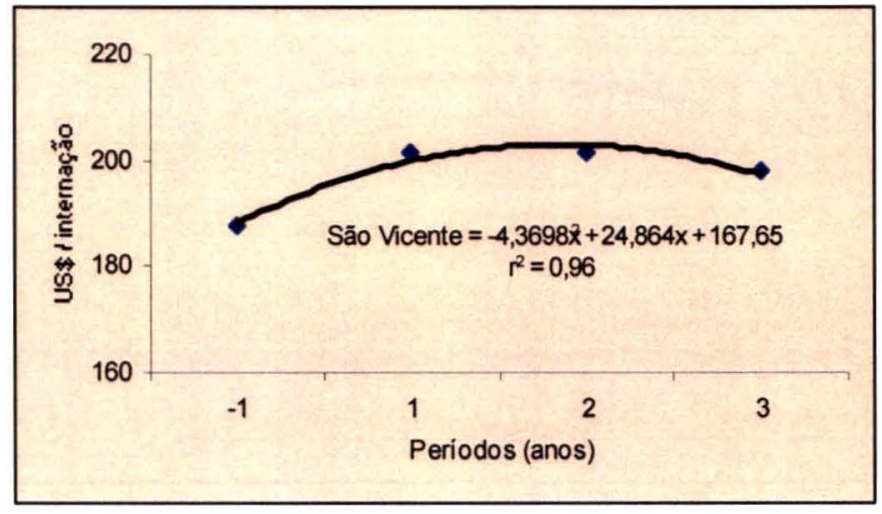

A Figura 49 corresponde ao município de Sertãozinho, onde observa-se que a evolução do gasto médio por internação é decrescente em função do tempo. Apresenta-se nessa figura a curva de regressão modelo 
polinomial de $2^{\circ}$ grau e seu respectivo $r^{2}=0,95$ e teste $F$ de 4047,408 significativo ao nível de probabilidade de $5 \%$.
Figura 49 - Ajuste por regressão dos gastos médios anuais das internações SUS no município de Sertãozinho, nos períodos antes e depois da implantação da gestão semi plena.

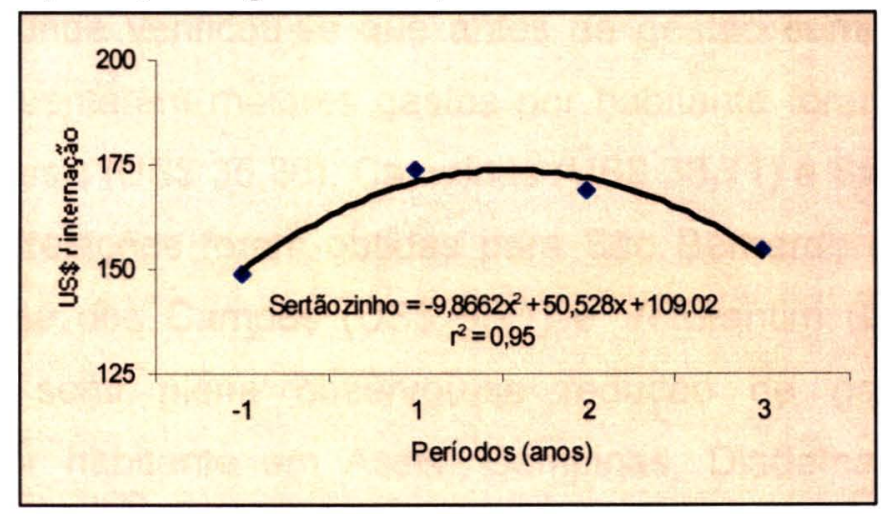

A Figura 50 corresponde ao município de Votorantim, onde observa-se que a evolução do gasto médio por internação é decrescente em função do tempo. Apresenta-se nessa figura a curva de regressão modelo polinomial de $2^{\circ}$ grau e seu respectivo $r^{2}=0,86$ e teste $F$ de 10,403 não significativo ao nível de probabilidade de $5 \%$.

Figura 50 - Ajuste por regressão dos gastos médios anuais das internações SUS no município de Votorantin, nos períodos antes e depois da implantação da gestão semi plena.

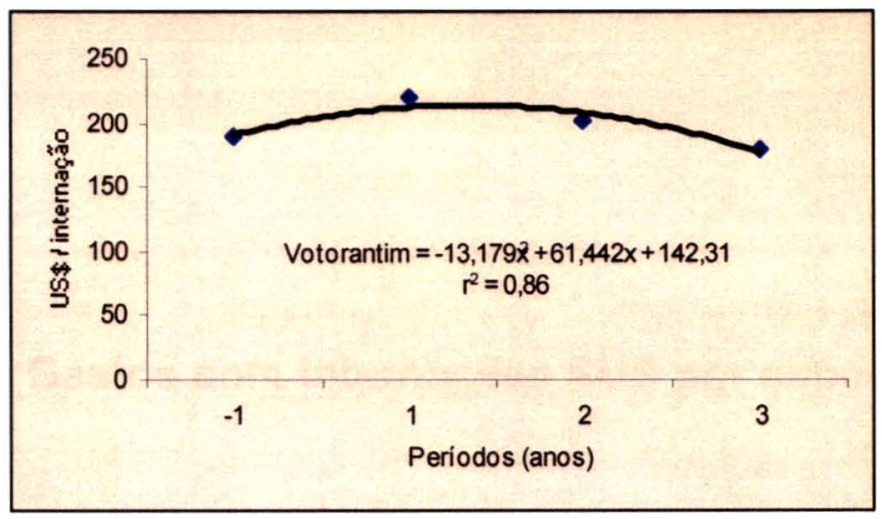




\subsubsection{Gastos com internações SUS por habitante}

$\mathrm{Na}$ Figura 51 são apresentados os gastos com pagamento de AlHs SUS por habitante, por município, antes e depois da implantação da gestão semi plena, onde verificou-se que antes da gestão semi plena, os municípios que apresentaram maiores gastos por habitante foram Ribeirão Preto (US\$ 67,35), Assis (US\$ 35,36), Campinas (US\$ 33,71) e Santos (US\$ 23,58). As menores relações foram obtidas para São Bernardo do Campo (US\$ 1,71), São José dos Campos (US\$ 5,71) e Votorantim (US\$ 8,17). Depois da gestão semi plena observou-se redução de gastos com internações SUS por habitante em Assis, Campinas, Diadema, Ribeirão Preto, São Vicente e Votorantim.

Figura 51 - AlHs pagas por habitante, por município, antes e depois da implantação da gestão semi plena.

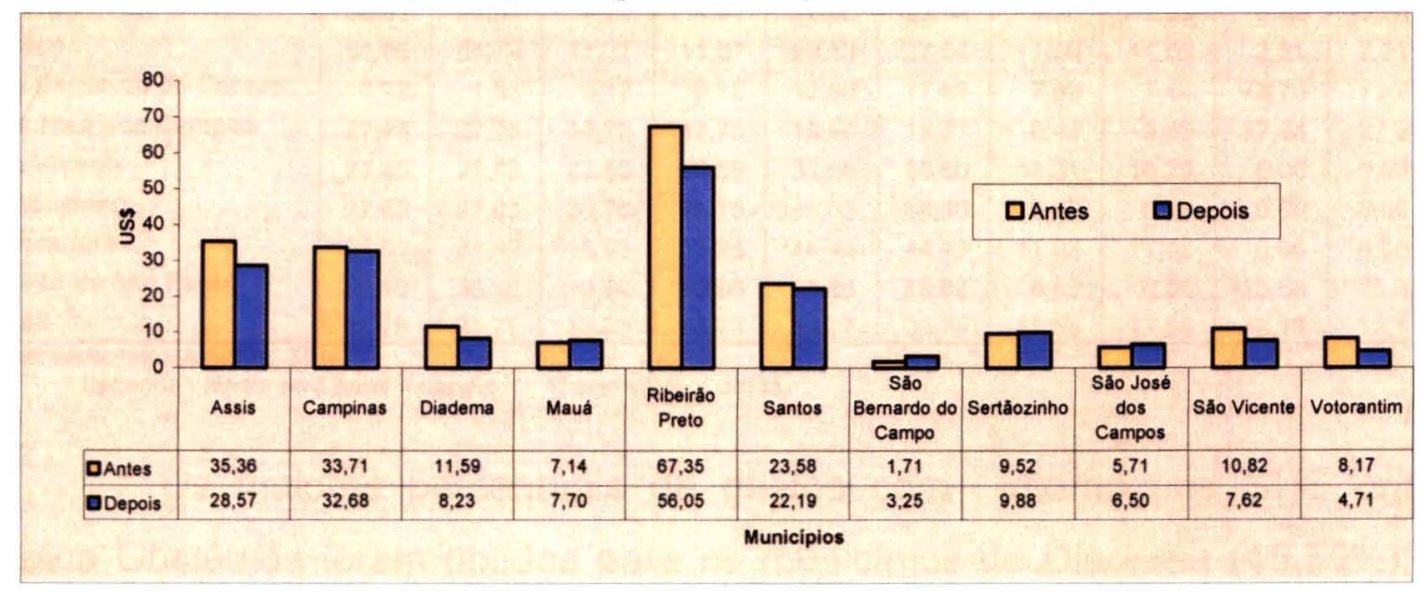

\subsubsection{Gastos com internações SUS por especialidade}

No Quadro 59 são apresentadas as distribuições percentuais dos gastos com internações SUS por especialidades e municípios antes e depois da implantação da gestão semi plena. 
O maior percentual de gastos com internações SUS em Clínica Cirúrgica antes da implantação foi obtido nos municipios de Ribeirão Preto $(56,81 \%)$; Santos $(51,80 \%)$ e Campinas $(46,42 \%)$, enquanto o menor percentual observou-se em Diadema $(9,16 \%)$, Mauá $(10,70 \%)$ e São Bernardo do Campo (0,72\%). Nos demais municipios os percentuais de internações SUS em Clínica Cirúrgica ficaram entre de 22 e $28 \%$.

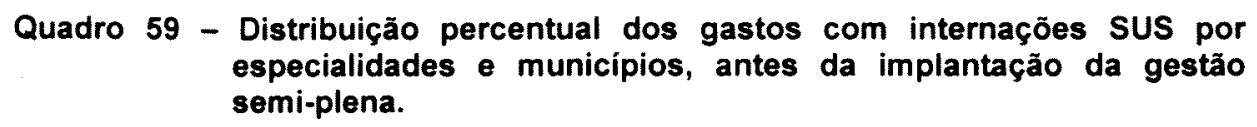
especialidades e municípios, antes da implantação da gestão semi-plena.

\begin{tabular}{|c|c|c|c|c|c|c|c|c|c|c|}
\hline \multirow{3}{*}{ Municipio } & \multicolumn{2}{|c|}{ Cirurgia } & \multicolumn{2}{|c|}{ Obstetrícia } & \multicolumn{2}{|c|}{$\begin{array}{l}\text { Clínica } \\
\text { Médica }\end{array}$} & \multicolumn{2}{|c|}{ Pediatria } & \multicolumn{2}{|c|}{ Outros } \\
\hline & A & D & A & D & A & $D$ & $\bar{A}$ & D & A & D \\
\hline & $\%$ & $\%$ & $\%$ & $\%$ & $\%$ & $\%$ & $\%$ & $\%$ & $\%$ & $\%$ \\
\hline Assis & 22,19 & 22,23 & 12,21 & 12,22 & 44,16 & 44,12 & 19,05 & 19,04 & 2,39 & 2,39 \\
\hline Campinas & 46,42 & 46,46 & 9,59 & 9,59 & 26.98 & 26,94 & 9,33 & 9,34 & 7,67 & 7,68 \\
\hline Diadema & 9,16 & 9.19 & 48,59 & 48,57 & 12,17 & 12,20 & 16,54 & 16,55 & 13.54 & 13,5 \\
\hline Mauá & 10,70 & 10,73 & 38,34 & 38,38 & 22,53 & 22,54 & 19,72 & 19,69 & 8,71 & 8,66 \\
\hline Ribeirāo Preto & 56,81 & 56,81 & 4.91 & 4,91 & 22,35 & 22,34 & 9,23 & 9,23 & 6,69 & 6,70 \\
\hline Santos & 51,80 & 51,79 & 11,37 & 11,37 & 23.53 & 23.54 & 11,09 & 11,09 & 2,21 & 2,21 \\
\hline Såo Bernardo do Campo & 0.72 & 1.53 & 0.12 & 0,12 & 17,88 & 17,69 & 7,53 & 7,44 & 73,75 & 73,2 \\
\hline São José dos Campos & 27,75 & 27,76 & 15.72 & 15,70 & 19,80 & 19,77 & 9,49 & 9,49 & 27,24 & 27,2 \\
\hline Săo Vicente & 27,45 & 27,52 & 23,59 & 23,59 & 32,65 & 32,60 & 16.31 & 16,29 & 0,00 & 0,00 \\
\hline Sertãozinho & 27,60 & 27,63 & 25,75 & 25,75 & 46,65 & 46,60 & 0,00 & 0,02 & 0,00 & 0,00 \\
\hline Votorantim & 27,61 & 27.59 & 16,93 & 16,95 & 44,44 & 44,43 & 11,02 & 11,02 & 0,00 & 0,00 \\
\hline Estado de Săo Paulo & 36,10 & 36.10 & 10.94 & 10.96 & 28,85 & 28.82 & 8,56 & 8,56 & 15.55 & 15,5 \\
\hline Brasil & 31,76 & 31.77 & 13.73 & 13,73 & 30.77 & 30,75 & 11,58 & 11,58 & 12,16 & 12,1 \\
\hline
\end{tabular}

Os maiores percentuais de gastos com internações SUS em Clínica Obstétrica foram obtidos para os municipios de Diadema (48,59\%); Mauá $(38,34 \%)$; São Vicente $(23,59 \%)$ e Sertãozinho $(25,75 \%)$.

Os municipios que apresentaram o menor número de internações em obstetrícia, antes da implantação da gestão semi plena, foram Campinas $(9,59 \%)$, São Bernardo do Campo $(0,12 \%)$; Ribeirão Preto $(4,91 \%)$, Assis $(12,21 \%)$ e Santos $(11,37 \%)$. Sendo que, os demais flutuaram entre 20 e $26 \%$.

$\mathrm{Na}$ especialidade de Clínica Médica, os municípios que mais gastaram com internações SUS foram: Sertãozinho (46,65\%) seguido por 
Votorantim (44,44\%) e Assis $(44,16 \%)$. E os menores percentuais de internação em Clinica Médica, antes da implantação da gestão semi plena ocorreram em Diadema (12,17\%), São Bernardo do Campo(17,88\%) e São José dos Campos(19,80\%).

Os maiores percentuais de gastos com internações SUS em Pediatria, verificou-se no municipio de Assis (19,05\%), seguido por São Vicente $(16,31 \%)$ e Mauá $(19,72 \%)$ enquanto os menores índices de gastos com internações SUS de Pediatria ocorreram em São Bernardo do Campo $(7,53 \%)$, Ribeirão Preto $(9,23 \%)$, Campinas $(9,33 \%)$ e São José dos Campos $(9,49 \%)$. No município de Sertãozinho não foram registradas internações SUS nessa especialidade, no periodo.

\subsubsection{Gastos com internações SUS e invasão}

O Quadro 60 mostra a distribuição dos percentuais de gastos com internações SUS, por origem dos pacientes, onde se observou que antes da implantação da gestão semi plena, nos municípios de Campinas, Ribeirão Preto e São Bernardo do Campo o percentual de gastos com internações SUS sem o registro da origem do paciente foi de 7,95\%; $14,75 \%$ e $21,49 \%$, respectivamente. Essas taxas após a implantação da gestão semi plena foram reduzidas em Campinas (2,78\%); Ribeirão Preto (4,66\%) e São Bernardo do Campo $(4,42 \%)$. Para os demais municipios não foram realizados os respectivos registros da origem dos pacientes antes da semi plena, totalizando portanto, $100 \%$ do total dos gastos, conforme mostram esses registros. 
Quadro 60 - Distribuição dos percentuais de gastos com internações SUS por origem dos pacientes e municípios antes depois da implantação da gestão semi plena.

\begin{tabular}{|c|c|c|c|c|c|c|c|c|}
\hline \multirow{3}{*}{ Municipios } & \multicolumn{4}{|c|}{ Antes } & \multicolumn{4}{|c|}{ Depois } \\
\hline & $\begin{array}{c}\text { Sem } \\
\text { Inform. }\end{array}$ & $\begin{array}{c}\text { Do } \\
\text { Munic. }\end{array}$ & Invasăo & Total & $\begin{array}{c}\text { Sem } \\
\text { Inform. }\end{array}$ & $\begin{array}{c}\text { Do } \\
\text { Munic. }\end{array}$ & Invasáo & Total \\
\hline & $\%$ & $\%$ & $\%$ & $\%$ & $\%$ & $\%$ & $\%$ & $\%$ \\
\hline Assis & 100,00 & 0,00 & 0.00 & 100,00 & 0.07 & 77,88 & 22,05 & 100,00 \\
\hline Campinas & 7,95 & 39,99 & 52,06 & 100,00 & 2,78 & 44,78 & 52,44 & 100,00 \\
\hline Diadema & 100,00 & 0,00 & 0,00 & 100,00 & 2,17 & 69,09 & 28,74 & 100,00 \\
\hline Mauá & 100,00 & 0.00 & 0,00 & 100,00 & 0.69 & 73,07 & 26,24 & 100,00 \\
\hline Ribeirăo Preto & 14.75 & 29,50 & 55,75 & 100,00 & 4,66 & 41,17 & 54,16 & 100,00 \\
\hline Santos & 100,00 & 0,00 & 0,00 & 100,00 & 25,29 & 40,24 & 34,47 & 100,00 \\
\hline Săo Bernardo do Campo & 21,49 & 48,38 & 30,14 & 100,00 & 4,42 & 59,68 & 35,90 & 100,00 \\
\hline Sáo José dos Campos & 100,00 & 0,00 & 0,00 & 100,00 & 1,08 & 90,26 & 8,66 & 100,00 \\
\hline Såo Vicente & 100,00 & 0,00 & 0,00 & 100,00 & 1,48 & 84,73 & 13,80 & 100,00 \\
\hline Sertáozinho & 100,00 & 0,00 & 0,00 & 100,00 & 0,26 & 99,35 & 0,39 & 100,00 \\
\hline Votorantim & 100,00 & 0,00 & 0,00 & 100,00 & 5,00 & 70,22 & 24,78 & 100,00 \\
\hline Total & 38,17 & 24,44 & 37,39 & 100,00 & 5,58 & 50,38 & 44,03 & 100,00 \\
\hline
\end{tabular}

Considerando-se os 11 municipios, depois da semi plena, 44,03\% dos gastos com internações SUS referiam-se a pacientes oriundos de outros municipios, $50,38 \%$ relativos às internações SUS de pacientes com domicilio no municipio e $5,58 \%$ de internações SUS sem informação da origem do paciente.

Depois da implantação da gestão semi plena, os municípios que gastaram mais com internações SUS de pacientes oriundos de outros municipios foram: Ribeirão Preto $(54,16 \%)$, Campinas $(52,44 \%)$, São Bernardo do Campo $(35,90 \%)$ e Santos $(34,47 \%)$ enquanto os que menos gastaram com invasões foram os municipios de Sertãozinho $(0,39 \%)$, São Bernardo do Campo (8,66\%) e São Vicente $(13,80 \%)$.

\subsubsection{Gastos com internações SUS e evasão}

Os dados de evasão em internações SUS, do periodo antes da implantação da gestão semi plena, a exemplo do que ocorreu com a 
invasão foram registrados apenas em Campinas, Ribeirão Preto e São Bernardo do Campo. Quadro 61- Distribuição dos percentuais de gastos com internações SUS por
origem dos pacientes e municípios antes depois da implantação da
gestão semi plena.

\begin{tabular}{|c|c|c|}
\hline \multirow{3}{*}{$\mathrm{Pun}_{\text {Municipios }}$ Periodo } & \multicolumn{2}{|c|}{ Evasåo } \\
\hline & Antes & Depois \\
\hline & US\$ & US\$ \\
\hline Assis & 0 & 597796 \\
\hline Campinas & 1311655 & 1238094 \\
\hline Diadema & 0 & 2042057 \\
\hline Mauá & 0 & 1378596 \\
\hline Ribeirão Preto & 212627 & 222409 \\
\hline Santos & 0 & 684886 \\
\hline Săo Bernardo do Campo & 1981125 & 3034234 \\
\hline Săo José dos Campos & 0 & 950176 \\
\hline Săo Vicente & 0 & 1856646 \\
\hline Sertảozinho & 0 & 844013 \\
\hline Votorantim & 0 & 1216848 \\
\hline Total & 3505407 & 14065754 \\
\hline
\end{tabular}

Fonte: www.datasus.gov.br_SIH

* Legenda - Média de 3 anos $=$ depois $1^{\circ}$ ano antes $=$ antes

O município de Campinas, depois da implantação da gestão semi plena, apresentou redução de $5,61 \%$ na evasão, quando comparados o período antes e depois da semi plena, enquanto Ribeirão Preto e São Bernardo do Campo apresentaram aumento nos gastos com internações SUS de $4,60 \%$ e $53,16 \%$, respectivamente nas evasões.

\subsubsection{Gastos com internações SUS por prestador}

O Quadro 62 mostra a distribuição dos percentuais gastos com internações SUS por prestador e municípios, nos períodos antes e depois da gestão semi plena.

Com relação aos percentuais dos totais de gastos, considerandose os 11 municipios, os hospitais universitários foram responsáveis pela 
maior parcela, tanto no periodo antes $(49,70 \%)$ quanto depois $(55,70 \%)$ da implantação da gestão semi plena nos municípios. A segunda posição correspondeu aos prestadores filantrópicos, que representaram $30,33 \%$ e $28,63 \%$, nos periodos antes e depois, respectivamente. Os prestadores municipais ocuparam a terceira posição, $7,62 \%$ (antes) e $9,92 \%$ (depois), seguidos pelos prestadores contratados $10,61 \%$ (antes) e $3,48 \%$ (depois) e os prestadores estaduais $1,71 \%$ (antes) e $2,24 \%$ (depois).

\footnotetext{
Quadro 62 - Distribuição percentual dos gastos com internações SUS, por prestadores e municipios, antes e depois da implantação da gestāo semi plena.
}

\begin{tabular}{|c|c|c|c|c|c|c|c|c|c|c|}
\hline \multirow[b]{3}{*}{ Municipio } & \multicolumn{2}{|c|}{ Contratado } & \multicolumn{2}{|c|}{ Estadual } & \multicolumn{2}{|c|}{ Municipai } & \multicolumn{2}{|c|}{ Filantrópico } & \multicolumn{2}{|c|}{ Universitário } \\
\hline & A & D & A & $\mathrm{D}$ & A & $D$ & $\mathrm{~A}$ & D & A & $\mathrm{D}$ \\
\hline & $\%$ & $\%$ & $\%$ & $\%$ & $\%$ & $\%$ & $\%$ & $\%$ & $\%$ & $\%$ \\
\hline Assis & 30,45 & 22,51 & 20.53 & 29,86 & & & 49,02 & 47,63 & & \\
\hline Campinas & 2,94 & 0,04 & & & 5,77 & 6,32 & 8,50 & 9,96 & 82,79 & 83,67 \\
\hline Diadema & 44,09 & 20,47 & & & 55,91 & 79,53 & & & & \\
\hline Mauá & & & & & 44,17 & 55,14 & 55,83 & 44,86 & & \\
\hline Ribeirão Preto & 17,00 & 5,24 & & & & & 23,42 & 20,88 & 59,58 & 73,88 \\
\hline Santos & 0,09 & 0,00 & 9,24 & 12,46 & 3,61 & 9,18 & 87,06 & 78.37 & & \\
\hline Sertăozinho & & & & & & & 100,00 & 100,00 & & \\
\hline Săo Bernardo do Campo & 3,05 & 0,00 & & & 24,89 & 11,51 & & & 72,06 & 88,49 \\
\hline Săo José dos Campos & 1,11 & 0,06 & & & 27,73 & 32,62 & 71,17 & 67,32 & & \\
\hline Såo Vicente & & & & & & & 100,00 & 100,00 & & \\
\hline Votorantim & 100,00 & 100,00 & & & & & & & & \\
\hline Total & \begin{tabular}{|l|}
10,61 \\
\end{tabular} & 3,48 & 1,71 & 2,24 & 7,62 & 9,92 & 30,33 & 28,63 & 49,7 & 55,7 \\
\hline
\end{tabular}

Ainda com relação aos totais de gastos com internações SUS, analisando-se os periodos antes e depois, registrou-se aumento nos percentuais gastos depois da semi plena, nos seguintes prestadores: hospitais universitários $(5,99 \%)$, municipais $(2,30 \%)$ e estaduais $(0,54 \%)$ e reduções para os prestadores contratados $(7,13 \%)$ e filantrópicos $(1,70 \%)$.

No Município de Assis, depois da semi plena, registrou-se redução de $7,94 \%$ nos gastos com internações SUS em prestadores contratados e 1,39\% com a categoria filantrópicos, enquanto que os gastos com prestadores estaduais cresceram em $9,33 \%$. 
Em Campinas, verificou-se aumento nos percentuais de gastos com internações SUS, depois da semi plena, dos prestadores filantrópicos $(1,46 \%)$, universitários $(0,88 \%)$ e municipais $(0,56 \%)$, observou-se redução dos gastos com internações SUS nos prestadores contratados $(2,90 \%)$.

Depois da gestão semi plena, registrou-se nos municípios de Diadema mudança de prestador contratado (antes $=44,09 \%$ e depois $=$ $20,47 \%$ ) para prestador municipal (antes $=55,91 \%$ e depois $=79,53 \%$ ), onde observou-se a redução de $23,62 \%$ para a categoria contratado e o aumento de $23,62 \%$ para a categoria municipal. O mesmo foi observado para Mauá, cujos percentuais de gastos da categoria dos prestadores filantrópicos representavam antes da semi plena $55,83 \%$ e depois da implantação para $44,86 \%$ das internações SUS, apresentando uma redução de $10,97 \%$, que foi o mesmo percentual de acréscimo verificado depois da semi plena para a categoria municipal, que antes respondia por $44,17 \%$ dos gastos no município, passando a representar $55,14 \%$, depois da semi plena.

No Municipio de Ribeirão Preto, depois da implantação semi plena, verificou-se a redução dos percentuais dos gastos com internações SUS nos prestadores contratados $(11,76 \%)$ e filantrópicos $(2,54 \%)$, enquanto observou-se aumento nos percentuais gastos com internações SUS em hospital universitário de $14,30 \%$.

Em Santos, depois da semi plena, reduziu-se em $8,70 \%$ os gastos com os prestadores filantrópicos e $0,09 \%$ com os contratados, enquanto que aumentou-se em $5,57 \%$ e $3,21 \%$ os percentuais de gastos com internações SUS nos prestadores municipais e estaduais, respectivamente.

Nos Municipios de Sertãozinho, São Vicente e Votorantim foram mantidos os percentuais de gastos, antes e depois da semi plena, sem alteração do prestador. 
Em São Bernardo do Campo, os percentuais dos gastos com internações SUS, relativos ao prestador universitário aumentou em 16,44\%, depois da semi plena, enquanto que para os prestadores municipais e contratados, observou-se redução de $13,38 \%$ e $3,05 \%$, respectivamente.

Depois da semi plena, em São José dos Campos, os percentuais de gastos com internações SUS, aumentaram em $4,89 \%$ para os prestadores municipais e reduziram em $3,84 \%$ e $1,05 \%$, nos percentuais dos gastos com os prestadores filantrópicos e contratados, respectivamente.

De maneira geral, depois da semi plena, observou-se a ocorrência do remanejamento dos percentuais dos gastos por prestador, sendo reduzidos os percentuais gastos com prestadores filantrópicos e contratados e aumentados os gastos com os prestadores municipais, universitários e estaduais. Ressalva deve ser feita ao Municipio de São Bernardo do Campo, que depois da semi plena reduziu seus percentuais de gastos com internações SUS em prestador municipal $(13,38 \%)$ e contratado $(3,05 \%)$ e aumentou em $16,44 \%$ os gastos com internações SUS em hospital universitário.

\subsubsection{Gastos com internações SUS por procedimentos}

O Quadro 63 apresenta a distribuição dos percentuais relativos aos 50 procedimentos de maior dispêndio, considerando-se os totais gastos com internações SUS nos 11 municípios estudados, onde é possivel observar que os 50 procedimentos selecionados representaram $55,96 \%$ do total dos gastos, sendo que antes da semi plena representavam $56,98 \%$ e depois passaram a representar em média $55,58 \%$, se considerarmos os 3 anos após a implantação. 
Dos totais de gastos com internações SUS nos 11 municipios estudados, os procedimentos de parto foram os que mais consumiram recursos, destacando-se na primeira posição as cesarianas que consumiram $4,68 \%$ dos totais dos gastos, sendo $4,71 \%$ antes e a média $4,67 \%$ depois da implantação da gestão semi plena nos municípios. A segunda posição foi ocupada pelos partos normais que com relação ao total representaram $4,24 \%$ dos gastos, sendo $4,28 \%$ antes e em média $4,23 \%$ depois. As cirurgias múltiplas ocuparam o terceiro lugar com $2,71 \%(2,99 \%$ antes e $2,61 \%$ depois), seguidos pelos procedimentos de insuficiência cardiaca que representaram $2,65 \%$ do total, sendo $3,21 \%$ (antes) e a média de $2,44 \%$ (depois). 
Quadro 63 - Distribuição percentual dos gastos com internações SUS pelos 50 procedimentos mais dispendiosos, ocorridos nos 11 municipios, antes e depois da implantação da gestão semi-plena.

\begin{tabular}{|c|c|c|c|c|c|c|c|c|c|c|c|}
\hline \multirow{2}{*}{\multicolumn{2}{|c|}{ Procedimentos }} & \multirow{2}{*}{\multicolumn{2}{|c|}{ Total }} & \multirow{2}{*}{\multicolumn{2}{|c|}{$\begin{array}{l}\text { Antes } \\
1^{\circ} \text { ano }\end{array}$}} & \multicolumn{6}{|c|}{ Depols } \\
\hline & & & & & & \multicolumn{2}{|c|}{$9^{\circ}$ ano: } & \multicolumn{2}{|c|}{$2^{\circ}$ ano } & \multicolumn{2}{|c|}{$3^{\circ}$ ano } \\
\hline Codlgo & Descriçăo & Pos. & $\%$ & Pos. & $\%$ & Pos. & $\%$ & Pos. & $\%$ & Pos. & $\%$ \\
\hline 3502201 & CESARIANA COM ATENDIMENTO RN SALA DE PARTO & 1 & 4,68 & 1 & 4,71 & 1 & 4,64 & 1 & 4,67 & 1 & 4,71 \\
\hline 3502101 & PARTO NORMAL COM ATENDIMENTO RN SALA DE PARTO & 2 & 4,24 & 2 & 4,28 & 2 & 3,90 & 2 & 4,20 & 2 & 4,59 \\
\hline 3100000 & CIRURGIA MULTIPLA & 3 & 2,71 & 4 & 2,99 & 3 & 3,40 & 3 & 2,48 & 7 & 1,94 \\
\hline 7750011 & INSUFICIENCIA CARDIACA & 4 & 2,65 & 3 & 3,21 & 4 & 2,85 & 5 & 2,31 & 5 & 2,16 \\
\hline 7130001 & PREMATURIDADE & 5 & 2,38 & 8 & 2,23 & 5 & 2,43 & 4 & 2,41 & 3 & 2,46 \\
\hline 4680020 & TRANSPLANTE DE MEDULA ALOGENICO APARENTADO & 6 & 2,10 & 9 & 1,99 & 7 & 1,93 & 6 & 2,15 & 4 & 2,34 \\
\hline 3202001 & IMPLANTE DE PROTESE VALVULAR & 7 & 2,09 & 7 & 2,34 & 6 & 1,99 & 8 & 1,98 & 6 & 2.01 \\
\hline 3201101 & CIRURGIA DE CORONARIA COM EXTRA-CORPOREA & 8 & 2,00 & 5 & 2,39 & 8 & 1,91 & 9 & 1,85 & 9 & 1,83 \\
\hline 3201501 & MARCA-PASSO CARDIACO(INTRACAVITARIO) & 9 & 1,94 & 10 & 1,99 & 10 & 1,81 & 7 & 2,13 & 8 & 1,84 \\
\hline 3202301 & CORONARIOPLASTIA & 10 & 1,91 & 6 & 2,37 & 9 & 1,86 & 10 & 1,59 & 10 & 1,79 \\
\hline 7000000 & TRATAMENTO DA AIDS & 11 & 1,59 & 11 & 1,83 & 11 & 1,64 & 12 & 1,51 & 12 & 1,35 \\
\hline 3180201 & TRANSPLANTE RENAL RECEPTOR & 12 & 1,52 & 12 & 1,75 & 12 & 1,57 & 11 & 1,52 & 15 & 1,23 \\
\hline 3900000 & POLITRAUMATIZADO & 13 & 1.44 & 13 & 1,61 & 13 & 1,48 & 13 & 1.49 & 16 & 1,19 \\
\hline 8150010 & AVC AGUDO & 14 & 1.20 & 14 & 1.43 & 15 & 1.24 & 15 & 1.06 & 17 & 1,05 \\
\hline 3202101 & CORRECAO DE CARDIOPATIA CONGENITA & 15 & 1,08 & 15 & 1.03 & 21 & 0,94 & 14 & 1,06 & 14 & 1,30 \\
\hline 7750002 & INFARTO AGUDO DO MIOCARDIO & 16 & 0,97 & 16 & 0.90 & 20 & 0,94 & 18 & 1,01 & 18 & 1.04 \\
\hline 3901612 & ARTROPLASTIA COXO-FEMURAL CIPROTESE NAO CIMENTADA & 17 & 0,94 & 22 & 0,85 & 16 & 1,04 & 19 & 0,98 & 20 & 0,87 \\
\hline 7630010 & CRISE ASMATICA & 18 & 0.90 & 19 & 0,88 & 25 & 0,82 & 16 & 1,05 & 21 & 0,87 \\
\hline 4680008 & TRANSPLANTE DE FIGADO & 19 & 0,90 & 46 & 0,39 & 24 & 0,84 & 17 & 1,05 & 13 & 1,35 \\
\hline 3301611 & LAPAROTOMIA EXPLORADORA & 20 & 0,86 & 24 & 0,81 & 22 & 0,87 & 21 & 0,90 & 23 & 0,87 \\
\hline 3201901 & VALVULOPLASTIAS & 21 & 0,86 & 21 & 0,86 & 27 & 0,77 & 20 & 0,94 & 22 & 0,87 \\
\hline 7630018 & INSUFICIENCIA RESPIRATORIA AGUDA & 22 & 0,83 & 18 & 0.89 & 18 & 1,01 & 25 & 0,75 & 27 & 0,65 \\
\hline 3500101 & PARTO NORMAL & 23 & 0,82 & 17 & 0,89 & 14 & 1,33 & 31 & 0,65 & 45 & 0,40 \\
\hline 7640008 & BRONCOPNEUMONIA EM LACTENTE & 24 & 0,80 & 23 & 0,84 & 19 & 0,95 & 24 & 0,75 & 29 & 0,63 \\
\hline 7650022 & DOENCA PULMONAR OBSTRUTIVA CRONICA & 25 & 0.77 & 25 & 0,79 & 23 & 0,84 & 26 & 0,74 & 26 & 0,70 \\
\hline 4006101 & VENTRICULO-PERITONIOSTOMIA COM INTERPOSICAO DE VAL & 26 & 0,74 & 27 & 0,68 & 28 & 0,77 & 23 & 0,79 & 25 & 0,71 \\
\hline 3300408 & COLECISTECTOMIA & 27 & 0,72 & 26 & 0,71 & 26 & 0,78 & 28 & 0,73 & 28 & 0,64 \\
\hline 7650023 & INSUFICIENCIA RESPIRATORIA AGUDA & 28 & 0,69 & 20 & 0,86 & 29 & 0,70 & 34 & 0,61 & 31 & 0,59 \\
\hline 4200403 & TRAQUEOTOMIA(INCLUSIVE CURATIVOS) & 29 & 0,69 & 43 & 0,44 & 33 & 0,63 & 27 & 0,74 & 19 & 0,98 \\
\hline
\end{tabular}


Quadro 63 - Continuação

\begin{tabular}{|c|c|c|c|c|c|c|c|c|c|c|c|}
\hline \multirow{2}{*}{\multicolumn{2}{|c|}{ Procedimentos }} & \multirow{2}{*}{\multicolumn{2}{|c|}{ Total }} & \multirow{2}{*}{\multicolumn{2}{|c|}{$\begin{array}{l}\text { Antes } \\
1^{\circ} \text { ano }\end{array}$}} & \multicolumn{6}{|c|}{ Depois } \\
\hline & & & & & & \multicolumn{2}{|c|}{$1^{1}$ ano } & \multicolumn{2}{|c|}{$2^{\circ}$ ano } & \multicolumn{2}{|c|}{$3^{\circ}$ ano } \\
\hline Codigo & Descrictio & Pos. & $\%$ & Pos. & $\%$ & Pos. & $\%$ & Pos. & $\%$ & Pos. & $\%$ \\
\hline 3501401 & CURETAGEM POS-ABORTO & 30 & 0,62 & 28 & 0,67 & 31 & 0,67 & 35 & 0,57 & 34 & 0,56 \\
\hline 3900913 & \multirow{2}{*}{$\begin{array}{l}\text { REDUCAO CIRURGICA DE FRATURA DA DIAFISE DO FEMUR, } \\
\text { DIABETE SACARINO }\end{array}$} & 31 & 0,59 & 47 & 0,37 & 30 & 0,70 & 22 & 0,80 & 37 & 0.53 \\
\hline 8250005 & & 32 & 0,59 & 29 & 0.65 & 34 & 0,62 & 39 & 0,55 & 38 & 0,53 \\
\hline 7750003 & INSUFICIENCIA CORONARIANA AGUDA & 33 & 0.59 & 33 & 0.57 & 32 & 0,66 & 41 & 0.52 & 32 & 0.58 \\
\hline 3500901 & CESARIANA & 34 & 0,59 & 30 & 0,63 & 17 & 1,03 & 49 & 0.44 & 50 & 0,22 \\
\hline 7640007 & PNEUMONIAS DO LACTENTE & 35 & 0.58 & 32 & 0,58 & 36 & 0,55 & 29 & 0,71 & 40 & 0.49 \\
\hline 3502401 & PARTO COM MANOBRAS C/ ATENDIMENTO RN SALA DE PARTO & 36 & 0,56 & 44 & 0,41 & 49 & 0.42 & 33 & 0,61 & 24 & 0,81 \\
\hline 8100101 & EXPLORACAO DIAGNOSTICA DA EPILEPSIA & 37 & 0,56 & so & $0, \infty$ & 50 & $0, \infty$ & 30 & 0,65 & 11 & 1,63 \\
\hline 3301111 & HERNIORRAFIA INGUINAL(UNILATERAL) & 38 & 0,52 & 35 & 0,55 & 35 & 0,56 & 43 & 0.51 & 43 & 0,44 \\
\hline 7650006 & PNEUMONIA NAO ESPECIFICADA & 39 & 0,51 & 42 & 0.47 & 42 & 0,50 & 42 & 0,51 & 33 & 0,56 \\
\hline 4200806 & TORACOTOMIA COM DRENAGEM FECHADA & 40 & 0.51 & 36 & 0,52 & 41 & 0,50 & 40 & 0.53 & 41 & 0.49 \\
\hline 7450024 & SEPTICEMIAS (CLINICA MEDICA) & 41 & 0.50 & 38 & 0,51 & 39 & 0.52 & 50 & 0.42 & 35 & 0.56 \\
\hline 3600504 & FACECTOMIA COM LENTE INTRA-OCULAR & 42 & 0.50 & 31 & 0.62 & 38 & 0.52 & 37 & 0,55 & 49 & 0,31 \\
\hline 7550012 & HEMORRAGIAS DIGESTIVAS & 43 & 0,50 & 34 & 0.56 & 37 & 0.53 & 47 & 0,45 & 42 & 0.45 \\
\hline 3201904 & BYPASS OU TROMBOENDARTERECTOMIA FEMURO-POPLITEIA & 44 & 0.47 & 48 & 0.35 & 47 & 0,43 & 38 & 0.55 & 36 & 0,55 \\
\hline 7250000 & DIAGNOSTICO EIOU $1^{\circ}$ ATENDIMENTO EM CLINICA MEDICA & 45 & 0,47 & 49 & 0.19 & 44 & 0,46 & 32 & 0,62 & 30 & 0,61 \\
\hline 8050017 & INSUFICIENCIA RENAL CRONICA AACIDOSE METABOLICA & 46 & 0.46 & 41 & 0.49 & 40 & 0,51 & 44 & 0,47 & 48 & 0,39 \\
\hline 7970047 & LEUCEMIAS AGUDAS & 47 & 0.46 & 39 & 0.49 & 48 & 0.42 & 36 & 0,55 & 46 & 0,39 \\
\hline 3300506 & APENDICECTOMIA & 48 & 0.46 & 45 & 0.39 & 43 & 0,48 & 46 & 0.45 & 39 & 0.51 \\
\hline 7630008 & BRONCOPNEUMONIA & 49 & 0,45 & 40 & 0.49 & 46 & 0.44 & 45 & 0,47 & 44 & 0,41 \\
\hline 4002801 & MICROCIRURGIA VASCULAR INTRACRANIANA & 50 & 0,45 & 37 & 0,52 & 45 & 0,44 & 48 & 0,44 & 47 & 0,39 \\
\hline & Sub-Total & & 55,96 & & 56,98 & & 56,83 & & 55,53 & & 54,39 \\
\hline & Outros & & 44,04 & & 43,02 & & 43,17 & & 44,47 & & 45,61 \\
\hline & Total & & 100,00 & & 100,00 & & 100,00 & & 100,0 & & 100,00 \\
\hline
\end{tabular}

* Legenda - Média de 3 anos $=$ depois $1^{\circ}$ ano antes = antes 
O Quadro 64, apresenta a distribuição dos percentuais dos gastos com internações SUS dos 50 procedimentos de internações SUS de maior dispêndio ocorridos no Município de Assis, onde observou-se $69,85 \%$ que do total dos gastos corresponderam aos 50 procedimentos e que antes estes representavam $69,44 \%$, passando a representar a média de $69,82 \%$ depois da implantação da gestão semi plena.

Dos gastos com internações SUS no Municipio de Assis, os procedimentos de parto foram os que mais consumiram recursos, destacando-se na primeira posição as cesarianas que consumiram 10,13\% dos totais dos gastos, sendo $8,64 \%$ antes e a média $10,96 \%$ depois da implantação da gestão semi plena. A segunda posição foi ocupada pelas insuficiências cardiacas que com relação ao total representaram $8,20 \%$ dos gastos, sendo $9,08 \%$ antes e em média $7,64 \%$ depois. O terceiro lugar foi ocupado pelas crises asmáticas com $3,71 \%(4,47 \%$ antes e a média de $3,43 \%$ depois), seguidos pelos procedimentos de Acidente Vascular Cerebral Agudo que representaram 3,45\% do total, sendo 3,93\% (antes) e a média de $3,26 \%$ (depois).

O Quadro 65, apresenta a distribuição dos percentuais dos gastos com internações SUS dos 50 procedimentos de internações SUS de maior dispêndio ocorridos no Municipio de Campinas, onde observou-se, que $53,64 \%$ do total dos gastos corresponderam aos 50 procedimentos e que antes estes representavam $53,25 \%$, passando a representar a média de $53,79 \%$ depois da implantação da gestão semi plena. 
Quadro 64 - Distribuição percentual dos gastos com internaçōes SUS pelos 50 procedimentos mais freqüentes, ocorridos no município de Assis - SP, antes e depois da implantação da gestão semi-plena.

\begin{tabular}{|c|c|c|c|c|c|c|c|c|c|c|c|}
\hline \multirow{2}{*}{\multicolumn{2}{|c|}{ Procedimentos }} & \multirow{2}{*}{\multicolumn{2}{|c|}{ Total }} & \multirow{2}{*}{\multicolumn{2}{|c|}{$\begin{array}{l}\text { Antes } \\
1^{\circ} \text { ano }\end{array}$}} & \multicolumn{6}{|c|}{ Depois } \\
\hline & & & & & & \multicolumn{2}{|c|}{$1^{\bullet}$ ano } & \multicolumn{2}{|c|}{$2^{\circ}$ ano } & \multicolumn{2}{|c|}{$3^{\circ}$ ano } \\
\hline Código & Descriçăo & Pos. & $\%$ & Pos. & $\%$ & Pos. & $\%$ & Pos. & $\%$ & Pos. & $\%$ \\
\hline 35022019 & CESARIANA COM ATENDIMENTO RN SALA DE PARTO & 1 & 10,13 & 2 & 8,64 & 1 & 9,52 & 1 & 10,47 & 1 & 12,90 \\
\hline 77500113 & INSUFICIENCIA CARDIACA & 2 & 8,20 & 1 & 9,08 & 2 & 9,17 & 2 & 7,61 & 2 & 6,16 \\
\hline 76300102 & CRISE ASMATICA & 3 & 3,71 & 3 & 4.47 & 4 & 3,08 & 3 & 3,75 & 3 & 3,47 \\
\hline 81500106 & AVC AGUDO & 4 & 3,45 & 4 & 3,93 & 3 & 3,54 & 4 & 2,88 & 4 & 3,35 \\
\hline 74300270 & ENTERO-INFECCOES (PEDIATRIA) & 5 & 2,28 & 5 & 2,64 & 5 & 2,71 & 9 & 1,78 & 7 & 1,72 \\
\hline 76500225 & DOENCA PULMONAR OBSTRUTIVA CRONICA & 6 & 1,99 & 12 & 1,48 & 6 & 2,12 & 5 & 2,72 & 8 & 1,59 \\
\hline 38025019 & PERDA SUBST CUTANEA-LESOES EXTENSAS PLANOS SUPER. & 7 & 1,71 & 15 & 1,41 & 21 & 1,13 & 10 & 1,69 & 5 & 3,10 \\
\hline 77500024 & INFARTO AGUDO DO MIOCARDIO & 8 & 1,67 & 7 & 1,61 & 8 & 1,77 & 8 & 1,82 & 12 & 1,40 \\
\hline 35021012 & PARTO NORMAL COM ATENDIMENTO RN SALA DE PARTO & 9 & 1,58 & 10 & 1,49 & 10 & 1,56 & 12 & 1,51 & 6 & 1,86 \\
\hline 76400085 & BRONCOPNEUMONIA EM LACTENTE & 10 & 1,54 & 8 & 1,58 & 7 & 1,92 & 15 & 1,26 & 15 & 1,29 \\
\hline 76500233 & INSUFICIENCIA RESPIRATORIA AGUDA & 11 & 1,50 & 6 & 1,70 & 28 & 0,86 & 6 & 2,09 & 13 & 1,38 \\
\hline 76300080 & BRONCOPNEUMONIA & 12 & 1,48 & 9 & 1,55 & 9 & 1,62 & 17 & 1,20 & 10 & 1,54 \\
\hline 70000000 & TRATAMENTO DA AIDS & 13 & 1,28 & 13 & 1,43 & 17 & 1,27 & 21 & 1,12 & 14 & 1,29 \\
\hline 38007142 & GRANDE QUEIMADO & 14 & 1,26 & 27 & 0,88 & 20 & 1,16 & 11 & 1,61 & 11 & 1,52 \\
\hline 71300015 & PREMATURIDADE & 15 & 1,25 & 30 & 0,79 & 11 & 1.54 & 19 & 1,20 & 9 & 1,58 \\
\hline 76300072 & OUTRAS PNEUMONIAS & 16 & 1,20 & 14 & 1,42 & 19 & 1,20 & 25 & 0,96 & 16 & 1,17 \\
\hline 75500124 & HEMORRAGIAS DIGESTIVAS & 17 & 1,18 & 21 & 1,11 & 16 & 1,27 & 16 & 1,26 & 19 & 1,01 \\
\hline 76400271 & ENTERO-INFECCOES EM LACTENTE & 18 & 1.14 & 11 & 1,49 & 14 & 1,32 & 28 & 0,85 & 30 & 0,71 \\
\hline 82500053 & DIABETE SACARINO & 19 & 1,14 & 19 & 1,17 & 13 & 1,33 & 24 & 1,02 & 21 & 0,95 \\
\hline 76500128 & CRISE ASMATICA & 20 & 1,06 & 16 & 1,23 & 24 & 0,98 & 23 & 1,02 & 20 & 0,85 \\
\hline 74500244 & SEPTICEMIAS (CLINICA MEDICA) & 21 & 1,05 & 24 & 1,01 & 15 & 1,31 & 20 & 1,15 & 39 & 0,56 \\
\hline 76400077 & PNEUMONIAS DO LACTENTE & 22 & 1,03 & 26 & 0,89 & 12 & 1,47 & 37 & 0,67 & 18 & 1,08 \\
\hline 39012131 & REDUCAO CIRURGICA DE FRATURA DO COLO DO FEMUR & 23 & 1,03 & 39 & 0,55 & 18 & 1,21 & 14 & 1,31 & 17 & 1,14 \\
\hline 76500071 & BRONCOPNEUMONIA & 24 & 1,01 & 18 & 1,19 & 23 & 0,99 & 27 & 0,93 & 24 & 0,88 \\
\hline 76500063 & PNEUMONIA NAO ESPECIFICADA & 25 & 1,00 & 23 & 1,01 & 27 & 0,88 & 18 & 1,20 & 22 & 0,90 \\
\hline 80500170 & INSUFICIENCIA RENAL CRONICA AACIDOSE METABOLICA & 26 & 0,86 & 25 & 0,98 & 22 & 1,00 & 36 & 0,67 & 31 & 0,71 \\
\hline 31000002 & CIRURGIA MULTIPLA & 27 & 0,79 & 48 & 0,31 & 33 & 0,79 & 13 & 1,41 & 29 & 0,71 \\
\hline 80500218 & OUTRAS AFECCOES DO AP. GENITO-URINARIO & 28 & 0,79 & 22 & 1.06 & 36 & 0,73 & 38 & 0,67 & 35 & 0,65 \\
\hline
\end{tabular}

Continua 
Quadro 64 - Continuação

\begin{tabular}{|c|c|c|c|c|c|c|c|c|c|c|c|}
\hline & & & otal & & & & & De & pois & & \\
\hline & Procedimentos & & & & ano & & ano & & ano & & ano \\
\hline Codigo & Descriçáo & Pos. & $\%$ & Pos. & $\%$ & Pos. & $\%$ & Pos. & $\%$ & Pos. & $\%$ \\
\hline 39000001 & POLITRAUMATIZADO & 29 & 0.77 & 50 & 0,03 & 42 & 0,47 & 7 & 1,87 & 23 & 0,89 \\
\hline 77500164 & EDEMA AGUDO DE PULMAO & 30 & 0,77 & 29 & 0,87 & 37 & 0.68 & 22 & 1.04 & 46 & 0,41 \\
\hline 74500252 & ENTERO-INFECCOES (CLINICA MEDICA) & 31 & 0,76 & 17 & 1.20 & 25 & 0.89 & 45 & 0.48 & 50 & 0,26 \\
\hline 39013138 & REDUCAO CIRURGICA DE FRATURA TRANSTROCANTERIANA & 32 & 0.75 & 28 & 0,88 & 30 & 0,82 & 34 & 0.72 & 43 & 0,47 \\
\hline 33011117 & HERNIORRAFIA INGUINAL(UNILATERAL) & 33 & 0,75 & 31 & 0,78 & 31 & 0,80 & 30 & 0.78 & 40 & 0.55 \\
\hline 80500072 & PIELONEFRITES & 34 & 0.74 & 32 & 0,77 & 29 & 0,84 & 32 & 0,76 & 42 & 0.52 \\
\hline 75500213 & CIRROSE HEPATICA & 35 & 0,66 & 36 & 0,59 & 34 & 0,77 & 31 & 0,78 & 44 & 0,45 \\
\hline 91500079 & TRAUMATISMOS CRANIOENCEFALICO & 36 & 0,66 & 37 & 0.57 & 26 & 0,88 & 43 & 0.49 & 34 & 0.66 \\
\hline 34008020 & COLPOPERINEOPLASTIA ANTERIOR E POSTERIOR & 37 & 0,65 & 20 & 1,16 & 47 & 0,37 & 47 & 0,46 & 37 & 0,58 \\
\hline 74300261 & SEPTICEMIAS (PEDIATRIA) & 38 & 0,64 & 45 & 0.44 & 32 & 0,79 & 41 & 0,54 & 25 & 0,82 \\
\hline 33004080 & COLECISTECTOMIA & 39 & 0,63 & 33 & 0.67 & 41 & 0.47 & 35 & 0.70 & 28 & 0,72 \\
\hline 35009012 & CESARIANA & 40 & 0,62 & 49 & 0,31 & 35 & 0.76 & 29 & 0,82 & 36 & 0,62 \\
\hline 76300188 & INSUFICIENCIA RESPIRATORIA AGUDA & 41 & 0,58 & 38 & 0,57 & 48 & 0.33 & 26 & 0,93 & 41 & 0,54 \\
\hline 34017038 & HISTERECTOMIA C/ANEXETOMIA UNI OU BILATERAL & 42 & 0.57 & 41 & 0.52 & 43 & 0.46 & 39 & 0,66 & 32 & 0,67 \\
\hline 33016119 & LAPAROTOMIA EXPLORADORA & 43 & 0,56 & 42 & 0,52 & 44 & 0,45 & 33 & 0,73 & 38 & 0,58 \\
\hline 39013081 & REDUC. CIR. FRAT. DOS OSSOS DO ANTE-BRACO COM FIXA & 44 & 0,54 & 43 & 0,52 & 49 & 0,33 & 40 & 0,64 & 26 & 0.76 \\
\hline 77500180 & ARRITIMIAS & 45 & 0,54 & 35 & 0,61 & 40 & 0,59 & 46 & 0,48 & 45 & 0.41 \\
\hline 33005060 & APENDICECTOMIA & 46 & 0,52 & 47 & 0.33 & 39 & 0.60 & 42 & 0,52 & 33 & 0.67 \\
\hline 77500121 & CRISE HIPERTENSIVA & 47 & 0,48 & 44 & 0,46 & 38 & 0,60 & 49 & 0.42 & 47 & 0.40 \\
\hline 81500025 & HEMATOMA SUBDURAL & 48 & 0,47 & 34 & 0,67 & 46 & 0,42 & 50 & 0,42 & 49 & 0.28 \\
\hline 77500032 & INSUFICIENCIA CORONARIANA AGUDA & 49 & 0.46 & 40 & 0,54 & 45 & 0.43 & 44 & 0.49 & 48 & 0,37 \\
\hline 39011151 & REDUCAO CIRURGICA DA DIAFISE DA TIBIA, COM FIXACAO & 50 & 0,43 & 46 & 0,33 & 50 & 0,32 & 48 & 0.45 & 27 & 0,74 \\
\hline & Sub-Total & & 69,85 & & 69,44 & & 70,52 & & 70,98 & & 67,95 \\
\hline & Outros & & 30,15 & & 30,56 & & 29,48 & & 29,02 & & 32,05 \\
\hline & & & 100,00 & & 100,0 & & 100,00 & & 100,00 & & 100,00 \\
\hline
\end{tabular}

Fonte: www.datasus.gov.br_SIH

$1^{\circ}$ ano antes $=$ antes 
Quadro 65 - Distribuição percentual dos gastos com internações SUS pelos 50 procedimentos mais freqüentes, ocorridos no municipio de Campinas - SP, antes e depois da implantação da gestão semi-plena.

\begin{tabular}{|c|c|c|c|c|c|c|c|c|c|c|c|}
\hline \multirow{2}{*}{\multicolumn{2}{|c|}{ Procedimentos }} & \multirow{2}{*}{\multicolumn{2}{|c|}{ Total }} & \multirow{2}{*}{\multicolumn{2}{|c|}{$\begin{array}{l}\text { Antes } \\
1^{\circ} \text { ano }\end{array}$}} & \multicolumn{6}{|c|}{ Depois } \\
\hline & & & & & & \multicolumn{2}{|c|}{$1^{\circ}$ ano } & \multicolumn{2}{|c|}{$2^{\circ}$ ano } & \multicolumn{2}{|c|}{$3^{\circ}$ ano } \\
\hline Codigo & Descriçăo & Pos. & $\%$ & Pos. & $\%$ & Pos. & $\%$ & Pos. & $\%$ & Pos. & $\%$ \\
\hline 35022019 & CESARIANA COM ATENDIMENTO RN SALA DE PARTO & 1 & 4.55 & 1 & 4,45 & 1 & 4,58 & 1 & 4,25 & 1 & 4,89 \\
\hline 35021012 & PARTO NORMAL COM ATENDIMENTO RN SALA DE PARTO & 2 & 3.77 & 2 & 3,93 & 2 & 3,79 & 4 & 3,31 & 3 & 4,02 \\
\hline 46800204 & TRANSPLANTE DE MEDULA ALOGENICO APARENTADO & 3 & 3,66 & 3 & 3.34 & 3 & 3.67 & 2 & 3.51 & 2 & 4,08 \\
\hline 71300015 & PREMATURIDADE & 4 & 3,15 & 4 & 3.24 & 4 & 3.29 & 3 & 3,39 & 5 & 2,70 \\
\hline 31802010 & TRANSPLANTE RENAL RECEPTOR & 5 & 2.70 & 5 & 3.11 & 5 & 3.06 & 5 & 2,99 & 7 & 1,72 \\
\hline 46800085 & TRANSPLANTE DE FIGADO & 6 & 2,52 & 15 & 1,14 & 6 & 2,48 & 6 & 2,81 & 4 & 3.58 \\
\hline 32020015 & IMPLANTE DE PROTESE VALVULAR & 7 & 1,67 & 9 & 1,66 & 8 & 1,82 & 8 & 1,65 & 9 & 1,58 \\
\hline 32019017 & VALVULOPLASTIAS & 8 & 1,66 & 10 & 1,50 & 7 & 1,83 & 9 & 1,55 & 6 & 1,77 \\
\hline 77500113 & INSUFICIENCIA CARDIACA & 9 & 1,64 & 7 & 1,99 & 9 & 1,67 & 10 & 1,53 & 10 & 1,38 \\
\hline 32015011 & MARCA-PASSO CARDIACO(INTRACAVITARIO) & 10 & 1,61 & 6 & 2,17 & 12 & 1,28 & 7 & 1,87 & 16 & 1,14 \\
\hline 33016119 & LAPAROTOMIA EXPLORADORA & 11 & 1,36 & 12 & 1,37 & 11 & 1,31 & 11 & 1,43 & 11 & 1,33 \\
\hline 31000002 & CIRURGIA MULTIPLA & 12 & 1,27 & 13 & 1,15 & 10 & 1,51 & 14 & 1,19 & 14 & 1,24 \\
\hline 77500024 & INFARTO AGUDO DO MIOCARDIO & 13 & 1.19 & 14 & 1,14 & 16 & 1,08 & 13 & 1,26 & 13 & 1,27 \\
\hline 35024011 & PARTO COM MANOBRAS COM ATENDIMENTO RN SALA DE PARTO & 14 & 1,18 & 18 & 0,86 & 19 & 0,89 & 12 & 1,34 & 8 & 1,60 \\
\hline 76300188 & INSUFICIENCIA RESPIRATORIA AGUDA & 15 & 1,12 & 16 & 0,97 & 15 & 1,09 & 15 & 1,19 & 15 & 1,23 \\
\hline 70000000 & TRATAMENTO DA AIDS & 16 & 1,00 & 11 & 1,48 & 18 & 0,90 & 18 & 0,85 & 19 & 0,78 \\
\hline 39000001 & POLITRAUMATIZADO & 17 & 0,99 & 8 & 1,87 & 24 & 0,75 & 24 & 0,69 & 23 & 0,68 \\
\hline 40061019 & VENTRICULO-PERITONIOSTOMIA COM INTERPOSICAO DE VAL & 18 & 0,92 & 19 & 0,84 & 13 & 1,22 & 16 & 0,95 & 25 & 0,68 \\
\hline 42004039 & TRAQUEOTOMIA(INCLUSIVE CURATIVOS) & 19 & 0,89 & 27 & 0,57 & 21 & 0,87 & 20 & 0,79 & 12 & 1,30 \\
\hline 39016129 & ARTROPLASTIA COXO-FEMURAL COM PROTESE NAO CIMENTADA & 20 & 0,84 & 23 & 0,78 & 14 & 1,15 & 17 & 0,91 & 30 & 0,56 \\
\hline 33004080 & COLECISTECTOMIA & 21 & 0.79 & 22 & 0,80 & 20 & 0,88 & 19 & 0.84 & 27 & 0,65 \\
\hline 42008069 & TORACOTOMIA COM DRENAGEM FECHADA & 22 & 0,78 & 21 & 0,82 & 22 & 0,83 & 23 & 0,73 & 22 & 0.73 \\
\hline 81500106 & AVC AGUDO & 23 & 0.75 & 17 & 0,96 & 23 & 0,75 & 27 & 0,64 & 26 & 0,66 \\
\hline 32023014 & CORONARIOPLASTIA & 24 & 0,72 & 20 & 0,84 & 27 & 0,67 & 30 & 0,60 & 20 & 0,76 \\
\hline 39009130 & REDUCAO CIRURGICA DE FRATURA DA DIAFISE DO FEMUR. & 25 & 0,69 & 30 & 0,55 & 17 & 0,92 & 21 & 0,79 & 32 & 0,50 \\
\hline 91904013 & TRATAMENTO DE AIDS EM HOSPITAL DIA & 26 & 0,64 & 43 & 0,40 & 28 & 0,65 & 31 & 0,56 & 17 & 0.94 \\
\hline 32021011 & CORRECAO DE CARDIOPATIA CONGENITA & 27 & 0,59 & 37 & 0,49 & 32 & 0,60 & 34 & 0,53 & 21 & 0,74 \\
\hline 32019041 & BYPASS OU TROMBOENDARTERECTOMIA FEMURO-POPLITEIA & 28 & 0.59 & 41 & 0,43 & 29 & 0,64 & 26 & 0,65 & 29 & 0,63 \\
\hline
\end{tabular}

Continua 
Quadro 65 - Continuação

\begin{tabular}{|c|c|c|c|c|c|c|c|c|c|c|c|}
\hline \multirow{2}{*}{\multicolumn{2}{|c|}{ Procedimentos }} & \multirow{2}{*}{\multicolumn{2}{|c|}{ Total }} & \multirow{2}{*}{\multicolumn{2}{|c|}{$\begin{array}{l}\text { Antes } \\
1^{\circ} \text { ano }\end{array}$}} & \multicolumn{6}{|c|}{ Depois } \\
\hline & & & & & & \multicolumn{2}{|c|}{$1^{\circ}$ ano } & \multicolumn{2}{|c|}{$2^{\circ}$ ano } & \multicolumn{2}{|c|}{$3^{\circ}$ ano } \\
\hline Codigo & Descriçăo & Pos. & $\%$ & Pos. & $\%$ & Pos. & $\%$ & Pos. & $\%$ & Pos. & $\%$ \\
\hline 72500000 & & 29 & 0,58 & 49 & 0,33 & 25 & 0,68 & 25 & 0,67 & 28 & 0,65 \\
\hline 79700470 & \multirow{2}{*}{$\begin{array}{l}\text { LEUCEMIAS AGUDAS } \\
\text { INSUFICIENCIA RENAL CRONICA AACIDOSE METABOUICA }\end{array}$} & 30 & 0.56 & 29 & 0,56 & 49 & 0,39 & 22 & 0,76 & 31 & 0,53 \\
\hline 80500170 & & 31 & 0,54 & 25 & 0,61 & 26 & 0,67 & 33 & 0,53 & 45 & 0,35 \\
\hline 74500244 & & 32 & 0,53 & 31 & 0,53 & 47 & 0,41 & 35 & 0,51 & 24 & 0,68 \\
\hline 36005045 & FACECTOMIA COM LENTE INTRA-OCULAR & 33 & 0,52 & 24 & 0,74 & 34 & 0,59 & 28 & 0,64 & 50 & 0,13 \\
\hline 82500053 & DIABETE SACARINO & 34 & 0,52 & 28 & 0,56 & 36 & 0.53 & 36 & 0.50 & 34 & 0,48 \\
\hline 32013019 & MARCA-PASSO(TROCA DE GERADOR DE ESTIMULO) & 35 & 0.48 & 33 & 0,52 & 30 & 0,62 & 29 & 0,61 & 49 & 0,20 \\
\hline 76500233 & INSUFICIENCIA RESPIRATORIA AGUDA & 36 & 0,47 & 32 & 0,52 & 48 & 0,41 & 39 & 0,48 & 35 & 0.48 \\
\hline 76500225 & DOENCA PULMONAR OBSTRUTIVA CRONICA & 37 & 0,47 & 36 & 0,49 & 37 & 0,50 & 42 & 0,45 & 41 & 0,43 \\
\hline 42705070 & MASTECTOMIA RADICAL COM LINFADECTOMIA & 38 & 0,47 & 26 & 0,58 & 42 & 0,46 & 37 & 0,50 & 46 & 0,35 \\
\hline 40038017 & TRATAMENTO CIRURGICO DE HEMATOMA SUB-DURAL & 39 & 0,46 & 45 & 0,39 & 31 & 0,61 & 32 & 0,56 & 48 & 0,29 \\
\hline 35014016 & CURETAGEM POS-ABORTO & 40 & 0.45 & 39 & 0,49 & 40 & 0,47 & 46 & 0,42 & 39 & 0,44 \\
\hline 40028011 & MICROCIRURGIA VASCULAR INTRACRANIANA & 41 & 0,45 & 34 & 0,50 & 35 & 0,53 & 48 & 0,39 & 44 & 0,38 \\
\hline 76500071 & BRONCOPNEUMONIA & 42 & 0,44 & 46 & 0,38 & 38 & 0,47 & 44 & 0.43 & 33 & 0,50 \\
\hline 74300261 & SEPTICEMIAS (PEDIATRIA) & 43 & 0,44 & 35 & 0,50 & 44 & 0,43 & 45 & 0,42 & 43 & 0.41 \\
\hline 77500032 & INSUFICIENCIA CORONARIANA AGUDA & 44 & 0,44 & 40 & 0,43 & 43 & 0,45 & 43 & 0.45 & 42 & 0.42 \\
\hline 33005060 & APENDICECTOMIA & 45 & 0.43 & 44 & 0,39 & 39 & 0,47 & 47 & 0,40 & 36 & 0,47 \\
\hline 71300058 & SINDROME DA A.P.I. DO R.N.(MEMBRANA HIALINA) & 46 & 0,43 & 47 & 0,35 & 50 & 0,10 & 50 & 0,39 & 18 & 0,93 \\
\hline 76300072 & OUTRAS PNEUMONIAS & 47 & 0,43 & 42 & 0,40 & 46 & 0,43 & 41 & 0,45 & 38 & 0,44 \\
\hline 33705054 & GASTRECTOMIA TOTAL & 48 & 0,43 & 38 & 0,49 & 41 & 0,46 & 38 & 0,49 & 47 & 0,30 \\
\hline 33001049 & CARDIOPLASTIA & 49 & 0,43 & 50 & 0,30 & 33 & 0,60 & 49 & 0,37 & 40 & 0,43 \\
\hline 39011151 & REDUCAO CIRURGICA DA DIAFISE DA TIBIA, COM FIXACAO & 50 & 0,42 & 48 & 0,34 & 45 & 0,43 & 40 & 0,46 & 37 & 0.45 \\
\hline & Sub-Total & & 53,64 & & 53,25 & & 54,91 & & 53,62 & & 52,85 \\
\hline & Outros & & 46,36 & & 46,75 & & 45,09 & & 46,38 & & 47,15 \\
\hline & Total & & 100,00 & & 100,00 & & 100,00 & & 100,00 & & 100,00 \\
\hline
\end{tabular}

* Legenda - Média de 3 anos $=$ depois $\quad 1^{\circ}$ ano antes $=$ antes 
Quadro 66 - Distribuiçāo percentual dos gastos com internaçōes SUS pelos 50 procedimentos mais freqüentes, ocorridos no município de Diadema - SP, antes e depois da implantação da gestão semi-plena.

\begin{tabular}{|c|c|c|c|c|c|c|c|c|c|c|c|}
\hline \multirow{2}{*}{\multicolumn{2}{|c|}{ Procedimentos }} & \multirow{2}{*}{\multicolumn{2}{|c|}{ Total }} & \multirow{2}{*}{\multicolumn{2}{|c|}{$\begin{array}{l}\text { Antes } \\
1^{\circ} \text { ano }\end{array}$}} & \multicolumn{6}{|c|}{ Depois } \\
\hline & & & & & & \multicolumn{2}{|c|}{$1^{\circ}$ ano } & \multicolumn{2}{|c|}{$\mathbf{2}^{\circ}$ ano } & \multicolumn{2}{|c|}{$3^{\circ}$ ano } \\
\hline Codigo & Descriçăo & Pos. & $\%$ & Pos. & $\%$ & Pos. & $\%$ & Pos. & $\%$ & Pos. & $\%$ \\
\hline 35021012 & PARTO NORMAL COM ATENDIMENTO RN SALA DE PARTO & 1 & 15.18 & 1 & 22.42 & 3 & 7.84 & 1 & 14,18 & 1 & 17,37 \\
\hline 35022019 & CESARIANA COM ATENDIMENTO RN SALA DE PARTO & 2 & 11,56 & 2 & 16,90 & 4 & 6.28 & 2 & 11,28 & 2 & 12,37 \\
\hline 35001011 & PARTO NORMAL & 3 & 8,59 & 3 & 5,82 & 1 & 16,80 & 3 & 6.41 & 49 & 0.01 \\
\hline 35009012 & CESARIANA & 4 & 7,52 & 4 & 5,49 & 2 & 14,20 & 4 & 5,84 & 50 & 0,00 \\
\hline 76400085 & BRONCOPNEUMONIA EM LACTENTE & 5 & 4,58 & 5 & 4,06 & 5 & 4,80 & 6 & 4,49 & 3 & 5,20 \\
\hline 77500113 & INSUFICIENCIA CARDIACA & 6 & 4,44 & 7 & 3,82 & 6 & 4,60 & 5 & 4,72 & 4 & 4,94 \\
\hline 76300102 & CRISE ASMATICA & 7 & 3,47 & 8 & 3,67 & 9 & 3,21 & 7 & 4,27 & 6 & 2,73 \\
\hline 35014016 & CURETAGEM POS-ABORTO & 8 & 3,10 & 6 & 4,02 & 8 & 3.29 & 9 & 2,02 & 10 & 2,20 \\
\hline 71300015 & PREMATURIDADE & 9 & 2.75 & 9 & 2,39 & 7 & 3.41 & 10 & 1,84 & 5 & 3,09 \\
\hline 31000002 & CIRURGIA MULTIPLA & 10 & 2,17 & 10 & 1.61 & 10 & 1,77 & 8 & 3,42 & 7 & 2,63 \\
\hline 76500225 & DOENCA PULMONAR OBSTRUTIVA CRONICA & 11 & 1.64 & 11 & 1,52 & 11 & 1,33 & 12 & 1.74 & 9 & 2,38 \\
\hline 81500106 & AVC AGUDO & 12 & 1,49 & 12 & 1,34 & 12 & 1,18 & 13 & 1,39 & 8 & 2.49 \\
\hline 33005060 & APENDICECTOMIA & 13 & 1,10 & 16 & 0,65 & 14 & 0,92 & 11 & 1,75 & 12 & 1.56 \\
\hline 42008069 & TORACOTOMIA COM DRENAGEM FECHADA & 14 & 1,00 & 15 & 0,78 & 15 & 0.91 & 14 & 1,35 & 14 & 1.23 \\
\hline 76300080 & BRONCOPNEUMONIA & 15 & 0,97 & 13 & 0,92 & 13 & 1.07 & 20 & 0,89 & 20 & 0.93 \\
\hline 75500124 & HEMORRAGIAS DIGESTIVAS & 16 & 0,95 & 14 & 0,88 & 17 & 0.78 & 15 & 1,24 & 17 & 1.09 \\
\hline 33021066 & ENTERECTOMIA & 17 & 0,78 & 22 & 0,51 & 19 & 0,69 & 17 & 1.06 & 15 & 1,15 \\
\hline 76300072 & OUTRAS PNEUMONIAS & 18 & 0,72 & 19 & 0,61 & 22 & 0,62 & 18 & 1,02 & 23 & 0,77 \\
\hline 77500024 & INFARTO AGUDO DO MIOCARDIO & 19 & 0,68 & 32 & 0,39 & 35 & 0,41 & 21 & 0,81 & 11 & 1,62 \\
\hline 82500053 & DIABETE SACARINO & 20 & 0,68 & 18 & 0,63 & 24 & 0,60 & 25 & 0,68 & 19 & 0.93 \\
\hline 33004080 & COLECISTECTOMIA & 21 & 0,67 & 35 & 0.34 & 23 & 0,60 & 19 & 0,94 & 16 & 1,11 \\
\hline 33006067 & COLECTOMIA PARCIAL(HEMICOLECTOMIA) & 22 & 0,66 & 23 & 0.51 & 18 & 0.70 & 24 & 0.69 & 21 & 0,85 \\
\hline 76400271 & ENTERO-INFECCOES EM LACTENTE & 23 & 0,64 & 17 & 0,64 & 16 & 0,84 & 26 & 0.61 & 43 & 0,27 \\
\hline 76400077 & PNEUMONIAS DO LACTENTE & 24 & 0,61 & 21 & 0.52 & 26 & 0.59 & 22 & 0,73 & 29 & 0,66 \\
\hline 35024011 & PARTO COM MANOBRAS COM ATENDIMENTO RN SALA DE PARTO & 25 & 0,58 & 31 & 0,39 & 38 & 0.40 & 30 & 0.51 & 13 & 1,37 \\
\hline
\end{tabular}

Continuaçăo 


\begin{tabular}{|c|c|c|c|c|c|c|c|c|c|c|c|}
\hline \multirow{2}{*}{\multicolumn{2}{|c|}{ Procedimentos }} & \multirow{2}{*}{\multicolumn{2}{|c|}{ Total }} & \multirow{2}{*}{\multicolumn{2}{|c|}{$\begin{array}{l}\text { Antes } \\
1^{\circ} \text { ano }\end{array}$}} & \multicolumn{6}{|c|}{ Depois } \\
\hline & & & & & & \multicolumn{2}{|c|}{$1^{\circ}$ ano } & \multicolumn{2}{|c|}{$2^{\circ}$ ano } & \multicolumn{2}{|c|}{$3^{\circ}$ ano } \\
\hline \multicolumn{2}{|r|}{ Descriçăo } & Pos. & $\%$ & Pos. & $\%$ & Pos. & $\%$ & Pos. & $\%$ & Pos. & $\%$ \\
\hline 76500071 & 1 BRONCOPNEUMONIA & 26 & 0.55 & 38 & 0.30 & 29 & 0.48 & 23 & 0,71 & 18 & 0,98 \\
\hline 33016119 & 9 LAPAROTOMIA EXPLORADORA & 27 & 0,53 & 28 & 0.41 & 28 & 0,51 & 29 & 0,57 & 24 & 0,76 \\
\hline 71300082 & ICTERICIAS NEO-NATAIS & 28 & 0.52 & 26 & 0.48 & 21 & 0.62 & 40 & 0.39 & 31 & 0.56 \\
\hline 76500233 & 3INSUFICIENCIA RESPIRATORIA AGUDA & 29 & 0,51 & 25 & 0,48 & 31 & 0.48 & 33 & 0,47 & 27 & 0,70 \\
\hline 74300261 & SEPTICEMIAS (PEDIATRIA) & 30 & 0,49 & 20 & 0.58 & 20 & 0.69 & 48 & 0,26 & 46 & 0.20 \\
\hline 76500128 & CRISE ASMATICA & 31 & 0.49 & 30 & 0.40 & 32 & 0,43 & 28 & 0,59 & 28 & 0,67 \\
\hline 38007142 & GRANDE QUEIMADO & 32 & 0.49 & 24 & 0.49 & 25 & 0,59 & 44 & 0,35 & 36 & 0,45 \\
\hline 72500000 & DIAGNOSTICO EIOU 1०ATENDIMENTO EM CLINICA MEDICA & 33 & 0,45 & 48 & 0,13 & 48 & 0,21 & 16 & 1.13 & 22 & 0.79 \\
\hline 76500209 & FIBROSES INTERSTICIAIS DIFUSAS DO PULMAO & 34 & 0,40 & 34 & 0.35 & 37 & 0.41 & 47 & 0,27 & 30 & 0,63 \\
\hline 75500213 & CIRROSE HEPATICA & 35 & 0,39 & 43 & 0.23 & 40 & 0,37 & 27 & 0,59 & 32 & 0,51 \\
\hline 74300229 & ESTREPTOCOCCIAS (PEDIATRIA) & 36 & 0,38 & 39 & 0,28 & 34 & 0,41 & 36 & 0,43 & 39 & 0,41 \\
\hline 74300113 & MENINGITES PURULENTAS (PEDIATRIA) & 37 & 0,37 & 45 & 0,23 & 30 & 0,48 & 41 & 0,38 & 38 & 0,43 \\
\hline 74300270 & ENTERO-INFECCOES (PEDIATRIA) & 38 & 0,37 & 27 & 0,44 & 36 & 0,41 & 45 & 0,33 & 45 & 0,20 \\
\hline 81500181 & POLINEUROPATIAS & 39 & 0,37 & 36 & 0,33 & 27 & 0,56 & 49 & 0,18 & 44 & 0,26 \\
\hline 33023069 & COLOSTOMIAS & 40 & 0,35 & 44 & 0,23 & 39 & 0,37 & 43 & 0,38 & 34 & 0.48 \\
\hline 91500079 & TRAUMATISMOS CRANIOENCEFALICO & 41 & 0.34 & 50 & 0.03 & 42 & 0,35 & 31 & 0,50 & 26 & 0,71 \\
\hline 33010064 & ENTERORRAFIA(QUALQUER SEGMENTO) & 42 & 0,34 & 46 & 0,19 & 41 & 0,35 & 34 & 0,46 & 37 & 0,43 \\
\hline 76300056 & BRONQUIOLITE AGUDA & 43 & 0,31 & 33 & 0,36 & 47 & 0,21 & 38 & 0.40 & 41 & 0,34 \\
\hline 76500063 & 3 PNEUMONIA NAO ESPECIFICADA & 44 & 0,31 & 40 & 0,26 & 43 & 0,32 & 39 & 0.40 & 42 & 0.27 \\
\hline 33006059 & GASTRORRAFIA & 45 & 0,30 & 37 & 0,30 & 49 & 0,17 & 42 & 0,38 & 33 & 0,48 \\
\hline 75500299 & 9 AFECCOES PANCREATICAS & 46 & 0,29 & 41 & 0,25 & 44 & 0,29 & 46 & 0,32 & 40 & 0,38 \\
\hline 39000001 & POLITRAUMATIZADO & 47 & 0,29 & 29 & 0,41 & 33 & 0.42 & 50 & 0.13 & 48 & 0,02 \\
\hline 74500244 & SEPTICEMIAS (CLINICA MEDICA) & 48 & 0,29 & 47 & 0.18 & 45 & 0,24 & 37 & 0,43 & 35 & 0,45 \\
\hline 71300007 & DIAGNOSTICO EIOU $1^{\circ}$ ATENDIMENTO EM CLINICA PEDIATRICA & 49 & 0,29 & 49 & 0.07 & 50 & 0,15 & 32 & 0.48 & 25 & 0,74 \\
\hline 33012083 & HEPATORRAFIA & 50 & 0,27 & 42 & 0.24 & 46 & 0.24 & 35 & 0,45 & 47 & 0.19 \\
\hline & Sub-Total & & 86,23 & & 88,47 & & 87,59 & & 84,84 & & 80,98 \\
\hline & Outros & & 13,77 & & 11,53 & & 12,41 & & 15,16 & & 19,02 \\
\hline & Total & & 100,00 & & 100,00 & & 100,00 & & 100,00 & & 100,00 \\
\hline
\end{tabular}

Fonte: www.datasus.gov.br_SIH

- Legenda - Média de 3 anos = depois

$1^{\circ}$ ano antes $=$ antes 
Dos gastos com internações SUS no Município de Campinas, os procedimentos de parto foram os que mais consumiram recursos, destacando-se na primeira posição as cesarianas que consumiram 4,55\% dos totais dos gastos, sendo $4,45 \%$ antes e a média $4,57 \%$ depois da implantação da gestão semi plena. A segunda posição foi ocupada pelos partos normais que com relação ao total representaram $3,77 \%$ dos gastos, sendo $3,93 \%$ antes e em média $3,71 \%$ depois. O terceiro lugar foi ocupado pelos transplantes de medula alogênico aparentado com 2,66\% (3,34\% antes e a média de $3,79 \%$ depois), seguidos pelos procedimentos de prematuridade que representaram $3,15 \%$ do total, sendo $3,24 \%$ (antes) e a média de $3,13 \%$ (depois).

O Quadro 67, apresenta a distribuição dos percentuais dos gastos com internações SUS dos 50 procedimentos de internações SUS de maior dispêndio ocorridos no Município de Diadema, onde observou-se, que $86,23 \%$ do total dos gastos corresponderam aos 50 procedimentos e que antes estes representavam $88,47 \%$, passando a representar a média de $84,47 \%$ depois da implantação da gestão semi plena.

Dos gastos com internações SUS no Município de Diadema, os procedimentos de parto foram os que mais consumiram recursos, destacando-se na primeira posição os partos normais com atendimento ao recém nascido na sala de parto que consumiram $15,18 \%$ dos totais dos gastos, sendo $22,42 \%$ antes e a média $13,13 \%$ depois da implantação da gestão semi plena. A segunda posição foi ocupada pelas cesarianas com atendimento ao recém nascido na sala de parto, que com relação ao total representaram $11,56 \%$ dos gastos, sendo $16,90 \%$ antes e em média $9,98 \%$ depois. O terceiro lugar foi ocupado pelos partos normais com $8,59 \%$ (5,82\% antes e a média de $7,74 \%$ depois), seguidos pelos procedimentos de cesarianas que representaram $7,52 \%$ do total, sendo $5,49 \%$ (antes) e a média de $6,68 \%$ (depois). 
O Quadro 68 , apresenta a distribuição dos percentuais dos gastos com internações SUS dos 50 procedimentos de internações SUS de maior dispêndio ocorridos no Municipio de Mauá, onde observou-se, que $85,32 \%$ do total dos gastos corresponderam aos 50 procedimentos e que antes estes representavam $87,02 \%$, passando a representar a média de $84,85 \%$ depois da implantação da gestão semi plena.

Dos gastos com internações SUS no Municipio de Mauá, os procedimentos de parto foram os que mais consumiram recursos, destacando-se na primeira posição os partos normais com atendimento ao recém nascido na sala de parto que consumiram $20,70 \%$ dos totais dos gastos, sendo $14,64 \%$ antes e a média $22,67 \%$ depois da implantação da gestão semi plena. A segunda posição foi ocupada pelas cesarianas com atendimento ao recém nascido na sala de parto, que com relação ao total representaram $16,85 \%$ dos gastos, sendo $14,56 \%$ antes e em média $17,52 \%$ depois. $O$ terceiro lugar foi ocupado pelas broncopneumonias em lactentes com $4,72 \%(5,59 \%$ antes e a média de $4,44 \%$ depois), seguidos pelos procedimentos de insuficiências cardiacas que representaram $4,69 \%$ do total, sendo $5,77 \%$ (antes) e a média de $4,33 \%$ (depois).

O Quadro 69, apresenta a distribuição dos percentuais dos gastos com internações SUS dos 50 procedimentos de internações SUS de maior dispêndio, ocorrido no município de Ribeirão Preto, onde observou-se, que $59,76 \%$ do total dos gastos corresponderam aos 50 procedimentos e que antes estes representavam $58,81 \%$, passando a representar a média de $60,11 \%$ depois da implantação da gestão semi plena.

Dos gastos com internações SUS no Município de Ribeirão Preto, dentre os procedimentos que mais consumiram recursos, destacam-se na primeira posição as coronarioplastias que consumiram $5,10 \%$ dos totais dos gastos, sendo $5,98 \%$ antes e a média $4,76 \%$ depois da implantação da gestão semi plena. A segunda posição foi ocupada pelas cirurgias de 
coronária com extracorpórea, que com relação ao total representaram 4,41\% dos gastos, sendo $5,11 \%$ antes e em média $4,15 \%$ depois. $O$ terceiro lugar foi ocupado pelos implantes de prótese valvular com $3,55 \%$ (4,31\% antes e a média de $3,27 \%$ depois), seguidos pelos procedimentos de marca-passo cardíaco (intracavitário) que representaram 2,93\% do total, sendo $2,54 \%$ (antes) e a média de $3,10 \%$ (depois).

O Quadro 70 , apresenta a distribuição dos percentuais dos gastos com internações SUS dos 50 procedimentos de internações SUS de maior dispêndio, ocorrido no Municipio de Santos, onde observou-se, que 70,89\% do total dos gastos corresponderam aos 50 procedimentos e que antes estes representavam $73,28 \%$, passando a representar a média de $69,78 \%$ depois da implantação da gestão semi plena.

Dos gastos com internações SUS no Municipio de Santos, dentre os procedimentos que mais consumiram recursos, destacam-se na primeira posição as cirurgias múltiplas que consumiram $11,07 \%$ dos totais dos gastos, sendo $14,90 \%$ antes e a média $9,32 \%$ depois da implantação da gestão semi plena. A segunda posição foi ocupada pelos politraumatizados, que com relação ao total representaram $6,11 \%$ dos gastos, sendo $5,38 \%$ antes e em média $6,48 \%$ depois. O terceiro lugar foi ocupado pelas cesarianas com atendimento ao recém nascido na sala de parto com $4,79 \%$ ( $4,73 \%$ antes e a média de $4,86 \%$ depois), seguidos pelos procedimentos de partos normais com atendimento ao recém nascido na sala de parto que representaram $3,57 \%$ do total, sendo $3,52 \%$ (antes) e a média de $3,75 \%$ (depois).

O Quadro 71, apresenta a distribuição dos percentuais dos gastos com internações SUS dos 50 procedimentos de internações SUS de maior dispêndio, ocorrido no Município de São Bernardo do Campo, onde observou-se, que $60,11 \%$ do total dos gastos corresponderam aos 50 
procedimentos e que antes estes representavam 53,55\%, passando à média de $61,15 \%$ depois da implantação da gestão semi plena.

Dos gastos com internações SUS no Município de São Bernardo do Campo, dentre os procedimentos que mais consumiram recursos, destacou-se na primeira posição as reduções cirúrgicas de fratura da diáfise do fêmur que consumiram $7,99 \%$ dos totais dos gastos, sendo $2,11 \%$ antes e a média $8,98 \%$ depois da implantação da gestão semi plena. A segunda posição foi ocupada pelas reduções cirúrgicas de fratura da diáfise da tíbia, com fixação, que com relação ao total representaram $4,83 \% \%$ dos gastos, sendo $0,85 \%$ antes e em média $5,48 \%$ depois. O terceiro lugar foi ocupado pelas artroplastia coxo-femural com 3,63\% (0,22\% antes e a média de $4,14 \%$ depois), seguidos pelos procedimentos de prostatectomia que representaram $2,91 \%$ do total, sendo $2,06 \%$ (antes) e a média de $3,04 \%$ (depois).

O Quadro 72, apresenta a distribuição dos percentuais dos gastos com internações SUS dos 50 procedimentos de internações SUS de maior dispêndio, ocorrido no Municipio de Sertãozinho, onde observou-se, que $76,51 \%$ do total dos gastos corresponderam aos 50 procedimentos e que antes estes representavam $77,36 \%$, passando à média de $75,96 \%$ depois da implantação da gestão semi plena.

Dos gastos com internações SUS no Município de Sertãozinho, dentre os procedimentos que mais consumiram recursos, destacou-se na primeira posição as cesarianas com atendimento ao recém nascido na sala de parto que consumiram $14,07 \%$ dos totais dos gastos, sendo $13,49 \%$ antes e a média $14,38 \%$ depois da implantação da gestão semi plena. A segunda posição foi ocupada pelos partos normais com atendimento ao recém nascido na sala de parto, que com relação ao total representaram $7,58 \%$ dos gastos, sendo $6,01 \%$ antes e em média $8,27 \%$ depois. O terceiro lugar foi ocupado pelas insuficiências cardiacas com $4,88 \%(5,87 \%$ antes e 
a média de $4,35 \%$ depois), seguidos pelos procedimentos de "bipass" ou tromboendarterectomia femuro-poplitea que representaram $3,88 \%$ do total, sendo $2,00 \%$ (antes) e a média de $4,64 \%$ (depois).

O Quadro 73, apresenta a distribuição dos percentuais dos gastos com internações SUS dos 50 procedimentos de internações SUS de maior dispêndio, ocorrido no Municipio de São José dos Campos, onde observouse, que $68,08 \%$ do total dos gastos corresponderam aos 50 procedimentos e que antes estes representavam $67,95 \%$, passando à média de $68,17 \%$ depois da implantação da gestão semi plena.

Dos gastos com internações SUS no Municipio de São José dos Campos, dentre os procedimentos que mais consumiram recursos, destacou-se na primeira posição as cesarianas com atendimento ao recém nascido na sala de parto que consumiram $8,97 \%$ dos totais dos gastos, sendo $8,02 \%$ antes e a média $9,24 \%$ depois da implantação da gestão semi plena. A segunda posição foi ocupada pelos partos normais com atendimento ao recém nascido na sala de parto, que com relação ao total representaram $7,54 \%$ dos gastos, sendo $5,64 \%$ antes e em média $8,11 \%$ depois. O terceiro lugar foi ocupado pelas cirurgias de coronárias extracorpórea com 4,07\% (2,87\% antes e a média de $4,50 \%$ depois), seguidos pelos procedimentos de insuficiência cardiaca que representaram $3,58 \%$ do total, sendo $4,45 \%$ (antes) e a média de $3,30 \%$ (depois).

O Quadro 74 , apresenta a distribuição dos percentuais dos gastos com internações SUS dos 50 procedimentos de internações SUS de maior dispêndio, ocorrido no Municipio de São Vicente, onde observou-se, que $77,35 \%$ do total dos gastos corresponderam aos 50 procedimentos e que antes estes representavam $81,38 \%$, passando à média de $75,68 \%$ depois da implantação da gestão semi plena. 
Dos gastos com internações SUS no Município de São Vicente, dentre os procedimentos que mais consumiram recursos, destacou-se na primeira posição os partos normais que consumiram $13,93 \%$ dos totais dos gastos, sendo $13,54 \%$ antes e a média $14,06 \%$ depois da implantação da gestão semi plena. A segunda posição foi ocupada pelas cirurgias múltiplas, que com relação ao total representaram $8,60 \%$ dos gastos, sendo $13,47 \%$ antes e em média $6,56 \%$ depois. O terceiro lugar foi ocupado pelas cesarianas com $7,08 \%$ ( $8,09 \%$ antes e a média de $6,65 \%$ depois), seguidos pelos procedimentos de insuficiência cardiaca que representaram $4,15 \%$ do total, sendo $4,95 \%$ (antes) e a média de $3,72 \%$ (depois).

O Quadro 75 , apresenta a distribuição dos percentuais dos gastos com internações SUS dos 50 procedimentos de internações SUS de maior dispêndio, ocorrido no Município de Votorantim, onde observou-se, que $79,28 \%$ do total dos gastos corresponderam aos 50 procedimentos e que antes estes representavam $74,77 \%$, passando a representar a média de $81,84 \%$ depois da implantação da gestão semi plena.

Dos gastos com internações SUS no Municipio de Votorantim, dentre os procedimentos que mais consumiram recursos, destacou-se na primeira posição as cesarianas que consumiram $11,63 \%$ dos totais dos gastos, sendo $7,53 \%$ antes e a média $13,98 \%$ depois da implantação da gestão semi plena. A segunda posição foi ocupada pelos partos normais, que com relação ao total representaram $10,94 \%$ dos gastos, sendo $13,47 \%$ antes e em média $6,56 \%$ depois. O terceiro lugar foi ocupado pelas insuficiências cardiacas com $6,31 \%(6,44 \%$ antes e a média de $6,34 \%$ depois), seguidos pelos procedimentos de Acidente Vascular Cerebral agudo que representaram $4,51 \%$ do total, sendo $5,46 \%$ (antes) e a média de $4,00 \%$ (depois). 
Quadro 67 - Distribuição percentual dos gastos com internaçōes SUS pelos 50 procedimentos mais freqüentes, ocorridos no municipio de Mauá - SP, antes e depois da implantação da gestão semi-plena.

\begin{tabular}{|c|c|c|c|c|c|c|c|c|c|c|c|}
\hline \multirow{2}{*}{\multicolumn{2}{|c|}{ Procedimentos }} & \multirow{2}{*}{\multicolumn{2}{|c|}{ Total }} & \multirow{2}{*}{\multicolumn{2}{|c|}{$\begin{array}{l}\text { Antes } \\
1^{\circ} \text { ano }\end{array}$}} & \multicolumn{6}{|c|}{ Depois } \\
\hline & & & & & & \multicolumn{2}{|c|}{10 ano } & \multicolumn{2}{|c|}{$2^{\circ}$ ano } & \multicolumn{2}{|c|}{$3^{\circ}$ ano } \\
\hline Código & Descriçăo & Pos. & $\%$ & Pos.] & $\%$ & Pos. & $\%$ & Pos. & $\%$ & Pos. & $\%$ \\
\hline 35021012 & PARTO NORMAL COM ATENDIMENTO RN SALA DE PARTO & 1 & 20,70 & 1 & 14,64 & 2 & 16,95 & 1 & 25,69 & 1 & 25,35 \\
\hline 35022019 & CESARIANA COM ATENDIMENTO RN SALA DE PARTO & 2 & 16,85 & 2 & 14,56 & 1 & 16,98 & 2 & 18,96 & 2 & 16,61 \\
\hline 76400085 & BRONCOPNEUMONIA EM LACTENTE & 3 & 4,72 & 4 & 5,59 & 4 & 5,26 & 3 & 4,61 & 4 & 3,43 \\
\hline 77500113 & INSUFICIENCIA CARDIACA & 4 & 4,69 & 3 & 5,77 & 3 & 5,55 & 4 & 3,46 & 3 & 3,98 \\
\hline 71300015 & PREMATURIDADE & 5 & 2,81 & 7 & 2,72 & 6 & 2,44 & 6 & 3,12 & 5 & 3,00 \\
\hline 35014016 & CURETAGEM POS-ABORTO & 6 & 2,75 & 9 & 2,58 & 5 & 2,57 & 5 & 3,43 & 6 & 2.43 \\
\hline 81500106 & AVC AGUDO & 7 & 2,14 & 10 & 2,49 & 8 & 2,33 & 8 & 1.76 & 8 & 1,99 \\
\hline 70000000 & TRATAMENTO DA AIDS & 8 & 1,91 & 11 & 1,99 & 10 & 2,06 & 7 & 1.97 & 10 & 1.61 \\
\hline 76300080 & BRONCOPNEUMONIA & 9 & 1,83 & 8 & 2.67 & 11 & 1,96 & 10 & 1,52 & 11 & 1,27 \\
\hline 35001011 & PARTO NORMAL & 10 & 1,72 & 5 & 4,38 & 9 & 2,09 & 38 & 0,31 & 34 & 0,37 \\
\hline 35009012 & CESARIANA & 11 & 1,53 & 6 & 3,30 & 7 & 2,41 & 42 & 0,25 & 45 & 0,22 \\
\hline 76500071 & BRONCOPNEUMONIA & 12 & 1,44 & 14 & 1,55 & 15 & 1,12 & 11 & 1,31 & 9 & 1,84 \\
\hline 77500024 & INFARTO AGUDO DO MIOCARDIO & 13 & 1,44 & 19 & 1,04 & 21 & 0,90 & 9 & 1,58 & 7 & 2,27 \\
\hline 33011117 & HERNIORRAFIA INGUINAL(UNILATERAL) & 14 & 1.24 & 15 & 1,38 & 12 & 1,21 & 12 & 1,31 & 16 & 1,07 \\
\hline 76500225 & DOENCA PULMONAR OBSTRUTIVA CRONICA & 15 & 1,21 & 13 & 1,70 & 14 & 1,16 & 16 & 0,87 & 13 & 1,16 \\
\hline 82500053 & DIABETE SACARINO & 16 & 1,16 & 16 & 1,19 & 13 & 1,17 & 14 & 1,05 & 12 & 1,24 \\
\hline 33005060 & APENDICECTOMIA & 17 & 0,93 & 30 & 0,67 & 16 & 1,01 & 15 & 0,91 & 15 & 1,10 \\
\hline 75500124 & HEMORRAGIAS DIGESTIVAS & 18 & 0,91 & 22 & 0,93 & 22 & 0,87 & 19 & 0,72 & 14 & 1,12 \\
\hline 76300102 & CRISE ASMATICA & 19 & 0.87 & 12 & 1,92 & 26 & 0,68 & 47 & 0,18 & 19 & 0,83 \\
\hline 33004080 & COLECISTECTOMIA & 20 & 0.82 & 25 & 0,79 & 20 & 0,93 & 20 & 0,71 & 18 & 0,83 \\
\hline 33016119 & LAPAROTOMIA EXPLORADORA & 21 & 0,72 & 28 & 0,70 & 19 & 0,94 & 24 & 0,52 & 20 & 0,70 \\
\hline 74300270 & ENTERO-INFECCOES (PEDIATRIA) & 22 & 0.70 & 17 & 1.12 & 23 & 0,85 & 41 & 0,27 & 23 & 0,61 \\
\hline 76400271 & ENTERO-INFECCOES EM LACTENTE & 23 & 0.70 & 18 & 1,11 & 17 & 1.00 & 26 & 0.49 & 47 & 0,20 \\
\hline 71300082 & ICTERICIAS NEO-NATAIS & 24 & 0.67 & 44 & 0.26 & 18 & 0,97 & 17 & 0.79 & 24 & 0.59 \\
\hline 76500233 & INSUFICIENCIA RESPIRATORIA AGUDA & 25 & 0,65 & 20 & 0,98 & 25 & 0,70 & 25 & 0.52 & 28 & 0.45 \\
\hline
\end{tabular}


Quadro 67 - Continuação

\begin{tabular}{|c|c|c|c|c|c|c|c|c|c|c|c|}
\hline & & & otal & & ntes & & & & pois & & \\
\hline & Procedimentos & & & & ano & & ano & & ano & & ano \\
\hline Codigo & Descriçáo & Pos. & $\%$ & Pos. & $\%$ & Pos. & $\%$ & Pos. & $\%$ & Pos. & $\%$ \\
\hline 31000002 & CIRURGIA MULTIPLA & 26 & 0,63 & 48 & 0,12 & 44 & 0,31 & 13 & 1,19 & 17 & 0,88 \\
\hline 34008020 & COLPOPERINEOPLASTIA ANTERIOR E POSTERIOR & 27 & 0,62 & 23 & 0,86 & 32 & 0,53 & 18 & 0,75 & 31 & 0.40 \\
\hline 77500121 & CRISE HIPERTENSIVA & 28 & 0,57 & 24 & 0,81 & 27 & 0,65 & 28 & 0,43 & 32 & 0.39 \\
\hline 34010033 & HISTERECTOMIA TOTAL & 29 & 0,56 & 26 & 0.79 & 28 & 0,63 & 22 & 0,55 & 41 & 0,30 \\
\hline 76300072 & OUTRAS PNEUMONIAS & 30 & 0.55 & 21 & 0,94 & 30 & 0.55 & 37 & 0,32 & 30 & 0.43 \\
\hline 42008069 & TORACOTOMIA COM DRENAGEM FECHADA & 31 & 0.48 & 27 & 0,78 & 29 & 0.62 & 31 & 0.39 & 50 & 0,16 \\
\hline 34017038 & HISTERECTOMIA C/ANEXETOMIA UNI OU BILATERAL & 32 & 0,48 & 43 & 0,28 & 31 & 0.54 & 29 & 0.41 & 21 & 0,66 \\
\hline 76500063 & PNEUMONIA NAO ESPECIFICADA & 33 & 0,46 & 32 & 0.51 & 35 & 0,45 & 39 & 0.29 & 22 & 0.61 \\
\hline 74500252 & ENTERO-INFECCOES (CLINICA MEDICA) & 34 & 0.45 & 31 & 0.62 & 24 & 0,71 & 44 & 0.23 & 46 & 0,21 \\
\hline 76500128 & CRISE ASMATICA & 35 & 0,44 & 29 & 0,67 & 36 & 0,45 & 36 & 0,33 & 36 & 0,35 \\
\hline 74300261 & SEPTICEMIAS (PEDIATRIA) & 36 & 0.42 & 34 & 0,42 & 38 & 0.42 & 23 & 0.54 & 40 & 0,30 \\
\hline 74300253 & INFECCOES MENINGOCOCICAS (PEDIATRIA) & 37 & 0.42 & 36 & 0,40 & 45 & 0,30 & 21 & 0,68 & 42 & 0,30 \\
\hline 73500011 & DESNUTRICAO (CLINICA MEDICA) & 38 & 0,40 & 33 & 0,48 & 37 & 0.45 & 33 & 0,36 & 37 & 0,34 \\
\hline 91500079 & TRAUMATISMOS CRANIOENCEFALICO & 39 & 0,39 & 35 & 0,42 & 33 & 0,49 & 46 & 0,20 & 29 & 0.44 \\
\hline 34005030 & CURETAGEM SEMIOTICA COM OU SEM DILATACAO DE COLO & 40 & 0,38 & 37 & 0,38 & 41 & 0,37 & 27 & 0,43 & 38 & 0,33 \\
\hline 33006067 & COLECTOMIA PARCIAL(HEMICOLECTOMIA) & 41 & 0,32 & 50 & 0,09 & 43 & 0,31 & 35 & 0,35 & 27 & 0,49 \\
\hline 72500000 & DIAGNOSTICO E/OU PRIMEIRO ATENDIMENTO EM CLINICA MEDICA & 42 & 0,32 & 46 & 0,20 & 50 & 0,12 & 30 & 0,41 & 25 & 0.55 \\
\hline 35024011 & PARTO COM MANOBRAS COM ATENDIMENTO RN SALA DE PARTO & 43 & 0,31 & 49 & 0.10 & 47 & 0,28 & 34 & 0,35 & 26 & 0.50 \\
\hline 76400077 & PNEUMONIAS DO LACTENTE & 44 & 0,30 & 41 & 0,32 & 34 & 0.46 & 45 & 0,21 & 49 & 0.18 \\
\hline 75500213 & CIRROSE HEPATICA & 45 & 0,29 & 39 & 0,37 & 42 & 0,31 & 43 & 0,24 & 44 & 0,26 \\
\hline 33021066 & ENTERECTOMIA & 46 & 0,29 & 45 & 0.21 & 40 & 0,41 & 50 & 0,13 & 33 & 0,38 \\
\hline 76300188 & INSUFICIENCIA RESPIRATORIA AGUDA & 47 & 0,29 & 40 & 0,37 & 39 & 0,41 & 49 & 0,17 & 48 & 0.18 \\
\hline 33006059 & GASTRORRAFIA & 48 & 0.28 & 47 & 0,17 & 49 & 0,22 & 32 & 0,39 & 35 & 0,36 \\
\hline 77500032 & INSUFICIENCIA CORONARIANA AGUDA & 49 & 0,28 & 38 & 0,37 & 46 & 0,30 & 48 & 0,18 & 43 & 0.28 \\
\hline 80500218 & OUTRAS AFECCOES DO AP. GENITO-URINARIO & 50 & 0,28 & 42 & 0,31 & 48 & 0,22 & 40 & 0,28 & 39 & 0,31 \\
\hline & Sub-Tot: & & 85,32 & & 87,02 & & 84,62 & & 86,08 & & 83,84 \\
\hline & Outro & & 14,68 & & 12,98 & & 15,38 & & 13,92 & & 16,16 \\
\hline & & & 100,00 & & 100,00 & & 100,00 & & 100,00 & & 100,00 \\
\hline
\end{tabular}


Quadro 68 - Distribuição percentual dos gastos com internaçōes SUS pelos 50 procedimentos mais freqüentes, ocorridos no municipio de Ribeirão Preto - SP, antes e depois da implantação da gestão semi-plena, no Estado de São Paulo.

\begin{tabular}{|c|c|c|c|c|c|c|c|c|c|c|c|}
\hline \multirow{2}{*}{\multicolumn{2}{|c|}{ Procedimentos }} & \multirow{2}{*}{\multicolumn{2}{|c|}{ Total }} & \multirow{2}{*}{\multicolumn{2}{|c|}{$\begin{array}{l}\text { Antes } \\
1^{\circ} \text { ano }\end{array}$}} & \multicolumn{6}{|c|}{ Depois } \\
\hline & & & & & & \multicolumn{2}{|c|}{$1^{\circ}$ ano } & \multicolumn{2}{|c|}{$2 \circ$ ano } & \multicolumn{2}{|c|}{$3^{\circ}$ ano } \\
\hline Codigo & Descriçâo & Pos. & $\%$ & Pos. & $\%$ & Pos. & $\%$ & Pos. & $\%$ & Pos. & $\%$ \\
\hline 32023014 & CORONARIOPLASTIA & 1 & 5.10 & 1 & 5,98 & 1 & 5,45 & 1 & 4,46 & 2 & 4,38 \\
\hline 32011016 & CIRURGIA DE CORONARIA COM EXTRA-CORPOREA & 2 & 4,41 & 2 & 5,11 & 2 & 4,34 & 2 & 4.37 & 3 & 3,75 \\
\hline 32020015 & IMPLANTE DE PROTESE VALVULAR & 3 & 3,55 & 3 & 4,31 & 3 & 3,59 & 4 & 3,16 & 4 & 3,05 \\
\hline 32015011 & MARCA-PASSO CARDIACO(INTRACAVITARIO) & 4 & 2.93 & 5 & 2,54 & 4 & 3,22 & 3 & 3,25 & 5 & 2,82 \\
\hline 77500113 & INSUFICIENCIA CARDIACA & 5 & 2.50 & 4 & 3,32 & 5 & 2,61 & 11 & 2.03 & 12 & 1,95 \\
\hline 46800204 & TRANSPLANTE DE MEDULA ALOGENICO APARENTADO & 6 & 2,48 & 6 & 2.47 & 8 & 2,36 & 5 & 2.78 & 9 & 2,33 \\
\hline 35021012 & PARTO NORMAL COM ATENDIMENTO RN SALA DE PARTO & 7 & 2,43 & 7 & 2.36 & 6 & 2,45 & 6 & 2,37 & 7 & 2,55 \\
\hline 71300015 & PREMATURIDADE & 8 & 2,33 & 8 & 2.17 & 7 & 2,40 & 9 & 2.12 & 6 & 2,62 \\
\hline 70000000 & TRATAMENTO DA AIDS & $\mathbf{9}$ & 2.16 & 9 & 2,15 & 10 & 2,20 & 7 & 2,32 & 11 & 2,00 \\
\hline 35022019 & CESARIANA COM ATENDIMENTO RN SALA DE PARTO & 10 & 2,05 & 10 & 2,12 & 11 & 2,04 & 13 & 1,94 & 10 & 2,08 \\
\hline 32021011 & CORRECAO DE CARDIOPATIA CONGENITA & 11 & 2,02 & 12 & 1,87 & 14 & 1,76 & 10 & 2,10 & 8 & 2,35 \\
\hline 31000002 & CIRURGIA MULTIPLA & 12 & 1,82 & 14 & 1,33 & 9 & 2,27 & 12 & 1,95 & 13 & 1,84 \\
\hline 81001010 & EXPLORACAO DIAGNOSTICA DA EPILEPSIA & 13 & 1,74 & 48 & 0,00 & 48 & 0,00 & 8 & 2,15 & 1 & 4,80 \\
\hline 31802010 & TRANSPLANTE RENAL RECEPTOR & 14 & 1,74 & 11 & 1,99 & 13 & 1,84 & 16 & 1,32 & 14 & 1,72 \\
\hline 39016129 & ARTROPLASTIA COXO-FEMURAL COM PROTESE NAO CIMENT & 15 & 1,72 & 13 & 1,69 & 12 & 1,85 & 14 & 1,72 & 15 & 1,64 \\
\hline 76400077 & PNEUMONIAS DO LACTENTE & 16 & 1,20 & 15 & 1,23 & 17 & 1,02 & 15 & 1,70 & 20 & 0,90 \\
\hline 40061019 & VENTRICULO-PERITONIOSTOMIA COM INTERPOSICAO DE VAL & 17 & 1,11 & 17 & 0,97 & 18 & 1,02 & 17 & 1,25 & 17 & 1,21 \\
\hline 77500032 & INSUFICIENCIA CORONARIANA AGUDA & 18 & 0,92 & 21 & 0,80 & 15 & 1,22 & 26 & 0,76 & 19 & 0,93 \\
\hline 42004039 & TRAQUEOTOMIA(INCLUSIVE CURATIVOS) & 19 & 0,92 & 31 & 0,53 & 21 & 0,91 & 19 & 1,16 & 18 & 1,14 \\
\hline 76300102 & CRISE ASMATICA & 20 & 0,91 & 24 & 0,68 & 20 & 0,93 & 18 & 1,21 & 21 & 0,89 \\
\hline 36005045 & FACECTOMIA COM LENTE INTRA-OCULAR & 21 & 0,78 & 18 & 0,95 & 23 & 0,82 & 25 & 0,78 & 29 & 0,57 \\
\hline 79700470 & LEUCEMIAS AGUDAS & 22 & 0.74 & 22 & 0,78 & 22 & 0.84 & 21 & 0,84 & 32 & 0,52 \\
\hline 76500063 & PNEUMONIA NAO ESPECIFICADA & 23 & 0.74 & 26 & 0.65 & 25 & 0.73 & 27 & 0,74 & 23 & 0,85 \\
\hline 32019017 & VALVULOPLASTIAS & 24 & 0,74 & 19 & 0,92 & 36 & 0.46 & 20 & 1,08 & 34 & 0,51 \\
\hline 40028011 & MICROCIRURGIA VASCULAR INTRACRANIANA & 25 & 0.73 & 20 & 0,84 & 26 & 0.70 & 24 & 0,79 & 27 & 0.59 \\
\hline
\end{tabular}




\begin{tabular}{|c|c|c|c|c|c|c|c|c|c|c|c|}
\hline \multirow{2}{*}{\multicolumn{2}{|c|}{ Procedimentos }} & \multirow{2}{*}{\multicolumn{2}{|c|}{ Total }} & \multirow{2}{*}{\multicolumn{2}{|c|}{$\begin{array}{l}\text { Antes } \\
1^{\circ} \text { ano }\end{array}$}} & \multicolumn{6}{|c|}{ Depois } \\
\hline & & & & & & \multicolumn{2}{|c|}{$1^{\circ}$ ano } & \multicolumn{2}{|c|}{$2^{\circ}$ ano } & \multicolumn{2}{|c|}{$3^{\circ}$ ano } \\
\hline Codigo & Descriçăo & Pos. & $\%$ & Pos. & $\%$ & Pos. & $\%$ & Pos. & $\%$ & Pos. & $\%$ \\
\hline 81500106 & AVC AGUDO & 26 & 0,71 & 16 & 0,99 & 30 & 0,65 & 31 & 0.58 & 28 & 0,59 \\
\hline 76500225 & DOENCA PULMONAR OBSTRUTIVA CRONICA & 27 & 0,66 & 27 & 0,64 & 24 & 0,78 & 30 & 0,62 & 26 & 0.59 \\
\hline 40001040 & TRATAMENTO CIRURGICO DA EPILEPSIA & 28 & 0,61 & 49 & 0,00 & 49 & 0,00 & 22 & 0,83 & 16 & 1,63 \\
\hline 77500024 & INFARTO AGUDO DO MIOCARDIO & 29 & 0,61 & 28 & 0,58 & 28 & 0,67 & 35 & 0,55 & 25 & 0,62 \\
\hline 39000001 & POLITRAUMATIZADO & 30 & 0,60 & 29 & 0,56 & 19 & 0,99 & 36 & 0,54 & 45 & 0,34 \\
\hline 79500048 & HEMOFILIAS E OUTROS DEFEITOS DE COAGULACAO & 31 & 0,60 & 41 & 0,38 & 27 & 0,70 & 23 & 0,81 & 30 & 0,56 \\
\hline 33016119 & LAPAROTOMIA EXPLORADORA & 32 & 0,53 & 38 & 0,44 & 29 & 0,67 & 34 & 0,56 & 36 & 0,47 \\
\hline 32013019 & MARCA-PASSO(TROCA DE GERADOR DE ESTIMULO) & 33 & 0,50 & 23 & 0,74 & 33 & 0,57 & 43 & 0,35 & 47 & 0,31 \\
\hline 33004080 & COLECISTECTOMIA & 34 & 0.49 & 32 & 0,50 & 31 & 0,64 & 40 & 0,41 & 41 & 0,42 \\
\hline 72500000 & DIAGNOSTICO E/OU PRIMEIRO ATENDIMENTO EM CLIN MEDICA & 35 & 0,48 & 47 & 0,14 & 32 & 0,62 & 32 & 0,57 & 24 & 0,63 \\
\hline 39013138 & REDUCAO CIRURGICA DE FRATURA TRANSTROCANTERIANA & 36 & 0.46 & 34 & 0.49 & 34 & 0,51 & 41 & 0,38 & 37 & 0.46 \\
\hline 47802014 & INTERCORRENCIA POS TRANSPLANTE & 37 & 0.46 & 39 & 0.42 & 16 & 1,15 & 49 & 0.22 & 50 & 0.07 \\
\hline 39022145 & ARTROPLASTIA TOTAL DO JOELHO(COM IMPLANTE) & 38 & 0,46 & 33 & 0,50 & 37 & 0.45 & 42 & 0,37 & 35 & 0,48 \\
\hline 74500244 & SEPTICEMIAS (CLINICA MEDICA) & 39 & 0,45 & 37 & 0,46 & 35 & 0,50 & 47 & 0.31 & 33 & 0,52 \\
\hline 32019041 & BYPASS OU TROMBOENDARTERECTOMIA FEMURO-POPLITEIA & 40 & 0,45 & 40 & 0,38 & 45 & 0,34 & 33 & 0,56 & 31 & 0,53 \\
\hline 79700209 & APARELHO GENITO URINARIO & 41 & 0,45 & 35 & 0,49 & 43 & 0,37 & 37 & 0.50 & 39 & 0,44 \\
\hline 82500053 & DIABETE SACARINO & 42 & 0,44 & 30 & 0,55 & 39 & 0,42 & 39 & 0,42 & 44 & 0,37 \\
\hline 76500233 & INSUFICIENCIA RESPIRATORIA AGUDA & 43 & 0,40 & 25 & 0,68 & 38 & 0,44 & 50 & 0,18 & 49 & 0.25 \\
\hline 76300072 & OUTRAS PNEUMONIAS & 44 & 0,40 & 42 & 0,38 & 46 & 0,34 & 38 & 0.42 & 38 & 0,45 \\
\hline 32021046 & CURA CIRURGICA DA PERSISTENCIA DO CANAL ARTERIAL & 45 & 0,40 & 46 & 0,26 & 47 & 0,31 & 29 & 0,64 & 42 & 0,41 \\
\hline 32031017 & ESTUDO ELETROFISIOLOGICO DIAGNOSTICOE TERAPEUTICO & 46 & 0,39 & 50 & 0,00 & 50 & 0,00 & 28 & 0,73 & 22 & 0,88 \\
\hline 40038017 & TRATAMENTO CIRURGICO DE HEMATOMA SUB-DURAL & 47 & 0,38 & 36 & 0,47 & 41 & 0.40 & 46 & 0,32 & 46 & 0,33 \\
\hline 33011117 & HERNIORRAFIA INGUINAL(UNILATERAL) & 48 & 0,36 & 45 & 0,32 & 42 & 0,38 & 45 & 0,33 & 40 & 0,42 \\
\hline 35014016 & CURETAGEM POS-ABORTO & 49 & 0,35 & 44 & 0,34 & 44 & 0.35 & 48 & 0.31 & 43 & 0,38 \\
\hline 40005011 & CRANIOTOMIA PITUMORES CEREBRAIS,INCLUSIVE DA FOSSA & 50 & 0.35 & 43 & 0,35 & 40 & 0,41 & 44 & 0,35 & 48 & 0,29 \\
\hline & Sub-Total & & 59,76 & & 58,81 & & 59,71 & & 60,23 & & 60,40 \\
\hline & Outros & & 40,24 & & 41,19 & & 40,29 & & 39,77 & & 39,60 \\
\hline & Total & & 100,00 & & 100,00 & & 100,00 & & 100,00 & & 100,00 \\
\hline
\end{tabular}


Quadro 69 - Distribuição percentual dos gastos com internações SUS pelos 50 procedimentos mais freqüentes, ocorridos no município de Santos - SP, antes e depois da implantação da gestão semi-plena.

\begin{tabular}{|c|c|c|c|c|c|c|c|c|c|c|c|}
\hline \multirow[b]{2}{*}{ Codigo } & Procedimentos & \multicolumn{2}{|c|}{ Total } & \multicolumn{2}{|c|}{$\begin{array}{l}\text { Antes } \\
1^{\circ} \text { ano }\end{array}$} & \multicolumn{6}{|c|}{ Depois } \\
\hline & Descriçăo & Pos & $\%$ & Pos & $\%$ & Pos & $\%$ & Pos & $\%$ & Pos & $\%$ \\
\hline 31000002 & CIRURGIA MULTIPLA & 1 & 11,07 & 1 & 14,90 & 1 & 12,05 & 1 & 9,98 & 2 & 5,91 \\
\hline 39000001 & POLITRAUMATIZADO & 2 & 6,11 & 2 & 5,38 & 2 & 5,54 & 2 & 7.44 & 1 & 6,47 \\
\hline 35022019 & CESARIANA COM ATENDIMENTO RN SALA DE PARTO & 3 & 4,79 & 3 & 4,73 & 3 & 4,54 & 3 & 4,87 & 3 & 5,18 \\
\hline 35021012 & PARTO NORMAL COM ATENOIMENTO RN SALA DE PARTO & 4 & 3,57 & 6 & 3,52 & 8 & 2,61 & 4 & 3,75 & 4 & 4,89 \\
\hline 70000000 & TRATAMENTO DA AIDS & 5 & 3,32 & 7 & 3.48 & 5 & 3.62 & 5 & 3,11 & 6 & 2,88 \\
\hline 32011016 & CIRURGIA DE CORONARIA COM EXTRA-CORPOREA & 6 & 3.24 & 4 & 4.27 & 6 & 3,55 & 6 & 2,61 & 8 & 2,14 \\
\hline 77500113 & INSUFICIENCIA CARDIACA & 7 & 2.91 & 8 & 3,00 & 7 & 2,86 & 7 & 2,59 & 5 & 3.20 \\
\hline 76300188 & INSUFICIENCIA RESPIRATORIA AGUDA & 8 & 2,59 & 5 & 3,56 & 4 & 3,68 & 14 & 1,56 & 23 & 0,81 \\
\hline 81500100 & AVC AGUDO & 9 & 2,36 & 9 & 2,41 & 9 & 2,33 & $\mathbf{9}$ & 2,30 & 7 & 2,40 \\
\hline 32015011 & MARCA-PASSO CARDIACO(INTRACAVITARIO) & 10 & 2,14 & 12 & 2,00 & 10 & 2,03 & 8 & 2,51 & $\mathbf{9}$ & 2,09 \\
\hline 40001008 & TRATAMENTO CONSERV DO TRAUMAT CRANEO-ENCEFALICO & 11 & 1,86 & 11 & 2,25 & 11 & 1,86 & 12 & 1.75 & 15 & 1,49 \\
\hline 76500233 & INSUFICIENCIA RESPIRATORIA AGUDA & 12 & 1,53 & 14 & 1,37 & 15 & 1,30 & 11 & 1,81 & 13 & 1,75 \\
\hline 32020015 & IMPLANTE DE PROTESE VALVULAR & 13 & 1,52 & 13 & 1,71 & 19 & 1,01 & 13 & 1,66 & 11 & 1,90 \\
\hline 38025019 & PERDA SUBST CUTANEA-LESOES EXTENSAS PLANOS SUPER. & 14 & 1,52 & 10 & 2,36 & 12 & 1,75 & 21 & 0,83 & 22 & 0,85 \\
\hline 35025018 & PARTO NORMAL - EXCLUSPI HOSPITAIS AMIGOS DA CRIANCA & 15 & 1,39 & 48 & 0,07 & 13 & 1,73 & 10 & 1,95 & 10 & 1,99 \\
\hline 32021011 & CORRECAO DE CARDIOPATIA CONGENITA & 16 & 1,27 & 17 & 0,85 & 17 & 1,15 & 15 & 1,44 & 12 & 1,83 \\
\hline 71300015 & PREMATURIDADE & 17 & 1,20 & 19 & 0,85 & 16 & 1,29 & 17 & 1,25 & 16 & 1,45 \\
\hline 35026014 & CESARIANA - EXCLUSIV PI HOSPITAIS AMIGOS DA CRIANCA & 18 & 1,13 & 49 & 0,05 & 14 & 1,54 & 16 & 1,40 & 14 & 1,62 \\
\hline 76500225 & DOENCA PULMONAR OBSTRUTIVA CRONICA & 19 & 0,97 & 18 & 0,85 & 18 & 1,03 & 22 & 0,82 & 19 & 1,18 \\
\hline 74300261 & SEPTICEMIAS (PEDIATRIA) & 20 & 0.93 & 22 & 0,70 & 21 & 0,97 & 19 & 0,85 & 17 & 1,24 \\
\hline 33011117 & HERNIORRAFIA INGUINAL(UNILATERAL) & 21 & 0,80 & 16 & 0,90 & 24 & 0,79 & 23 & 0.75 & 27 & 0,74 \\
\hline 76500071 & BRONCOPNEUMONIA & 22 & 0,79 & 23 & 0,69 & 20 & 0,99 & 27 & 0,63 & 26 & 0,80 \\
\hline 75500124 & HEMORRAGIAS DIGESTIVAS & 23 & 0,77 & 15 & 0,98 & 22 & 0,90 & 32 & 0.54 & 34 & 0.58 \\
\hline 76300080 & BRONCOPNEUMONIA & 24 & 0.72 & 32 & 0.48 & 45 & 0.35 & 18 & 1,08 & 18 & 1,20 \\
\hline 77500024 & INFARTO AGUDO DO MIOCARDIO & 25 & 0.71 & 21 & 0.76 & 26 & 0.71 & 26 & 0.66 & 30 & 0,71 \\
\hline
\end{tabular}




\begin{tabular}{|c|c|c|c|c|c|c|c|c|c|c|c|}
\hline \multirow[b]{3}{*}{ Codigo } & \multirow[b]{2}{*}{ Procedimentos } & \multirow{2}{*}{\multicolumn{2}{|c|}{ Total }} & \multirow{2}{*}{\multicolumn{2}{|c|}{$\begin{array}{l}\text { Antes } \\
1^{\circ} \text { ano }\end{array}$}} & \multicolumn{6}{|c|}{ Depois } \\
\hline & & & & & & \multicolumn{2}{|c|}{$1^{\circ}$ ano } & \multicolumn{2}{|c|}{$2^{\circ}$ ano } & \multicolumn{2}{|c|}{$3^{\circ}$ ano } \\
\hline & Descriçato & Pos & $\%$ & Pos & $\%$ & Pos & $\%$ & Pos & $\%$ & Pos & $\%$ \\
\hline 82500053 & DIABETE SACARINO & 26 & 0.69 & 24 & 0,66 & 25 & 0,74 & 28 & 0,62 & 28 & 0,73 \\
\hline 33004080 & COLECISTECTOMIA & 27 & 0,65 & 27 & 0,54 & 28 & 0,63 & 25 & 0,68 & 24 & 0,81 \\
\hline 42008069 & TORACOTOMIA COM DRENAGEM FECHADA & 28 & 0,62 & 31 & 0.49 & 37 & 0,46 & 20 & 0,85 & 25 & 0,81 \\
\hline 74500244 & SEPTICEMIAS (CLINICA MEDICA) & 29 & 0,62 & 26 & 0,59 & 23 & 0,88 & 41 & 0,41 & 38 & 0,50 \\
\hline 33016119 & LAPAROTOMIA EXPLORADORA & 30 & 0,55 & 30 & 0.49 & 38 & 0.42 & 31 & 0,55 & 21 & 0,85 \\
\hline 76400085 & BRONCOPNEUMONIA EM LACTENTE & 31 & 0,55 & 36 & 0,46 & 29 & 0,61 & 29 & 0,61 & 35 & 0,52 \\
\hline 35014016 & CURETAGEM POS-ABORTO & 32 & 0,55 & 34 & 0.47 & 35 & 0.47 & 30 & 0.58 & 29 & 0,73 \\
\hline 76300102 & CRISE ASMATICA & 33 & 0,52 & 46 & 0.32 & 50 & 0.16 & 24 & 0,73 & 20 & 1,08 \\
\hline 74300113 & MENINGITES PURULENTAS (PEDIATRIA) & 34 & 0,50 & 20 & 0,79 & 30 & 0,55 & 44 & 0,34 & 48 & 0,21 \\
\hline 77500032 & INSUFICIENCIA CORONARIANA AGUDA & 35 & 0.49 & 29 & 0.49 & 31 & 0,53 & 36 & 0,47 & 43 & 0,44 \\
\hline 38007142 & GRANDE QUEIMADO & 36 & 0,48 & 38 & 0.45 & 33 & 0,49 & 34 & 0.52 & 40 & 0.47 \\
\hline 80500170 & INSUFICIENCIA RENAL CRONICA AACIDOSE METABOLICA & 37 & 0,48 & 35 & 0.46 & 44 & 0,36 & 33 & 0,53 & 32 & 0,62 \\
\hline 77500164 & EDEMA AGUDO DE PULMAO & 38 & 0,46 & 25 & 0,60 & 27 & 0,63 & 45 & 0,31 & 47 & 0,21 \\
\hline 77500202 & VASCULOPATIAS PERIFERICAS & 39 & 0,46 & 41 & 0,42 & 34 & 0,48 & 38 & 0,45 & 39 & 0,48 \\
\hline 75500213 & CIRROSE HEPATICA & 40 & 0,44 & 33 & 0.47 & 32 & 0,53 & 39 & 0,41 & 45 & 0,31 \\
\hline 76500063 & PNEUMONIA NAO ESPECIFICADA & 41 & 0,42 & 42 & 0,37 & 36 & 0.46 & 43 & 0,37 & 41 & 0,47 \\
\hline 76500055 & PNEUMONIA ESTAFILOCOCICA & 42 & 0,40 & 45 & 0,34 & 46 & 0,34 & 35 & 0,48 & 37 & 0.50 \\
\hline 39003124 & ARTROPLASTIA COXO-FEMURAL & 43 & 0.40 & 43 & 0,36 & 42 & 0,38 & 42 & 0,37 & 36 & 0.51 \\
\hline 38003147 & MEDIO QUEIMADO & 44 & 0,38 & 44 & 0,35 & 47 & 0,33 & 40 & 0,41 & 42 & 0,44 \\
\hline 91500141 & COMPLICACOES DE PROCED. CIRURGICOS OU MEDICOS & 45 & 0,37 & 40 & 0,43 & 41 & 0,38 & 47 & 0,27 & 44 & 0,39 \\
\hline 75500132 & PERITONITE & 46 & 0,35 & 39 & 0.44 & 40 & 0,38 & 49 & 0,25 & 46 & 0,30 \\
\hline 39016129 & ARTROPLASTIA COXO-FEMURAL COM PROTESE NAO CIMENTADA & 47 & 0,33 & 50 & 0,00 & 48 & 0,27 & 37 & 0,47 & 31 & 0,67 \\
\hline 74300270 & ENTERO-INFECCOES (PEDIATRIA) & 48 & 0,32 & 37 & 0.45 & 43 & 0.37 & 46 & 0,28 & 50 & 0,13 \\
\hline 73500011 & DESNUTRICAO (CLINICA MEDICA) & 49 & 0,32 & 47 & 0,27 & 49 & 0,23 & 48 & 0,25 & 33 & 0,59 \\
\hline 39012131 & REDUCAO CIRURGICA DE FRATURA DO COLO DO FEMUR & 50 & 0,31 & 28 & 0,49 & 39 & 0,39 & 50 & 0,11 & 49 & 0,18 \\
\hline & Sub-Tot & & 70,89 & & 73,28 & & 71,65 & & 69,44 & & 68,23 \\
\hline & Outro & & 29,11 & & 26,72 & & 28,35 & & 30,56 & & 31,77 \\
\hline & & & 100,00 & & 100,00 & & 100,00 & & 100,00 & & 100,00 \\
\hline
\end{tabular}


Quadro 70 - Distribuição percentual dos gastos com internações SUS pelos 50 procedimentos mais freqüentes, ocorridos no município de São Bernardo do Campo - SP, antes e depois da implantação da gestão semi-plena.

\begin{tabular}{|c|c|c|c|c|c|c|c|c|c|c|c|}
\hline \multirow{2}{*}{\multicolumn{2}{|c|}{ Procedimentos }} & \multirow{2}{*}{\multicolumn{2}{|c|}{ Total }} & \multirow{2}{*}{\multicolumn{2}{|c|}{$\begin{array}{l}\text { Antes } \\
1^{\circ} \text { ano }\end{array}$}} & \multicolumn{6}{|c|}{ Depois } \\
\hline & & & & & & \multicolumn{2}{|c|}{$1^{\circ}$ ano } & \multicolumn{2}{|c|}{20 ano } & \multicolumn{2}{|c|}{$3^{\circ}$ ano } \\
\hline Codigo & Descriçăo & Pos. & $\%$ & Pos. & $\%$ & Pos. & $\%$ & Pos. & $\%$ & Pos. & $\%$ \\
\hline 39009130 & REDUCAO CIRURGICA DE FRATURA DA DIAFISE DO FEMUR, & 1 & 7,99 & 7 & 2,11 & 1 & 9,64 & 1 & 11,09 & 1 & 6,20 \\
\hline 39011151 & REDUCAO CIRURGICA DA DIAFISE DA TIBIA, COM FIXACAO & 2 & 4,83 & 23 & 0,85 & 2 & 5,55 & 2 & 6.91 & 3 & 3.99 \\
\hline 39003124 & ARTROPLASTIA COXO-FEMURAL & 3 & 3,63 & 38 & 0.22 & 4 & 2,71 & 3 & 4,62 & 2 & 5.09 \\
\hline 31003052 & PROSTATECTOMIA & 4 & 2.91 & 8 & 2,06 & 5 & 2,48 & 4 & 3.30 & 4 & 3,34 \\
\hline 31000002 & CIRURGIA MULTIPLA & 5 & 2,44 & 11 & 1,85 & 10 & 1,84 & 5 & 2.57 & 5 & 3.13 \\
\hline 33004080 & COLECISTECTOMIA & 6 & 2,23 & 3 & 3,32 & 9 & 2,20 & 8 & 1,74 & 7 & 2,23 \\
\hline 39013081 & REDUC. CIR. FRAT. DOS OSSOS DO ANTE-BRACO COM FIXA & 7 & 1.89 & 41 & 0,15 & 6 & 2,38 & 6 & 2.43 & 9 & 1,71 \\
\hline 36005045 & FACECTOMIA COM LENTE INTRA-OCULAR & 8 & 1,81 & 19 & 1,10 & 7 & 2,31 & 9 & 1,46 & 8 & 2.01 \\
\hline 38022010 & EXCISAO E ENXERTO DE PELE(HEMANGIOMA NEVUS OU TUMO & 9 & 1,63 & 2 & 3,74 & 13 & 1,38 & 10 & 1,46 & 16 & 1,04 \\
\hline 33011117 & HERNIORRAFIA INGUINAL(UNILATERAL) & 10 & 1,45 & 5 & 2,56 & 11 & 1,73 & 12 & 1,28 & 26 & 0,83 \\
\hline 39011160 & REDUCAO CIRURGICA DAS FRATURAS DO TORNOZELO COM F & 11 & 1,42 & 36 & 0,35 & 8 & 2,22 & 7 & 1,83 & 27 & 0,80 \\
\hline 80500170 & INSUFICIENCIA RENAL CRONICA AACIDOSE METABOLICA & 12 & 1.41 & 9 & 2,00 & 15 & 1,11 & 15 & 1,19 & 10 & 1,64 \\
\hline 76400085 & BRONCOPNEUMONIA EM LACTENTE & 13 & 1.29 & 1 & 4,54 & 12 & 1,43 & 43 & 0,44 & 40 & 0,47 \\
\hline 33016119 & LAPAROTOMIA EXPLORADORA & 14 & 1,25 & 12 & 1,73 & 14 & 1,37 & 14 & 1,19 & 21 & 0,97 \\
\hline 39015130 & TRATAMENTO CIRURGICO DE OSTEOMIELITE DO FEMUR & 15 & 1,22 & 49 & 0,00 & 36 & 0,48 & 17 & 1,13 & 6 & 2,55 \\
\hline 76300102 & CRISE ASMATICA & 16 & 1.07 & 10 & 1.98 & 26 & 0,69 & 26 & 0,68 & 11 & 1,37 \\
\hline 32019041 & BYPASS OU TROMBOENDARTERECTOMIA FEMURO-POPLITEIA & 17 & 1,02 & 21 & 0,91 & 17 & 0,89 & 16 & 1,14 & 15 & 1,08 \\
\hline 39009068 & REDUCAO CIRURGICA DE FRATURAS DE DIAFASE DO UMERO. & 18 & 0,89 & 45 & 0,12 & 18 & 0,81 & 11 & 1,32 & 24 & 0,92 \\
\hline 76300080 & BRONCOPNEUMONIA & 19 & 0,87 & 16 & 1,35 & 25 & 0,69 & 34 & 0,54 & 14 & 1,14 \\
\hline 33005044 & ESOFAGOGASTRECTOMIA & 20 & 0,87 & 17 & 1,29 & 23 & 0.70 & 21 & 0.77 & 22 & 0.93 \\
\hline 39016129 & ARTROPLASTIA COXO-FEMURAL $C$ PROTESE NAO CIMENTADA & 21 & 0,81 & 50 & 0,00 & 3 & 2,97 & 50 & 0,00 & 50 & 0,00 \\
\hline 72500000 & DIAGNOSTICO E/OU $1^{\circ}$ ATENDIMENTO EM CLINICA MEDICA & 22 & 0,80 & 46 & 0,08 & 46 & 0,26 & 13 & 1,20 & 13 & 1,22 \\
\hline 33006067 & COLECTOMIA PARCIAL(HEMICOLECTOMIA) & 23 & 0,80 & 14 & 1,57 & 27 & 0,67 & 23 & 0,72 & 31 & 0,62 \\
\hline 75500124 & HEMORRAGIAS DIGESTIVAS & 24 & 0,79 & 15 & 1,52 & 24 & 0,69 & 27 & 0,65 & 30 & 0,68 \\
\hline 77500113 & INSUFICIENCIA CARDIACA & 25 & 0,77 & 18 & 1,14 & 35 & 0,50 & 29 & 0,61 & 20 & 0,99 \\
\hline 33024065 & LIBERACAO DE ADERENCIAS INTESTINAIS & 26 & 0,67 & 4 & 2,79 & 32 & 0,53 & 48 & 0,24 & 48 & 0,23 \\
\hline 33005052 & GASTRECTOMIA TOTAL & 27 & 0,67 & 27 & 0,76 & 34 & 0,51 & 20 & 0,91 & 36 & 0,54 \\
\hline 76500071 & BRONCOPNEUMONIA & 28 & 0,66 & 20 & 1,00 & 43 & 0,36 & 42 & 0,44 & 19 & 0,99 \\
\hline
\end{tabular}


Quadro 70 - Continuação

\begin{tabular}{|c|c|c|c|c|c|c|c|c|c|c|c|}
\hline \multirow{2}{*}{\multicolumn{2}{|c|}{ Procedimentos }} & \multirow{2}{*}{\multicolumn{2}{|c|}{ Total }} & \multirow{2}{*}{\multicolumn{2}{|c|}{$\begin{array}{l}\text { Antes } \\
1^{\circ} \text { ano }\end{array}$}} & \multicolumn{6}{|c|}{ Depois } \\
\hline & & & & & & \multicolumn{2}{|c|}{$1^{\circ}$ ano } & \multicolumn{2}{|c|}{$2^{\circ}$ ano } & \multicolumn{2}{|c|}{$3^{\circ}$ ano } \\
\hline Código & Descriçăo & Pos. & $\%$ & Pos. & $\%$ & Pos. & $\%$ & Pos. & $\%$ & Pos. & $\%$ \\
\hline 76500233 & INSUFICIENCIA RESPIRATORIA AGUDA & 29 & 0,66 & 13 & 1,70 & 41 & 0,39 & 45 & 0,34 & 29 & 0,75 \\
\hline 39004139 & AMPUTACAO DA COXA & 30 & 0,64 & 40 & 0,16 & 21 & 0,74 & 41 & 0.47 & 23 & 0,93 \\
\hline 33004056 & GASTRECTOMIA SUBTOTAL COM OU SEM VAGOTOMIA & 31 & 0,62 & 22 & 0,86 & 16 & 0,96 & 33 & 0.56 & 46 & 0.27 \\
\hline 36001112 & CORRECAO CIRUGICA DO ESTRABISMO & 32 & 0.62 & 29 & 0.51 & 30 & 0,63 & 25 & 0.68 & 33 & 0,61 \\
\hline 34010033 & HISTERECTOMIA TOTAL & 33 & 0.62 & 31 & 0,46 & 19 & 0,80 & 35 & 0,53 & 32 & 0,61 \\
\hline 34017038 & HISTERECTOMIA C/ANEXETOMIA UNI OU BILATERAL & 34 & 0,61 & 24 & 0,84 & 42 & 0,37 & 38 & 0,50 & 25 & 0,84 \\
\hline 40007049 & NEUROLISE & 35 & 0,59 & 48 & 0,03 & 47 & 0,22 & 22 & 0,75 & 17 & 1.02 \\
\hline 80500218 & OUTRAS AFECCOES DO AP. GENITO-URINARIO & 36 & 0.59 & 33 & 0,45 & 33 & 0,52 & 24 & 0,70 & 34 & 0,60 \\
\hline 42005078 & MASTECTOMIA RADICAL COM LINFADENECTOMIA & 37 & 0,58 & 32 & 0,45 & 20 & 0,77 & 36 & 0,52 & 37 & 0,53 \\
\hline 39014150 & TRATAMENTO CIRURGICO DA OSTEOMIELITE DOS OSSOS DA & 38 & 0.57 & 44 & 0.12 & 50 & 0,15 & 37 & 0,50 & 12 & 1,24 \\
\hline 39013073 & REDUC CIR. FRAT DOS OSSOS DO COTOVELO COM FIXACA & 39 & 0,56 & 47 & 0,08 & 22 & 0,72 & 19 & 0,91 & 45 & 0,28 \\
\hline 43000002 & DIAGNOSTICO EIOU $1^{\circ}$ ATENDIMENTO EM CLINICA CIRURGICA & 40 & 0,55 & 25 & 0,83 & 28 & 0,65 & 40 & 0.48 & 43 & 0,40 \\
\hline 34005030 & CURETAGEM SEMIOTICA COM OU SEM DILATACAO DE COLO & 41 & 0,54 & 6 & 2,43 & 38 & 0.46 & 49 & 0,20 & 49 & 0,08 \\
\hline 77500024 & INFARTO AGUDO DO MIOCARDIO & 42 & 0,53 & 26 & 0,80 & 49 & 0,17 & 47 & 0,27 & 18 & 1,00 \\
\hline 31023037 & RESSECCAO ENDOSCOPICA DE TUMOR & 43 & 0.52 & 34 & 0.43 & 40 & 0.44 & 32 & 0,57 & 35 & 0.58 \\
\hline 39003159 & AMPUTACAO DA PERNA & 44 & 0,50 & 35 & 0,42 & 29 & 0,63 & 44 & 0,40 & 38 & 0,51 \\
\hline 38003139 & PLASTICA MAMARIA FEMININA NAO ESTETICA & 45 & 0,50 & 39 & 0.19 & 45 & 0,28 & 30 & 0,59 & 28 & 0.75 \\
\hline 32017049 & BYPASS OU TROMBOENDARTERECTOMIA AORTO-ILIACA & 46 & 0.46 & 42 & 0.15 & 48 & 0,18 & 18 & 0.98 & 44 & 0.34 \\
\hline 34001042 & SALPINGECTOMIA UNI OU BILATERAL & 47 & 0,45 & 43 & 0,13 & 31 & 0,56 & 39 & 0.48 & 39 & 0,48 \\
\hline 36001104 & RETINOPEXIA PRIMARIA & 48 & 0,44 & 37 & 0,25 & 44 & 0,33 & 28 & 0,65 & 42 & 0,44 \\
\hline 33001081 & ANASTOMOSE BILEO-DIGESTIVA & 49 & 0,44 & 28 & 0,68 & 37 & 0,46 & 46 & 0,29 & 41 & 0,45 \\
\hline 42004071 & MASTECTOMIA SIMPLES & 50 & 0,43 & 30 & 0.50 & 39 & 0.45 & 31 & 0.58 & 47 & 0.26 \\
\hline & Sub-Total & & 60,11 & & 53,55 & & 59,99 & & 63,78 & & 59,67 \\
\hline & & & $\begin{array}{r}39,89 \\
100,0\end{array}$ & & 46,45 & & 40,01 & & 36,22 & & 40,33 \\
\hline & & & 0 & & 100,00 & & 100,00 & & 100,00 & & 100,00 \\
\hline
\end{tabular}


Quadro 71 - Distribuição percentual dos gastos com internações SUS pelos 50 procedimentos mais freqüentes, ocorridos no municipio de Sertãozinho - SP, antes e depois da implantação da gestão semi-plena.

\begin{tabular}{|c|c|c|c|c|c|c|c|c|c|c|c|}
\hline \multirow{2}{*}{\multicolumn{2}{|c|}{ Procedimentos }} & \multirow{2}{*}{\multicolumn{2}{|c|}{ Total }} & \multirow{2}{*}{\multicolumn{2}{|c|}{$\begin{array}{l}\text { Antes } \\
1^{\circ} \text { ano }\end{array}$}} & \multicolumn{6}{|c|}{ Depois } \\
\hline & & & & & & \multicolumn{2}{|c|}{$1^{\circ}$ ano } & \multicolumn{2}{|c|}{$2 \bullet$ ano } & \multicolumn{2}{|c|}{$3^{\circ}$ ano } \\
\hline Código & Descriçăo & Pos. & $\%$ & Pos. & $\%$ & Pos. & $\%$ & Pos. & $\%$ & Pos. & $\%$ \\
\hline 35022019 & CESARIANA COM ATENDIMENTO RN SALA DE PARTO & 1 & 14,07 & 1 & 13,49 & 1 & 13,62 & 1 & 14,49 & 1 & 15,02 \\
\hline 35021012 & PARTO NORMAL COM ATENDIMENTO RN SALA DE PARTO & 2 & 7,58 & 2 & 6.01 & 2 & 8.26 & 2 & 8.43 & 2 & 8.13 \\
\hline 77500113 & INSUFICIENCIA CARDIACA & 3 & 4,88 & 3 & 5,87 & 3 & 5,77 & 4 & 3,80 & 3 & 3,50 \\
\hline 32019041 & BYPASS OU TROMBOENDARTERECTOMIA FEMURO-POPLITEIA & 4 & 3,88 & 8 & 2,00 & 4 & 5,02 & 3 & 6,76 & 6 & 2.14 \\
\hline 76500225 & DOENCA PULMONAR OBSTRUTIVA CRONICA & 5 & 2,84 & 4 & 3,62 & 5 & 3.20 & 5 & 2,32 & 10 & 1,80 \\
\hline 76500063 & PNEUMONIA NAO ESPECIFICADA & 6 & 2,55 & 5 & 3,39 & 7 & 2,23 & 6 & 2,18 & 7 & 2,12 \\
\hline 76400077 & PNEUMONIAS DO LACTENTE & 7 & 2,24 & 9 & 1.92 & 6 & 2,40 & 7 & 1.99 & 4 & 2,76 \\
\hline 39000001 & POLITRAUMATIZADO & 8 & 1,68 & 7 & 2,09 & 15 & 1.26 & 23 & 0,99 & 5 & 2.34 \\
\hline 33005060 & APENDICECTOMIA & 9 & 1,62 & 12 & 1,76 & 9 & 1,82 & 22 & 1,10 & 11 & 1.75 \\
\hline 71300015 & PREMATURIDADE & 10 & 1,62 & 22 & 1.17 & 8 & 1,91 & 13 & 1,54 & 9 & 2.00 \\
\hline 81500106 & AVC AGUDO & 11 & 1,61 & 10 & 1,90 & 10 & 1,75 & 19 & 1,18 & 17 & 1,45 \\
\hline 34010033 & HISTERECTOMIA TOTAL & 12 & 1,54 & 14 & 1,42 & 11 & 1,60 & 9 & 1.70 & 15 & 1,49 \\
\hline 35014016 & CURETAGEM POS-ABORTO & 13 & 1,47 & 13 & 1,45 & 12 & 1.49 & 12 & 1,60 & 19 & 1,31 \\
\hline 76400085 & BRONCOPNEUMONIA EM LACTENTE & 14 & 1,46 & 16 & 1,32 & 13 & 1,36 & 10 & 1,67 & 13 & 1.55 \\
\hline 39012131 & REDUCAO CIRURGICA DE FRATURA DO COLO DO FEMUR & 15 & 1,39 & 31 & 0,81 & 17 & 1,25 & 8 & 1,71 & 8 & 2,08 \\
\hline 76300072 & OUTRAS PNEUMONIAS & 16 & 1,38 & 11 & 1,86 & 24 & 1.03 & 14 & 1,40 & 22 & 1,08 \\
\hline 33011117 & HERNIORRAFIA INGUINAL(UNILATERAL) & 17 & 1,35 & 19 & 1,20 & 16 & 1,25 & 15 & 1,35 & 12 & 1.71 \\
\hline 35001011 & PARTO NORMAL & 18 & 1,21 & 6 & 3,21 & 27 & 0,87 & 50 & 0,00 & 50 & 0,00 \\
\hline 75500124 & HEMORRAGIAS DIGESTIVAS & 19 & 1,18 & 17 & 1,23 & 19 & 1,19 & 17 & 1,21 & 23 & 1.08 \\
\hline 76400271 & ENTERO-INFECCOES EM LACTENTE & 20 & 1,16 & 25 & 1,03 & 22 & 1,12 & 18 & 1,20 & 18 & 1,37 \\
\hline 33004080 & COLECISTECTOMIA & 21 & 1,13 & 29 & 0,94 & 18 & 1,22 & 16 & 1,25 & 21 & 1,16 \\
\hline 77500202 & VASCULOPATIAS PERIFERICAS & 22 & 1,11 & 45 & 0,38 & 20 & 1,15 & 11 & 1,65 & 14 & 1,54 \\
\hline 34008020 & COLPOPERINEOPLASTIA ANTERIOR E POSTERIOR & 23 & 1,08 & 24 & 1,03 & 14 & 1.26 & 21 & 1,14 & 27 & 0,86 \\
\hline 76500047 & PNEUMONIA BACTERIANA & 24 & 0,93 & 27 & 0,97 & 32 & 0,72 & 24 & 0,88 & 20 & 1,19 \\
\hline 91500125 & LESOES SUPERFICIAIS INFECTADAS & 25 & 0,89 & 26 & 1,00 & 26 & 1,01 & 26 & 0,78 & 30 & 0,67 \\
\hline 39013138 & REDUCAO CIRURGICA DE FRATURA TRANSTROCANTERIANA & 26 & 0,86 & 20 & 1.18 & 35 & 0,62 & 36 & 0.53 & 24 & 1,05 \\
\hline 74500252 & ENTERO-INFECCOES (CLINICA MEDICA) & 27 & 0,83 & 28 & 0,96 & 21 & 1.14 & 28 & 0,72 & 40 & 0.38 \\
\hline
\end{tabular}


Quadro 71 - Continuação

\begin{tabular}{|c|c|c|c|c|c|c|c|c|c|c|c|}
\hline \multirow{2}{*}{\multicolumn{2}{|c|}{ Procedimentos }} & \multirow{2}{*}{\multicolumn{2}{|c|}{ Total }} & \multirow{2}{*}{\multicolumn{2}{|c|}{$\begin{array}{l}\text { Antes } \\
1^{\circ} \text { ano }\end{array}$}} & \multicolumn{6}{|c|}{ Depois } \\
\hline & & & & & & \multicolumn{2}{|c|}{$1^{\circ}$ ano } & \multicolumn{2}{|c|}{$2^{\circ}$ ano } & \multicolumn{2}{|c|}{$3^{\circ}$ ano } \\
\hline Codigo & Descriçăo & Pos. & $\%$ & Pos. & $\%$ & Pos. & $\%$ & Pos. & $\%$ & Pos. & $\%$ \\
\hline 74300270 & ENTERO-INFECCOES (PEDIATRIA) & 28 & 0,83 & 23 & 1.09 & 23 & 1,07 & 33 & 0,59 & 39 & 0,42 \\
\hline 80500072 & PIELONEFRITES & 29 & 0.89 & 30 & 0.92 & 29 & 0,85 & 27 & 0.75 & 29 & 0,68 \\
\hline 39011151 & REDUCAO CIRURGICA DA DIAFISE DA TIBIA, COM FIXACAO & 30 & 0.81 & 50 & 0.07 & 28 & 0,86 & 20 & 1.15 & 16 & 1,47 \\
\hline 39009130 & REDUCAO CIRURGICA DE FRATURA DA DIAFISE DO FEMUR, & 31 & 0,80 & 38 & 0,58 & 25 & 1,02 & 29 & 0,67 & 25 & 1.00 \\
\hline 76300102 & CRISE ASMATICA & 32 & 0.75 & 15 & 1.40 & 42 & 0.45 & 37 & 0,50 & 37 & 0.45 \\
\hline 83500022 & LUMBAGO AGUDO & 33 & 0.75 & 18 & 1,22 & 36 & 0,57 & 42 & 0.43 & 32 & 0,63 \\
\hline 82500053 & DIABETE SACARINO & 34 & 0,71 & 32 & 0.77 & 30 & 0,84 & 35 & 0,53 & 31 & 0.64 \\
\hline 69000204 & TRABALHO DE PARTO PREMATURO & 35 & 0,67 & 33 & 0,77 & 31 & 0,76 & 34 & 0.57 & 33 & 0.53 \\
\hline 39012190 & TENORRAFIA & 36 & 0,63 & 36 & 0,70 & 41 & 0,46 & 40 & 0,47 & 26 & 0,92 \\
\hline 75500213 & CIRROSE HEPATICA & 37 & 0,62 & 35 & 0.71 & 33 & 0,72 & 32 & 0.61 & 41 & 0,38 \\
\hline 73500011 & DESNUTRICAO (CLINICA MEDICA) & 38 & 0.59 & 21 & 1,17 & 37 & 0,52 & 48 & 0.22 & 49 & 0,22 \\
\hline 31000002 & CIRURGIA MULTIPLA & 39 & 0,52 & 47 & 0,21 & 43 & 0,42 & 25 & 0,83 & 28 & 0,78 \\
\hline 33006067 & COLECTOMIA PARCIAL(HEMICOLECTOMIA) & 40 & 0,51 & 34 & 0,71 & 47 & 0,34 & 39 & 0,48 & 35 & 0,48 \\
\hline 75500272 & COLICISTITE AGUDA & 41 & 0,44 & 41 & 0,46 & 38 & 0,51 & 44 & 0,39 & 43 & 0,37 \\
\hline 77500121 & CRISE HIPERTENSIVA & 42 & 0.44 & 39 & 0,49 & 34 & 0,69 & 47 & 0,25 & 47 & 0,23 \\
\hline 76300080 & BRONCOPNEUMONIA & 43 & 0,42 & 42 & 0,46 & 49 & 0,32 & 38 & 0,48 & 38 & 0,43 \\
\hline 75500159 & LINFADENITE AGUDA MESENTERICA & 44 & 0,42 & 40 & 0,46 & 45 & 0,37 & 41 & 0,46 & 42 & 0,37 \\
\hline 76500128 & CRISE ASMATICA & 45 & 0.42 & 37 & 0,64 & 40 & 0,49 & 49 & 0,21 & 48 & 0,22 \\
\hline 77500164 & EDEMA AGUDO DE PULMAO & 46 & 0,40 & 46 & 0,22 & 46 & 0,35 & 30 & 0,65 & 36 & 0,46 \\
\hline 34005030 & CURETAGEM SEMIOTICA COM OU SEM DILATACAO DE COLO & 47 & 0,39 & 43 & 0,44 & 48 & 0,34 & 43 & 0,42 & 45 & 0,36 \\
\hline 39013081 & REDUC. CIR. FRAT. DOS OSSOS DO ANTE-BRACO COM FIXA & 48 & 0,36 & 49 & 0,09 & 39 & 0,50 & 31 & 0,64 & 46 & 0.26 \\
\hline 39003159 & AMPUTACAO DA PERNA & 49 & 0,35 & 48 & 0,21 & 44 & 0,41 & 46 & 0,35 & 34 & 0,50 \\
\hline 38004011 & ENXERTO LIVRE DE PELE TOTAL & 50 & 0,35 & 44 & 0,38 & 50 & 0.26 & 45 & 0.37 & 44 & 0,37 \\
\hline & Sub-Total & & 76,51 & & 77,36 & & 78,58 & & 75,59 & & 73,70 \\
\hline & Outros & & 23,49 & & 22,64 & & 21,42 & & 24,41 & & 26,30 \\
\hline & Total & & 100,00 & & 100,00 & & 100,00 & & 100,00 & & 100,00 \\
\hline
\end{tabular}


Quadro 72 - Distribuição percentual dos gastos com internações SUS pelos 50 procedimentos mais freqüentes, ocorridos no município de São José dos Campos - SP, antes e depois da implantação da gestão semi-plena.

\begin{tabular}{|c|c|c|c|c|c|c|c|c|c|c|c|}
\hline \multirow{2}{*}{\multicolumn{2}{|c|}{ Procedimentos }} & \multirow{2}{*}{\multicolumn{2}{|c|}{ Total }} & \multirow{2}{*}{\multicolumn{2}{|c|}{$\begin{array}{l}\text { Antes } \\
1^{\circ} \text { ano }\end{array}$}} & \multicolumn{6}{|c|}{ Depois } \\
\hline & & & & & & \multicolumn{2}{|c|}{$1^{\circ}$ ano } & \multicolumn{2}{|c|}{$2^{\circ}$ ano } & \multicolumn{2}{|c|}{$3^{\circ}$ ano } \\
\hline Codigo & Descriçăo & Pos. & $\%$ & Pos & $\%$ & Pos. & $\%$ & Pos. & $\%$ & Pos. & $\%$ \\
\hline 3502201 & CESARIANA COM ATENDIMENTO RN SALA DE PARTO & 1 & 8,97 & 1 & 8,02 & 1 & 9,69 & 1 & 9,76 & 1 & 8,26 \\
\hline 3502101 & PARTO NORMAL COM ATENDIMENTO RN SALA DE PARTO & 2 & 7,54 & 2 & 5,64 & 2 & 8,24 & 2 & 8.07 & 2 & 8,03 \\
\hline 3201101 & CIRURGIA DE CORONARIA COM EXTRA-CORPOREA & 3 & 4,07 & 5 & 2,87 & 6 & 2,77 & 3 & 4,26 & 3 & 6,47 \\
\hline 7750011 & INSUFICIENCIA CARDIACA & 4 & 3,58 & 3 & 4,45 & 3 & 3,71 & 6 & 3,05 & 7 & 3,14 \\
\hline 3202001 & MPPLANTE DE PROTESE VALVULAR & 5 & 3,17 & 12 & 1,90 & 4 & 3.20 & 4 & 3,92 & 4 & 3,60 \\
\hline 3201501 & MARCA-PASSO CARDIACO(INTRACAVITARIO) & 6 & 2,93 & 6 & 2,80 & 5 & 2,77 & 7 & 2,69 & 5 & 3,49 \\
\hline 3900000 & POLITRAUMATIZADO & 7 & 2,54 & 9 & 2,19 & 11 & 1,86 & 5 & 3,38 & 8 & 2,77 \\
\hline 7130001 & PREMATURIDADE & 8 & 2,21 & 19 & 1,05 & 9 & 1,92 & 8 & 2,47 & 6 & 3,36 \\
\hline 8150010 & AVC AGUDO & 9 & 1,86 & 11 & 1,94 & 10 & 1,89 & 12 & 1,71 & 9 & 1,88 \\
\hline 7640008 & BRONCOPNEUMONIA EM LACTENTE & 10 & 1,84 & 10 & 2,19 & 7 & 2,17 & 10 & 2.02 & 15 & 0.94 \\
\hline 7750002 & INFARTO AGUDO DO MIOCARDIO & 11 & 1,68 & 15 & 1,62 & 8 & 2,00 & 11 & 1.74 & 11 & 1,31 \\
\hline 7630010 & CRISE ASMATICA & 12 & 1,57 & 18 & 1,22 & 14 & 1,42 & 9 & 2,07 & 10 & 1.54 \\
\hline 3100000 & CIRURGIA MULTIPLA & 13 & 1,56 & 8 & 2.22 & 12 & 1,72 & 13 & 1,49 & 19 & 0,83 \\
\hline 3202101 & CORRECAO DE CARDIOPATIA CONGENITA & 14 & 1,41 & 7 & 2,40 & 18 & 1,13 & 15 & 1,31 & 16 & 0,90 \\
\hline 7000000 & TRATAMENTO DA AIDS & 15 & 1,23 & 13 & 1,68 & 13 & 1,53 & 18 & 1.08 & 31 & 0,60 \\
\hline 7650022 & DOENCA PULMONAR OBSTRUTIVA CRONICA & 16 & 1.21 & 17 & 1,38 & 17 & 1,18 & 17 & 1,20 & 12 & 1,07 \\
\hline 3300408 & COLECISTECTOMIA & 17 & 1,19 & 16 & 1,48 & 16 & 1,18 & 14 & 1,45 & 25 & 0,65 \\
\hline 3301111 & HERNIORRAFIA INGUINAL(UNILATERAL) & 18 & 1.12 & 22 & 0.97 & 15 & 1,31 & 16 & 1,30 & 17 & 0,85 \\
\hline 3500101 & PARTO NORMAL & 19 & 1,01 & 4 & 3,19 & 35 & 0,44 & 48 & 0,34 & 48 & 0,24 \\
\hline 7640007 & PNEUMONIAS DO LACTENTE & 20 & 0,86 & 28 & 0,78 & 20 & 0,96 & 20 & 0,88 & 20 & 0,81 \\
\hline 3300506 & APENDICECTOMIA & 21 & 0,86 & 27 & 0,79 & 24 & 0,73 & 19 & 0,90 & 14 & 1.01 \\
\hline 8250005 & DIABETE SACARINO & 22 & 0,79 & 26 & 0,81 & 19 & 0,99 & 23 & 0,70 & 28 & 0,63 \\
\hline 7650004 & PNEUMONIA BACTERIANA & 23 & 0,76 & 20 & 1,02 & 21 & 0,89 & 29 & 0,58 & 36 & 0,55 \\
\hline 3501401 & CURETAGEM POS-ABORTO & 24 & 0,76 & 25 & 0,83 & 22 & 0,89 & 26 & 0,62 & 23 & 0,70 \\
\hline 4200403 & TRAQUEOTOMIA(INCLUSIVE CURATIVOS) & 25 & 0,75 & 34 & 0,59 & 23 & 0,73 & 28 & 0,60 & 13 & 1,06 \\
\hline 7630007 & OUTRAS PNEUMONIAS & 26 & 0,74 & 31 & 0,68 & 27 & 0,69 & 22 & 0.74 & 18 & 0,85 \\
\hline 3301611 & LAPAROTOMIA EXPLORADORA & 27 & 0,66 & 23 & 0,87 & 25 & 0.69 & 34 & 0,51 & 35 & 0,56 \\
\hline
\end{tabular}

Continua 


\begin{tabular}{|c|c|c|c|c|c|c|c|c|c|c|c|}
\hline \multirow{2}{*}{\multicolumn{2}{|c|}{ Procedimentos }} & \multirow{2}{*}{\multicolumn{2}{|c|}{ Total }} & \multirow{2}{*}{\multicolumn{2}{|c|}{$\begin{array}{l}\text { Antes } \\
1^{\circ} \text { ano }\end{array}$}} & \multicolumn{6}{|c|}{ Depois } \\
\hline & & & & & & \multicolumn{2}{|c|}{$1^{\circ}$ ano } & \multicolumn{2}{|c|}{$2^{\circ}$ ano } & \multicolumn{2}{|c|}{$3^{\circ}$ ano } \\
\hline \multicolumn{2}{|r|}{ Descriçăo } & Pos. & $\%$ & Pos. & $\%$ & Pos. & $\%$ & Pos. & $\%$ & Pos. & $\%$ \\
\hline 40038017 & TRATAMENTO CIRURGICO DE HEMATOMA SUB-DURAL & 28 & 0,65 & 30 & 0,68 & 31 & 0,63 & 21 & 0.78 & 38 & 0.53 \\
\hline 76300080 & BRONCOPNEUMONIA & 29 & 0.65 & 21 & 0.99 & 26 & 0.69 & 41 & 0,42 & 39 & 0.53 \\
\hline 75500124 & HEMORRAGIAS DIGESTIVAS & 30 & 0,65 & 29 & 0.75 & 29 & 0,63 & 27 & 0.61 & 30 & 0.60 \\
\hline 42008069 & TORACOTOMIA COM DRENAGEM FECHADA & 31 & 0,60 & 33 & 0.60 & 36 & 0.43 & 25 & 0.64 & 22 & 0.76 \\
\hline 75500213 & CIRROSE HEPATICA & 32 & 0,58 & 32 & 0,66 & 28 & 0,66 & 36 & 0,47 & 37 & 0,53 \\
\hline 80500170 & INSUFICIENCIA RENAL CRONICA AACIDOSE METABOLICA & 33 & 0,55 & 24 & 0,84 & 47 & 0,33 & 38 & 0.45 & 29 & 0,62 \\
\hline 74300261 & SEPTICEMIAS (PEDIATRIA) & 34 & 0,54 & 42 & 0.43 & 37 & 0,43 & 24 & 0,66 & 24 & 0.68 \\
\hline 74500244 & SEPTICEMIAS (CLINICA MEDICA) & 35 & 0,54 & 35 & 0,54 & 32 & 0,57 & 35 & 0,50 & 34 & 0.56 \\
\hline 39009130 & REDUCAO CIRURGICA DE FRATURA DA DIAFISE DO FEMUR, & 36 & 0.50 & 40 & 0.47 & 30 & 0,63 & 30 & 0,57 & 45 & 0,33 \\
\hline 35009012 & CESARIANA & 37 & 0,50 & 14 & 1,64 & 49 & 0.23 & 50 & 0,14 & 50 & 0,08 \\
\hline 39011151 & REDUCAO CIRURGICA DA DIAFISE DA TIBIA, COM FIXACAO & 38 & 0,47 & 44 & 0,42 & 34 & 0,55 & 47 & 0,36 & 40 & 0.52 \\
\hline 40028011 & MICROCIRURGIA VASCULAR INTRACRANIANA & 39 & 0.46 & 36 & 0.52 & 48 & 0.32 & 32 & 0,53 & 41 & 0,50 \\
\hline 76500128 & CRISE ASMATICA & 40 & 0.46 & 37 & 0,50 & 45 & 0.36 & 43 & 0,41 & 32 & 0.59 \\
\hline 76500233 & INSUFICIENCIA RESPIRATORIA AGUDA & 41 & 0,46 & 45 & 0.41 & 39 & 0.40 & 46 & 0,38 & 26 & 0.64 \\
\hline 40029018 & MICRO-CIRURGIA DE TUMORES CEREBRAIS & 42 & 0,44 & 41 & 0,46 & 44 & 0.37 & 37 & 0,46 & 42 & 0.50 \\
\hline 39012131 & REDUCAO CIRURGICA DE FRATURA DO COLO DO FEMUR & 43 & 0.44 & 39 & 0.49 & 42 & 0,38 & 42 & 0,42 & 43 & 0,48 \\
\hline 40001008 & TRAT CONSERVADOR DO TRAUMATISMO CRANEO-ENCEFALICO & 44 & 0,42 & 47 & 0.30 & 41 & 0.40 & 40 & 0,42 & 33 & 0,56 \\
\hline 34010033 & HISTERECTOMIA TOTAL & 45 & 0.40 & 43 & 0.42 & 38 & 0,42 & 31 & 0.54 & 49 & 0.23 \\
\hline 71300058 & SINDROME DA A.P.I. DO R.N.(MEMBRANA HIALINA) & 46 & 0,40 & 50 & 0,01 & 46 & 0.34 & 39 & 0,44 & 21 & 0,77 \\
\hline 77500032 & NSUFICIENCIA CORONARIANA AGUDA & 47 & 0,39 & 38 & 0.49 & 43 & 0.38 & 44 & 0.40 & 46 & 0,32 \\
\hline 39013138 & REDUCAO CIRURGICA DE FRATURA TRANSTROCANTERIANA & 48 & 0,39 & 48 & 0,27 & 33 & 0,55 & 49 & 0,33 & 44 & 0,38 \\
\hline 76500063 & PNEUMONIA NAO ESPECIFICADA & 49 & 0,37 & 49 & 0.09 & 50 & 0,23 & 33 & 0,53 & 27 & 0.63 \\
\hline 74300270 & ENTERO-INFECCOES (PEDIATRIA) & 50 & 0.37 & 46 & 0,38 & 40 & 0,40 & 45 & 0,39 & 47 & 0.30 \\
\hline & Sub-Total & & 68,08 & & 67,95 & & 67,04 & & 69,73 & & 67,72 \\
\hline & Outros & & 31,92 & & 32,05 & & 32,96 & & 30,27 & & 32,28 \\
\hline & Total & & 100,00 & & 100,00 & & 100,00 & & 100,00 & & 100,00 \\
\hline
\end{tabular}


Quadro 73 - Distribuição percentual dos gastos com internações SUS pelos 50 procedimentos mais freqüentes, ocorridos no municipio de São Vicente - SP, antes e depois da implantação da gestão semi-plena.

\begin{tabular}{|c|c|c|c|c|c|c|c|c|c|c|c|}
\hline \multirow{2}{*}{\multicolumn{2}{|c|}{ Procedimentos }} & \multirow{2}{*}{\multicolumn{2}{|c|}{ Total }} & \multirow{2}{*}{\multicolumn{2}{|c|}{$\begin{array}{l}\text { Antes } \\
1^{\circ} \text { ano }\end{array}$}} & \multicolumn{6}{|c|}{ Depois } \\
\hline & & & & & & \multicolumn{2}{|c|}{$1^{\circ}$ ano } & \multicolumn{2}{|c|}{$2^{\circ}$ ano } & \multicolumn{2}{|c|}{$3^{\circ}$ ano } \\
\hline Codigo & Descriçăo & Pos. & $\%$ & Pos. & $\%$ & Pos. & $\%$ & Pos. & $\%$ & Pos. & $\%$ \\
\hline 35001011 & PARTO NORMAL & 1 & 13,93 & 1 & 13,54 & 1 & 14,45 & 1 & 13,31 & 1 & 14.42 \\
\hline 31000002 & CIRURGIA MULTIPLA & 2 & 8,60 & 2 & 13,47 & 2 & 14,11 & 9 & 2,15 & 5 & 3.42 \\
\hline 35009012 & CESARIANA & 3 & 7,08 & 3 & 8,09 & 3 & 7,81 & 2 & 6,36 & 2 & 5,79 \\
\hline 77500113 & INSUFICIENCIA CARDIACA & 4 & 4.15 & 5 & 4,95 & 4 & 5,07 & 3 & 3,86 & 10 & 2,23 \\
\hline 76500233 & INSUFICIENCIA RESPIRATORIA AGUDA & 5 & 3.76 & 4 & 6.96 & 5 & 4,78 & 11 & 1,73 & 13 & 1,37 \\
\hline 76400085 & BRONCOPNEUMONIA EM LACTENTE & 6 & 3.52 & 7 & 3,43 & 6 & 3.47 & 4 & 3.33 & 3 & 3,94 \\
\hline 81500106 & AVC AGUDO & 7 & 3,02 & 6 & 3,45 & 7 & 2.83 & 5 & 3.24 & 7 & 2.51 \\
\hline 76300080 & BRONCOPNEUMONIA & 8 & 2,68 & 8 & 2,98 & 8 & 2,79 & 7 & 2,53 & 9 & 2,39 \\
\hline 77500024 & INFARTO AGUDO DO MIOCARDIO & $\mathbf{9}$ & 1,64 & 10 & 1,37 & 11 & 1,53 & 10 & 1,87 & 12 & 1.80 \\
\hline 40001008 & TRAT. CONSERVADOR DO TRAUMATISMO CRANEO-ENCEFALICO & 10 & 1,54 & 40 & 0,14 & 9 & 2.25 & 12 & 1,64 & 11 & 1,88 \\
\hline 39016129 & ARTROPLASTIA COXO-FEMURAL CI PROTESE NAO CIMENTADA & 11 & 1,37 & 47 & 0,00 & 44 & 0,14 & 6 & 2,92 & 6 & 2.67 \\
\hline 39000001 & POLITRAUMATIZADO & 12 & 1.16 & 13 & 1,14 & 10 & 1,62 & 28 & 0,69 & 17 & 1.14 \\
\hline 76500071 & BRONCOPNEUMONIA & 13 & 1,14 & 24 & 0,77 & 18 & 0.91 & 13 & 1,59 & 15 & 1,28 \\
\hline 76300102 & CRISE ASMATICA & 14 & 1,12 & 11 & 1,37 & 22 & 0.75 & 15 & 1,22 & 14 & 1.30 \\
\hline 75500124 & HEMORRAGIAS DIGESTIVAS & 15 & 1,10 & 16 & 1,01 & 16 & 1,03 & 14 & 1,23 & 18 & 1,13 \\
\hline 32013019 & MARCA-PASSO(TROCA DE GERADOR DE ESTIMULO) & 16 & 1,09 & 48 & 0,00 & 49 & 0,00 & 8 & 2,23 & 8 & 2,43 \\
\hline 35014016 & CURETAGEM POS-ABORTO & 17 & 1,07 & 9 & 1,38 & 13 & 1,25 & 21 & 0,98 & 33 & 0,59 \\
\hline 32015011 & MARCA-PASSO CARDIACO(INTRACAVITARIO) & 18 & 1,00 & 46 & 0,02 & 50 & 0,00 & 17 & 1,06 & 4 & 3,56 \\
\hline 82500053 & DIABETE SACARINO & 19 & 0,99 & 12 & 1,15 & 14 & 1,09 & 26 & 0,78 & 23 & 0.95 \\
\hline 76300188 & INSUFICIENCIA RESPIRATORIA AGUDA & 20 & 0.94 & 18 & 0,91 & 12 & 1,51 & 35 & 0,62 & 35 & 0,51 \\
\hline 77500180 & ARRITIMIAS & 21 & 0,86 & 14 & 1,07 & 15 & 1,05 & 34 & 0,63 & 30 & 0,66 \\
\hline 74300261 & SEPTICEMIAS (PEDIATRIA) & 22 & 0,83 & 23 & 0,79 & 20 & 0,81 & 25 & 0,78 & 21 & 0.99 \\
\hline 76500225 & DOENCA PULMONAR OBSTRUTIVA CRONICA & 23 & 0,81 & 22 & 0,82 & 21 & 0,77 & 16 & 1,12 & 40 & 0,43 \\
\hline 42008069 & TORACOTOMIA COM DRENAGEM FECHADA & 24 & 0,78 & 17 & 0,92 & 25 & 0,69 & 32 & 0,66 & 22 & 0.96 \\
\hline 71300015 & PREMATURIDADE & 25 & 0,76 & 29 & 0,60 & 17 & 0.92 & 31 & 0,68 & 25 & 0,79 \\
\hline 33011117 & HERNIORRAFIA INGUINAL(UNILATERAL) & 26 & 0,74 & 20 & 0.89 & 24 & 0.71 & 30 & 0.68 & 27 & 0.72 \\
\hline 80500170 & INSUFICIENCIA RENAL CRONICA AACIDOSE METABOLICA & 27 & 0,61 & 30 & 0.55 & 37 & 0,37 & 19 & 1.00 & 36 & 0.51 \\
\hline 38025019 & PERDA SUBST CUTANEA-LESOES EXTENSAS PLANOS SUPER. & 28 & 0,59 & 15 & 1,01 & 23 & 0.71 & 49 & 0.22 & 41 & 0,41 \\
\hline
\end{tabular}

Continua 
Quadro 73 - Continuação

\begin{tabular}{|c|c|c|c|c|c|c|c|c|c|c|c|}
\hline \multirow{2}{*}{\multicolumn{2}{|c|}{ Procedimentos }} & \multirow{2}{*}{\multicolumn{2}{|c|}{ Total }} & \multirow{2}{*}{\multicolumn{2}{|c|}{$\begin{array}{l}\text { Antes } \\
1^{\circ} \text { ano }\end{array}$}} & \multicolumn{6}{|c|}{ Depois } \\
\hline & & & & & & \multicolumn{2}{|c|}{$1^{\circ}$ ano } & \multicolumn{2}{|c|}{$2^{\circ}$ ano } & \multicolumn{2}{|c|}{$3^{\circ}$ ano } \\
\hline \multicolumn{2}{|r|}{ Descriçăo } & Pos. & $\%$ & Pos. & $\%$ & Pos. & $\%$ & Pos. & $\%$ & Pos. & $\%$ \\
\hline 77500032 & INSUFICIENCIA CORONARIANA AGUDA & 29 & 0,58 & 19 & 0.90 & 30 & 0.57 & 43 & 0,47 & 45 & 0,37 \\
\hline 76300072 & OUTRAS PNEUMONIAS & 30 & 0,57 & 31 & 0.53 & 35 & 0.38 & 27 & 0.72 & 28 & 0,69 \\
\hline 77500121 & CRISE HIPERTENSIVA & 31 & 0,56 & 28 & 0.69 & 32 & 0,52 & 44 & 0,45 & 32 & 0,64 \\
\hline 75500213 & CIRROSE HEPATICA & 32 & 0,56 & 27 & 0.71 & 29 & 0.58 & 33 & 0.65 & 49 & 0.25 \\
\hline 33016119 & LAPAROTOMIA EXPLORADORA & 33 & 0,56 & 35 & 0.40 & 19 & 0,88 & 48 & 0.36 & 37 & 0.51 \\
\hline 39013138 & REDUCAO CIRURGICA DE FRATURA TRANSTROCANTERIANA & 34 & 0.56 & 43 & 0.10 & 42 & 0,17 & 20 & 0,99 & 20 & 1,07 \\
\hline 76400271 & ENTERO-INFECCOES EM LACTENTE & 35 & 0.55 & 21 & 0.83 & 26 & 0,67 & 40 & 0.49 & 50 & 0.15 \\
\hline 80500218 & OUTRAS AFECCOES DO AP. GENITO-URINARIO & 36 & 0,55 & 25 & 0.75 & 28 & 0,62 & 42 & 0.47 & 46 & 0.34 \\
\hline 76500063 & PNEUMONIA NAO ESPECIFICADA & 37 & 0,55 & 33 & 0,44 & 33 & 0.51 & 22 & 0,87 & 47 & 0,28 \\
\hline $7430027 d$ & ENTERO-INFECCOES (PEDIATRIA) & 38 & 0.55 & 26 & 0,74 & 27 & 0,62 & 47 & 0,40 & 42 & 0.41 \\
\hline 33005060 & APENDICECTOMIA & 39 & 0,54 & 34 & 0.44 & 34 & 0,47 & 37 & 0,56 & 26 & 0.74 \\
\hline 39011151 & REDUCAO CIRURGICA DA DIAFISE DA TIBIA, COM FIXACAO & 40 & 0,50 & 44 & 0,05 & 45 & 0.08 & 23 & 0,84 & 16 & 1,18 \\
\hline 77500164 & EDEMA AGUDO DE PULMAO & 41 & 0.47 & 32 & 0,44 & 39 & 0,30 & 39 & 0.52 & 29 & 0,69 \\
\hline 38007142 & GRANDE QUEIMADO & 42 & 0.47 & 36 & 0,38 & 36 & 0,37 & 36 & 0,57 & 34 & 0,56 \\
\hline 33023069 & COLOSTOMIAS & 43 & 0.44 & 42 & 0.12 & 43 & 0.17 & 18 & 1,01 & 38 & 0.46 \\
\hline 34017038 & HISTERECTOMIA C/ANEXETOMIA UNI OU BILATERAL & 44 & 0.40 & 38 & 0.34 & 31 & 0,54 & 46 & 0,41 & 48 & 0,25 \\
\hline 39009130 & REDUCAO CIRURGICA DE FRATURA DA DIAFISE DO FEMUR. & 45 & 0,38 & 39 & 0.19 & 48 & 0,03 & 38 & 0.54 & 24 & 0.91 \\
\hline 39004139 & AMPUTACAO DA COXA & 46 & 0,36 & 37 & 0,35 & 40 & 0.29 & 45 & 0,42 & 44 & 0.37 \\
\hline 74300253 & INFECCOES MENINGOCOCICAS (PEDIATRIA) & 47 & 0,34 & 41 & 0.13 & 38 & 0.34 & 41 & 0,47 & 43 & 0,39 \\
\hline 40039013 & TRATAMENTO CIRURGICO DE HEMATOMA EXTRA-DURAL & 48 & 0,34 & 49 & 0,00 & 41 & 0.22 & 50 & 0,19 & 19 & 1.11 \\
\hline 39013081 & REDUC. CIR. FRAT. DOS OSSOS DO ANTE-BRACO COM FIXA & 49 & 0,33 & 45 & 0.04 & 47 & 0,04 & 24 & 0,82 & 39 & 0,44 \\
\hline 39011160 & REDUCAO CIRURGICA DAS FRATURAS DO TORNOZELO. COM F & 50 & 0,33 & 50 & 0,00 & 46 & 0,04 & 29 & 0,68 & 31 & 0,65 \\
\hline & Sub-Total & & 77,35 & & 81,38 & & 81,82 & & 72,01 & & 73,22 \\
\hline & Outro & & 22,65 & & 18,62 & & 18,18 & & 27,99 & & 26,78 \\
\hline & Total & & 100,00 & & 100,00 & & 100,00 & & 100,00 & & 100,00 \\
\hline
\end{tabular}


Quadro 74 - Distribuição percentual dos gastos com internações SUS pelos 50 procedimentos mais freqüentes, ocorridos no municipio de Votorantim - SP, antes e depois da implantaçăo da gestão semi-plena.

\begin{tabular}{|c|c|c|c|c|c|c|c|c|c|c|c|}
\hline \multirow{2}{*}{\multicolumn{2}{|c|}{ Procedimentos }} & \multirow{2}{*}{\multicolumn{2}{|c|}{ Total }} & \multirow{2}{*}{\multicolumn{2}{|c|}{$\begin{array}{l}\text { Antes } \\
1^{\circ} \text { ano }\end{array}$}} & \multicolumn{6}{|c|}{ Depois } \\
\hline & & & & & & \multicolumn{2}{|c|}{$1^{\circ}$ ano } & \multicolumn{2}{|c|}{$2^{\circ}$ ano } & \multicolumn{2}{|c|}{$3^{\circ}$ ano } \\
\hline Codigo & Descriçăo & Pos. & $\%$ & Pos. & $\%$ & Pos. & $\%$ & Pos. & $\%$ & Pos. & $\%$ \\
\hline 35009012 & CESARIANA & 1 & 11,63 & 2 & 7,53 & 2 & 10,19 & 1 & 15,04 & 1 & 16,71 \\
\hline 35001011 & PARTO NORMAL & 2 & 10,94 & 1 & 7.78 & 1 & 10.57 & 2 & 12.45 & 2 & 15,04 \\
\hline 77500113 & INSUFICIENCIA CARDIACA & 3 & 6.31 & 3 & 6.44 & 5 & 4.62 & 3 & 7.74 & 3 & 6,65 \\
\hline 81500106 & AVC AGUDO & 4 & 4.51 & 4 & 5.46 & 4 & 5.36 & 5 & 4,45 & 9 & 2,18 \\
\hline 76500233 & INSUFICIENCIA RESPIRATORIA AGUDA & 5 & 3,94 & 5 & 3,51 & 3 & 5.37 & 6 & 3,55 & 5 & 3,52 \\
\hline 76400085 & BRONCOPNEUMONIA EM LACTENTE & 6 & 3,69 & 6 & 2,73 & 7 & 3.26 & 4 & 4,49 & 4 & 4,98 \\
\hline 77500024 & INFARTO AGUDO DO MIOCARDIO & 7 & 2,34 & 16 & 1,36 & 8 & 2,62 & 7 & 3,51 & 6 & 2,62 \\
\hline 77500180 & ARRITIMIAS & 8 & 2,33 & 13 & 1.93 & 6 & 3,68 & 8 & 2,98 & 16 & 1.07 \\
\hline 76500225 & DOENCA PULMONAR OBSTRUTIVA CRONICA & 9 & 2,32 & 7 & 2,71 & 14 & 1.61 & 11 & 2,27 & 7 & 2.47 \\
\hline 77500032 & INSUFICIENCIA CORONARIANA AGUDA & 10 & 2,22 & 14 & 1.92 & 9 & 2.48 & 10 & 2,28 & 8 & 2,38 \\
\hline 76300080 & BRONCOPNEUMONIA & 11 & 2,02 & 11 & 1,96 & 10 & 2,15 & 12 & 2,07 & 10 & 1,94 \\
\hline 76500071 & BRONCOPNEUMONIA & 12 & 1.89 & 8 & 2,68 & 11 & 2,06 & 14 & 1,34 & 19 & 0,96 \\
\hline 82500053 & DIABETE SACARINO & 13 & 1,76 & 15 & 1,79 & 15 & 1,51 & 9 & 2,30 & 11 & 1,50 \\
\hline 75500124 & HEMORRAGIAS DIGESTIVAS & 14 & 1,70 & 10 & 2.02 & 12 & 1.83 & 15 & 1.24 & 12 & 1.43 \\
\hline 33004080 & COLECISTECTOMIA & 15 & 1,37 & 9 & 2,62 & 22 & 1,13 & 42 & 0,24 & 27 & 0.57 \\
\hline 40001008 & TRAT. CONSERV DO TRAUMATISMO CRANEO-ENCEFALICO & 16 & 1,24 & 12 & 1,93 & 16 & 1,47 & 30 & 0,54 & 29 & 0.50 \\
\hline 33016119 & LAPAROTOMIA EXPLORADORA & 17 & 1,11 & 22 & 0,94 & 13 & 1,73 & 20 & 0,81 & 18 & 0,98 \\
\hline 77500164 & EDEMA AGUDO DE PULMAO & 18 & 1,08 & 21 & 0,97 & 17 & 1,41 & 13 & 1,39 & 25 & 0,66 \\
\hline 33005060 & APENDICECTOMIA & 19 & 0,94 & 19 & 1,06 & 23 & 1,04 & 27 & 0,66 & 22 & 0,89 \\
\hline 35014016 & CURETAGEM POS-ABORTO & 20 & 0,92 & 27 & 0.72 & 19 & 1,27 & 17 & 0,96 & 23 & 0,84 \\
\hline 75500213 & CIRROSE HEPATICA & 21 & 0.90 & 18 & 1,12 & 18 & 1,28 & 31 & 0,48 & 30 & 0,50 \\
\hline 76500063 & PNEUMONIA NAO ESPECIFICADA & 22 & 0,88 & 30 & 0,65 & 20 & 1,19 & 26 & 0,67 & 14 & 1,11 \\
\hline 74300270 & ENTERO-INFECCOES (PEDIATRIA) & 23 & 0,78 & 24 & 0,89 & 21 & 1,13 & 23 & 0,70 & 39 & 0.31 \\
\hline 80500218 & OUTRAS AFECCOES DO AP. GENITO-URINARIO & 24 & 0.77 & 23 & 0.90 & 24 & 0,86 & 22 & 0,74 & 28 & 0.50 \\
\hline 76300102 & CRISE ASMATICA & 25 & 0.76 & 31 & 0,65 & 38 & 0,45 & 16 & 1,19 & 21 & 0,91 \\
\hline 33012113 & HERNIORRAFIA INGUINAL(BILATERAL) & 26 & 0.76 & 39 & 0.50 & 30 & 0.60 & 24 & 0,69 & 13 & 1,37 \\
\hline 40061019 & VENTRICULO-PERITONIOSTOMIA COM INTERPOSICAO DE VAL & 27 & 0,64 & 17 & 1,30 & 25 & 0,77 & 47 & 0,00 & 47 & 0,00 \\
\hline 39013138 & REDUCAO CIRURGICA DE FRATURA TRANSTROCANTERIANA & 28 & 0,58 & 20 & 1.03 & 42 & 0,34 & 28 & 0,56 & 42 & 0,15 \\
\hline
\end{tabular}

Continua 


\begin{tabular}{|c|c|c|c|c|c|c|c|c|c|c|c|}
\hline \multirow{2}{*}{\multicolumn{2}{|c|}{ Procedimentos }} & \multirow{2}{*}{\multicolumn{2}{|c|}{ Total }} & \multirow{2}{*}{\multicolumn{2}{|c|}{$\begin{array}{l}\text { Antes } \\
1^{\circ} \text { ano }\end{array}$}} & \multicolumn{6}{|c|}{ Depois } \\
\hline & & & & & & \multicolumn{2}{|c|}{$1^{\circ}$ ano } & \multicolumn{2}{|c|}{$2^{\circ}$ ano } & \multicolumn{2}{|c|}{$3^{\circ}$ ano } \\
\hline Codigo & Descriçăo & Pos. & $\%$ & Pos. & $\%$ & Pos. & $\%$ & Pos. & $\%$ & Pos. & $\%$ \\
\hline 76500110 & COR PULMONALE DESCOMPENSADO & 29 & 0.57 & 34 & 0,60 & 26 & 0.74 & 34 & 0,39 & 31 & 0,50 \\
\hline 76500128 & CRISE ASMATICA & 30 & 0,56 & 36 & 0.55 & 28 & 0.62 & 21 & 0,81 & 38 & 0,31 \\
\hline 33011117 & HERNIORRAFIA INGUINAL(UNILATERAL) & 31 & 0.53 & 42 & 0.36 & 48 & 0,19 & 18 & 0,89 & 24 & 0,82 \\
\hline 80500056 & INSUFICIENCIA RENAL AGUDA & 32 & 0.52 & 26 & 0.78 & 41 & 0,34 & 25 & 0,68 & 41 & 0,17 \\
\hline 77500121 & CRISE HIPERTENSIVA & 33 & 0,52 & 28 & 0,67 & 29 & 0,62 & 35 & 0,38 & 37 & 0,32 \\
\hline 81500076 & EPILEPSIAS & 34 & 0,50 & 33 & 0,63 & 34 & 0,51 & 38 & 0.26 & 35 & 0,48 \\
\hline 74500244 & SEPTICEMIAS (CLINICA MEDICA) & 35 & 0,49 & 29 & 0,66 & 37 & 0,45 & 32 & 0,41 & 36 & 0,33 \\
\hline 76300064 & PENUMONIA ESTAFILOCOCICA & 36 & 0,48 & 47 & 0,20 & 31 & 0,57 & 45 & 0,18 & 15 & 1,08 \\
\hline 80500072 & PIELONEFRITES & 37 & 0,43 & 25 & 0,83 & 43 & 0,28 & 39 & 0.25 & 44 & 0.12 \\
\hline 39000001 & POLITRAUMATIZADO & 38 & 0,40 & 40 & 0,49 & 49 & 0,11 & 48 & 0,00 & 20 & 0,91 \\
\hline 76400271 & ENTERO-INFECCOES EM LACTENTE & 39 & 0,39 & 37 & 0,53 & 33 & 0,54 & 37 & 0,28 & 43 & 0.13 \\
\hline 33006067 & COLECTOMIA PARCIAL(HEMICOLECTOMIA) & 40 & 0,39 & 50 & 0,00 & 35 & 0.51 & 43 & 0,22 & 17 & 1,04 \\
\hline 38007142 & GRANDE QUEIMADO & 41 & 0,38 & 35 & 0,59 & 27 & 0.74 & 49 & 0,00 & 48 & 0,00 \\
\hline 75500299 & AFECCOES PANCREATICAS & 42 & 0,36 & 41 & 0.44 & 36 & 0,50 & 44 & 0,20 & 40 & 0,21 \\
\hline 32019041 & BYPASS OU TROMBOENDARTERECTOMIA FEMURO-POPLITEIA & 43 & 0,35 & 48 & 0.11 & 50 & 0,00 & 19 & 0,83 & 26 & 0,66 \\
\hline 75500272 & COLICISTITE AGUDA & 44 & 0,33 & 43 & 0.32 & 45 & 0,25 & 40 & 0,25 & 32 & 0,50 \\
\hline 42008069 & TORACOTOMIA COM DRENAGEM FECHADA & 45 & 0,30 & 45 & 0,24 & 39 & 0,39 & 29 & 0,54 & 46 & 0,10 \\
\hline 74500252 & ENTERO-INFECCOES (CLINICA MEDICA) & 46 & 0,30 & 38 & 0,50 & 40 & 0,35 & 46 & 0,08 & 45 & 0,11 \\
\hline 74300261 & SEPTICEMIAS (PEDIATRIA) & 47 & 0,29 & 44 & 0,28 & 32 & 0,57 & 36 & 0,34 & 49 & 0,00 \\
\hline 76300072 & OUTRAS PNEUMONIAS & 48 & 0.29 & 46 & 0,21 & 46 & 0,24 & 41 & 0,25 & 34 & 0,49 \\
\hline 40005011 & CRANIOTOMIA P/TUMORES CEREBRAIS, INCLUSIVE DA FOSSA & 49 & 0,28 & 32 & 0,64 & 47 & 0,22 & 50 & 0,00 & 50 & 0,00 \\
\hline 31004105 & POSTECTOMIA(CIRCUNCISAO) & 50 & 0,28 & 49 & 0,07 & 44 & 0,28 & 33 & 0,40 & 33 & 0,49 \\
\hline & Sub-Tota & & 79,28 & & $\mathbf{7 4 , 7 7}$ & & 81,01 & & 83,00 & & 81,53 \\
\hline & Outro & & 20,72 & & 25,23 & & 18,99 & & 17,00 & & 18,47 \\
\hline & Tota & & 100,00 & & 100,00 & & 100,00 & & 100,0 & & 100,00 \\
\hline
\end{tabular}




\subsubsection{Tempo de permanência em internações SUS hospitalares nos municípios}

A Figura 52 apresenta o tempo médio anual de internações SUS hospitalares, por município, nos períodos antes e depois da implantação da gestão semi plena.

Comparando-se o tempo médio de permanência em internações SUS, nos períodos antes e depois da implantação da gestão semi plena, obteve-se para o total dos 11 municípios, o tempo médio de 5 dias de internações SUS e não houve alteração nessa média, depois da implantação da semi plena.

Figura 52 - Média anual de dias de permanência internações SUS por município, antes e depois da implantação da gestão semi-plena.

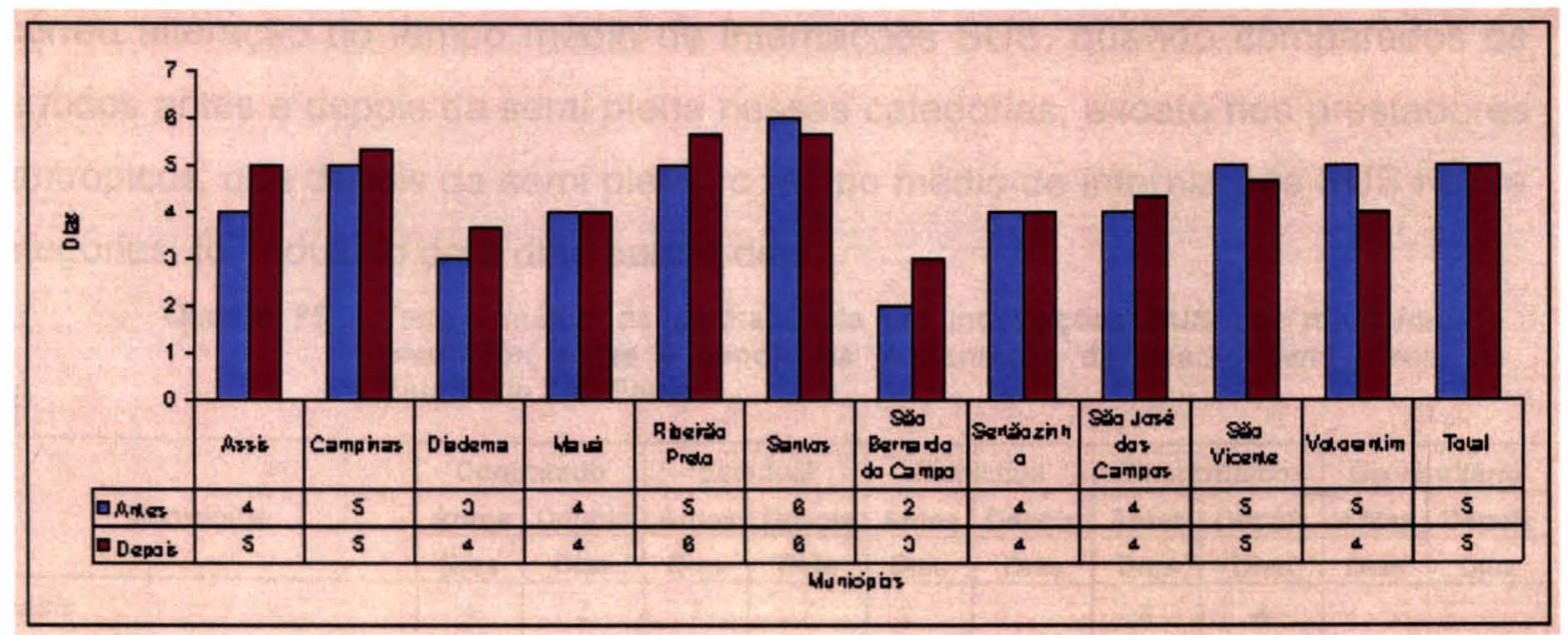

Analisando-se os períodos antes e depois da semi plena, o tempo médio de permanência em internações SUS verificou-se aumento nos municípios de Assis de 4 para 5 dias, em Diadema ou aumento foi de 3 para 4 dias, em Ribeirão Preto de 5 para 6 dias, em São Bernardo do Campo de 2 para 3 dias. 
Nos municípios de Campinas (5 dias), Mauá (4 dias), Santos (6 dias), Sertãozinho (4 dias), São José dos Campos (4 dias) e São Vicente (5 dias), o tempo médio de internação não foi alterado depois da implantação da semi plena.

Registrou-se redução do tempo médio de internação no Municipio de Votorantim, que antes era de 5 dias e depois da semi plena passou para 4 dias.

\section{Tempo Médio de Permanência em Internações SUS Hospitalares, por Municípios e Prestador}

O Quadro 75 apresenta o tempo médio de permanência em internações SUS nos municipios, por prestador, onde se verificou que os maiores tempos médios, considerando-se os 11 municípios, foram registrados para os prestadores estaduais ( 7 dias), universitários (6 dias), municipais (5 dias) e o menor tempo médio foi verificado para os prestadores contratados (3 dias), sendo que não ocorreu alteração do tempo médio de internações SUS, quando comparados os periodos antes e depois da semi plena nessas categorias, exceto nos prestadores filantrópicos, que depois da semi plena, o tempo médio de internações SUS nessa categorias, foi reduzido de 5 dias para 4 dias.

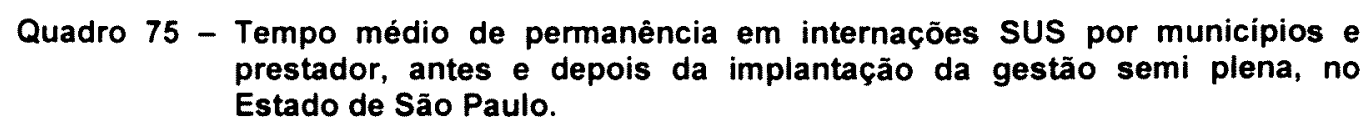

Quadro 75 - Tempo médio de permanência em internações SUS por municipios e prestador, antes e depois da implantação da gestão semi plena, no Estado de São Paulo.

\begin{tabular}{|c|c|c|c|c|c|c|c|c|c|c|}
\hline \multirow{3}{*}{ Municipios } & \multicolumn{2}{|c|}{ Contratado } & \multicolumn{2}{|c|}{ Estadual } & \multicolumn{2}{|c|}{ Municipal } & \multicolumn{2}{|c|}{ Filantrópico } & \multicolumn{2}{|c|}{ Universitário } \\
\hline & Antes & Depois & Antes & Depois & Antes & Depois & Antes & Depois & Antes & Depois \\
\hline & Dias & Dias & Dias & Dias & Dias & Dias & Dias & Dias & Dias & Dias \\
\hline Assis & 4 & 3 & 7 & 7 & & & 4 & 4 & & \\
\hline Campinas & 4 & 6 & & & 6 & 7 & 3 & 3 & 6 & 6 \\
\hline Diadema & 2 & 3 & & & 4 & 4 & & & & \\
\hline Mauá & & & & & 4 & 5 & 4 & 3 & & \\
\hline Ribeirão Preto & 4 & 4 & & & & & 4 & 4 & 6 & 6 \\
\hline Santos & 9 & & 7 & 7 & 4 & 4 & 6 & 6 & & \\
\hline São Bernardo do Campo & 4 & & & & 2 & 3 & & & 3 & 3 \\
\hline Sertãozinho & & & & & & & 4 & 4 & & \\
\hline São José dos Campos & 4 & 6 & & & 6 & 6 & 4 & 4 & & \\
\hline Sāo Vicente & & & & & & & 5 & 5 & & \\
\hline Votorantim & 5 & 4 & & & & & & & & \\
\hline Total & 3 & 3 & 7 & 7 & 5 & 5 & 5 & 4 & 6 & 6 \\
\hline
\end{tabular}

Fonte: www.datasus.gov.br_SIH

- Legenda - Média de 3 anos $=$ depois $\quad 1^{\circ}$ ano antes $=$ antes 
Analisando-se a categoria dos prestadores contratados, registrou-se depois da implantação da semi plena, redução no tempo médio de internações SUS nos municipios de Assis (antes $=4$ dias, depois $=3$ dias) e Votorantim (antes $=5$ dias, depois $=4$ dias). Aumento no tempo médio se registrou para Campinas (antes $=4$ dias, depois $=6$ dias), Diadema (antes $=2$ dias, depois $=3$ dias $)$ e São José dos Campos (antes $=4$ dias, depois $=6$ dias). No municipio de Ribeirão Preto, o tempo de permanência não se alterou nos períodos antes e depois da semi plena. Nos municípios de Santos e São Bernardo, depois da implantação da semi plena, essa modalidade de prestador deixou de prestar serviços no municipio.

Os prestadores estaduais, representados nos municipios de Assis e São Bernardo do Campo, apresentaram o tempo médio de permanência de 7 dias, em ambos os municípios e não ocorreram alterações nessa média nos períodos antes e depois da semi plena.

Dentre os prestadores municipais, os municípios que apresentaram aumento no tempo médio de permanência depois da semi plena foram: Campinas (antes $=6$ dias, depois $=7$ dias), Mauá (antes $=4$ dias, depois $=5$ dias) e São Bernardo do Campo (antes $=2$ dias, depois $=3$ dias) e os municípios onde 0 tempo médio de permanência não foi alterado nos periodos antes e depois da semi plena foram: Diadema (4 dias), Santos (4 dias) e São José dos Campos (6 dias).

$\mathrm{Na}$ categoria prestadores filantrópicos, não se registrou alterações no tempo médio de internações SUS, quando comparados os periodos antes e depois da implantação da gestão semi plena nos municipios de Assis (4 dias), Campinas (3 dias), Ribeirão Preto (4 dias), Santos (6 dias), Sertãozinho (4 dias), São José dos Campos (4 dias) e São Vicente (4 dias). Nessa categoria, verificouse redução no tempo médio de internações SUS em Mauá, de 4 dias (antes) para 3 dias (depois). 
Não se registrou alterações no tempo médio de permanência nas internações SUS, nos prestadores universitários nos municípios de Campinas (6 dias), Ribeirão Preto (6 dias) e São Bernardo do Campo (3 dias).

A Figura 53 apresenta a tendência do número anual de dias de permanência em internações SUS, por municipios estudados, antes e depois da implantação da gestão semi plena que refletem os dados anteriormente referidos.

Figura 53 - Tendência do número anual de dias de permanência em internações SUS, por município, antes e depois da implantação da gestão semi-plena, no Estado de São Paulo.
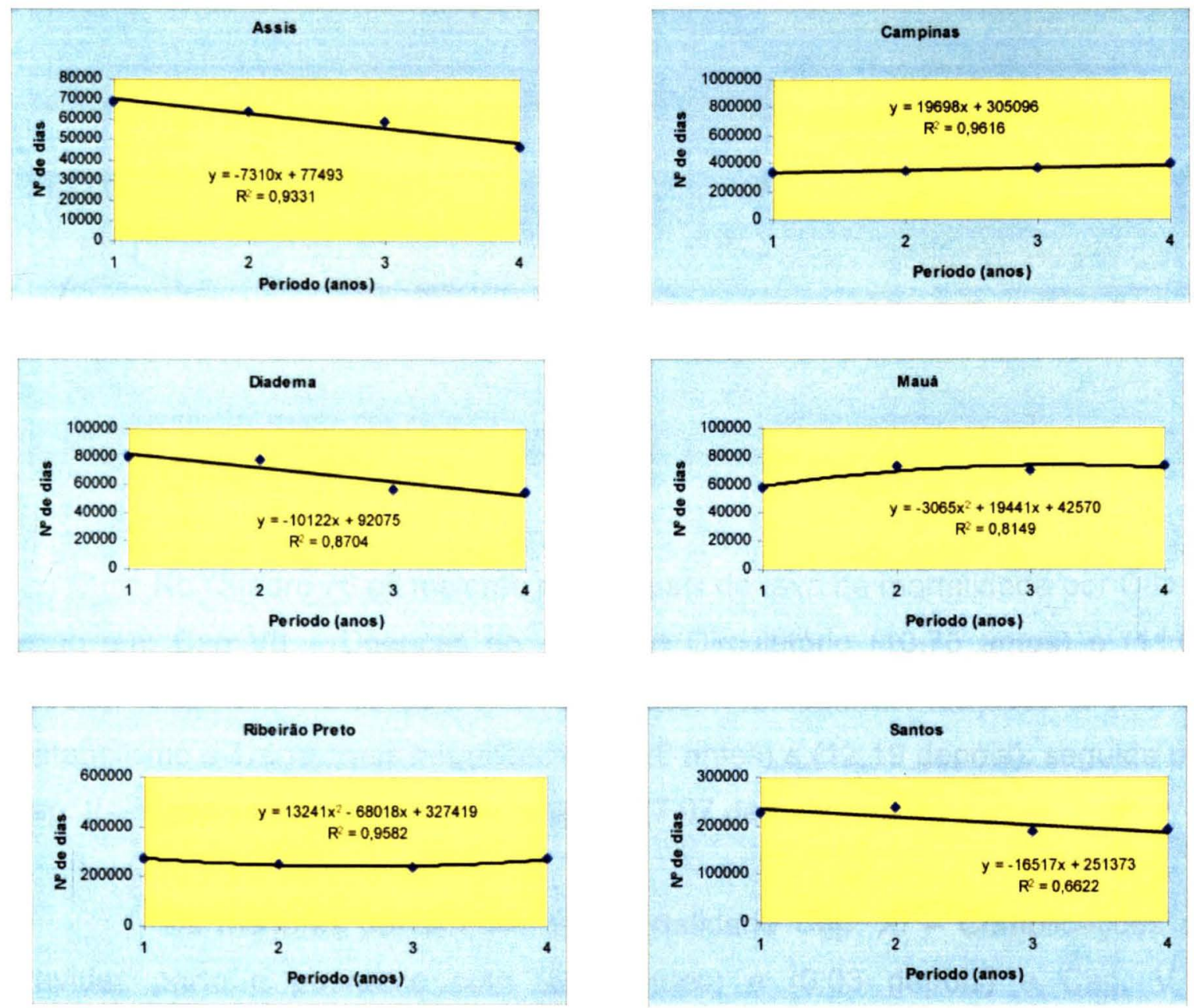

Continua 
Figura 53 - Continuação
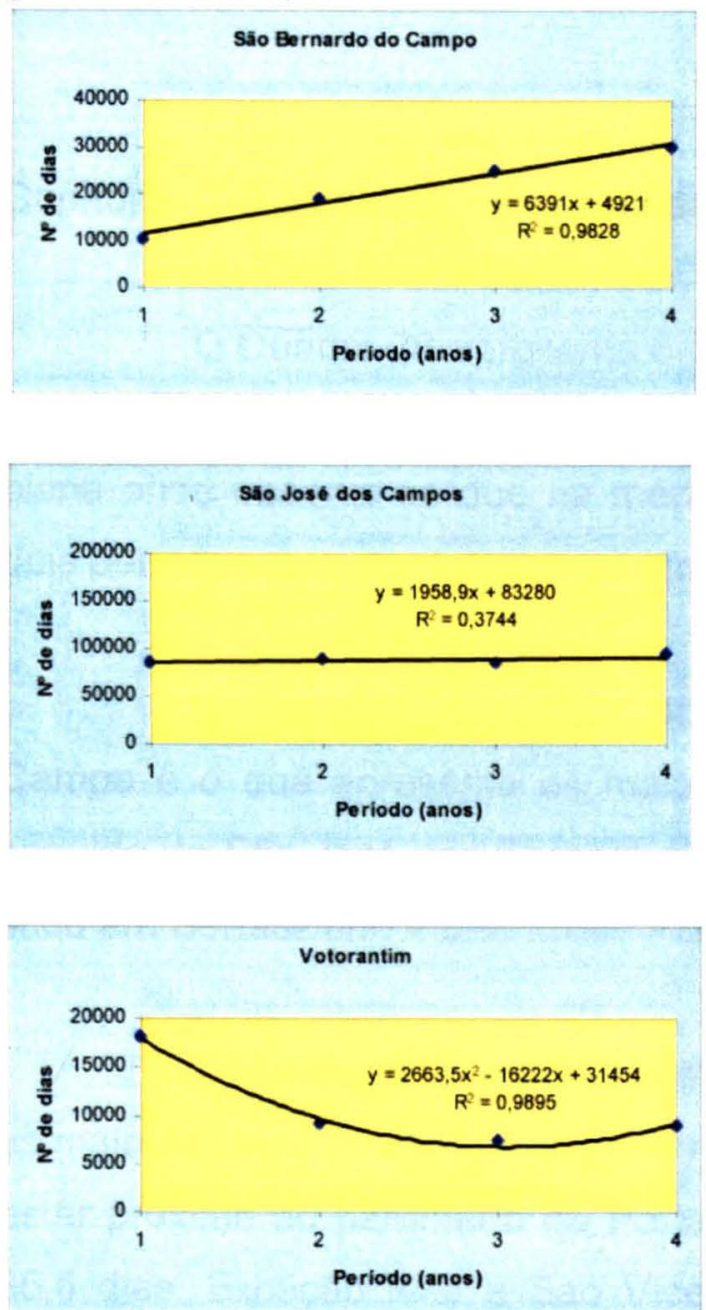
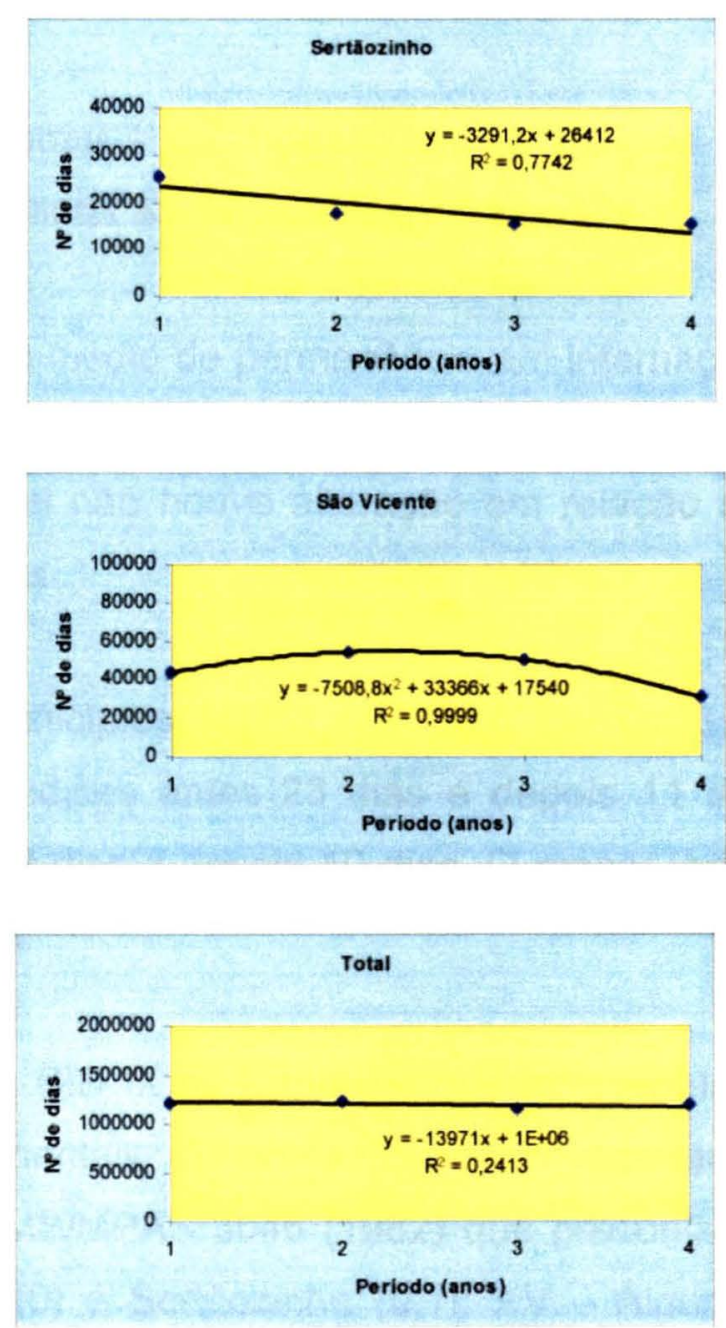

No Quadro 76 os maiores percentuais de taxa de mortalidade por CID IX estão em: Cap VII - Doenças do Aparelho Circulatório (10,75 antes) e (11,67 depois); Cap. III - Doenças das Glândulas Endócrinas, da Nutricão e do Metabolismo e Transtornos Imunitários (10,20 antes) e (12,19 depois); seguida por Cap. II - Neoplasmas com (6,96\% antes) e (7,97 depois).

Os menores percentuais de mortalidade Cap. XI - Complicações de gravidez parto e puerpério com $(0,04$ antes $)$ e $(0,03$ depois $)$ e Cap. V Transtornos mentais com $(0,22$ antes) e $(0,47$ depois $)$. 
Chama a atenção o indice de CID não especificado ou inválido em Assis (66,67 antes) e (3,26 depois).

Observa-se aumento de percentuais de mortalidade na maioria dos Capitulos CID e municípios depois da implantação da gestão semi plena.

O Quadro 76 apresenta o tempo médio de permanência em internações por localidade e Capítulo CID IX nos periodos antes e depois da gestão semi plena onde observa-se que na média total não houve alteração em relação aos dois períodos que mantiveram-se em 7 dias.

No entanto, a análise dos municipios revela que São Bernardo do Campo é o que apresenta os maiores índices antes 23 dias e depois 11 dias seguido de São José dos Campos antes 9 dias e depois 10 dias. $O$ menor indice ficou em Sertãozinho 4 dias antes e depois.

Observa-se que em relação ao CID IX os Capítulos que apresentaram as maiores taxas foram $V$ - Transtornos mentais (39 antes, 39 depois), apesar de estar próximo ao parâmetro da Portaria MS/MPAS 3046 (1982) que preconizava 36,5 dias. Exceção feita a São Vicente $(0)$ e Sertãozinho $(0,1)$; XV - Algumas afecções originadas período perinatal. Com uma média de 9 dias (antes) e 11 dias (depois); os menores índices por Capitulo foram para XI - Complicações da gravidez parto e puerpério ( 3 dias antes) e ( 3 dias depois). 
Quadro 76 - Tempo médio de permanência em internações SUS por localidade e Capítulo CID IX, nos periodos antes e depois da gestão semi plena, no Estado de São Paulo.

\begin{tabular}{|c|c|c|c|c|c|c|c|c|c|c|c|c|c|c|c|c|c|c|c|c|c|c|c|c|}
\hline \multirow{3}{*}{ Municipios } & \multicolumn{2}{|c|}{ Assis } & \multicolumn{2}{|c|}{ Campinas } & \multicolumn{2}{|c|}{ Diadema } & \multicolumn{2}{|c|}{ Mauá } & \multicolumn{2}{|c|}{$\begin{array}{c}\text { Ribeiráo } \\
\text { Preto }\end{array}$} & \multicolumn{2}{|c|}{ Santos } & \multicolumn{2}{|c|}{$\begin{array}{c}\text { Sao Bemardo } \\
\text { do Campo }\end{array}$} & \multicolumn{2}{|c|}{$\begin{array}{c}\text { Salo José dos } \\
\text { Campos }\end{array}$} & \multicolumn{2}{|c|}{ Săo Vicente } & \multicolumn{2}{|c|}{ Sertăozinho } & \multicolumn{2}{|c|}{ Votorantim } & \multicolumn{2}{|c|}{ Total } \\
\hline & A & D & A & D & A & D & A & D & A & D & A & D & A & D & A & D & A & D & A & D & A & D & A & D \\
\hline & dias & dias & dias & dias & dias & dias & dias & dias & dias & dias & dias & dias & dias & dias & dlas & dias & dias & dias & dias & dias & dias & dias & dias & dias \\
\hline 1- Doenças Infecciosas e parasitárias & 5 & 4 & 6 & 8 & 4 & 5 & 5 & 8 & 7 & 10 & 8 & 10 & 3 & 5 & 5 & 6 & 7 & 6 & 5 & 5 & 6 & 4 & 6 & 8 \\
\hline$\|$ - Neoplasmas & 4 & 6 & 6 & 7 & 5 & 5 & 4 & 5 & 6 & 8 & 8 & 10 & 4 & 5 & 6 & 12 & 13 & 7 & 4 & 4 & 8 & 3 & 6 & 8 \\
\hline III. Dças glând endócr nutriç metab transt imun & 6 & 6 & 6 & 10 & 4 & 5 & 5 & 7 & 6 & 6 & 8 & 8 & 2 & 4 & 7 & 7 & 10 & 7 & 5 & 6 & 7 & 6 & 6 & 8 \\
\hline IV. Doenças do sangue e dos órgãos hematop. & 5 & 6 & 6 & 6 & 5 & 6 & 4 & 5 & 5 & 8 & 7 & 6 & 2 & 3 & 5 & 4 & 7 & 9 & 4 & 3 & 4 & 5 & 6 & 6 \\
\hline V. Transtornos mentais & 15 & 7 & 29 & 41 & 50 & 2 & 26 & 3 & 50 & 43 & 16 & 12 & 46 & 47 & 46 & 38 & 0 & 0 & 0 & 1 & 6 & 0 & 39 & 39 \\
\hline VI. Doenças sistema nervoso órgãos dos sent. & 5 & 5 & 6 & 7 & 3 & 4 & 4 & 6 & 6 & 6 & 7 & 6 & 7 & 2 & 7 & 8 & 3 & 5 & 3 & 4 & 8 & 6 & 6 & 6 \\
\hline VII. Doenças do aparelho circulatório & 5 & 6 & 6 & 7 & 4 & 6 & 5 & 8 & 6 & 7 & 8 & 8 & 3 & 5 & 6 & 7 & 8 & 7 & 6 & 5 & 7 & 7 & 6 & 7 \\
\hline VIII Doenças do aparelho respiratório & 5 & 5 & 6 & 7 & 4 & 5 & 6 & 8 & 6 & 7 & 7 & 6 & 2 & 3 & 5 & 5 & 8 & 6 & 6 & 6 & 6 & 6 & 6 & 6 \\
\hline IX. Doenças do aparelho digestivo & 5 & 6 & 5 & 5 & 5 & 5 & 4 & 5 & 4 & 5 & 7 & 6 & 3 & 4 & 4 & 4 & 7 & 5 & 4 & 3 & 6 & 4 & 5 & 5 \\
\hline X. Doenças do aparelho geniturinário & 4 & 4 & 4 & 4 & 3 & 4 & 3 & 5 & 4 & 5 & 6 & 5 & 2 & 3 & 4 & 4 & 6 & 5 & 3 & 3 & 4 & 3 & 4 & 4 \\
\hline XI. Complicaçðes da gravidez parto e puerpério & 2 & 3 & 3 & 3 & 3 & 3 & 3 & 3 & 2 & 2 & 3 & 3 & 2 & 4 & 2 & 2 & 2 & 2 & 2 & 2 & 2 & 2 & 3 & 3 \\
\hline XII. Doenças da pele e tecido celular subcutáned & 4 & 6 & 5 & 6 & 4 & 4 & 6 & 7 & 5 & 6 & 5 & 8 & 2 & 2 & 5 & 7 & 7 & 5 & 5 & 5 & 5 & 3 & 5 & 6 \\
\hline XIII. Doenças sistema osteomusc e tecido conj. & 4 & 6 & 6 & 7 & 4 & 4 & 6 & 6 & 5 & 5 & 8 & 7 & 3 & 3 & 6 & 8 & 7 & 8 & 4 & 4 & 6 & 7 & 6 & 6 \\
\hline XIV. Anomalias congênitas & 4 & 4 & 5 & 5 & 9 & 7 & 5 & 4 & 6 & 9 & 8 & 10 & 3 & 1 & 5 & 8 & 12 & 6 & 3 & 12 & 10 & 5 & 6 & 7 \\
\hline$X V$. Algumas afeçoes originadas periodo perin. & 8 & 12 & 12 & 16 & 10 & 9 & 9 & 8 & 14 & 14 & 5 & 5 & 1 & 2 & 10 & 13 & 3 & 6 & 16 & 17 & 7 & 4 & 9 & 11 \\
\hline XVI. Sintomas, sinais e afecçðes mal definidas & 3 & 3 & 4 & 3 & 2 & 2 & 4 & 6 & 4 & 4 & 5 & 2 & 4 & 2 & 18 & 5 & 10 & 2 & 3 & 3 & 4 & 3 & 5 & 3 \\
\hline XVIII.Lesठ̌es e envenenamentos & 4 & 5 & 5 & 6 & 4 & 5 & 4 & 6 & 5 & 5 & 7 & 7 & 3 & 3 & 6 & 9 & 8 & 6 & 7 & 4 & 5 & 5 & 6 & 6 \\
\hline Class supl fatores oport contato serviços saúde & 8 & 3 & 4 & 5 & 3 & 2 & 3 & 3 & 4 & 3 & 2 & 6 & 0 & 2 & 2 & 1 & 0 & 5 & 2 & 0 & 1 & 1 & 4 & 4 \\
\hline CID năo especificado ou inválido & 10 & & 2 & & 5 & & 4 & & 14 & & 8 & & 0 & & 6 & & 0 & & 3 & & 0 & & 6 & \\
\hline Total & 4 & 5 & 7 & 7 & 5 & 4 & 5 & 4 & 8 & 9 & 7 & 6 & 23 & 11 & 9 & 10 & 5 & 4 & 4 & 4 & 5 & 4 & 7 & 7 \\
\hline
\end{tabular}

Fonte: Sistema de Informaçoes Hospitalares do SUS (SIH/SUS) 
Quadro 77 - Taxa de mortalidade de internaçōes SUS por percentual e localidade de ocorrência e Capitulo CID IX, nos períodos antes e depois da gestão semi plena, no Estado de São Paulo.

\begin{tabular}{|c|c|c|c|c|c|c|c|c|c|c|c|c|c|c|c|c|c|c|c|c|c|c|c|c|}
\hline \multirow[b]{3}{*}{ Capitulo } & \multicolumn{2}{|c|}{ Assis } & \multicolumn{2}{|c|}{ Campinas } & \multicolumn{2}{|c|}{ Diadema } & \multicolumn{2}{|c|}{ Mauá } & \multicolumn{2}{|c|}{$\begin{array}{c}\text { Ribeirăo } \\
\text { Preto }\end{array}$} & \multicolumn{2}{|c|}{ Santos } & \multicolumn{2}{|c|}{$\begin{array}{c}\text { Săo Bernardo } \\
\text { do Campo }\end{array}$} & \multicolumn{2}{|c|}{$\begin{array}{c}\text { Sâo José dos } \\
\text { Campos }\end{array}$} & \multicolumn{2}{|c|}{ Săo Vicente } & \multicolumn{2}{|c|}{ Sertăozinho } & \multicolumn{2}{|c|}{ Votorantim } & \multicolumn{2}{|c|}{ Média } \\
\hline & A & D & A & D & A & D & A & D & A & D & A & D & A & D & A & D & A & D & A & D & A & D & A & D \\
\hline & $\%$ & $\%$ & $\%$ & $\%$ & $\%$ & $\%$ & $\%$ & $\%$ & $\%$ & $\%$ & $\%$ & $\%$ & $\%$ & $\%$ & $\%$ & $\%$ & $\%$ & $\%$ & $\%$ & $\%$ & $\%$ & $\%$ & $\%$ & $\%$ \\
\hline I - Doenças Infecciosas e parasitárias & 3,15 & 1,34 & 10,15 & 15,40 & 4,53 & 5,87 & 7,59 & 9,15 & 9,44 & 11,88 & 7.87 & 10.74 & 10,00 & 5.70 & 6.45 & 5,52 & 9,92 & 9,01 & 1,82 & 3,53 & 5,59 & 9,52 & 6,96 & 7,97 \\
\hline II - Neoplasmas & 5,90 & 6,84 & 6,15 & 7,03 & 17.41 & 20,92 & 1,52 & 3,17 & 5,34 & 7,21 & 12,15 & 14,22 & 2,30 & 4,81 & 8.51 & 13,86 & 20,59 & 18.57 & 1,12 & 8,16 & 15,22 & 3,64 & 8.75 & 9,86 \\
\hline III. Dças glānd endócr nutriç metab transt imun & 4,33 & 5,13 & 7,59 & 6,98 & 5,02 & 7,41 & 10,86 & 19.79 & 4.41 & 3,85 & 15,13 & 6,65 & 1.91 & 8,84 & 14,01 & 14,72 & 23,35 & 34,41 & 11,34 & 20,25 & 14,29 & 6,06 & 10,20 & 12,19 \\
\hline IV. Doenças do sangue e dos órgãos hematop. & 0,00 & 0,00 & 5,68 & 3,25 & 1,27 & 5,05 & 2,86 & 8,21 & 4.15 & 5.30 & 4,10 & 6,06 & 2,78 & 3,66 & 3,70 & 6.90 & 6,90 & 5,26 & 6.25 & 7,69 & 3,45 & 0,00 & 3,74 & 4,67 \\
\hline V. Transtomos mentais & 0,00 & 1,35 & 0,10 & 0,19 & 0,10 & 0,00 & 0,62 & 2,27 & 0.40 & 0,25 & 0.35 & 0,54 & 0,46 & 0,36 & 0.38 & 0.26 & 0,00 & 0.00 & 0,00 & 0,00 & 0,00 & 0,00 & 0,22 & 0.47 \\
\hline VI. Doenças sistema nervoso órgăos dos sent. & 1,29 & 3,77 & 2,71 & 2,78 & 2,95 & 3,36 & 6.90 & 4.93 & 1,66 & 1,81 & 3,47 & 4.13 & 0.00 & 0.88 & 3,59 & 4,92 & 5,65 & 9,90 & 0.46 & 1,54 & 1,56 & 7,69 & 2,75 & 4.16 \\
\hline VII. Doenças do aparelho circulatório & 7.03 & 10,50 & 9,86 & 10,32 & 10.71 & 15,33 & 12,29 & 15,16 & 8,29 & 8,89 & 10,45 & 9,53 & 11,20 & 7,01 & 11,56 & 11,13 & 18,86 & 19,32 & 6,74 & 8,85 & 11,28 & 12,37 & 10,75 & 11,67 \\
\hline VIII. Doenças do aparelho respiratório & 2,46 & 3,70 & 6,95 & 10,04 & 3,74 & 5,16 & 4,80 & 10,37 & 7,25 & 7.02 & 8,55 & 7,50 & 8,91 & 4,22 & 5,17 & 5,98 & 8,46 & 7,45 & 4,39 & 7,30 & 7,12 & 6,13 & 6,16 & 6,81 \\
\hline IX. Doenças do aparelho digestivo & 3,59 & 4,47 & 5,04 & 5,15 & 5,18 & 6,03 & 5,38 & 6,86 & 3,53 & 3,90 & 5,86 & 5,27 & 3,18 & 4,31 & 5,15 & 5.41 & 9,37 & 8,41 & 2,28 & 3,97 & 6.64 & 5.10 & 5.02 & 5,35 \\
\hline$X$. Doenças do aparelho geniturinário & 0.97 & 2,21 & 1,87 & 1,64 & 0,88 & 2,81 & 1,44 & 3,94 & 1,61 & 2,62 & 3,61 & 2,25 & 3,24 & 2,77 & 3,74 & 3,51 & 3,52 & 3,85 & 0,61 & 0,42 & 3.14 & 0,80 & 2,24 & 2,44 \\
\hline XI. Complicaçőes da gravidez parto e puerpério & 0,00 & 0,00 & 0.02 & 0,02 & 0,01 & 0,02 & 0,05 & 0,03 & 0,13 & 0,09 & 0,09 & 0,04 & 0,00 & 0,00 & 0,04 & 0,05 & 0,10 & 0,04 & 0,00 & 0,00 & 0,00 & 0,00 & 0,04 & 0.03 \\
\hline XII. Doenças da pele e tecido celular subcutáneo & 0,68 & 1.11 & 1,54 & 1.47 & 1,67 & 0,00 & 1.43 & 2,50 & 0.47 & 1,46 & 1,49 & 1,64 & 0,00 & 0,52 & 2,23 & 2,46 & 1,84 & 6,12 & 0,99 & 0,00 & 2,56 & 0,00 & 1,35 & 1.57 \\
\hline XIII.Doenças sistema osteomusc e tecido conj. & 0,00 & 0.46 & 0,56 & 1,14 & 0,00 & 1,08 & 0,00 & 2,33 & 0.21 & 0,83 & 1,67 & 1,27 & 0,00 & 0,00 & 1,06 & 0,70 & 0,55 & 2,27 & 0,00 & 0,00 & 1,47 & 3,23 & 0,50 & 1,21 \\
\hline XIV. Anomalias congẽnitas & 5,26 & 0.00 & 2,26 & 2,50 & 14,29 & 0,00 & 0,00 & 2,86 & 4.05 & 4,11 & 0.75 & 7,57 & 0,00 & 0,00 & 3,82 & 4,05 & 0,00 & 0,00 & 0,00 & 0,00 & 10,00 & 0,00 & 3,68 & 1,92 \\
\hline XV. Algumas afecçes originadas periodo perin. & 6.09 & 9,71 & 6.48 & 7,86 & 6.47 & 7,44 & 6,69 & 8,00 & 7,00 & 10,96 & 2,13 & 3,95 & 0,00 & 0,00 & 5,10 & 10,98 & 0.91 & 3,45 & 3,64 & 10,91 & 0,00 & 0,00 & 4,05 & 6,66 \\
\hline XVI. Sintomas, sinais e afecçðes mal definidas & 1,15 & 4.59 & 6,82 & 3,91 & 5,64 & 2,42 & 7,41 & 3,90 & 5,26 & 5,22 & 3,50 & 6,18 & 6,45 & 2,85 & 11,05 & 4.44 & 7,25 & 7,62 & 0,82 & 0,74 & 2,08 & 0,00 & 5,22 & 3,81 \\
\hline XVIIILesð̌es e envenenamentos & 0,95 & 1.40 & 3,54 & 3,97 & 3.57 & 4,39 & 0,94 & 4,45 & 3,22 & 2,76 & 4,00 & 3,38 & 2,65 & 0,53 & 4,96 & 4,84 & 2,42 & 3,77 & 1,66 & 0,37 & 2,27 & 3,49 & 2,74 & 3.03 \\
\hline Class supl fatores oport contato serviços saúde & 0,33 & 2,30 & 3,69 & 3,42 & 0,00 & 0,00 & 0,00 & 0.00 & 0,44 & 0,64 & 7,69 & 0,00 & 0,00 & 33,33 & 0,00 & 0,00 & 0,00 & 0,00 & 0,00 & 0,00 & 5,56 & 0,00 & 1,61 & 3,61 \\
\hline CID năo especificado ou inválido & 66,67 & 3,12 & 0,00 & 4,09 & 0,00 & 3,84 & 0,00 & 3,85 & 33,33 & 4,12 & 15,00 & 4,87 & 0,00 & 2,75 & 12,50 & 4,25 & 0,00 & 5,31 & 0,00 & 2,99 & 0,00 & 2,89 & 11,59 & 3,83 \\
\hline Média & 5,78 & 3,26 & 4,26 & 4,80 & 4,39 & 4,80 & 3,73 & 5,88 & 5,27 & 4,36 & 5,68 & 5,04 & 2,79 & 4,34 & 5,42 & 5,47 & 6,30 & 7,62 & 2,22 & 4,04 & 4,85 & 3,21 & 4,61 & 4,80 \\
\hline
\end{tabular}

Fonte: Sistema de Informaçoes Hospitalares do SUS (SIH/SUS) 


\section{Evolução do Tempo de Permanência em Internações SUS}

As Figuras de 54 a 65 apresentam os ajustes de regressão entre tempo médio anual de permanência nas internações nos municípios em função do tempo em anos. O primeiro ano de avaliação é representado por -1 no eixo $x$ e corresponde ao período antes da implantação da gestão semi plena no município. Os anos seguintes, representados por 1,2 e 3 no eixo $x$, correspondem aos três anos seguintes, após a implantação da gestão semi plena no município.

A Figura 54 corresponde ao total dos 11 municipios, onde se observa que a evolução do tempo médio de permanência é decrescente em função do tempo. Apresenta-se nesta figura a curva de regressão, modelo polinomial de segundo grau e seu respectivo $r^{2}=0,95$, o que demonstra que ocorreu uma excelente aderência dos pontos obtidos à reta teórica, possibilitando a utilização dessa equação para a prospecção e a simulação deste indicador ao longo do tempo.

Figura 54 - Ajuste por regressão do tempo de permanência nas internações SUS nos 11 municípios estudados, nos períodos antes e depois da implantação da gestão semi plena, no Estado de São Paulo.

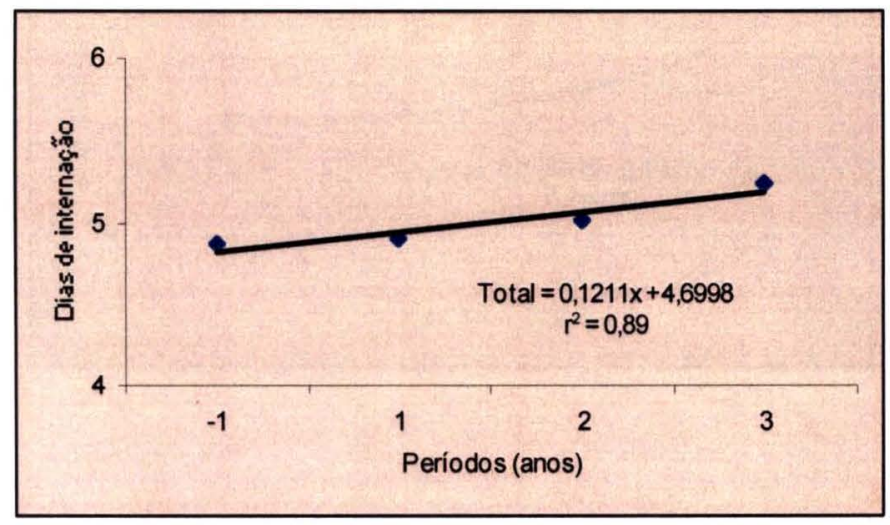

A Figura 55 corresponde ao Município de Assis, onde observa-se que a evolução do tempo médio anual de permanência em internações é crescente em função do tempo. Apresenta-se nessa figura a curva de regressão modelo polinomial de $2^{\circ}$ grau e seu respectivo $r^{2}=0,95$. 
Figura 55 - Ajuste por regressão do tempo de permanência nas internações SUS no município de Assis, nos períodos antes e depois da implantação da gestão semi plena, no Estado de São Paulo.

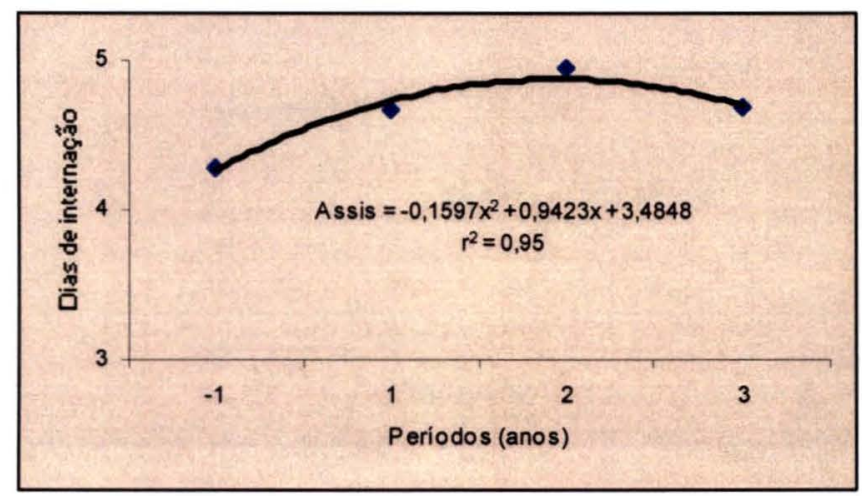

A Figura 56 corresponde ao Municipio de Campinas, onde observase que a evolução do tempo médio anual de permanência em internações é crescente em função do tempo. Apresenta-se nessa figura a curva de regressão modelo polinomial de $2^{\circ}$ grau e seu respectivo $r^{2}=0,93$. Figura 56 - Ajuste por regressão do tempo de permanência nas internações SUS no
municipio de Campinas, nos períodos antes e depois da implantação da
gestão semi plena, no Estado de São Paulo.

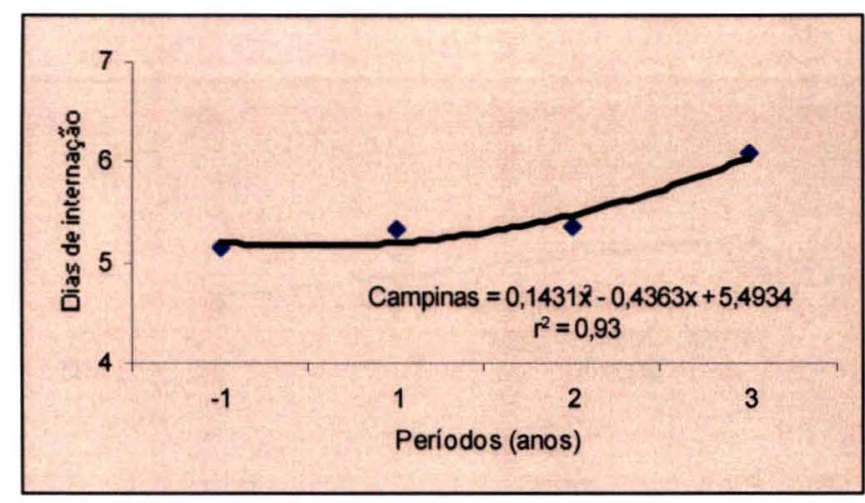

A Figura 57 corresponde ao Município de Diadema, onde observa-se que a evolução do tempo médio anual de permanência em internações é crescente em função do tempo. Apresenta-se nessa figura a curva de regressão modelo linear de $1^{\circ}$ grau e seu respectivo $r^{2}=0,90$. 
Figura 57 - Ajuste por regressão do tempo de permanência nas internações SUS no municipio de Diadema, nos períodos antes e depois da implantação da gestão semi plena, no Estado de São Paulo.

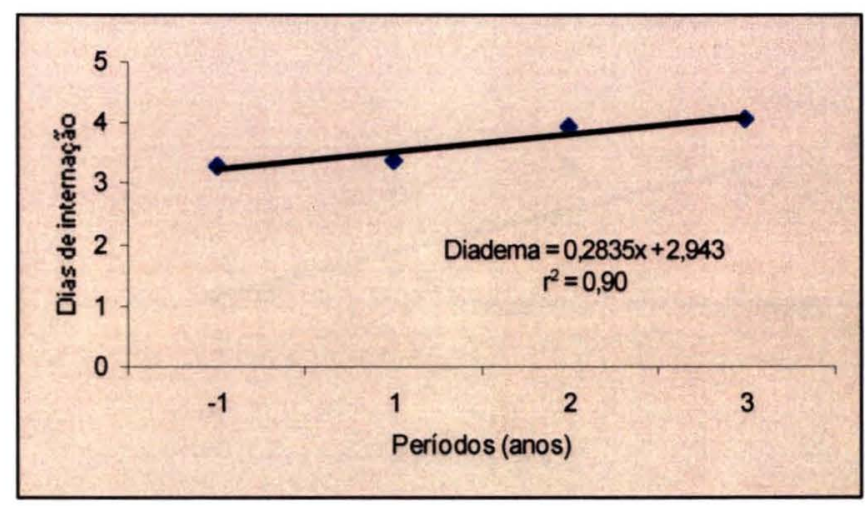

A figura 58 corresponde ao Municipio de Mauá, onde observa-se que a evolução do tempo médio anual de permanência em internações é crescente em função do tempo. Apresenta-se nessa figura a curva de regressão modelo linear de $1^{\circ}$ grau e seu respectivo $r^{2}=0,83$.

Figura 58 - Ajuste por regressão do tempo de permanência nas internações SUS no município de Mauá, nos períodos antes e depois da implantação da gestão semi plena, no Estado de São Paulo.

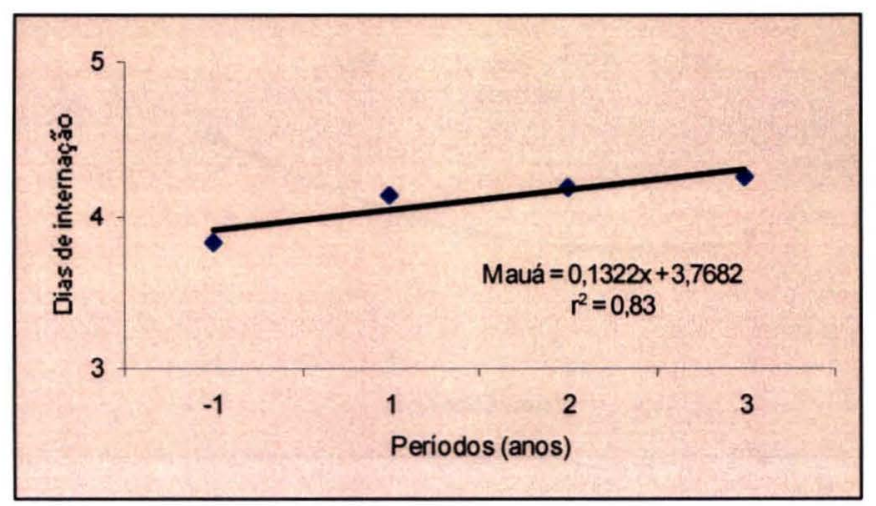

A Figura 59 corresponde ao Município de Ribeirão Preto, onde observa-se que a evolução tempo médio anual em internações é crescente em função do tempo. Apresenta-se nessa figura a curva de regressão modelo linear de $1^{\circ}$ grau e seu respectivo $r^{2}=0,77$. 
Figura 59 - Ajuste por regressão do tempo de permanência nas internações SUS no município de Ribeirão Preto, nos períodos antes e depois da implantação da gestão semi plena, no Estado de São Paulo.

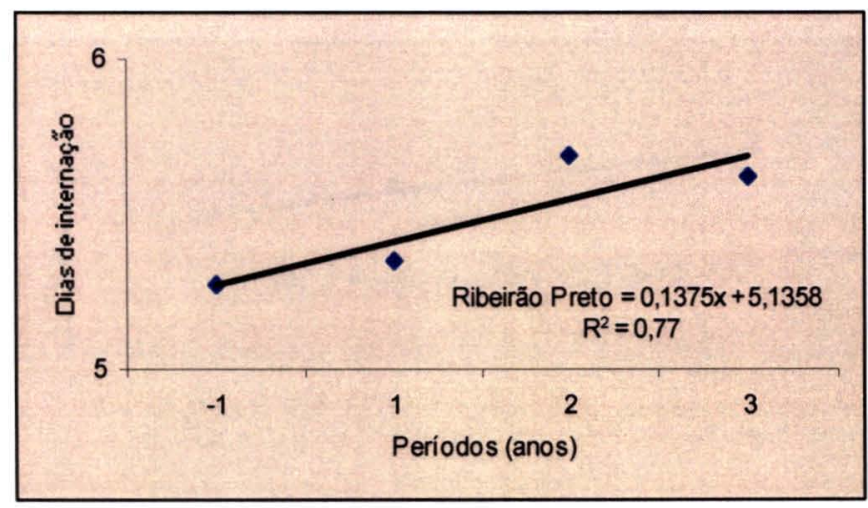

A Figura 60 corresponde ao Município de Santos, onde observa-se que a evolução do tempo médio anual de permanência em internações é decrescente em função do tempo. Apresenta-se nessa figura a curva de regressão modelo linear de $2^{\circ}$ grau e seu respectivo $r^{2}=0,99$.
Figura 60 - Ajuste por regressão dos gastos médios anuais das internações SUS no município de Santos, nos períodos antes e depois da implantação da gestão semi plena, no Estado de São Paulo.

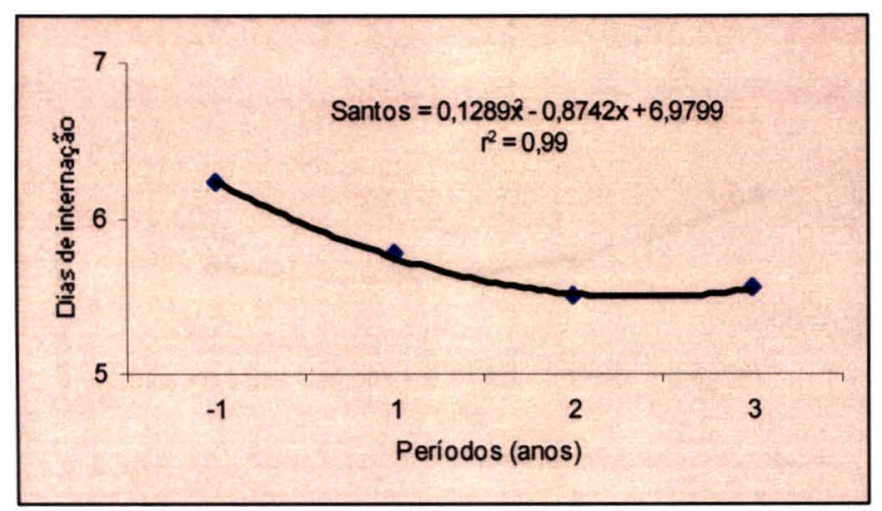

A Figura 61 corresponde ao Município de São Bernardo do Campo, onde observa-se que a evolução do tempo médio anual de permanência em internações é crescente em função do tempo. Apresenta-se nessa figura a curva de regressão modelo linear de $1^{\circ}$ grau e seu respectivo $r^{2}=0,98$. 
Figura 61 - Ajuste por regressão do tempo de permanência nas internações SUS no município de São Bernardo do Campo, nos períodos antes e depois da implantação da gestão semi plena, no Estado de São Paulo.

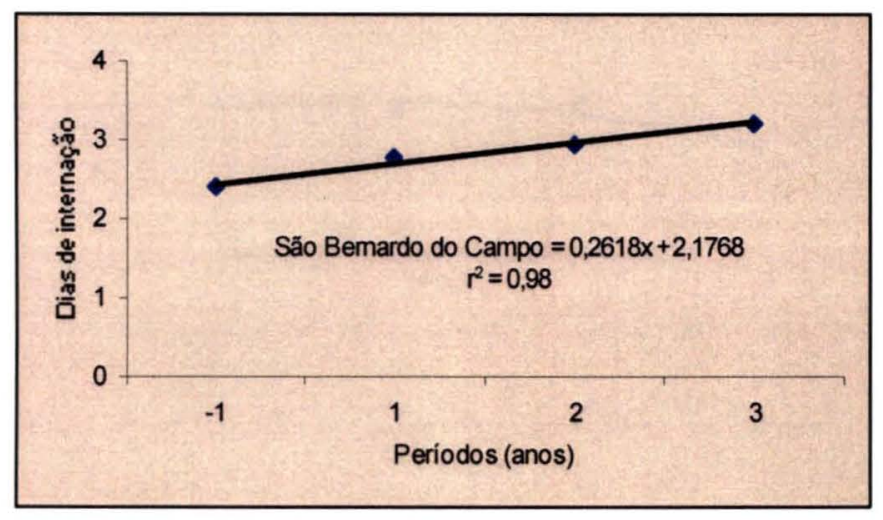

A Figura 62 corresponde ao Município de São José dos Campos, onde observa-se que a evolução do tempo médio anual de permanência em internações é crescente em função do tempo. Apresenta-se nessa figura a curva de regressão modelo polinomial de $2^{\circ}$ grau e seu respectivo $r^{2}=0,96$.

\footnotetext{
Figura 62 - Ajuste por regressão do tempo de permanência nas internações SUS no município de São José dos Campos, nos períodos antes e depois da implantação da gestão semi plena, no Estado de São Paulo.
}

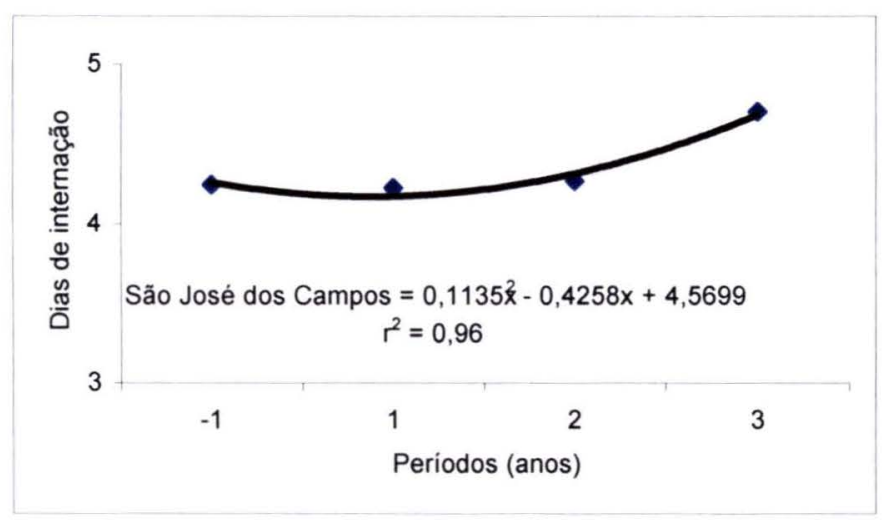

A Figura 63 corresponde ao Município de São Vicente, onde observa-se que a evolução do tempo médio anual de permanência em internações é decrescente em função do tempo. Apresenta-se nessa figura a curva de regressão modelo polinomial de $2^{\circ}$ grau e seu respectivo $r^{2}=0,80$. 
Figura 63 - Ajuste por regressão do tempo médio de permanência nas internações SUS no município de São Vicente, nos períodos antes e depois da implantação da gestão semi plena, no Estado de São Paulo.

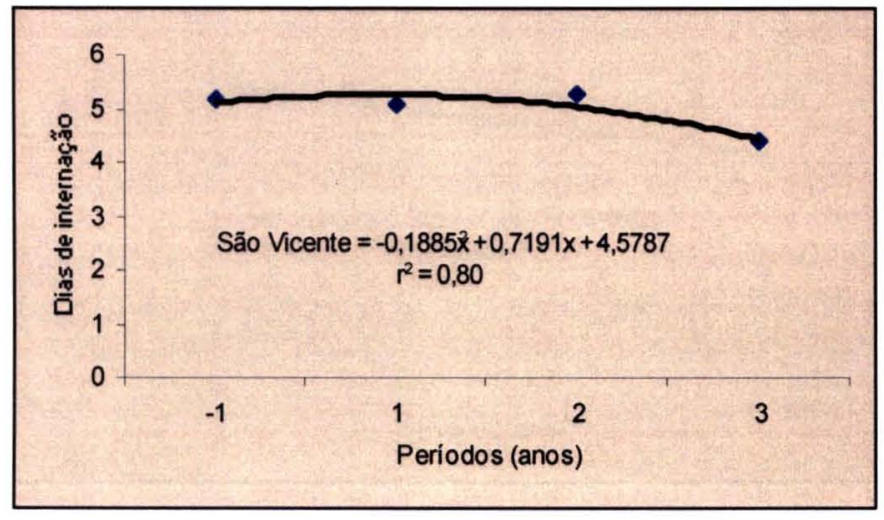

A Figura 64 corresponde ao Município de Sertãozinho, onde observase que a evolução do tempo médio anual de permanência em internações é decrescente em função do tempo. Apresenta-se nessa figura a curva de regressão modelo linear de $1^{\circ}$ grau e seu respectivo $r^{2}=0,97$.

Figura 64 - Ajuste por regressão do tempo de permanência nas internações SUS no município de Sertãozinho, nos períodos antes e depois da implantação da gestão semi plena, no Estado de São Paulo.

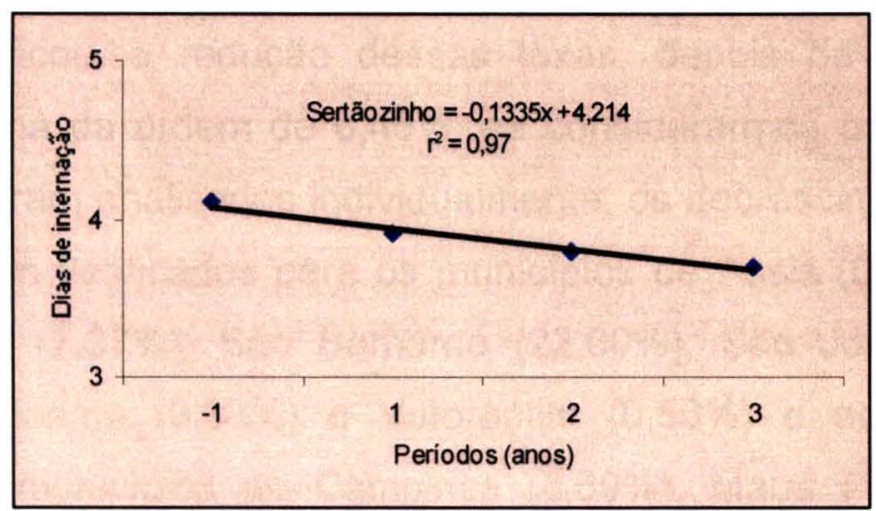

A Figura 65 corresponde ao Município de Votorantim, onde observase que a evolução do tempo médio anual de permanência em internações é decrescente em função do tempo. Apresenta-se nessa figura a curva de regressão modelo polinomial de $2^{\circ}$ grau e seu respectivo $r^{2}=0,99$. 
Figura 65 - Ajuste por regressão do tempo de permanência nas internações SUS no municipio de Votorantin, nos períodos antes e depois da implantação da gestão semi plena, no Estado de São Paulo.

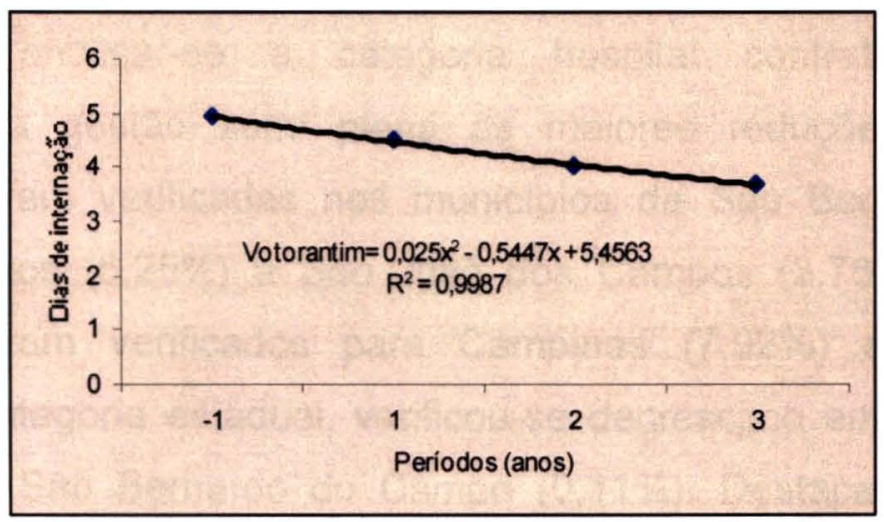

\subsubsection{Mortalidade Hospitalar nos Municípios por Prestador}

O Quadro 78, mostra a comparação da taxa de mortalidade hospitalar, por município e tipo de prestador, nos períodos antes e depois da implantação da gestão semi plena.

Comparando-se as taxas de mortalidade ocorridas nos 11 municipios, verificou-se redução dessas taxas, depois da implantação da gestão semi plena da ordem de $0,46 \%$, se considerarmos os 11 municípios. Quando estes foram analisados individualmente, os decréscimos nas taxas de mortalidade foram verificados para os municípios de Assis (0,54\%), Diadema $(0,03 \%)$, Santos $(7,37 \%)$, São Bernardo $(22,00 \%)$, São José dos Campos $(4,55 \%)$, São Vicente $(0,38 \%)$ e Votorantim $(0,56 \%)$ e acréscimos foram verificados nos municípios de Campinas $(8,69 \%)$, Mauá $(1,41 \%)$, Ribeirão Preto $(0,92 \%)$ e Sertãozinho $(0,48 \%)$.

Com relação aos prestadores, considerando-se os 11 municipios, observou-se decréscimos nas taxas de mortalidade, depois da implantação da gestão semi plena nos hospitais contratados $(0,16 \%)$, nos estaduais $(0,11 \%)$, nos filantrópicos $(0,10 \%)$ e nos universitários $(0,50 \%)$ e acréscimo nas taxas 
de mortalidade em hospitais municipais, que cresceram $0,41 \%$, depois da implantação da gestão semi plena.

Ao analisar-se a categoria hospital contratado, depois da implantação da gestão semi plena as maiores reduções das taxas de mortalidade foram verificadas nos municípios de São Bernardo do Campo $(21,52 \%)$, Santos $(6,25 \%)$ e São José dos Campos $(3,76 \%)$ e os maiores acréscimos foram verificados para Campinas $(7,92 \%)$ e Ribeirão Preto $(1,48 \%)$. Na categoria estadual, verificou-se decréscimo em Assis $(0,77 \%)$ e acréscimo em São Bernardo do Campo (0,11\%). Destacam-se as maiores taxas de redução relativas aos municipios de Santos e São Bernardo, por conta de não existir hospital contratado no municipio após a implantação da semi plena.

Quadro 78 - Taxa de mortalidade de internações SUS nos municípios, por prestador, antes e depois da implantação da gestão semi plena, no Estado de São Paulo.

\begin{tabular}{|c|c|c|c|c|c|c|c|c|c|c|c|c|}
\hline \multirow{3}{*}{$\begin{array}{c}\text { Prestadores } \\
\text { Municiplos }\end{array}$} & \multicolumn{2}{|c|}{ Contratados } & \multicolumn{2}{|c|}{ Estaduais } & \multicolumn{2}{|c|}{ Municipais } & \multicolumn{2}{|c|}{ Filantropicos } & \multicolumn{2}{|c|}{ Universitarios } & \multicolumn{2}{|c|}{ Total } \\
\hline & A & D & A & D & A & D & A & D & A & D & A & D \\
\hline & $\%$ & $\%$ & $\%$ & $\%$ & $\%$ & $\%$ & $\%$ & $\%$ & $\%$ & $\%$ & $\%$ & $\%$ \\
\hline Assis & 0.42 & 0,36 & 11,09 & 10,32 & & & 1.81 & 2.09 & & & 13,32 & 12,78 \\
\hline Campinas & 3,51 & 11,43 & & & 8,35 & 9,31 & 1,27 & 1,40 & 4,94 & 4,61 & 18,07 & 26,76 \\
\hline Diadema & 0,27 & 0,20 & & & 3.34 & 4,10 & 1.78 & 1,06 & & & 5,39 & 5,36 \\
\hline Mauá & & & & & 5,23 & 6,42 & 3,65 & 3,87 & & & 8,88 & 10,29 \\
\hline Ribeirăo Preto & 3,19 & 4,67 & & & & & & & 5,38 & 4,83 & 8,57 & 9,49 \\
\hline Santos & 6,25 & & & & 6,69 & 5,97 & 5,5 & 5,10 & & & 18,44 & 11,07 \\
\hline Săo Bernardo do Campo & 21.52 & & 5,73 & 5,84 & 5,44 & 4,20 & 2,25 & 2.74 & 1,54 & 1,70 & 36,48 & 14,48 \\
\hline Sertaozinho & & & & & & & 2,83 & 3,31 & & & 2,83 & 3.31 \\
\hline Sáo José dos Campos & 7.42 & 3,66 & & & 8,43 & 7,64 & & & & & 15,85 & 11,30 \\
\hline Săo Vicente & & & & & & & 5,72 & 5,34 & & & 5,72 & 5,34 \\
\hline Votorantim & 4,77 & 4.21 & & & & & & & & & 4,77 & 4,21 \\
\hline Total & 1,87 & 1,71 & 7,44 & 7,33 & 5,78 & 6,19 & 3,57 & 3,47 & 5,01 & 4,51 & 23,67 & 23,21 \\
\hline
\end{tabular}

A categoria dos prestadores municipais apresentou decréscimo nos municípios de São Bernardo do Campo $(1,24 \%)$, São José dos Campos $(0,79 \%)$ e Santos $(0,72 \%)$ e acréscimos em Mauá $(1,19 \%)$, Campinas $(0,96 \%)$ e Diadema $(0,76 \%)$. Os hospitais filantrópicos apresentaram reduções na taxa de mortalidade, depois da implantação da semi plena em Diadema $(0,72 \%)$, Santos $(0,40 \%)$ e São Vicente $(0,38 \%)$ e acréscimos em São Bernardo do 
Campo (0,49\%), Sertãozinho (0,48\%), Assis $(0,28 \%)$ e Campinas $(0,13 \%)$. A categoria universitário, apresentou decréscimos em Ribeirão Preto $(0,55 \%)$ e em Campinas $(0,33 \%)$ depois da semi plena, e, apresentou acréscimos nas taxas de mortalidade de $0,16 \%$, no municipio de São Bernardo do Campo.

\subsubsection{Mortalidade Hospitalar e Capítulos do CID IX}

No Quadro 79 são apresentadas as taxas em percentual de mortalidade por municipios, segundo os capitulos do CID IX, nos períodos antes e depois da implantação da gestão semi plena no municipio.

Comparado-se as taxas obtidas, levando-se em conta os 11 municípios, verificou-se que depois da implantação da gestão semi plena os maiores acréscimos nas taxas de mortalidade corresponderam aos capítulos: $X V$ - Algumas afecçōes originadas período perinatal $(2,61 \%)$ antes $=4,05 \%$ e depois $=6,66 \%$ ), Capitulos III - Doenças glândulas endócrinas, nutrição, metabolismo, transtornos imunológicos $(1,99 \%)($ antes $=10,20 \%$ e depois $=$ $12,19 \%), \mathrm{VI}$ - Doenças sistema nervoso órgãos dos sentidos $(1,41 \%)$ (antes $=$ $2,75 \%$ e depois $=4,16 \%), \|$ - Neoplasmas $(1,11 \%)$ (antes $=8,75 \%$ e depois $=$ $9,86 \%$ ) e I - Doenças Infecciosas e parasitárias $(1,01 \%$ ) (antes $=6,96 \%$ e depois $=7,97 \%$ ). Esses resultados, segundo LAURENTI, MELLO JORGE, LEBRÃO \& GOTLIEB (1987).

As maiores reduções depois da implantação da semi plena, foram registradas nas morbidades relativas aos capitulos XIV - Anomalias congênitas $(1,76 \%$ - antes $=4,05 \%$ e depois $=6,66 \%), X V I$ - Sintomas, sinais e afecções mal definidas $(1,41 \%$ (antes $=5,22 \%$ e depois $=3,81 \%)$ e XI - Complicações da gravidez parto e puerpério $(0,01 \%)$ (antes $0,04 \%$ e depois $0,03 \%$ )

Uma observação interessante é que depois da semi plena, as taxas de mortalidade relativas aos CIDs não especificado ou inválido foram reduzidas em $7,77 \%$ (antes $=11,59 \%$ e depois $=3,83 \%$ ), o que demonstra uma melhora geral na avaliação e no registro dos pacientes internados. $O$ item 
Classificação suplementar: fatores oportunidade de contato serviços saúde, aumentaram em $2 \%$ (antes $=1,61 \%$ e depois $3,61 \%$ ).

Considerando-se os 11 municípios verificou-se o aumento médio geral de $0,19 \%$, nas taxas de mortalidade depois da implantação da gestão semi plena.

Os municipios que depois da implantação da gestão semi plena apresentaram os maiores aumentos médios nas taxas de mortalidade foram Mauá $(2,16 \%)$, Sertãozinho (1,82\%), São Bernardo do Campo (1,55\%), São Vicente $(1,32 \%)$, Campinas $(0,53 \%)$, Diadema $(0,40 \%)$ e São José dos Campos $(0,53 \%)$ e decréscimos nas taxas de mortalidade nos municípios de Santos $(0,64 \%)$, Ribeirão Preto $(0,91 \%)$, Votorantim $(1,65 \%)$ e Assis $(2,52 \%)$.

No Município de Assis registrou-se a redução de $63,55 \%$ nas taxas de mortalidade com CID não especificado ou inválido, mostrando uma melhora na qualidade do registro enquanto o item Classificação suplementar: fatores oportunidade de contato serviços saúde, aumentaram em 1,97\%. Os capitulos que apresentaram redução nas taxas de mortalidade, depois da semi plena foram: XIV - Anomalias congênitas $(5,26 \%)$ e I - Doenças Infecciosas e parasitárias $(1,81 \%)$ e os que apresentaram maiores aumentos foram dos capitulos VI - Doenças sistema nervoso órgãos dos sentidos (2,48\%), XVI. Sintomas, sinais e afecções mal definidas $(3,44 \%)$, VII - Doenças do aparelho circulatório $(3,47 \%)$ e XV - Algumas afecções originadas período perinatal $(3,62 \%)$.

No Municipio de Campinas registrou-se o aumento de 4,09\% nas taxas de mortalidade com CID não especificado ou inválido, enquanto o item Classificação suplementar: fatores oportunidade de contato serviços saúde, reduziram $0,27 \%$. Os capitulos que apresentaram redução nas taxas de mortalidade, depois da semi plena foram: XVI - Sintomas, sinais e afecções mal definidas (2,91\%), IV - Doenças do sangue e dos órgãos hematopoéticos $(2,43 \%)$, III - Doenças das glândulas endócrinas, da nutrição do metabolismo e transtornos imunitários $(0,61 \%), X$ - Doenças do aparelho geniturinário $(0,23 \%)$ 
e XII - Doenças da pele e tecido celular subcutâneo $(0,07 \%)$ e os que apresentaram maiores aumentos foram os capitulos I - Doenças Infecciosas e parasitárias $(5,25 \%)$, VIII - Doenças do aparelho respiratório $(3,09 \%), X V$ Algumas afecções originadas periodo perinatal $(1,38 \%)$ e II - Neoplasmas $(0,88 \%)$.

No Município de Diadema registrou-se o aumento de $3,84 \%$ nas taxas de mortalidade com CID não especificado ou inválido, enquanto o item Classificação suplementar: fatores oportunidade de contato serviços saúde, não se alterou. Os capitulos que apresentaram redução nas taxas de mortalidade, depois da semi plena foram: XIV - Anomalias congênitas $(14,29 \%), X V I$ - Sintomas, sinais e afeç̧ões mal definidas $(3,22 \%)$, XII Doenças da pele e tecido celular subcutâneo $(1,67 \%)$ e os que apresentaram maiores aumentos foram os capítulos: III - Doenças das glândulas, endócrinas da nutrição metabolismo e transtornos imunitários (2,39\%), II - Neoplasmas (3,51\%), IV - Doenças do sangue e dos órgãos hematopoéticos $(3,78 \%)$, VII Doenças do aparelho circulatório $(4,62 \%)$.

No Municipio de Mauá registrou-se o aumento de 3,85\% nas taxas de mortalidade com CID não especificado ou inválido, enquanto o item Classificação suplementar: fatores oportunidade de contato serviços saúde, não se alterou. Os capítulos que apresentaram redução nas taxas de mortalidade, depois da semi plena foram: XVI - Sintomas, sinais e afecções mal definidas $(3,51 \%), \mathrm{VI}$ - Doenças sistema nervoso órgãos dos sentidos $(1,97 \%)$ e XI - Complicações da gravidez parto e puerpério $(0,02 \%)$ e os que apresentaram maiores aumentos foram os capitulos: III - Doenças das glândulas endócrinas, da nutrição metabolismo e transtornos imunitários (8,93\%), VIII - Doenças do aparelho respiratório (5,57\%), IV - Doenças do sangue e dos órgãos hematopoéticos (5,35\%), XVII - Lesões e envenenamentos $(3,51 \%)$, VII - Doenças do aparelho circulatório $(2,87 \%)$,

Depois da implantação da gestão semi plena, no Municipio de Ribeirão Preto registrou-se a redução nas taxas de mortalidade com CID não especificado ou inválido em 29,21\%, enquanto o item Classificação 
suplementar: fatores oportunidade de contato serviços saúde, aumentou $0,20 \%$. Os capitulos que apresentaram redução nas taxas de mortalidade, depois da semi plena foram: III - Doenças das glândulas endócrinas, da nutrição e do metabolismo e transtornos imunitários $(0,56 \%)$, XVII - Lesões e envenenamentos $(0,46 \%)$, VIII - Doenças do aparelho respiratório $(0,23 \%), \mathrm{XI}$ Complicações da gravidez parto e puerpério $(0,04 \%)$ e XVI - Sintomas, sinais e afecções mal definidas $(0,04 \%)$ e os que apresentaram maiores aumentos foram os capitulos: XV - Algumas afeç̧ões originadas periodo perinatal $(3,96 \%), I$ - Doenças Infecciosas e parasitárias $(2,44 \%)$, II - Neoplasmas $(1,87 \%)$, IV. Doenças do sangue e dos órgãos hematopoéticos $(1,15 \%)$.

No Municipio de Santos, depois da semi plena, registrou-se a redução de $10,13 \%$ nas taxas de mortalidade com CID não especificado ou inválido, enquanto no item Classificação suplementar: fatores oportunidade de contato serviços saúde, obteve-se a redução de $7,09 \%$. Os capitulos que apresentaram redução nas taxas de mortalidade, depois da semi plena foram: III - Doenças das glândulas endócrinas, da nutrição e do metabolismo e transtornos imunitários $(8,48 \%), X$ - Doenças do aparelho geniturinário $(1,36 \%)$, VIII - Doenças do aparelho respiratório $(1,05 \%)$ e VII - Doenças do aparelho circulatório $(0,92 \%)$ e os que apresentaram maiores aumentos foram os capitulos: XIV - Anomalias congênitas(6,82\%), I - Doenças Infecciosas e parasitárias $(2,87 \%), X V I$ - Sintomas, sinais e afecções mal definidas $(2,68 \%)$, II - Neoplasmas (2,07\%), IV - Doenças do sangue e dos órgãos hematopoéticos $(1,96 \%)$ e XV - Algumas afecções originadas no periodo perinatal $(1,82 \%)$.

No Municipio de São Bernardo do Campo registrou-se o aumento de $2,75 \%$ nas taxas de mortalidade com CID não especificado ou inválido, enquanto o item Classificação suplementar: fatores oportunidade de contato serviços saúde aumentou em $33,33 \%$. Os capítulos que apresentaram redução nas taxas de mortalidade, depois da semi plena foram: VIII - Doenças do aparelho respiratório $(4,69 \%)$, I - Doenças Infecciosas e parasitárias $(4,30 \%)$, VII - Doenças do aparelho circulatório $(4,19 \%), X V I$ - Sintomas, sinais e afecções mal definidas (3,60\%), XVII - Lesões e envenenamentos $(2,12 \%)$ e os que apresentaram maiores aumentos foram os capitulos: III - Doenças das 
glândulas endócrinas, da nutrição e do metabolismo e transtornos imunitários (6,93\%), II - Neoplasmas (2,51\%), IX - Doenças do aparelho digestivo $(1,13 \%)$, IV - Doenças do sangue e dos órgãos hematopoéticos $(0,88 \%)$ e VI Doenças sistema nervoso órgãos dos sentidos $(0,88 \%)$.

No Municipio de São José dos Campos registrou-se a redução de $8,25 \%$ nas taxas de mortalidade com CID não especificado ou inválido, enquanto $\mathrm{o}$ item Classificação suplementar: fatores oportunidade de contato serviços saúde, não se alterou. Os capitulos que apresentaram redução nas taxas de mortalidade, depois da semi plena foram: XVI - Sintomas, sinais e afecções mal definidas $(6,61 \%)$, Doenças Infecciosas e parasitárias $(0,93 \%)$, VII. Doenças do aparelho circulatório $(0,43 \%)$, XIII - Doenças sistema osteomuscular e do tecido conjuntivo e tecido conjuntivo $(0,36 \%)$ e os que apresentaram maiores aumentos foram os capitulos: XV. Algumas afecções originadas período perinatal $(5,88 \%), \|$ - Neoplasmas $(5,35 \%)$, IV. Doenças do sangue e dos órgãos hematopoéticos $(3,20 \%), \mathrm{VI}$ - Doenças sistema nervoso órgãos dos sentidos $(1,33 \%)$, VIII - Doenças do aparelho respiratório $(0,81 \%)$, III - Doenças das glândulas endócrinas, da nutrição e do metabolismo e transtornos imunitários $(0,71 \%)$.

No Municipio de São Vicente registrou-se o aumento de 5,31\% nas taxas de mortalidade com CID não especificado ou inválido, enquanto o item Classificação suplementar: fatores oportunidade de contato serviços saúde, não se alterou. Os capitulos que apresentaram redução nas taxas de mortalidade, depois da semi plena foram: II - Neoplasmas (2,02\%), IV Doenças do sangue e dos órgãos hematopoéticos $(1,64 \%)$, VIII - Doenças do aparelho respiratório $(1,01 \%), I X$ - Doenças do aparelho digestivo $(0,96 \%)$ e I Doenças Infecciosas e parasitárias $(0,91 \%)$ e os que apresentaram maiores aumentos foram os capitulos: III - Doenças das glândulas endócrinas, da nutrição e do metabolismo e transtornos imunitários (11,06\%), XII - Doenças da pele e tecido celular subcutâneo $(4,28 \%), \mathrm{VI}$ - Doenças sistema nervoso órgãos dos sentidos $(4,25 \%), X V$ - Algumas afecções originadas periodo perinatal $(2,54 \%)$, XIII - Doenças sistema osteomuscular e do tecido conjuntivo $(1,72 \%)$ e XVII - Lesões e envenenamentos (1,35\%). 
No Municipio de Sertãozinho registrou-se o aumento de $2,99 \%$ nas taxas de mortalidade com CID não especificado ou inválido, enquanto o item Classificação suplementar: fatores oportunidade de contato serviços saúde, não se alterou. Os capítulos que apresentaram redução nas taxas de mortalidade, depois da semi plena foram: XVII - Lesões e envenenamentos $(1,29 \%)$, XII - Doenças da pele e tecido celular subcutâneo $(0,99 \%), X$ Doenças do aparelho geniturinário $(0,19 \%)$ e XVI - Sintomas, sinais e afecções mal definidas $(0,08 \%)$ e os que apresentaram maiores aumentos foram os capitulos: III - Doenças das glândulas endócrinas, da nutrição e do metabolismo e transtornos imunitários (8,91\%), XV - Algumas afecções originadas período perinatal $(7,27 \%)$, II - Neoplasmas $(7,04 \%)$, VIII - Doenças do aparelho respiratório $(2,91 \%)$ e VII - Doenças do aparelho circulatório $(2,11 \%)$.

No Municipio de Votorantim registrou-se o aumento de $2,89 \%$ nas taxas de mortalidade com CID não especificado ou inválido, enquanto o item Classificação suplementar: fatores oportunidade de contato serviços saúde, foi reduzida em $5,56 \%$. Os capitulos que apresentaram redução nas taxas de mortalidade, depois da semi plena foram: II - Neoplasmas (11,58\%), XIV Anomalias congênitas $(10,00 \%)$, III. Doenças das glândulas endócrinas, da nutrição e do metabolismo e transtornos imunitários $(8,23 \%)$, IV - Doenças do sangue e dos órgãos hematopoéticos $(3,45 \%)$, XII - Doenças da pele e tecido celular subcutâneo $(2,56 \%), X$ - Doenças do aparelho geniturinário $(2,34 \%)$, $X V I$ - Sintomas, sinais e afecções mal definidas $(2,08 \%)$ e os que apresentaram maiores aumentos foram os capitulos: VI - Doenças sistema nervoso órgãos dos sentidos $(6,13 \%), I$ - Doenças Infecciosas e parasitárias $(3,93 \%)$ e XIII - Doenças sistema osteomuscular e do tecido conjuntivo $(1,76 \%)$. 
Quadro 79 - Taxa de mortalidade em percentual por localidade de ocorrência e Capitulo CID IX, nos periodos antes e depois da gestão semi plena.

\begin{tabular}{|c|c|c|c|c|c|c|c|c|c|c|c|c|c|c|c|c|c|c|c|c|c|c|c|c|}
\hline \multirow[b]{3}{*}{ Capitulo } & \multicolumn{2}{|c|}{ Assis } & \multicolumn{2}{|c|}{ Campinas } & \multicolumn{2}{|c|}{ Diadema } & \multicolumn{2}{|c|}{ Mauá } & \multicolumn{2}{|c|}{$\begin{array}{c}\text { Ribeiråo } \\
\text { Preto }\end{array}$} & \multicolumn{2}{|c|}{ Santos } & \multicolumn{2}{|c|}{$\begin{array}{c}\text { Sao Bernardo } \\
\text { do Campo }\end{array}$} & \multicolumn{2}{|c|}{$\begin{array}{c}\text { Sáo José dos } \\
\text { Campos }\end{array}$} & \multicolumn{2}{|c|}{ Săo Vicente } & \multicolumn{2}{|c|}{ Sertăozinho } & \multicolumn{2}{|c|}{ Votorantim } & \multicolumn{2}{|c|}{ Média } \\
\hline & A & D & A & D & A & D & A & D & A & D & A & D & A & D & A & D & A & D & A & D & A & D & A & D \\
\hline & $\%$ & $\%$ & $\%$ & $\%$ & $\%$ & $\%$ & $\%$ & $\%$ & $\%$ & $\%$ & $\%$ & $\%$ & $\%$ & $\%$ & $\%$ & $\%$ & $\%$ & $\%$ & $\%$ & $\%$ & $\%$ & $\%$ & $\%$ & $\%$ \\
\hline I - Doenças Infecciosas e parasitárias & 3,15 & 1,34 & 10,15 & 15,40 & 4,53 & 5,87 & 7,59 & 9.15 & 9,44 & 11,88 & 7,87 & 10,74 & 10,00 & 5,70 & 6,45 & 5,52 & 9,92 & 9,01 & 1,82 & 3,53 & 5,59 & 9,52 & 6.96 & 7,97 \\
\hline I1 - Neoplasmas & 5,90 & 6,84 & 6,15 & 7,03 & 17,41 & 20,92 & 1,52 & 3,17 & 5,34 & 7,21 & 12,15 & 14,22 & 2,30 & 4,81 & 8,51 & 13,86 & 20,59 & 18,57 & 1,12 & 8,16 & 15,22 & 3,64 & 8.75 & 9,86 \\
\hline III. Dças glând endócr nutriç metab transt imun & 4,33 & 5,13 & 7.59 & 6,98 & 5,02 & 7,41 & 10,86 & 19,79 & 4,41 & 3,85 & 15,13 & 6.65 & 1,91 & 8,84 & 14,01 & 14,72 & 23,35 & 34,41 & 11,34 & 20,25 & 14,29 & 6,06 & 10,20 & 12,19 \\
\hline IV. Doenças do sangue e dos órgăos hematop. & 0,00 & 0,00 & 5,68 & 3,25 & 1,27 & 5,05 & 2.86 & 8.21 & 4.15 & 5,30 & 4,10 & 6,06 & 2,78 & 3,66 & 3,70 & 6,90 & 6,90 & 5,26 & 6,25 & 7,69 & 3,45 & 0,00 & 3,74 & 4,67 \\
\hline V. Transtornos mentais & 0,00 & 1,35 & 0,10 & 0,19 & 0,10 & 0,00 & 0,62 & 2.27 & 0,40 & 0.25 & 0,35 & 0,54 & 0,46 & 0,36 & 0,38 & 0,26 & 0,00 & 0,00 & 0,00 & 0,00 & 0.00 & 0,00 & 0,22 & 0,47 \\
\hline VI. Doenças sistema nervoso órgãos dos sent. & 1,29 & 3,77 & 2,71 & 2,78 & 2,95 & 3,36 & 6,90 & 4,93 & 1.66 & 1.81 & 3.47 & 4.13 & 0.00 & 0,88 & 3.59 & 4,92 & 5,65 & 9.90 & 0,46 & 1,54 & 1,56 & 7,69 & 2,75 & 4,16 \\
\hline VII. Doenças do aparelho circulatório & 7,03 & 10,50 & 9,86 & 10,32 & 10,71 & 15,33 & 12,29 & 15,16 & 8,29 & 8,89 & 10,45 & 9.53 & 11,20 & 7,01 & 11,56 & 11,13 & 18,86 & 19,32 & 6,74 & 8,85 & 11,28 & 12,37 & 10,75 & 11,67 \\
\hline VIII Doenças do aparelho respiratório & 2,46 & 3,70 & 6,95 & 10,04 & 3,74 & 5,16 & 4,80 & 10,37 & 7.25 & 7,02 & 8,55 & 7.50 & 8.91 & 4.22 & 5,17 & 5,98 & 8.46 & 7.45 & 4,39 & 7,30 & 7,12 & 6,13 & 6,16 & 6,81 \\
\hline IX. Doenças do aparelho digestivo & 3,59 & 4,47 & 5,04 & 5,15 & 5.18 & 6,03 & 5,38 & 6,86 & 3,53 & 3,90 & 5,86 & 5.27 & 3,18 & 4.31 & 5,15 & 5,41 & 9,37 & 8,41 & 2,28 & 3,97 & 6,64 & 5,10 & 5,02 & 5,35 \\
\hline X. Doenças do aparetho geniturinário & 0,97 & 2,21 & 1,87 & 1,64 & 0.88 & 2,81 & 1,44 & 3.94 & 1,61 & 2.62 & 3,61 & 2.25 & 3.24 & 2,77 & 3.74 & 3,51 & 3,52 & 3.85 & 0,61 & 0.42 & 3,14 & 0,80 & 2,24 & 2,44 \\
\hline XI. Complicaçðes da gravidez parto e puerpério & 0,00 & 0,00 & 0,02 & 0,02 & 0,01 & 0,02 & 0,05 & 0,03 & 0,13 & 0.09 & 0.09 & 0.04 & 0.00 & 0.00 & 0.04 & 0.05 & 0.10 & 0.04 & 0,00 & 0.00 & 0,00 & 0,00 & 0,04 & 0.03 \\
\hline XII. Doenças da pele e tecido celular subcutâneo & 0,68 & 1,11 & 1,54 & 1,47 & 1,67 & 0,00 & 1,43 & 2,50 & 0,47 & 1,46 & 1,49 & 1.64 & 0,00 & 0.52 & 2,23 & 2,46 & 1,84 & 6,12 & 0,99 & 0.00 & 2,56 & 0,00 & 1,35 & 1,57 \\
\hline XIII. Doenças sistema osteomusc e tecido conj. & 0,00 & 0,46 & 0,56 & 1,14 & 0,00 & 1,08 & 0,00 & 2.33 & 0,21 & 0,83 & 1,67 & 1.27 & 0,00 & 0,00 & 1,06 & 0,70 & 0,55 & 2.27 & 0.00 & 0,00 & 1,47 & 3,23 & 0,50 & 1,21 \\
\hline XIV. Anomalias congênitas & 5.26 & 0,00 & 2,26 & 2.50 & 14,29 & 0,00 & 0,00 & 2,86 & 4,05 & 4,11 & 0,75 & 7.57 & 0,00 & 0,00 & 3,82 & 4.05 & 0,00 & 0,00 & 0,00 & 0.00 & 10,00 & 0,00 & 3.68 & 1,92 \\
\hline$X V$. Algumas afecçð̌es originadas período perin. & 6,09 & 9,71 & 6,48 & 7,86 & 6,47 & 7.44 & 6,69 & 8,00 & 7,00 & 10,96 & 2,13 & 3,95 & 0,00 & 0,00 & 5,10 & 10,98 & 0,91 & 3,45 & 3,64 & 10,91 & 0.00 & 0,00 & 4.05 & 6,66 \\
\hline XVI. Sintomas, sinais e afecçð̋s mal definidas & 1,15 & 4.59 & 6.82 & 3,91 & 5,64 & 2,42 & 7,41 & 3,90 & 5,26 & 5,22 & 3,50 & 6.18 & 6,45 & 2,85 & 11,05 & 4,44 & 7,25 & 7,62 & 0,82 & 0.74 & 2.08 & 0,00 & 5.22 & 3,81 \\
\hline XVII.Lesర̋es e envenenamentos & 0,95 & 1,40 & 3.54 & 3.97 & 3,57 & 4,39 & 0,94 & 4.45 & 3,22 & 2,76 & 4,00 & 3,38 & 2,65 & 0.53 & 4,96 & 4,84 & 2,42 & 3,77 & 1,66 & 0,37 & 2,27 & 3.49 & 2,74 & 3,03 \\
\hline Class supl fatores oport contato serviços saúde & 0,33 & 2,30 & 3,69 & 3,42 & 0,00 & 0,00 & 0.00 & 0,00 & 0,44 & 0,64 & 7,69 & 0,00 & 0,00 & 33,33 & 0,00 & 0,00 & 0,00 & 0,00 & 0,00 & 0,00 & 5,56 & 0.00 & 1,61 & 3,61 \\
\hline CID nåo especificado ou inválido & 66,67 & 3,12 & 0,00 & 4.09 & 0,00 & 3,84 & 0.00 & 3,85 & 33,33 & 4,12 & 15,00 & 4,87 & 0,00 & 2,75 & 12,50 & 4.25 & 0,00 & 5,31 & 0,00 & 2,99 & 0,00 & 2.89 & 11,59 & 3,83 \\
\hline Média & 5,78 & 3,26 & 4,26 & 4,80 & 4,39 & 4,80 & 3,73 & 5,88 & 5,27 & 4,36 & 5,68 & 5,04 & 2,79 & 4,34 & 5,42 & 5,47 & 6,30 & 7,62 & 2,22 & 4,04 & 4,85 & 3,21 & 4,61 & 4,80 \\
\hline
\end{tabular}




\subsubsection{Evolução da Taxa de Mortalidade em Internações SUS}

As Figuras de 66 a 77 apresentam os ajustes de regressão entre taxa média anual de mortalidade nas internações nos município em função do tempo em anos. O primeiro ano de avaliação é representado por -1 no eixo $x$ e corresponde ao período antes da implantação da gestão semi plena no município. Os anos seguintes, representados por 1,2 e 3 no eixo $x$, correspondem aos três anos seguintes, após a implantação da gestão semi plena no município.

A Figura 66 corresponde ao total dos 11 municípios, onde se observa que a evolução do tempo médio de permanência é crescente em função do tempo. Apresenta-se nesta figura a curva de regressão, modelo polinomial de segundo grau e seu respectivo $r^{2}=0,99$ e teste $F$ de 2,180 não significativo ao nivel de probabilidade de $5 \%$.

Figura 66 - Ajuste por regressão das taxas médias anuais de mortalidade nas internações SUS realizadas nos 11 municípios estudados, nos períodos antes e depois da implantação da gestão semi plena.

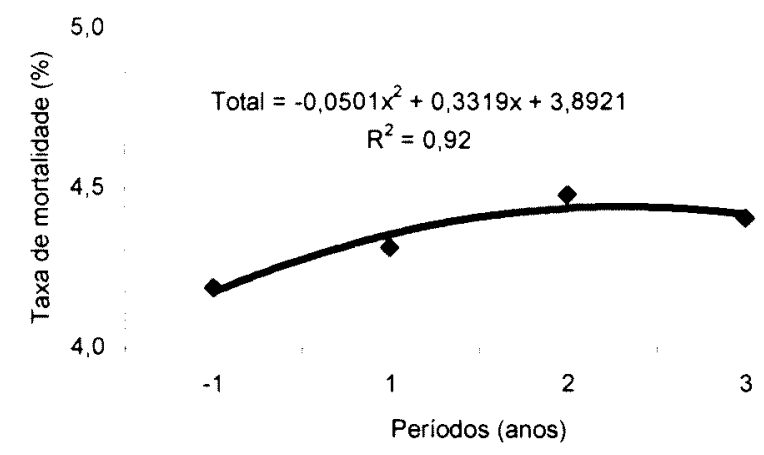

A Figura 67 corresponde ao Municipio de Assis, onde observa-se que a evolução taxas médias anuais de mortalidade é crescente em função do tempo. Apresenta-se nessa figura a curva de regressão modelo 
polinomial de $2^{\circ}$ grau e seu respectivo $r^{2}=0,99$ e teste $F$ de 14,612 não significativo ao nível de probabilidade de $5 \%$.

Figura 67 - Ajuste por regressão das taxas médias anuais de mortalidade nas internações SUS realizadas no município de Assis, nos períodos antes e depois da implantação da gestão semi plena.

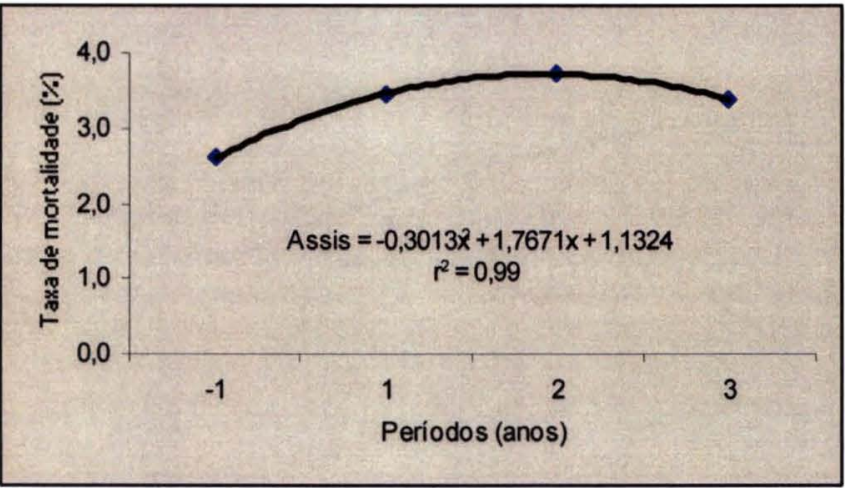

A Figura 68 corresponde ao Município de Campinas, onde observa-se que a evolução taxas médias anuais de mortalidade é decrescente em função do tempo. Apresenta-se nessa figura a curva de regressão modelo polinomial de $2^{\circ}$ grau e seu respectivo $r^{2}=0,26$ e teste $F$ de 0,365 não significativo ao nível de probabilidade de $5 \%$.

Figura 68- Ajuste por regressão das taxas médias anuais de mortalidade nas internações SUS realizadas no município de Campinas, nos períodos antes e depois da implantação da gestão semi plena.

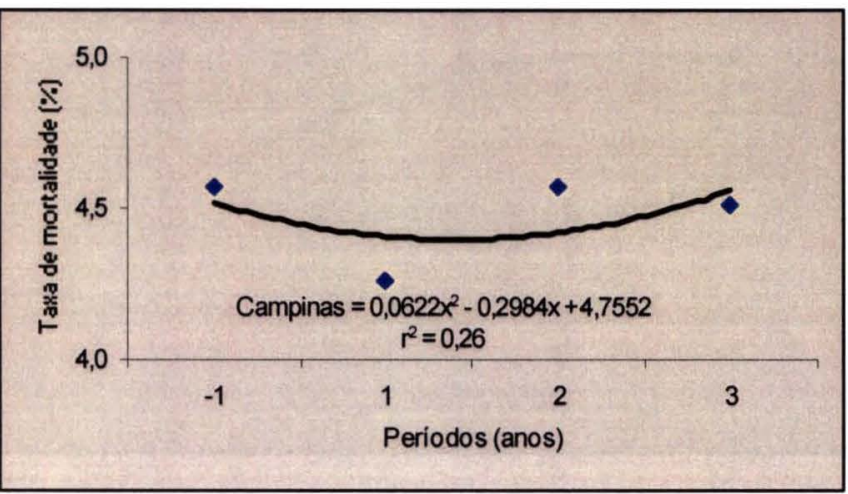

A Figura 69 corresponde ao Municipio de Diadema, onde observa-se que a evolução taxas médias anuais de mortalidade é crescente em função do tempo. Apresenta-se nessa figura a curva de regressão 
modelo polinomial de $2^{\circ}$ grau e seu respectivo $r^{2}=0,88$ e teste $F$ de 2,396 não significativo ao nível de probabilidade de $5 \%$.

Figura 69 - Ajuste por regressão dos das taxas médias anuais de mortalidade nas internações SUS realizadas no municipio de Diadema, nos períodos antes e depois da implantação da gestão semi plena.

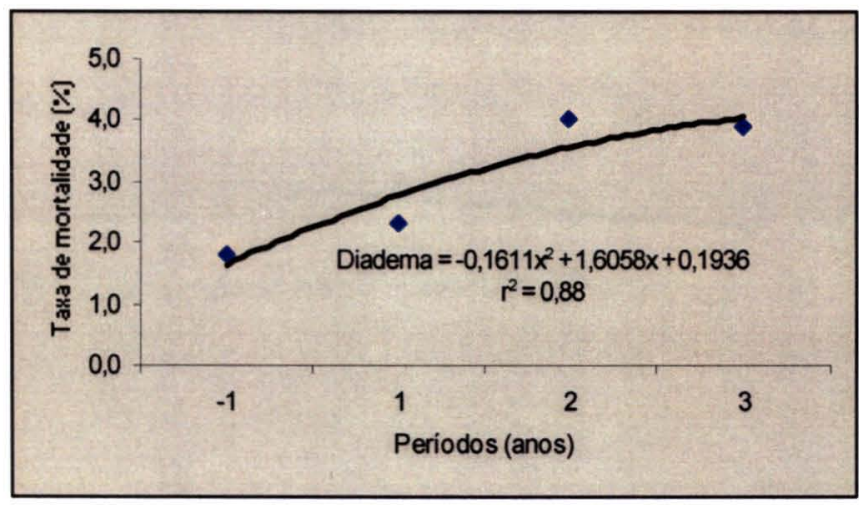

A Figura 70 corresponde ao Município de Mauá, onde observa-se que a evolução taxas médias anuais de mortalidade é crescente em função do tempo. Apresenta-se nessa figura a curva de regressão modelo polinomial de $2^{\circ}$ grau e seu respectivo $r^{2}=0,83$ e teste $F$ de 5,120 não significativo ao nivel de probabilidade de $5 \%$.

Figura 70 - Ajuste por regressão das taxas médias anuais de mortalidade nas internações SUS realizadas no município de Mauá, nos períodos antes e depois da implantação da gestão semi plena.

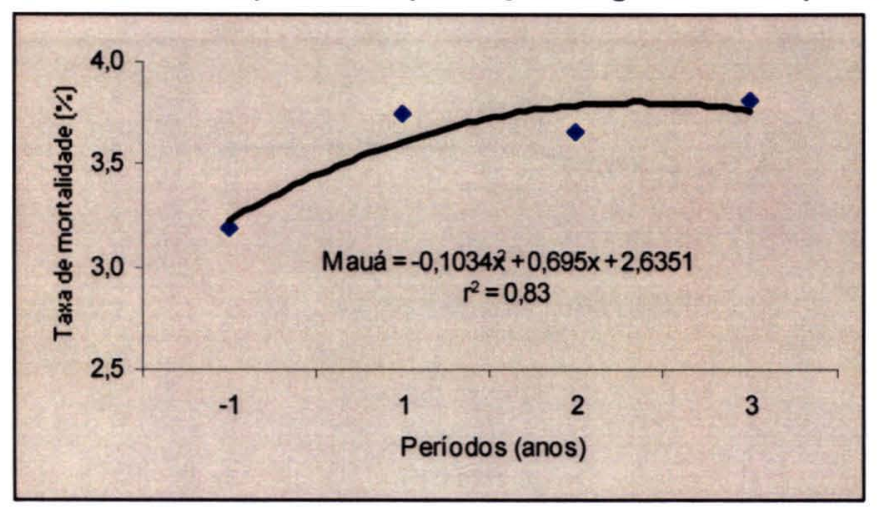

A Figura 71 corresponde ao Município de Ribeirão Preto, onde observa-se que a evolução taxas médias anuais de mortalidade é decrescente em função do tempo. Apresenta-se nessa figura a curva de 
regressão modelo linear de $1^{\circ}$ grau e seu respectivo $r^{2}=0,67$ e teste $F$ de 1,976 não significativo ao nível de probabilidade de $5 \%$.

Figura 71 - Ajuste por regressão das taxas médias anuais de mortalidade nas internações SUS realizadas no município de Ribeirão Preto, nos periodos antes e depois da implantação da gestão semi plena.

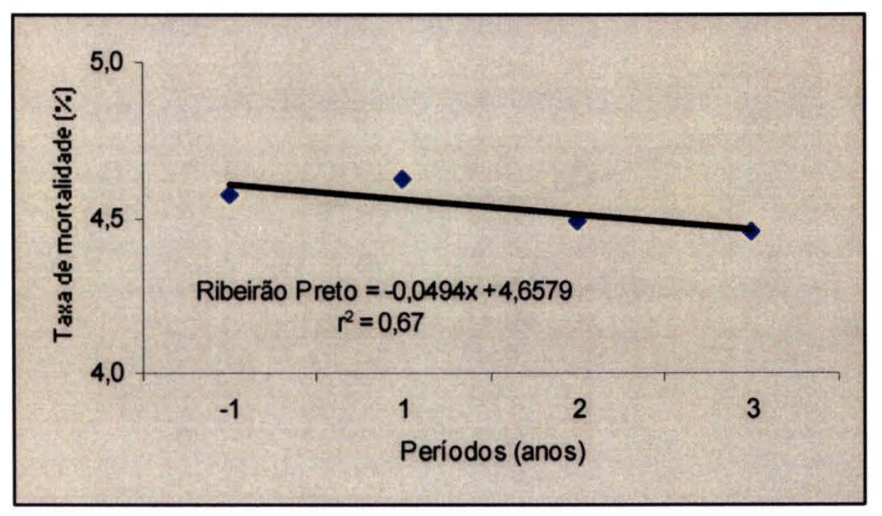

A Figura 72 corresponde ao Municipio de Santos, onde observase que a evolução taxas médias anuais de mortalidade é decrescente em função do tempo. Apresenta-se nessa figura a curva de regressão modelo polinomial de $2^{\circ}$ grau e seu respectivo $r^{2}=0,96$ e teste $F$ de 24,407 não significativo ao nível de probabilidade de $5 \%$.
Figura 72 - Ajuste por regressão das taxas média anuais de mortalidade nas internações SUS realizadas no município de Santos, nos períodos antes e depois da implantação da gestão semi plena.

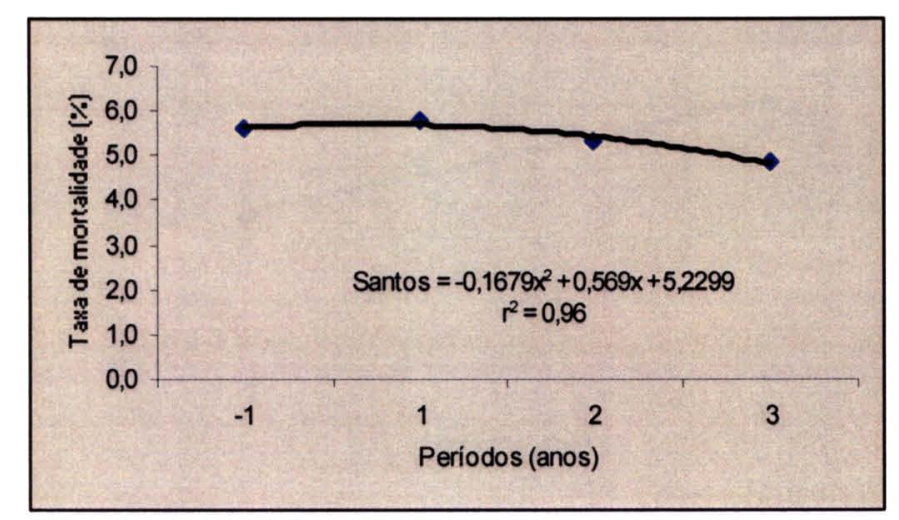

A Figura 73 corresponde ao Município de São Bernardo do Campo, onde observa-se que a evolução taxas médias anuais de mortalidade é crescente em função do tempo. Apresenta-se nessa figura a 
curva de regressão modelo polinomial de $2^{\circ}$ grau e seu respectivo $r^{2}=0,88$ e teste $\mathrm{F}$ de 7,728 não significativo ao nível de probabilidade de $5 \%$.

Figura 73 - Ajuste por regressão das taxas média anuais de mortalidade nas internações SUS realizadas no município de São Bernardo do Campo, nos períodos antes e depois da implantação da gestão semi plena.

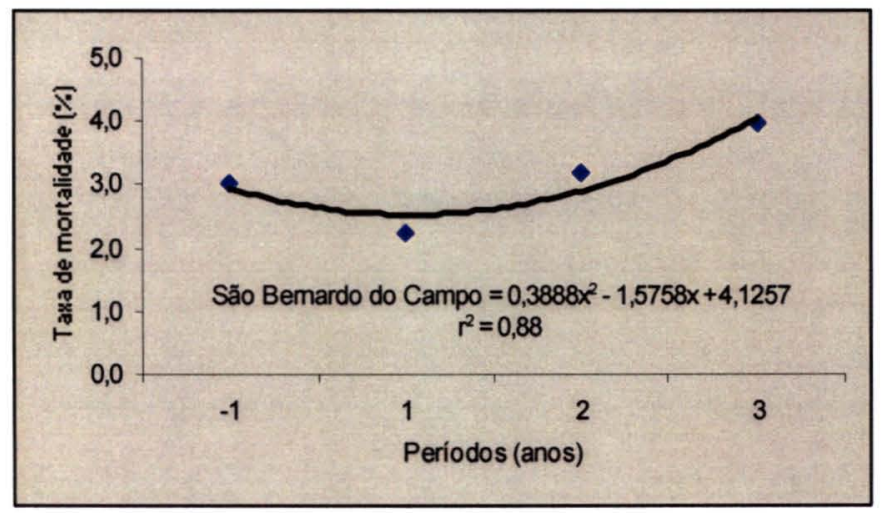

A Figura 74 corresponde ao Município de São José dos Campos, onde observa-se que a evolução taxas médias anuais de mortalidade é crescente em função do tempo. Apresenta-se nessa figura a curva de regressão modelo linear de $1^{\circ}$ grau e seu respectivo $r^{2}=0,97$ e teste $F$ de 14,569 não significativo ao nivel de probabilidade de $5 \%$.

Figura 74 - Ajuste por regressão das taxas média anuais de mortalidade nas internações SUS realizadas no município de São José dos Campos, nos períodos antes e depois da implantação da gestão semi plena.

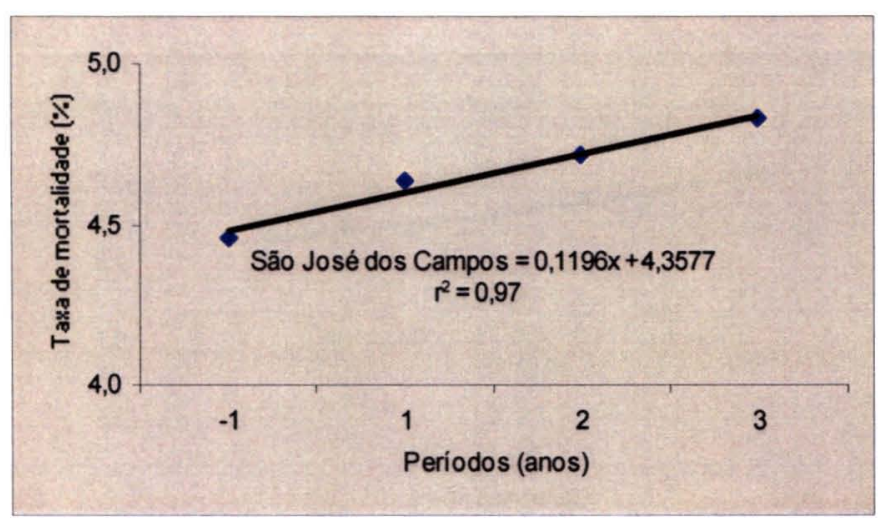

A Figura 75 corresponde ao Município de São Vicente, onde observa-se que a evolução taxas médias anuais de mortalidade é crescente em função do tempo. Apresenta-se nessa figura a curva de regressão 
modelo polinomial de $2^{\circ}$ grau e seu respectivo $r^{2}=0,95$ e teste $F$ de 213,607 significativo ao nível de probabilidade de $5 \%$.

Figura 75 - Ajuste por regressão das taxas médias anuais de mortalidade nas
internações SUS realizadas no município de São Vicente, nos
períodos antes e depois da implantação da gestão semi plena.

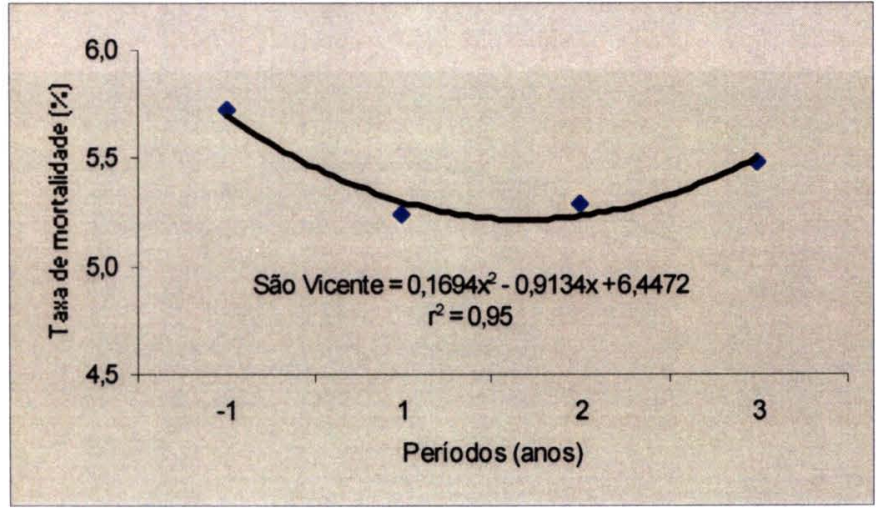

A Figura 76 corresponde ao Município de Sertãozinho, onde observa-se que a evolução taxas médias anuais de mortalidade é crescente em função do tempo. Apresenta-se nessa figura a curva de regressão modelo polinomial de $2^{\circ}$ grau e seu respectivo $r^{2}=0,98$ e teste $F$ de 465,861 significativo ao nivel de probabilidade de $5 \%$.

Figura 76 - Ajuste por regressão das taxas médias anuais de mortalidade nas internações SUS realizadas no município de Sertãozinho, nos períodos antes e depois da implantação da gestão semi plena.

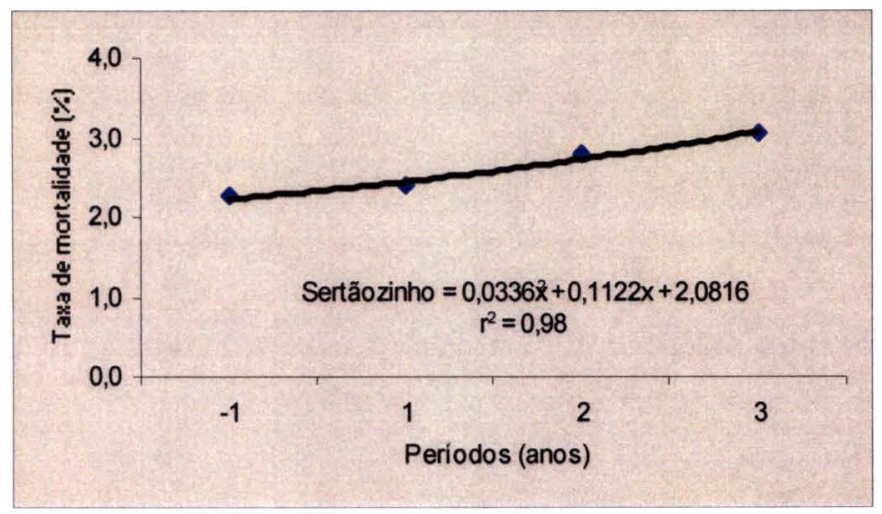

A Figura 77 corresponde ao Municipio de Votorantim, onde observa-se que a evolução taxas médias anuais de mortalidade é decrescente em função do tempo. Apresenta-se nessa figura a curva de 
regressão modelo polinomial de $2^{\circ}$ grau e seu respectivo $r^{2}=0,96$ e teste $F$ de 33,500 não significativo ao nível de probabilidade de $5 \%$.

Figura 77 - Ajuste por regressão das taxas médias anuais de mortalidade nas internações SUS realizadas no município de Votorantin, nos períodos antes e depois da implantação da gestão semi plena.

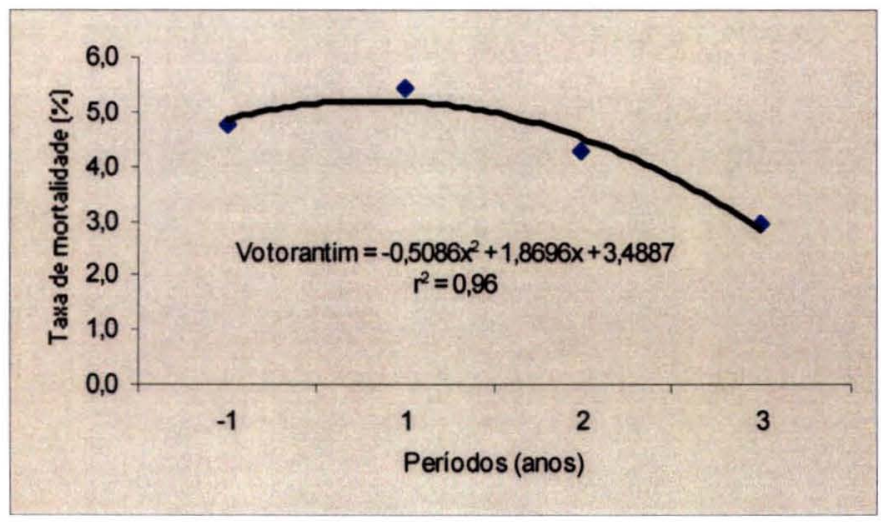


V CONCLUSÕES 
Após a implantação da gestão semi plena, considerando-se os 11 municipios, concluiu-se que :

Ocorreram reduções:

- nos volumes das internações $(5,20 \%), \mathrm{e}$

- gastos com internações $(4,84 \%)$;

Ocorreram acréscimos:

- nos gastos médios com internações $(0,43 \%)$;

- no tempo médio de permanência em internações $(3,66 \%)$, e

- na taxa média de mortalidade nas internações $(5,04 \%)$.

Para cada município estudado, após a implantação da gestão semi plena concluiu-se:

- Assis: redução de gastos e volume de internações e aumento de gasto médio por internação, taxa de permanência e taxa de mortalidade;

- Campinas: aumento nos gastos, volume e taxa de permanência nas internações e reduções de gasto médio e taxa de mortalidade;

- Diadema: reduções dos gastos e volume de internações e aumentos nos gastos médios, taxa de permanência e taxa de mortalidade nas internações;

- Mauá: Aumentos dos gastos, volume, gasto médio, taxa de permanência e taxa de mortalidade nas internações;

- Ribeirão Preto: Reduções nos gastos, volume, gasto médio e taxa de mortalidade e aumento na taxa de permanência;

- Santos: Reduções nos gastos, volume, gasto médio, taxa de permanência e taxa de mortalidade;

- São Bernardo do Campo: Aumento nos gastos, volume, gasto médio, taxa de permanência e taxa de mortalidade; 
- Sertãozinho: Reduções nos gastos, volume e taxa de permanência e aumento nos gastos médios e, taxa de mortalidade nas internações;

- São José dos Campos: Aumento nos gastos, volume, gastos médios, taxa de permanência, e taxa de mortalidade;

- São Vicente: Aumento nos gastos, volume e gasto médio. Reduziu taxa de permanência e taxa de mortalidade;

- Votorantim: Reduziu gastos, volume, taxa de permanência e taxa de mortalidade e aumento no gasto médio.

A evolução dos indicadores avaliados após a gestão semi plena, considerando-se os 11 municipios e os 4 anos de avaliação dessa modalidade, nos permite concluir que:

- O volume de internações, gastos com internações e tempo médio de permanência, são decrescentes em função do tempo;

Os gastos e o volume de internações segundo os prestadores depois da gestão semi plena aumentaram nos estaduais, municipais e universitários e foram reduzidos nos prestadores filantrópicos e contratados. A taxa de mortalidade foi aumentada nos prestadores municipais após a implantação da gestão semi plena. O tempo médio de permanência não se alterou depois da implantação da gestão semi plena nos prestadores contratados, estaduais, municipais e universitários, reduzindo-se somente nos filantrópicos. O maior tempo médio de permanência em internações observado foi para os prestadores estaduais ( 7 dias), e 0 menor correspondeu aos prestadores contratados ( 3 dias).

Os cinqüenta procedimentos de maior freqüência corresponderam a $60,18 \%$ do volume total das internações. Sendo que os oito primeiros procedimentos corresponderam a percentagem acumulada de $52,02 \%$ volume total das internações. Do total dos gastos com internações, $55,96 \%$ 
corresponderam aos procedimentos mais dispendiosos considerando-se os 11 municipios e o periodo total do estudo.

Concluiu-se que a invasão correspondeu a $44,03 \%$ dos gastos com internação e representou $30,33 \%$ do volume de internações considerando-se os 11 municípios e o periodo após a implantação da gestão semi plena.

A análise de eficácia da utilização de serviços com a utilização de indicadores de observação de performance como a relação número de procedimentos antes e depois da implantação da gestão semi plena permitiu o estabelecimento de rankings para o conjunto e individualmente para os municípios, assim como indicou os valores alcançados pelos 50 procedimentos e suas variações. Sendo portanto possivel buscar melhorias de desempenho operacional agregando-se a esses outros indicadores centros de interesse do gestor como já proposto por MARINHO (1998) ao estudar a eficiência de hospitais.

Podemos até repensar o modelo de gestão como proposto por CECILIO (1997) a partir do sistema de saúde como circulo tirando o hospital e as internações do topo da pirâmide e redirecionando-os na forma horizontal.

O estudo mostra, então, a ocorrência de mudanças importantes nas internações hospitalares SUS no periodo de gestão semi plena.

Estas mudanças ocorreram em diversas variáveis e aspectos que precisam ser melhor especificadas.

Não foi possivel, e não era objetivo do trabalho, identificar as causas destas mudanças e o quanto isso significa em termos de Modelo de Atenção e Modelo de Gestão. 
Em última instância, este estudo é indicativo das mudanças ocorridas e deve ser complementado com outros estudos que possam analisar o quanto estas mudanças foram resultantes da modalidade de gestão semi plena da NOB SUS 01/93, assumido pelos Municípios objetos do estudo. 
VI BIBLIOGRAFIA 
Almeida ES de. Contribuição à implantação do SUS - Estudo do processo com a estratégia norma operacional básica 01/93. São Paulo; 1995. [Tese de Livre Docência - Faculdade de Saúde Pública USP].

Arreteche MTS. Mitos da Descentralização. Rev Bras Ciênc Soc 1996; 11(31).

Banco Mundial / Banco Internacional de Reconstrucción y Fomento: Informe sobre el desarrollo mundial 1993. Washington (DC): Oxford University Press; 1993.

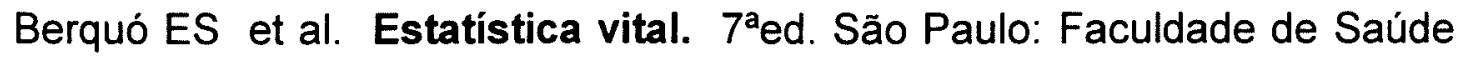
Pública; 1971.

Betio LF, Galvão MCCP, Silva A da et al. Novas formas de gestão dos serviços Públicos: a relação pública-privada. São Paulo: FUNDAP, 1997; p. 68.

Borba JR. Municipalização da saúde: roteiro básico e plano diretor. São Paulo: CEDAS; 1993. 228p.

Brasil. Lei n. ${ }^{\circ} 8080$, de 19 de setembro de 1990. Dispõe sobre as condições para a promoção, proteção e recuperação de saúde, a organização e funcionamento dos serviços correspondentes e dá outras providências. Diário Oficial da União, Brasília, 1990. p.18055-59.

Brasil. Constituição: República Federativa do Brasil. Promulgada em 05.10.88 - Título VIII Cap. II da Seguridade Social - Seção II da Saúde. Artigos 196 a 200. São Paulo: Atlas, 1995. 
Brasil. Norma Operacional Básica SUS n. ${ }^{\circ}$ 01/96. Gestão plena com responsabilidade pela saúde do povo. Portaria n. ${ }^{\circ} 1742 / 96$. Diário Oficial da União, Brasília, 30 ag 1996.

Bruyne $P$ de et al. Dinâmica da pesquisa em Ciências Sociais: polos de prática metodológica. Rio de Janeiro: Francisco Alves; 1977252 p.

Buss PM. Assistência hospitalar no Brasil (1984-1991): uma análise preliminar baseada no sistema de informação hospitalar do SUS. Informe Epidemiológico do SUS 1993; mar/abr:5-42.

Campos GW de S. Propostas para debate: diretrizes operacionais para implantação do Sistema Único de Saúde em Campinas. Rev Saúde em Debate 1990; (29):18-23.

Capote RM. O processo de Organización e regionalizacion dos serviços. Washington (DC):OPS; 1987.

Carvalho Al et al. Os caminhos da descentralização no setor saúde brasileiro. Rev Saúde em Debate 1993; (38):49-54.

Carvalho DM. Grandes sistemas nacionais de informação em saúde: revisão e discussão na situação atual. Informe Epidemiológico SUS 1997; out/dez:7-46.

Carvalho G. Saúde: avanços e entraves ao processo de descentralização. Rev Desenv Econ Social :136-48

Carvalho GCM. O momento atual do SUS ... a ousadia de cumprir e fazer cumprir a Lei. Saúde e Sociedade 1993; 2(1): 9-24. 
Castro CGJ. O processo de implantação do Sistema Único de Saúde (SUS): Estudo de caso em município de gestão semi-plena. São Paulo; 1998. [Tese de Doutorado - Faculdade de Saúde Pública da USP].

Cecilio LC O. Modelos tecno-assistenciais em saúde: da pirâmide ao círculo, uma possibilidade a ser explorada. Cad Saúde Pública 1997; 13(3):469-78.

Cecílio LC O. O estado como prestador direto da assistência hospitalar: Sim ou Não? Rev Adm Pública 1999; 55(7) 25-37.

Cesar JA, Victora CG, Santos IS, Barros FC, Albernaz EP, Oliveira LM, et al. Hospitalização por pneumonia influência de fatores sócio econômicos e gestacionais em uma coorte de crianças no Sul do Brasil. Rev Saúde Pública 1997; 31:53-61.

Chyioshi FY. Broncopneumonia como evento sentinela para o estudo de complexidade hospitalar. s.l:s.n, 1986. 12p. [mimeo].

Confederação das Misericórdias do Brasil. Santas Casas de Misericórdia e Hospitais Filantrópicos. In: Cadernos da nona: Descentralizando e democratizando o conhecimento. Brasilia. 1992. p.133 - 9. [IX Conferência Nacional de Saúde].

Contadriopoulos AP, Champagne F, Denis JL, Leal MC, Pineault R, Hartz ZMA. Avaliação em Saúde dos modelos conceituais à prática na análise da implantação de programas. Rio de Janeiro: Fiocruz; 1997 A avaliação na área da saúde; conceitos e métodos; p. 29-47.

Correa MCMMA, Barata LRB, Oliva R. A filiação universitária e hospitais públicos. Rev Paulista de Hospitais 1990; 38(1-4). 
Costa ES. Ações integradas de saúde: reforma sanitária e poder. São Paulo; 1986. [Tese de Mestrado - Fundação Getúlio Vargas].

Denis JL, Champagne. Avaliação em Saúde: dos modelos conceituais à prática da análise da implantação de programa. Rio de Janeiro: Fiocruz; 1997 Análise de implantação; p. 49-88.

Dever GEA. Epidemiologia na administração dos serviços de saúde. São Paulo: Pioneira; 1988 Epidemiologia e política de saúde; p. 37-40.

Donalisio MR. A informação e o município. Saúde em Debate 1993; (39): 64-69.

Duchiade MP, Carvalho ML, Leal MC. As mortes "em domicilio" de menores de um ano na região metropolitana do Rio de Janeiro em 1986 - um "evento sentinela" na avaliação dos serviços de saúde. Cad Saúde Pública 1989; 5 (3):251-63.

Elias PEM. Das propostas de descentralização da saúde ao SUS: as dimensões técnica e político-institucional. São Paulo; 1996. [Tese de Doutorado - Faculdade de Medicina da USP].

Favero N. Estudo do processo de referência a um hospital universitário. São Paulo; 1986. [Tese de Doutorado - Faculdade de Saúde Pública da USP].

Goldsmith J. A radical prescription for hospitales. Harvard. Bus Rev 1989; mai/jun:104-11.

Gouvea CSD. Tendências recentes na assistência hospitalar no Estado do Rio de Janeiro. 1992 - 1995. Rio de Janeiro; 1996. [Tese de Mestrado Escola Nacional de Saúde Pública]. 
Governo do Estado de São Paulo. Secretaria de Estado da Saúde. Plano Estadual de São Paulo. São Paulo; 1994. p. 61.

Governo do Estado. As normas de operacionalização do Ministério da Saúde para o SUS e sua implantação no Estado de São Paulo.1994. [mimeogr.]

Hartz ZMZ. Avaliação em saúde: dos modelos conceituais à prática na análise da implantação de programas. Rio de Janeiro: Fiocruz; 1997 Explorando novos caminhos na pesquisa avaliativa das ações de saúde.1928.

Instituto Brasileiro de Administração Municipal. IBAM.MS.FNS. Perfil dos municípios na área de saúde. 1991 (3).

Ibañez N. Municipalização e sistema local de saúde: estudo de experiências na implantação do sistema único de saúde. São Paulo; 1994. [Tese de Livre Docência - Faculdade de Saúde Pública da USP].

IDEC. Instituto do Direito do Consumidor. A taça do mundo das cesarianas é nossa. In: Consumidor S.A. Rev Ind Def Consumidor 1997;(23):17-21.

lunes RF. III Impacto econômico das causas externas no Brasil: Um esforço de mensuração. Rev Saúde Pública 1997; 31(Supl 4):38-46.

Junqueira LAP. Descentralização e intersetorialidade: a construção de um modelo de gestão municipal. Rev Adm Pública 1998; 32(2):11-21.

Keineri TMM. A organização da saúde ao nível local. Rev Adm Públ 1999; 33(3):175-83. 
Kimura AF. Reflexões acerca da incidência de operação cesariana no Brasil. Rev Paul Enferm 1995; 14(2/3): 93-7.

Lebrão ML. Análise da fidedignidade dos dados estatísticos hospitalares disponiveis na Secretaria de Estado da Saúde de São Paulo em 1974. Rev Saúde Pública 1978; 12:234-49.

Lebrão ML. Morbidade hospitalar no Vale do Paraíba, 1975. São Paulo; 1982. [Tese de Doutorado - Faculdade de Saúde Pública da USP].

Lebrão ML. Evolução da morbidade hospitalar - Vale do Paraíba, 1975 e 1988. São Paulo; 1994. [Tese de Livre Docência - Faculdade de Saúde Pública da USP].

Lebrão ML. Determinantes da morbidade hospitalar em região do Estado de São Paulo (Brasil) Rev Saúde Pública 1999; 33(1):55-63.

Marinho A. Estudo de eficiência em hospitais públicos e privados com a geração de rankings. Rio de Janeiro. Rev Adm Pública 1998; 32(6):14558.

Mathias TAF e Soboll ML de MS Morbidade hospitalar em municipio da região sul do Brasil em 1992. Rev Saúde Pública 1996; 30(3):224-32.

Médici A. Gastos com saúde, nas três esferas de Governo. Rev Saúde em Debate 1993; 40: 26-32.

Médici AC. Financiamento e contenção de custos nas políticas de saúde: tendências atuais e perspectivas futuras. Planej Polit Públicas 1990; (4): 83-98. 
Mello DZ. O governo municipal brasileiro: uma visão comparativa com outros paises. Rev Adm Pública 1993.

Mendes EV. Distrito Sanitário: 0 processo social de mudanças das práticas sanitárias do Sistema Único de Saúde. São Paulo: HUCITEC/ABRASCO; 1994.

Ministério da Previdência e Assistência Social/MPAS Reorientação da Assistência à Saúde no Âmbito da Previdência Social: portaria $n^{\circ} 3062$ de 23/08/1982 e portaria 3046 de 20/07/1982. Diário Oficial da União, Brasília, 20 jul. 1992.

Ministério da Saúde - Lei 8142 de 20 de dezembro de 1990. Dispõe sobre a participação da comunidade na Gestão do Sistema Único de Saúde - SUS e sobre as transferências intra governamentais de recursos Financeiros na área de saúde e da outras providências. Diário Oficial da União, Brasília, 20 dez 1990.

Ministério da Saúde. Portaria n..$^{\circ}$ 896: dispõe sobre a implantação SIH-SUS e SIA-SUS. Diário Oficial da União, Brasilia, 1990.

Ministério da Saúde. Portaria n. ${ }^{\circ} 16$ : implantou no SIH-SUS a tabela única de remuneração para assistência a saúde à nivel hospitalar. Diário Oficial da União, Brasilia, 08 jan 1991.

Ministério da Saúde. INAMPS. Resolução n. ${ }^{\circ}$ 227: regulamentou em âmbito nacional o SIH/SUS tendo como base o sistema médico hospitalar da previdência. Diário Oficial da União, Brasília, 27 jul 1992.

Ministério da Saúde. Portaria n. ${ }^{\circ}$ 545: estabelece normas e procedimentos reguladores do processo de descentralização e gestão ações e serviços de 
saúde, através da norma operacional básica SUS 01/93. Diário Oficial da União, Brasília, 24 mai 1993, p. 6961-5.

Ministério da Saúde: NOB SUS 01/96. Portaria 2203 de 05 nov 1996 Norma operacional básica Sistema Único de Saúde - SUS. Diário Oficial da União, Brasília, 6 nov 1996, 36 p.

Ministério da Saúde. Secretaria Executiva. Coordenadoria da Criança e do Adolescente. Tratamento de Pneumonia em hospitais de pequeno e médio porte. Brasilia; 1997 36p.

Ministério da Saúde. Secretaria de Assistência à Saúde. Assistência Hospitalar no SUS 1995-1999. Brasilia, 2000a; 392p.

Ministério da Saúde. Caderno de Informações [online] Datasus. Disponivel em:<http://www.datasus.gov.br[1998]> [27 out 2000].

Ministério da Saúde. Secretaria de Assistência à Saúde. Assistência hospitalar no SUS. 1995/1999. Brasilia; 2000b. 392p.

Ministério da Saúde. Sistema Único de Saúde Descentralização das ações e serviços de saúde: a ousadia de cumprir e fazer cumprir a lei. Brasilia; 1993 p. 67.

Ministério da Saúde: decreto n. 1232 de 30/08/1994. Dispõe sobre a transferência regular de recursos do Fundo Nacional de Saúde para os estado, município e Distrito Federal. Diário Oficial da União, Brasília,

Misoezky MC. Distrito sanitário: desafio de descentralizar com democracia. Rev Saúde em Debate 1991; (33):54-60. 
Montero D'Oleo RJ. Utilização dos leitos hospitalares na região de Ribeirão Preto. 1988. Brasil. São Paulo; 1991.[Tese de Mestrado Faculdade de Saúde Pública da USP].

Monti JFC Sistema único de saúde, uma reforma no meio do caminho. São Paulo Perspec 1992; 6(4):38-44.

Motta PR. Alguns desafios administrativos na gestão pública de saúde Seminário "Novas concepções em administração e desafio ao SUS. Em busca de estratégias para o desenvolvimento gerencial. São Paulo: ENSP/FIOCRUZ, FUNDAP; 1990.

Neto GV, Fatheazam S. Investimentos em leitos hospitalares no Estado de São Paulo: Visão prospectiva. Rev Adm Públ 1991; 39(9-12):109-15.

Neto JSM. Descentralização e democracia tópicos de um debate. Saúde Debate 1996; (33):33-9.

Niobey FML, Duchiade MP, Vasconcelos AGG, Carvalho ML de, Leal M do C, Valente JG. Fatores de risco para morte por pneumonia em menores de um ano em uma região metropolitana do Sudeste do Brasil. Um estudo tipo caso-controle. Rev Saúde Pública 1992; 26(4):229-38.

Noronha MF, Machado CV, Lima LD de. Proposta de indicadores e padrōes para avaliação de qualidade da atenção hospitalar: $O$ caso de asma bronquica. Cad Saúde Pública 1996; 12 (supl. 2): 43-58.

Oliveira JB. Sistema local de saúde. Washington (D.C):OPS; 1988 (Serie Pesarollo de Servicios de Salud, 59). 
Piriou SALL S. Decentralization and rural development: a review of evidence world bank. [online] <http://www.rimisp.cl/semmexsp.html> [1995 ag].

Portela MC et al. Estudo sobre os hospitais filantrópicos no Brasil. Rev Adm Pública 2000; 34(2):79-98.

Post CLA, Victora CG, Valente JG, Leal MC, Niobey FML, Sabroza PC. Fatores prognósticos de letalidade hospitalar por diarréia ou pneumonia em menores de um ano de idade. Estudo de caso e controle. Rev Saúde Pública 1992; 26 (6): 369-78.

Prada HA. The basic Hospital . Its role in programs for extending health service conerage. Brell Panam. Health. org 13-325-41, 1979.

Pupo TRGB. Participação dos conselhos municipais de saúde no processo decisório de formulação e implantação das políticas de saúde: estudo de caso em dois municipios em gestão semi-plena. São Paulo; 1999. [Tese de Mestrado - Faculdade de Saúde Pública da USP].

Ramos R. Indicadores do nivel de saúde: sua aplicação no município de São Paulo (1894-1959). São Paulo; 1962. [Tese à cadeira de técnica de Saúde Pública - Faculdade de Saúde Pública da USP].

Reis EJFB dos, Santos FP dos, Campos FE de, Acurcio F de A, Leite MTT, Leite MLC, et al. Avaliação da qualidade dos serviços de saúde: Notas Bibliográficas. Cad Saúde Pública 1990; 6(1):50-61.

Reis O. Como vai nossa amiga AlH? Rev Conj Saúde 1994; p.14-20.

Rocha JSY. Estudo da utilização de leitos hospitalares gerais do município de Ribeirão Preto, pela população do município, no ano 1972. 
São Paulo; 1974. [Tese de Doutorado - Faculdade de Medicina de Ribeirão Preto da USP].

Rocha JSY, Ortiz PC, Fung YT. A incidência de cesáreas e a remuneração da assistência ao parto. Rev Paul de Med 1986;104 (3): 167-71.

Rodrigues CS, Magalhães Júnior HM, Evangelista PA, Ladeira RM, Laudares S. Perfil dos nascidos vivos no Município de Belo Horizonte, 19921994. Cad Saúde Pública 1997; 13(1):53-7.

Rodrigues Filho J. Alocação de recursos de saúde: um estudo de utilização hospitalar. João Pessoa: Universidade UFPb; 1991 145p.

Roux $B$ et al. Participación social en los Sistemas locales de salud. Washington (DC): 1988. (OPS serie Desarollo de Servicios de Salud,35).

Ruiz EAC. A Cultura Institucional e a Viabilização do Sistema Único de Saúde (SUS). Papel dos Gerentes de Hospital. São Paulo; 1992. [Tese de Doutorado - Faculdade de Saúde Pública da USP].

Ruiz JA. Dimensión Política de la Descentralización. Ministro da Agricultura da Venezuela. [online] Rome, 1997. Available from: < http://www.fao.org/ WAICENT/faoinfo/sustdev/Rodirect/Rofo0015.htm> [03 jul 2001].

San Martin H. Salud Y Enfermedad. Ecologia Humana, Medicina preventiva Y Social. México: Press. Méd; 1968.

Santana JP de. Municipalização da Saúde: Desafios para a Cooperação Técnica. Saúde Debate 1990; (30): 59-60. 
Santos L. A llegalidade das Normas Baixadas pelo INAMPS de Financiamento do SUS para 1991: Contribuições Para sua Mudança. Saúde Debate 1991; (31):14-18.

Santos L. Aspectos do Financiamento das Ações e dos Serviços de Saúde no SUS: Seguro Saúde e Outras Modalidades de Medicina Supletiva. Saúde Debate 1992; (37):26-30.

Santos NR. A IX C.N.S., O SUS e "Este" Estado. Saúde Debate 1992; (35):25-29.

Santos NR. O SUDS, O SUS, Os Vetos e a Sanção do Projeto. Saúde Debate 1990; (30):5-7.

Scatena JHG, Tanaka OY. Distribuição dos estabelecimentos de saúde no Brasil: para qual modelo caminhamos? Rev Adm Pública 1998; 12(4):7-25.

Secretaria de Estado. Relatório Técnico de Gestão. Período: julho de 1993 a dezembro de 1994. São Paulo:Imprensa Oficial do estado/IMESP; p. 51-53, 83-85, 89-93.

Selcher W. O Futuro do Federalismo na Nova República. Rev Adm Pública 1990; 24(1).

Shoukay Decentralization. indexb4.html, Local Tax System <czais.html>, Furusato-zukuri <indexb2.html>, Iternatio-nalization \& Informatization <indexb6.html>, Fire \& Disaster (Fire \& Disaster Management Agency). Available from: <http://www.fdma.go.jp/>, Election System Reform <senkyos.html>, Ministry Gateways <indexb11.html> [ 07 jul 1996]. 
Silva LK; Escosteguy CC; Machado CV. Metodologia para a estimativa de padrões de qualidade: o caso infarto agudo do miocardio. Cad Saúde Pública 1996; 12(supl. 2):71-83.

Silva PLB. Descentralização de politicas sociais: marco teórico e experiências internacional e brasileira. In: Velloso, JPP ; Albuquerque RC; Knoop J, coords. Políticas sociais no Brasil: Descentralização, eficiência e equidade. Rio de Janeiro: Inal/lldes; 1995. 236p.

Silva SF, Cavanese SV, Carvalho BG. Hospitais garantia de acesso aos que realmente necessitam. In: A Construção do SUS a Partir do Municipio Etapas Para a Municipalização Plena da Saúde. São Paulo: Hucitec. 1996 p. 71-75. (Série Saúde em debate).

Silva SF, Sugmyama LCY. Construção do SUS a partir do municipio: Etapas para a municipalização plena da saúde. São Paulo: Hucitec; 1996. 76-82p.

Souto ALS e outros. Como reconhecer um bom governo? O papel das administrações municipais na melhoria da qualidade de vida. São Paulo: Pólis; 1995. 72p (Publicações Pólis, 21).

Souto L. Além da latrogênese. Saúde Debate 1992; (35): 33-4.

Souza C. Dez Anos de Descentralização Fachin, Roberto e Chanlat, Alain. Governo Municipal na America Latina: Inovações e perplexidades. Porto Alegre: Ed. da Universidade; 1998.

Spinola AWP, Carvalho LF. Como diminuir a incidência das cesarianas: relato de uma experiência. Rev Paul Hosp 1989; 37(5-8): 46-9. 
Teixeira SMF. O Dilema Reformista e a Reforma Sanitária Brasileira. In: BERLINGUER, G A reforma sanitária Brasil-Itália. São Paulo: HUCITEC 1988.

Triviños ANS. Introdução à pesquisa em Ciências Sociais a pesquisa qualitativa em educação. São Paulo: Atlas; 1987. p. 98-158.

Ugá $M A O$, Reis $O$. Notas a cerca dos repasses financeiros no âmbito do sistema SAl e SIH/SUS. Conjuntura e Saúde (NUPES/DAPS/ENSP) 1994. 15-20.

Veras CMT, Martins MS. A Confiabilidade dos Dados nos Formulários de Autorização de Internação Hospitalar (AlH). Rio de Janeiro, Brasil Cad Saúde Pública 1994; 32 (2):339-55.

Viana AL D'Avila. Novos riscos, a cidade e a intersetorialidade das políticas públicas. Rev Adm Pública 1998; 32 (2):23-33.

Vianna SM, Piola SF, Guerra AJ, Camargo SF. O financiamento da descentralização dos serviços de saúde: critérios de transferência de recursos federais para Estados e Municipios. Brasilia. (D.F): IPEA; 1991. $29 p$ (documento de Politico, 3).

Wicehers M. Legal structures for development and democracy in unequal societiessouth Africa and Brazil [online] Disponivel em: <http://www.unisa.ac.za/ dept/ press/lar/112/wiechers.html> [ 03 jul 2001].

Wonnacott $\mathrm{H}$. Introductory statstics for business and economics. $2^{\text {nd }}$ ed. New York: Jonh Wiley \& Sons; 1977.

Zucchi P, Nero C, Malik AM. Gastos em saúde: os fatores que agem na demanda e na oferta dos serviços de saúde. Rev Adm Pública 1998 32(5):125-47. 